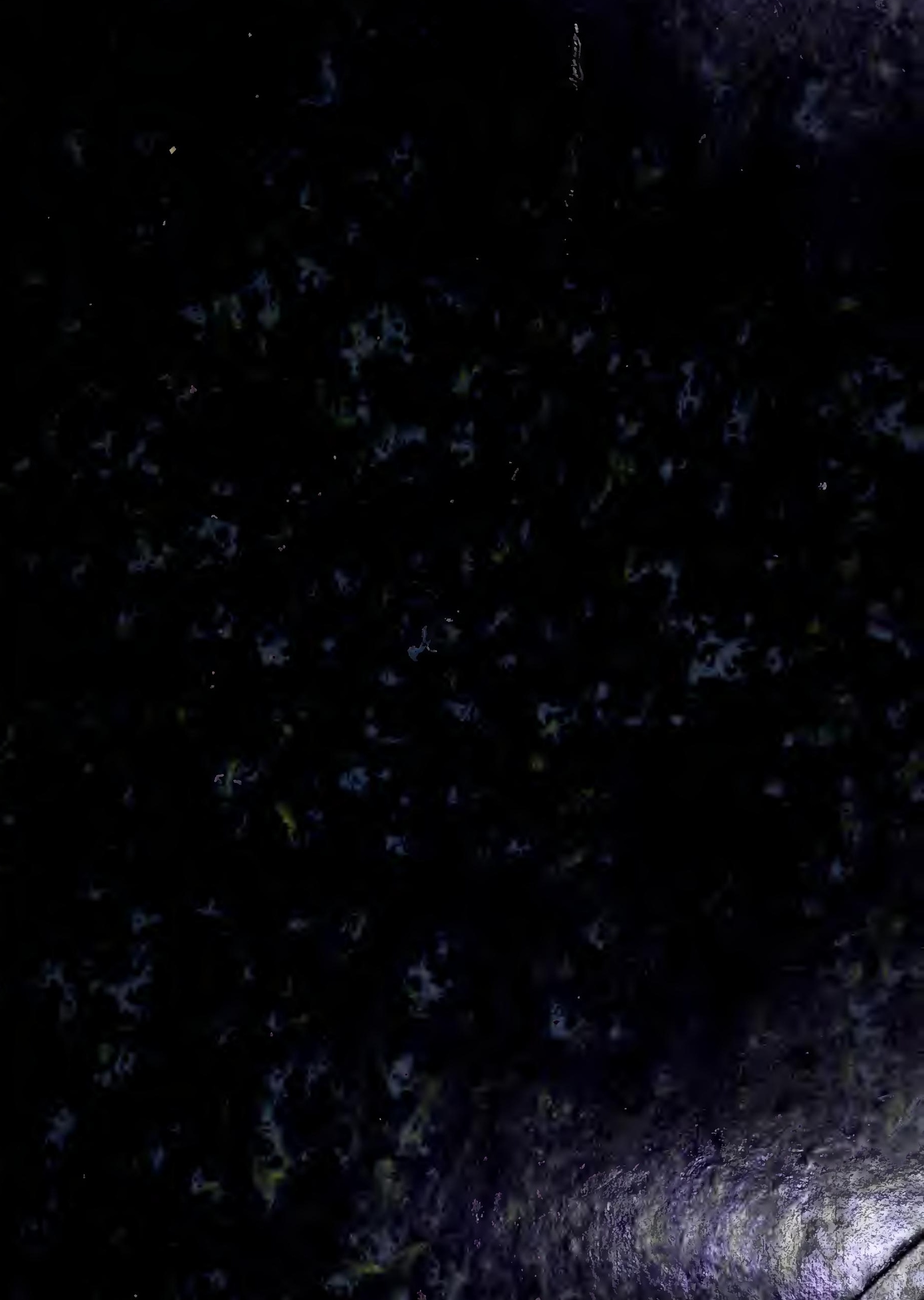




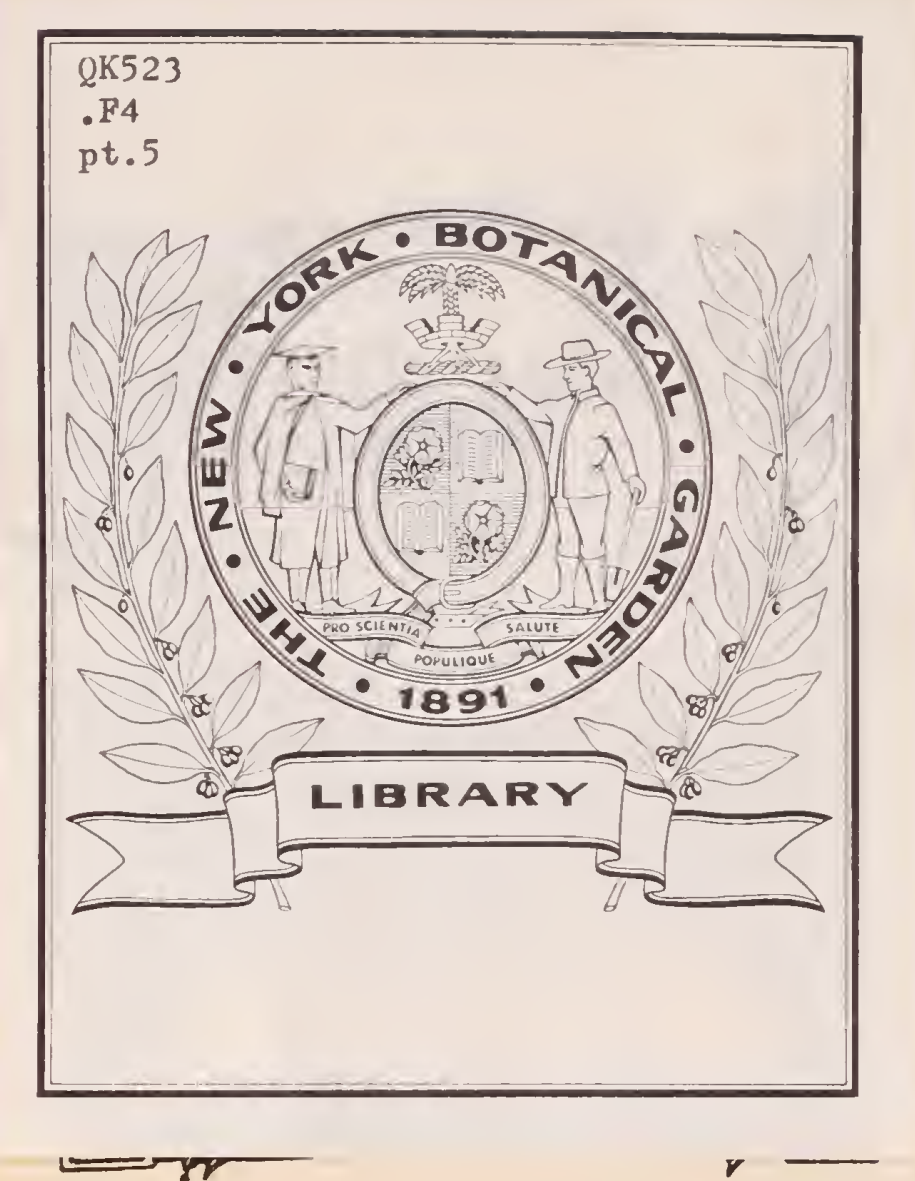


DUPLICATA DE LA BIBLIOTHÊQUE DU CONSERVATOIRE BOTANIQUE DE GINEVE יזיDU EN 1922 


\section{Digitized by the Internet Archive in 2016}




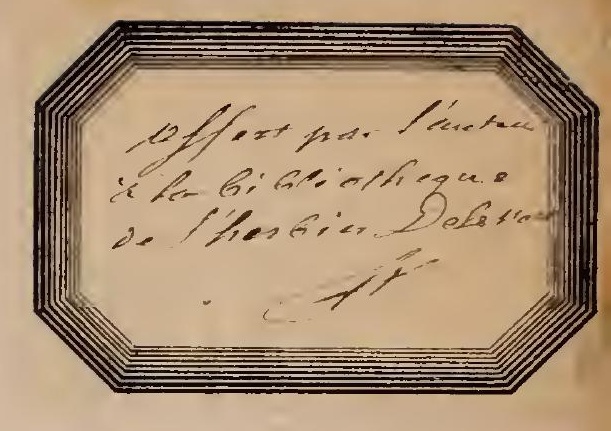

e

\section{GENERA FILICUII.}

\section{POLYPODIACÉES.}

DUPLICATA DE LA BIBLIOTHÊQUE

DO CONSERVATOIRE BOTANIQUE DE GENEVA

YTDU EN 1922 



\title{
GEVARA NIUICUM.
}

\section{EXP0SITION}

\section{DES GENRES DE LA FAMILLE}

DES

\section{POLYPODIACÉES}

(CLASSE DES FOUGËRES).

PAR

\author{
A. L. A. FEE, \\ Professeur de hotanique à ia Facullé de médeciue de Stratbourg.
}

Natura opus semper esl SPECles el GEve' ; Cuturut

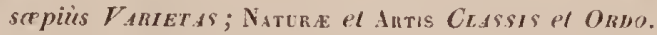
Linn., Philosoph. bol., 1102.

(Cingunième Mémoire sur la famille des rongères.)

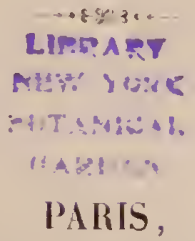

J. B. BALLLERE, L1BatRE, rue Hantefeuille, 19.

VICTOR NASSON, LIBRARE, place de l'ḱcole de Mideciue, 17.

STRASBOURG,

I. BERGER-LETRALLT ET FILS, LIBRAllES.

$1850-1852$.

CONSERVATOIAE
BOTANIQUE

$\rightarrow$ omprams

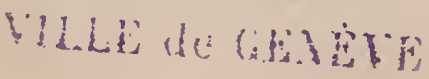


$Q K 523$
.$F 4$
$p+5$ 


\title{
EXPOSITION

\section{DES GENRES IDE LA FAMIMEE}

DES

\section{POLIPODILCÉES}

\author{
(CLASSE DES FOLGËBES),
}

\section{PROLÉGOMÈNES.}

La méthode naturelle ne se borne pas uniquement à coordonner les familles et à les fonder sur des bases solides; elle doit aussi s'efforcer de les fractionner en genres, également bien circonscrits, et ne renfermant que des espèces analogiques.

Les botanistes ne sont pas éloignés de s'entendre sur les limites qui doivent être assignées aux familles, et s'ils diffèrent parfois sur la manière dont ils les encbaînent, ils sont généralement d'accord sur la valeur respective des organes, au noyen desquels il faut les établir.

Il n'en est pas de même du genre dont la valeur rigoureuse est très-diversement comprise et appréciée. Chacun de ces petits groupes, en s'éloignant de l'époque de sa création, se montre dans chaque ouvrage nouveau, tantòt plus étendu et tantôt plus restreint, suivant le point de vue auquel se sont placés les auteurs; souvent même il disparaît pour revivre et disparaitre encore. Certaines espèces de plantes sont, en ce qui concerne le genre auquel elles doivent se rattacher, véritablement erratiques, elles ne peuvent, quoi qu'on fasse, avoir nulle part droit de cité. 
Ton-seulement les botanistes n'accordent pas une même valeur aux organes qui servent à la formation des genres, mais encore il est évident que ces caractères n'ont pas dans toutes les plantes un égal degré d'importance.

L'appareil de la fructification qui, chez les mousses, peut servir à grouper les espèces en genres, est insuffisant chez les fougères. Dans les labiées, les tribus sont surtout établies d'après des considérations tirées de l'étamine, tandis que dans les cruciferes, elles ont été fondées principalement sur les modifications que présentent les cotylédons et la radicule, etc.

Ces appréciations, qui varient d'importance suivant les auteurs et qui ne pourraient, si on voulait les exprimer en chiffres, donner lieu à des évaluations invariables dans leur quotité, expliquent une instabilité très-préjudiciable aux vrais intérêts de la science, et rendent inutiles ou même nuisibles une foule de travaux très - estimables d'ailleurs.

En cherchant à savoir comment les auteurs ont compris et défini le genre, il est facile de voir que les définitions reposent sur des considérations différentes et que sourent elles semblent manquer de précision; en voici des exemples : il y a autant de genres, dit Lixxé, qu'il y a d'espèces ayant des fructifications établies sur un même plan (Philosophica bolanica, p. 100). Cette manière de considérer le genre ne semble-t-elle pas convenir surtout à la famille?

Un genre, écrit DE Candolle (Théorie élémentaire, p. 196), est une division des végétaux d'une famille, fondée sur des considérations de nombre, de grandeur, de forme ou d'adhérence; mais quelles seront les limites de ces modifications et comment déterminer leur valeur respective?

Suivant M. DE Mırbel, le genre est un groupe d'espèces qui s'enchaînent naturellement par des analogies de structure et de forme (Physiologie, p. 480). Mais quel est le lien qui les unit? Comment le reconnaitre et surtout comment le préciser?

Le genre, assure MI. Raspall, est un type idéal des rapports essentiels que l'esprit a découverts entre un certain nombre d'espèces (Physiologie régétale, p. 101 ). Cette définition, si elle fait en effet connaître le genre, ne dit pas comment on le forme et quels sont ces rapports essentiels qui, d'après l'auteur, lient les espèces entre elles.

D’après M. A. Richard (Nouveaux Éléments de botanique, p. 566), la réunion des espèces ayant entre elles une ressemblance évidente dans leurs caractères intérieurs et leurs formes extérieures, constitue les genres; nais d'après quelles règles les constitue-t-on?

Il y a, comme on le voit, des définitions plutôt que des préceptes, et le genre est encore aujourd'hui dans le domaine de la métaphysique. Chacun le comprend à sa manière et le soumet, dans l'appréciation qu'il en fait, à la nature des idées systématiques qui le dominent. 
On a voulu établir qüil existait trois sortes de genres : genres systématiques, genres par enchainement ou polytypes, genres groupés ou monotypes (Dict. des sciences nat., t. 53 , p. 478).

Les premiers seraient composés d'espèces qui ne se distinguent de celles composant les genres voisins que par un seul trait de l'organisation reproduit dans toutes, et l'on cite le genre Salvia dont le connectif grêle et allongé est porté transversalement par le filet comme sur un pivot. Les seconds existeraient lorsque les espèces destinées à les constituer se rattachent les unes aux autres comme les anneaux d'une chaîne, et se suivent sans interruption de manière à pouvoir passer de la première à la dernière par des nuances insensibles. Exemple : Melissa, Thymus. Enfin les derniers grouperaient des êtres étroitement liés par des rapports faciles à saisir du premier coup d'œil. Exemple : Rosa, Dianthus, Scutellaria. Nous ne pouvons admettre ces distinctions; il ne peut et il ne doit y avoir que des groupes naturels; c'est à tort que l'on cite le genre Salvia comme le type d'un genre systématique; le caractère que l'on invoque à l'appui de cette opinion esı loin d'ètre le seul. Il n'esiste que deux étamines dans les sauges et elles sont portées sur un processus filiforme qui naît de la gorge de la corolle; celle-ci a une forme toute spéciale. Le facics est également caractéristique et il n'est pas jusqu'à la nervation qui ne puisse servir de moyen confirmatif. Ce que nous disons ici des genres systématiques, s'applique parfaitement aux genres par enchaînenent; s'ils sont par trop hétéroclites, on les partage en sous-genres, mais ce moyen terme proure qu'on a cédé à la nécessité de consacrer le principe des analogies naturelles; car, rigoureusement parlant, ces subdivisions sont des groupes réels et distincts ayant la valeur du genre, puisquills ont, avec une physionomie pareille, un caractère commun qui unit les espèces, caractères qu'on chercherait vainement dans les autres. Nous avons dejà dit, et beaucoup l'avaient répété avant nous, l'espèce seule est hors du domaine de la controverse.

Les genres qui réunissent des espèces différentes, la famille elle-même qui n'est qu'un grand genre, la classe, sorte de ġrande famille, toutes ces réunions sont plus ou moins heureusement constituées, nrais jamais parfaitement naturelles.

Une espèce étant une réunion d'individus, séparés les uns des autres par de simples nuances d'organisation, semble offrir l'exemple de ce quil faut tenter dans la formation du geure; le groape ne doit recevoir que des espèces ayant entre elles les plus grandes analogies possibles. Il s'agit de faire une sorte de faisceau dont tous les éléments tendent au parallélisme. Le lien qui unit ces créations, établies sur un type commun, est toujours rérélé par lhabitude extérieure. Toute ressenblance dans les organes de faible importance, indique une parenté; elle avertit qu'il faut chercher des analogies ailleurs, et peut, jusqu’à un certain point, faire croire qu'elles existent en effet. Rien n'est plus rare que de trouver deux plantes, séparées par les organes de la nutrition, se montrer identiques 
quant aux organes de la reproduction ou quant à l'appareil qui en tient lieu. L'harmonie végétale se compose de l'ensemble de toutes les parties de la plante; les caractères se reflètent les uns sur les autres; souvent une modification, en apparence légère, en indique une plus profonde, il ne s'agit que de la trouver. L'obliquité de l'anneau dans les polypodiacées n'a généralement lieu que pour des fougères arborescentes; dans les vittariées se trouvent toujours des sporangiastres, des écailles cancellaires et des radicelles tomenteuses. Les adiantées ont constamment un stipe lisse, luisant, fragile et noiràtre. Ces caractères, en apparence peu importants, fournissent d'excellents moyens de confirmation; ce sont des indices qui conduisent au genre et qui plus tard le confirment.

Il faut donc tenir grand compte de la physionomie générale d'une plante, et tous les naturalistes sont d'accord sur ce point. Ne dit-on pas d'un botaniste ou d'un zoologiste qu'il a du tact et que son coup d'cil est juste? Les auteurs qui ont le mieux compris le genre ont été guidés autant peut-être par une sorte d'instinct scientifique que par des qualités acquises par l'étude. Les espèces dont les formes se heurtent sont violemment réunies; ce sont des notes fausses dans l'échelle diatonique et les yeux sont blessés par ces rapprochements forcés, comme il arrive aux oreilles de l'ètre par des accords sans justesse.

Lor'squ'il existe, avec un facies semblable, un caractère commun tiré de l'appareil générateur, il y a des raisons de croire que les plantes chez lesquelles on constate cette communauté d'organisation sont congénères; il y a au contraire lieu de les croire disgénères, lorsque, la physionomie étant différente, les organes qui servent à la reproduction, offrent des dissemblances marquées; nous avons donc tenu grand compte de la physionomie des plantes de la famille des fougères dans les limites à donner aux genres, sans toutefuis négliger de nous assurer si des caractères plus importants venaient confirmer ou non ces analogies extérieures. Il est résulté de cette manière de voir un accroissement assez considérable de genres et peut-être les trouvera-t-on trop nombreux. Cependant si l'on évalue à 2000 espèces le nombre total des polypodiacées, et celte évaluation ne semble pas être au-dessus de la réalité, il se trouvera que la moyenne des espèces par genre (nous en avons près de 170 ) sera de 12 environ, proportion qui reproduit exactement celle du Nomenclator de Steudel pour les phanérogames, puisque sur 78,000 espèces énumérées, il se trouve 6722 genres.

S'il faut l'avouer, nous ne trouverons aucune raison de regretter que les genres soient nombreux. Le but à atteindre consiste à séparer nettement tous les groupes établis sur des types différents, et c'est ce que nous avons essayé de faire.

Les plantes filicö̈des constituent une vaste classe divisée encore aujourd'hui en plusieurs tribus indiquées par Bersharni, Swartz et Willdexow, et aujourd'hui élevées à la condition de famille. Ces grands groupes, généralement adnis, ont été établis sur des considérations importantes, et il est bien douteux qu'on puisse 
en trouver de meilleures. Voici comment on peut les présenter dans leur ensemble.

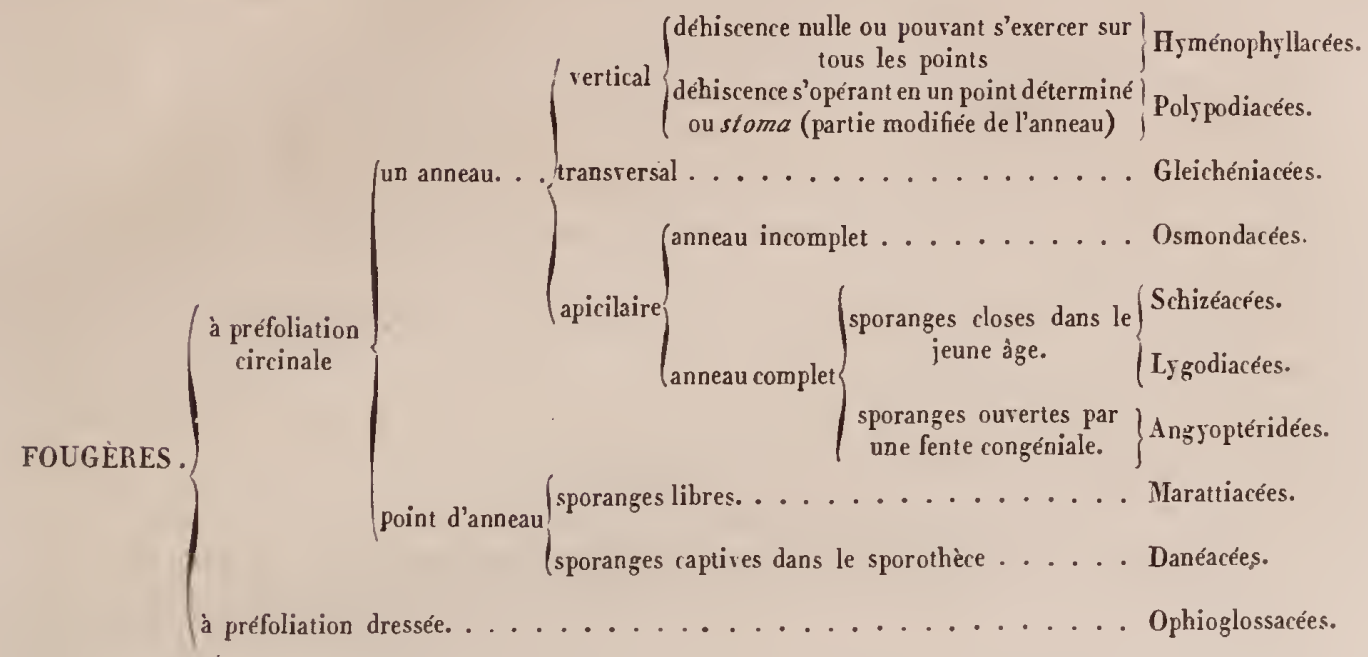

Les fougères, dans le sens étendu du mot, se lient aux mousses par les hyménophyllacées et aux lycopodiacées par les ophioglossacées. Les familles qui partagent cette immense classe, quoique nettement séparées par la structure des sporanges et souvent même par celle des sporothèces, ont une physionomie peu différente quant aux organes de la nutrition; cependant les hyménophyllacées, les osmondacées, les schizéacées et les ophioglossacées en ont une qui permet facilement de les reconnaître.

La famille la plus nombreuse, celle qui représente la classe dans sa plus grande splendeur, est celle des polypodiacées. Elle semble s'unir aux gleichéniacées par le sous-groupe des cyathées; quelques genres rappellent, par le port, les osmondacées; d'autres grimpent à la manière des lygodiacées ou tiennent par la délicatesse de leur tissu à la curieuse famille des hyménophyllacées. Variété dans le port et dans la stature, variété dans les formes et dans la disposition des sporothèces, tout attire l'attention rers les polypodiacées que les auteurs. regardent comme les vraies fougères (Eufilices): c'est à elles que nous consacrons ce travail.

Depuis une quinzaine d'années environ, les botanistes se sont beaucoup occupé des fougères. Parmi eux, MNI. Presl, Schott, J. Simth et Bater ont publié des genera. Le premier en date est M. Schoтr qui, en 1834 , a commencé un genera filicum, qui malheureusement est resté à l'élat d'ébauche. Vingt genres seulement ont été analysés. Il est bien regrettable que cet auteur n'ait pas terminé une tâche qu'il remplissait d'une manière si distinguée; ses dessins sont un modèle d'exactitude et de perfection. Sil eût persévéré jusqu'au bout, le livre de MI. Bacek ou n'eût pas paru, ou bien n’aurait été que le complément de celui de M. Sснотт. 
C'est en $184^{2}$ que M. Baver, aidé de M. Hooker, a publié une suite de gravures sous le nom de Genera filicum. Ce livre n'est autre chose qu'une simple illustration de l'ouvrage de M. Press; le tableau des genres et jusqu'au texte, qui a seulement été abrégé, lui appartiennent; pourtant ce travail est utile; il l'eut été davantage, si les auteurs n'avaient pas cru devoir enluminer les planches. Les figures y ont perdu bien plus qu'elles n'y ont gagné, et ce luxe de couleurs, rarement naturelles, ajoute singulièrement à l'élévation du prix et le rend inaccessible à la plupart des botanistes.

L'ouvrage de M. PREsL doit être regardè comme fondamental. Cet auteur a exploité le premier une idée qui déjà était en germe, et il l'a fait avec une rare supériorité d'intelligence. Il décrit environ 120 genres très-savamment ordonnancés. Quelques années plus tard, M. J. Syıти, dans un mémoire très-estimable, plus concis, mais rédigé en termes clairs, a repris le travail de MI. PRESL et modifié heureusement plusieurs genres admis par cet auteur. M. J. Sмiти ayant eu le premier à sa disposition la curieuse collection de fougères, rapportée des Philippines en Angleterre par M. Cumixg, s'est liabilement servi de ces précieux matériaux.

La classification que nous proposons, bien qu'elle nous appartienne à plusieurs titres, est cependant plus voisine de celle de M. PresL que de celle de M. J. SMrth. Nous allons discuter rapidement la valeur des bases principales admises par cet auteur et par ses devanciers.

Les filicacées ont été partagées, dans le Tentamen pteridogrcuphice, en deux grands sous-ordres, d'après les caractères proposés par BERNHARdi la situation de l'anneau, excentrique dans les hélicogyratées, est marginale dans les cathétogyratées. Les premières renferınent les gleichéniacées et les cyathéacées; les dernières les polypodiacées. Pour nous, les fougères à anneau vraiment excentrique constituent un groupe tout à fait distinct, les gleichéniacées, famille adoptée par la plupart des botanistes modernes et qui renferme des fougères ayant un port spécial et des sporanges construites sur un plan nettement tranché. Quant aux cyathéacées, s’il est bien vrai que l'anneau ne soit pas rigoureusement marginal, cette légère déviation dans la direction, outre qu'elle n'est pas universelle, ne peut empêcher ces fougères de figurer parmi les polypodiacées. L'liabitude extérieure, qui est rigoureusement celle des Phegopteris et des Aspidium, doit l'emporter sur la modification légère dont il vient d'être parlé; c'est elle qui détermine le choix du groupe dans lequel il convient de les faire entrer. M. PresL attache une grande importance à l'arrangement des faisceaux vasculaires dans l'intérieur du stipe; il ne se sert point de ce caractère comme hase de classification, mais il en détermine soigneusement le nombre et la forme. Dans un mémoire publié récemment, cet estimable savant a donné un grand nombre de coupes de stipes. Il semblerait, à roir les figures qui accompagnent le mémoire, que les espèces d'un même genre offriraient des dispositions semblables. Les maratiacées, les 
ophioglossacées, les osmondacées, les schizéacées, les lygodiacées, les liyménophyllacées, les gleichéniacées et les cyathéacées, familles dans lesquelles les genres sont généralement bien tranchés, seraient soumises à cette loi d'organisation.

M. Gradichaud avait bien longtemps auparavant émis cette opinion que l'on peut confirmer le genre en s'aidant de la coupe du stipe; nous croyons difficilement à la possibilité d'obtenir un pareil résultat; mais outre que cette détermination complète la description des espèces, elle peut servir dans plusieurs cas de moyen de confirmation, lorsqu'il s'agit de fixer la limite de certains groupes. Nous conseillons donc de figurer, autant qu'on le pourra, la coupe horizontale du stipe et du rhizome; on verra plus tard ce qu'on doit penser définitivement de la valeur de ce caractère, difficile à apprécier dans un grand nombre de fougères exotiques, et qu'il fuudrait étudier principalement sous les tropiques.

Le second ordre admis par M. Press, les calhelogyralae, fougères ayant un anneau marginal et une déhiscence latérale, sont divisées en deux cohortes suivant qu'elles ont ou qu'elles n'ont pas d'indusium; cherchons à apprécier la valeur de ce caractère.

Longtemps avant Lıxxé, les botanistes avaient constaté que les sporothèces ou sores des fougères étaient nus ou recouverts d'un tégument, sorte de culicule à laquelle le nom d'indusium fut donné pour exprimer qu'ils servaient d'organe de protection. Dès lors toutes les classifications qui se succẹdèrent, consacrèrent l'importance de cette disposition organique.

Cependant lïndusium, considéré comme caractère de première ou même de seconde valeur; est loin d'avoir l'importance qu'on lui accorde. Les auteurs semblent l'avoir implicitement déclaré en admettant des indusium vrais et des indusium faux; les premiers ayant une structure qui les rend indépendants de la cuticule, les derniers, au contraire, ne paraissant être autre chose que la cuticule elle-même, plus ou moins amincie et devenue scarieuse par une sorte d'arrêt de développement.

Il est difficile et souvent même impossible de reconnaitre le point de transition entre les indusium qualifiés de faux et la cuticule non nodifiée. Certains genres très-naturels présentent des espèces à indusium très-apparent et des espèces à indusium ambigu ou même nul. Les genres Cheilanthes, Myriopteris, Jamesonia, Phorolobns et beaucoup d'autres, se présentent sous ce double état, circonstance propre à expliquer comment les espèces qui les composent ont pu passer successivement dans les fougères angyosores et gymnosores. Il y a plus : nous avons constaté que dans une mêne espèce l'indusium pourail se constituer ou bien avorter. Le Sagenia macrodonta, vu par M. J. Swith à l'élat gynınosore, est devenu pour cet auteur un Diclyopteris; le Podopellis plantaginea que JACQur n'a pas étudié indusié, a pris place parmi les Polypodium, etc. Nous pouvons citer 
comme exemple de la mobilité de l'indusium un specimen de Selliguea parfaitement caractérisé, dont tous les sporothèces sont chlamydiés. Nous possédons encore dans notre collection le Pleocnemia leuceana et le Bathmium trifoliatum, qui se trouvent à l'état gymnosore et à l'état angyosore.

Des particularités semblables expliquent comment il a pu se faire que les auteurs aient placé le genre Vitlaria parmi les fougères angyosores (Swartz et Willdexow), et parmi les gymnosores (PRfsl et Lisk); le genre Jamesonia parmi les angyosores (НоOKER) et parmi les gymnosores (KLOTZsCH), et ainsi des genres Ceterach, Hymenolepis, Leptochilus, Monogramme, Antrophyum et Pleopeliis.

Une autre considération tend encore à affaiblir la valeur de lindusium considéré comme base de classification; soit qüll existe, soit qu'il n'existe pas, la physionomie des fougères ne change point. Or, on sait quill n'est pas un seul caractère important qui ne se reflète sur l'organisation tout entière. Les Lomaria ressemblent aux Lomariopsis, les Schizoloma aux Schizolepton, les Aspidium aux Goniopteris, les Sagenia aux Dictyopteris, les Cyathea aux Alsophila, etc.

Lorsque les genres sont séparés en deux grands ordres, suivant quils ont ou qu'ils n'ont pas d'indusium, les affinités naturelles sont fréquemment rompues et nous avons voulu les conserver.

Les indusiun vrais sont indépendants de la cuticule et affectent une forme spéciale qui permet de les reconnaitre arec une très-grande facilité. Il en est de supères et d'inferes; ceux-ci s'ouvrent sur l'un des côtés ou dans leur pourtour, ou bien encore vers leur partie antérieure; ceux-là ayant une déhiscence apicilaire et présentant une base cupuliforme persistante. Ces sortes dindusium sont bien rarement marginaux; les nervilles sur lesquelles ils naissent, tombent angulairement sur le mésonèvre. Le nom de circonscrits leur conviendrait très-bien.

Les indusium faux sont marginaux, étendus, non parfaitement déterminés; ils continuent la marge de laquelle ils naissent; tendent toujours à la forme allongée et n'ont pas un déreloppement parfaitement arrêté. On pourrait les qualifier d'indéterninés ou de diffus. Il ne faut pas confondre ces indusium vrais ou faux avec l'enveloppe ou sporange des marattiacées et des danéacées.

Comment doit-on considérer l'indusium ? Est-il l'analogue du calice ou bien est-ce simplement une bractée? Nous nous arrêterons à cette dernière opinion. Il est purentent cellulaire et de nature écailleuse, et c'est à son aisselle, sil est attaché latéralement, ou dans son pourtour, s'il est fixé par le centre, que viennent s'attacher les sporanges, comme on voit dans les phanérogames le bourgeon floral ou bouton, se constituer à l'aisselle de la bractée. En le considérant comme un organe accessoire, et il ne semble pas possible de lui assigner aucun rôle important dans la vie physiologique des fougères, on a droit de s'étonner de le voir choisir constamment conme base principale de la classification des polypo- 
diacées; c'est exactement comme si on établissait en phanérogamie les groupes naturels sur la présence ou sur l'absence de la bractée.

Mais si nous refusons de lui donner un rôle important comme organe taxonomique de premier ordie, nous lini accordons volontiers une certaine valeur comme caractère de troisième ou de quatrième. La situation qu'il affecte, la manière dont il s'ouvre, sa forme, assez diversifiée, donnent lieu à des considérations dont on peut tirer parti. L'indusium, considéré relativement à sa situation, se montre tantôt fixé sur les côtés et tantôt sur le dos des nervilles, quand il est dorsal; sa forme tend à être arrondie et plus ou moins allongée quand il est latéral. Dans les deux cas, il ne s'étend pas sur tout le trajet de la nerville et n'en occupe d'ordinaire que la moindre partie.

La déhiscence des indusium vrais n'est pas sans importance comme caractère de tribu; elle est suturale quand elle s'opère à l'opposite du point d'atlache sur la nerville (exemple: les Asplenium); dorsale, au contraire, quand elle sépare le tégument de la nerville sur laquelle il s'était fixé (exemple: les Lindsaya). Elle est univalve dans les aspléniées, bivalve dans les balantiées, circumsessile dans les Cyclodium, etc.

Lor'sque les sporothèces se fixent sur la marge, ils s'attachent souvent sur un réceptacle linéaire et deviennent continus. Ce réceptacle, dont nous parlerons plus tard, n'est autre chose qu'une sorte de bourrelet linéaire simulant une nerville qui se manifeste dans toute la longueur du point d'attache de lindusium sur la niarge elle-mème. Les sporanges naissent à l'aisselle de cette sorte de bractée, mais non toujours. Dans les pellaca et dans plusieurs lomaria, ils s'attachent sur les nervilles de haut en bas, sur une étendue limitée à la largeur même de l'indusium.

C'est lorsque les sporothèces sont recouverts par un indusium narginal quil devient difficile de se prononcer sur l'existence de ce tégument, qui ne fournit plus qu'un caractère incertain ou embarrassant.

Ce qu'on veut bien nommer indusium faux, n'est autre chose que la marge des lames repliée sur elle-mème, laquelle conserve son caractère, ou bien se modifie; ce repli n'est pas nécessairement contemporain de la formation des sporarges. L'indusium vrai, au contraire, apparâit en mêne temps et s'accroît avec, elles comme s’il en était une annexe. La vie dont il jouit est indépendante. Il est souvent caduc et se détache tout d'une pièce.

Les indusium vrais sont supra-culiculaires et apparaissent sur la cuticule inférieure; les indusium faux naissent de la marge, et ils se trouvent exactement dans la position où naissent les cils, avec cette différence qu'ils se replient sur la lane et s'y appliquent plus ou moins exactement. On peut dire d'eux qu'ils sont bicuiculaires, puisqu'ils résultent du prolongement des deux faces de la lame et qu'ils la continuent. Les genres Pleris, Phorolobus, Litobrochia sont dans ce cas. Les 
indusium vrais sont appendiculaires et conséquemment axillaires; les indusium faux, terminaux, opposés ou parallèles.

Ce que nous avons dit de l'indusium comme base de classification, en ce qui concerne la forme et la situation, s'entend nécessairement des sporothèces circonscrits par cette enveloppe cellulaire, étant situés de même et de niême forme. Ces caractères sont pourtant ì peu près les seuls qui aient servi à Swartz, à WilldeNow, à Schicur, à Katlfuss pour former leurs genres, et parmi les modernes, I. Kixze les apprécie au plus haut point. Cependant ils nous paraissent impuissants à constituer des groupes réguliers.

Swartz et ses successeurs regardenit encore comme Polypodium toute fougère sans indusiun, à sporothèces arrondis, épars; comme Grammitis, toute fougère qui montre des sporothèces linéaires droits, égalennent épars; comme Aspidium, toute fougère à sporothèces arrondis, èpars, pourvus d'un induvium ombiliqué et hénisphérique; comme Asplenium, toute fougère à sporothèces linéaires droits, épars, ayant un indusium latéral, s'ouvrant intérieurement, etc. Disons d'abord que dans ces quatre genres les groupes de sporanges ne sont point épars, ainsi que le disent les auteurs, mais réguliers et sériaux. En les adoptant avec des caractères aussi vigues, on agit exactement comme agirait le botaniste qui nommerait Tilia toute plante à fruit arrondi; Arabis, toute phanéroganı à fruit linéaire; Amaranthus, toute plante ayant un périanthe simple; Ribes, tout arbuste portant une baie. En présence de caractères aussi légers, on serait en droit d'exiger du moins que tous les Polypodium aient des sores ou sporothèces arrondis; les Grammitis des sores allongés, etc. Cependant il n'en est rien, et ces genres, tels même que les comprennent les auteurs qui les ont créés, sont empiriques et sortent des limites qui leur ont été assignées; aussi ne peut-on savoir oì ils commencent et où ils finissent. C'est donc ailleurs que dans la forme et dans le node de situation des sporothèces qu'il faut espérer de trouver des caractères génériques.

Sera-ce le réceptacle, la sporange et ses annexes qui les fourniront? sera-ce la spore? ou bien faudra-t-il les demander à la nervation? C'est ce qüil conrient d'examiner.

Le réceptacle est souvent très-développé, mais on connaît peu de genres étendus chez lesquels il soit universel. Très-apparent dans les cyathées, genres $C_{y}$ athea et Alsophila, il est à peine visible dans les genres Cnemidaria et Amphidesminm. On ne le voit plus dans les aspidiées; il reparait dans les polypodiées et se montre fréquemment dans les vittariées. Lorsque les sporothèces n'occupent qu'une seule nervure, le point prolifère, servant d'attache aux sporanges, qu'il soit proéminent ou non, est un réceptacle, et il l'est, en effet, nonjinalement et au même tiıre que celui des phanérogames, consistant parfois et uniquement dans le sommet non modifié du pédicelle, support des verticilles floraux. C'est donc un être de raison ou un ètre réel, et il peut ètre visible ou invisible dans un même genre, 
sans qu'on puisse rien conclure de son absence. La nervure prolifêre dans les Gymnogramme, Nerrogramme et Notochlona ne se modifie en aucune nanière ou se modifie à peine, et l'on dit alors qu'il n'y a point de réceptacle; dans beaucoup de Polypodium cette même nervure se renfle légèrement et devient gibbeuse; il en est de même dans plusieurs Drynaria; elle s'élève davantage et devient conique dans les genres Cyathea et Alsophila, chez lesquels le réceptacle prend une valeur générique. Les sucs, en s'accumulant au point prolifique, donnent naissance à ce bourrelet, uniquement constitué de tissu cellulaire et toujours passif. Dans certains genres à sporothèces allongés et marginaux, il senıblerait, ainsi que nous l'avons déjà fait remarquer, que le réceptacle serait formé par l'indusium au point même ò̀ il adhère à la lame, mais il faut le chercher plus bas; on doit regarder seulement comme réceptacle la partie de la lame qui donne attache aux sporanges; celle où se fixe l'indusium est simplement une nervure suturale. Ce sont des réceptacles spéciaux que ceux observés dans les fougères à sporothèces nus, courant sur la lame à travers les nervilles, sans appartenir à aucune nerville en particulier. Dans les genres Tanilis, Hymenolepis, Selliguea, Nevrodium, Drymoglossum, il existe un bourrelet longitudinal continu sur lequel s'attachent les sporanges; c'est là le véritable réceptacle ayant une origine propre. Il suit de ce qui précède, que dans le plus grand nombre de cas le réceptacle n'est pas essentiellement lié à l'organisme; c'est un organe modifié et non spécial; il n'est donc pas possible de s'en servir comme caractère absolu. Il faut constater sa présence lorsqu’il y a lieu, mais sans y attacher une trop grande importance.

Les sporanges, quant à leur situation, se montrent superficielles ou innmergées; les prenières sont de beaucoup les plus nombreuses; celles qui ont une situation inférieure se trouvent particulièrement dans les vittariées, dans les genres $A n / r o-$ phyum, Ctenopteris, et dans plusieurs espèces de Drynaria et de Niphobolus; quant à leur arrangement les unes à l'égard des autres, il n'est déterminé que dans les genres Niphobolus où les sporanges sont accombantes, (t Alsophila, où elles sont imbriquées, ce qui ne veut pas dire qu'elles ne soient pas disposées de plusieurs autres manières, qu'il serait utile de déterminer. Relativement à la longueur de leur support, elles se montrent très-variables et souvent dans un même genre: exemple le Necroplatyceros. Lorsque les sporanges sont immergées, les pédicelles s'allongent, autant qu'il le faut, pour se mettre en rapport avec la lumière, comme on le remarque dans les fleurs. Il en est de même lorsqu'elles s'attachent à l'aisselle des indusium. On les voit assez généralement dressés dans les fougères gymnosores, flexibles et souvent couchés dans les angyosores.

La dinıẹsion des sporanges est manifestement et universellenient plus grande dans certains genres que dans certains autres, et l'on peut s'aider de ce caractère. La configuration varie peu. C'est toujours une forme lenticulaire avec des contours arrondis ou elliptiques. Il en est de fortensent bombées; d'autres, presque globu- 
laires ou sphérö̈dales. Ces modifications sont rarement génériques, et quand elles le deviennent, c'est une donnée confirmatrice et non un véritable caractère.

Les parties constituantes de la sporange offrent plus de ressources au classificateur.

L'anneau, vertical et à peine oblique dans les alsophilées ou cyathéacées, n'est presque jamais complet. Quelquefois c'est à peine s'il dépasse le sommet organique de ce curieux appareil dont il est le plus splendide ornement; sa couleur est rubiconde ou succinoïde, rouge même ou carminée. Les cloisons ou articles ont seuls cette couleur, tandis que leurs intervalles sont diaphanes et incolores. Cet anneau a une épaisseur variable et contracte une adhérence plus ou moins intime avec le sacculus; dans certains genres il semble dépourru de toute élasticité et conserve sa courbe sans aucune altération après la destruction du sacculus; parfois, au contraire, il s'en détache très-facilement: Lomaria, Plebiogonium et une foule d'autres; sourent alors il se contourne sur lui-même, libre ou adhérent au pédicelle. Ces circonstances sont utiles à noter; si elles se généralisent, on peut avoir un caractère confirmatif du genre; si, au contraire, elles sont exceptionnelles, elles ne peurent servir qu'à déterminer l'espèce.

Le nombre des articulations de l'anneau n'a pas, à beaucoup près, cliez les fougères, limportance du péristome chez les mousses, mais il ne faut cependant pas négliger de le déterminer. Il n'est jamais moindre de 10 (quelques Grammitis) et ne dépasse pas 32 (Onoclea). Si le nombre ne s'altérait pas par suite d'arortement ou de multiplication, on le verrait suivre assez régulièrement la proportion suivante: $12,14,16,18,20,22,24,26,28,50,52$. Voici quel est le rapport qui existe entre les genres à sporothèces nus et indusiés quant au nombre des articulations de l'anneau des sporanges:

GYMYYOSORES. GO GENRES.

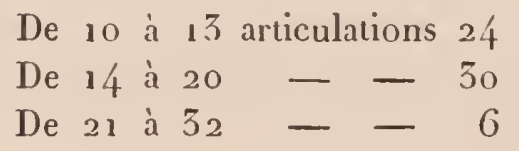

ANGYOSORES. 75 GENRES.

De 10 ¿ 13 articulations 14

De 14 à 20 - 45

De 21 à $32-18$

Ce premier aperçu nous indique que les fougères sans indusium ont généralement des anneaux à articulations moins nombreuses que les fougères indusiées. Il nous démontre encore que sur 135 genres chez lesquels le nombre des articulations de l'anneau a été déterminé, il en est 73 , plus de la moitié, qui portent de 15 à 20 articulations à l'anneau. Mais ces calculs ont peu de valeur; beaucoup de genres nombreux et parfaitement naturels, possèdent des espèces à anneau pauci-et multi-articulé, parcourant sous ce rapport une assez grande échelle. En roici quelques exemples : 
DES POLYPODIACÉES.

\begin{tabular}{|c|c|c|c|c|c|c|c|c|}
\hline Polypodium & - & 11 & - & 16 & Hewardia & - & 16 & - \\
\hline Craspedaria & - & 12 & - & 16 & Blechnum & - & 13 & - \\
\hline Goniopteris & - & 12 & - & 18 & Stenoloma & 一 & 18 & - \\
\hline Goniophlebium & - & 12 & - & 16 & Aspidium & - & 18 & - \\
\hline Anogramime & - & 20 & - & 28 & Polystichum & - & 14 & \\
\hline
\end{tabular}

L’anneau des aspléniées, des hélicogyratées et des dicksoniées est assez généralement multi-articulé; celui des acrostichées et d'un assez bon nombre de polypodiées.est au contraire pauci-articulé.

Le sacculus, c'est-à-dire la capsule, abstraction faite du pédicelle et de l'anneau, est une membrane cellulaire, mince, close de toutes parts, dans laquelle se forment les spores. Les mailles de son tissu sont sinueuses ou rectangulaires, plus ou moins déliées, parfois proéminentes et plus rarement scrobiculées. Nous n'avons pu nous assurer si ces particularités étaient ou non génériques, mais nous ne pensons pas qu'elles le soient. On doit lui reconnaître une partie postérieure ou dorsale, toujours appuyée sur l'anneau, et une partie.antérieure ou ventrale, jamais complétement recouverte par l'anneau. Les exceptions à cette sorte d'organisation se trouvent dans les hélicogyratées. A la base de cette partie antérieure ou dorsale vers le centre, ou bien encore vers le tiers supérieur, suivant que l'anneau entoure plus ou moins conplétement le sacculus, se trouve le stoma, ouverture destinée à livrer passage aux spores. Là, le tissu ordinairement réticulé et hexagonal, subit une modification singulière. Les mailles deriennent parallèles et forment des parallélogrammes ou des courbes à intervalles libres; c'est dans la partie moyenne ou vers le tiers supérieur de ce tissu que s'opère la déhiscence, quoique parfois cette déchirure ait lieu vers tout autre point. Il nous semble évident que le stoma tire son origine de l'anneau dont il est la continuation modifiée. Les nervures qui le composent proviennent des articulations anincies et étendues. Dans quelques sporanges, et notamment dans celles de l'Humata ophioglossa, Cav., le stoma, quoique très-apparent, conserve la couleur de l'anneau, reste épais, charnu et semble moins profondément modifié que dans la plupart des sporanges des autres genres. Cet amincissement des cloisons devient favorable à la déhiscence. L'anneau, fortement hygroscopique, se resserre de bas en haut; il est tantôt plus long et tantôt plus court et ces contractions, purement mécaniques, parviennent facilement à séparer les mailles du stoma, qui, étant parallèles, se disjoignent facilement pour livrer passage aux spores. Celles-ci, en s'accroissant, distendent en outre le tissu et facilitent singulièrement cette rupture. On pourrait dire, avec M. Sснотт, de chaque maille du stoma qu'elle est une articulation; cependant nous préférons lui donner le nom de nervure, afin de ne pas avoir les mèmes termes pour deux parties d'un organe donnant lieu à des phénomènes physiologiques différents. Pour apprécier la valeur du stoma comme caractère générique, 
il faudrait l'étudier dans toutes les espèces d'un genre; or, rien n'est plus long ni plus difficile. La forme du sacculus sur lequel il se constitue étant lenticulaire, ne permet de le voir que de profil. Si l'on s'en rapportait aux figures données par MM. Martics, Kunze el Bauer, on pourrait croire qu'il manque dans les hélicogyratées, mais nous nous sommes assuré que ce fait ne pouvait, à beaucoup près, être généralisé, et qu'il existait chez un grand nombre de plantes oì ces auteurs n'ont pu les voir.

Le sloma a été soigneusement étudié par M. Schotr, mais sur un trop petit nombre de fougères et exclusivement sur des types de genres. On ne peut donc savoir si la forme est la même pour chaque congénère. M. Kuxze, dans ses suites à Scнкинr, l'a constamment indiqué, nrais d'une manière qui ne semble pas suffisamment rigoureuse. Nos travaux particuliers nous disposent à croire qu'il a une importance incontestable, malheureusement ce caractère étant purement microscopique, ne peut être appliquee qu'avec une excessive difficulté.

Les spores, ce dernier terme de la végétation des fougères, prennent naissance au milieu du réseau cellulaire du sacculus, dont ils forment la masse la plus considérable. Lorsqu'elles quittent cette sorte de kiste, elles se présentent nues ou recouvertes des débris de la cellule-mère qui forme, en les entourant, des appendices membraneux, presque toujours déchiquetés. La spore nue est fort semblable aux grains de pollen; sa paroi est constituée par deux téguments : l'un extérieur plus épais, cxosporium, et l'autre intérieur, plus mince, endosporium. Il n'est pas rare de trouver des spores réduites à l'endospore; elles ont alors un aspect vitreux très-remaquable. Ces corps sont sourent remplis de petites granulations (genre Myriopteris) flottantes dans une guttule de matière huileuse qui rraisemblablement, lors de l'évolution de la plantule, remplit le rôle dévolu cliez les phanérogames, aus cotylédons ou à l'albumen, qui se changent, conme on sait, en un liquide émulsil facilement assimilable. La forme que les spores affectent varie ainsi que leur aspect, et probablement suivant qu'elles sont plus ou moins éloignés de l'époque de leur formation.

Examinés dans une même espèce, les spores peuvent affecter plusieurs formes suivant qu'on les voit nues ou revètues des débris de la cellule-mère dans laquelle tlles se développent. Sur 157 genres de polypodiées oì nous les arons reconnues, il s'en est trouvé 73 ovoïdes, 42 trigones et 26 rénifornes; 16 tendaient à la forme globuleuse.

Le secours qu'on pourrait tirer de leur configuration extérieure n'est pas aussi grand qu'on devait espérer qu'il le serait. Cette forme s'altère par l'état de compression dans lequel ces sortes d'atònes vivent, ressemblant en cela aux ovules qui se déforment en passant à l'état de graine. C'est ainsi que les spores ovoïdes se présentent parfois réniformes ou même anguleuses. Cependant il est dans chaque sacculus des spores à forme prédominante. Ainsi l'on peut dire d'une manière 
générale que les acrostichées ont des spores ovoïdes ainsi que les aspléniées, les diplaziées et la plupart des dicksoniees; chez les vittariées, les ptéridées, les alsophilées ils sont trigones ou trièdres. Presque toujour's les espèces d'un même genre produisent des spores de mème forme; exemples: Antroplıyum, Polypodium, Phegopteris, Ceropteris, Acrostichum, Meniscium, Davallia, Lomaria, Blechnum et beaucoup d'autres; ils sont variables dans les diverses espèces des genres CheiJantlıes, Lindsaya, Pleris, etc. Ce n'est point là que se trouve le caractère générique, mais les sporès mettent sur la voie qui permet de confirmer le genre et mème de le circonscrire, lorsqu'on s'est aidé de l'étude des autres organes.

La surface des spores donne lieu aux mêmes considérations que celles fournies par le pollen. Il en est de lisses, de rugueuses, de prismatiques, de polyédriques, de triédriques, etc. Les unes sont relevées par des rides, des côtes, des pointes, des papilles; les autres, bordées par des membranes. Celles-ci s'ouvrent régulièrement, celles-là se déchirent vers un ou plusieurs points de leur étendue, quelquesunes sont parcourues par un véritable réseau proéminent. Toutes ces particularités semblent donner une grande importance à ces organes, mais leur prodigieuse ténuité rend leur étude, étendue à toutes les espèces, bien difficile.

On trouve avec les sporothèces des poils étoilés, simples ou articulés : Nevroplatyceros, Niphobolus, Drymoglossum, Hecistopteris, Cyathea, Alsophila, etc., des écailles : Lomagramme, Pleopeltis, Craspedaria; des glandes: Adenophorus; enfin des sporangiastres ou sporanges modifiées et arrètées dans leur développement : genres Chrysodium, Villaria, Pleropsis, Tanitis, Schizolepton, Monogramme, Antroplyyum, Pterosonium, Cheilanthes, Ochropteris, etc. Ces sporangiastres subissent des modifications plus ou moins profondes et leur forme est extrèmement variée. Ce sont encore là des moyens de confirmer le genre dans quelques cas douteux. On voit parfois, à la base du pédicelle des sporanges, des productions auxquelles Prest a donné le nom d'étamines. Nous avons pu quelquefois les observer; ce sont des sporanges non encore développées. Les pédicelles se montrent fréquemment fasciculées, et l'on voit sur un neeme support des sporanges et des sporangiastres. Dans un petit nombre de cas, on trouve sur le trajet du pédicelle des productions piliformes articulées; dans le genre $S_{c h i z o-}$ crena, elles naissent à la base et à la partie moyenne du pédicelle, et dans le genre Bathmium à son sommet. Dans quelques autres genres ces corps allongés apparaissent aussi sur les sacculus ou même à la base de l'anneau. Ils sont en hameçon dans les Meniscium de l'Inde, coniques dans le genre Pleuridium, articulés dans le Cibotium et le Culcila. Il est à remarquer que ces productions accessoires appartiennent surtout aux fougères gymnosores. Les sporangiastres, par exeniple, sont exceptionnelles dans les fougères angyosores. Parfois ces corps prennent une apparence écailleuse, et comme ils sont pédicellés au centre, on les qualifie d'écailles peltées (ex. genre Lomagramme, Hymenolepis, Pleopeltis). Ce 
- sont de véritables sporanges chez lesquels le sacculus et l'anneau, au lieu de s'arrondir pour former une cavité close ou sacculus, s'étendent et constituent une sorte de parasol. En y regardant bien, on voit que les bords de ces espèces d'écailles sont entourés d'une zone extérieure dont les aréoles appartiennent à l'anneau et au stoma, distincts l'un de l'autre par la disposition du tissu et par la couleur; celles du centre, plus irrégulières, se font reconnaître conme dépendantes du sacculus.

Cette revue des organes serait incomplète si nous ne parlions des frondes. Nous nous contenterons de les ètudier au point de vue taxonomique.

Ce sont elles qui donnent à la plante sa physiononie propre. Sur ı 68 genres, il en existe 46 à lame simple et 14 à fronde pinnatifide; 88 sont pinnées avec pinnules pinnatifides, bipinnées ou décomposées; 20 genres sont mixtes, c'est-àdire, qu'ils renferment des espèces à frondes simples et des espèces à frondes plus ou moins décomposées.

Les frondes simples se trouvent surtout dans les fougères gymnosores et les frondes décomposées dans les fougères angyosores. Nous ferons encore observer que les polypodiacées européennes, à l'exception du seul genre Scolopendriurn, sont toutes à frondes divisées.

Dans le plus grand nombre de cas, le mode de division de la fronde est en rapport avec le genre et il le confirme. Nous ferons remarquer en outre que certains genres semblent ne devoir renfermer que des espèces herbacẻes, et d'autres que des espèces ligneuses. Les genres mixtes sont extrênement rares.

Il est dans la fronde un caractère facile et très-naturel, fortement préconisé par les uns et trop négligé par les autres; la nervation, c'est-à-dire la disposition du système vasculaire ou son mode d'épanouissement dans la lame. Déjà dans un premier mémoire sur les plantes de cette famille, exanıen des bases adoptées dans la classification des fougères et en particulier de la nervation (1844, in-fol.), nous avons fait voir de quel secours elle pouvait être dans la formation des genres; nous ne répèterons pas ici ce que nous avons dit ailleurs, cependant nous ferons connaître que plus nous avançons dans l'étude des genres et plus nous arrivons à nous convaincre que ce caractère l'emporte en inportance sur celle que l'on accorde à la forme et mêne à la situation des sporothèces. En séparant en groupes toutes les fougères, suivant les différences que prẻsentent les nervures, et en faisant l'application de ce caractère dans toute sa rigueur, il en résulte un grand nombre de genres. Mais ce désavantage, si c'en est un, ne donne lieu qu'à des inconvénients sans importance et se trouve, bien au delà, compensé par la prodigieuse facilité avec laquelle on reconnait les genres sans laisser d"incertitude dans la déternination. Nous ne doutons pas un instant que cette base n'acquière tôt ou tard dans l'opinion des botanistes une valeur égale à celle que nous lui accordons. 
Déjà les opposants reconnaissent que la nervation peut servir à former des sous-genres; c'est quelque chose, sans doute, mais ce n'est point encore assez. En se restreignant ainsi, il arrive que plusieurs sous-genres sont séparés du genretype par des caractères beaucoup plus considérables que ceux qui séparent certains genres entre eux.

Il est à remarquer que les auteurs qui refusent de reconnaître l'importance de la nervation et qui ne veulent point adopter les genres de M. Presl comne n'étant pas établis sur des caractères suffisamment solides, en créent d'autres qui semblent l'être bien moins. En voici quelques exemples.

Le genre Amauropelta de M. Kunze a le port des Aspidium à frondes divisées et ses sporothèces sont aussi recouverts d'un indusium réniforme; mais comme la marge des frondes se replie sur les sporothèces pour former un faux indusium, un genre a été créé. Il en a été de même du genre Hypodematium du même auteur, qui ne diffère de l'Aspidium et de l'Amauropelia que par des indusium déprimés vers leur point d'attache, coriaces, persistants, et recourbés plus tard à leur base. Cet auteur estimable a cru devoir proposer ces genres et quelques autres aussi peu solides, tandis qu'il regarde comme un simple sous-genre de l'Aspidium le genre Oleandra de Cavanjlues, fougère à nervures parallèles, à fronde simple, soyeuse, articulée sur une souche grimpante et écailleuse, à sporothèces presque costaux, et croit pouvoir placer à côté les uns des autres les Aspidium nobile, augescens, pedatum et stenopteris, de nervation et de port si différents.

C'est ainsi que M. Klotzsch réunit, dans son genre Pleris, les Allosorus et les Litobrochia de PResL pour conserver le genre Doryopteris de J. Sмiтн; qu'il met dans son genre Aspidium, les genres Oleandra, Polystichum, Lastrea, Nephrodium, Cyclodium, Phanerophlebia, Amblia, Bathmium; dans son genre Polypodium, les Goniopteris, Goniophlebium, Anaxetum, Campylonevron, Pleopeltis, en même temps qu'il crée un genre Mecosorus, qui aurait pu prendre place dans quelques-uns des genres cités plus haut, et un genre Lotzea, qui ne paraît être autre chose qu'un Diplazium à indusium frangé vers la marge.

Ce n'est point ainsi que M. PresL en avait jugé. En combinant les caractères tirés des sporothèces considérés dans leur vestiture, leur forne et leur situation avec ceux fournis par la nervation, il est parvenu à coordonuer les espèces dans les genres, et les genres dans les groupes d'une manière heureuse. Si cet auteur n'a pas fait un travail irréprochable, c'est qu'il est le premier entré dans une voie nouvelle où il a marché sans guide.

Les bases que nous croyons propres à établir une classification ont été déjà indiquées par nous dans un autre ouvrage; ce sont les suivantes: 


\section{Pour les ordres ou familles:}

Présence ou absence de l'anneau.

Situation de l'anneau.

Mode de déhiscence des sporanges.

Pour les sous-ordres:

Lieu d'élection de la pujssance prolifique.

Absence ou présence de l'indusium.

Direction des sporothèces par rapport au mésonèvre ou axe de la feuille.

\section{Pour les genres:}

Altache et mode de déhiscence des sporothèces.

Siluation, forme et étendue des sporothèces.

Nervation.

Monotaxie ou diplotaxie des frondes (suivant que les fougères ont ou n'ont pas leur fructification sur des frondes séparées).

On pourra voir, par le tableau que nous donnons à la suite de ces prolégomènes, comment s'enchainent les groupes; nous allons indiquer ici brièvement quelles sont les analogies qui les lient entre eux, et quels sont leurs caractères différentiels les plus imposants.

\section{\$. 1. Folgères a sporanges portant un anvead vertical : cathétogiratées,}

\section{Fruclification naissant sur toute létendue des lames.}

1. Acrostichées. Fougères extrèmenent proliferes, dont les lames fertiles se chargent de sporanges altachées sur toute la surface, sans lieu d'élection spécial. Dans quelques genres, les deux lames en sont entièrement courertes. Ces plantes ont une grande tendance à produire des écailles et vivent presque toutes darrs les régions tropicales, acquérant parfois des dimensions considérables, mais restant néanmoins toujours à l'état herbacé. Les acrostichées se lient étroitement aux lomariées par les genres Lomariopsis, Leptochilus et Photinopteris, chez lesquels on peut constater la présence d'une membrane scarieuse, marginale, sinulant un faux indusium. Dans ces trois genres, les pinnules fertiles sont extrèmement étroites, et dans la jeunesse les sporanges se cachent sous un repli que forme la marge. En prenant leur complet développement, les lames deriennent tout à fait planes ou mème bombées; c'est alor's que leurs bords s'amincissent et se 
modifient. Les faux indusium ne revêtent le caractère scarieux des indusium vrais que quand les sporanges ont acquis tout leur développement; dans la jeunesse, les bords repliés des lames conservent la couleur et la consistance du reste de la fronde. C'est à l'épuisement des sucs nourriciers, qui se portent sur les sporanges, qu'il faut attribuer le changement opéré dans cette partie de la lame.

\section{Fougères à fructification localisée.}

A. Sporothèces occupant plusieurs nervures.

1. Nous avons désigné sous le nom de leptocarpidées les fougères chez lesquelles la puissance prolifique agit sur toute l'étendue des lames pour former des sporothèces longitudinaux perpendiculaires au mésonèvre dont ils sont plus ou moins écartés. Les sporanges naissent fréquemment sur un réceptacle spécial longitudinal ou bien forment une ligne continue qui entoure la marge. Elles s'attachent quelquefois au mésonèvre et parfois naissent sous la cuticule inférieure, de manière à paraitre situées dans le mésophylle. Lorsque les frondes ou lames fructifères sont linéaires ou lancéolées, le parallélisme des sporothèces est évident; mais si elles affectent des formes arrondies comme dans certaines lindsayées ou dans plusieurs ptéridées, ces sporothèces bordent la marge; cependant la disposition est exacteinent la mème, puisque dans tous les cas ils coupent les nervures en travers sans se fixer sur aucune d'elles en particulier. Ces diverses considérations ont permis de former sept groupes distincts : nous allons dire un mot de chacun d'eux.

2. LomariÉes, premier groupe des leptocarpidées, grandes fougères de consistance ferme, dressées ou volubiles, munies d'un indusium évident qui s'ouvre de dedans en dehors, et se déchire irrégulièrement lorsqu'il est déjeté à l'extérieur par suite de l'accroissement des sporanges qui s'attachent très-fréquemment sur un réceptacle spécial. Les lames fertiles sont envahies complétement par ces corps reproducteurs (Lomaria et Stenochlcena), ou bien inconplétement (Blechinum et Salpichloena). L'Hymenolepis qui a rarement été vu indusié, n'est fructifié que vers le somnet, modifié d'une manière curieuse. Ainsi qu'il a été dit, ce petil groupe se lie aux acrosticliées. On pourrait, sans trop d'inconvénients, y faire entrer les genres Leptochilus, Lomariopsis et quelques autres, chez lesquels pourtant les sporanges sont cuticulaires. Le genre $H_{y}$ menolepis n'est pas sans analogies avec le genre Nevrodiurn de la tribu des vittariées. L'Acropteris se rattache, quoique de loin, aux aspléniées. L'Onychium s'èloigne par le port des lomariées; mairs la disposition des sporanges ne permet guère de l'en séparer.

3. Vittarí́Es. Fougères tropicales, presque toujours simples, glabres et flexibles, qui tendent à la forme linéaire et vivent pour la plupart sur les troncs d'arbres d'où elles pendent à la manière des usnées. Leur's lanies sont bordées ou parcourues par des sporothèces linéaires, immergés ou superficiels, plus rarement 
situés dans le mésophylle, ayant d'ordinaire un réceptacle nervilliforme conme dans les ptéridées. Il n'y a point d'indusiun; cependant il arrive quelquefois que la cuticule inférieure, en cédant à l'action des sporanges qui la soulèvent, se modifie, devient scarieuse et simule un faux indusium.

On trouve dans ces plantes, mêlés aux sporanges, des corps de forme et de couleur variée, ordinairentent scyphuliformes : ce sont des sporangiastres. Le rhizome se charge toujours d'écailles cancellaires et de fibrilles radicales abondamment couvertes d'un épais lomenlum jaunâtre. Ces organes accessoires prennent, en se généralisant, limportance d'un véritable caractère générique.

Le genre Drynoglossum, qui se lie aux Niphobolus, ayant, conme les espèces de ce genre curieux, des ècailles peltées et des frondes diplotaxiques, doit être regardé comme dissident. Le genre Schizoleplon se rapproche beaucoup des lindsayées. Il est à remarquer que dans les Cuspidaria, genre à nervation réticulée, une espèce a des nervures libres; c'est la seule anomalie de ce genre que nous ayons à signaler.

4. Plectrogrannées. Fougères sans indusium, caractérisées par des sporothèces appuyés sur le mésonèvre. Elles sont petites, souvent graniniformes et privées d'un facies propre. Les genres Monogramme et Vaginularia n'ont point de nervilles latérales. Toutes portent leurs fructifications ver's le sommet des frondules. Le genre Plcurogramme se rattache aux lomariées par l'Hymenolepis, et aux Villaria par le Monogramme, qui, l'un et l'autre, ont des frondes linéaires et étroites, ainsi que des sporangiastres, des écailles cancellaires et des fibrilles tomenteuses; nuais là s'arrête l'analogie. La grande simplicité d'organes dans ces plantes pourrait les faire placer à la tête ou à la suite de la série des genres. L'Adenophorıs de AI. Gaudichacd troure une place parmi les pleurogrammées, quoiquil soit dissident à certains égards.

5. LINDSAıÉES, fougères herbacées, glabres, dressées, à frondes simples, ayant des marges entières chargées de sporothèces linéaires, étroits, continus ou interrompus, à pinnules dans la plupart des genres, dimidiées, courbes et comme arquées. Les nervilles n'atteignent pas la marge, c'est sur leur extrémité, un peu renflée, que s'étendent les sporothèces. L’indusium est formé par une étroite bande de tissu, à l'aisselle de laquelle se constituent les sporanges. Cet indusium se dirige de bas en haut. Si on l'enlève, il reste au point de développenent ou d'attache un petit bourrelet, qui simule un réceptacle et unit toutes les nervures entre elles. Les lindsayées prennent presque toutes, en se desséchant, une teinte jaune-paille très-prononcée; le stipe lisse et glabre ne revêt presque jamais cette teinte noire d'ébène si souvent observée chez les Adiantum. Le Lindsaya et le Synaplllebium ont le port de l'Adianlum; le Schizoloma ressemble aux Pleris; le Diclyoxyphium rappelle le Doryopleris. Dans le Schizoloma, l'indusium, extrènement étroit, semble résulter dı dédoublement des deux cuticules; cette particularité 
tend à faire croire que les sporothèces sont endophylles, mais il n'en est rien. Si l'on enlève la cuticule inférieure, on reconnaît bientôt que c'est un indusiunı et qu'il s'attache comme dans les autres genres à l'extrémité des nervures. Toutefois le Schizolorna semble s'unir au genre Schizolepton, du groupe des vittariées.

6. AdintéEs. Ce groupe ne renferme que quatre genres; le type, l'Adianlum, ainsi que l'Hewardia, offrent une particularité curieuse moins évidente chez les autres genres. Lorsque la marge devient fertile, les nervures s'allongent et se divisent en se bifurquant. Cette partie ainsi accrue, devient épaisse et coriace; elle se colore en brun, se réfléchit et constitue un véritable réceptacle, dont les bords s'amincissent et forment un indusium scarieux qui varie d'étendue et de configuration. En examinant ce réceptacle, il est facile de constater la présence des nervures; elles sont en relief et en nombre double ou même quadruple de celui des nervures sous-jacentes. C'est sur elles que s'attachent les sporanges. Ce réceptacle peut être continu et interrompu dans le même genre; parfois il est réniforne ou cordiforme; ses bords sont toujours entiers.

7. PTÉRIdÉEs. Grandes plantes cosmopolites, dressées, rampantes, herbacées et par exception ligneuses; à segments pinnulaires, tendant à la forme linéaire et s'amincissant en pointe. Il en est de pédiaires et de palmées. La marge se replie pour devenir prolifere; le repli est ètroit et de même largeur dans toute son étendue. C'est là que se constitue, ou que vient s'altacher, un indusium étroit, scarieux, qui se soulève tout d'une pièce et disparaît parfois sans qu'on puisse en retrouver de traces. Dans plusieurs espèces des genres Pleris et Pellaca il nuanque entièrement. On ne le voit pas dans l'Amphibleslra, quoique les auteurs aient écrit le contraire. Les sporanges toujours marginales se fixent sur un réceptacle linéaire posé à l'extrémité des nervures. Il n'existe pas dans les Pellaca, et des nervilles le suppléent. Cette particularité pourrait suffire pour placer ce genre dans un autre groupe, si ses autres caractères n'en faisaient une véritable ptéridée.

Le genre Pleris, le plus considérable de ce groupe, renferme des espèces à seginents étroits dont toute la surface est occupée par les indusium, qui souvent atteignent le mésonèvre; dans cet état, ces plantes ont quelque chose de l'organisation des Lomaria. Toutes les ptéridées ont des fructifications continues; elles ne sont interrompues que dans le genre Lonchitis, et accidentellement, que dans un très-petit nombre de Pleris. Les sporothèces occupent, dans le Lonchitis, le sinus des lobes pinnulaires, nais il arrive assez souvent qu'ils s'étendent sur la marge. On retrouve une disposition bien voisine chez deux ou trois espèces de Pleris réunies dans une section spéciale, à laquelle nous avons donné le nom de Lonchilidium.

8. CheilanthéEs. Elles sont caractérisées par des sporothèces nus ou recouverts par la marge devenue scarieuse, occupant le sommet des nervilles pour constituer des groupes continus, formés d'un petit nombre de sporanges. Ce sont 
des fougères herbacées, délicates, couvertes d'écailles ou de poils abondants, dressées, fasciculées sur un rhizòme ordinairement dressé ; jamais simples, divisées en segments obtus, nombreux et fort petits; offrant dans l'un de ses genres, le Jamesonia, l'exemple unique d'une évolution circinale indéfnie. Dans ces plantes, lindusium n'est point universel et le même genre a des espèces gymnosores et angyosores avec des transitions extrênement ménagées qui ne permettent pas de les séparer, tant elles sont du reste étroitement unies. La place que doivent occuper ces fougères dans la série des groupes est difficile à déterniner; elles se lient aux ptéridées par le genre Phorolobnıs et aux hénionitidées par quelques espèces de Cheilanthes; mais dans les plantes de ce groupe, les sporanges naissent au-dessous de la marge pour tomber angulairement sur le mésonèrre, tandis que dans les cheilanthées elles se déreloppent tout à fait sur les dernières limites des lames qu'elles bordent, et ne descendent vers le mésonèvre qu'à titre exceptionnel; ajoutons qu'elles sont presque toujour's indusiées.

\section{B. Sporothèces occupant une seule nervire.}

Ces groupes terminent la série des fougères à anneau des sporanges vertical ou cathétogyratées, renfermant les fougères ayant des sporothèces nervillaires, latéraux, tombant angulairement sur le mésonèvre, auquel se rattachent les nervures ou nervilles prolifêres; nous leur avons donné le nom de GoxiocarpidéEs; quinze groupes y trourent place.

9. HĖMioxitıdéEs. Fougères à sporothèces allongés, toujours nus, occupant toute l'étendue de la nerville prolifere. Elles varient et par le port et par la nature des téguments qui chargent les lames. Celles-ci sont nues dans les genres Coniogramme, Anogramme, Callogramme, Syngramme et Diclyogramme, couvertes de poils nombreux dans les genres Nevrogramme et Hemionilis. Elles sécrètent une matière céreuse, de couleur diverse, dans les genres Trismeriu et Ceropleris. Le Nevrogramme se couvre de poils pareils à ceux de l'Hemionitis; les genres Ceropleris et Anogramme ressemblent à des Phegopleris. Les hémionitidées ont entre elles d'assez grandes analogies, ainsi le Trismeria ne diffère guère du Ceropteris que par le port, qui, en effet, lui donne une physionomie toute particulière. Les Coniogranme et le Diclyogramme ont, avec des sporothèces semblables, une nervation bien différente. On peut encore trouver des analogies entre le genre Gymnogramme et le Phegopleris, entre l'Anogramme et le Cyslopleris, etc. Ce groupe n'est donc pas aussi naturel qu'on pourrait le désirer; cependant il est fondé sur des caractères communs qui ont leur importance.

10. Axtrophýes. Deux genres seulement constituent ce groupe. Les nerrures sont anastomosées. Les aréoles se chargent de sporanges sur les plans perpendiculaires des aréoles dans l'Antrophyum, qui se rapproclie des vittariées par 
l'immersion des sporothèces ainsi que par la présence des sporangiastres, des écailles cancellaires et des radicelles tonıenteuses. Les aréoles régulières inclinent leur plus grand diamètre vers le mésonèvre, ce qui les soumet à la loi d'organisation commune aux fougères à nervures prolifères, se dirigeant obliquement vers la côte médiane. Le genre Selliguea a des frondes simples et plus rarement pinnées; les lames se chargent de sporothèces linéaires continus ou interrompus qui tombent angulairement sur le inésonèvre et envahissent plusieurs nervures. La nerville commune aux deux aréoles, s'épaissit et constitue un réceptacle linéaire. Ce genre se rapproche de l'Antrophyum beaucoup plus qu'il ne parait, et si la disposition des sporothèces semble différente, cela tient uniquenent à la direction des aréoles qui, dans le Selliguea, forment des angles très-ouverts, et dans l'Antrophyım des angles très-aigus; il en résulte que dans le premier genre les sporothèces paraissent presque perpendiculaires, tandis que dans le second ils sont évidemment et fortement obliques. Faisons aussi remarquer que dans le Selliguers les grands plans aréolaires ne sont fertiles que par alternance.

11. Leptogrammées. Petit groupe de transition, faiblennent caractérisé, qui diffère des hémionitidées et des antrophyées par des sporothèces allongés, nus, qui n'occupent qu'une partie restreinte des nervilles. Ce sont des plantes bien voisines des aspléniées, ou, si l'on veut, mêne des aspléniées non indusiées.

12. Asplénićes. Fougères herbacées, dressées, à frondes presque toujours glabres, très-diversement divisées, souvent pinnées, plus rarement simples, tendant presque constamment à allonger leurs segments et à reproduire la forme lancéolée, etc. Les sporothèces linéaires ou ellipsoïdes sont recouverts d'un indusiun simple, étroit, coupé en biseau à ses extrénités, attaché latéralenent sur la nervure fructifere dont il n'atteint jamais le sommet; les sporanges naissent à l'angle interne que forme l'indusium vers son point d'attache; les spores sont ovoides et plus rarement réniformes. Ce groupe est bien distinct. Il se lie aux scolopendriées par le Neottopteris, aux diplaziées par le genre Asplenium, et aux leptogrammées par le genre Plecosorus, dont les espèces avaient été placées jusqu'ici dans le Gymnogramme. On ne trouve de sporangiastres que dans l'Asplenium serratım, grande espèce à frondes simples et à port spécial. Ce groupe pourrait revendiquer le genre Darea, mais comme les sporothèces sont absolument marginaux et que le port est distinct, nous l'avons placé dans les davalliées auxquelles il se lie par le mode de déhiscence de l'indusium.

Ce tégument, qui est latéral dans tous les genres composant les aspléniées, est dorsal dans le genre Allyrium. Cette circonstance qui s'accompagne de quelques particularités tirées des organes de la nutrition est assez importante, et pourrait motiver la formation d'un sous-groupe: les athyriées, sortes de fougères à frondes - délicates, décomposées, glabres, à sporothèces ovoïdes, protégés par un indusium épais, persistant, bombé, qui se redresse de dedans en dehor's à la maturité. 
13. SColopeidriées. Ces fougères présentent ce caractère singulier, d'avoir un double indusium, occupant deux nervures, prolifères au même point. Cette corélation, entre deux nervures séparées, est un fait curieux, sans exemple dans la famille des fougères. De ces deux indusium, l'un est supra- et l'autre infra-nervillaire; ils sont unis dans leur jeunesse, et s'ouvrent en leur centre à l'àge adulte; les deux rangées de sporanges sont séparées par une nerville spéciale longitudinale qui ne remplit pas les fonctions de réceptacle. Dans le genre Camplosorus, il y a rapport de situation, mas l'opposition est moins directe. Les scolopendriées sont des fougères ordinairement simples, cordées à la base ou même sagittées, assez mobiles dans lcurs formes: on les trouve en Europe, dans l'Amérique septentrionale, et jusque dans les iles de la mer du Sud. Ce groupe, parfaitement distinct, est peu nombreux en espèces.

14. DipliziéEs : fougères tropicales, herbacées, ou plus rarement arbores centes, ordinairement divisées, quelquefois simples, étalées, tantôt inernıes, et tantòt épineuses, dont les sporothèces tendent d'une manière narquée à la forme allongée. Les deux indusiun opposés prennent leur attache sur les deux còtés correspondants de la même nervure prolifère, pour s'ouvrir à deux battants, l'un extérieurement et l'autre intérieurement. Lorsque l'un de ces deux téguments manque, c'est ordinairement l'inférieur qui asorte; cet avortement a lieu surtout au préjudice des sporothèces qui se déreloppent dans le bas de la fronde, à l'époque de son premier développement: dans cet état, la plante est un véritable Asplenium. Quoique parfaitement distinctes, les diplaziées ne sont pas sans analogie avec les aspléniées.

15. Méxisciées. Ce groupe doit son nom à la forme des sporothèces, arqués ou seni-lunaires, qui se développent sur des nervilles transverses, arquées ou anguleuses, unissant des nerrures pinnées : la puissance prolifique s'étend à la nerville tout entière. Ce sont des plantes tropicales, dressées, d'une texture délicate, herbacées ou, par exception, arborescentes; leur féracité est extraordinaire. Nous en possédons une espè̀ce fertile des deux côtés de la lame. Le sacculus des sporanges porte fréquenment des poils dressés, roides, à base épaisse et recourbés au sommet en hameçon. Quoique ce groupe soit distinct, il a néanmoins une trèsgrande analogie avec le genre Goniopteris du groupe des polypodiées. La nervation est absolument la mème, et si la puissance prolifique ne se manifestait pas sur deux points latéraux pour donner naissance à des sporothèces arrondis, on serait tenté de les croire identiques. Lorsque ces sporothèces deviennent confluents, il est extrêmement difficile de les différencier. On trouve aussi des poils en hameçon sur le sacculus d'un grand nombre d'espèces de Goniopleris.

16. Struthoptíridées. Les fougères qui composent ce petit groupe, ont un port bien différent de toutes celles dont il vient d'être parlé : elles sont lierbacées, diplotaxiques, c'est-à-dire, pourvues de frondes fertiles et stériles séparées. Dans le 
Struthiopteris les frondes fructiferes naissent tardivement au centre du panache que forment les frondes stériles; c'est une sorte d'évolution centripèie qui a lieu à deux périodes de l'année pour donner des frondes, à ce point différentes les unes des autres, que si les botanistes les eussent vues toujours séparées, il leur aurait été impossible de les rapporter à une même plante. Lindusium est nul dans le Struthiopteris; il existe dans l'Onoclea, quoiqu'on puisse cependant regarder la membrane qui recouvre les sporothèces comme la cuticule elle-nême modifiée, en raison du milieu où elle vit et se développe, étant, comme on sait, privée du contact de la lumière et abreuvée de sucs nourriciers très-abondants. L'épithète de sensibilis donnée à une espèce d'Onoclea, indique seulement que la fronde stérile se flétrit rapidement par le contact le plus léger.

Ces plantes sont cosmopolites, l'une d'elles se trouve en Europe; l'Amérique septentrionale nourrit la plupart des autres espèces, du reste fort peu nombreuses.

17. PolypodíEs: groupe le plus considérable de la famille des polypodiacées à laquelle il donne son nom. Ce sont des fougères herbacées, rarement arborescentes, offrant dans leurs frondes tous les modes possibles de découpures : elles varient d'aspect et de port. En parler avec. détail, serait répéter ce qui a été dit précédemment dans nos considérations générales.

On les trouve sous toutes les latitudes; la plupart se plaisent sur les vieux troncs d'arbres ou sur les branches, d'où elles pendent quelquefois vers la terre. Leurs spores sont réniformes ou ovoïdes. Quoique les sporothèces tendent à la forme arrondie, cette tendance n'est pas à beaucoup près universelle. Presque tous les genres nombreux ont des espèces à sporothèces ovoïdes; exemples : Grammitis, Polypodium, Goniophlebium, Niphobolus, Chrysopteris, Drynaria, Dryostachyon. Lors même que ces groupes paraissent globuleux, ils naissent sur un réceptacle ovoïde ou exceptionnellement elliptique. Ce réceptacle n'est point spécial, mais uniquement formé par le renflement de la nervure prolifère. La turgescence s'opérant sur un faisceau vasculaire allongé, ne peut donner que difficilement lieu à la forme sphéroïdale régulière. Souvent ce réceptacle, qui n'est pas toujours apparent, prend un aspect glanduleux, il se colore, la lame inférieure s'affaisse et la supérieure se tache en noir, puis devient bombée (Goniophlebii, Niphoboli, Drynarice species). On trouve des poils sur le sacculus de plusieurs. espèces de Goniopteris, de Pleuridium et de Dryostachyon. Il existe des écailles mêlées aux sporanges dans le Drynaria et le Craspedaria, et des poils dans le Niphobolus. Nous n'y avons jamais vu de sporangiastres, et peu d'entre elles sont proliferes. Ces fougères se lient aux acrostichées par le genre Niphobolus, et elles marchent parallèlement avec les cyclodiées, les aspidiées et les nephrolépidées.

18. CyclodiéEs; groupe très-naturel, facile à reconnaître à l'indusiumı, pelté en son centre, et porté sur un pédicelle attaché au sommet de la nerville prolifere. Autour de ce pédicelle se trouve un réceptacle bombé ou corique sur lequel s'at- 
tachent les sporanges. Celles - ci sont soumises à un développement centripète, comme les néplirolépidées, et leurs pédicelles s'allongent autant qu'il le faut pour faire dépasser à la sporange les limites de l'indusium. A l'époque adulte, celui-ci est soulevé dans son pourtour et se crispe plus ou moins complétement. Si le pédicelle est grêle, le disque ou capitule de lindusium tombe et le sporothèce se nıontre à nu; beaucoup de cyclodiées, conservées dans les collections, et qui ont été méconnues, sont dans ce cas. Le pédicelle de lindusium s'appuie directement sur la nerville; c'est une sorte de columelle, autour de laquelle se développe un réceptacle, véritable placentaire central, riche en principes nourricịers.

Les cyclodiées sont des plantes cosmopolites, robustes, dressées, Jobées, souvent terninées par une pointe parfois roide et presque vulnérante (Polystichum). Elles ont une grande tendance à se couvrir d'écailles (Polystichum et Cyrlomium), et se présentent parfois sous la forme gymosorienne par avortement de l'indusium.

19. AspidiÉEs; groupe très-vaste et très-bien circonscrit, avec indusium et réceptacle réniformes. Les frondes fertiles, dès leur premier déreloppenent, montrent l'appareil de la fructification sur le trajet des nervilles, comme s'il était contemporain de la formation de la fronde; l'indusium n'est pas attaché par le còté comme on l'a dit, mais sur un pédicelle central qui en est indépendant. Ce support est souvent très-délié, le réceptacle l'entoure, comme le placentaire entoure la columelle. Il est cylindroïde, largement implanté sur la lame, ou bien déprimé et même lamineux. Dans le premier cas les téguments protecteurs sont exactement planes; dans le second, froncés au centre. Le réceptacle est verdâtre, et se rapproche plus ou moins de la forme de lindusium. Autour de cet axe, de nature charnue, naissent les sporanges, soumises à un véritable développement centripète. Il est facile de reconnaître que lïndusium s'accroît par ses bords en même temps que les organes qu'il protége. A la maturité, il se souleve par les côtés, qui s'appliquent l'un contre l'autre, devient rouillé, et disparaît quelquefois au milieu des sporanges, accrues et distendues par les spores.

Les sporolhèces sont toujours superficiels. On trouve des sporangiastres dans le genre Pleocnemia; les spores ont une forme ovoïde ou rénaire. Les aspidiées sont herbacées, flexibles, souvent délicates, terrestres ou arboricoles et cosmopolites.

20. TePIRolépidéEs. Ce groupe renferme des fougères à sporothèces pourvus d'un indusium, plutôt héenisphérique que réniforme, fixé par la base, qui reste toujours adhérente à la lame; toutes ont des frondes pinnatifides, allongées, trèssouvent pendantes et arboricoles. Le genre Nephrolepis possède une espèce dont le rhizome se charge de tubercules. Nous avons donné l'analyse de cette singulière production, unique dans la famille des fougères. Les faisceaux vasculaires, régulièrement disposés dans ce tubercule, sont formés de vaisseaux annulaires.

21. Davalisers. Ce groupe tire son caractère principal du sporotlièce, qui dillère essentiellewrent de celui des aspidiées. Cet appareil est terminal, ovoide, 
engaîné et attaché de tous côtés; il s'ouvre antérieurement par un orifice béant. Le réceptacle consiste en un simple renflement du sommet de la nervure prolifere. Les sporanges sont attachées sur cette base étroite, et les pédicelles, en s'allongeant, les sortent de cette espèce de gaine. Dans plusieurs genres, l'indusium peut être regardé comme douteux (ex. : Scyphnlaria, Prosaptia, Odontosoria); les deux cuticules conservent leur caractère, et le sporothèce n'est indiqué que par une gibbosité plus ou moins marquée. Le genre Davallia, tel que nous l'avons caractérisé et restreint, se charge de sporothèces situés au sommet d'une nervure, et celle-ci, bifurquée au point d'attache, fournit deux nervilles sur lesquelles s'appuie l'indusium; puis s'élèvant au-dessus de la marge, forment deux prolongements inégaux, semblables à deux petites cornes. Ce sont des plantes à forme variée qui se plaisent dans les régions chaudes.

22. Dicisoniées : petit groupe remárquable par un indusium infère et membraneux, naissant au-dessous du réceptacle, et s'ouvrant, non pas antérieurement, comme dans les davalliées, mais vers le centre; les sporothèces sont redressés et non couchés. On peut diviser ce petit groupe en tribus, d'après la forme de l'indusium. Le port général de ces plantes les rapproche des Hypolepis, des Aspidium, des Alhyrium et des Cystopteris. Ce sont de grandes fougères très-divisées, tendres et délicates.

23. BaLANTIÉES : fougères à indusium infere et bivalve; des deux valves, l'une est ordinairement formée par la fronde, l'autre a une organisation spéciale; elle est ferne et dure, comme les élytres d'un coléoptère. Elles vivent sous les tropiques et semblent se rapprocher des maratiacées.

\section{§. 2. Fougères a sporanges portant un anNeau oblique : hélicogyratées.}

Ce sont de très-belles plantes, toutes arborescentes, qui contribuent à donner aux régions tropicales l'aspect qui les distingue entre toutes les régions du globe. On doit voir en elles les analogues des fouggères en arbre des époques antédiluviennes. Le caractère des hélicogyratées est d'avoir un anneau large et oblique, presque toujours complet, embrassant étroitement le sacculus. L'obliquité de l'anneau n'est pas un caractère universel : plusieurs espèces ont des sporanges tout à fait semblables à celles des polypodiées et un anneau absolument vertical ; ce n'est donc pas une tribu parfaitement naturelle. Le réceptacle est toujours globuleux et couvert de poils courts. Tantôt l'indusium existe, et tantôt il n'existe pas; quand il existe, il est infère, comme celui des dicksoniées, scarieux, cyathiforme et fragile. Les fougères qui le composent ont de magnifiques frondes plusieurs fois pinnées; ce qui les caractérise, ce sont leurs stipes vigoureux, souvent aiguillonnés, terminés par un faisceau de feuilles gigantesques, à pétioles presque toujours épineux, se balançant comme de grandes plumes au moindre souffle des vents. 
Les hélicogyratées peuvent être partagées en trois groupes, qui ne diffèrent que bien peu entre eux.

24. Aisophilées. A ce groupe se rattache ce que nous avons dit, en donnant les caractères généraux des hélicogyratées. Les sporothèces sont nus; le réceptacle est fortement proéminent et villeux. Le genre Hemilelia, qui montre des rudiments d'indusiun, lie ce groupe au suivant.

25. Crathées : très-voisin du précédent. Les fougères qui y sont renfermées ont un indusium, tantôt complet et tantôt incomplet; souvent il est d'une tenuité extrême, ayant été fortement distendu par les sporanges. Le port est le mêne que celui des alsophilées, tous deux se rapprochent beaucoup des polypodiées et des aspidiées par la manière dont se partagent les frondes.

26. THYrsoptéridéEs : groupe constitué d'un seul genre monotype; il est arborescent; les frondes fertiles et les frondes stériles sont différentes; les sporothèces, au lieu d'être dorsaux, ont une disposition racénifornie, et chacun d'eux est porté sur un pédicelle distinct.

Les CÉratoptéridées ou parkériées, que quelques auteur's placent parmi les polypodiacées, méritent, suivant nous, de former une famille distincte. Tout dans leur organisation est curieux : ce sont des plantes annuelles, aquatiques, a frondes succulentes et translucides. La disposition des sporothèces et le mode de division des frondes tendent à en faire des ptéridées : elles ont un faux indusiunı. L'anneau est extrêmement large, incomplet, et parfois réduit à quelques anneaux situés près du pédicelle; les spores sont trièdres, striés de lignes régulières; ils renferment une matière huileuse extrêmement abondante.

Telles sont les particularités auxquelles donnent lieu l'exanen et l'appréciation des divers groupes qui composent la grande famille des polypodiacées. Nous allorrs entrer maintenant dans tous les détails de leur organisation, en les considérant dans la longue série des genres que nous avons cru devoir adopter. 


\section{POLIPODIACEA.}

GENERA. 
CONSPECTLS ORDINUM.

POLYPODIACEAE.
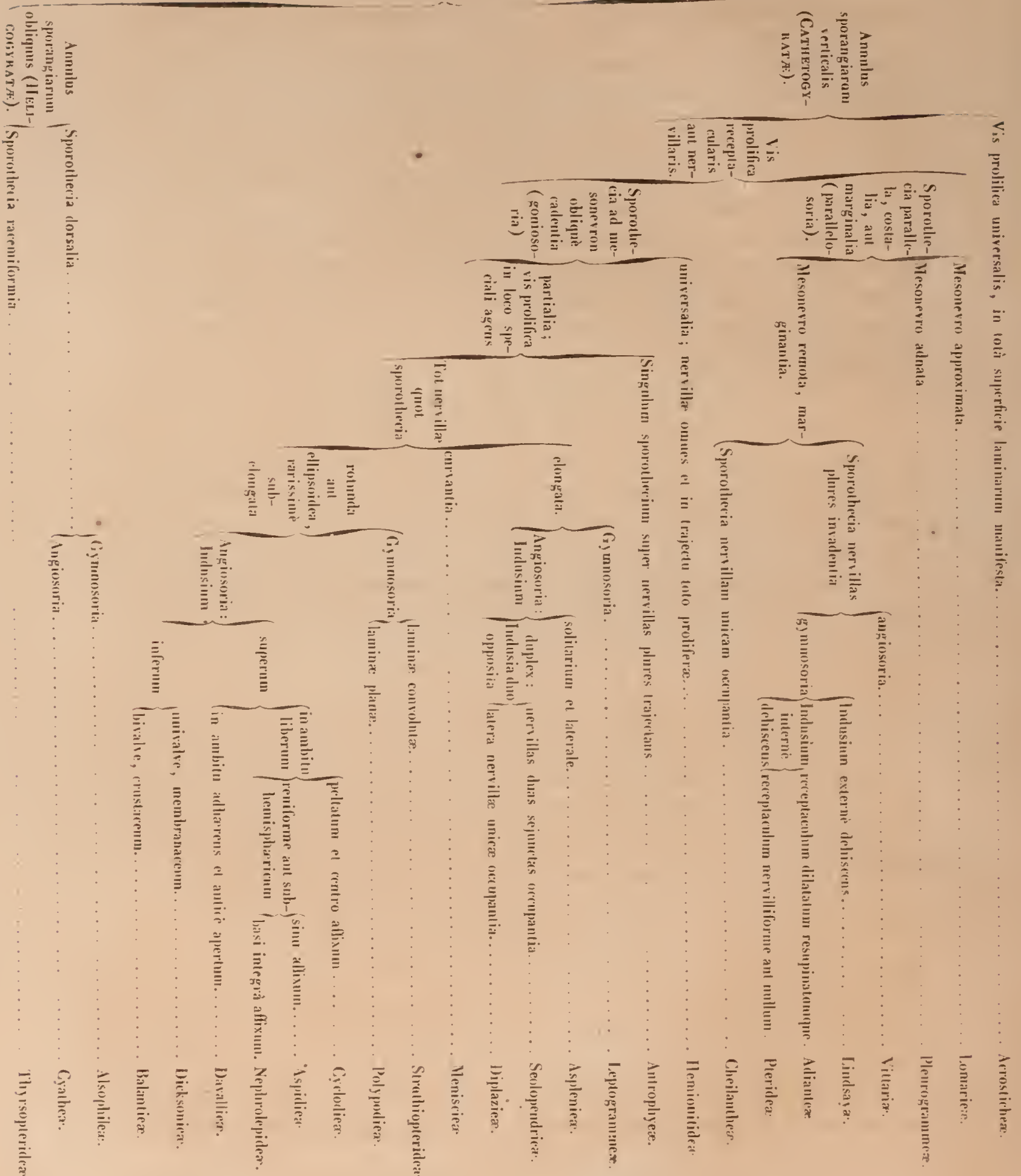
Nous avons exposé, dès le début de cet ouvrage, le plan que nous comptions suivre dans la coordination des genres de la famille des polypodiacées; il ne reste plus qu'à donner ici quelques explications de détail.

Beaucoup de genres ayant été illustrés par MII. Hooker et Bauer, ainsi que par M. Scholt, dont nous avons plusieurs fois loué l'exactilude, il nous a paru inutile de reproduire des analyses bien faites et suffisamment élendues. On ne trouvera donc dans nos planches que les diagnoses qui se rapportent aux genres récemment créés. Néanmoins il a été fait exception pour celles déjà publiées, quand il nous a été démontré qu'elles étaient inexactes ou incomplètes. Nous avons en outre accompagné plusieurs de nos diagnoses de détails empruntés à des genres analogiques, afin de permettre des comparaisons et des rapprochements. Près de cent vingt genres ont été ainsi plus ou moins complétement analysés. Si nous eussions été plus loin, ce livre aurait eu une valeur vénale trop élevée.

L'énumération des espèces qui accompagne chaque genre est très -étendue, mais non complète. Elle ne va guère au delà des espèces figurées par les auteurs, du moins pour les grands genres. Le nom de ces botanistes porte un astérisque $\left({ }^{*}\right)$, mais le titre de l'ouvrage n'a point été donné, toutefois il sera facile de faire des recherches, et chacun saura bientôt que Plumier a publié ses planches dans le Traité des fougères américaines, Schkubr les siennes dans les Kryptogamische Gewäachse, ouvrage continué par Kunze; que les fougères illustrées par MII. Hooker et Gréville l'ont été dans les Icones filicum, etc. On trouvera plus loin la liste des ouvrages iconographiques daus lesquels il faudra les chercher. Des indications plus précises étaient du ressort des Species.

A la suite de ces énumérations se trouvent plusieurs espèces nouvelles étudiées dans les herbiers et notamment dans le nôtre. Quoiqu'il y en ail uı nombre assez grand, il eût pu être bien plus considérable si nous n'avions pris la résolution de décrire uniquement celles qui nous ont présenté des caractères netlement tranchés; il en est plusieurs parmi elles que nous arons fait figurer.

La concordance synonymique est très-restreinte et comprise entre deux parenthèses. Lorsque le nom générique se trouve seul, on doit conclure que 
les noms spéeifiques ne diffèrent pas. Ainsi, page 43, on lit parmi les Acrostichum, - A. hybridum, Bory (Olfersia, Presl), ee qui veut dire : A. hybridum (Olfersia hybrida, Presl) : le nom spéeifique est alors le mêmı et sous-entendu.

Enfin, lorsque la synonymie ne porte qu'un non spéeifique, il faut le rattaeher au genre dont les espèees sont énumérées. En royant, à la même page, - marginatum, Wall. (conforme Blunı.), on saura qu'il s'agit de deux acrosichum et que le marginatum de Wallich et le conforme de Blume sont une seule et mème espèce; e'est alor's le nom générique qui est sous-entendu. Nous arons indiqué les planehes donıées par les auteur's antérieurs à Linné, sans nous préoeuper de leur nomenelature qui est diffuse.

La première partie de ee travail, en y comprenant l'Ordo generum et le Conspectus ordinum, a paru dans les Mémoires de la Société du Muséum d'histoire naturelle de Strasbourg en 1850 (tome IV, $10^{\text {re }}$ livraison); le manuserit avait été présenté à eette eompagnie en 1848. Il a fallu près de deux ans pour terminer les planches, faites arec beaueoup de talent et surtout arec une très-grande intelligenee du sujet, par M. Villemin, aide de botanique à la Faculté de médeeine, auquel nous payons iei, avee une vive satisfaction, la dette d'une affectueuse gratitude. Dans eet intervalle, M. Presl a bien voulu nous adresser ses Epinelice botanicce (Prague, 1849). Les fougères y sout traitées aree une grande prédileetion. Le sarant auteur $y$ modifie profondément les genres établis dans le Tentamen pteridographice, et les modifieations qu'il propose, s'étendent aux travaux de ses eontemporains. Il est résulté de eette rérision plus de quarante genres noureaux, parmi lesquels il en est qui, suivant nous, demandent à être mieux eonnus. Aueune figure ne donne les détails analyliques de ees genres, et nous avons virement regretté eette laeune; loutefois nous les avons étudiés aree toute l'attention que eommandaient les travau. antérieurs du savant botaniste qui les a fondés. Nous n'en avons eependant adopté qu'un bien petit nombre. La plaee qu'il fallait donner aux genres de II. Presl, admis par nous, et la possession de nouveaux éléments de travail, nous ont mis dans la néessité de faire réimprimer la série linéaire de nos genres. Nous nous y sommes déeidé d'autant plus facilement, que ees ehangeinents, très-peu nombreux d'ailleurs, ne touchaient nullement aux prineipes que nous arons établis ou défendus dans la première partie de eet ourrage. 


\section{FILICES. \\ POLYPODIACE E. \\ DRDO GENERUM.}

1. Annulus sporangiarum verticalis: Cathetogyrate.

I Vis prolifica universalis : ATaxıocarpea. Sporangiæ effusæ, superficienı laminarunı inferiorum aut rarius laminas ambas totas vestientes: AcrostsCHE.s.

* Nervillis liberis.

A. Parallelo-furcatis.

† Frondibus simplicibus.

1. Acrostichum, F.

t† Frondilus conpositis.

a. Sterilibus et fertilibus pinnatis.

2. Lomariopsis, F.

l. Sterilibus pinnatis; fertilibus bi- aut tripinnatis.

3. Lomariobotrys, $\mathbf{F}$.

B. Nervillis pinnatis.

† Frondibus sterilibus et fertilibus pinnatis; nervillis omnibus inclusis.

4. Polybotrya, 11. et Bonpl.

计 Frondibus pinnatis, salten sterilibus; nervilla

5. Egenolfia, Schots. exteriori basilari exsertà.

6. Rhipidopteris, Schott.

** Nervillis conniventibus.

7. Soromanes, F.

$\rightarrow$ * Nervillis anastomosantibus.

1. Sporangiis ad frondem universaliter operientibus. t Areolis partialibus.

a. Nervillis ad marginem a rcum unicum effingentibus.

8. Aconiopteris, Presl.

9. Olfersia, Radd.

b. Nervillis plures areolas circà mesonevron consti-

10. Stenosemia, Presl.

t+ Areolis universalibus.

a. Appendiculatis.

11. Leptochilus, Kliss.

12. Gymnopteris, F.

b. Exappendiculatis.

$a^{*}$. Nervillis rectis.

a. Frondibus pinnatis.

1. Sporangiis in sulco longitudinali nascentibus.

13. Cheilolepton, F.

14. Nevrocallis, F.

2. Sporangiis superficialibus.

15. Hymenodium, F. b * Nervillis aliis curvatis, aliis rectis, in eådem fronde.

16. Heteronevron, $F$.

II. Sporangiis in loco deterninato nascentibus. $\dagger$ Areolis exappendiculatis.

17. Chrysodium, F.

t† Areolis appendiculatis.

$\alpha$. Frondibus pinnatis.

18. Photinopteris, J. Snt.

6. Frondihus laciniatis.

19. Nevroplatyceros, Pluk.

It $V$ is prolifica ad receptaculum proprium vel ad nervillas manifesta (receplaculum proprium aut nervillare) : Taxiocarpe.e.

I. Sporothecia secundim lineam rectam excurrentia, parallela, costalia aut marginalia: LEPTOCARPEE.

1. Angiosoria (sporothecia indusiata, sub marginalia aut mesonevro approximala): LoMARIEF.

$$
\text { * Nervillis liberis. }
$$

A. Sporangiis receplacularibus, rarius nervillar ibus a*. Sporotheciis superficialibus.

$$
\text { a. Indusium verum. }
$$$$
\text { 1. Marginale. }
$$

20. Lomaria, IVilld.

2. Coslale, plits ninusve mesonerro proximum

21. Blechnum, L.

22. Acropteris, Lh.

$$
\text { 6. Indusium spuriunt. }
$$

$$
\text { b). Sporotheciis immersis. }
$$

23. Stenochlæna, J. Sin.

B. Sporangiis coslalibus; indusio fornicale.

24. Salpichlæna, J. Sm.

:p: Nervillis anastomosantibus.

A. Areolis costalibus.

25. Sadleria, Gaud.

B. Areolis universalibus. (Pseddo-Lomakie.z.)

a. Frondibus sterilibus el fertilibus diversis.

26. Dendroglossa, Presl.

b. Frondibus conformibus; apice fertilium plus

27. Hymenolepis, KIfss.

2. Gymnosoria (sporothecia nuda, superficialin ü immersa, rarius endophylla): Vitrariex.

* Nerrillis liberis.

Nervillis conniventibus.

28. Vittaria, Sm.

29. ? Dihlenma, J. Sm. 
30. Pteropsis, Presl.

* Nerrillis anastomosantibu
+ Areolis exappendiculatis.
A. Frondibus simplicibus.

31. Cuspidaria, F. $B$. Frondibus dirisis.

32. Schizolepton, F

C. Frondibus hetcromorphis.

33. Tænitis, Sw.

D. Frondibus pinnatis.

E. Frondibus sterilibus ct fertilibus diversis.

34. Lomagramma, J. Sm.

it Areolis appendiculatis. $A$. Frondibus pinnatis.

35. Jenhinsia, H. et B.

B. Frondibus simplicibus.

a. Froudibus monotaxicis.

36. Nicrodium, F.

b. Frondibus diplotaxicis (fertilibus et sterilibus diversis.)

37. Drymoglossum, Presl.

3. Sporothecia mesonevro adnata: Pleurocanamea. * Nervillis lateralibus nullis.

38. Vaginularia, F.

39. Monogramme, Comn.

40. Adenophorus, Gaud. ** Nervillis pinnatis.

41. Xiphopteris, Kilss.

42. Pleurogramme, Presl.

4. Sporothecia mesonevro remota, marginalia (indusiata): Preridixes.

1. Indusium extrorsum dehiscens : LuNDSArE. * Nervillis liberis.

43. Lindsaya, Dryand

44. Isoloma, J. Sm.

;.) Nervillis anastomosantibus.

$\dagger$ Areolis exappendiculatis.

45. Schizoloma, Gaud.

46. Synaphlebium, J. Sm.

ti Areolis appendiculatis.

47. Dictyoxyphium, Hooh.

2. Indusium introrsim dehiscens.

1. Receplaculum carnosum, nervalum, dilatalum resupinalumque : ADIANTEx.

48. Adiantum,

$$
\text { * Nervillis liberis. }
$$

49. Casebeeria, Kliss.

50. Ochropteris, J. Sm

\# Nervillis conniventibus.

......... .

*** Nervillis anastomosantibus.

51. Hewardia, J. Sm.

11. Leceptaculum nervilliforme, raro nullum; indu. sium continuum, membranaceum, pellucidum, planum : Ptendex.

1. Sporothecia marginem totam ambientia. (Indusium lineare, rectum.)
52. Pteris, $\mathrm{L}$.

53. Pellaa, Lk.

54. Phorolobus, Lh.

55. Onyclium, Kilfs.

$\because \%$ Nervillis anastomosatis.

t Areolis exappendiculatis.

A. Frondibus simplicibus aut palmatis.

56. Doryopteris, J. Sm.

$B$. Frondibus pinnatis.

57. Litobrochia, $\mathrm{F}$.

58. Heterophlebiun, F. t† Areolis appendiculatis.

59. Amphiblcstra, Presl.

B. Sporothecia abbreviata; indusium curvatum, breve, lunulatum : Loxchiтidex.

60. Lonchitis, L

I1. Sporotheeia nervillam unicam oecupantia (difformia, sæè̀ coufluentia, depauperata, marginalia, extensa) : CueıLantue.玉.

1. Acerois paucis, remolis, indusio orbiculari :

61. Adiantopsis, F HYPOLEPIDEA.

62. Hypolepis, Beruh.

2. Acervis multis, approximatis, sape confuentibus

A. Evolutio frondium definita (terminata,

63. Myriopteris, F. EUcheILAxтUE.

64. Plecosorus, F.

65. Eriosorus, F.

66. Aleuritopteris, F.

67. Cheilanthes, Sw.

68. Nothochlana, R. Br.

† Cincinalis, Desv.

$B$. Evolutio frondium indefinita: Janesonies.

69. Jamesonia, H. et $\mathbf{C r}$.

III. Sporothecia aut nervillæ proliferæe ad mesonevron obliquè currentia.

1*. Vis prolifica universalis, id est sporothecia lum. nas integrè vestientia; nervillis omnilus et in trajectu loto proliferis: HenonitideE. * Nervillis liberis.

a. Frondulis pulvere ceracco restitis.

70. Trismeria, F.

b. Frondulis nudis A. Frondibus diplotaxicis.

71. Botryogramme, $F$.

$B$. Frondibus monotaxicis.

72. Coniogramme, F.

73. Nevrogramue, Link.

* Nervillis conniventibus.

. . . . .

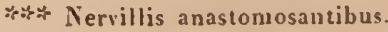

† Areolis partialibus.

A. Frondulis simplicibus.

74. Callogramne, F.

75. Sungramne, J. Sm. 
76 Dictyogramme, F.

77. Henionitis, $L$.

†t Areolis universalibus.

2. Vis prolifica in loco determinato agens.

1. Singulum sporothecium super nervillas plures transiens: AntropHYEer.

$\dagger$ Areolis exappendiculatis.

78. Antrophyum, KIfss.

计 Areolis appendiculatis.

A. Frondilus monotaxicis; sporangiis interruptis. 79. Colysis, Presl.

B. Frondilus diplotaxicis; sporotheciis continuis. 80. Selliguea, Bory.

II. Tot sporuthecia, quot nervilla.

1. Elongata recta (ferè universalia).

A. Gymnosotia : Leptogranies. † Frondibus simplicibus.

81. Pterozonium, F.

†t Frondibus lacerato-flabellatis.

82. Hecistopteris, J. Sni. t† Frondibus divisis.

83. Pleurosorus, $\mathrm{F}$.

84. Gymnogranme, Desv.

85. Ceropteris, Link.

86. Anogramme, Link.

\section{B. Angiosoria.}

S. 1. Indusium solitarium et laterale : Asplevies. * Nervillis liberis.

87. Athyrium, Roth

88. Aspleniunı, L.

89. Hypochlamys, F.

$$
\text { * Nervillis conniventibus. }
$$

90. Neottopteris, J. Sm.

91. Stenogramme, Blum.

**\% Nervillis anastomosantibus.

92. Hemidictyon, Presl.

93. Ceterach, Willd.

94. Woodwardia, F.

95. Lorinsoria, Presi.

5. 2. Indusia opposita nervillas duas sejunctas occupantia : Scolopendrien.

96. Scolopendrium, Sm

$$
\text { * Nervillis liberis. }
$$

$*$ Nervillis conniventibus.

........ .

*** Nervillis anastumosantibus.

97. Antigramne, Presl.

98. Camptosurus, Link.

\$. 3. Indusium bivalve, aut abortu univalve, valvis oppositis, dorso conniventibus: DipLAzIEE.

* Nervillis liberis.

A. Pinnulis seu segmentis symetricis.

99. Diplazium, Sw.
B. Pinnulis dimidiatis.

100. Didymochlæna, Desv.

\% Nervillis conniventibus.

101. Digrammaria, Presl.

102. Callipteris, Bory.

«* Nervillis circà marginem in areolas anastomosantibus.

103. Pteriglyphis, $F$.

$2^{*}$. Sparothecia curvata in dorsum venularum trans. versarum curvatarum evulgata: Mexisciex. $*$ Nervillis liberis.

104. Menisciunı, Sclıreb.

:** Nervillis anastonjosantibus.

$\dagger$ Dryomenis, F.

$3^{*}$. Sporothecia rolunda vel ellipsoidca rarò subelongata; venulâ proliferấ ad mesonevron obliquè tendens.
A. Gymnosoria.

1. Lamina frondiun fertilium convolutce, siliqureformes vel bacciformes : Struthlopteridex.

a. Bacciformia.

* Nervillis liberis.

105. Struthiopteris, Willd.

$$
\text { * Nervillis conniventibus. }
$$

................

106. Ónoclea, $\mathrm{L}$

N\% Nervillis anastomosantibus

1. Siliqueformia.

107. Ceratodactylis, J. Sm.

2. Lamine frondium plante seu rarissimè plicalı, nunquam revoluta: PoLYPODIEE.

$$
\text { * Nervillis liberis. }
$$

A. Margine inferiori laminarum replicato, sporangias

108. Plectopteris, F. tectante.

$B$. Margine sporangias non tectante.

A. Sporangiis inmersis (subcuticularibus).

109. Cryptosorus, F.

B. Sporangiis superficialibus.

a. Frondibus sinplicibus, receptaculo elongato.

110. Grammitis, Sw.

b. Frordibus plùs minùsve divisis; receptaculo elongato seu nullo.

111. Polypodiun, L.

112. Plsegopteris, F.

$\because$ Nervillis conniventibus.

113. Coniopteris, Presl.

*:\% Nervillis anastomosatis.

$A^{*}$. Sporotheciis nervillam unicarn occupantilus.

$\dagger$ Frondibus monotaxicis.

A. Areolis exappendiculatis.

114. Goniophlebium, Presl.

B. Areolis appendiculatis.

115. Campylonevron, Presl.

116. Lecanopteris, Blun.

计 Frondibus diplotaxicis.

117. Niphobolus, Kliss.

118. Craspedaria, LK. 
$\mathrm{B}^{*}$. Sporotheciis plurinervillatis.

a. Sporotheciis ad apicem duarum nervillarum

119. Clirysopteris, Lk.

120. Aglaomorpha, Schott.

b. Sporotheciis ad nexum nervillarum evolutis. $\dagger$ Areolis exappendiculatis.

121. Dictyopteris, Presl.

t† Areolis appendiculatis.

- Frondibus homonorphis.

122. Microsorium, Link.

* Frondibus monotaxicis.

123. Drynaria, Bory.

124. Pleuridium, $F$.

125. Dipteris, Reinw

*. Frondibus heteromorphis.

126. Dryostachyon, J. Sm.

\section{B. Angiosoria.}

I. Indusium superum : Eріснцамие...

1. Peltatum, in anbitu liberum: Crchoviex. * Nervillis liberis.

127. Polystichum, Roth.

128. Phanerophlebia, Presl.

129. Hemicardion, $F$.

130. Amblia, Presl. ** Nervillis conniventibus.

131. Cyclodium, Presl. 낭 Tervillis anastomosatis.

A. Arcolis exappendiculatis

. . . . . . . .

$B$. Areolis appendiculatis.

132. Cyrtonium, Prcsl.

133. Podopeltis, F.

134. Bathmium, Lh.

2. Indusium reniforme, subhemispharicum aut cordatum.

A. Sinu afixum : Aspidiex.

* Nervillis liberis.

135. Aspidium, Sw. A. Pinnatis.

A. Oochlauys, F.

B. Hypodculatium, Kze.

C. Anauropelta, Kze.

D. Camptodiun, $\mathbf{F}$.

136. Cystopteris, Beruli

137. Lepidonerron, F.

138. Dichasium, A. Braun.

B. Ncrvillis parallelis ad marginem in arcu coalitis. 139. Oleandra, Cavan.

** Nervillis conniventibus.

140. Nephrodium, Rich.

141. Ilaplodictyon, Pres1.

142. Abacoptcris, F.
*** Nervillis anastomosantibus

+ Frondibus monotaxicis.

1. Areolis exappendiculatis.

143. Pleocnemia, Presl.

144. Sagenia, Presl.

145. Phlebiogonium, 1 .

B. Arcolis appendiculatis.

146. Cardiochlacua, F.

† Frondibus diplotaricis.

147. Fadycnia, Hook. et Bauer.

B*. Indusium basi lata afixum: Nephrolepinex.

148. Nephrolepis, Schott.

149. Pteronevron, $F$.

150. Saccoloma, Kifss.

151. Pachypleuria, Presl.

152. Humata, Cavan.

3. Indusium in ambitu adherens et antice apertum Davalliex.

* Nervillis liberis.

+ Sporotheciis terminalibus.

153. Prosaptia, Prcsl.

151. Scyphularia, F.

155. Odontosoria, F.

156. Microlepia, Presl.

157. Davallia, Sm.

158. Odontoloma, J. Sns.

159. Stenolonia, F.

160. Wibelia, Bernh.

it Sporotheciis dorsalibus et lateralibus.

161. Darea, Juss.

$\because *$ Nervillis conniventibus, ad margineu coaduuatis

162. Lindsayuium, $F$.

II. Indusium inferum membranaceum :

\section{HrPoCuLAYIDE.E.}

A. Lnisalie: Dichsoxieat

a. Indusio cupuliformi, à primà atate aperto.

163. Dichsonia, L'Herit.

161. Deparia, Hook. et Bauer.

b. Indusium involucrale lacerum, basilare.

165. Hypodcris, R. Br.

c. Indusium globulare, antè cvolutionem clausumt. dein irregulariter apice apertum.

166. Woodsia, R. Br

167. Diacalpc, Blum.

168. Sphropteris, Wall.

B. Indusium bivalve: BaLANIE.T.

a. Valvis duabus; una vera, altera accessnira.

169. Culcita, Presl.

170. Balantium, Presl.

171. Leptopleuria, Prcsl.

172. Cystodium, J. Sm.

b. Valvis duabus propriis : Сıвотіt.

173. Cibotiun, lilfss.

t Paesia, A. Saint.llil 
II. Annulus sporangiarum excentricus: Helicograte.

1. Sporothecia dorsalia : Cystar...

A. Sporotheciis nudis : A Aso PHLLEE.

* Nervillis pinnatis, monosoris.

174. Alsophila, R. Br.

175. Trichopteris, Presl.

** Nervillis parallelis, polysoris.

176. Amphidesmium, Schott.

B. Sporotheciis semi-indusiatis, id est indusium internum dimidiatum ferentibus: Нвмттенце.
* Nervillis liberis.

177. Hemithelia, Presl.

** Nervillis conniventibus.

178. Hemistegia, Presl.

C. Sporotheciis indusiatis (Angiosori): Eucyatnex: * Nervillis pinnatis.

179. Cyathea, $\mathrm{Sm}$. *** Nervillis parallelis.

180. Schizocæna, J. Sm.

2. Sporothecia raccmiformia : Thrrsopteridex. 181. Thyrsopteris, Kize.

\section{Explicatio signorum ef verborum abbreviatorum in genere filicum usitatorum.}

\begin{tabular}{|c|c|c|c|c|c|}
\hline anrm & valet & anormale vel transformatum. & $m g n . n$ & ralet & magnitudo naturalis. \\
\hline ann & - & annulus. & $m r g$ & - & margo. \\
\hline & - & auctum. & rchs & - & rachis. \\
\hline$"$ & - & multium auctum. & $r h z$ & - & rhizoma. \\
\hline q & - & foemina, id est fructifer. & reptc & - & receptaculum. \\
\hline $0-0$ & - & sterilis seu neuter. & $r d c$ & - & radicella. \\
\hline gmm & 一 & gemma. & $r d x$ & - & radix. \\
\hline frdl & - & frondula. & $r d t$ & - & reductunt. \\
\hline cut & - & cuticula. & sprth & - & sporothecium. \\
\hline f. vas & - & fasciculi vasorum. & sprg & - & sporangia. \\
\hline ep & - & episporium et episporialus. & $s p r$ & - & spora. \\
\hline frs & - & frons. & sprl & 一 & sporula. \\
\hline $\begin{array}{l}\text { ind } \\
\text { ind. spr }\end{array}$ & - & $\begin{array}{l}\text { indusium et indusialus. } \\
\text { indusium spurium. }\end{array}$ & sprgtr & 一 & $\begin{array}{l}\text { sporangia sterilis set sporangins- } \\
\text { ter. }\end{array}$ \\
\hline & - & pilus. & $s / m$ & - & stoma. \\
\hline frgm & - & fragmenlum. & stmt & - & stomata. \\
\hline glnd & 一 & glandula. & sace & - & sacculus. \\
\hline pedc & - & pedicellus. & $\operatorname{segm}$ & - & segmentum vel lacinia. \\
\hline petl & - & petiolus. & $s q m$ & 一 & squama. \\
\hline pinn & - & pinnula vel pinna. & $\operatorname{sip}$ & - & stipes. \\
\hline$m s n$ & - & mesonevron. & vest & 一 & vestitum. \\
\hline nd & - & nudum. & $\nu g n$ & - & vagina. \\
\hline nrut & - & nervatio. & & & \\
\hline
\end{tabular}




\section{ACROSTICHEF}

ORDO GENERUII.

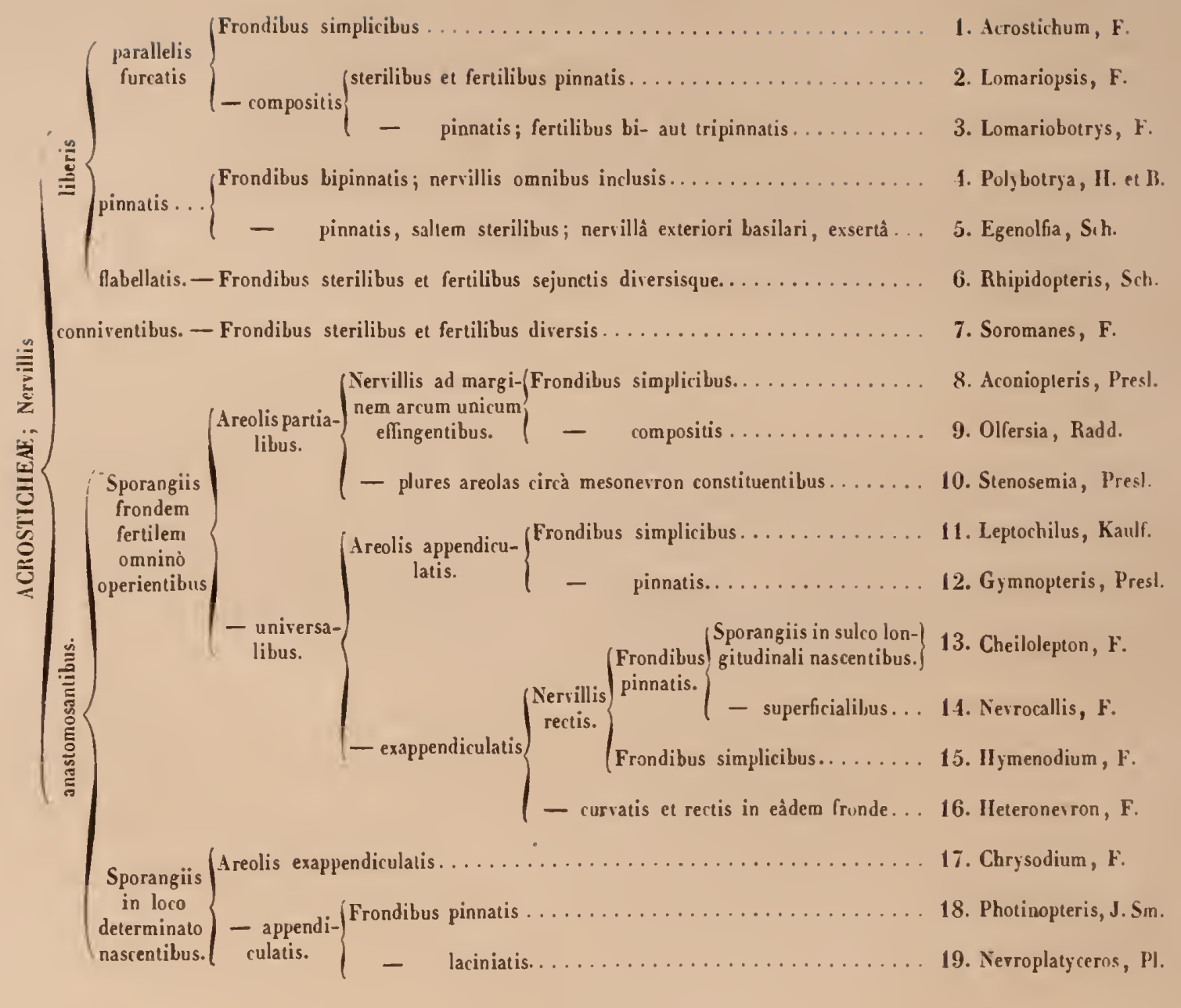

$\boldsymbol{N}$. B. Les espèces indiquées $\mathrm{F} .{ }^{*}$ qui ne se trouvent pas dans l'Histoire des acrosticlıées, sont figurées et décrites dans un supplément manuscrit. 


\title{
I. Annulus sporangiarum verticalis : CATHETOGYRATE.
}

\author{
t Vis prolifica universalis : ITIXIOCARPEE.
}

Sporangiæ effusæ, superficiem laminarum inferiorum aut rariùs laminas ambas totas vestientes : ACROSTICHEAE.

* Nervillis liberis.

\author{
A. Parallelo-furcatis. \\ † Frondibus simplicibus.
}

1. ACROSTICHUM, F. (1844.)

Hist. des acrostichées, P. 8 et 27 ; tab. I-XXIV.

Acrostichi spec. Асст. var. - Elaphoglossum, Sснотт. In notis (nomen solim). - J. Sмiтн, in Journ. bot. Ноoк., Iv, p. 148. - Olfersice spec., PresL, Tentanı. pterid., p. 232. - Candollea, Mırв., Encycl. méth. bot. suppl. 1 (1810). Scolopendrii spec., Ray, Hist. Pl. gener. - Acrostichum et Phyllitis, NEck., Elem. bol.

SPORANGIIS subrotundis; annulo $11-12$ articulato, pedicello lato; sporis ovoideis, episporio membranaceo persistenti, sapè vestitis.

Frondibus simplicibus, integris; sterilibus latioribus, robustis; fertilibus conformibus aut diversis, sapè angustioribus brevioribusque, margine plis minùsve extenso, sterili, aliquandò reflexo; nervillis liberis, parallelo-furcatis, angulurı 50-85 cum mesonevro metientibus; rlizomate surculiformi, erecto aut repente, raro scandente, squamigero.

Filices ut plurimìm lanceolate, raio lineares vel obovate; imprimis tropicales, arboricolce, terrestres, muscosc. Genus vastissimum omninò difficile.

Diagnosis: Hoor. et Baurr, Gen.fil., t.105(Elaphoglossum [Acrostichum] simplex, Scнотт).

Icon. nostr.: Tab. I, A, fig. 1, Acrostichum rhabdolepis, F. - Fig. 2, A. Boryanum, F. - Fig. 3, A. Meridense, Кьотzсн. - Fig. 4, A. andicola, F. - Fig. 5, A. ophioglossoides, Goldm. - Fig. 6 et 7, A. Mathes'sii et Schomburghï, F. (fragmenta vario.)

Le genre Acrostichum, tel que nous le comprenons, correspond assez exactement au genre Elaphoglossum de M. Schott, indiqué seulement dans une note par cet auteur. Il est nombreux en espèces, et par cela même très-difficile. Rien n'est plus remarquable que la prodigieuse variété de forme de ces plantes, si l'on réflécliit à l'extrême simplicité du type. Leur patrie est fort étendue. Quoiqu'on les trouve 
dans des régions plus froides que l'Europe, cette partie du monde n'en possède point. Les îles $A$ çores et Sandwich en tracent les limites. Ces fougères ont urie très-grande tendance à se couvrir d'écailles; elles affectent d'ordinaire la forme lancéolée. Il en est qui atteignent à peine trois centimètres ( $\boldsymbol{A}$. piloselloides, $\mathrm{Pr}$.); d'autres approchent de la taille d'un mètre ( $A$. laminarioides, Bory). On les trouve sur les arbres et sur les rochers moussus. Linné est le créateur du genre Acrostichum, mal défini de son temps. Toutes les espèces qu'il y renfermait, ont pris place dans dautres genres, de sorte quil ne reste plus que le nom; mais ce nom a dì être conservé, afin de respecter la synonynie des auteurs linnéens et celle mème des botanistes contemporains. Si l'on eùt agi autrement, un grand trouble en serait résulté, et nous avons voulu l'éviter. (Toyez sur ce genre, pour de plus: grands déluils, l'Histoire des acrostichées, l. c.)

\section{SPECIES NONDUM DESCRIPTE.}

I. Rabdolt:pis, F., tab. I, fig. I.

Frondibus sterilibus ovatis, concavis, spissis, petiolatis, laminis duabus hirto-squamosis, supernè punctatis; petiolis rigidis; fer tilibus majoribus, subrotundis, petiolo longiori; sporangiis rotundis; annulo lato, subarticulato; sporis ovalibus; caulibus humifusis, filiformibus, ramosis, flexuosis; squamis laceratis plantum totam vestientibus.

Habital in Quito (Jameson, 1845).

Filix repens, ramosa, rufescens, squamosa.

(Longueur totale : variable, comme dans toutes les plantes rampantes : des frondes stériles, $y$ conpris le pétiole, 9-10 millim.; frondes fertiles; supérieures de "//3 en toutes dimensions. Les lames égalent en longueur les pétioles.)

II. Crispatcluv, F.

Frondibus sterilibus ovatis, petiolatis, margine subrepundis, apice obusis, basi leviter acutis; squamis rufescentibus, lanceolatis, crispatulis, petiolos graciles longosque vestientibus; nervillis flabelliformibus, marginem altingentibus, apice incrassatis; fertilibus pacùm minoribus, basicuneatis; caulibus filiformibus, squamosis, ramis Interalibus, brevioribus.

Ilabitat in Quito (Jameson).

Filix repens, romosu, rufescens, squanis crispis iestita.

(Longucur totale indéterminable; des frondes stériles 4-6; les lames ne dépassent pas 18 millim.)

III. Cochleariafolici, F.

Frondibus sterilibus ovutis, crassis, cochleariformibus, petiolatis, glabris, siccitate pallidè glaucescentibus, busi decurrentibus, margine integerrimis; petiolis longis, curvis, planiusculis; nervillis flabelliformibus, mesonevro evonescenti; cuulibus sulcatis, parcè ramosis, magnitudine pennce corvince, squamis lanceolatis, oblusissinis, inbricatis, brunneis undique tectis; fusciculo v'usorum al centrum caulium unico.

Reliqua desiderantur.

Habilat in Quito Andibus (Jameson, 11. 213). 
Fïlix repens, rigida, caule squamoso, frondibus glabris, crassis, opacis, palliele viridibus.

(Longueur totale indéterminable : tiges de la grosseur d'une plune d'oic lorsqu'elles sont courertes de squames; frondes stériles, les seules connues, 4 centim. avec le pétiole qui égale la lame, celle-ci presque orbiculaire a près de $\mathbf{2 5}$ millim. de diamètre.)

\section{ENUMERATIO SPECIERUII.}

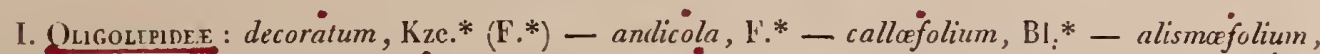
F.* - brevipes, Kze. - crassinerve, Kze. - Sieberi, H. et $\mathrm{Gr}^{*}{ }^{*}$ - ellipticum, F.* — macropodium, F.* - conforme, Sw.* et var. Schraderi, F. (angustatum, Schk. Schlecht.*) - angustunt, Kze. - glandulosum Carmich., in H. et Gr.* - marginatum, Wall. (conforme Blum.*) — angulatum, Blum.* - Scapellum, Mart.* - consobrinum, Kze. - Schomburgkii, F.* - impressum, F.* - scandens, Bory. - Lingüa, Radd.* - ophioglossoides, Goldın., Herb. Berol. - decurrens, Desr: (decurrens el obtusifolium, BI.*) - luridum, F.* - flaccilum, F.* - alatum, F.* calophyllum, Kze. - Funckii, F.* - attenuatum, F., I!ort. Lips. - Lloense, Hook* - laurifolium, P. Th. (F.*) - Lepervanchii, Bory (F**) - Gajanum, F** aphlebium, Kze.*-didynamum, F.* - gorgoneum, Klfss. (Blum.*) - notalum, F.* - Huacssaro, Ruiz. - stipitatum, Boly (F.*) - petiolosum, Desv. $\left(\mathrm{F}_{*}^{*}\right)$ - caudatum, Hook.* - minutum, Pohl (F.*) - acrocarpon, Mart.*-dimoiphum, Ilook.*et var.bifurcatum, Schkh.* - Borjanum, F** hybridum, Bory (F.*); (Olfersia, Presl. [nervat.*]) et var. Vulcani, Leperv. $\left(\mathbf{F}^{*}\right)$ - erinaceum, F. (hy.bridum, IIook.* non Bory.) - Tambillense, Hook.* - undulatum, Willd. (Plum.*) - apodum, KIfss. (II. et Gr.*) - scolopendrifolium, Radd.* - IJystrix, Kze. - platyevron, F.* - micradenium, F.* — stigmatolepis, F.* - L'Ilerminieri, Bory et F.* - dissimile, Kze. - unituin, Bory, (afjine, Galcolt.?*) falcatum, F** - Karstenianum, Kze. - Martínicense, Desv. (F**) - sessile, F. (Elaphoglossum alatum, Gaud.*) - leptophyllinn, F.* - Aubertii, Desv. (F.*) - Pappigianum, F. - stenopteris, Kltz. - viscosum, Sw. (Plum.*, H. et Gr.*) et var. salicifoliun, Willd. - Préslianum, F.* - puchydermum, F. - lineare, F** - rubiginosum, F** - Feei, Bory (F.*).

II. Polylcpide : blepharodes, F.* - Lindénii, Bory (F.*) - heteroinorphum, KI. - Moritzianum, Kl. - brachjnesron, F.* - strictum, Radd.* (Nart.*) - villosum, Sw. (Lmik.*. II. et Gr.*) melanolepis, F. - Plumieri, F. non Desv. (Plum.*) - squarrosum, KI. - Weebii, Bory (F.*)

III. Pilosrule : pilosélloides, $\operatorname{Pr} *^{*}\left(G a l e o t t *, F_{*}^{*}\right)$ - spathulatum, Bory (F.*) - horridülum, Klfss. (Radd.*, Hook. et Gr., F.*) - Jamesoni, Hook. et Gr.* (F.*) et var. obtusatum, Carmich. (11. et Gr.*) - oratum, Jam. $\left(\mathrm{F} .{ }^{*}\right)$ - squamipes, Hook.* $\left(\mathbb{F}^{*}\right)$ - ramosissimum, F.* - crispaiulum, F. - rabdolepis, F.* - Martivegii, F** Mathewsii, F.*

IV. CuRosutolepide : muscosum, Siv. - plumosum, F** perelegans, F.* (Plım.*?) - Gardnerianum, Kze. (F.*) - Meridense, KI. - Orbignjanum, F.* - heterolepis, F.* - Langisdôrfi, PresI. (II. et Gr.*, Mart.*) - laminimioides, Bory (F.*) - cusfidatum, Willd. (F.*) - curcans, Kze. elongatum, Kze. - 8bductum, Kltz. - adenoleris, Kzc. - Mombeyanum, F** - lepidotum, Willd. auricomum, F. - Bellermanñianum, Klotzch. - splendens, Bory (F.*) - erytlirolepis, F. - vestitum, Schlech. (Galeot.*) - hiriurn, Sw. (II. ct Gr.*) - succisafolium, P. Th. (II. et Gr.*).

\section{SPECIES MINUS COGNITE.}

Actinotrichum, Mart., Flor. Bras. - cemulum, Klfss., Enum., p.63. - Blumeanum, F. (Cuning, 1. ${ }^{0}$ 194.) - pilosum, II. et B. - cochleatum, Bory (F.*) - squamatum, Car. - Banksianum, F.; patria? - cocblearifolium, F. (Jameson, Pl. Quil., n. 212 [incompl.]). - ? Breu'elinnum, Kze.* - simplex, Sw. (H. et Bauer*). 


\section{计 Frondibus compositis.}

a. Sterilibus et fertilibus pinnatis.

\section{LOMARIOPSIS, F. (1844.)}

Hist. des acrostichées, p. 10 et 66; tab. XXV-XXXIII et LVI, fig. 2.

Olfersie spec. Acct. - Acrostichi spec., Lisn., Mart., KzE., Bory. - Lomarice spec., Witcd., Kıғss., Bıcs., J. Sx. - Stenochlenne spec., J. Sw. in Hook., Journ. bot., iv, 149. - Onoclere, Anemice el Osmunder spec. Aucr. var.

Sporaxgns subrolundis; annulo 14-16 arliculato; sporis ovoideis, episporio firmbriato vestilis.

Froxdibs pinnatis, sapè heleromorphis; frondulis sterilibus lanceolatis, integris denlatisve, rarò irregulariler crenalis vel subpinnalifidis; aliquandò margine explicilo, tenui, scarioso, indusium spurium simulanle; fertilibus linearibus, elongatis; nervillis parallelis, bifurcalis, impressis; caudice ereclo aut scandente, inermi aul aculeato, plures fasciculos vasorum ferenle.

Filices glabrir, magnie, arboricola, repentes vel scandentes, sicpè heterophyllie, tropicules, inermes au aculeatc.

Diagnosis !nostra: tab. I, B. - Fig. 1, Lomariopsis erythrodes, F. - Fig. 2 , L. sorbifolia, F., et fig. 3, L. Smithii F., fragmenta. - Fig. 4, Lomaria L'Herminieri, Bory; ad demonstrandum receptaculum, indusium verum et situm sporangiarum.

Les espèces que renferme ce beau genre sont très-étroitement ünies entre elles par le facies; elles se rapprochent des Lomaria; mais outre qu'elles n'ont pas de véritable indusium, les sporanges ne s'atlachent pas sur .un -réceptacle spécial; étant toujours éparses et ataxiques. (tab. I, A, fig. 4). Il y a communauté de nervation entre les Acrostichum et les Lomariopssis; cependant le port est différent, et les frondes, toujours entières dans les unes, se montrent pinnées dans les autres. Enfin les frondes fertiles, comparées aux stériles, varient peu de forme dans le genre Acrostichum et sont dissemblables dans les Lomariopsis.

Dans ce genre, les frondes sont toujours portées sur des stipes robustes et très-fréquemment armés d'épines. Souvent ces frondes, en se développant, prennent un aspect si différent de celui qu'elle's présentent étant adultes, qu'on a peine à les reconnaitre. Les Lomariopsis spinescens et Smithii (Hist. des acrost., tab. XXXIII, fig. 1 et 2) se chargent de frondes stériles normales, grandes, pinnées, lancéolées, 
et de frondes stériles anormales, considérablement divisées. Il existe un lomariopsis hétérophylle au point de justifier le nom de ludens, que nous lui avons imposé (ouv. cit., pl. XXX). Les auteurs modernes n'adoptent pas tous ce genre dont ils réunissent les espèces aux acrostichum, et pourtant il est bien plus voisin des lomaria, par le port et par l'amincissement de la marge en faux indusium.

\section{ENUMERATIO SPECIERUMI.}

1. Номомонрнеє : Prieureana, F.*-Cochinchinensis, F.*-phlebodes, F.* (Mart.*) - erythrodes, F. - elongata, F. - cuspidata, F.* - Boryana, F. (Olfersia integrifolia, Presl [nervatio*]; Acrostichum lomarioides, Bory*) - recurvata, F.* - leptocarpa, F.* - buxifolia, F. (Acrostichum, Kze.*) - Hugelii, Pres! (Stenochlonce spec., F., in Ilerb. Vindob.) - acuminata, F. (Lomaria, Desv.).

II. Heteronorphes : sorbifolia, F. (Plum.*, Ray*) - ludens, F.* - variabilis, F.* - Smithii, F.* - spinescens, F.*

b. Frondibus sterilibus pinnatis; fertilibus bi- aut tripinnatis.

\section{LOMARIOBOTRYS, F. (1851.)}

Lomariobotrys, F.

Stenochleena, subgenus Cafraria, Press, Epim. bol., p. 166.

Sporangris longè pedicellatis, osatis; annulo 12-13 articulato (in L. Hugelii 16-18); sporis sub reniformibus, ovoideis, rugosis.

Frondibus diplolaxicis, heleromorphis, magnis; sterilibus pinnalis; frondulis lanceolatis, serratis, acuminatis; nervillis creberrimis, tenuissimis, approximatis, ad marginem incrassalum coalitis; fertilibus 2-3-4 pinnatis, feracissimis; frondulis sessilibus, linearibus, longissimis, ad malurilatem sporangiarum gibbosis, margine integerrimo, vix aliquandò leviler scarioso; rachi primario robuslo, rachibus secundariis subfiliformibus, flexuosissimis; fasciculis vasorum quatuor, ovoideis, magnis, agno numero minorum inaqualiun circumdalis.

Filices scandentes, magnce, ferè omnes Africance, Madagascarienses, Mauritienses et Indicce orientales.

Diagnosis nostra, tab. V, A. (L. Meyeriana, F.)

Ce genre est formé aux dépens du genre Lomaria; il a pour type le Lomaria tenuifolia de Desvaux, trouvé d'abord à Madagascar, puis dans les autres îles d'Afrique. Nous avons longtemps hésité à lui donner une place parmi les acrostichées. Les frondules fertiles sont si étroites qu'il est bien difficile de décider si les sporanges sont effuses ou reçues sur un réceptacle particulier. Nous n'avons pu voir de spécimens jeunes; mais à juger par l'état de la marge, on peut s'assurer qu'il n'existe 
pas d'indusium. Le nom de lonariobolrys rend compte de ses rapports analogiques avec les lomaria; il tient étroitement aux acrosliclum par la disposition des frondes fertiles qui rappellent celle des polybotrya, notamment celle du $P$. caudala de Kunze, quoiqu'elle soit plus divisée et à rameaux plus divariqués. Le véritable Stenochlacna est réduit maintenant à deux espèces des Philippines évidemment diffërentes : voyez le groupe de Lonariées.

\section{ENUVIERTTIO SPECIERUII.}

Ileyeriana, F.* (Lomaria, Kze.); fronde fertili bipinnala. - tenuifolia (Lomaria, Desr.); fronde fertili subtripinnata. - decomposita (Lomaria, Desr.); fronde fertili decomposita.

\section{B. Nervillis pinnatis.}

\section{${ }_{\uparrow}$ Frondibus sterilibus et fertilibus pinnatis; nervillis ommibus inclusis.}

\section{POLYBOTRYA, H. et Bonpl. (1825.)}

Nova gener. et spec. plant. Americ. meridionalis, t. II, p. 28, tab. II.

Polj-botrya (1825) Auct. plurimorum. - F., Hist. des acrost., p. 13 et 72, sub. genus secundum; Eupolybotrya, tab. xxxrv-xxxvir. - Polybotryce spec., J. Sis. in" Ноoк, Journ. bot., 1v, 150. - Acrosticlii spec., Auct. var. - Psomiocripia, Presl., Epim. bot., p. 161 (1849). - Gymnogrcummalis spec., Kaclf., Enum., p. 78 et 79.

SPORAxGins rolundalis, laminam inferiorem solim aul rarius ambas densè leclanlibus; anmulo lalo; slomio anguslo, pauci-newato; sporis ovalis.

FroxDlBc's amplis, ferè semper decomposilis, pinnalo-pinualifudis aul bi-lripinualis; lachi robuslo, ereclo aut rariìs scandente, fasciculos v'asoruu numerosus ferente; sterilibus amplioribus; fertilibus sejunclis, segrueulis linearibus continuis aul inlerruplis, sapè convolulis, racemos ramosos referenlibus.

Filices arboricolce, robusta, feracissima; in America australi vigentes.

Diagnosis : I. Schotт, Gen. filic. [optima] (P. cylindrica, Klfss.). H. Hoor. et Bavel, Gen. filic., t. Lxxu, B. (P. osmundacea, H. et B.)

Ce genre renferme des plantes en général très-amples et très-vigoureuses, à frondes stériles, toujours découpécs et au moins bipinnatifides. Les frondes fertiles sont tantôt fertiles des deux côtés de la lame, tantòt du côté inférieur seulement. Nous avons fait remarquer ailleurs que M. de Humboldt, fondateur de ce genre, s'esi 
trompé en adoptant, pour caractère essentiel du $P$. osmundacea, qu'il a décrit et figuré, une fructification recouvrant les deux lames; elles ne sont fertiles que du côté inférieur. Les deux plantes qui offreıt ce caractère et que l'illustre auteur n'a pas connues, sont les $P$. caudata et apïfolic seulement. Ces fougères, étant extrêmement proliferes, roulent leurs lames fertiles qui prennent un aspect cylindrique, très-propre à expliquer l'erreur dans laquelle plusieurs botanistes distingués sont tombés.

Les deux Polybotrya, fructifiés des deux côtés de la lame, sont une sorte d'exception parmi leurs congénères. Cette considération eût pu suffire pour en faire un genre distinct, M. Presl en a jugé ainsi, et nous aurions adopté son opinion, si nous avions découvert quelque différence dans le port; comme il est absolument le même, nous n'avons pas osé le faire.

Le $P$. incisa, Lk. 'n'a pas des frondes stériles et fertiles toujours séparées. Le spécimen que nous avons figuré est fertile vers la partie supérieure seulement; mais nous nous sommes assuré sur d'autres spécimens que cette circonstance n'était pas universelle, et que d'ordinaire il rentre dans la règle comme étant diplotaxique.

\section{SPECIES NONDUII DESCRIPTA.}

P. SCANDENS, F.

Frondibus sterilibus bipinnatis? pinnulis basi pinnatis, supernè pinnatifidis, segmentis upice serratis, obtusis, glabris, ovatis, rachibus tenuioribus, suprà angustè canaliculatis; fertilibus 3-4 pinnatis, pinnulis remolis, segmentis abbreviatis obtusissimis, ovatis; sporangiis magnis, annulo $12-13$ articulato; sporis ovalibus, laminam inferiorem convolutam solim tegentibus; caudice scandente (ex Graleotti).

Habitat in sylvis humidis; Lagunetta, Mexico.

\section{ENUMERATIO SPECIERUM.}

1. Psomocanpa, Presl.; Frondes in utrìque lamina fertiles. = Caudata, Kze. (F.*, Pres] [nervatio*j]). - apiifolia, Kze.*

II. Eupolyвoтпy. Lamina inferior frondium solim prolifera. = Nutans, Kze. - pubens, Mart.* acuminata, Lk. - incisa, Lk. (F.*). - cylindrica, KIfss. (F.*, Scholl [fragmenta*], Pres! [nercatio*]). - osmundacea, II. et B.* (II. et Baner [fragmenta*], Presl [nersat.*]). - scandens, $\mathrm{F}$. - canaliculata, Kltz. - articulata, J. Sm. (F.*. 


\section{$\dagger+$ Frondibus pinnatis, saltem sterilibus; nervilla exteriori basilari exsertü.}

\section{丂. EGENOLFIA, Schott. (1834.)}

\section{Genera Filicum.}

Polybotrya spec., Buw., Fil. Jav.; Prtse, Tentam. pterid.; J. Ss., Enum. filCumingii. Ejusd. in Ноок., Journ., Iv, 150; Fú , Mém. sur les acrostich., p. 14, tab. xxxvm-xt. - Acrostichi spec., Wictd., Spec. filic.; Hоoк., elc. Sulgenus primum, Egenolfia. - Gymnoyrammes spec., Kaulf., Enum.

SPORANGis rolundalis, laminam inferiorem solim proliferam legentibus; annulo crasso, 1-12 arliculato; sporis episporio lato, incequaliter laceralo, vestilis.

FROXdibus pinnatis, in ambilu elongalo-lanceolatis; sterilibus pinnulis ovalo-elliplicis, margine dentatis, nervillâ exteriore basilari exsertâ el mucronem curcalum referente; fertilibus angustioribus, mulicis, margine irregulariler dentalâ, leviler plicalâ (in subgenere granulinâ, pinnulac ad formam pinnalifidam Iransientes); rhizomate crasso, brevi.

Filices arboricola, erecta', elongatc', flexibiles, laminis transhucidis; Philippinenses, Zeylanicre, Nepalenses.

Diagnosis : Sснотт, loc. cit. (Egenolfia Hamilloniana, Scнотт non F.); optima.

Nous avons cru devoir rétablir le genre Egenolfia de M. Schott, bien distiuct par le port du Polybotrya. Ces fougères conservent toujours la forme pinnée et ne vivent jamais en Amérique. Les frondes stériles, parfois radicantes vers le sommet, présentent une singulière particularité. Les nervilles sont pinnées et libres, elles se bifurquent, et le rameau extérieur sort de la lame, se recourbe et devient dur conme un mucron. Dans le sous-genre Granulina, les frondes fertiles ont des pinnules qui tendent à devenir pinnatifides; leurs segments assez éloignés les uns des autres sont courts et orbiculaires.

\section{ENUMERITIO SPECIERUM.}

1. Eufgexolfia : Schottii (Egenolfia Ilamilioniana, Scholl*; Polybotrya, Blum.*, F.*; Acrostichum, Hook.*) - intermedia (Polybotrya, F.*) - serrulata (Polybotrya, F.*) - neglecta (Polybotrya, F.*) - rhizophylla (Polybotrya, Presl) - asplenüfolia (Polybotrya, F.; Acrostichum, Bory*). - ? nana (Polybotrya, F.*).

II. Gravulixa, Bory. - nodiflora (Polybotrya, Bory *, F.*) - Ilamilioniana, F. non Scholl (Polybolrya, Ilook.*). 


\section{Nervillis flabellatis.}

\section{RHIPIDOPTERIS, Schott. (1834.)}

FÈE, Hist. des acrostichées, p. 14 et 78 .

Rhipidopteris, Schotr (1834) nomen solim in notis. - Peltapteris, Livк, Filic. spec., p. 147. - Polybotryce spec., J. Sмiтн, subgenus Rhipidopleris, Journ. bot.; Hоoк., Iv, p. 150, 1842. - Olfersice spec., PresL, Tentam. pterid., p. 235. - Acrostichi spec., Auct. Pluris. - Platycerotis spec.; Buus., Filic. Jav., p. 43. - Osmundice spec., Sw., Prod. filic.

SPORATGis magnis, pedicello lalo, tribus seriebus cellnlarum formato; annulo crasso, maturitate non explicito; articulis 10-11 sejunctis prominentibusque; sporis episporio latissimo vestitis, ovatis, subreniformibus, in ambilu incequelibus, angulatis, opacis, nudis, loevibus, pellucidis.

Froxdibus diplotaxicis, heteromorphis; sterilibus flabellatis, bipartitis, segmentis linearibus, dicholomis aut raro bifido-cuneatis; fertilibus integris, obcordatis bilobalisque, margine sapè irregulari; nervillis liberis, flabellatis; caulibus squamosis, triquelris; rhizomate surculiformi, tenui, repente.

Filices arboricolce, parvulce, tenerce, repentes, longè petiolatce; in Americâ australi nascentes.

Diagnosis nostr. : Tab. II, A; fig. 1. R. peltata, Sснотт; var. feniculacea, Hоок. Fig. 2. R. sphenophylla, Kusz. (ex ipso).

Le genre Rhipidopteris est le seul du groupe qui ait des nervilles en éventail. L'évidence de ce caractère est manifeste, même dans le $R$. sphenophylla, Kze., dont les frondes stériles, au lieu d'être à segments multifides, sont seulement bi- ou trifides. Le port de ces fougères est tout à fait spécial, et cependant ce genre n'a point été admis par Kunze qui en réunit les espèces au genre Acrostichum, ni par MM. Presl et Hooker qui reconnaissent en elles des olfersic, ni par M. Blume qui en fait des nevroplatyceros, ni enfin par M. J. Smith qui voit dans ce genre un simple démembrement du Polybotrya; cependant, malgré tout ce que ces autorités ont d'imposant, nous ne doutons pas que le genre Rhipidopleris ne soit définitivement adnis.

\section{ENUMERATIO SPECIERUM.}

Peltata, Schott* (F.*; Olfersia, Presl [neriat.*], Plum.*; Acrostichum, Schkh.*); et var. faniculacea, F.* (Acrostichum, Hook. et Grev.*) - flabellata, F. (Rhip. Humboldtiana, Schott. ; Acrostichum, H. et B.*) - tripartita, Schott (Acrostichum, H. et Grev.*) - sphenophylla, F.* (Acrostichum, Kze.*; Olfersia, Presl [nervatio*]). 


\section{** Nervillis conniventibus.}

\section{SOROMANES, F. (1844.)}

Hist. des acrostichées, p. 16 et 82 , tab. XLIII.

Polybotrya, subgenus Soromanes, KLoтzsch in Linnca, t. xx, 1817, p. 430.

SPOHAxGns rolundatis priformibusque; annulo lato, 12-14 arliculato: sporis magnis, alris, opacis, ovoideis, episporio delapso lavibus.

Froxdibus diplotaxicis, heleromorphis, amplis; frondulis sterilium ovatis, aculis, margine denlatis, glabris, petiolo brevi munitis; pinnis fertilium pinnatifudis, allenualis, segmentis sessilibus, brevibus, oblusissimis, marginibus reflexis, laminâ superiore sterili; nervillis pinnatis, venulis, lium inferioribus, lium superioribus, inter se opposilis, in angulum plìs minusve acutum anostornosantibus; caudice scandente, robuslo, fasciculos vasorum quinque, solulos ferente.

Filix mexicana, magna, erecta, glabra, frondibus sterilibus, sapè variabilibus et polymorphis.

Diagnosis nostr.: Tab. 1, B, S. serratifolium; F.*, loc. cit. (in icone, dentatum).

La nervation du genre Soromanes ne permet pas de le confondre avec les genres Polybotrya et Olfersia. La disposition ataxique des sporanges le sépare nettentent du $C$ yclodium, avec lequel il a de l'affinité quant au mode d'anastomose des nervilles. C'est cette grande analogie qui explique comment il a pu se faire que nous ayons cru à l'existence d'un $S$. inlegrifolium, la fronde stérile dı Cyclodium meniscioides, Presl, ayant été mise à côté de la fronde fertile d'une autre fougère par M. A. Braun, qui nous avait communiqué cet assentblage incorrect. (Voy. 5.' Mèm. supp. à l'Hist. des acrostichées.)

Ce genre est aujourd'hui monotype et ne renferne plus que le $S$. serralifolinm; nous possédons vivante cette espèce; elle est assez polymorphe; souvent ses frondes se découpent et tendent à devenir pinnatifides; alors la nervation se modifie et n'offre plus que de rares anastomoses. Le stipe ou caudex est grimpant et montre à l'intérieur cinq faisceaux vasculaires, entourés chacun d'un tissu qui semble indépendant, aussi sont-ils séparables. La coupe horizontale de ce stipe le fait ressenıbler à certaines tiges anormales de la famille des sapindacées et notamment à celle figurée par M. Gaudichaud. (Recherches sur l'organe gén. des végétaux, tab. XIII, fig. 2. [Voy. notre diagnose.])

\section{SPECIES.}

Genus monolypum : vide diagnosim generis. 


\title{
*** Yervillis anastomosantilbus.
}

\section{Sporangiis frondem universaliter operientibus.}

\author{
$\uparrow$ Areolis partialibus.
}

a. Nervillis ad marginem arcum unicum effigentibus.

\section{8. ? ACONIOPTERIS, Presl. (1836.)}

$$
\text { Tentamen pteridographiæ, p. } 236 .
$$

Aconıopteris, F., Mém. cité, p. 15 et 79, tab. xL, fig. 2, et tab. xu; J. Sx. in Ноок, Journ, Iv, p. 151. - Acrostichi spec., Jacg. et Auct. pцuRIM. - Olfersice spec, Prest. - Candollea, Mırв., Encycl. meth. 11, p. 111.

Sporayglis et sporis Acrostichorum.

Froxdibts simplicibus, integris, obovatis, lanceolatis; fertilibus contractis; nervillis ad mesonevron parellelo-furcatis, circà marginem in arcum coalitis; rhizomate crasso, surculiformi.

Filices erectce, arboricolce, habitı omninò Acrostichorum. Patria extensc : America australis, Sancta-Helena, Borbonia, insulce Sandwich, etc.

Diagnosis, Ноок. et Baver, Gen. filic., tab. Lxxix, B. (Acroslichum subdiaphanum, Hour. et GREv., Icon. Fil., tab. 205 [optima]).

Nous disions (Hist. des acrost., p. 15) que ce genre, établi par M. Presl, pouvait être cité comme une exagération de l'application du système qui admet la nervation conme une base importante de classification. Les aconiopteris sont des acrostichum à nervilles arquées vers la marge et l'on chercherait vainentent un autre caractère différentiel. Nous ne refusons pas de le regarder comme étant à peine suffisant; mais il faut suivre les conséquences du principe que l'on admet, faute de quoi on ne saurait plus où s'arrêter. Aucune méthode, au reste, n'est exempte de ces côtés faibles. Nous l'avons dit et nous ne saurions nous lasser de le redire: toute classification, quel que soit le nom qu'on lui donne, est artificielle. La nature a multiplié les formes et prodigué la vie; l'homme groupe les êtres et cherche, sans toujours pouvoir y parvenir, les rapports qui les unissent. Le genre Aconiopteris est donc artificiel, car ici, quoique la modification indiquée dans la nervation ait son importance, le port, étant exactement le même que celui des acrostichum, tend à les rapprocher. 
II. Presl (Epimel. bol., p. 166) propose de réunir à ce genre nos Acrostichum! heterolepis et alismafolium (Mém. cit., t. XV, fig. 1, et t. III); mais dans les spécimens qui nous ont servi de type et que nous avons figurés, les nervilles, renflées it leur point de terminaison, sont libres et non arquées. Sans doute, l'observation porte sur des espèces différentes des nôtres.

\section{ENUMERATIO SPECIERUM.}

I. Elacosioptrris : subdiaphana, Presl ([nervatio*]; Acrostichum, II. et Grev.*) - obtusa, F.*

II. Nebroglossi, Presl; longifolia, F.* (Plum.*) - Richardi, Bory el F.*

\section{OLFERSIA, Radd. (1819.)}

Oper. scient. di Bolonia, vol. III, p. 283, t. 11.

Olfersia, F., Mém. cil., p. 15 et 81 ; J. Sмith in Hook., Journ, iv, 151. - Olfersia et Dorcapteris, PresL, Epim. bot., p. 167 (Prag., 1849). - Polybotryat spec., Klffs. et Spresg. - Olfersice spec., Presl, Tentam. pterid., p. 23j. Acrostichi, Osmundie el Pteridis spec., Auct. var.

SPORANGHS rolundis, subglobosis; annulo crassissimo, 12-13 articulato, curculo, partem maximam sacculi amplectente; sporis parvis, vitreis, subreniformibus vel ovalibus.

Frovdibes sterilibus diplotaxicis, pinnatis, glaberrimis; frondulis integris, ovatolanceolatis, brevè petiolatis; nervillis parallelis, bifurcatis, cum nervillâ marginali coalescentibus; fertilibus bipinnatis, ultimis segmentis sessilibus, oratis, obtusis, in utrâque paginâ sporangïferis.

Filices erectce, magnce, terrestres, robusti, feracissima; frondibus diplotaxicis.

Diagnosis, Schотт, Gen. filic. (optima); Ноок. et Bacer, tab. Lxxix (O. corcovadensis, RAdD. [ bona $]$ ).

Deux espèces, appartenant à la végétation du Brésil et à celle de diverses autres contrées de l'A mérique tropicale, constituent ce genre, très-nettement caractérisé. II. Presl (Epimel. bot., l. cit.) a cru pouvoir, sur l'une d'elles, fonder un genre nouveau le Dorcapteris, se basant sur une particularité dont nous n'avons pu, malgré toutes nos recherches, constater l'exactitude. Dans l'O. cervina, Kze., la lame de la fronde serait seule fructifiée du côté inférieur, la plupart des auteurs disent le contraire, et ils nous paraissent être dans le vrai. Non-seulement nous ne pensons pas qu'il y ait lieu à former un genre, mais encore nous regardons 
la fusion des deux espèces en une seule comme infiniment probable; l'O. Corcacadensis n'étant qu'une modification assez rare du type, l'O cervina de Kunze. Nous possédons l'O. cervina de Saint-Domingue (Tussac), de la Guadeloupe (L'Herminier), de la Martinique (M. . $^{\text {lle }}$ Rivoire), et nous ne voyons pas qu'il diffère des spécimens du Corcovado (Martius) et de Groyaz (Pohl) qui tous ont des pinnules fructiferes sur l'une et l'autre côté des lames.

\section{ENUMERATIO SPECIERUM.}

Ceriina, Kze. (Plum.*, Hook. et Grev.*, Presl. [nervat.*]) - Corcovadensis, Radd.* (Pteris IRrab.*: Schott*, Hook.* et Bauer [Fragm. analyt.*]).

b. Nervillis plures areolas circà mesonevron constituentibus.

\section{STENOSEMIA, Presl. (1836.)}

Tentamen pteridographiæ, p. $23 \%$.

Stenosema, F., Mém. cité, p. 17 et 82. - Polybotryce spec., Bucu, Enum. Pl. Jav., p. 99. - Acrostichi spec., Sw., Syn. filic., p. 13 et 198.

Эроналgns rolundis, pedicellatis; annulo crasso, 12-13 arliculato, articulis obliquis, remolis; sporis ovoideis reniformibusque, episporio translucido, irregulari veslitis.

FroNdbus diplotaxicis, heteromorphis, pinnatis aut bipinnatis, in axillis sepè bulbilliferis; sterilibus dilatatis, segmentis ultimis pinnatifidis, ternatim divisis; nervillis circà mesonevron anastomosantibus el ad marginem liberis; frondulis et laciniis ferlilium extramodìm angustioribus.

Filices erecte, terrestres, indicce; in herbariis rarce aut confusce.

Diagnosis nostr.: Tab. III, fig. A. (S. aurila, PresL, loc. cil.)

In frondibus fertilibus, nervillce sunt omninò liberce. Nervatio frondium steritium similis est nervationi generis Dictyopteridis e tribu Potypodiearum.

Ce genre a été nettement caractérisé par M. Presl, mais cet auteur n'a figuré qu'un simple fragment de la fronde stérile (l. cil.). MM. Hooker et Bauer ont analysé, comme étant un stenosernia, unẻ tout autre plante à sporothèces nus, les uns arrondis et les autres ovales; circonstance très-propre à faire croire quill s'agit de deux espèces distinctes. Nous avons établi (Mém. sur les acrost., p. 17) que les plantes, distribuées par M. Cuming sous les n. ${ }^{05} 295,302,321,341$, comme 
appartenant au Stenosemia aurila, étaient différentes. Il sera facile de s'en convaincre, en comparant avec elles la figure que nous donnons (tab. III, $\boldsymbol{A}$ ); elle reproduit le véritable Stenosemia aurila provenant de La Billardière, qui l'a recueillie sur les côtes du détroit de Bouton. Ce spécimen rappelle, avec des proportions plus petites, la figure citce de Blume. (Vuy. Pleocnemia.)

\title{
ENUMERATIO SPECIERUM.
}

Aurita, Presl* [nervat.*]; (F.*; Rumph.*; Polybotrya, Blum.*) - ?Cicutaria, Presl (Polybotrya, Bl.* [sterilis $])$.

\section{$\dagger \dagger$ Areolis universalibus.}

a. Appendiculatis.

\section{LEPTOCHILUS, Kaulf. (1824.)}

\author{
Enumeratio filicum, p. 147 ; tab. I, fig. 10.
}

Leptochilus, Fí: , Hist. acrostich., p. 19 et 86 , tab. xuvn et xuvu. - Leptochili el Anapausice spec., Prest, Epim. bol., p. 183 et suiv. - Gymnopteridis spec., Ejusd. Tentam. pterid., p. 244. - Acrostichi spec., Lisx. Cavan., Sw., KzE., elr.

SpoRaxgiss rolundis; annulo 14-16 arliculato; sporis subreniformibus, episporio lacerato latè marginatis; sporangiastris viltatis, articulatis (in leptochilo axillari capilatis).

Froxdrus diplotaxicis, heteromorphis, simplicibus; fertilibus angustè lineuribus, sapè filiformibus; in juventute subcanaliculatis, mesonevro prominente; sporangiis adultis sapè gibbosis; nervillis lateralibus crassis (in L. axillari nullis); sterilibus amplis, glaberrimis; nervillis anastomosantibus, primarïs in areolas hexagonas irregulares coadunatis, appendiculis liberis, rectis and hamatis el apice incrassalis; câdice scandente, novem fasciculos vasorum gerente.

Filices repentes, in India orientali vigentes; sapè ad urbores crescentes.

Diagnosis nostr.: Tab. III, B. (Leptochilas axillaris, Kaclf.).

Après avoir donné les caractères du Leplochilus (Mém. cit.), nous faisions connaitre que lés espèces qui composent ce genre, n'étaient pas étroitement liẻes entre elles, et qu'il y avait lieu de former un groupe de transition. Ce que nous avions 
indiqué a été esécuté par N. Presl (Epim. bot., p. 149 et suiv.). Cet observateur ayant constaté que les sporanges étaient nervillaires chez plusieurs leptochilus, les a séparées de ce genre pour constituer deux petits groupes génériques, le Dendroglossa et le Gymnopleris. Reconnaissant la justesse de l'observation, nous avons adopté le Dendroglossa, en le réunissant toutefois au Gymnopteris de M. Presl, qui est distinct du nôtre; il ne nous a pas semblé qu'll y eût lieu à former decux genres, mais seulement un seul. (Voy. Dendroglossa, groupe des lomariées.)

\section{ENUMERATIO SPECIERUM.}

Axillaris, KIfs.* (F.*; Gymnopteris, Presl [Fragmenta*]). - lanceolatus, F.* - Zotlingeri. (Acrostichum, Kze.) - decurrens, Blum. (F.*; Anapausia, Presl).

\section{GYMNOPTERIS, F. (1844.)}

Hist, des acrostichées, p. 18 et 83 ; tab. XLIII-XLVI.

Gymnopteridis spec., Bernh., Presl, Tentam. pterid., p. 244 (1836); J. Sw. in Ноoк., Journ., 1v, 156. - Acrostichi spec., Sw., Wiuld., el Auct. puurım. - Anapausia spec., Prusu, Epimel. bot., p. 185. - Pceilopteridis spec., Ejusd., loc. cit., p. 171.

SPORANGIIS ovoideis, magnis; annulo lato, 14-16 arliculalo _(in Gymnopt., aliena 20); sporis ovoideis, episporio lato, lacerato vestitis.

Frondibus diplotaxicis, heteromorphis; sterilibus amplioribus, pinnatis; frondulis ovatis lanceolatisve; sterilibus angustioribus; nervillis areolas irregulares efformantibus; primariis pinnalis, rectis vel undulatis, nervillarum secundarium ope, in areolas disposilarum et inter se coalitis; appendiculis in quấque areolâ divaricatis.

Filices erectce, amplce, arboricolce, pinnatce, cum impari libern, seu apice pinnatifide"; ut plurimùm Americance, in Indiâ orientali paucissimce.

Diagnosis, Hook. et Baver, Gen. filic., to 85. (G. aliena, Presl.)

Ce beau genre diffère de l'Heteroneuron, par des aréoles appendiculées; du Leptochilus par la situation superficielle des sporanges, et du Slenosemia par des frondes simplement pinnées à nervilles appendiculées conme dans l'Heleronevron. Il ne renferme qu'une partie des espèces énumérées dans le genre Gymnopieris de 11. Presl, tel que cet auteur le comprenait autrefois (Tentam. plerid., p. 244), et n'a plus de rapport aujourd'hui avec le genre fondé sous ce même nom, dans les Epimelico bolanica. Nos espèces font maintenant partie de son gerre Anapausia, grossi du Leptochilus decurrens de M. Blume. 
La nervation du Gymnopteris est presque identique avec celle des bathmium, des amphiblestra et des podopeltis; mais ici les sporothèces sont nervillaires et non ataxiques.

\section{ENUMERATIO SPECIERUY.}

Decurrens, F. (Leptochilus, F.*) - subsimplex, F.* - semipinnatifida, F.* - Heudelotii, Bory et F.* - aliena, Presl (Filix latifolia... Plum.*, Hook et Bauer [Fragm. analyt.*]) - Portoricensis, F. - dentata, F. - acuminata, Presl (Lingua cervina scandens, Plum.*) - nicotianafolia, Presl $\left[\right.$ nervatio*] $\left(\mathrm{F}^{*}\right.$ )

II. Presl (Epim. bot., p. 189) place à còté de son Anapausia qui, ainsi que nous venons de le dire, correspond à notre Gymnopteris, le genre suivant, dont nous n'avons pu faire la diagnose et sur lequel nous ne pouvons nous prononcer.

$$
\text { † CHEIROPLEURIA, Presl. ( } 1849 .)
$$

Epimeliæ botanicæ, p. 189.

Acrostichi spec., Hasskarl, Cat. hort. bog., 3. - Kuvze, in Bot. Zeit., vi, 101. - Polypodii spec., Bư̊r., Enum. 125; Gynnopteridis spec., Hоoк., Jourı. bot., v, 193; tab. vil et vilr.

SPORANGIIs superficiariis, totam paginam inferiorem obtegentibus.

Frovdibus dimorphis, simplicibus; sterilibus palmato-multinerviis, transversis; venis elevatis, costaformibus, venulis primariis elevatis, in areolas magnas rolundato-hexagonoideas, secundariis internis, in areolas parvas reticulatim! anastomosantibus, ramulis liberis, curvulis, apice incrassatis; fertilibus minoribus, angustioribus, venis duabus-tribus costaformibus, longitudinaliter excurrentibus, instructis; rhizomate repente.

Filices Javance, coriacere, glaberrima, stipitata; frons sterilis semilunata, bilnbu; frons fertilis integra, lineari-lanceolata, brevius petiolata.

Hoc genus ab omnibus acrostichearum generibus differt venis palmatis, sen flabellatis costæformibus, quem admodum in Dipteride et in Nevroplatrcerote observatur.

\section{ENUMERATIO SPECIERUM.}

Bicuspis, Presl, l. c. (Acrostichum, Hassk., Kze.) - Vespertilio, Presl (Gymnopteris, Hook.*). 
b. Areolis exappendiculatis.

a. Nervillis rectis.

a. Frondibus pinnatis.

1. Sporangiis in sulco longitudinati nascentibus.

\section{CHEILOLEPTON, F. (1844.)}

Hist. des acrostichées, p. 19 et 89 ; tab. LI.

Nevrocallidis spec., Prust, Epim. bot., p. 177. - Leplochitus tomarioides, Blum, Filic. Jav., p. 206.

SpORANGus in sulco longiludinali nascenlibus, pyriformibus; annulo lato, $16-18$ arliculato; sporis rotundatis, subangulatis.

FRoNdibus pinnatis; frondulis integris, subsessilibus, acuminatis; sterilibus angustè lanceolatis, acutis; fertilibus longioribus, linearibus, in sulco angusto, longitudinali sporangia recipientibus; mesonevro plano; nervillis anastomosantibus; areolis hexagonis, appendiculis carentibus, incequalibus; caudice scandente.

Filix arboricola, repens, elela, Javensis.

Diagnosis nostr.: Tab. II, fig. C. (C. Blumeanum; F. ${ }^{*}$, loc. cil.)

SPECIES.

Genus monotypun; vide diagnosim generis.

2. Sporangiis superficialibus.

\section{NEVROCALLIS, F. (1944.)}

Hist. des acrostichées, p. 19 et 90 ; tab. LII.

Nevrocallis el Chellolepton, Prest, Epim. hot., p. 177. - Acrostichi spec., Gaudich, Voy. de l'Uranie, p. 304.

SPORANGirs amplissimis, rolundis, latè pedicellatis; stomate $11-12$ nervalo; annulo $20-22$ articulato; sporis trigonis.

Frondibus pinnatis, diplotaxicis, glabris, integris, petiolatis; sterilibus majoribus; frondulis lanceolatis, acuminatis, sessilibus; fertilibus linearibus, margine 
explicito, in juventule, indusiun spurium sinulante; mesonevro prominulo; nervillis in fronde fertili et sterili conformibus, proninentibus, reticulatis; areolis hexagonis, appendiculo carenlibus, tenuioribus; rachi (in $N$. prestanlissimâ), trisulcato; rhizomate repente.

Genera Cheilolepton et Nevrocallis proxima videntur; in Cheilolepto tamen sporangiu sulcum longitudinalem continuum occupant; nullun verò apud nevrocallides.

Filices erecta, arboricole, glabra; una species Americana, altera Indica.

Diagnosis nostr. : Tab. iv, A. (N. prostantissima, F.)

Les genres Cheilolepton et Nerrocallis diffèrent à peine, et nous comprenons que M. Presl les ait réunis. Cependant le Cheilolepton se rapproche des leptochilus par l'étroitesse de ses frondes fertiles, tandis que le Nevrocallis a bien plutòt le facies d’un lomariopsis; ajoutons que la marge dans la jeunesse recouvre entièrement les sporanges, ce qui n'a pas lieu pour le Cheilolepton. Enfin les sporanges, dans ce dernier genre, occupent un sillon longitudinal très-marqué. La nervation des deux frondes diffère dans celui-ci, étant à peine visible dans la fronde fertile, tandis yu'elle ne présente aucune différence dans les deux lames des frondes du nerrocallis, plantes dressees, tandis que le Cheilolepton est rampant.

\section{ENUMERATIO SPECIERUM.}

Prestantissima, F** - Requieniana, F. (Acrostichum, Gaud.*)

6. Frondibus simplicibus.

\section{HYMENODIUM, F. (1844.)}

Hist. des acrostichées, p. 20 et 90; tab. LIII, fig. 1, et LVIII.

Anetium sect. 2; Hymenodium, Prest, Epim. bot., p. 176. - Acrostichi el Olfersice spec. Acct. var.

SPORAxGIS rotundis, parvis, stomate nervato; annulo $11-12$ articulato; pedirello tenui longoque; sporis rotundatis, atris, episporio ruoroso vestitis; sporangiastris (in $H$. crinito) filiformibus, apice clavatis, basi tergeminatis, strangulatis.

Froxdres simplicibus, petiolatis, ovalis lanceolatisve; fertilibus conformibus, sed minoribus et peliolo longiori; nervillis reticulatis, areolis elongatis (in H. Kunzeano irregularibus, in H. crinilo hexagonoideis, regularibus); rhizomale crasso, syuamis lanceolatis, integris operto; peliolis sex fasciculos vasorum gerentibus. 
Filices magnce, erecte, arboricolce, integerrima, coriacea, Antillance et Sandriicenses.

Diagnosis nostr.: Tab. 1v , B, fig. 1 (Hymenodium crinitum, F.) et fig. 2 (H. Kunzeani frugmentum.)

Les hymenodium ont le port des acrostichum et des nervilles anastomosées. La nervation est semblable à celle des antrophyum, mais les sporanges sont ici ataxiques et universelles. Le genre Anetium se rapproche beaucoup de l'Hymenodium, si l'on ne veut pas avoir égard au facies et à l'ensemble des caractères tirés des organes de la nutrition. Quoique les sporanges soient superficielles, l'Anetium est un véritable Antrophyum (voy, ce que nous en avons dit: Hist. des acrost., p. 19 el 93); aussi avons-nous abandonné l'idée d'en faire un genre distinct. M. Presl (Epim. bot., p. 176) fait de notre Hymenodium le deuxième sous-genre de l'Anelium qu'il conserve.

\section{ENUMERATIO SPECIERUY.}

Crinitum, F* (Lingua cervina villosa, Plum.*, Petir., Hook.). - Kunzeanum, F.* - crassifolium. F.*

b. Nervillis atiis curvatis, aliis rectis, in eadem fronde.

\section{IEETERONEVRON, F. (1844.)}

Hist. des acrostichées, p. 20 et $91 ;$ lab. LIV-LVII.

Heteronevron, F., Múm. cit., p. 20 et 91 , exclus. spec. 16.

Precilopteris; Eschw. - Campium et Prcilopteris, PresL, Tentam. pterid., p. 238 et 241. - Campium, Pacilopteris et Heteronevron, Ejusd., Epim. bot., p. 168-175. - Bolbitis, Sснотт, Gen. Filic. - Cyrtogonii spec., J. Sr., in Journ. bot. Ноюк., Iv, 154. - Acrostichi spec., Avcr. var.

Subgenera duo constituenda:

1. Caspenu ; nervillis curvatis. (Campii et P'ocilopteridis spec., Prest.)

2. Poecilopterıs; nervillis subrectis.

SPORANGus rotundis, sparsis, aliyuandò nervillis adharentibus; anuulo lato, 13-34 articulato; stomate nervato; sporis ovalibus rolundisque.

Frondrus diplotaxicis, heteromorphis; sterilibus pinnatis, froudulis lanceolatis, dentatis vel crenatis; fertilibus angustioribus; nervillis anastomosantibus; areolis incequatibus, aliis angulatis, aliis polygonalibus, exappendiculatis, an rurius, appendiculos paucissimos, rectos, simplices producenlibus. 
Filices erecte, magna, arboricolø, sapè prolifera, ferè omnes tropicales.

Diugnosis: I. Sснотт, Gen. filic., fasc. III, fig. 3 ; sub Bolbiti (optima). II. Hook. et B., Gen. filic., lab. Lxxx, fig. A. (Campium smbcrenatum, PresL) mediocris, et lab. Lxixı, fig. 2. (P'ccilopteris fraxinifolia, PresL.)

Les aréoles basilaires sont de même forme dans toutes les espèces. Il existe chez toutes des prolongements libres, près de la marge; ce sont des aréoles qui, faute d'espace, n'ont pu se constituer. Dans l'H. diversifolimm, la nervation est pinnée; mais entre chacune des nervures secondaires se forment des aréoles de srandeur inégale, à pans courbes, semblables à celles de toutes les autres espèces.

\section{ENUMERATIO SPECIERUII.}

1. Cinpıcu : diversifoliune, F. (non Gymnopteris trilobata, J. Sm.; Acrostichum, Blum.*) punctulatum, F.* (Pocilopteris, Presl [nervatio*]). - Preslianum, F.* - heteroclitum, F. (Pacilopteris, Presl [nerwatio]; Acrostichum, Presl*, IIook.*, Blum*, Panna-Mara, Rheed.*) - subcrenatum, F. (Acrostichum, Hook.*) - virens, F. (Acrostichum, Hook. et Gr.*) - meniscioides, F. (frondula*). - lonchophorum, F. (Acrostichum, Kze.*)

II. Peciloprerıs : serratifolium, F.* (Pocilopteris fraxinifolia Presl [nersatio*] Bolbitis, Scholl Fragm, analy\%.] Acrostichum, Arrab.*) - Raddianum, F. (Acrostichum, Radd.*) - scalpturatum, F. (Campium costalum, Presl [nervatio*]). - proliferum, F.* - sinuosmn, F. (frondula sterilis*). - repandum, F.* (Acrostichum, Blum.*). - Quojanum. F. (Acrostichum, Gaud.*) - lobulosum, F., Herb. Vind. (Pocilopteris, Presl).

\section{Sporangiis in loco determinato nascentibus. $\uparrow$ Areolis exappendiculatis.}

\section{CHRYSODIUM, F. (1844.)}

Hist. des acrostichées, p. 22 et 97 ; tab. LIX-LXII.

Acrostichum, Prest, Epim. bot., p. 178; J. Sw. in Ноoк., Journ., iv, 152. - Acrostichi spec., Alct. var.

SPORaxGIS ovatis, amplis; annulo 20 articulato; arliculis angustis, approximalis, pedicello lato; sporis sublrigonis; sporangiastris (sporangüsve in evolutione impedilis) agariciformibus, villatis, cupulatis, longè pedicellatis, succineo colore. FRoxdвLs pinnatis, monolaxicis, robustis, rigidis; rachi sulcato, apice frucliferis; frondulis superioribus ferlilibus, conformibus, paululim angruslioribus; nervillis anaslomosantibus; areolis parris, hexagonis, regularibus, sulcatis, exappendiculatis.

I. B. Delendum est genus Anetium Splitgerberi; A. cittifolium speeies rera AuIrophyi habebilur. 
Filices excelsa, erecter, firmce; frondulis lanceolatis, crassis, opacis, angulum aculum cunn rachi crasso formantibus. Genus distinclissimum, speciebus orbem novum ferè omnibus inlabitantibus.

Diagnosis : Hоoк. et B., t. vin, fig. A. (Acrostichum aureum [C. vulgare, F.]) mediocris.

Ce beau genre, le seul du groupe qui se plaise dans les eaux stagnantes comme les typha, est bien distinct. Linné connaissait l'espèce-type et il en avait fait un acroslichum. Toutes ces fougères montrent des sporangiastres succinoïdes mélangès arec les sporanges. Leur forme est très-variée et peut servir dans la détermination des espèces. Nous avons établi que ces corps singuliers étaient des sporanges arrêtées dans leur développement, et nous les avons vus sous tous leurs états (voy. genre Hymenolepis; consultez aussi Hist. des acrostichées, p. 22). Les regarder comme des corps pilifornes est une erreur, dans laquelle sont tombés plusieurs botanistes.

\title{
EXUMERATIO SPECIERCM.
}

Vulgare, F. (Acrostichun aureun, L., Schkh.*, Presl [nervatio*]; Lingua cercina aurea, Plum.*, Pluk.*, Peliv.*), var. rigens, F. (Sieb., exsicc., n. ${ }^{\circ} 3$ ) et var. minus, F. (Acrost. obliyuum, Blum.*) - hirsutum, F. (Acrostichum aureum, Arrab.*) et var. marginatum, F. (Acrostichum marginatum, Schkh.*) - incequale, F. (Acrostichum, Willd., Blum.*) - Cayennense, F.* - Urvillei, F.* sculpturatum, F.* - sreciosum, F.* (Acrostichunt, Willd., Blım.*) - fraxinifolium, F.* danceeefolium, F. (Acrostichum, Willd., Langsd. et Fisch.*).

\section{i† Areolis appendiculatis.}

«. Frondibus pinnalis.

\section{PHOTINOPTERIS, J. Sm. (1858.)}

\author{
Genera of ferns, in Hook. Journ. bot., IV, p. 155.
}

Рhotinopreris, F., Mém. cit., p. 24 et 102 ; tab. LuII.

Sporangns ovalis, lonarissimè pedicellat is; annulo crasso, $11-12$ arliculato; sporis ovoideis reniformibusque.

Froxdibes pinnalis, superioribus linearibus, apicem ferlilem conslituentibus; onnibus verò peliolo brevi instruclis, in lobulum sculiformem desinente; frondulis sterilibus ovalis, aculis, coriaceis, lacvibus, siccilale fragilibus; fertilibus linearibus, flexuosis, elongatis; nervillis anastomosantibus; areolis quadrangularibus, in areolas secundarias parvulas partitis; "ppendiculis punclo globuloso, pellucido nolatis. 
Filix insignis, eluta, pinnatu, erecta, Indira; facie sui generis.

Diagnosis : Hook. ct B., Gen. filic., tab. xcu (bonu). (l'. Horsfieldii, J. Sis., loc. cit.; 2. Mim., F., tab. Lxin.)

II. J. Sunith est le créateur de ce genre curieux. Nous disions de cette singulière fougère qu'elle ètait lit seule présentant des pinnules ou frondule's articulées, dont le pétiole semble accompagnè d'une sorte de stipule, s'il est permis de donner ce nonı au petil disque horizontal attaclıè à la base du pétiole; en nous exprinant ainsi, nous n'entendions pas dire que ce fussent des stipules véritables, conme on nous l'a fait dire, mais seulement une expansion discoide stipulifurne. née du pétiole.

M. Presl (Epim. bol., p. 191) dècrit un P. simplex, J. Sm., Cuming, Fil. Phil., n.0 64, qüil regarde comme douteux, et un P. Cumingii, Presl (Cuming, Fil. Phil., n. $56_{2}$ partim), que nous hésitons à regarder comme distinct du P. Horsfieldii. L'espèce américaine, $P$. Humboldtii, nous laisse encore plus de doutes.

\section{SPECIES.}

Genus monotypum : vide diagnosim generis.

6. Frondibus Jacinialis.

\section{NEVROPLATYCEROS, Pluk. (1696.)}

Alnagestum botanicum, p. 151 ; tab. CDXXIX, fig. 2.

Netroplatyceros, F., Mém. cit., p. 25 el 102 ; t. Lxiv.

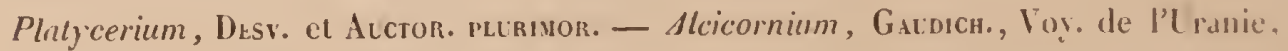

p. 48. - Acrostichi spec., Accr. vir.

Duo subgenera constituenda :

I. PLaticeraa; acervis ad sunmilates frondium silis.

II. Scutigrera; acervis sculum rolundum occupautibus.

Sponsagns magnis, rolundis, pedicellatis, rario sessilibus, pilis stellatis commixtis; annulo 18-20 arliculato; acervis sporangiarnm latissinis, ad apicem dicholomiarum seu sinuum frondium nascentibus; in N. biformi suprì laminam sculelliformem silis; sporis uniformibus.

Froxdвus heleromorphis; primordialibus radicalibus, suborbiculato-lobatis vel palmatis, siccilale scariosis; secundariis segmentis digitatis, dichotomis, ferlilibus; nervillis primariis liberis, parallelo-furcatis; secundariis anastomosemlibus, areolas magnas constituentibus; terliariis appendiculatis; "ppendicibus. hamalis. 
Filices insignes, ad arbores el rupes pendulce; coriacece, pubescentes, partite; in variis regionibus orbis terrarum, habitantes.

Diagnosis: Ноок. et B., tab. Lxxx, B. (Plalycerium biforme, Buим.) F., l. cit., tab. Lxiv.

Nous avons adopté le nom de Plukenes, quoiqu'il fùt antélinnéen, dans un esprit de justice, sans être arrêté par la longueur de ce mot que nous trouvons hien plus euphonique qu'une foule d'autres '. M. Blume l'avait syncopé; cependant en créant son platycerium, il avait songé au vieux botaniste et se rattachait à sa nomenclature. La philosophie botanique prescrit de ne se servir que de noms faciles à prononcer, mais elle prescrit aussi de respecter l'antériorite. 11 existe entre certaines espèces du genre Niphobolus et le genre Nevroplatyceros, une analogie évidente. Les sporanges ne sont pas ataxiques dans le $N$. cethiopicus, Pluk., et le système pileux, quoique très-singulier, est le même.

\section{ENUMERATIO SPECIERLM.}

1. Platyceria : alcicornis, F. (Acrostichum, Turp.*, Presl* [neriatio]). - Eihiopicus, Pluk. (F.* Acrostichum, Palis. Beaur.*) - grandis, F. (Platycerium, Hook. et Bauer [Fragm. analyt.*]; Platycerium biforme, Hook. non Blum. [Fragm. analytica.*])

II. Scutigera : biformis, F. Fragm. analyt.* (Platycerium, Blum.*; Osmunda coronaria, MIull.*)

\section{Considérations générales sur le groupe des Acrostichées.}

Les genres qui composent ce beau groupe, ne sont pas tous de même valeur. On peut reconnaitre qu'ils peuvent être ramenés à sept types distincts; savoir:

1. Acrostichum, F, auquel se rattachent les genres Aconiopteris, Presl; Hyımenodium, F.; Leptochilus, Klfss.; Lomariopsis, F.; Cheiloleplon, F.; Gymnopleris, Presl; Heteronewron, F.

2. Polybotrya, H. et B., ayant pour analogues: Egenolfia, Schott; Soromanes, F.; Stenosemia, Presl; Lomariobotrys, F.; Olfersia, Radd.

5. Leptochilus, Kaulf.

4. Rhipidopteris, Schott.

5. Chrysodium, F.

6. Photinopleris, J. Sm.

7. Nevroplatyceros, Pluk.

Ces cinq derniers sans analogues et de physionomie particulière.

Il a été dit plus haut, p. 20 , que dans les genres Lomariopsis, Leptochilus, Pholinopteris et très-vraisemblablement dans le genre Lomariobotrys, la marge

1. Apatophtebia, Psomiocarpa, Cheiropteuria, Pronephrium, Senflenbergia, parni les fougères; IIangenheimia, Krascheninikovia, Chamasciadium, Eupolyalthia, Euxerocarpaa dans d'autres familles. 
des frondes fertiles s'amincit en faux indusium, tant il est vrai que l'mportance, tirée de ce caractère, est faible et de secours incertain.

Nous avions adopté le genre Anetium, mais sous toutes réserves; aujourd'hui il nous est bien démontré que cette plante est une espèce du genre Antrophyum et nous l'avons supprimé. (Voyez plus loin ce que nous en disons : groupe des Hémionitidées.)

Depuis la publication de notre Histoire des acrostichées, M. Presl a proposé, dans ce groupe, la formation de quatre genres nouveaux. Nous avons déjà fait connaitre notre opinion sur la valeur du genre Dorcapteris, p. 52 , et donné les caraclères principaux du Chciropleuria, p. 56 ; nous allons parler ici du Microslaphyla et du Psomiocarpia.

Le premier de ces deux genres est fondé sur une plante extrêmement embarrassinte que nous croyons devoir placer parmi les anogramme. Si nos conjectures sont vraies, cette fougère se présenterait sous deux états très-distincts : $10^{\circ}$ avec le facies d'un acroslichum, tel que l'a figuré M. Hooker, sous le nom de dimorphum et alors simplement denté; $20^{\circ}$ pinnatifide à segments nombreux et bifurqués avec le port voisin de celui des anogramme, tel que l'a vu Swartz, qui en a fait son Acrostichum bifurcatum. Nous possédons celle plante dans notre collection, offrant tous les passages possibles de la lame simple à la fronde découpée, mais seulement stérile. Pour décider la question, il faudrait recueillir de nouveau à Sainte-Hélène, île souvent visitee, l' $\boldsymbol{A}$. dimorphum fructifié, qui n'a été jusqu'ici vu prolifere que par M. Hooker. Il est bien remarquable que les voyageurs aient toujours récolté l' $A$. bifurcatum, qui abonde dans les herbiers, sans jamais avoir pu recueillir l' $A$. dimorphum, fructifié. Il n'est pas moins extraordinaire de trouver la fronde stérile de l'un passant à la fronde stérile de l'autre, par des nuances extrèmement ménagées; les lames dentées prennent facilement la forme pinnatifide, et la forme pinnatifide, en s'exagérant, donne fréquemment lieu à des segments étroits. En présence de toutes ces difficultés, nous croyons qu'il faut attendre encore pour se prononcer sur la validité du genre Microslaphyla de M. Presl.

Le Psomiocarpia est un démembrement du genre Polybotrya, destiné à recevoir les espèces, dont les frondes sont fruclifères des deux côtés de leur surface. Nous avions constaté que cette circonstance se présentait, en effet, pour certaines espèces et nous les avions séparées (Hist. des acrostichées, p. 72). Toutefois ce caractère ne nous avait pas semblé suffisant pour étre regardé comme générique (Ouv. cit., p. 12 et 13 ), nous croyons devoir persister dans notre opinion première. II. Presl (Ouv. cit., p. $16_{1}$ ) renferme quatre espèces dans son genre Psomiocarpa; naais les $P$. acuminata et incisa, n'étant fructifiés que d'un còté, doivent rester parmi les polybotrya, et l'on devrait y placer le Polyb. nodiflora, Bory, qui l'est sur l'une et l'autre lame. 
tot Vis prolifica ad receptaculum proprium rel ad nervillas manifesta (receptaculum proprium aul nervillare) : TAXIOCARPE E.

§. 1. Sporothecia secundium lineam rectam excurrentia, parallela, costalia aut marginalia: LEPTOCARPEAE.

\section{Angiosoria : LOMARIEE.}

Blechnucere, Prest, Epim. bot., p. 103.

Blechnacearum, Adiantariarum, Acrostichacearum pars, Prest, Tentam. pterid., p. 97,139 et 228.

Filices feracissima, erecke, rarissimè volubiles, herbaceœ, ferè nunquam caulescentes, simplices, sapiris pinnalce vel pinnatifudce, diplotaxicce, scilicet frondibus fertilibus et sterilibus diversis; patria extensa.

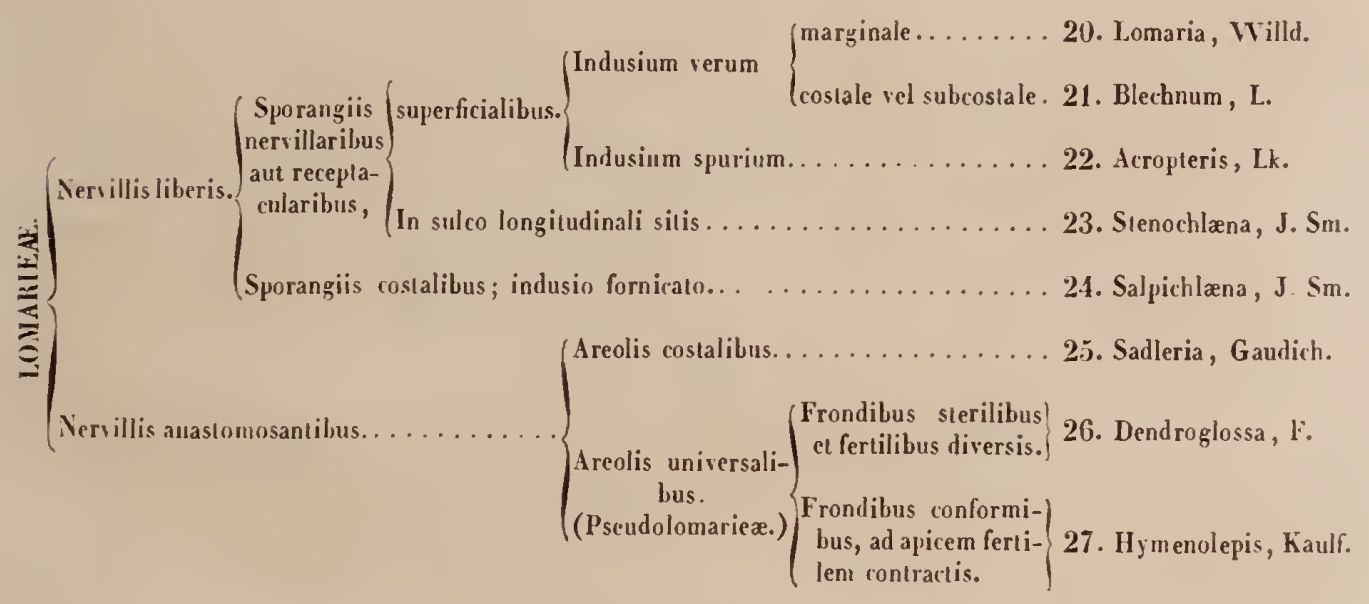


$\doteqdot$ Frondibus pinnatifidis pinnatisve, rarò et abortu simplicibus.

\section{* Yervillis liberis.}

A. Sporangiis reeptacularibus rariùs nervillaribus.

a. Sporotheciis superficialibus.

a. Indusium verum.

1. Marginate.

\section{LOMARIA, Willd. (1809.)}

In Mag. d. Ges. Naturf. F. z. Berl., 1809 , p. 160.

Lomarice spec., Prest, Tentam. plerid., p. 141. - Spicanta, Orthogranma, Parablechnum et Lomaridium, Ejusd. Epim bot., p. 114 et seq. Mesothematis spec., l. cit., p. 111.

Onoclece, Acrostichi, Osmunder, Pteridis, Henionitidis, Polypodii spec., Auct. var.

Sporotuecus linearibus, continuis, parallelis, marginalibus, mesonevron attingentibus; indusio vero scarioso, adulto laciniato, reflexo, persistente; margine incrassato, receptaculi, sapè nervati, locum tenente, rarò nulli el tunc sporangiis nervillaribus; sporangiis magnis; annulo crasso, 18-20-22-28 articulato, ad sacculum leviter adhcerente et facilè soluto; sporis magnis, ovoideis, reniformibus, aliquoties oculo nudo perspicuis.

Froxplbus diplolaxicis, pinnalifidis aul pinnatis; frondulis sterilibus integris (in L. procercî argulè serralis); frondulis fertilibus contractis, longioribus; stipitibus crassis, coloratis, sulcatis rigidisque, rarò helveolis, tenuibus; nervillis liberis, pinnatis, parallelis, creberrimis, aequalibus.

Filices robusta, feraces, terrestres, rigida, Blechni aliquando, non autem proxinua"; cosmopolitanc; in Europa modò species una; ferè onules in Indiis orientalibus, promontorio Bonce Spei, insulis Africanis, nec non in Antillis vigentes.

Diagnosis : Ноoк. et Bader, Gen. Filic., t. Lxiv, B; sub L. chilense, Klfss. - Prest, Tentam. pterid., p. $17-32$ (uervatio sola).

Icon. uostra : Tab. I, B, fragm. L. L'Herminieri, Bonx, et tab. V, B, fig. 1, L. Spicant, DEsv. - Fig, 2, L. lanceolata, SPr. - Fig. 3, L. striata, Sw. - Fig. 4, L. punctata, Kze. - Fig. 5, L. heterophylla, Wint. - Fig. 6, L. attenuata, Willd. - Fig. 7 , L. callosa, F. - Fig. 8, L. spissa, F. - Fig. 9, L. Gueinzii, Movg. - Fig. 10, L. Magellanica, Desv. (Fig. 1-5, Fragmenta varia frondularum; fig. 6-10, Sectiones stipitum.) 
Si le genre Lomaria se lie étroitement aux lomariopsis par le port, le mode de nervation et la diplotaxie des frondes, il en est complètement séparé par des sporanges non effuses, mais réceptaculaires ou nervillaires, ainsi que par la présence d'un indusium vrai. Dans ces deux genres il arrive assez souvent que les frondes stériles se déforment et deviennent irrégulières. La marge des frondules du L. punctulata, Kze., prend une apparence lobée ou crẻnelée, comme il arrive dans le Lomariopsis variabilis (tab. XXII, Mém. sur les acrostichées). Le sommet des frondules du $L$. capensis, Willd., se divise en segments dichotomes. Nous avons observė un effet pareil dans une varièté du Scolopendrium officinarum $L$., particulière à la Corse. Les frondules du L. heterophylla, Desv., passent facilement de la forme simple à la pinnatifide. Enfin le $L$. attenuata, Willd., dordinaire pinnatifide, a [parfois des frondes stériles simples; le même effet se produit dans le Stenochlona Patersonii, F. Dans le L. attenuata, les frondules fertiles se roulent sur elles-mêmes d'une manière extrèmement curieuse. Il n'existe à notre connaissance aucun Lomaria prolifere ou radicant. Nous possédons un spécimen de L. Spicant d'Europe, Desv., donné par M. A. Braun: il offre cette particularité d'avoir des nervilles réticulées. C'est un passage curieux dụ genre Lomaria au genre $W$ oodwardia. (Voy. tab. V, fig. 1.)

Les stipes sont d'ordinaire extrênenient robustes. Il n'y a d'exception que pour un petit nombre d'espèces, et c'est parmi elles qu'il faut chercher celles qui se rapprochent le plus des blechnum (voyez ce genre). Le réceptacle des sporanges n'a pas toujours les mêmes caractères. Il prend parfois la forme d'un bourrelet, et ce bourrelet est tantôt énerve et tantôt nervé en travers, tantôt èpais ( $L$. Boryana, Willd.), et tantôt mince ( $L$. mucronulata, F.). Quelques espèces n'en présentent aucune trace. Les sporanges sont alors fixèes à l'aisselle de l'indusium, c'est-à-dire au point où il s'attache à la frondule. Ce tégument est ordinairement assez large; les sporanges, en le soulevant, le déchirent d'une manière irrégulière et lui donnent une apparence frangée. Il se fixe à la marge, et dans deux ou trois espèces cette marge s'ètend un peu au delà du point d'attache de l'indusium. Cependant cette modification n'influe en rien sur le facies qui reste le même.

Ces fougères sont toujours herbacées, dressées et robustes; elles peuvent atteindre un mètre et plus de hauteur. Le $L$. Boryana prend la forme d'un petit arbre rabougri dont le port se rapproche de certaines cycadées. Leur géographie est trèsétendue. Elles s'avancent fort loin vers les pôles, savoir : le $L$. discolor vers le pôle antarctique, et le $L$..Spicant vers le pôle arctique. Cette dernière espèce est la seule qui soit européenne, et elle est un peu dissidente; lindusium n'étant pas exactemient marginal. (Voy. ce que nous disons, p. 83, du genre Spicanta de II. Presl.) 


\section{EXLYIER.ITIO SPECIEILII.}

1. Euconan.f. Sporothecüs marginalibus.

1. Frondibus pinnatifidis $=$ villosa, $\mathrm{F} .-$ punctata, Kze.* (Java, L.obb. , $\left.110^{\circ} 273\right)-$ decrescens, F. - triloba (Bleclinum, Ilook. et Grev.*) - pteropus, Kze.* - L'Ilerminieri, Bor. (Kze.*) heterophylla, Desv. (Blechnum, Schlceht.*) - altenuata, Willd. - alpina, Spr. - lanceolatu, Spr. - inflexa, Kze*- Spicant, Desr. (Blechnum, Schk.*) - nuda, Willd. (Onoclea, Lalbill.*) - Magellanica, Desr. - Plumieri, Desr.

11. Frondibus rinnatis = longifolia, Sehl. non Klfss. - Gueinzii, Moug., Ilerb. - eriopus, Kze** - robusta, F. (an L. rufa, Spr.?) —Clilensis, KIsss. - cullose, F. - euphlebia, Kzc.* - glauca, Blım. (Kze.*) - Ryani, Klfss. (Kze.*) - Gilliesii, H. el Grev.* - vestita, Blum. (Cuming, Filic. Phil. , $1 .{ }^{\circ} 141$ ) - discolor, Willd. (Ilemionitis, Sehk.*) - Boryana, Willd. (Pteris osmundoides, Bor.*) - Olivieriana, F. - unguiculata, F. - scabra, Klfss. (Orthogramma, Presl) - marginata, F. capensis, Sehl.* - gibba. Labill.* - obtusata, Labill.* - punctulata, Kze. (Blechnum, Sehl.*)rigida, F. (L. punctulata, Drège) - striata, Sw. - spissa, F.

B. Paralomanta. Sporotheciis a margine remotiusculis.

Pumila, KIfss. -- procera, Desv. (Homb. et Jacr.*; Blechnum, Labill.*; Sieganin, Ricl.*; Asplenium, Beruh.*) - ambigua (Parablechnum, Piesl ; Blechnum, K!fss.) - mucronulata, I: - salicifolia (Parablechnum, Presl.)

\section{SPECIES NONDUM DESCRIPTE}

A. Sporotheciis marginalibus. (Eulomarix.)

1. Frondibus pinnatifidis.

I. Viliost.

Frondibus piunatifidis, slipilibus helveolis, canaliculatis; slevilibus lanceolalis, luciuiis lanceolatis, usque ad costam liberis, approximalis, basi latioribus, aculis, subuis pilosis; nervillis furcato-purallelis, apice incrassatis, coloralis, una-gineun non attingentibus; fertilibus ovalo-lunceolalis, laciniis linearibus, basi sublastatis, infri oppositis; sublìs iugosis, glabris, rachi villoso; sporolheciis marginalibus, receptaculo ctasso; sporangiis tabacinis, ovoideis; annulo luto, 18.20 atliculato; sporis ovatis, brevibus lavibusque.

Habitat in Java (Lobb., n. ${ }^{\circ} 266$ ).

Filix stricta; fionde stevili blechniforme; laciniis basi vix decresceutibus.

(Longueur : 35 centim.; envergure des segments stériles, 9 centim.; des fertiles, 13 centim.; largeur des stériles, 12-13 millim.; des fertiles, $4-5$ millim.)

\section{DeCrescess.}

Frondibus pinuatifulis, in aubitu lanceolatis, caulibus crassitudine digiti uninoris, squanis rufis, lanceolatis, nitentibus, longissimè acuuinatis vestitis; lncinuis sterilium intermediis lauceolatis, oppositis, obtusis, inferiovibus hemisplucricis, alternis, teruninali longâ, lanceolatâ; stipite supreruè helveolo, angustè canaliculato, infì̀ nigro, lırvi; nervillis crassis, "upice prominentibus, dentibus marginis iuter se coulitis membranulam simulantibus; frondibus fertilibus subpinnatis; laciniis linerribus, upice callosis, euervis; indusio rubescente, seuper integro; receptaculo crasso, 
gibboso; sporangïs ovatis; annulo 13-14 articulato; sporis reniformibus, episporio delıpso vitreis.

Habitat in Cubâ. (Linden, n. 2019.)

Filix singuluris, scandens, glaberrima; frondibus sterilibus pinnatifdis, fertilibus subpinnatis; stipites bicolores.

(Longueur totale de la fronde, 36-40 centim.; segments de la fronde stérile, 20 -23 millim., sur 5-6 millim. de largeur; segments de la fronde fertile dépassant 5 centim.; ils mesurent à peine 3 millim. de largeur.)

11. Frondibus pinnatis.

III. GereszzII, Moug. Herb.

Frondibus sterilibus pinnatis, paleaceis, squamis rubellis, linearibus, longissimè attenuatis, tortilibus; stipite lèvi, subtìs convexo, suprà profundè cunaliculuto, fusciculos vasorum sex, duos superiores majores, quatuor inferiores minores ferente; frondulis sterilibus angustè lanceolatis, acuminatis, basi attenuatis; inferioribus in petiolum desinentibus, superioribus sessilibus et basi inferiore adnatis; nervillis tenuibus, scalpturatis, marginem altingentibus, parallelis; fertilibus linearibus, vix angustioribus; indusio latissino, fulvo, statu adulto lobato-lacerato; receptaculo angustissimo, nigrescente; sporangiis ovoideis; annulo 16-18 articulato; sporis crassis, ovoideis.

Habitat ad Promontorium Bonce Spei. (Gueinzius, Herb. Moug.)

Filix magna, elegans, siccitate helveola, firma.

(Longueur des frondules stériles, 20-22 ecntim. Les frondules fertiles linéaires sont à peine plus longues. Largeur des frondules stériles, 15-18 millim. Les éeailles de la base des stipes; finement atténuées, atteigncut 4 centim.; elles sont roussàtıcis et élégamment contournées.)

Dans le spécimen que nous décrivons, les frondules fertiles sont réunies aux stériles sur le mène stipe dont elles oceupent chacune un côté. Celtc particularité, qui existe dans le $L$. procera, Desr. (Blechnum, Labill.), nous semble aceidentelle.

\section{Robusta.}

Frondibus ovatis, pinnatis, stipitibus validis, paleaceis, irreguluriter striatis, angululis canaliculutisque; squamis rigidis, longissimis, integris, opacis, linearibus, imbricatis; frondibus fertilibus longioribus, rigidis, stipite curvato, basi glandulos atros, gibbosos ferente; frondulis patulis, squamosis, basi sessilibus, supernè connexis, lanceolatis, obtususculis, margine integris, suprà fuscis, subtus auratis; nervillis parallelis, tenuissimis; frondibus sterilibus longioribus, stipite nigrescente, crasso; frondulis linearibus, erectis; inferioribus petiolatis; superioribus sessilibus; indusio fumbriato, receptaculo crasso; sporangiis nagnis; annulo 20 articulato; sporis brevè ovalis, crassis.

Habitat in Guadclupâ. (L'Herminier.)

Filix robusta, squamosa, mullifrondulosa, colorata, fragilis; marginibus frondularum sterilium siccitate convolutis; squanis rigidis, proprïs. (L. rufice Spreng. proxima?) 
(Longueur totale : 45 centim,; des frondules slériles, 9 eentim.; des fertiles, 12 eentim.; le slipe, qui est déprimé, est de la grosseur d'une plume de eygne.)

\section{Callosa.}

Frondibus rigidis, pinnatis, ovuto-lanceolutis; frondulis omnibus, ad basin mesonevi, callositaten rolundun ferentibus; stipitibus glabris, fiusco-rubris, depressis, membranulâ coloratî marginatis, fasciculum vasorum unicum, angustuun, arcuutum gerenlibus; frondulis sterilibus acuminatis, lanceolatis, serrato-crenatis, vix petiolatis, $p a-$ tulis, basi truncatis, siccilate rufescentibus; nervillis tenuilus, furcato-parallelis, pellucilo-rubris; fertilibus assurgentibus, subsessilibus, linearibus, subtìs rufo-fuscis, inturessis; sporolheciis extensis, marginalibus, fusco-tabacinis; receplaculo crasso, transversè lineato; indusio tenui; sporangïs ovatis; annulo 20.22 articuluto; sporis irregularibus, lavibus.

Habitat in Javâ. (Lobb., n. 274.)

Filix rufescens, glabra, rigida, inter omnes species basibus frondularun supernè callosis notala.

(Longueur de la partie feuillée, 30 centim.; frondules stériles, $7-8$ centim., séparées par un entre-noud de 9-10 millim.; largeur, 8-9 millim.; froudules fertiles un peu plus longues et linéaires.)

\section{Olivieriatid.}

Frondibus pinnatis; sterilibus ovalo-lanceolatis, stipitibus squanosis, mbro-maculatis; frondulis 20 jugis, lanceolutis, sessilibus, acuminatis, cordatis, margine serratis; serraturis obtusis; nervillis parallelo-furcatis, prominentibus, imbricatis, angulum $45^{\circ}$ cun rachi netientibus; frondulà terminali conformi; frondibus fertilibus robustis, elatiorilus; frondulis petiolatis, longioribus, linearibus, usque ad apicem proliferis, basi subcordatis; indusio lato, maturitute sporangiarum multipartito; receptaculo nervalo, crasso; sporangiis magnis, ovatis; annulo 26-28 articulato; sporis crassis, ovatis, obliquis.

Habitat in Indiis orientalibus. (Olivier.)

Filix magna, robusıla, rigidu; rachi maculato, profundè sulcuto.

(Longueur tolale, 1 mètre; des frondules stériles, $T$ centim.; des fertiles, 14 centim.; largeuı des stériles, 1 cention. environ; des fertiles, 5 millim.; le slipe alleint à la grosseur d'une grosse plume d'oie.)

\section{V́li. Unguicl lata.}

Frondibus rigidis, pinnatis; stipile suprà canaliculato-striato, parcè rufo, squnnıso; fusciculos vasorum octo gerente: duos superiores minores, duos internedios nujores, quatuor inferiores nuinutos; frondulis sterilibus approximatis, subimbricatis, lunceolatis, brevè petiolatis, apice obtusiusculis, mucrone calloso donatis, suprà viridibus, subtìs rubellis; nervillis tenuibus, parallelis; frondulis fertilibus longiori- 
bus, linearibus, petiolatis, undulatis, apice longè unguiculatis, subtìs angustè tri-. sulcatis; sporangiis rufis, receptaculo crasso, lineari, enervato; indusio lato; annulo $20-22$ articulato; sporis lcevibus, obliquè ovoideis.

Habitat in insulâ Madagascariensi (Pervilliẻ).

Filix magna, rigida, rufescens, multifrondulata; ungue longo, curvato, frondulas fertiles terminanti.

(Longueur de la partie fronduleuse, 36 centimètres; des frondules stériles, 10 centim.; des fertilcs, 18- 20 centim.; largeur des frondules strériles, 15 mill.; des frondules fertiles, 5 millim.)

\section{Margivata.}

Frondibus pinnatis, rachi squamoso, sulcato; sterilibus in ambitu ovatis; frondulis lanceolatis, obtusis, brevè petiolatis, cordatis, alternis, pallidè virescentibus; mesoneuro canaliculato, squamoso; nervillis parallelis, apice turgidis, marginem pellucidum non attingentibus; fertilibus robustis, frondulis longissimis, flexuosis, attenuatis, ad basinn dilatatan cordatis, aliis linearibus omninò proliferis, alïs lcnceolatis dilatatis, circà mesonevron mod̀̀ fertilibus; receptaculo crasso, nervato; indusio maturitate sporangiarum laceralo; sporangïs amplissimis, ovatis; annulo crassissimo, 18-20 articulato; sporis ovoideis, crassis.

Hubitat in insulâ Borbonia (Nontbrison).

Filix erecta, magna, squamosa, robusta.

(Longueur totale , 75 centim. et probablement plus; des frondules stériles et fertiles, 15 centim.: largeur des stériles, 24-26 millim.; des fertiles, 6- $\mathbf{7}$ millim.; ses spores sont visibles à l’œil nu.)

IX. SpIssa.

Frondibus ovatis, rigidis, pinnatis, suprâ pinnatifidis, siccitate rubris; stipite depresso, supernè vix canaliculato, infrà subalato; fasciculis vasorum octo: sex inferioribus in circulun dispositis, duobus inferioribus distantibus, elongूatis, rectè dispositis; frondulis sterilibus crussis, opacis, lanceolatis, acutiusculis, patulis, basi rotundatis; inferioribus et intermediis adnatis; nervillis approximatis; mesonevro et rachi squamosis; fertilibus linearibus, obtusis, mucronatis; nucrone calloso; indusio latissimo, maturitate sporangiarum bulloso; receplaculo crasso, mesoncvro connivente; sporangiis magnis, ovatis, cum squamis angustis, lanceolatis immixtis; annulo 20-22 articulato; sporis ovatis, crassis, levvibus.

Lonaria Boryana, Kze. non Willd.

Habitat ad Promontorium Bona Spei (Drège).

Filix robusta, crassa, multifrondulosa, pinnata, siccitale rufa.

(Longuer totalc : 30-36 centim.; des frondules stériles, 9 centim. sur 16-18 millim.; les frondes stériles plus longues; l'indusium a de 3 à 4 millim. de largeur : c'est la seule espéce portant des écailles mêlées aux sporanges.)

Dans le $L$. Boryana, Willd., il n'y a point d'écailles arec les sporanges; les spores sont beancoup plus gros et tuberculeux; l'anneau ne porte que $\mathbf{1 6}$ articulations; les frondules sont obtuses et toutes libres à la base, etc. 
I. Mсckonchata

B. Sporangiis a margine remotiusculis. (Paralomaria.)

Frondibus glabris, pinnatis, slipitibus glabris, helveolis, crassitudine pennce corvina', supri sulcalis, duos fusciculos ovoideos, parvos gerentibus; rhizomate repente, squamoso, squanis rufis, lonceolotis, longè acmminatis vestito; frondulis slerilibus globerrimis, sessilibus, medianis upproximatis subimbricatisque, basi cordatis, fulcatis, lanceolatis, morgine denticuloto, aspero, nutcronulutis, inferioribus distuntibus, hastutis; fertilibus angustioribus, couformibus, iuferioribus slerilibus, omnibus nmrronulutis; sporotheciis submarginalibus, marginem nec basin allingentibus; indnsio temui, receplaculo lineari, angustissimo, enervato; sporangïs ovoideis; unnulo 18 articulato; sporis ovoideis, lervibus.

Habitut in Indiis orientolibus (Olivier).

Filix glıbra; facie Lomarice Spicanti; stipitibus gracilibus.

Longueur totale : 40-45 centim.; du stipe, environ 10 centim.; longuenr des frondules. 3 centim.; largeur des stériles, $7-8$ millin.; les fertiles sont plus étroites.

2. Indusium coslate, plis minusve proximum.

\title{
21. BLECHNUM, L. (17T4.)
}

\author{
Spec. plantarum, 153\%.
}

Blechum, Blechnopsis, Mesolhematis spec. et Distaxia, PrEcr, Epim. bot., p. 103 el seq. Lomarice spec., Acct. Paccur.

Sровотнесиs linearibus, contimuis, costalibus aul subcoslalibus; indusio plamiusculo, persistente, cuu malurilate inlegrè dehiscente; sporangiis oralibus, axillaribus; receplaculo nullo; anmulo 13-18 arliculalo; sporis ovalibus vel reniformibus. Frovidacs homomorphis, pinnalifidis, pinnato-pinnalifidis, pinnatis, rarius simplicibus aul bipinnalis; nervillis pinnalo-furcalis; fasciculis vasorum in slipile lemui, helveolo, 2-4 parvulis, inceyualibus; rhizomate repente, rarì stolonifero.

Filices terrestres, arboricola, tropicales, herbacea, rarissimè subarborescentes; ad forman lanceolutan tendentes; plures Lonariaum fucie, sed frondibus monotuxicr.

Diagnosis : Шоок. et B., tab. LIV, B. (Blechnum occidentule, L.)

lcon. nosti. : Tab. V, B, fig. 11, B. glandulosum, LK. - Fig. 12, B. (Hesothemo) hastahun, hifss. - Fig. 13, B. Maluccense, F. - Fig. 14, B. extensum, F., el caudatum, Cavas. (11 et 12 Fragnenta frondulurmu; 13 et 14 secliones stipilum.)

Ce genre se compose d'espèces unies entre elles par une plyysionomie commune, les frondes tendant à la forme lancéolée; elles sont pinnatifides, tantòt complétement, tantôt seulement vers le sommet. Il en est de tout à fait pinnées. 
La marge des frondules ou des segments est entière dans les vrais blechnum; elle est élégamment denticulée dans le sous-genre Blechnopsis, qui renferme surtout les espèces pinnées. Les nervilles sont égales, bifurquées, pinnées, flahelliformes; elles atteignent ou n'atteignent pas la marge; dans les blechnopsis, elles sortent de la lame, s'épaississent et constituent les dents qui garnissent la narge. Les stipes ne renferment que 4 à 5 vaisseaux vasculaires assez petits; ils sont déliés et de couleur de paille. Rarement les frondes sont squameuses; une espèce a des poils glanduleux ( $B$. glandulosum, Lk.). Nous ne connaissons point d'espèces radicantes; dans le $B$. distans, Presl, le rhizome produit des stolons radiciformes et gemmiferes. Dans quelques espèces les frondules se montrent accidentellement bifides au sonmet. Le $B$. Lanceola, Sw., quoique simple, tend à devenir pinné. Il existe aussi une singularité à noter dans la disposition des sporothèces; parallèles dans toutes les espèces, ils sont tout à la fois parallèles et costaux, obliques et uninervillaires dans le $B$. helerocarpum (voy. la description de cette curieuse espèce). Dans le B. hastatum, Klfss., les sporothèces sont interrompus et parfois punctiformes; sauf ce pelit nombre de particularités, les blechnum ont des formes bien arrêtées et très-rarement mobiles.

Les vrais blechnum sont presque tous américains; les blechnopsis presque tous indiens. L'Europe n'en possède pas. Dans le sous-genre Mesolhema les sporothèces, comme dans le Trenilis, sont situés entre la marge et le mesonèvre; mais le port restant le même, ainsi que le nombre de faisceaux vasculaires du stipe, l'indusium conservant les mêmes caractères, et les sporanges s'attachant à l'aisselle de cet indusium, sans qu'il y ait trace de réceptacle, nous n'avons pas cru devoir l'èlever à la condition de genre. C'est parni les mesothema qu'il faut chercher les espèces qui se rapprochent le plus des lomaria, et ce sont principalement les $B$. (mesothema) australe et hastatum, qui offrent cette affinité au plus haut degré.

\section{ENUMERATIO SPECIERUII.}

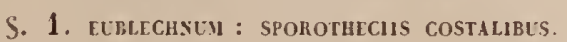

$$
\text { A. Margine integro. }
$$

1. Simplices aut pinnatifidx.

Lanceola, Sw.*(Hook.*, Kze.*; Radd.*, sub B. lanceolato $)$ - unilaterale, Willd.* (B.poly podioides, Radd.*, Kze.*) - heterocarpon, F. - asplenioides, Sw. (ceteraccinunt, Radd.*) - glandulosum, I.h. (Pohlianum, Presl; conditio neriationis*) - meridionale, Presl — occidentale, L. (Linrk.*, Jacq.*. Spreng.*, Radd.*; B. suburbicum, Arrab.*; Filix minor...., Sloan.*; Lonchitis ...., Plum.*, ctc.) - caudatum, Cavan. (cartilagineum, Schih.*) - validun, F. - helicolum, F. - acuminatum, F. - impressum, F. - extensum, F. - pectinatum, Hook.* - fulciculatum, Presl - cognatun , Presl (B. glundulosum, Kze.*) - ciliatum, Gralcol1. Mexic., n. ${ }^{\circ} 6284$ bis, non P1esl - rubescens, Desr. - rectinatum, Hook.* - distans, Presl.

$$
\text { 2. Pinnata. }
$$

Intermedium, Lk., Kze.* - gracile, Klfss. - longifolium, II. el Bonpl. - arcuntunt, Rem! (Chili) - Meridense, Kliz. 
B. Margine dentalo; BLECHNOPSIS.

Cartilagineum, Sw. - Brasiliense, Dess. (B. Corcovadense, Radd.*; Fluminense, Arrab.*) pyrophyllum, Blum. (Zolling, Pl. Jas., 11.03094) - stenophyllum (Blechnopsis, Presl; Cuming: 1'. Philipp., n. ${ }^{\circ} 165$, partim) - serrulatum, Rieh. (Selık.*, All. du Dict. des sc. nat., Levr.*; B. crlophyllum, Langsd. ct F.*; B. stagninum, Radd.*) - striatum, R. Br. (B. squamulosum, Sieber, Fl. mixt. , n. 242; Ejusd. Syn. filic., 11. 125) - Malaccense (Blechnopsis, Pres1, Cuming, Pl. Phil., 11." 385) - stramineum, Labill.*

S. 2. SPOROTHECIS I: MEDio disco SITIS; MESOTHEMA.

Fraxineum (Dislaxia, Presl) - remolum, Pıcsl, olim (13. pubescens, Hook.*; Lomaria pubescens, Kzc.*) - haslatum, Klfss (Tanitis sagillifera, Bory*; Lomaria, Kze.* ${ }^{*}$ - trilobum, Presl* (Hooh. et Gr.*) - australe, I.. (Schkl..*) - punctulatum, Sw. (Schlecht.*) - rigidum, Sw.

\section{SPECIES NONDUM DESCRIPTE.}

\section{Heterocirpen.}

Frondibus pimnatifulis, elliptico-lanceolatis, faciem Polypodii vulgaris referentibus, sed sessilibus; nervillis pimatis, flexuosis; nervillâ basilari superiore extensa ; rhizomate. repente; stipite brevi, squamoso; segmentis intermedïs lanceolatis, mucronutis; infimis semi-orbiculuribus; terminalibus angulatis, elongatis, margine undulato; sporotheciis mulliformibus, costalibus simul atque normalibıs, lateralibus brevioribus asplenioideis; superioribus linearibus, interruptis; indusio angustissimo, membranaceo, tenui; sporangïs ellipticis, brevi pedicello donatis; sporis ovoideis reniformibusque.

Habitat in Brasilici (Claussen).

(Dimeusions: 20-22 centim.; envergure, $30-35$ millim.; largeur, 5 millim.)

Se ripproclse du $B$. polypodioides, Radel.

\section{VALIDEM.}

Frondibus lanceolatis, pinnatis, subolivaceis, apice pimnatifidis, glaberrimis, stipite tenui, sulcato, helveolo, fasciculos vasorum tres ferente; frondulis lanceolutis, arcuatis, patulis, acutis, sessilibus, ultinis deflexis, conformibus, ad marginem minutissimè serrulatis, basi cordatis, anriculà inferiore magnâ, suprà stipitem positâ, aperturam rotundam constitnente ( $\mathrm{ffr}$. diagnosim Hemicardii); nervillis distantibus, apicè pellucido-turgidis; indusio tenui, colorato; sporangiis parvis; annulo angusto, $18-20$ articulato; sporis ovoideis.

Habitat in Americê Arstrali (V. S. Herb. clar. Moug.).

Filix majuscula, ad Blechnım Brasiliense acredens; glabra, frondulis arcuatis, sessilibus, incequalè cordatis.

(Longueur de la froude, moins le stipe gui manque, 45 centin.; envergure des pinnules, 18 centim.; les deux inférieures réfléehies, 7 centim.; $20-22$ doubles pinnules; la terminale lancéolée, ondulée, fruetiferc; le stipe, quoig̨ue fort long et flexueux au sommet, u’a guère que la grosseur d'une plume de pigeon.) 


\section{Helveolum.}

Frondibus glaberrimis, helveolis, pinnatis, supermè pimnatifidis, acuninatis; stipite tenui, pallidè rufescente, basi squamoso; rhizontale repente, fibrillas multas emiltente; frondulis lanceolutis, arcuatis, acuminatis, ultimis deflexis, terminali elongato-lineari, basi subcordiformibus, margine scabro; nervillis remotiusculis, tenuibus; sporotheciis abbrevialis, in medio frondularum sitis; indusio coloralo; sporangiis parvulis, annulo 14-16 articulato; sporis subreniformibus.

Habitat in Brasiliâ (Bahia Blanchet, n..$^{\circ} 243$ ]; Carac as [Moritz, n. ${ }^{\circ} 17$, in Herbario nostro $]$ ).

(Longueur de la fronde, $y$ eompris le stipe qui fait moilié de la dimension totale, $55-58$ centin.: envergure, 11 centim. sur environ 15 eentim. de largeur; on eompte envirou 15-17 doubles frondules.

\section{Acuminatum.}

Frondibus elongatis, piunatis, glabris, lanceolatis, stipite et rachi helveolis; frondulis mullis, angustè lanceolalis, arcuatis, inferioribus deflexis, longè acuminatis, basi subcordatis, inferioribus sessilibus; intermediis connatis; superioribus, stalu pinnatifido; margine scabro; nervillis pinnatis, creberrinis; sporotheciis nec apicem, uec basim attingentibus, angustis; sporangiis parvulis; annulo angusto, 14-16 articulato; sporis ninimis, subreniformibus.

Habitat in Columbia (Moritz, Colonia nomine de Tovar).

(Longueur totale : $65-70$ centim.; le stipe cst à la fronde :: 1 : 2; envergure, 10 centim.; fronlules, 6- $\tau$ millim. de large. Nous eomptons de chaque còté de la fronde $34-38$ pinnules.)

\section{Iypressum.}

Frondibns lanceolato-lineatibus, pinnatis, glabris; stipite helveolo, lavi; frondulis sessilibus, horizontalibus, spissis, opacis, sublinearibus, basi cordatis, obtusis; nervillis impressis, siccitate fragilibus; sporotheciis a margine ad apicem extensis, fusco-tabacinis, prominentibus; indusio crasso, colorato, latiusculo, persistente; sporangïs ovoideo-obliquis, curriculam referentibus; annulo angusto, 16-18 artirulato, articulis parvis, approximatis; sporis minutis, ovoideis.

Habitat in Columbiâ (Linden, n. ${ }^{\circ}$ 286).

Fïlix rigida, crassa, opaca, angustè luuceolata; frondulis horizontalibus; margine convolutis.

(Longueur totale : 36-38 centim. Le stipe fait la moitié dc ectte dimension ; cnvergure, 6 centim. : largeur des frondules, 3-4 millim. Les spores sont les plus petits du genre tout enticr.)

\section{Extexsum.}

Frondibus angustè lanceolatis; basi pinnatis, supernè pimatifulis, stipite tenui, stramilleo, subtùs sulcato, infernè paleaceo; rhizomate repente, mullifibrilloso; frondtilis lanceolatis, inferioribus remotis, obtusè nuccronatis, serratulo-scabris; inferioribus 
cordatis; intermediis horizontalibus, supernè gibbosis; superioribus fatcatis, terminali lanceolota, conformi; sporotheciis crassis, extensis, indusio angusto; sporangïs parvis; annulo 14-16 articulato; sporis subreniformibus, levibus.

Habitat in Brasilia (Claussen).

Fitix elata; frondulis basi remotis, apice decrescentibus; rhizomate crasso.

(Dimensions : longueur totale, 50 centim. et plus; stjpe, 22.25 centim., atleignant à peine la grosseur d'une plumc de pigeon; envergurc vers le centre, 10 centim.; les pinnules stériles ont de $9-12$ millim. de largeur; les fertiles sont plus élroites.)

b. Indusiun spurium.

\section{ACROP'TERIS, F.}

Acropteris et Actimiopteris, Lisk, Spec. filic., p. 79 et $80 ; 1841$. - Asplenii el Acrostichi spec., Auct. var.

Sporotнecus linearibus, terminalibus el marginalibus, confluentibus, partem proliferan apicilarem invadentibus, indusio scarioso, tenui, pellucido; sporangiis magnis, rolundis, nervillaribus; slomate 6 nervato; nervis spissis, obliyuis; arnulo 18-24 articulato; sporis crassis, oculo nudo facilè videndis, reniformibus, ovalibus trigonisque.

Froxdines fasciculatis, rachiformibus, rigidis, opacis, albidulis, panci-nervatis, radiatis aut simplicibus, bi-lripartitis; novellis (in $A$. septentrionali) flabellatis; nervillis laminarum fertilium parallelis, instùr foliorum palmarum sapè parlitis; stipilibus basi rufescentibus, nitentibus.

Diagnosis : Tab. v1, A. - Fig. 1, A. septentrionalis, Lk. - Fig. 2, A. australis, F. - Fig. 3, Asplenium Montbrisoni, F. (Fragntentum.)

Filices rachiformes, rigide, feraces; in Europâ, Promontorio B. Spei, in Abyssinia, $e t$ in insulis Africanis crescentes.

Genus dislinctissimum; facie peculiari ad Asplenium furcutım et affinin tendens.

Ce n'est pas seulement avec le gense Blechnum ou Lomaria, mais encore avec le genre Asplenium que les acropteris ont des rapports. Les frondes sont rachiformes, et l'on sail que les $A$. furcalum et Serra tendent à l'être: les nervilles marginales remplissent dans toute leur étendue le rôle de réceptacle; l'indusiun est continu et marginal. Le port de l'A. radiata, est un peu différent de celui de l'A. septentrionalis; mais l'A. australis, les unit entre eux par des tran- 
sitions très-ménagées. Les frondes des $A$. australis et radiata, en s'ouvrant, se comportent exactement comme les feuilles des chamarops, des latania et de lat plupart des palmiers.

\section{EIUIIERATIO SPECIERLM.}

Septentrionalis, Lk. (F** Asplenium, Schkh.*; Filix saxatilis, Lobel) - Australis, F.* (Actiniopteris, Lk.; Asplenium, Sw.*) -- radiata (Actiniopteris, Lk.; Acrostichum, Walı.*).

b. Sporotheciis immersis.

\section{STENOCHLENA, J. Sm. (1842.)}

In Journ. bot., Ноok, $184^{2}$, p. 149.

Lomarice el Acrostichi spec., Atct. var. - Olfersice spec., Prest. - Sleganice spec., R. Br, et $\mathrm{LK}$.

SPOROTHECIIs pinnulas frondium fertilium invadentibus et in sulco angustissimo collocatis, ut apud Vittarias; indusio marginali, scarioso, tenui, fugaci; sporangiis oratis; annulo in plurimis $12-13$ articulato; sporis oroideis vel reniformibus.

Froxnibes diplotaxicis, pinnatis; nervillis liberis, pirnatis seu parallelis, creberrimis, tenuioribus, marginem incrassalum, argutè dentatum attingentibus; frondulis sterilibus rigidis, lanceolatis, glaberrimis, dentatis, petiolatis; fertilibus anguslissimis, marginibus in juventute plicatis; stipite fasciculos vasorum plures minutos ferente (in $S$. fraxinifoliâ, Presl).

Filices erectce, rigider, glaberrince, rarò scandentes, feracissintce.

Diagnosis: Hook. el BatER, lab. cv, B (S. scandens, J. S.x.); indusio carente.

Genus facie et habitu Olfersice, Lomariopsidis et Lomariobotrydis, silu autem infero sporotheciormm viltariis affine.

Dans ce genre, les frondes stériles se rapprochent tout à fait de celles des Salpichlàna; mais les frondes fertiles s'en éloignent complètement. Les unes ont des frondules ovales, lancéolées, aiguement dentées et unies à la marge qu'elles fortifient en l'èpaississant. Les autres sont étroites, linéaires, entières et fructiferes dans toute leur étendue. Dans leur jeunesse, elles ressemblent tellement à certaines espèces de villaria, que si l'on voyait pour la première fois des frondules fertiles détachẻes de leurs frondes, on pourrait les décrire comme telles. La marge forme 
un repli régulier qui atteint le mésonèvre; peu à peu cette espèce d'indusium s'écarte et se déjette pour laisser conmuniquer les sporanges avec l'air extérieur, mais sans jamais se réfléchir. Ce genre dont nous énumérons seulement cinq espèces, s'augmentera probablement de plusieurs autres, encore douteuses ou peu connues; nous en avons retiré le $S$. Meyeriona, Presl, devenu le type du genre Lomariobotrys, de la tribu des acrostichées.

\section{ENUIERATIO SPECIERUN.}

Fraxinifolia, Presl (scandens, var. 2, J. Su. ; Cuming, Fill. Philipp., 11.0347) - scandens, J. Sm. (Rheed.*, Burm.*, Schkh.*, statu sterili; Ilook.*) - laurifolia, Presl (scandens, var. है, J. Sm.) - gracilis, Kzc. (Zolling, Pl. Jav., $110^{03} 333$ ct 365) - juglandifolia, Presl (Cummg, Fil. Philipy.. 11. ${ }^{\circ} 133$, partion. $)$.

B. Sporangiis costalibus; indusio fornicato.

\section{SALPICHLENA, J. Sm. (1\$12.)}

In Journ. hot., Ноок., iv, p. 168.

Sulpichlanet et Blechnopsidis spec., Press, Epim. bot., p. 115 ct 122.

Blechni spec., L. Kaulf., Presl, J. Sis., etc.

Steganice spec., R. BR.

Sровотнесиs angustis, elongatis, apicem frondium non allingentibus; mesonevro "pproximatis, angustissimis in frondulâ lalâ; indusio crasso, primìm gribboso, inflexo, postè resupinato, rufescente; receptaculo limeari; sporangiis ocoideis; annulo facilè solnio, 18-26 arliculato; sporis orordeis, lavibus.

l'rovolbes homomorphis, pinnatis vel bipinnatis; frondulis fertilibus angustioribus (in S. volubili); margine integerrimo; nervillis parallelis, tenuissimis, densissimis, ad marginem incrassatum, planum coalitis; rachi erecto aut scandente; fasciculis v'asorum 8-10: duobus basilaribus linearibus, 6-8 superioriburs, orbiculatim dispositis.

Filices magne, erectex aut scandentes, pinnata, elegantes.

Diıgnosis : Hook. et B., I. cit., tab. xc11 (bona). (S. volubilis, J. Su.)

Genus proprium, ad Blechnum tendens.

Le facies de ces plantes est parfaitentent distinct. Dans toutes les espèces les pinnules sont alternes, lancéolées ou lancéolées-linéaires, entières, à nervilles exıêtmentent nonbreuses, très-déliées, rapprochées, colorées et comme pellucides, étant vues entre l'oeil et la lumière; elles se rendent vers la marge qui est épaisse 
et forme une petite bande étroite et continue. Les sporothèces, parallèles, étroits, n'atteignent pas le sommet de la pinnule fructifère; ils sont formés d'un très-large indusium .coloré, attaché très-près d'un mesonèvre étroit qui fait saillie. Les sporanges s'attachent à l'aisselle de cet indusium, lequel étant enlevé, laisse voir une nervure qui court le long du trajet de la lame, sur laquelle ce tégument était fixé; c'est là le receptacle. Dans le $S$. volubilis, les sporothèces sont bombés et ont une apparence cylindroïde; l'indusium se roule sur le mesonèvre sans y adhérer; il s'ouvre à la maturité de dedans en dehors, et s'étale à plat sous l'aspect d'une nembrane scarieuse, colorée; dans les autres espèces il est moins apparent. Le $S$. Finlaysoniana a cette même organisation, mais les sporothèces et leur indusium sont excessivement étroits; on croirait voir une fronde de villaria, posée sur une lame large de lomariopsis ou de toute autre fougère à frondules dilatees. Le mẻsonèvre est en saillie; il est conıme creusé à sa base, sur laquelle s'attachent les sporanges.

\section{ENUMERATIO SPECIERUM.}

Scandens, Presl (volubilis, J. Sm. in Hook., loc. cit. [particulce*] ; Blechnum, Bory*) - volubilis, Pres!, non J.Sm. (Blechnum, Kzc.*) - Finlay-soniana (Blechnum, Hook. el Gr.*) - Orientalis (Blechnum, Schkh.*) — Cumingiana (Blechnum orientale, J. Sm., var. Cuming, Filic. Philipp., n. ${ }^{\circ} 166,257$ et 259) - Patersonii (Lomaria, Spr., Kze*; Stegania, R. Br.).

\section{** Yervillis anastonnosantibus.}

A. Areolis costalibus.

\section{SADLERIA, Kaulf. (1824.)}

Enum. Filicum, p. 162.

Blechnum (Sadleriu), Gaddich., Voy. de la Bonite, tals. cxuviu et cxrxiv.

SPORотиеси costalibus, marginem non attingentibus; indusio crasso, persislente, ad receplaculum cristaformi adlucerente; sporangïs ovoideis; annulo $16-17$ articulato, stomio angusto, $10-12$ nerato; sporis ovoideis, crassis.

Froxdines crassis, opacis, rirridis, pinnato-pinnalifidis; frondibus altcinis, approximatis, linearibus, longis, acuminatis, sessilibus; segmentis $40-60 \mathrm{el}$ ultrà, subarcuatis, obtusis; stipitibus profundè canaliculatis; fasciculis vasorium 15-17, incegualibus; caudice subarborescente; nervillis juxtà mesonevion areolas arcuatas primim formantibus: posteà liberis et ad uarginem incrassatum coalescentibus. 
Filices magnce, arborescentes.

Diugnosis nostr.: Tab. vil, A. - Fig. 1, S. cyathoides, Kaulf.

Ce genre renferme des fougères que nous croyons toutes arborescentes. Les nervilles sont anastomosées près de la còte médiane ou mésonèvre. Toutefuis, II. Graudichaud, dans les détails qui accompagnent les sadleria, n’a point représenté ces aréoles dans le $S$. squarrosa, dont il a donné cependant une excellente figure. N. Presl ne parle pas non plus d'aréoles costales, quand il donne (Epim. bot., 1) 120 ) les caractères de son Sadleria; mais il y a onission évidente, car elles existent pour les $S$. Kaulfussiana et Souleytiana.

Ces fougères sont fort belles, très-développées, à pinnules linéaires, dont les segments sont profonds, roides, obtus, étroits, opaques et épais. Elles sont rares dans les collections.

\section{ENUMERATIO SPECIERUM}

S. c)alheoides, Kifss. (S. Kaulfussiana, Gaul.*; B. Fontanesianum, Ejusd.*) - squarrosa. Eijuscl.* - Souleytiana, lijusd.*

B. Areolis universalibus. (Pseudo-lomariex.)

a. Frondibus sterilibus el fertilibus diversis.

\section{DENDROGLOSSA, F.}

Dendroglossa el Gymnopteris, PResL, Epimcl. bolanic., P. 149 (1819).

Leptochili spec., F., Hist. des acrostich., p. 87.

Gynnopterilis spec., J. S». in Ноок., Journ. Jol., 11, 403.

Acrostichi spec., L. Amœnit. acad., 1, 148; Ejusd. Sp. Pl., 1523; Reтz, Observ. v1, 39.

l'oxpabes simplicibus pinnalifidisyue; sterilibus dissimilaribus, lanceolatis, integris, sinuatis, pinnatifidis, lacinüs lanceolatis, infinis bipartitis; nervillis anastomosantibus, appendiculatis; fertilibus linearibus, simplicibus aul pinnutis, segrmentis angustissimis, nervillis crassis, areolas longras hexagonoüteas formantibus; rhizomate crasso.

Sровотнесиs nervillaribus, coufluentibus, acervos acrostichearum simulautibus, rano superiori areolarnm insertis; indusio spurio, anguslo, marginali; sporangiis uniseriatis, oroideis; annulo $12-14$ arliculato; sporis papillatis.

Filices tenera, aspectu v'ario; Indica nut Philippinenses; frondes steriles amplu'; fertiles angustissina.

Iliagnosis nostra: Tab. vil, B. - Fig. 1, D. subquinqnefida, B. - Fig. 2. I). querrifolic, R. - Fig. 3, D. tuccrefolia, F. (Gymnopleridis spec., Pв:sь.) 
Le mode d'attache des sporanges ayant été déterminé par M. Presl dans un certain nombre de leplochilus, nous les avons fait sortir des acrostichées pour leur donner une place parmi les lomarièes, en convenant toutefois qu'elles ne l'occupent peut-être pas d'une manière définitive. Aucun groupe ne peut, sans inconvénient, recevoir ce genre. Il s'éloigne considérablement par le port des selliguen et des antrophyum, ainsi que des hémionitidées; il a, par ses frondes fertiles, de l'analogie avec le Stenochlona et par ses frondes stériles avec le Gymnopteris. C'est un genre de transition assez convenablement placé entre les lomariées et les vittariées.

\title{
ENUIIERATIO SPECIERUII.
}

Normalis, Presl (Leptochilus minor, F.*). - lanceolata, Presl (Acrostichum, L.; Leptochilus Linneanus, F.*) - latifolia (Gymnopteris, Presl; Leptochilus hilocarpus, F.*) - subquinquefida (Leptochilus, F.*) - taccefolia (Leptochilus, F.*) - quercifolia (Gyninopteris, Presl; Ophioglossum. Houtt.*; Osmunda, Jacq.*; Acrostichum, Schkh.*).

b. Frondibus conförmibus; apice fertitiun plùs minùsve contracto.

\section{HYMENOLEPIS, Kaulf. (1824.)}

\author{
Enum. filic., p. 146.
}

Hynenolepis, PresL, Epim. bot., p. 158, et Macroplethus, 1. cil., p. 141.

Gymnopteridis spec., Ejusd., Tentam. pterid., p. 244.

Lomarice, Onoclece, Schizcere el Acrostichi spec. Auct. var.

Sровотнесіs linearibus, confluentibus, mesonevron tegentibus; in juventute frequenter margine laminarum revoluto, absconditis; receptaculo lineari, mesonevro contiguo; sporangiis rolundis, maximis, fasciculatis, pedicello ramoso, lìn nudis, lùm episporio spurio donalis, inter squamas (scilicel sporangiastra transmulatione annuli el sacculi pros enientia) immixtis; slornate sex nersalo, nervis obliquis, incqualibus; annulo latissimo, 1 2-13 articulato, rarò, sacculis el sporangiis aborlivis, ad apicem pedicellorum solilario; sporis reniformibus.

FroNdibus simplicibus, spissis, opacis, linecari-lanceolatis, apice fruclifero contraclo. angustissimo, recto aul curvalo; basi abruplè strangulalo; nervillis anaslonosantibus, areolis irregularibus, creberrimis, appendiculatis; rhizomate repente.

Filices Africance el Asiatick, erecte, integerrince, coriacere; mesonevio robusto.

Diagnosis: KLFss., l. cil. (pessina). Tab. nosl. VI, B, fig. 1, H. uncroulala, F. - Fig. 2, H. ophioglossoides, KıFss., el fig. 2', Stalu iudusialo: fig. 1' et 1", Sporangice in squamas transmulatc; ;ig. 2", Sporangia ad annulum reducle.

Ce genre est parfaitement distinct. Les lames se modifient à la manière des photinopleris et des nevroplatyceros en devenant fructiferes; elles se rétrécissent 
considèrablement vers le sommet et passent à la forme linéaire. Kaulfuss attribuait à cette plante un double indusium, et il est bien établi qu'elle n'en a qu'un seul; encore ètant produit par l'amincissement de la marge, prend-il place parmi les faux indusium, semblables à ceux qu'on observe dans un grand nombre d’acrostichées. Les sporanges sont attachées sur un réceptacle qui touche le mésonèvre; il est de couleur noirâtre et très-peu proéminent. Dans l'H. platyrhynchus, la lame devient elliptique ainsi que le réceptacle. Celte particularité a paru suffisante à M. Presl pour former le genre Macroplethus (l. cil.); mais celte modification, qui n'est qu'une sorte de dilatation, ne nous a pas semblé avoir l'importance que lui accorde cet auteur; tous les autres caractères, notamment ceux fournis par la nerration, la consistance, le mode d'attache et la formie des sporanges, etc., étant exactement semblables.

Yous avons représenté dans notre diagnose les modifications que subit la sporange; elles sont la constatation éclatante de notre opinion à l'égard des sporangiastres, que nous regardons comme des sporanges arrêtées dans leur déreloppe-

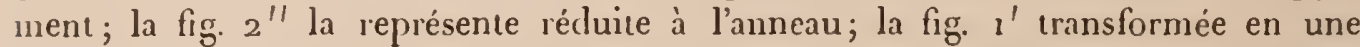
écaille qui perniet de reconnaitre l'anneau et le stoma; enfin la figg. I $^{\prime \prime}$ difforme et simulant un sac irrégulièrement lobé.

\section{ENUMERATIO SPECIERUM.}

Ophioglossoides, Klfss.* (F*; Gymnopteris spicata, Piesl, fragm.*) - mucronatn, $\mathrm{F}_{*} *$ fragm. (Ophioglossoides, Blum, Kze.* non Klfss.) - resolula, Blum. (Kze.*) - platyrhynchos, Kre. (Macroplethus, PresI). - validinersis, Kze.

\section{Considérations générales sur le groupe des Lomariées.}

M. Presl vient tout récemment (Epimelice botanica, 1848) de créer dans ce groupe un assez grand nombre de genres, sur la valeur desquels nous ne sommes pas parfaitement édifié. Ils sont au nombre de six, savoir:

1. Parablechnum (l. cit., p. 109), Blechnum à frondes monotaxiques, intermédiaire entre ce même genre et le Mesolherna. Il existe un indusium propre, qui, au lieu de s'attacher à la marge, s'en éloigne un peu. Du reste, les espèces, faisant partie de ce genre, on le facies des lomaria, avec lesquels nous croyons devoir les laisser; nous basant sur cette considération que dans tous les lomaria les indusium ayant une origine qui leur est propre, laissent toujours entre eux et la marge un espace restreint, il est vrai, mais plus ou moins appréciable. Type: Blechnum procerum, Labill.*

2. Distaxia (ouv. cit., p. 110 ), distinct du genre Mesolhema par des frondes monomorphes et du Blechnum par des sporothèces, situés au milieu de la lame 
ou, pour parler plus exactement, entre la marge et le mésonèvre. Type: Blechnum fraxineum, Willd.

3. Mesolhema (ouv. cit., p. I1 1), à sporothèces placés comme ceux du Distaxiı, mais avec des frondes dimorphes. Nous accordons une assez grande valeur à ce caractère, cependant il ne nous semble pas évident dans les espèces de blechnum, ramenées par l'auteur au Mesolhema. Les frondes fertiles sont un peu rétrécies, mais elles conservent la même forme et souvent même sans altération.

4. Spicanti (ouv, cit, p. 114), fondé sur le Lomaria Spicant d'Europe et intermédiaire entre les blechnum et les lomaria, quoique bien plus voisin de celui-ci, car le caractère dimorphique est ici assez prononcé pour lui accorder de l'importance. Les sporothèces ne confinent pas rigoureusement avec la marge, la partie libre est plus considérable que dans les lomaria et moins que dans le Mesothema.

5. Blechnopsis (ouv. cit., p. 115), véritables blechnum de port et d'organisation. Ils en diffèrent toutefois, d'après M. Presl, par des nervilles qui atteignent la marge et forment des arcs en s'unissant à leurs correspondantes. Vuici ce que nous avons vu: les nervilles se rendent vers la marge, mais elles en sortent toutes sous forme de dents, de manière à douner à la pinnule une apparence serretée. Elles sont donc absolument libres et leur indépendance résulte de ces denticulations mèmes. Si l'on voulait regarder ce caractère comne générique, il y aurait lieu de former une foule de genres nouveaux, de port et d'organisation semblables.

6. Orthograrume (ouv. cit., p. 121), nous ne connaissons ce genre que par la planche 207 , des Icones filicum de MM. Hooker et Greville. Il paraît que les nervilles, se comportent comme dans le Blechnopsis. Ce caractère n'est pas apparent dans la figure que nous venons de citer. Le facies du type permet facilement de reconnaitre un Lomaria. Le dimorphisme est évident. Ce genre est au Lomaria ce que le Blechnopsis est au Blechnum.

Toutefois, en refusant de reconnaître ces genres, nous avons mis à profit quelquesuns des caractères sur lesquels ils ont été fondés, pour en faire des sous-genres.

Quoique nous ayons admis dans ce groupe huit genres, il en est quelquesuns qui peuvent être regardés comme légèrement dissidents : l'Acropleris, par ses frondes rachiformes, à peu près dépourvues de chromule et qui semble se rapprocher de certains asplenium, à frondes roides et étroites; le Dendroglossa qui mériterait peut-être à lui seul de former un groupe distinct, intermédiaire entre les lomariées et les viltariées; enfin l'Hymenolepis, qui se rapproche du Nerrodium par la consistance et la nervation de la fronde, et du Pleurogramme par la situation des sporanges, altaclıées au mésonèvre. 


\section{IJ. Gymnosoria : VITTARIEE.}

5." Némoite sur les fougères: Histoire des viltariées, etc.

Vittarlacea, Presl, Tentam. pterid., p. 165. Tenitidearum genera plur., Ejusd., 1. cil., p. 222.

Shizolomea, partim, Gaudich.

A"gnste', glaberrima", ad arbores suspensa, flexibiles, rarò repentes, radicellis whzomratis tomentosis.

ad marginem irnniventibus.

28. Vitlaria, J. Sm.

三 Frondibus simpli- $\left.\begin{array}{l}\text { Sporotheciis biformibus; } \\ \text { marginalibus el centra- } \\ \text { libus. }\end{array}\right\}$ 29. ? Diblemma, J. Sm cibus. s $\left.\begin{array}{c}\text { Sporotheciis uniformi- } \\ \text { bus; marginalibus. }\end{array}\right\}$ 30. Pteropsis, Presl. $\left.\begin{array}{c}\text { Areolis } \\ \text { exappendiculatis. }\end{array}\right)$ Frondibus divisis; segmentis digitatis.... 31. Cuspiduria, F. Frondibus pinnatifidis, heteromorphis.... 32. Schizolepion, F.

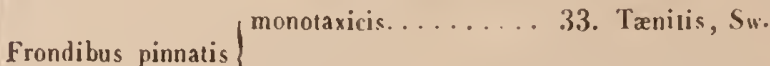
diplolaxicis 34. Lomograunme, J. Sm.

Arenlis Frondibus pinnatis. 35. Jenkinsia, Honk, et B. appendiculatis. Frondib.simplicibus

monotaxicis 36. Nevrodium, F. 
DES POLYPODIACÉES.

\section{* Nervillis liberis.}

\section{** Vervillis conniventibus.}

\section{VITTARIA, Smith. (1791.)}

Mém. académ. de Turin, V, p. 413, t. 1x, fig. 5 .

FíE, 3.e Mém. : Hist. des vittariées, etc.

Vittaria et Treniopsis, J. Sм., Journ. bol., Ноок., t. 1v, p. 67.

Vittaria et Treniopteris, Ноoк., Gen. filic., t. Lxvı, B. et to Lvı, B.

Pteridis spec., L. el Auct. plunis.

SPOROTHEcIs angustis, plùs minùsve immersis, continnis, nudis, vel rarissimè indusio spurio vestitis; extrà, juxtà aut intrà marginem hospitantibus; sporangïs longè pedicellatis, rotundatis; annulo 14-20 articulato; sporis reniformibus, trigonis verò in pancissimis speciebus; sporangiastris succineis, cyalliformibus, viltatis, mastoideis, pedicello ramoso alboque donatis.

Froxdibus monotaxicis, linearibus, elongatis, flexibilibns, integerrimis; nervillis pinnatis, ad marginem anastomosatis; rhizonıate repente, squamis cancellatis et radicellis tomento fulvo densoque vestitis.

Filices ad arbores usnearum instar pendentes; ferè omnes Indica, Africance, Ameriçe tropicalis; in Philippinis insulis, in Anstraliâ paucre; facie similes pteridibus sed multò angustiores; species numerosa; costalce seu ecostatce; arctè inter se unitce.

Dingnosis: Ноoк. et Bauer, Gen. filic., t. Lxwu, B ( $V$. rigida, Ktrss. [optima], I. cit.), et t. Lxvı, B (Treniopteris Forbesii, Ноок.).

Icon. nostr. VIII, B : Fig. 2, V. bisulcata, KzE. (fragmentum).

Ces fougères, d'une détermination ardue et difficile, ont un port tout à fait spécial; elles sont linéaires, rubanées, ensiformes, entières, et peuvent atteindre jusqu'à trois mètres de longueur sur une largeur qui souvent n'excède pas un millimètre. Les sporothèces occupent la partie supérieure de la cuticule, et ils sont marginaux ou extra-marginaux, ou bien se logent dans l'épaisseur même de la lame, ce qui les fait dire endophylles (voy. . $^{\mathrm{e}}$ Mém. : Hist. des viltariẻes et des pleurogrammées). Cette particularité, parfaitement reconnue par MI. J. Smith, lui a fait créer le genre Taniopsis, aux dépens du genre Vittaria. Il existe une grande confusion dans la distinction des espèces, et les figures qui en ont été données ne peuvent toujours exprimer leurs caractères différentiels.

Nous avons fait remarquer que dans le genre Stenochloena, les frondes fertiles étaient absolument organisées comme des vittaria. 


\section{ENUMERITIO SPECIERUM.}

I. Sporohifcils stpra clticllaribus : Taniopsis, J. S11. = Amboinensis, F.* (ensifornnis, Willd.. Herb., 11. ${ }^{\circ}$ 20,030?) - loricea, F** (Zollinger, n. ${ }^{\circ}$ 1001) - Forbesii (Taniopleris, Hook. el B., Fragmenta* - Zeylanica, F.* (Walker, Pl. Zeyl., n. ${ }^{\circ} 210$ ) - Gardneriana, F.* (Gardu., Brasil., n. ${ }^{\circ 147}$ ) - Ruiziana, F.* - fexuosa, F. (Wallich, n. ${ }^{\circ} 144$, Mlerb. Berol.) - stipitata, Kzc.* - lenera, F.* (Guenzius, Pl. Afric.) -surmentosa, Ruiz (graminifolia, Klfss.) - lineala, Sw. (Schkh.*, Plum.*) el var. graminifolia, F.* (taniopsis, J. Sm.) - angustifolia, Blum. (F.*. Cuming, Philipp., n. ${ }^{\circ} 381$ ) - isoelifolia, Bory (F*) - Guineensis, Desv. - revolula, Willı. Pleris villarioides, Aub. Dupelit-Thouars* - filifolia, F.* (Toenitis linearis, Mert. et Gal., p. 144, $11{ }^{\circ} 6337$ ) - scabrida, Klı. - minor, F. (angustifolia, J. Sm.; Cuming, Philipp. n. 381 [parlinı]).

II. Sporothecus exdopuylus : Euvillariea $=$ Zosterafolia, Bory $\left(\mathrm{F}_{*}^{*}\right)$ - bisulcala, hze. (F.*. Fragmı.; Zolling., Pl. Jai., n. ${ }^{\circ} 867$ ) - falcala, Kze., Herb. (Java) - Owariensis, F.* - ricida, Klfss. (plantaginea, Hook. et Grev.*) el var. $\beta$, elongala, Sw. (F.*) - plantaginea, Willd. (non Hook. et $\mathrm{G}_{1}$.; F.*) — anodontolepis, F.).

Düuloe. Acrostichoides, II. et G1.* - caudiformis, BI., Enunı. Pl. Jav., p. 200. - filiformis, Car. - pusilla, Blum., loc. cit., p. 199. - parrula, Bory, dans le Voy. de Bélang., p. 35.

\section{9. ? DIBLEMIA, J. Sm. (1842.)}

Hook. Journ. of botan., iv, p. 399

SPOROTHECus angustissimis, superficialibus, ad latera externa areolarum nascenlibus; praterè, el ferè semper, gerentibus acersulos sporangiarum subrolundos vel elongalos, super laminas inferiores sparsos, ut in polypodicis; sporangiis rolundis; arnnlo 14 arliculato; sporis reniformibus.

FRovubes linearibus, elongratis; rarò el fortuiter apice divisis; nervillis tenuissimis; areolis apperdiculatis, subhamalis; rhizomate repente, fibrillis tomenlosis, synamis cancellatis.

Filix tenera, membranacea, glaberrima, Philippinensis; habitn Drynarice.

Diagnosis: Hook. et Baver, Gen. Filic., l. cix, B. (D. samarensis, J. Sm.)

Exsiccala: A, forma Leplocarpidea: Diblemma Samarensis, J. Sn.; Cumns, Fil. Philippinæ n. ${ }^{\circ} 332$. - B, forma Polypodina : Drynaria tenmilora, J. Ss., Enum. filic.; Cusns, Fil. Philippinarum, n. ${ }^{\circ} 287$ ?

Nous regardons ce genre comme très-ambigu, la plante sur laquelle il est fondé, étant très-paradoxale. Le nom imposé par M. J. Smith, exprine que la fructification est soumise à deux arrangements différents : occupant la marge en même temps que la lame; ici, étendue, étroite, linéaire, flexueuse, superficielle; là, irrégulièrement arrondie en groupes analogues à ceux des polypodes. Il faudrait la voir vivante et en spécimens nombreux pour décider la place définitive où il convient de la mettre; mais quelle que soit celle qu'on lui donne, elle constituera 
toujours une anomalie fort singulière. La bizarrerie de son organisation a peut-être trompé M. J. Snith, si exercé à démêler les formes des fougères, quand il a placé daus les drynaria le spécimen n. $^{\circ} 287$ de M. Cuming, qui semble être la même plante que le n." 332 , devenu son Diblernma. C'est tout à la fois, en effet, une leptocarpée et une polypodiée. (Voy. Microsorium.)

\section{*** Nervillis anastomosantibus.}

\section{Areolis exappendiculatis.}

A. Frondibus simplicibus.

\section{PTEROPSIS, Presl. (1836.)}

Tentan. pterid., p. 225.

Pteropsidis spec., Desv. - Pteridis spec., L. - Tenitidis spec., Wilcd. - Antroplyyi spec., Веuм.

SPOROTHECIs linearibus, continuis, seu forluitò interruptis; receptaculo immerso, lineari, planiusculo, submarginali; annulo $12-14$ arliculato; sporis niagnis, lavibus reniformibusque; sporangiastris villatis. apice spatulatis, succineo colore.

FronduUs simplicibus, integerrimis, lanceolalo-linearibus, acutis, in peliolum desinentibus; areolis hexagonalibus, cxappendiculatis, mesonevro parallelis, ad marginem clausis; rhizomate repente, radicellis tomento fulvo densè vestitis.

Filices simplices, rigida, lanceolate, acuminate, arboricolar; Antillance vel Indicre.

Diagnosis : Hook. et Bauer, Gen. filic., t. Lxxvi, B (P. anglestifolia, Desv.). Prest, l. cil., t. $\mathrm{x}$, fig. 3 (nervatio).

Dans ce genre, les sporothèces sont marginaux; cependant le sillon qui les reçoit, laisse entre lui et la marge un intervalle régulier d'environ 0,5 millim. Il diffère du genre Trenitis par la direction perpendiculaire au mésonèvre des mailles qui forment le réseau; par la situation des sporanges altachées, près de la marge, dans un sillon très-prononcé. Le nombre des articulations de l'anneau, la forme des spores et celle des sporangiastres l'en éloignent encore; ajoutons que le Pteropsis a une fronde simple, tandis qu'elle est pinnée dans le Trenitis.

\section{ENUMERATIO SPECIERUM.}

Angustifolia, Desv. (Vittaria costata, Kzc.*) - Blumei, F. (Antrophyum marginale, BI.*) 


\section{B. Frondibus divisis.}

\section{CUSPIDARIA, F.}

5. Mém. : Hist. des vittariées, etc.

Plevidis spec., Auct. var. - Pleropsidis spec., Desv., Presl. - Tenilidis spec., Willd., Spresg., etc.

SPOROTHeciss angustis, superficialibus, marginalibus, ad apicem segruentorum frondium conlractorurn nascentibus; sporangiis maxiunis, annulo valdè crenulato, $12-14$ articulato; stomate trinervato; sporis magnis, laevibus, ovoideis, subreniformibus, tuberculosis; sporangiastris nullis.

Froxdics digitalis, segment is ferlilibus angustioribus, elongalis, nervillis reticulatis, exappendiculatis, rarius liberis, operosè perspicuis; areolis obovatis; squamis lanceolatis, suprì laminas sparsis; thizomate repente, crasso, fibrillis tornentosis onuslo.

Filices Americanre, erecte, bifida, trifide, dichotoma, subpinnatifida; habitu proprio.

Diagnosis: Tab. VIII, A : Fig. 1, C. subpinnatifida, F. - Fig. 2, C. furcata, F. Fig. 3, C. tricuspis, F.* (ex Plumierio; fragmentum).

Ce genre est très-naturel. La division des frondes, qui tendent à la dichotonie et s'allongent en segments linéaires pointus, les organes accessoires, radicelles tomenteuses, écailles ovoïdes, dont le sommet est tourné du même côté, etc. : tout concourt à réunir étroitement l's espèces. Pourtant l'une d'elles, le $C$. pinnatifida, it des nervilles anastomosées et de même disposition que celles des villaria; néanmoins nous n'avons pas voulu l'en détacher, tant les autres caractères offrent de similitude. La nervation est pour nous un moyen de classification, mais il n'est pas le seul et demande à être confirmé par d'autres caractères. Par la squamation des frondes les cuspidaria se rapprochent des drynaria, sous-genre Pleopeltis. Les squames sont éparses, lancéolées et attachées au-dessous de leur base, qui est libre (squanze basi soluta).

\section{ENUIERATIO SPECIERUM.}

C. furcata, F.*; (Tanitis, Willd. non Hook.; Plum.*, Pelix.*) - subpinnatifida, F. (Tanitis , Hook. et Gr.*, non Willd.) - tricuspis, F.* (Pteris, Linn. Pteropsis tricuspidata, Prest, Plum.*, Petiv.*) 
C. Frondibus heteromorphis.

\section{SCHIZOLEPTON, F.}

3. Mém. : Hist, des viltariées, etc.

Schizolomatis et Lindscece spec., Gaudich., Voy. de l'Uran., Botan., p. 378.

SPORотнесris linearibus, endophyllis, laminam undique cingentibus, cuticulâ superiori intìs allevalâ, consistentiam el aspectum servanti; sporangïs magnis; annulo 18 articulato, stomate sub 4 nervato, basi sporangiarum occupanti, nervis obliquis; sporis trigonis subellipticisque, ad centrum depressis; sporangiastris viltatis, apice claviformibus, planiusculis, succineo colore.

FRoxibus crassis, polymorphis, simplicibus, cordatis pinnatifidisque; fertilibus verò lobatis et angiastioribus; nervillis anastomosatis flabellatis, exappendiculatis; squamis cancellatis, radicellis tomentosis.

Filix Moluccana, erecla, crassa, polymorpha, glabra, arboricola.

Diagnosis: Tab. nostr. VIII, B, fig. 1, S. cordatum, F.; fig. 2, Vittaria bisulcnlu, KzE. (fragmentum ad comiparandum).

Genus schizolomati affine, sed frondibus fertilibus el sterilibus diplotaxicis diversum; sporangiastris, squamis, radicellis et rhizomate vitlariearum.

Ce genre monotype se rapproche par la nervation du Schizoloma; toutefois le port differe essentiellement, ainsi que la disposition des frondes; l'absence de tout indusium, la présence de sporangiastres, d'écailles cancellaires et de radicelles tomenteuses, qui existent universellement dans les vittariées, le distinguent également. Ajoutons que dans le Schizolepton les nervilles qui atteignent la marge, ne laissent libres aucune d'entre elles; toutes forment des aréoles, tandis que dans le $S$ chizoloma elles se terninent avant de parvenir à la marge, en laissant des appendices libres. Cette organisation explique comment il se fail que dans le premier de ces genres les sporothèces soient endophylles, condition extrême de la station malginale, et comment il arrive que dans l'autre l'indusium, attaché à l'extrémité de nervilles non terninales, puisse donner lieu à la station endomarginale.

\section{SPECIES.}

Typus diagnosis. (Schizoloma, Gaudich.*) 
D. Frondibus pinnatis.

\section{TENITIS, Sw. (1806.)}

Syn. filic., p. 24 .

Teenitidis spec., Auct. var. - Pleridis spec., W' illd.

Sровотнеси linearibus, longissimis, rarò apicem pinnarum allingentibus; lunc in medio disco, tunc propè marginem silis, non tamen marginalibus, in sulco longiludinali collocalis; receplaculo nervilliformi; sporangiis rotundis, amplis; annulo 16-18 articulato; sporis trigonis; ; sporangiastris magnis, apice torulosis, annulo transmulato provenientibus.

Froxdibus pinnalis, pinnis lanceolatis; nervillis anastomosalis; areolis exappendiculatis; squanis, radicellis, rhizomate, ut in generibus antecedentibus.

Filices evecta, rigide, glaberrimce, Indicce; habitu pteridium.

Diagnosis : Schотт, Gen. filic., fasc. Iv, 5 (optima). - Hooк. et Bauer, Gen. filic,, Lxxvu, B. (T. blechnoides, Sw.)

Ce genre monotype est parfaitement distinct; il offre ce caractère remarquable de constituer ses sporothèces tantôt au centre de la frondule, tantót plus près de la marge, tantôt plus près du mésonèvre, sans cependant les montrer jamais ni costaux, ni marginaux. La forme des sporangiastres, qui proviennent évidemment d'une métamorphose de l'anneau, est singulière et sans analogues dans ce groupe.

Le Tanitis est aux vittariées ce que les blechnum du sous-groupe Mesothema sont aux lomariées; mais il justifie pleinement l'impossibilité, où nous nous sommes tróuvé, d'adopter le genre Mesolhenı comme distinct du Blechnum. L'instabilité de situation des sporothèces, suivant que les frondules sont plus larges ou plus étroites, met en évidence la faiblesse du caractère admis comme base de genre par M. Presl, pour le Mesothema.

\section{SPECIES.}

Blechnoides, Willd.* (Schkh.*, Spreng.*). 
E. Frondibus sterilibus et fertilibus diversis.

\section{LOMAGRAMMA, J. Sm. (1844.)}

$$
\text { Hook., Journ. bot., III, p. } 152 .
$$

SPORотнеси linearibus, apice frondiun conniventibus; receptaculo nullo; sporangiis rotundis, subsessilibus (ex icone Baueri); squamis peltatis (ut in pleopeltide) immixtis; annulo lato, ferè universali; sporis ovoideis.

Froxdbus pinnatis; pinnis lineari-lanceolatis, articulatis, fertilibus contractis, apice longè decrescentibus; areolis exappendiculatis.

Filix Philippinensis, pinnata, erecta; nervatione Heteronevri generis, e tribu Acrostichearum.

Diagnosis : Ноok. et Bauer, Gen. filic., t. xcvin. (L. pleroides, J. S., t. cit.)

Ce genre monotype ne nous est connu que par la diagnose donnée par IM. Hooker et Bauer.

Les écailles peltées, qui se trouvent dans les sporothèces, sont pédicellées; elles proviennent évidemment d'une transmutation des sporanges. Le pédicelle s'allonge et le sacculus ainsi que l'anneau avortent, ne laissant d'autre trace de leur existence qu'un disque irrégulièrement arrondi à nervilles rayonnantes. Il ne paraît pas y avoir de réceptacle.

SPECIES.

Typus diagnosis. 


\title{
计 Areolis appendiculatis. \\ A. Frondibus pinnatis.
}

\section{JENKINSIA, Hook. et Bauer. (1842.)}

\author{
Gen. filic., tab. LXXV, B.
}

Volhochleena undulata, Wabl., Cat. n. 140.

ऽровотнесиs linearibus, marginalibus, inceyualibus, apicem allingenlibus, crassis; sporangiis rolundis; unnulo I 4 arliculalo; sporis globulosis, muricalis.

Froxuвbs pinnalis, dissimilaribus (helerolaxicis); pinnis lanceolatis, undulatodenlalis, membranulâ coriaceâ latè marginalis.

Differt ab omnibus filicibus cognitis, frondibus sterilibus et fertilibus diversis.

Filix erecta, rigida, Indica.

Diagnosis: Нoor. et Baver, I. cil. (J. undulala.)

Ious ne connaissons ce genre que par l'analyse citée plus haut; le type est fort rare dans les herbiers. Si la planche est fidèle, ce que nous ne pouvons nettre en doute, ce genre est parfaitement distinct et surtout renrarquable par une nervation, qui diffère pour la fronde fertile et la fronde stérile. Cependant, un détail grossi de la frondule prolifere donne des nervilles pareilles à celles de la frondule stérile, c'est-à-dire, anastomosées. Est-ce une erreur?

SPECIES.

Genus monotypum: vide diagnosim generis. 
B. Frondibus simplicibus.

a. Frondibus monotaxicis.

\section{NEVRODIUM, F. (1842, sub heteropteride.)}

Heteropteris, F., Congr. scient. de Fr. de 1842 , t. 1, p. 178.

Paltonium, PresL, Epim. bot., p. 156.

Pteropsidis spec., Desv. - Pteridis spec., Lix.. - Treniditis spec., Kaclf.

SpоRотнесі1 linearibus, latis, superficialibus, ex apice frondium emergentibus; receptaculo crasso, lineari; sporangïs maximis; annulo 14 articulato; stomate trinervato, nervis brevibus; sporis ovalibus, tuberculatis; sporangiastris nullis. Froxdвеs simplicibus, lanceolatis, apice fertili contracto: nerrillis in areolis hexagonis appendiculatis, inter sese anastomosantibus; rbizomate surculiformi, fibrillis tomentosis, densè intricatis involuto.

Filix Antillana, erecta, coriacea, opaca, rigida, arboricola; frondibus fascicnlatis.

Diagnosis : Tab.VIII, C. (N. lanceolatum, F., l. cit.)

Nervatione et habitu Hymenolepidis.

Ce genre, dont nous avons annoncé la formation à la dixième session du Congrès scientifique de France en 1842, sous le nom de Heteropteris, destiné à exprimer la dissimilitude de la fronde, qui est presque linéaire au sommet et lancéolée dans le reste de son trajet, a été constitué par M. Presl (Epimel. bot., loc. cit.) en 1849 , sous le nom de Paltonium. Nous avons cru devoir changer le nom primitif qui exprime une circonstance vraie, mais qui n'est peut-être pas aussi marquée que l'indique l'étymologie. C'est un Pleropsis avec des aréoles appendiculées. Cependant les sporothèces, au lieu de régner dans toute l'étendue de la marge, n'occupent que le sommet de la fronde, rétrécie au point prolifère, comme dans les hymenolepis, quoique d'une manière moins prononcée. On retrouve bien dans cette plante le port général des vittariées, mais les sporanges ne se métamorphosent point en sporangiastres.

\section{SPECIES.}

N. lanceolatum (Pteropsis, Desv., Plum.*, Petiv.*). 


\section{b. Frondibus diplotaxicis (fertilious el sterilibus diversis).}

\section{DR YMOGLOSSUM, Presl. (1844.)}

'Tent. pterid., P. 227, tab. X, fig. 5 et 6.

Drymoglossum et Lemmaphyllum, Ejusd. Epim, bot., p. 157.

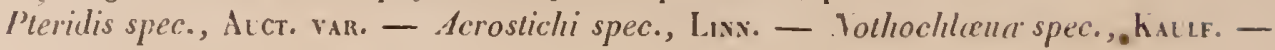
Pleropsidis spec., Desv.

Sporotuecus linearibus, inmersis, in sulco lato habitantibus; receptaculo crasso, lineari, a marrine plìs minusve remolo; sporangïs amplis; anmulo crasso, Í-18 arliculalo, pilis stellatis (ut in niphobolis) immivtis; sporis walibus, la's ibus a'ul muricalis.

Froxnucs simplicibus, diplotaxicis; sterilibus ovalis, elliplicis, curdatis, coriaceis: fertilibus linearibus, obtusis; areolis irregularibus, appendiculatis; areolarum appendice reclo, lurgido, glanduloso; caudicibus fasciculo unico curvalo 'asorun peragratis; rhizomate longè repente, fibrillis brevibus, tenuibus, toinerlosis.

Filices repentes, arboricolce, parvula , fucie Niphsbolorum el Craspedariarmun; ferè onnes Indica.

Diagnosis: Tab. IX, A (fig. 1, D. subcordatun! , F.; fig. 2, D. piloselloides, Prest; fig. 3, Niphobolus mummularinfolins, J. Sm., ad comparandumi). - Hook. et Bater, Gen. filic., 1. Lxxvm, A. (Drymogloss. carnosum species paululìm anomala.)

C.e genre est généralement adopté. La nervation rappelle celle des niphobolus et des craspedaria; mais la situation des sporothèces qui affectent la forme linéaire et le mode d’attache des sporanges, fixẻs sur un réceptacle linéaire, ne permettent pas de le confondre avec aucune des espèces appartenant à ces deux genres. Il suffira de jeter un coup d'ocil sur notre diagnose pour le reconnaitre comme parfaitement distinct. L'analyse donnée par MM. Hooker et Bauer se rapportant à une espèce dissidente, nous avons cru devoir donner celle du véritable type, et nous l'avons nise en rapport avec le Niphobolus mummularicefolius, J. Sn. (Galeogrlossa mummulariafolia, Presl), afin de pouvoir comparer.

\section{ENUMERATIO SPECIERLII.}

1. Euonmociossty : Sporotheciis submarginantibus = subcordatum, F** - rotundifolium " Presl - riloselloides, Presl*. F.* (Fragm.) - Pteris, Sw.*, Banhs*, Schkh.* (Rheed*, Petiv.*. Iloult.*: male).

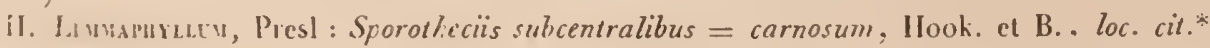




\section{Considérations générales sur les Vittariées.}

Les fougères qui appartiennent à cette tribu s'élèvent environ à cinquante, et le genre-type seul en renferme une trentaine; l'Europe n'en possède aucune espèce; presque toutes sont arboricoles, allongées, souvent très-étroites et à frondes graminiformes. Quelques-unes sont extrêmenıent petites, d'autres atteignent et même dépassent un mètre sur une largeur de deux ou trois millimètres.

Cette tribu s'unit aux piéridées par quelques espèces de villaria, aux lindsayées par le Schizoleplon, aux polypodiées par le Niphobolus nummularicefolius, J. Sm. (graleoglossa, Presl), par les drymoglossum et mêrne par le Tanitis aux lomariées. On peut remarquer encore que dans le Nesrudium le sommet des frondes est rétréci comme dans le genre Hymenolepis; mais ces rapports sont assez éloignés pour laisser à ce petiı groupe toute l'importance de ses caractères.

Il est à remarquer encore que les frondes se divisent très-peu, et quand cette circonstance se présente, elles sont simplement pinnées. Les marges restent entières, et à peine pouvons-nous indiquer une exception à cette loi. La denticulation des feuilles est une première tendance à l'isolement des nervures, et l'on roit les frondes devenir dentées, puis crénelées, puis lobées, puis enfin pinnatifides; l'exagération de cette loi les fait multifides ou disséquées. Rien de pareil n'a lieu dans les vittariées; les ptéridées au contraire se divisent et se subdivisent à l'infini, et il est très-rare de les trouver à l'état de simplicité.

Les genres Lomagramma et Jenkinsia ne nous sont connus que par les diagnoses données par M. Hooker dans son Genera. M. Presl a fondé aux dépens du Drymoglossum son genre Lemmaphyllum, se basant sur ce que la situation des sporothèces est éloignée de la marge dans le Drymoglossum carnosum, Hooh. Ce caractère a tout autant d'évidence dans le $\boldsymbol{D}$. subcordatum, et il se retrouve dans le $D$. piloselloides, quoique la puissance prolifique se manifeste en un point plus rapproché de la marge. (Voy. pl. vill, fig. $1^{\prime}$ et $2^{\prime}$.) 


\section{2. Sporothecia mesonerro adnata: PLEUROGR AMMEA.}

5. Mém. sur les fougères: Hist. des vittariées et des pleurogrammées.

Tenilidece, partim, Prest, Tentam. pierid., p. 222.

Granmitidece, partim, Prtst, l. cit., p. 206.

Polypodiere, pratim, Bory, in oper. var.

Hemionitidearum el Polypodiearum spec., Gavdich., Voy. de l'U ran., Botan., p. 308 (t) 345 .

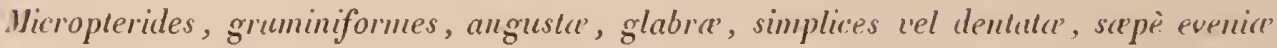
et nervilla ad mesonevron reducta.

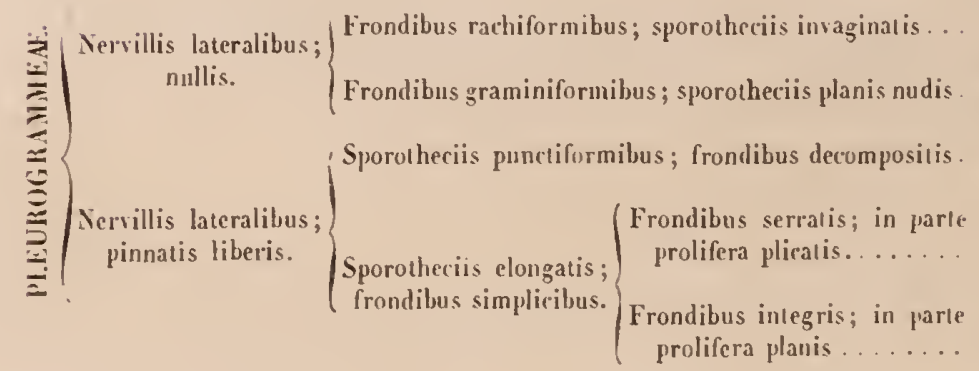

38. Vaginularia, F.

39). Monogramine, Comm.

40. Adenophorus, Gaud.

11. Iiphopteris, Kaulf.

12. Pleurogramme, Presl. 


\section{* Vervillis lateralibus nullis.}

\section{VAGINULARIA, F. (1843.)}

Congr. scient. de France, 10. ${ }^{e}$ session, I, p. $178 ; 1843$.

Fíe, 3. Mém. sur les fougères: Vittariézs el Pleurogramimécs.

Monogrammes spec., J. Si., in Ноок. Journ. bot., iv, p. 45.

SPOROTHECHS in vaginâ oblongo-trinervalâ abscondilis, nunquàm terminalibus; vaginis in eâdem frondulâ solitarïs, non rarò geminis, ferè nunquàm trigeminis; sporangïs rolundis, costalibus, longè pedicellatis; annulo tenui, subcompleto, 14-18 arliculato; stomate nullo? sacculo turgido, perfacilè soluto; pilis internis contorlis, pellucidis, plicatis; sporis trigonis, tuberculosis; sporangiastris mullis.

FRoxdibus setaceis, flexibilibus, rachiformibus; siccilate fuscis; nervillis lateralibus nullis; rhizomate tenui, repente, syuamis cancellatis vestilo.

Diagnosis nostra : Tab. IX, B. (V. trichoidea, F. Monogramme trichoidea, J. Sw.)

La plante délicate sur laquelle nous avons fondé ce genre est, avec le Monogramrme, la plus petite de la classe des fougères. Les frondes noircissent par la dessiccation; elles sont traversées par un faisceau vasculaire unique qui, à lui seul, constitue plus du tiers de leur diamètre total. La disposition vaginale de la partie fructifère des frondes ne permet pas de confondre ce genre avec le Monogramme, dont les frondes planes et gramineuses ne sont pas réduites au rachis. Il n'y a point de sporangiastres, car il n'est pas possible de donner ce nom aux poils internes, incolores, pellucides et contournés, qui sont mêlés aux sporanges. Les radicelles ne sont pas tomenteuses.

\section{SPECIES.}

Cienus monolypum : vide diagnosim generis. 


\title{
59. MONOGRAMME, Commers.
}

\author{
Sclikh., Crypt. Gew., p. 82, t. LXXXVII (sub Canopleride).
}

Fie, 3. Mlém. sur les fougères: Vitrariles el Pleflogramíes.

Pleridis spec., Lмкк., Encyc. - Grammitidis spec., Sw. et WiLun. - Monogrammes spec., Prest, Sprexg.

SPOROTHECIIS linearibus, in plicalurâ frondis conlortce absconditis; sporangiis longè slipilalis; annulo 16-18 arliculalo; sporis Irigonis; sporangiastris scypluuliformibus; scyphulis coloralis, sublriquelris.

FRохпив-s linearibus, leneris, inlegerrimis, aculis, nerwalione, prater mesonewron, mullâ; rhizomate repenle, filiformi, squamis cancellatis obsilo.

Filix parvuta, graminiformis, pellucida, tenerrima, erecta, arboricola, inter muscos crescens; habilu proprio.

Diagnosis : Scнотт, Gen. filic., Fasc. iv, fig. 3. (M. linearis, Kallf. Loplima.)

Icon. "rostr. IX, C (fragmentum ejusdem planter).

Le genre Monogramme se rapproche des vituriées par la forme des sporangiastres et la nature du tomen/um qui charge les radicelles d'un rhizome rampant. Il n'y a point d'indusiurn, mais comme si les sporanges éprouvaient le besoin de se dérober à l'action de la lumière, elles se cachent sous un repli que forme la lame, en se repliant sur elle-même au point fructifère. Le port du Monogramme la sépare de toutes les fougères connues. Elle ressemble tout a fait à une graninée naine; les frondes, excessivenent étroites, sont planes, entières et dressées. C'ést parmi les mousses, au pied des arbres, qu'il faut chercher l'espèce-type. Les botanistes l'eussent connue et décrite plutờ, si la petitesse extrême de ses proportions ne l'eùt longtemps dérobée à leurs regards. Elle liabite au sud de l'Afrique et dans les îles de l'Archipel africain.

\section{ENUMERATIO SPECIERUM.}

Linearis, Klfss. (graminea, Schklı.*).

Nous indiquons comme douteux Je M. extensa, F. (Villaria gracilis, de l'herbicr de Kuuze). 


\title{
** Vervillis pinnatis.
}

\section{ADENOPHORUS, Gaud.}

\author{
Freyc. Voy., t. VIII, p. 365.
}

Fée, 3. Mém. sur les fougères: Vittariées et Pleurogramaíes.

Sровотнесіs solitariis, superficialibus, rotundis, apicem mesonevri laciniarum coronantibus; sporangiis ovoideis, cum glandulis pyriformibus, pedicellatis, fulgentibus, coccineis immixtis; stomate 8 nervato, nervis spissis; annulo lato, $11-12$ arliculato; sporis ovoideis, rugosis, nigrescentibus.

FRoNdıbus bi-tripinnatis, rigidis, coriaceis, opacis, segmentis linearibus, obtusis, uninervatis, glandulosis; apice dilatatis.

Filices erecta, fusciculatce, in insulis Sundwich, super arbores vigentes.

Diagnosis nostra: Tab. X, A, fig. 1. (A. bipinnatus, Gaud., l. cil.) - fig. 2, Polypodium fallax, Sснкн. (fragmentum ad comparandum).

In opere citalo cl. Gaudichaudii, plures species describuntur, sed in unican forsun conjungenda.

Quoique ce genre ne soit pas sans analogie avec le Xiphopteris, nous ne pouvons nous dispenser de reconnaitre qu'il est bien voisin des polypodiées; pourtant le port est différent. Chaque segment des frondes, qui sont bi- et même tripinnatifides, est monosore et les sporothèces naissent au sommet de l'unique nerville qui le traverse. Cette nerville prend, en se renflant, un aspect pyriforme très-remarquable. Les frondes ont une rigidité prononcée et leur épaisseur est assez considérable. Les segments se replient facilement sur leurs voisins par redressement. De nombreuses glandes pyriformes, sessiles ou pédicellées, les recouvrent. Ces corps ont une couleur de feu qui les décèle même à l'œil nu. On trouve les Adenophorus aux îles Sandwich, et M. Gaudichaud est le premier naturaliste qui les y ait récoltées.

\section{ENUNIERATIO SPECIERUM.}

A. bipinnatus, Gaud.*, H. et Gr.* - A. hymenophylloides, Ilook. et Gr.*; A. minutus, Gaud.* - A. tamarisci, H. et G.*. - tripinnatifidus, Gaud.* (an ejusdem typi forma?). 


\title{
41. XIPHOPTERIS, Kaulf.
}

\author{
Enum. filic., p. 85.
}

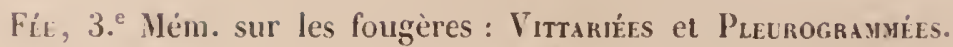

Grammitidis spec., Auct. var. - Micropteridis spec., Desv.

SPOROTHECIS subconlinuis, confluentibus, superficialibus, in apice frondiurn dilalalo sitis; sporangiis rotundis; stomale anguslo, sub 12 nervalo; annulo 1 arliculalo; sporis rolundis; sporangiastris mullis.

Froxniвes fasciculalis, simplicibus, parle sterili profundè denlalâ; ferlili undulalâ, aliquandò subplicalâ; nervillis pinnalis, margineu allingenlibus; rhizomate surculiformi, ereclo, fibrillas longas, nudas, alras cmillente.

Filix parvula, erectu, denticulata, muscicola, Americana, tropicalis; Mubitu planè distincto.

Diagnosis: Tab. $\boldsymbol{X}$, B. (Xiphop. serrulata, Kanlf.; Grammitis myosuroides, Sснкн." R.DD.*)

Des frondes simples dentées avec tendance pinnatifide, un port raide, labsence d'organes accessoires, caractérisent ces petites plantes, nettement séparées des autres genres. Quoiqu'on ait décrit plusieurs espèces de xiphopteris, nous les regardons comme rentrant dans un même type. Les frondes se dilatent vers le sommet pour recevoir les sporanges attachées sur le mésonèvre; dans le premier àge, cette partie de la lame se replie sur elle-même pour mettre les sporanges à l'abri des rayons lumineux; mais à la maturité, elle est plane et même bomhẻe.

\section{SPECIES.}

Genus monolypum : vide diagnosim generis. 


\section{PLEURogramine, Presl.}

Tentam. pterid., p. 223.

Fíe, 3. Mém. sur les fougères: Vittariées et Pleqrograumíes.

Blechni et Grammitidis spec., Willd. - Cochlidium, Kaclf., Schotт. - Tcenitidlis spec., Kaulf. - Micropleridis spec., Desw.

SPorothecus costalibus, plìs minùsve elongatis, ex apice aliquandò dilatato plicatoyue nascentibus, sapè confluentibus; receplaculo ad, mesonevron reducto; aliyuandò duplici, parallelo, leviler sinuato, cum mesonecro lateraliter subcoalito; sporangiis magnis, rolundatis; annulo $11-13$ arliculato; sporis latè ovoideis; sporangiastris nullis.

FROXdres fasciculalis, linearibus, rarò ovoideis, inlegris; nervillis liberis, simplicibus aut furcatis, marginem non attingentibus; radicibus fibrosis; rhizomate repente.

Filices parvulce, erectce, arboricolce, tropicales; habitu omninò distincto.

Diagnosis : Schotr, Gen. filic. (sub Cochlidio [optinu]). - Hoor. et Baufr, Gen. filic., t. Lxxxiv (Monogramme furcata, Desv.), et t. Lxxr. (P. linearis, Prest, l. cit., t. $\mathrm{x}$, fig. 2 [nervatio]).

Icon. nostra: Tab. X, C. (Pleurogr. myrtillifolia, F.*)

Ces fougères frrment des touffes serrées et s'attachent à la terre à l'aide de nombreuses fibrilles. Le $P$. myrtillifolia est rampant et ses frondes, au lieu d'être dressées et linéaires, sont grimpantes et elliptiques. Toutes les espèces ont pour caractère commun d'avoir des sporanges attachées au mesonèvre dans sa partie moyenne et supérieure. Les deux côtés de la lame se creusent dans le $P$. immersa pour les recevoir, et le mésonèvre qui fait office de réceptacle, s'épaissit légèrer ment au point fructifère. Le port de la plupart des espèces les rapprochent des grammitis; mais le rapport existe uniquement dans la fronde; d'autres semblent voisins des monogramme; cependant les analogies sont plutôt apparentes que réelles. Toutes ces plantes sont anéricaines. Il paraitrait que le $P$. pumila fait exception et croîtrait en Guinée. Dans le $P$. graminoides, les sporanges occupent la partie supérieure de la fronde, qui est arrondie et creusée en cuiller.

\section{ENUYERATIO SPECIERUM.}

Linearis, Presl (Hook, et Bauer*; Tanitis, Klfss.) - graminoides (Grammitis, Sw.? Monogramme furcata, Desr.; Hook. et B.*; Cochlidium, Klfss., Schott*) - immersa, F. (Monogr. linearifolia, Desv.*) - myrtillifolia, F** graminifolia, F. (Tonitis, Hook.) - pumila, Presl. (Grammitis seminuda, Will.*; Micropteris, Desv.). 


\section{Considérations générales sur les Pleurogrammées.}

Nous avons bien peu de chose à ajouter à ce que nous avons, dit de ce petit groupe, page 22. Il renferme les plus petites fougères connues. Des cinq genres qui le composent, trois ont des frondes simples et linéaires; dans le Xiphopteris elles tendent à la forme pinnatifide, étant, relativement à leurs dimensions, assez profondément dentées. Dans le genre Adenophorus elles sont tout à fait pinniatifrdes et même bipinnatifides; ce genre, ainsi que nous l'avons fait remarquer, est quelque peu anornal et le groupe des polypodiées pourrait le recevoir sans trop' d"inconvénients. Cependant les sporothèces, étant attachées sur le dos d'un réceptacle ellipsoïde, naissent sur le mésonèvre, rentrent dans les conditions qui soumettent les autres pleurogrammées, et c'est ce qui a dî nous décider à le placer dans ce groupe. 


\section{§. 3. Sporothecia mesonevro remota, marginalia: PTERIDINEAE.}

Schizolomere et Pteridere, Gaudich., partim, Voy. de l'Uranie, p. 378 et 383.

Lindsayaccea, Press, Tentam. pterid., p. 130.

Adiantacece, Ejusd., l. cit., p. 139.

Lonchitidece, Ejusd., l. cil., p. 161.

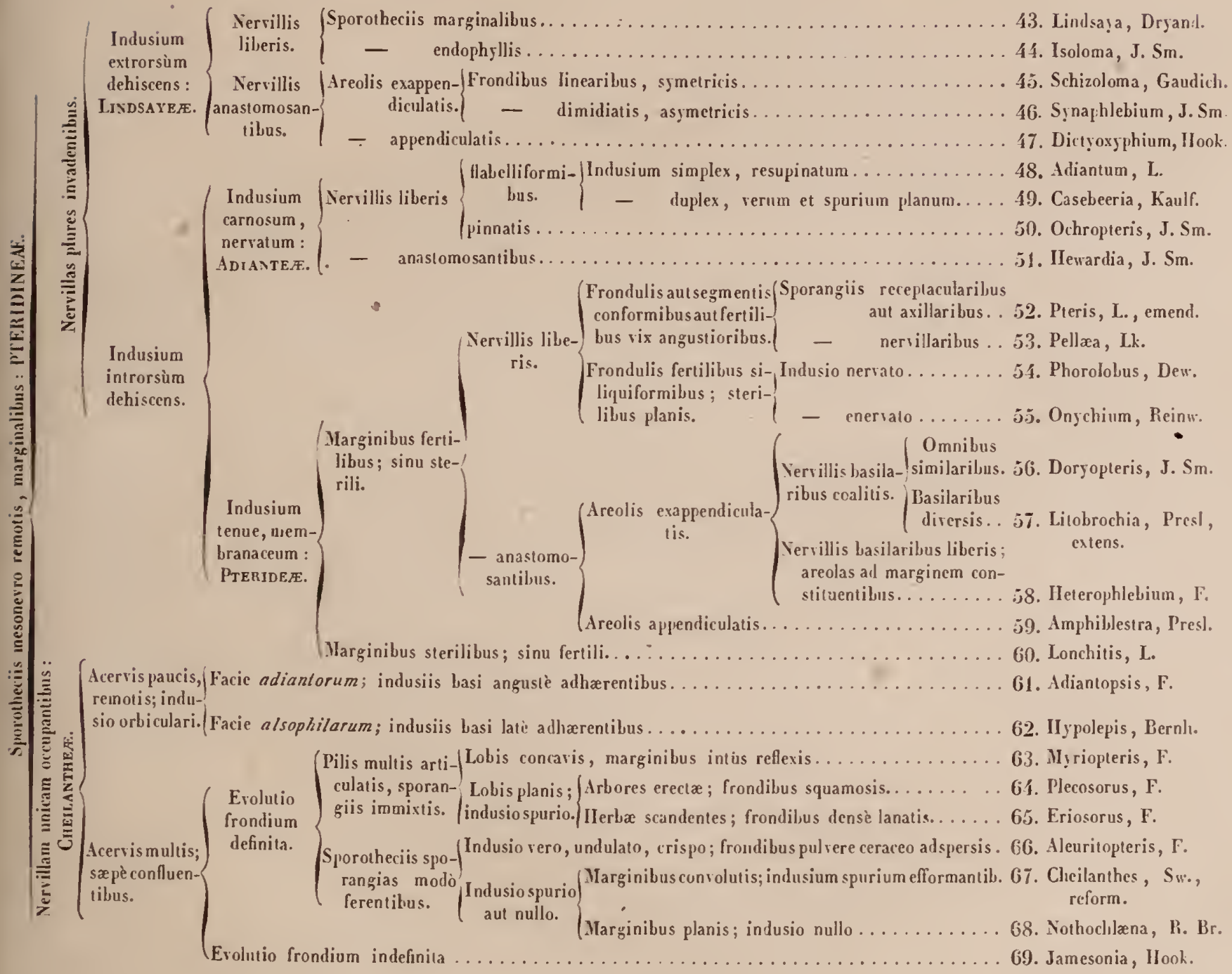




\section{†. Indusium extrorsim dehiscens : LINDSIYEE.}

LINDSACEe, Presl, Tentam. pterid., p. 150.

LMDSEEÆ, Hook., Syn. filic., t. I, p. 202

Glaberimæ, rigidæ, erectæ, pinnæ ferè semper dimidiatæ. nervilla flabelliformes.

\section{* Vervillis liberis.}

\section{LINDSAYA, Dryand.}

Act. societ. Linn. Lond., III, p. qo.

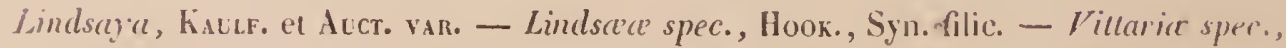
Galdici., Ronв. - Olontolomalis spec., J. Sw.

SPOROTnECns marginalibias sen submarginalibus, continuis vel internptis; indusio membranaceo, tenuissimo, apice nersillatum coalitarum adharente; sporangiis ovoideis; anmulo 11-14 arliculato; sporis ovoideis, rarò trigonis.

FROXdBCS reniformibus, sagitlatis, pinnalis vel bipinualis; pinnulis ferè semper obliqnis; nervillis flabelliformibus, furcatis; slipilibus fusco-badiis, stramincis aut rufrscentibus.

Filices tropicales, herbacere, terrestres, mpicolar, tenerce, pellucida, graciles; fucie in plurimis adiantorum; paucis ad Davallias tendentibus.

Dinguosis: Hoon et B., Gen., t. LxuI, A (L. trapeziformis, Dryand.)

Íou. nostr: : Tab. XI, B, fig. 7 et 8. (Lindscea polymorpha, Hook. el GREv.)

lindsceam el Liudsayam scribunt auctores; quum istud genus memorice cl. Lindsu! consecrutum sit, melius est Lindsaya scribere.

Ce genre correspond au genre Adiantrm; mais la déhiscence de lindusium a lieu en sens inrerse. Les espèces sont noins nombreuses, le port plus uniforme et les frondes moins divisées. Les frondules, courtes et obtuses, se rapprochent plus ou moins de la forme arquée ou cunéiforme. Les sporothèces, linéaires et étroits, sont continus; cependant si la frondule est fendue ou lobée, ils s'interrompent pour border chaque segment. Cette disposition exceptionnelle rapproche des odontoloma les espèces ainsi conformées. 


\section{ENUMERATIO SPECIERUM.}

A. Frondibus indivisis. = Reniformis, Sw. (Dryand.*, Kze.*) - sagittata, Dryand. (H. et Gr.*; Adiantum, Aubl.*).

B. Frondibus pinnatis. = Falcata, Dryand.* (Adiantum, Aubl.*) - cultrala, Sw. (Willd.*, Schkh.*, Ilook. et Gr.*) - oblongifolia, Reinw. (Hook.*) - adiantoides, J. Sm. (Hook.*) crenulata, F. - Lobbiana, Hook.* - scandens, Ilook.* - ovata, J. Sm. (Ilook.*) - Schomburgkii, Kltz. (Kze.*) - securifolia, PresI (Kze.*) - apiculata, Kze.* - linearis, Sw.* (Kze.*) - multifrondulosa, F. - concinna, J. Sm. (Cuming, Philipp., n. ${ }^{\circ} 198$; Hook.*) - microphylla, Presl* non Hook. - Leprieurei, Hook.* - falciformis, Hook.*

C. Frondibus bipinnatis. = Quadrangularis, Radd.* - horizontalis, Hook.* - trapeziformis, Dryand.* (Salisb.*, Langsd.* et Fisel. var.) - caudata, Hook. - caudifera, F. - pendula, Kl. , (Hook.*) - heterophy.lla, Dryand.* (Cuming, n. ${ }^{\circ} 275$ ) - trichomanoides, Dryand.* (Sehkh.*) Lessonii, Bory* - pallida, Kltz. - stricta, Dryand. (Sehkh.*; Javitensis, II. B. et K.) - rigida, J. Sm. Hook.*) - tenera, Dryand.* - virescens, Mart. - arcuata, Kze. — Guyanensis, Dryand.* (Hook.*; Adiantunt, Lubl.*; rufescens, Kze.) - daiallioides, Blum. (Kze.*, Hook.*) - elegans, F. non Hook. (Moritz, n. ${ }^{\circ}$ 238) - curvans, F. (Galeott., n. ${ }^{\circ 6489}$ ) - Catharinee, Hook.* Gardneri, Hook.* - Galeottii, F. (Galeott., n.* 6469).

D. Frondibus tripinnatis. = Cuneifolia, Presl. - filiformis, Ilook.*

\section{SPECIES NONDUM DESCRIPTIE.}

I. Multifroxdllosa, tab. XXVIII, fig. 1.

Frondibus linearibus, stipitibus brevibus el rachi helveolis, glabris, apice attenuatis; frondulis dimilliatis, subsessilibus, subdeltoideis, superioribus obovatis, inferioribus flabellutis, sterilibus approxinatis, margine crenatis, intermediis el basilaribus deflexis; rhizomate tenui, squumoso, repente; sporotheciis continuis, upicem ferè tolum invadentibus; indusio tenui, nembranaceo, discolori, sporangiis parvis, ovoideis; annulo crassissimo, 9-10 articulato; sporis succineo colore, rotundatotrigonis.

Habitat in Mexico. (Provinc. Oaxaca, Galeolti, n. 6170.)

Filix eluta, linearis, mullifrondulosa; habitu L. concinna sed diversissima.

(Longueur totale, 45-50 centim.; le stipe ayant à peine 5-6 centim. de haut; envergure, 15-17 millim.; hauteur des frondules, 4-5 millim. Nous eomptons jusqu’à 80 paires de frondules sur une seule fronde.)

Dans le $L$. concinna, J. Sm., les sporothèces sont interrompus; le stipe est quadrangulaire, nu dans une assez grande partie de son étendue, elc.

II. Crevulata, tab. XXViII, fig. 2.

Frondibus lanceolato-linearibus, attenuatis; stipite basi fuscescente et rachi quadrangularibus, helveolis, glabris, longè altenuatis; frondulis multis, petiolatis, semiovatis, dimidiatis, oblusissimis, crenatis, crenis incrqualibus, rentotis, inferioribus distantibus; nervillis paucis, distantibus, marginem non attingentilus; rhizomate tenui, repente (an scandente? ${ }^{\text {) }}$, radicellas fuscus, longissimas emiltente; sporotheciis interruptis, 4-5 incqualibus, prccipuè all partem anteriorem evolventibus; indusio 
tenuissino, plunè marginali; sporangiis ovatis, parvis; annulo 11.12 articulruto, crenato, sloris minutis, trigonis.

Habitut in Indiis orientalibus. (Mulacca? Griffitb.)

Filix tenera, membranacea, pallidu, nultifrondulosa; frondulis crenatis, superioribus triangulatis.

(Longueur totale, 20-24 centim. Le stipe est it la fronde :: $1: i$; envergure, 2 centim.; frondules, 4-5 millim. de hauteur; Ie rachis et le stipe sont presque filiformes. Cette fongere se rapproche du $L$. adiantoides, J. Sm. : cependant ou ne peut la rapporter à la planche LXI, fig. C. du Synopsis filicum de M. Hooker.)

\section{CiUdifert.}

Frondibus bipinnalis, stipitibus glabris, flaccidis, helveolis, glabris, in ambilu ovoideis; pinnulis longissimis, linearibus, allernis, multi-frondulosis, flexuosis; frondulis multis, 50 jugis et ultrì, glaberrimis, lunulatis, obtusissimis, apice minoribns, cauda terminali lineari, integrâ; sporotheciis angustis, continuis; sporangiis purvulis; annulo crenato, 10 articuluto, pedicellis angustissimis; sporis minutis, trigonis.

Habitut in Guadalupâ. (L'Herminier, Y. S.)

Filix elata; pinnulis longissinus.

(Longueur totale, 45-60 centim.; les frondules atteigneut 9-12 centim.; le prolongement caudiforne des pinnules dépasse 2 centim.)

\section{El.EGANS.}

Frondibus bipinnatis, in ambitu ountis, glaberrimis, flexibilibus; stipite quadranguluri, rufescente, lcevi; pimnulis linceolatis, rachi albido, apice attenuatis; frondulis dimidiatis, flabelluto-cuneatis, supernè crenatis, onnibus proligeris; sporotheciis incequulibus; indusio tenui; rhizomate crassitudine penure columbre, squumis mefis obsito, radiculas longas rigidasque ferente.

Habitat in sylvis unbrosis ad scopulos. (Columbia [Tovar], Moritz, n. ${ }^{\circ}$ 238.)

Filix tenera, flexibilis, stipite tenui, frondulis decrescentibus, pellucidis, pinuulis $1-5$ jugis, suboppositis. (T. S. in Herb. Moug.)

(Longueur totale : 45 centim.; les pinnules mesurent 15 centin.)

\section{Curitis.}

Fronlibus bipinnatis, glabris; stipite helveolo, maculuto, quadiangulari, lecvi; pinnes lanceolatis, 3-1 jugis, extus curvatis, atlenuatis, rachi qundranguluri, apice filiformi; frondulis remotiusculis, dimidiatis, subtrianguluribus, obtusis, curvatis, basi truncatis, siccitate viridibus; terminalibus parvulis, sessilibus; inferioribus delloideis; nervillis tenuibus, distuntibus; sporotheciis marginem superiorem occupantibus, interinptis, indusio a margine remoto; sporotheciis ovoideis, parvulis; annulo 11 arli culcuto; sporis trigonis. 
Habital in Mexico [provincia Oaxaca; altit., $12-1300$ metr.] (Galeotti, n. ${ }^{\circ} 6489$, sub Adianto).

Filix elegans; pinnis flexibilibus, attenuatis, viridibus; sporotheciis incequalibus.

(Longueur des pinnules latérales et de la terminale, 19-20 centim.; envergure, 2 centim.; largeur des frondules, 5-6 millim. Le stipe est gros comme une plume de pigeon; nous comptons de 20 à 22 frondules sur chaque pinnule.)

\section{Galeottil.}

Frondibus in anbilu ovalis, glaberrimis, stipite suprà plano, subtùs convexo, helveolo; pinnis remotis, alternis, 5 jugis, stipilatis, lanceolato-linearibus, incurvatis, apice longè attenualis; frondulis dimidiatis, subtrapeziformibus, basi cuneato, in petiolo desinente; apice obııso, infernè gibboso, nervillis sex, fiırcatis; sporotheciis continuis, marginem superiorem el apicem invadentibus, indusio concolori; sporangiis parvulis, ovoideis; annulo crasso, 11 articulato; sporis incequaliter trigonis.

Habitut in Mexico [provinc. Oaxaca; altit., 1000 metr.] (Galeotti, n. ${ }^{\circ} 6469$, sub Adianto).

Filix elegans, glabra; pinnis longis, incurvatis, multifrondulutis.

(Longueur de la partie fronduleuse, 20-22 centim.; pinuules, 25-27 centim., laissant entre elles un espace de 5 centim.; envergure, $25-27$ millim.; largeur des frondules au centre, 3 millim. Nous comptons sur une pinnule environ 48 paires de frondules; celles-ci sont extrêtuement rapprochées.)

\section{ISOLOMA, J. Sm. (1838.)}

In Gener. filic. Hook, et Bauer, tah. CII.

SроRотнесIs linearibus, continuis, marginalibus, in mesophyllo nascentibus, margiuem lolun incaderulibus, usque ad apicem frondium, culiculâ inferiori indusiiformi; sporangiis ellipticis; annulo 16 arliculalo; sporis reniformibus trigonisque.

FroNDIBUs lanceolatis, pinnalis; frondulis approximalis, dimidialis; nervillis liberis, furcalis, tenuissimis, apice incrassalis, marginem non allingentibus, stipitibus et rachi lavibus ebeneisque.

Filices terrestres, Indice, Americance, erecte, opacc, rigida, arboricola; facie, Lindscarum, sed sporotheciis mesophyllis.

Diagnosis : Ноок et B., Gen. filic., t. cu. (I. Lanuginosum, J. Sм.)

Les nervilles sont libres, renflées à leur extrémité qui n'aueint pas la marge, c'est dans le mésophylle et à leur sommet que naissent les sporanges. La cuticule 
supérieure se soulère, s'anincit en indusium, et les sporanges la forcent en s'accroissant, à se déjeter de dehors en dedans, tandis qu'elles prennent un point d'appui sur la lane inférieure non modifiée. Ce genre se rapproclıe beaucoup des villaria.

\section{ENUMERATIO SPECIERUM.}

Guerinianum (Schizoloma, Gaud.* [in icone Voy. de l'Lranic, t. 18 nersillo depictee sunt anastomosantes, sed certissimè likerce]) - divergens, J. Sm. (Lindscea, II. et Grev.* [Cuming, Malacca, 11. 395]; Vittaria truncata, Gaud. ex ipso) - lanuginosum, J. Sm. (Hook. et B.*, fragm. unalyt.*) - Valkera (Lindscea, Hook.*).

\section{** Vervillis anastomosantibus.}

\section{Areolis exappendiculatis.}

\section{SCHIZOLONA, Gaud., reductum. (1826.)}

roy. de l'Uranie; Botan., p. 3-8.

Lindsayce spec., Labillard., Gaudich. - Pteridis spec., Lyrk.

Sporothecus linearibus, continuis, anguslis, marginalibus; indusio Lindsayte: sporangiis ovoideis; annulo crasso, 16-18 arliculalo; sporis trigonis.

Froxdibus pinnatis, frondulis longis, angustè lanceolatis, nervatione anastomosalâ, areolis subhexagonis; nervillis ad marginem liberis.

Filices pinnate, glabre, tenerce, Indice, Madagascarienses; fucie pteridum pinnatarum.

Diagnosis : Ноок. et B., Gen. filic., t. Lxm, B.

Ces fougères ont le port des pteris à frondes pinnées ( $P$. crelica, L.; pellucida, Presl; longifolia, L.; etc.), quoique plus souples et plus délicates; mais la déhiscence est extror'se et les nervilles sont anastomosées. Les sporothèces occupent exactement la marge des frondules, sans pourtant être précisément endophylles, ainsi que le nom semble l'indiquer, tandis que ce caractère est très-saillant dans le S. crisifolia, J. Sm.

La plupart des genres du groupe des Lindsayées portent des frondules dimidiées; ici elles sont linéaires-lancéolées, et ce caractère leur donne un port particulier.

\section{ENUMERATIO SPECIERUN.}

Billardieri, Gaudich.* (Lindsa a lanceolata, Labill.*) - ensifolium, J. Sm. (Cuming, F. Philipp., 11. 369), et var. \& Lindsa membranacea, Kze. (Guenzius, Pl. port. natal.) - Jaice, F. (Zolling. 11. 1501) - macrophy.llum, Presl. (Hook. et Bauer, Fragm.*) - Griffithianum (Lindsaa, IIook.* a finis cum genere Schizoleptone]) - pentaphy-llum (Lindsaa, Hook.*) - Fraseri (Lindsca, Ilook.*) 
SPECIES NONDUM DESCRIPTA.

JAve, tab. XXIX, fig. 1.

Frondibus tetraphrllis, stipite helveolo, quadrangulari, rhizomate tenui; frondulis petiolatis, lanceolatis, basi semi-hastatis, in acumine dentato extensis, terminali lateralibus vix longiori; nervillis omnibus anaslomosantibus, areolis sub-hexagonoideis, elongatis; sporotheciis angustis, continuis, indusio brevi; sporangïs parvis; annulo crenulato, 11-12 articulato, facilè soluto, pedicello longiusculo; sporis ininutis, atris, ovoideis trigonisque.

Habital in Java. (Zollinger, n. ${ }^{\circ}$ 1504.)

Filix parvula, subtriplyylla, glabra; stipite tenui, frondulis semi-hastatis.

(Longueur totale, 16 centim. Les frondules atteignent 10-11 centim. sur un peu moins de 2 centim. de largeur; le stipe est moins long que les frondules.)

\section{SYNAPHLEBIUM, J. Sm. (1838.)}

In Gen. filic., Hook. et B., tab. CI.

SPOROTHECIS angustis, continuis aut interruptis, marginalibus; indusio propro, tenui, membranaceo tectis; sporangiis ovalis; annulo 14-18 arliculato; sporis obscurè trigonis, fuscis.

Froxdibs pinnatis vel bipinnatis, stipite quadrangulari; pinnulis dimidiatis, pellucidıs, sapè crenatis; crenis omnibus proliferis; nervillis tenuissimis, in areolas hexagonas anastomosantibus.

Filices Indice, tenerce, glabre; nervillis tenuissimis.

Diagnosis : Ноок. et B., Gen. filic., l. cit. (S. recurvalum, J. См.)

Les synaphlebium sont des Lindsaya à nervation anastomosante; ce genre renferne aussi des espèces à fructification continue ou interrompue. Leurs frondules dimidiées, obtuses et très-courtes ne permettent pas de les confondre arec. les schizoloma, à frondes symétriques, linéaires, lancéolées, portant des sporanges logées dans l'épaisseur même du mésonèvre. Les sporothèces sont situés sur la dernière limite de la marge, comme dans les schizoloma. Synphlebium eìt été la véritable orthographe de ce nom de genre; Synaphlebium, prenant un a privatif, semble indiquer le contraire de ce qu'a voulu exprimer l'auteur.

\section{ENUMERATIO SPECIERUM.}

1. Sporotheciis continuis $=$ recurvatum, J. Sm. (Cuming, Pl. Malacca, $\mathrm{n} .^{\circ} 392$ ) (I.indswa intermedia, Hook.*).

2. Sporotheciis interruptis = tetraphyllum, F. (Adiantum, H. B. et Kth.) - Urillei, F. (Lindsay: interrupta, d'Urvill. msc.) - obtusum, J. Sm. - propinquum (Lindsaya, Hook.*). 
C'RThlei, F.

\section{SPECIES NONDUII DESCRIPTA.}

Frondibus in ambitu ovatis, bipinnatis; pinnis suboppositis, lanceolatis, apice atlenuatis, stipite rubescente, lavi, quadrisulcato, sulcis lateralibus; pinnulis dimidialis, basi cuneatis, supernè obtusis; inferioribus et superioribus triangularibus, apice obtusis, crenatis, pellucidis, approximatis, brevi petiolo donatis.

Sporolheciis $5-7$, in utrâque crenâ sedentibus; indusio tenui; sporangïs minutis, ovatis, 12 - 13 articulatis; sporis triedricis, parvulis, fruscis lavibusque.

Habital in O-Wahu. (Archip. Carolin. d'Urville. [V. S. in Herbario clar. Lenormand.])

Filix elegans, tenera, pellucida.

Dimensions : la partie chargée de pinnules a 28 centim. de longueur; les pinnules latérales ouvrent arec le stipe nu angle de $60^{\circ}$ environ; elles ont 14-16 centim. de longueur; la termiwale en a 20 environ; l'envergure des pinnules est de 2 centim.

\section{计 Areolis appendiculatis.}

\section{DICTYOXIPHIUM, Ilook. (1858.)}

Gen. filic., t. LXIIJ.

Sровотнеси inframarginalibus, continuis; indusio margine frondis parallelo; sporangiis oroideis, longè pedicellatis; annulo crasso, arliculis 18-20; sporis ovalibus, rugosis.

Froxdibcs simplicibus, elongatis, ensiformibus, coriaceo-membranaceis; fertilibus paululim angustioribus; nevillis crassis, uppendiculis rectis, furcato-divaricalis, in areolas hexagonas coalitis; llizomate crasso, surculiformi.

Filix Ponamensis, herbacea, recta; facie Pteridum.

Diugnosis: Ноок el B., l. cil. (D. Panamense, Ноок.)

Les frondes fertiles ne different des stériles que par une largeur moins grande; dans la planche donnée par MI. Hooker, la fronde fertile est fructifere vers le sommet. Cette fougère de l'Amérique tropicale ressemble à une espèce gigantesque de viltaria; elle atteint jusquà un mètre de hauteur. Sa nervation est analogue à celle des gymnopteris et des bathmium.

SPECIES.

Genus nonulypum : vide diagnosim generis. 


\section{Considérations générales sur le groupe des Lindsayées.}

Quoique les lindsayées se rapprochent des adiantées par le port, il n'est pas absolument le mêne. Aucune d'elles, par exemple, n'a de rapport de facies avec les fougères du type de l'Adiantum Capillus veneris. Il faut chercher les analogies parmi celles qui sont voisines des $A$. obliquum, pulverulentum et azarifolium. On peut constater qu'elles tendent vers les davalliées par les Lindsaya à sporothèces interrompus, mais cependant les deux groupes sont très-nettement séparés.

Les genres appartenant aux lindsayées ne sont pas tous isolés les uns des autres au même degré. Le Diclyoxiphium est parfaitement distincı par son port et par ses aréoles appendiculées. Le $S$ chisoloma est le seul qui ait des frondules linéaires symétriques; mais entre le Lindsaya et le Synaphlebium, il n'existe d'autres différences appréciables que dans les nervilles, libres dans le premier de ces genres et soudées dans le second. Pourtant les sporothèces, dans le Synaphlebium, se rapprochent tellement de la marge qu'ils semblent naître dans le mésophylle et n'avoir d'autre indusium que la culicule inférieure sous laquelle ils naissent, et qui s'est amincie en une membranule transparente. Une pareille organisation se retrouve d'une manière encore plus marquée dans le genre Isoloma, à nervilles libres, ayant aussi pour indusium la cuticule supérieure de la lame; mais ici elle conserve sa consistance et sa couleur.

Ces fougères ne produisent point d'organes accessoires, ni sporangiastres, ni poils étoilés; elles ne sont point non plus proliferes et leurs formes sont trèsstables. Il est à remarquer que les plantes glabres ou médiocrement écailleuses sont aussi celles qui restent le plus rigoureusement dans les limites de leur condition organique. 


\section{ț Indusium interiüs deliscens.}

\section{Receptaculum carnosum, nervosum, dilatatum resupinatum- que : $A D I A N T E A$.}

Filices cosmopolitanæ, ferc̀ omnes tropicales, crectæ, glaberrinx , frondulis sxpè dimidiatis, teneris, pellucidis; stipitilus semper ebeneis . fragilibus.

\section{* Mervillis liberis.}

\section{$\dagger$ Flabellatis.}

\section{ADIANTUM, Linn. (1764.)}

\section{Species plantarum, 1556.}

Sровотнесіs interruptis, rarissimè continuis, plìs munisve linearibus, rarì subrolundis, nunquam confluentibus; indusio marginali intìs dehiscente, lineari, continuo, interruplo, semilumulato, persistente; receplaculo nerioso, reflexo, è margine orto, crasso coloraloque; sporangiis ovatis, suprì venulas temuissimas, parallelas, prominentes, è bifurcatione ultimä nervillarum provenientes sitis: annulo $14-20$ articulato; sporis trigonis.

FRoxibus glaucescentibus, hydrophugis, simplicibus, pinnatis decompositisque, pinnulis sapè dimidiatis; nervillis sapissimè flabellato-furcatis, tenuissimis, apice proliferis; stipitibus fusco-badiis, nilescentibus, corlice frarili vestitis.

Adiantum, Аuст. ғеві̀ оммичм - Allianti spec. Ноок., Spec. filic., p. 1.

Filices ferè omnes tropicales; dure extratropicales, una Europara, altera polaris; planter terrestres, herbacer, rupicolce, tenerce; stipitibus capillaceis.

Diagnosis: Hook et B., Gen. filic., 1. Lxv, B. (A. Capillus-veneris, L.)

Icon. nostr.: XI, B. Fig. 2, A. curdiochlecua, KzE. et fig. 3, A. mucrophyllum, Sw.

Genus nulurulissimum, in duas sectiones fortè dividendum:

1." Aротоит.t; sporotheciis interruptis.

2. SYrecut i; sporolheciis continuis.

Facie Lindsæarum, sed in Adiantis sporothecia nervillaria sunt et extrorsìm dehiscentic.

Ce genre renferme au delà de cent espèces, nettement caractérisées. Les sporothèces sont très-rarement continus et alors étroits comme ceux des ptéridées, ordinairement limités et tendant à la forme arquée ou semi-lunaire. On peut les diviser facilement, d'après la disposition des frondes, en symétriques et en dimidićes. Les frondes sont simples, ou pinnées une ou plusieurs fois. Aucune n'est pinnatifide. Il en 
est de réniformes, de cordiformes, de trapézoïdes, dę deltoides; beaucoup ont des frondules cunéiformes.

La synonynie du genre Adiantum est peu chargée, ce qui s'explique par la facilité arec laquelle on constate les caractères génériques. La nervation est presque universellement flabelliforme. Dans les espèces à sporothèces interrompus et arqués, les nervilles latérales aux indusiun se recourbent vers le point d'attache, manifestant ainsi une grande tendance à la connivence. L'A. cardiochloena et ses analogues offrent ce caractère d'une manière très-marquée, mais il ne suffit pas pour justifier la formation d'un genre; les plantes qui en font partie, ont leurs sporothèces situés dans un sinus de la marge, exacienient comme les lonchitis. Les frondules de beaucoup d'espèces, notamment celles qui se rapprochent des $A$. Capillus-Veneris, ont des pétioles courts, noirs et lisses conme les stipes. Ils sont articulés et se terminent ainsi brusquement au point où commence l'épanouissement des nervilles dont ils se montrent ainsi indépendants.

\section{ENULIERATIO SPECIERUII.}

S. 1. Srrechia : Sporotheciis continuis.

Hacrophyllum, Sw. (Browne*, Sloan.*, H. el B.*, Hook. et Grev.*) - platyphyllum, Sw.*(Kze.*) - lucidum, Sw. (Hook.*; A. pteridioides, Lepr., msc.) - Phyllitidis, J. Sm. (Hook.*) - deltoideum, Sw. (Kze*) - falcatum, Sw. (Sloan.*, Pluken.* [pessime] ) - Lancea, L. (Seba*) - pulverulentun, L. (Sw.*, Peliv.*, Plum.* [male], Schkh.*) et var. camplocarpon, F. - incisum, Presl* - propinquum, F. - varium, H. B. et Kth.* - Claussenii, F. - Jacobina, F. — villosum, L. (Sehkh.*) - asperum, F. -- lanceolatum, F. - serrulatum, L. (Sloan.*).

\section{S. 2. Aротоми : Sporotheciis distinctis et interruptis.}

Reniforme, L. (Schkh.*, Ilook.*) - asarifolium, Willd. (Lmrk.*, Sehkh.*, Hook.*, fragm.) Philippense, L. (Peliv.*).

Subcordatum, Sw. (Iruncatum, Radd.*) - Seemanni, Ilook.* (fragm.*).

Obliquum, Willd. (Hook. fragm.*) - Kaulfussii, Kze. (obliquum, H. et Gıev.*) - nıacrodon, Klfss., Herb. (Mart., Pl. bras., n. ${ }^{\circ} 355$ ) - intermedium, Sw. (fovearum, Radd.*) -- triangulatun,, Klfss. - denticulatum, Sw. (Plum.*, Pluk.*) - fuliginosum, F. - Wilesianum, Hook.* (fragm.) - Brnsiliense, Radd.* (pubescens, Radd.*) - Cayennense, Willd., msc. (Ilook.*) - pachysorum, Reich. (Kappl., 1.。 1732) - fructuosum, Spr. (Kze.*) - prionophyllum, H. B. el K. - crenatum, Willd. (Plum.*) - Kunzeanum, Kltz. (Plum.*) - pyramidale, Willd. (Peliv.*, Plum.*) - macrocladum, Kl. (Hook., fragm.*) - Klotzschianum, Ilook.* - nrophyllunı, Hook.* - glaucescens, KIIz.

Hirtum, Kltz. (Hook., fragm.* - hispidulum, Sw. (pubescens, Sebkh.*?) - pedatum, L. (Schhh.*) - Mathewsianum, Hook.* (fragm.*) - sinuosum, Gardn.* in Hook. - pulchellum, Blum. tetragonum, Sehrad. (Hart.*) - patens, Willd. (Hook.*) - curvatum, Kaulf. (Hook., fragnı.*). Gracile, F.

Grande, F.

Cristatum, L. (striatum, Sw., Jacq**) - nigrescens, F. - microphyllum, KIfss. (striatnm, Sehkh.*). Obtusum, Desv. (H. et Grer.).

Setulosum, J. Sm. - diaphanum, Hooh.* - afine, Wilkl. (trapeziforme, Forsl., Sehkh.*).

1. Chaque alinéa renferme des cspèces analogiques dont la première espèce dénommée est le type. 
Trapeziforme, I. (Sloan.*, Plum.*; rhomboideum, Schhl.*; rentadact)lon, Langsd. et F.*.

llook. et Grer.*) - Perusianum, Kltz. (Ilook.*, fragm.*) - trafezoides, F.

Lunulatum, Bum. (Retz.*, Rheed.*, Willd.*, Ilook. et Grev.*) - flagellum, F.

Cardiochliena, Kze. (llook., fragm.*; A. polyphyllum, Willd. ex Kze.) - Cubense, Ilook.*

Capillus-Veneris, L. (Jacq. *, Sm.**) - irifudum, Willd., IIerb., 11. 20,108 (Aby.ssin., W. Schimper)

- tenerum, Sw. (Pluk.*) - thalictroides, Willd. (rellucidum, Mart. el Gal.*) - Pseudocapillus, F.

- cunentum, Langsd. et $\mathrm{F} *$ (Radd.*, II. et $\mathrm{Gr}_{1} *$ ) - assimile, Sw. (non hortor.) - trigomum, Labill.*

(A. . Ehiopici proximum sed diversum) - Ethiopicum, L. (Plnk.*, Hook., excl. sinonym) - emarginatum, Bory (Ilonk.*) - sulfureum, KIfss. (Kze.*, Ilook.*) - excisım, Kze.* - scabrum, hlfss. - extensum, F. - Chilense, Klfss. - pilosum, F. (Chilense \& hirsutum, Ilook. et Gicr.*: Ilook.* - fabellulatum, L. (Retz.*, Pluh.*; amœnum, Ilook. et Grev.*) - radicans, F.* - gratum, F. - lobatum, Presl* - Moritzianum, Kltz. - Galeottianum, IIook., fragm.* - pensile, Kz.. var. alchemilloefolium - sessilifolium, Ilook.* - steciosum, Ilook.*, fragm. - formosum, R. Br. (Inook.*, fragm. - concinnum, H. B. et K.* (tenerum, Schkh.*) - glaucophyllum, Ilook.* venustum, Don. (Hook.*. fragm.) - fragile, Sw. - lutescens, Iloug., IIerb. - Lobbianum, Hook.* - Cunninghami, Ilook.* - fulvum, Raoul (Hook.*, fragm.).

Pumilum, Sw. (Pluk.* [male] , Mart.*) - delicatulum, Mart.*

Caudatum, L. (Burm.*, Sclıklı**, IIook.*, et var. fissum, F.: Cumiug, Philipp., 11. 11 et $29: 2$ - rhizophy.llum, Sclirad. (Mart.*) - rhizophorum, Sw. (Ilook.*) - dolabriforme, Ilook.* - veslitum, Wall. - soboliferum, WalI. (Hook.*, fragm.) - Edgeworti:ii, Ilook.* - calcareum, Gardn.* -- filiforme, Gurdn.* - Shepherdi, Hook.*

\section{SPECIES NONDLY DESCRIPT.E.}

\section{Sporotheciis continuis : SYvechr.t.}

I. Pulverllentey, L., var. Chyptocirpox.

Frondibus bipinnatis, in ambiue ovatis; stipite quadrangulato, fiusco, pilis rufis hirto; pimnis 6-8 lanceolatis, busi nudis, aculis; frondulis 20-24 jugis, arcuatis, upproximatis, apice cristato, basi truncato; sporolheciis submeniscioideis, continuis, brevibus; sporangiis ovatis; aumulo $\mathbf{1 6 - 1 8}$ articulato; sporis parvulis, trigonis.

Hubitat in Americâ meridionali. (Herb. Houg.)

Filix aspectu A. pulverulenti, sed sporohtheciis curvatis, brevioribus el frondulit terminali ecaudutâ lanceolatúque. An spec. distinctu?

(Les dimensions sont les inèmes que celles de $1 \%$. pulierulentum, L.)

\section{Propisquen.}

Frondibus bipinnatis, in ambitu ovatis; stipitibus atro-fuscis, hirto-ferrugineis, semicylindricis, latè sulcutis; pinnis 6 jugis, remotis, alt-rnis, curvatis, linearibus; frondulis 2024 jugis, brevissimè petiolatis, integris, truncatis, apice obliquè obtusis, subtrapeziformibus, gradatim decrescentibus, terminalibus triungulatis, busi incequalibus; nervillis tenuissimis, flubellatis, creberrimis, approximatis; sporotheciis continuis, marginem superiorem et apicem, internè gibbosum, invalentibrs; sporangiis ovatis; anuulo 11-13 articnlato; sporis trigonis.

Ilabital in Guyanâ gallicî. (Leprieur, Herb. Hougeol.)

In A. obtuso anmulus sporangiarum 16-18 articulatus est et sporre cordiformar; nervilla remotiores; frondulce superuè non gibbosa et sporolhecice interrupto. 
III. Claussevil.

Frondibus bipinnatis; pinnis 4-8 jugis, lanceolutis, crudalis; frondulis ovatis; oblısis, approximatis; basi truncalis, argutè serratis, apice sterili; vachibus rufo-villosis, subtrigonis, atro-fuscis; rhizomate repente, squamoso, squamis cancellatis parvulis, lanceolatis, acuminatis obsito; infernè fibros crassos, longos ferente el supernè fragmenta velusla petiolorum; sporolheciis abbreviatis, crassis, ratò interruptis, basim pinnularum occupantibus; annulo 20 -2.2 articulato; sporis trigonis.

Habital in novo Friburgensi Brasiliensium. (Claussen.)

Fillix ovala, pinnis palulis, caudalis; cun A. pulverulenti confusa.

(Longueur totale, 25-26 centim.; celle des pinnules étant de 12-13. Les frondules les plus longues atteignent $2 \frac{1}{2}$ ecntim. sur $7-8$ millim. de largeur.)

\section{JACOBIN.}

Frondibus bipinnatis, lanceolatis; pinnulis luteralibus paucis; frondulis basi ovalibus, terminalibus triangularibus, oblusiusculis, cceteris obtusissimis, dentatis, cuneatis, inlegris, rachibus hirtis, rufis, angulatis; sporolheciis continuis, latus superitus, apicen el partem nediam inferiorem pinnularum occnpantibus, interruptis, sed confluentibus; sporangiis ovatis, longè pedicellatis; aunulo 11.16 articulalo; sporis cordifornibus, lcevibus.

Habital in Jacobinâ Brasiliensium. (Blanchet.)

Filix olivacea-glaucescens; pinnis patulis; frondulis trmncatis, oblusis.

(Longueur totale des pinnules, 15 centim. Nous comptons sur ehacuae d'elles environ 20 frondules, fructifiécs dans toule leur marge supérieure el leur sommel, ainsi que dans la moitié inférieure, ce qui n'a lieu ni dans l' $A$. pulieralentum, ni dans l'A. Claussenii.)

\section{Asperum}

Frondibus pinnatis, pinnulis infimis partilis, in anbilu ovalis, slipite atro, sulcato, subtùs aspero, in parte frondosâ pilos hreves ferente; pinuis longis, curvatis, remolis; frondulis approxinatis, triangulari-cuneatis, integris; brevè petiolatis, nervillis impressis, dimidiatis, glaberrimis; terminali elongato-lineari; sporotheciis continuis, aliquandò bipartitis; indusio lato, opaco; sporangiis ovatis; annulo 16-18 articnlato; sporis salis magnis, trigonis cordiformibusque.

Habilat in Cubâ. (V. S. Herb. Mougeot.)

Fïlix rigida, plumbea, subtripinnata; e sectione synechix.

(Longueur totale, $30 \mathrm{ccntim}$ ? Les divisions primaires atteignent 12 centim.; les frondules ne dépassent guère 11 millim.)

\section{LaNiceolatur.}

Frondibus elatis, in ambitu lunceolatis, stipitibus villosis, atro-fuscis, nitentibus, letragonis, fasciculos vasorum plures lineares gerente; rhizomate contorlo, crasso, lignoso; frondulis allernis, 12 jugis, cum impari, brevè petiolatis, lanceolatis, 
acuminatis, supernè gibbosis, iufernè cuneatis, virescenti-olivaceis; sporolhecuis contimuis, margines ambas invadentibus; indusio angusto; sporangiis elliplicis, longè pedicellutis; anmulo 14 articulato; sporis atris, trigonis.

IIabitat in. Gựanâ gallicá. (Leprieur, Herb. Cl. Mougeot.)

Filix elata, robusta, ad A. fulcatun accedens; sed frondulis nou fulcatis, annulo sporangiarmu 14 et uon 18 articulato; sporolheciis continuis, etc.

(Lungueur totale, 80 centim., des frondules $7-9$ centim. sur 15 millim. de largeur. Les frondules stćriles sont un peu plus larges que les fertiles.)

\section{II. Feligivosem.}

\section{Sporolheciis intermuptis : Aвотоми..}

Frondibus in ambilu rolundatis, sub 9 jugis, stipite elongato, tetrugono, pilis fnliginosis, obsitis; rhizonate irregulari, fibroso; pinnis lanceolatis, lemuibus, rigidis, sub angulo $15^{\circ}$ metientibus, tomento-fuliginoso tectis; frondulis patulis, subdinnidiatis, acuminatis, ultimis oblusis, nuargine superiori dentatû, dentibus inarqualibus, inferiori crenali, basi truncalî; sporotheciis interruptis, parvulis, suprì dentes frondulurun sitis; sporangiis ovalis; annulo 14 articulnto; sporis trigonis.

Hubitat in Gujanâ gallicî. (Leprieur, Catal. filic. guyan., n. 256 , Herb. Mougg.)

Filix elegans, fuligineo-tomentosu, ad apicen stipitis elongatcr frondulosa; frondulis alas avium simulantibus.

Longueur tolale, 50 centim.; des pinnules, $15-17$ centim.; enrrgure, 4 centim.; largeu des frondules, 5 millim.)

\section{V'III. Gracile.}

Frondibus bipinnatis, in anbilu ovalis; pinnis curvatis, sublinearibus, frondulis numerosis, approximutis, curvatis, basi truncalis, dentatis, approximatis, 30 jugis et ultrà; lerminalibus elongatis; rachibus ferrugineis, flexibilibus, hirtis, fili emporetici crassitudine; sporolheciis $3-4$ parvulis; anmulo 14 arliculalo; sporis irregulatim lrigonis.

\section{Habilat in Brasiliâ (Claussen?).}

(Longucur totale, 35-38 centim.; la frondule terminale alteint 15 centim.; les latérales sont plus courtes. Les poils qui recourent le rachis et le stipe sont laciniés et d'un aspect curicux.)

\section{Gravde.}

Frondibus bipinnatis, in anbiut ovutis, stipitibus quallangularibus quadrisulcatisque, glabriusculis, in parte frondosâ depressis; pinnis linearibus, longissinis, angulumu $45^{\circ}$ cun rachi metientibus; frondulis $30-36$ jugis, dimidiatis, approximatis, subimbricatisque, brevè petiolatis, glabris, obtusissinis; infunis ovatis; intermediis oblongis, margine su periori curvalu, nuargine iuferiori suberecto; terminalibus angulatis; sporotheciis 18-20 parvulis, marginem superiorem occupantibus, suprì nervillas duas sedentibus; indusio binervato.

Habitat in Guyanî gallicî (Herb. Moug.). 
Filix magna; robusia, decem circiler pinnas ferentibus.

(Longuew totale, 1 mètre et plus; les pinnules latérales atteignent 32 centim.; la terminale mesure 40 centim.; l'envergure atteint 4 centim.; les frondules ont de $7-9$ millim.)

\section{Nigrescess.}

Glubunu; siccitate nigrescens; froudibus bipinnatis, pinuis basi bipartitis, linearibus, elougalis, longè decrescentibus; frondılis uumerosis, dentulis, brevibus, ovalibus, basi truncatis, nervillis scalpluratis, terminali caudata; rachibus rugosis, vix nitentibus, brevè toulentosis; sporotheciis 3-4 ad marginem superiorem, 1-2 ad apicen frondularum et uno, sed non semper, ad natginem inferiorem, onunibus semper dislinctis; indusio crasso; sporangiis parvulis, ovoideis; annulo 18-20 articulato; sporis triedricis, parvis.

Habitat in S. Domingo (Port-au-Prince, l'Épagnier).

Filix glabra, rigida. Ad A. strintun Schkuhrii accedens, sed diversunt.

(Longueur totale, 18 cenlim. Nous comptons plus de 50 paires de frondules sur les principales divisions.)

\section{TRAPEZOIDES.}

Frondibus ovatis, quodripiunatis, ramis subdichotonis; slipitibus atris, glabertimis; frondulis trapezoideis, dimidiatis, obliquis, pedicello longiusculo; superioribus flabellato-digitatis; segmentis deuticulatis; rhizonnote crusso, lignoso; sporolheciis 6 -8, contiguis; iudusio crasso, orbiculari, vix curvato; sporalgiis ovoideis; annulo 16-18 arliculato; sporis crassiusculis, trigonis.

Habitat in Vera-Cruz (Galeolli, $10^{\circ} 6317$, in S. Doulungo [ex Bory]). - A. tenerunu, Martens et Galeot., non Sw. - trapeziforme, Bory Herb.

Filix elegans, subdichotoma, glabra, dilatata. (Specimen Boryaum ex herb. nostr. glaucescens.)

(Longueur totale, 40 centim. sur 25 de largeur dans la partie frondulense. Les frondules varient entre 12-18 millim. sur 8-12 de largeur. Elle est fort distincle de l'A. tenerum, Sw.)

\section{Flagelleur.}

Frondibus piunatis, decumbentibus, radicantibus; stipitibus crassitudine fili emproretici, ebeneo rufescentibus, flexnosis; radice fibrosô; frondulis lougè pedicellatis, pedicello capillaceo; sterilibus obliquè ovoideis, ad apicen decrescentibus, margine incrquali, inciso, basi cuneato; fertilibus flabelliformibus, multicrenatis; crenis omnibus proliferis; iudusiis pellucidis, eleganter uervatis; sporangiis ovoideis, parvnlis; annulo $16-18$ articulato; sporis fusco-bruneis, trigonis.

Inbitat in Brasilia (T.S. in Herb. Mous.).

Filix tenera, glabra; stipitibus longissimis, apice tadicantibus; habitus A. Inunhuti sed ab aliis charncteribus diversa.

(Longueur totale, 36-42 centim.; celle des frondules ne dépasse pas 11 -13 millim.) 


\section{AII. Pseudo Capilles.}

Frondibus subtripinnatis; stipitibus atro-fuscis; rachibus roseis, glaberrinis; fiondulis terminalibus cuneatis, longè petiolatis, in segmentis 3-4 fissis, irregulutimn denutuis; cleutibus oblusiusculis; lateralibus obliquè cuneatis; sporotheciis incrqualibus, arcuatis, receptaculo multinervato; sporangiis ovatis; sporis crussis, fuscis, rolundis rel obscurè trigonis.

Ilabitat ad prontontorium Bonce Spei.

Adiantum Capillus-Veneris, Spreng. in Dregco, Pl. Capensium, non L.

(Dimensions de l' $/$. Capillus-Veneris; elle en diffère par la lorme des frondules et par celle des sporullièces qui sont inégaux, profondément arqquées, plus longss et conséquemment moins nonbreux. L'anneau est plus large; les spores plus gros, etc. L'A. Capillus-Veneris, var. africamum, distribué par. M. Guenzius, est en effet une forme de l'espèce européenne.)

\section{NIV. Pilosum.}

Frondibus bipinnatis, basi subtripinnatis; piunis remotis, divaricatis; frondulis longè petiolutis, ovatis; nervillis flexuosis, subtus pilosis, pilis albidulis, longiusculis mollibusque; sporolheciis approximatis, distinctis; indusiis curvatis, fuscis; sporangiis subglobosis; annulo $12-13$ articulato; sporis rotundis vix trigonis.

Hubitat in Chili (C. Gay).

A. Chilense, Hook. et Grev., tab. 173; var. 3 hirsutum, Hook., Spec. filic., p. 43, tab. $75, \mathrm{~B}$.

(Cette fougère, bien connue, et regardée comme une simple variété velue de l' $A$. Chilense, esı unc espèee bien distinete du type décrit par Kaulfuss. La forme des frondules ı'est pas la mème et leurs supports sont bien plus longs. Le véritable $\lambda$. Chilense n'a point été figuré; il est parfaitement glabre; les pinnules sont moins étalées et plus distantes; le stipe est rougeàtre et non noirâtre; l'anncau porte de 16 à 18 articulations, et les spores ont une forme trigone bien arrètée.)

IV. Radicans, pl. IXIX, fig. 2.

Frondibus bi-tripinnatis, ovatis, rachi stipitibusque glabertimis, fusco-rufis; novellis virgatis, radicantibus, Iumifusis, pinnis remotis; frondulis cunéat is, petiolatis; sporotheciis paucis, 3 -5, fusco-badiis, scepè geminatis; receptuculo latissimo, multi-nervato; sporangiis ovatis, subglobosis; annulo angusto, 18 articulato; sporis lavibus, os'atis trigonisque.

\section{Habilat in insulâ Borboniâ (Pervillié).}

Filix flexibilis, stipite flexnoso, siccitate pallidè viridis.

(Lougueur totale, 25- 28 eentim.; les prineipales divisions qui sont dressées, 6 - 7 eentiu. ; froudules fertiles, 1 eentin. de hanteur. Les frondules stériles sont plus dilatées, incisćes-lobées, inégalement dentieulées; les segments sont obtus; les sporothèees ont des indusiun épais, roussàtres, l'une largeur, relativement très-considérable.) 


\title{
XVi. Gratum.
}

Frondibus triangularibus, ramis divaricatis, flexuosis, tripinnatis, rachi et stipite tervibus, rubellis; frondulis semi-orbicularibus, cordatis, rarò subcuneiformibus, tong̨̀ petiotatis; nervillis flabellatis, sculpturatis; sporotheciis regularibus, mediocribus, hippocrepideis, in simubus affixis, pauci-nervatis; indusio crasso, albidulo, concavo; sporangiis rotundatis; annulo 18-20 articulato; sporis ovoileis trigonisque.

Habitat in Mexico, propè Nolasco (Oaxaca altit., 2000 metr. Galeotti, n. 6542 )

Filix elegans; frondulis crenatis, dilatatis.

(Longueur de l' $A$. Capillus-Veneris, L.; rameaux flexueux; frondules mesurant de $\mathbf{1 2 - 1 6}$ millim. de largeur, sur $7-9$ millim. de hanteur; les pétiolules ont de 4-5 millim. Se rapproche de l'A. affine.)

XVII. Lutescens, Moug. in litter.

Frondibus bi-subtripinnatis, ovato-lanceolatis; stipite glabro, cylindrico, flexuoso, atro, nitido, pinnis atternis, usquè ad basim frondosis, atris, capittaceis, decrescentibus, patulis; frondulis ovato-cuneatis, ad marginem dilatatis, tutescentibus, glabris; sporotheciis $5-9$, parvulis, hippocrepideis; indusio crasso, opaco; sporangïs roundis; annulo $14-15$ articulato; sporis trigonis.

Habitat in Oaxaca (Hexico [Herb. Moug.]).

Filix venusta, lutescens, erecta, rigida, glabra; A. trigono affinis.

\section{CASEBEERIA, Kaulf.}

\author{
Enum. filic., p. 216 .
}

Adianti spec., Auct. var.

SPOROTHecis marginalibus, subrotundis, ad apicem nervillarum nascentibus; tot acervos quot nervillas prabentibus, seriem linearem continuam formantibus, sed dislinctis; indusiis infrì marginalibus, suborbicularibus, regularibus, se intìs aperientibus, scariosis, pellucidis, tennibus, persistentibus; margine prolifero (receptaculo?) reflexo; sporangiis ovoideis; annulo $16-18$ articulalo; sporis trigonis, lavibus.

Froxdrus triphyllis, bipinnalis, bipinnato-radiatis; frondulis ovoideis, dimidiatis; nervillis flabellalo-furcatis, tenuissimis, apice sporangiiferis.

Filix Americana, terrestris, paruula.

Diagnosis: in Kactf., l. cit., t. 1, p. 11 (insufficiens); Hoor. et B., Gen. filic., t. Lxw, fig. A. (C. triphylla, Kacte.) 
Fucie Adian!orum; sed differt ab Adianto situ sporotheciorum, super unicam nervillım nascentium, à Pelliè longè distut, preccipuè sporolheciis subrolındis connivenlibus el indusio interrupto.

Le Casebeeria diffère de l'Adianhum par le purt et aussi par la situation des sporothèces uninervillaires ou binerrillaires, posés sur le sommet des lobes d'une frondule régulièrement lobée, fructifere dans tout son pourtour. Le réceptacle est parcouru par des nervilles proligè: es. Ce genre ne renferme qu'une espèce, il ést fondé sur l'A diantum triphyllum de Swartz, charmante fouggère, dont le port tout spécial indique à la première vue un type gẻnérique.

SPECIES.

Cienus monotypun; vide diagnosim generis.

\section{ら̀. OCHROPTERIS, J. Sm.}

In Hook. Journ. bot., IV, p. 158.

Adianti spec., Sw. et Auct. - Cheilanthis spec., Bony, P'Rlst. - Cusebeeria', spec. Al. Braun, Herb.

Sporotuecus marginalibus, transversè oblongis, ad apices v'enularum nascentibas ; indusio scarioso, albido, crasso, suborbiculato, margine integro; sporangiis pancis, amplis; annulo lato, 20 el ulirì articulos ferente; sporangriastris: piliformibus, longis, arliculalis, in tomento denso coalitis; sporis maguis. trigonis.

Frovibes deltoideis, decompositis, glaberrimis, stramincis; nervillis pinnatis, furcotis, $2-4$ convergentibus.

Filices insularum Africa australis; magne, rigidle, terrestres.

Diagnosis; Ноок. et B., Gen., t. cv1, B. (O. pallens, J. Sir., I. cil.)

Icon. nostr. xxix, fig. 3 -5 (O. anguslu, J. Sm.; angusla, F.; peltigera, F. [fragmentu*]).

Differt a Cheilanthe et Adianto habiu generali, naturâ indusiorum el convergentia nervillarum ad apicem laminarum.

Genre de fougères portant des divisions nombreuses, cunéiformes, absolument glabres, à stipes roides, lisses; sporothèces occupant le sommet des lobes; indusium concase, épais, presque liénisphérique, un peu dilaté au sommet, strié. Les nervilles atteignent la marge qu'elles épaississent; la plante desséchée a une couleur jaune-paille très-remarquable, qui a valu au type le nom spécifique de pallens.

ENUMERATIO SPECIERUII.

Pallens, J. Sm. (F.*. Ilook. el B.*, Pluk.* [fragm.* $])$ - angusta, F.* peltigern, F.* $^{*}$ 


\section{SPECIES NONDUM DESCRIPTE.}

\section{Angusta, pl. XXIX, fig. 3.}

Frondibus decompositis, glaberrimis; pinnis tripinnatis, subtriangularibus; pinnulis lanceolatis, longè acuminatis, usque ad apiceın fertilibus; segnentis ovoideis, angustis, rigidis, in petiolum desinentibus; sporotheciis geminis, incequalibus, superiori extentiori, laciniis superioribus sterilibus; indusio membranaceo, integro; sporangïs amplis, ovoideis, subprriformibus; annulo lato, 18-19 articulato, profundè crenato; sporis magnis, trigonis lavibusque; pilis internis raris.

Habitat in insula Mauritii (V. S. in Herb. cl. Mougeotiano ex Grevilleo).

Filix dissecta, segmentis angustis, remotis, apicibus attenuatis; sporotheciis phoroloborum et onychiorum.

(Longueur des pinnules primaires, 30 centim. sur 22 centim. d'envergure; longueur des divisions secondaires, à la base des pinnules, 20 centim.; les pinnules ont de $3-5$ centim. de longueur: les segments sont oroïdes, pédicellés; ils tendent à devenir pinnatifides à la base.)

II. Peltigera, pl. XXIX, fig. 4.

Frondibus quadripinnatis, lucidis, helveolis, flexuosis, in ambitu ovoideis; pinnis et pinnulis remotis, attenuatis; segmentis ovoideis, incisis; incisuris monocarpicis; sporotheciis solituriis, ovoideis; indusio lato, regulari, unguiculiforni, convexo fuscoque; sporangiis ovoideis, nuagnis; annulo lato, 16.18 articulato; sporis crassis, trigonis, fuscis; pilis internis nultis, intestiniformibus, flexuosis, lutescentibus.

Habitat in insulâ Borbonin.

Filix elata, expansa, partitionibus virgatis, longè attenıatis; sporotheciis regularibus, unguiculiformibus.

(Longueur totale, 1 mètre sur 30-35 de développement; toutes ses partics sont flexibles; les deruicrs segments ont la forme oroüde et sont crénelés. Dans l'espèce-type $(O$. pallens $)$ l'indusium est épais, crustacé, ct les sporothèces inégaux sont difformes. Toute la plante est en outrc plus ferme et à divisions plus élargies.)

Les trois espèces peurent se différencier comme il suit : 1. Pallens, J. Sm. : Frondes raides: derniers segments ovales, cunéiformes; sporothèces ptéridiformes, inégaux, geminés; marge légèrement inclinée en dedans; spores assez gros, lisses, noirs ct opaques; poils internes rares. 2. ${ }^{\circ}$ Peltigera : Frondes flexibles, allongées; segments pinnatifides, crénelés; chaque petite découpure porte uı seul sporothc̀ce scmi-orbiculaire, unguiforme, régulier, à marge non inclinéc cn dedans; spores lisses, gros, obtusement trigones; poils interues abondants. $30^{\circ}$ Angusta: Frondes raides, à découpures élroites, ovales, lancéolécs, écartécs; sporothèces geminés, conrrant presque tout le segment fructifère, de manière ì les faire ressembler aux sporothèces des phorolubus ct des onychium; spores gros, incolores. 


\section{* Nervillis conniventibus.}

\section{*** Nervillis anastomosantibus.}

\section{HEWARDIA, J. Sm.}

In Hook. Journ., III, 432, t. XVI et XVII.

Adicinti spec., Aucr.

SPоRотпеси continuis, aut rarius interruptis, marginalibus; indusio terui, intù. dehiscenle; sporangiis ovalis, nervillaribus; annulo $16-24$ articulato, pedicello lalo; sporis ovoideis trigonisque.

Froxdues pinnatis, slipitibus fusco-badiis, fragilibus; pinnis ovalis, basi saepè bipinnatis, dentatis, obliquis; nervillis reliculatis, areolis elongatis, ultimus cum margine incrassato sejunctis.

Diagnosis, Hoor. et B., t. Lxxix. (H. adiantoides, J. S.м.)

Filices erectce, terrestres, Brasiliuna aut Guyunenses.

Facie adiantorum pinnatorum, indusio sinili, sed nervillis anastomosatis.

Ce genre ne diffère des adiantum que par une nervation réticulèe. L'H. serrata rappelle surtout les Adiantum fovearum, crenatum, Jacobina el telraphyllum: mais les sporothèces sont continus, et cette particularité rapproche sous ce rapport l'Hewardia des adiantum de la division synechia.

Les Hewardia Leprieurei, Hook., et serrala, F., ont une nervation toute pareille; dans la première espèce les sporothèces sont interrompus. L'H. adiantoides, J. Sm., rappelle par sa nervation les genres Hymenodium et Nevrocallis, du groupe des acrostichées.

\section{ENUMERATIO SPECIERUM.}

H. serrata, F. - adiantoides, J. Sm.* (Hook.*, Ilook. et Baner, fragmenta*; Adiantum, Kze.*) - Leprieurei (Adiantum, Hook.*) - Wilsoni (Adiantum, Hook.*) - dolosa (Adiantum, Hook.*, fragm.*).

\section{SPECIES NONDUM DESCRIPTA}

SERRATA.

Frondibus lanceolatis, elongatis, glaberrimis, in ambitu lanceolatis; stipitibus ebeneis, lucidis, quadrangularibus, villosis, in parte foliffera rufo-hirtis; pinnulis 9 jugis cum impari, alternis, brevissimè petiolatis, lanceolatis; nervillis in areolis angustis coalitis; sterilibus incequalè serratis, obtusiusculis, basi supernè gibbosá, infernè cuneiformi; terminali longiori, supè triangulari; fertilibus integris, angustioribus, munifestè acutiusculis; sporotlıciis continuis, aut rarò interruptis, sed semper uni- 
versulibus; sporangiis pyriformibus, parvulis; sporis ounideis, parvulis, nigrescentibus.

Adiantum obliquun, Schlecht., in schedul. (Hert. nostr.) Habitat in Bahiâ Brasiliensium. (Luschnath, Pl. Brasil., n. ${ }^{\circ}$ 27.)

Longueur totale, 90 eentim. et au de!à; les pinnules stériles, 7 centim., sur $12-15$ millim. de largeur; ies fertiles sont plus étroiles.)

\section{Considérations générales sur le groupe des Adiantées.}

Le groupe des adiantées est fort naturel; les genres qui le composent, marchent parallèlement avec les lindsayées : Adiantum •et Lindsaya, Hevardia et Synai)hlebium, etc.; cependant ces rapports n'empêchent pas que pour un œil exercé chacun de ces deux groupes nail une physiononie propre. Le mode de déliscence des sporothèces établit une séparation facile à constater. Le réceptacle est charnu; les nervillés qui le parcotrent, et sur lesquelles s'attachent les sporanges, proviennent des frondules, et souvent elles se bifurquent au point même de leur flexion. Les adiantées sont toutes herbacées, parfois d'une délicatesse extrême, translucides, et ayant pour support des stipes noir d’ébène, luisants el capillaires, dernière circonstance qui leur a valu le non franģais sons lequel on les désigne. Parmi les nombreuses espèces du genre Adianlum, il en est quelques-unes qui perdent très-facilement leur's frondules, laissant le rachis nu. En examinant attentivement ces espèces, on reconnaît que ces frondules ont un pétiole articulé avec la lame. Ce pétiole qui est très-noir, change brusquentent de couleur au point oì naît cette articulation. Nous avons constaté ce caractère sur les $A$. patens, Willd.; rhizophorum, Willd.; assimile, R. Br.; trapezoides, F., et deltoidemu, Sw.; il peut servir à la détermination de quelques espèces difficiles.

Quelques anciennes espèces d'adiantum ont un indusium attachè a une seule nerville, qui sert tout à la fois de point d'attache à cette membrane protectrice et de réceptacle aus sporanges. Nous les arons distraites de ce groupe pour leur donner une place dans les cheilanthées. Les adiantées à sporothèces continus qui sont très-peu nombreux, se rapprochent des ptéridéts; mais seulentent, par ce caractère, le port étant absolument di!férent.

Ces plantes vivent sous les tropiques et sous l'équateur'; l'Europe et le bassin méditerranéen n'en possèdent qu'une seule espèce qui, du reste, est cosmopolite, l'A. Capillus-Veneris. Il faut aller ensuite jusqu'aux iles du Cap-Vert pour trouver un second capillaire, l'A. reniforme. L'Amèrique septentrionale n'en a que deux espèces, celle d'Europe et l'A. pedatum, qui lui est particulière. Ces fougères abondent dans l'Amérique méridionale et dans les îles de la mer du Sud. On les trouve sur la terre et sur les troncs d'arbres, toujours dressées et vivant in touffes: 
II. Receptaculum nervillare, rarò nullum, indusium continuum membranaceum, pellucidum, planum : PTERIDEA.

Filices amplæ, divisæ, pinnatisectæ, erectæ, sæpissimè glabrex, cosmopolitanæ.

\section{f. 1. Sporothecia marginem tolam ambientia.}

- Yervillis liberis.

52. PTERIS, L., emend. (1737.)

Hort. Cliffortian., p. $47^{5}$.

Lonchilidis spec., Acct. - Allosori spec., PresL el alct. var.

Sporotuecus linearibus, conlinuis, marginalibus; indusiu margini frondis adnalo, ab ipso dislinclo, nembranaceo, scarioso, inlegrè dehiscenle; sporangiis osulibus, ad receplaculum lineare, conlinum, cum indusio affixis, sive ad axillam indusii nascenlibus; annulo lalo, 16-20 arliculalo; sporis brevibus. woideis Irigonisque, rarò renifarmibus; sporangoiastris in plurimis speciebus: piliformibus, strmolulalis, succinco colore.

Froxdats monolaticis, pimnalis, 1, 2, 3 pinnaio-pinnalifidis; frondibus sen sermenlis frondium ferlilibus, non rarì anguslioribus; nervillis pinnalo-furcalis, margonem allingenlibus, aliquandò coloralis: nervillis frondium ferlilium cum, receplaculo coalilis.

Fïlices variè partito-pinnate, herbacer, magnat, terrestres, rupicole, cosmopolitana.

Diagnosis, Ноок. et B., Gen. fil., 1. เxir, A. (P. nemoralis, Wıl...)

Tab. nost., XI, A. - Fïg. 1, 2, Pteris Cretica, L. - Fig. 3, P. aquilina, L. (sect. stipitis). - Fig. 4, P. setrulutu, L. (id.), F. - Fig. 5, Pteris longifolin, L., Lk. (in P. chrysocarpâ, Hook. et Grev., sectio stipitis similis est).

Genus Pteris vix differt à genere Haplopteride Preslii; in suis speciebus palmutopedatis, cun Pellæà congruit. Plerilles suâ fronde pinnatî affines sum Schizolomati, tanen fere ounnes aspectum proptiuun habent; in P. aquilinâ scepè nervilla' areolan ad basiun efformunt, ounninò ut apud Campterias. In Casebecrià sporothecin globosı, approximata sumı el indısium partitum; in Pellæâ sporothecia linearia continua sunt et sporangia nervillaria; in Pteride sporothecia continua et sporangin receptacularia.

Des sporothèces linéaires, très-étroits, exactement marginaux, recouverts d'un inclusium membraneux, mince et pellucide, se soulevant tout d'une pièce dans 
l'àge adulte, et de dedans en dehors, caractérisent ce genre, type du groupe. Les sporanges naissent à l'aisselle de cet indusium et s'attachent sur un bourrelet linéaire, sorte d'épaississement de la lame au point même où nait l'indusium; c'est un véritable réceptacle, et il est bien rare qu'il inanque. Les sporanges ont un large anneau, portant de 16 à 28 articulations, à spores presque universellement trigones. Ce sont des plantes cosmopolites, grandes, amples et vigoureuses, souvent traçantes, herbacées, tendant à se diviser, mais conservant la forme linéaire dans leurs segments ou frondules. Il n'en est point qui soient entièrement pinnatifides, mais presque toutes ont l'extrémité de leurs pinnules ainsi disposées. Les frondes semblent établies sur deux types, sur le Pleris Crelica, L., et sur le Plerís aquilina. Lorsque les frondules sont très-étroites, l'indusium peut atteindre le mésonèvre. Plusieurs auteurs ont ru dans cette circonstance un caractère générique, et le genre Allosurus a été créé. Les passages qui lient les espèces à segments étroits à celles qui en ont de plus larges, et qui portent des indusium distants du mésonère, sont nombreux, mais le facies reste absolument le mème.

Le genı Pleris a un port qui le fait reconnaitre facilement à la prenière vue. Il differe par la nervation des genres formés à ses dépens, mais ayant des nervilles anastomosées. Il est analogique avec les genres Lilobrochia et $A$ inphiblestra, dont il est séparé par la nervation, et du genre Pellaca, dont il diffère par des sporanges non attachées sur les nervilles; le facies n'est pas non plus identique.

Les faisceaux vasculaires qui parcourent le stipe, sont en grand nombre et se groupent avec symétrie pour constituer des figures singulières. On a cru, par exemple, reconnaitre la grossière inage des armes d'Autriche dans la coupe oblique d'un Pleris qualifié d'aquilinaire, à cause de cette particularité.

\section{ENUMERATIO SPECIERUM.}

I. Eupteris.

A. Frondibus pinnatis, frondulis linearibus longis.

Longifolia, L. (vittata, Schkh.*; Filix latifolia, Plum.*) - costata, Bory - stipularis, L. (Plum.*, Peliv.*) - cqualis, Pres!. - opaca, J. Sm. (Cuming, Plilipp., n. ${ }^{\circ} 342$ ) - Bahamensis (P. diversifolia, Agardh, var. $\beta$ ) - stenophylla, H. et Grer.* - aspera, F. - pellucida, Presl (Cuning, Philipp., n.0 85) - taniosa, J. Sm. (Cuming, n. ${ }^{\circ}$ 283, Fil. Philipp.)

\section{B. Frondibus basi bifinnatis.}

Cretica, L. (Tournef.*, Schkh.*) - serraria, Sw. (Cretica, L. , var. Capensis, Agardh) - prionitis, F. (Cuming, Philipp., n.०46; Pt. crenata, J. Sm. non Sw.) - heteromorpha, F. (Cuming, Malacc., n. 409; Pt. propinqua, J. Sm. non Agardh) - umbrosa, R. B. (Sieber, n." 128, Nov. Holl.) - serrulata, Willd. (Schkh.*, Pluk.*) - propinqua, Agardh non J. Sm. - ? Sloani, Radd.* - melanocaulon, F. (Cuming, Filic. Philipp.) - heterophylla, L. (Sloan.*, Plum.*) - crenata, Sw. (Burm.*, Hontl.*)

\section{Frondibus basi pinnatifida.}

Semipinnata, L. (Osbeck*; fiabellata, Schkh.*; alata, Lmrk.*, Hoult.*) 
D. Frondibus bipinnatis.

Distans, J. Sm. (Cuming, Malacca, n. $\circ^{\circ} 10$ ) - irregularis, Kaulf. (alata, Gaud.*)

E. Frondibus bipinnatis, basi divisis.

Yemoralis, Willd. - biaurila, L. (Plum.*, Ilook. cl Baner*) - pungens, Willd. (Plum.*, Petir.*) - asperula, J. Sun. (Malacc., Cuming, n. ${ }^{\circ} 413$ ) — I'resliana, Agardlı (Cuming, Philipp., n. ${ }^{\circ} 69$ ) - spinescens, Presl (Cuming, Philipp., n. 79 - scabra, Bory. - paleacea, Roxb. (Cuming, Fil. S. Jelen., n. $0^{\circ 24)}$ - defiexa, Lmrk. - fabellata, Tlumb. - Adscensionis, Forst. (Schkh.*) -

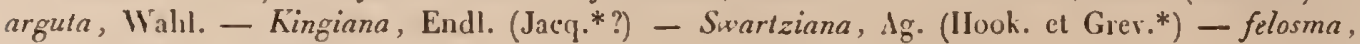
J. Sm. (Plumieri, Hort.)

F. Frondibus bipinnatis, basi tri- quadripinnatis.

Pellucens, Ag. (Cuming, Philipp., n. ${ }^{\circ}$ ) - trenula, R. Br. - nutilata, L. (Plum.*, Peliv.*)

G. Frondibus tripinnatis.

Helerophylla, L. (Plum.*, Petir.*, Sloan.*) - gracilis, I.

II. AQuLix.e.

Aquilina, L. (Jacq.*, Sclıkh.*, Bolt.*, elc.) - caudata, L. (Plum.*, Sloan.*, Jacq.*j - lanuginosa, Bory (Schlecht.*) et var. 3 Capensis, Ag. - villosa, F. (Cuming, Philipp., $11 .{ }^{\circ} 353$ et 408 partim) - arachnoidea, Kllss. - esculenta, Forst. (Schklı.*, Labill.*) - crosus, Bory. - intramarginalis, Kilss. (Kze.*)

\section{Loschitidicy.}

Laciniata, Willd. - flaccida, F. (Lonchitis, Bory, Herb.)

\section{SPECIES NONDUII DESCRIPTE.}

I. ASPERA.

Frondibus ovalibus, lnnceolatis, multifrondulatis; slipite spinescenti, squamoso, fulvo, canaliculato; frondulis angustis, sessilibus, auricnlatis, ad basim oppositis, superni allernis; marginibus convolutis, glabris, linearibus, longissimè acruninatis; mesonevro robuslo; sporotheciis conlimuis; indusio angusto, scepè eleganter crenulato; receptaculo tenui, lineari; sporangïs ovoideis; annulo 18 articulato : sporis trigonis, nigrescentibus.

Habilat in insulâ Borbonin (de Montbrison).

Filix elatn, flexibilis; pinnulis 40 jugis.

(Longueur totale, 75-80 centim. Les pinnules centrales ont environ 10-12 centim. de long sur 4 millim. de large; les cutrc-nœuds laissent cutre eux un intervallc de $9-12$ millim.)

\section{- II. Prionitis.}

Frondibus pinnalis, basi inaqualè bipartitis, aliquoties pinnatifidis; rachi pollido, strinto, glabro; frondulis brevè petiolatis, obınsinsculis, basi rolındatis, integris; slerilibus lanceoloto-linearibus, acuminatis, supernè serratis, dentibus incrqualibus, inferni: crenotis, basi integris; nervillis bifurcatis, tenuibus, marginem non attingentibns; fertilibus linearibus, versis apicem sterilem crenatis; rhizomale crasso, vix crassitudine. pennce anserince; sporolheciis angustis; indusio tenui, membranaceo; sporangiis 
ovatis; annulo 20 articulato; sporis crassis, trigonis; sporangiastris intestiniformibus (sporangiis ad pedicellum reductis), torulosis, contortis albidulisque.

Habitat in insulis Plilippinis (Cuming, $\mathrm{n} .^{\circ} 46$ ).

Filix facie Pteridis Cretica, glaberrima, tenera, pellucida.

Pteris crenata, J. Sm. in Enumer. filicum Cumingii non Sw.

(Longueur totale, 30 centim. jusqu’à la base de la pinnule terminale; frondules stériles, 15-18 centim.; 15-16 millim. de largeur; les stériles n’ont que le tiers de cette largeur, mais elles sont un peu plus longues. Une fronde de notre spécimen, non encore développée, promet d'être plus grande; le stipe seul s'élève à 36 centim.)

\section{HeTERonorpha.}

Frondibus pinnatis, basi bipinnatis, glabris; stipile helveolo, rufescente, infernè squumoso; frondulis suboppositis, jugis remotis, terminali longissimâ, marginibus siccitate undulatis, incequaliter crenulatis, sessilibus, basi inferiori latere decurrente; nervillis marginem atlingentibus, mesonevro valido; fertilibus el sterilibus conformibus, linearibus, obtusiusculis, mucrone acnto, tenui terminatis; sporotheciis angustis; sporangiis ovoideis; annulo 20 articulato; sporis crassis, atris.

Habitat in Malacca (Cuming,.$^{\circ}$ 409).

Filix facie $P$. crenatce, sed diversissima; frondulis superioribus simplicibus, ad dispositionem pinnatifidam tendentibus; inferioribus omninò pinnatifidis.

P. heteroclita, Bory, voy. Belang., p. 41 ? P. propinqua, J. Sm. non J. Agardh.

(Longueur, 30 centim. Les frondules terminales sont très-longues; l'une d'elles mesure 24 centim.; les latérales atteignent environ moitié de cette dimension; largeur, 8-11 centim. Les paires de pinnules sont iucomplétement opposées, sessiles, et mème décurrentes. Les frondules tendent à l'irrégularité; il en est d'entières, d'autres sont à demi-pinnatifides, d'autres pinnatifides . quelquesunes enfin produisent un, deux, ou plusieurs segments, plus ou moins allongés sur divers points de leur surface. Ces dispositions donnent à la plante un aspect irrégulier, très-remarquable. Elle est très-différente du $P$. propinqua d'Agardh, fils.)

\section{Melanocaulon.}

Frondibus ovoideis, ad basim bi-trifidis, apice pinnato; stipite capilliformi, nigro, lavvi, lucido, fragili; mesonevro aterrino; frondulis petiolatis, longissinè arcuatis, linearibus, in parte sterili crenulatis, acumine longissimo, lamina supernè sterili; indusio lato; receptaculo lineari; sporangiis ovoideis; annulo lato, 18-20 articulato; sporis trigonis, lavibuls, pellucidis.

Habitat in insulis Philippinis (Cuming).

Filix delicatula, herbacea; rhizomate erecto, parvilo.

(Longueur totale, 25 à 30 centim. Les plus grandes frondules peuvent dépasser 24 centim. de longueur; elles ont 4 millim. de largeur.)

Le stipe dressé est presque capillaire. Quclques étiquettes de M. Cuming portent par erreur : tree fern (fougère en arbre); elle est positivement herbacée. 


\section{Grachlis.}

Frondibus golubris, tripinuatis, Iriungularibus, elongatis; stipitibus longissinis, flexibilibus, helveolis, caualicnlalis; segmentis brevibus, basi contraclis, dentibus angulatis, longissimè setaceis; sporolheciis in medio marginis lanuinarum silis; indusio auguslo, vix distiucto; receptaculo uullo; sporangïs ovoideis; annulo 18-20 articuluto; sporis minutis, trigonis brevibusqne.

IInbitat in Brasilia (Claussen).

Filix elata, glabra; stipile basi rubescente, Lit obrochine leptophy'ller affinis; nervillis verò liberis, froude magis dissechi, segmentis augustioribus; dentibus upice selıceis.

(Longueur tolale, 45 a 50 eculim. Le slipe est à la fronde :: 1 : 5. Les principales division unt environ 9 ecntim.; les segments alteignent ì peine 15 millim. de large; le segment terminal, très-long, est fortement denté.)

\section{VilLLOSA.}

Frondibus tri-quadri-alatis, anuplis, pilis cinereis, intestiuiformibns, atticulatis, abunulè vestilis; slipile fasciculos vasorum nullos ferente; pinuulis piunulifuliis, acuminatis; segruentis ovoideis, oblısis, sıpè ad busin subpiunatifulis; sporotheciis apicenu nou allingentibus; indnsio angustissino; sporangiis rolmudis; annmlo 14 arliculuto; sporis parvulis, nigrescentibus, rolundis subtrigonisque.

Habilat in insulis Plilippinis (Cuming, $\mathrm{n}^{\circ} 353$ et 408 ).

Filix rigida, ciueren, villosa.

(Longueur des pinnules, 45 centim. environ. Les pinnelles, assez rapprochées, mesurent environ 8 centim.; les derniers segments ne dépassent guère 1 cent.)

Celle plante a étć déterminée par. II. Smith sous le nom de P. lanuginosa, Bory; mais elle cu diffère essenticllement par le port, par la nature des poils el par la forme des segunents.

\section{PELLEA, Link. (1841.)}

$$
\text { Spec. filic., p. } 59
$$

Doryopleridis spec., Kьotzcu, in Linn., xx, p. 342. - Pteridis spec., L., Schк., Cavax., Sw., etc. - Allosori spec., Presu, Tentam. - Platyloma, J. Ss., in Journ. bot., Ноок., Iv, p. 160.

Sронотнесиs linearibus, conlinuis, ferè laminas aubienlibus, ad apicem nervillarum extensis confluentibusque; indusio spurio, tenui, pellucido, continuo, subcrispalo, marginibus frondium scaviosis formalo, aliquando vix perspicuo: sporangïs oroideis, nervillaribus; annulo 14-20-arliculato; sporis crassis, globulosis, scepè luberculosis; sporangriaslris nullis. 
Frondibus 1-2-3 pinnalis, pedatis palmalisve, glabris, ferè semper glaucescenlibus; pinnis abbrevialis, elongatis, triangularibus, oblusis; nervillis flabellalis; stipilibus fusco-badiis, nigrescenlibus, lucidis.

Filices erectce, terrestres, arboricolce, tropicales; fucie et aspectu propriis; ad Nevrogrammata et Pterides tendentes, sed indusio spurio et sporangiis nervillaribus differentes. In Casebeeria indusia rotunda et serialia sunt.

Diagnosis, Ноок. et B., Gen. filic., t. cxv, A. (Platyloma Brownii, J. S..)

Pellaca à Pteride differt sporotheciis nervillaribus et absentia receptaculi peculiaris. Evolutio est contemporanea in sporangiis et in indusiis. Margo laminarum extensione suct indusium efformat.

Les pellcea ont les sporothèces des pteris, mais les sporanges sont nervillaires. Les frondes ne sont ni aussi amples ni aussi divisées que celles des pleris. Elles affectent quelquefois la forme pédiaire. Il en est de grimpantes avec des frondules cordiformes. On les reconnaît à la première vue à l'épaisseur des lames, souvent opaques et à la couleur verte olivâtre qu'elles prennent en se desséchant. Les stipes et les nervures principales ont cette consistance crustacée fragile et cette couleur noire luisante, si renarquable dans les adianlım. Elles ne produisent que bien rarement des écailles frondulaires, et leurs dernières divisions tendent à la forme linéaire ou se terminent en pointe; la dessiccation ne les crispe jamais. Les spores sont plus souvent ovoïdes que trigones.

Le genre Pelloca se lie aux cheilanthes à frondes glabres; mais il s'en éloigne par le port et par un indusium continu; les espèces pédiaires et palmées marchent parallèlenıent avec les doryopleris palmés et pédiaires. Ces plantes sont tropicales et d'une culture facile. Les espèces peuvent être groupées d'après leurs facies.

\section{ENUMERATIO SPECIERUII.}

1. Frondes flexuosa, sarmentosce.

Flexuosa, L. (Allosurus, KIfss.*, Kze.*)

2. Frondes erectee, frondulae cordiformes seu ovatoe.

Sagittata, Link. (Allosurus, Piesl, Kze.*) - calomelanos, Link. (Pteris, Schlecht.*) - andromedafolin (Allosurus, Kze.*) - pulchella (Allosurus, Mart. et Gal.*) - Chilensis (Lindsa $a$, Desv., testè Remy, Fl. Chil. ined.) - macrophylla (Illosurus, Kze.).

3. Frondulie hastatc.

Ilastata (Allosurus, Piesl) - spiculata (Pteris, Schkl.*) - contricta (Cheilanthes, Kze.) auriculata, Link. (Cheilanthes, Sw.; Pteris, Hook. et Grev.*)

4. Frondula lanceolate vel ocalce.

Falcata (Pteris, R. Br.) - cordata (Pteris, Sicb., Fl. mixt., 11.0269 [cap.]).

5. Frondulo lineares seu sublineares.

Ternifolin (1'teris, Calvan., Hook. et Grev.*) - atropurpurea, Lmrk. (Pteris, Scliklı.*) 
6. Frondes pedata.

Pedata (Casebeeria, J. Sin.; Cuming, Philipp., 11. 260; non Pteris pedata, L.) - palmescens, l. (Cuming, Prilipp.) - Prabica (Cheilanthes Arabica, Kze., Sehimper, Pl. Abyss., n.॰ 1431) - geraniifoliz (Pteris jedata, Kze. non Auct.; Pteris, Radd.*).

\section{CORD.ITA.}

\section{SPECIES NONDUM DESCRIPTA.}

Frondibus pimatis, rachi rufo-villoso; stipite glabro, adiantino, tavi, nilente, flexuoso; froudulis discoloribus, bi-jugis, suped fulvo-roseis, sublis fuscis, oppositis, brevi stipitalis, ovoideis, acuminatis, basi cordatis; teruinali latiuscula, longiùs stipitatri. Hubilat promontocium Bona Spei.

Ptevis coctulu Sieb. fl. mixta, n. ${ }^{\circ}$ 269, non Auctor.

(Longueur, :0 centiu.; frondules, 45 millim., 2 centim. de largeur.)

Nous décrivons cette plante, qui est incomplète, pour appeler sur elle l'attention des botanistes: elle se rapproche du $P$. falcata.

\section{丂4. PHOROLOBUS, Desv.}

C'yplogramma, R. Br. - Ptecidis spec., L. - Allosuci spec., Prest.

Sporothecus limearibus, nervillaribus, siliquiformibus, continuis, tola segmenta occupautibus; margine altenuato, ferè convoluto, indusii locum tenente, nervillis temuibus peragrati; sporangiis nervillaribus; annulo lato, 20-24 articulato; sporis ovoideis.

Froxdвеs slerilibus, multifudis, segmentis dilatatis seu dentatis; fertilibus angruslioribus, linearibus, integris; nervillis pinnatis, paucis.

Filices herbacece, tenecre, terrestces, fucie peculiuci, Europcre aut Chimenses; sporotheciis Allosuros referentibus, sed frondibus dissimilaribus; a Struthiopteride differt presentic indusii nervati.

Diagnosis, Hook. et B., Gen. filic., t. crv, B. (Sub Cryptogrammâ.)

Icon. nostr., VII, D. (Phocolobus crispus, Desv.)

La différence qui sépare le genre Phorolobus de l'Onychium est tirée des sporothèces. Dans le Phorolobus, lindusium provient de la marge, ainsi que le temoignent les nervures qui le parcourent, comme dans les adiantum. Les frondes sont dissimiliaires et non rachiformes. Le port est aussi bien différent. Nous ne trouvons aucun rapport entre ce gente et l'Allosurus que nous n'avons pu conserver. 
Les phorolobus sont des plantes délicates, très-divisées; les frondes stériles, à lobes dilatés se montrent très-diffẻrentes des fertiles, étroites et rachiformes. On les trouve en Europe et dans l'Amérique septentrionale.

\section{ENUMERATIO SPECIERUM.}

Crispus, Desv. (Osmunda, L.*, Bolt.*, Moriss.*) - acrostichoides (Cryptogramma, Hook. et Gr.*)

-- Brunoniana (Cryptogramma, Wallich., Hook. et Grev.*).

\section{$\dagger$ Frondibus decompositis.}

\section{ONYCHIUM, Kaulf.}

Enum. filic., p. 144 .

Allosuri spec., Prest, Tent. pterid., p. 152, et Auct. Plurim.

Cheilanthis spec., Waluch. - Leptostegice spec., Dow. - Pteridis et Lomarice spec.,

Auct. var.

SPOROTHEcus linearibus vel oblongo-linearibus, apicem dilatatam el elongatam segmentorun frondis occupantibus; indusiis linearibus, incequalibus, membranaceis, marginalibus vel submarginalibus, oppositis aut conniventibus, pinnulam integrètransmutatam tegentibus; sporangiis subrolundis, ad axillas indusiorum nascentibus; annulo 18-20 articulato; sporis trigonis, magnis.

Frondibs monotaxicis, decompositis, segmentis sterilibus linearibus; stipitibus locibus, fuscis, fasciculos vasorim unum aut duosferentibus; fertilibus dilatatis, glaberrimis, subrachiformibus; terminali proliferâ, sapè longissimâ.

Filices erecter, graciles, Indice, Abyssinicre et Capenses.

Diagnosis, Ноок. et B., Gen. filic., t. xı. (O. lucidunn.)

Diagnosis nostra, tab.VII, C; fig. 1, O. auratum, KLess., et fig. 2, O. Caperise, KLFss.

Onychium Acropteridi proximum est, sed ejus frondes non rachifornes et sporangia ad venulas pinnatas nascentia sunt.

Les frondes à segments étroits et linéaires sont presque rachiformes; tous peuvent être fructifères. Ces fougères, plusieurs fois pinnées, à stipes lisses, glabres et déliés, à fructification portée sur d'étroites pinnules, ne rappellent guère les plantes du groupe auquel nous les rattachons. Cependant elles ne sont pas sans analogie avec les acropteris, quoique multifides. La structure des sporothèces ne 
diffère pas. Les indusiums, continus, exactement marginaux, s'étendent jusqu'i la nervure médiane et sont inéquilatẻraux à la base. Les pinnules ne montrent qu'une seule nervure dans les $O$. auratum, tenuilorum et Japonicum; elles sont pinnées dans l'O. Capense; à la maturité des sporanges on croirait, en voyant les sporothèces de cette fougère, avoir sous les yeux un Lomaria de proportions naines fructifié.

Il existe quelques rapports entre ce genre et le Phorolobus; mais ici les sporanges naissent à l'aisselle de l'indusium qui tient lieu de réceptacle, tandis qu'elles sont nervillaires dans le Phorolobus.

\section{ENUMERATIO SPECIERUM.}

Lucidum, Hook.* - Carense, Klfss.* - Japonicum, Kze. - auralum, Klfss. (Pleris chrysosperma, Ilook.*) - carcifolium (Lomaria? Wallich.) - melanolepis, Kze.* (Allosurus cuspidatus, Hochst., Jaubert et Spaclı*) - Chorophyllum (Allosurus, Mart. et Gal.*) - Chinense (Gaud.) -? robustum (Allosurus, Kzc.*).

\section{CARVIFOLICM.}

\section{SPECIFS NONDUM DESCRIPTA.}

Frondibus decompositis, multifidis, glabris, ultimis segmentis linearibus, scepè incequuliter bifidis; stipile lievi, lucido, fuscescente, fasciculum v'usorum hippocrepidem unicum ferente; frondulis fertilibus, linearibus, integerrinis, lutescentibus, terminali longiori; tunc sejunctis, tunc cun ramis sterilibus confusis; sporangïs ellipticis, magnis, opacis; annulo lato, adhcrente, non crenato, 18.20 articulato; sporis magnis, nigris, obtusè trigonis.

Habitat in "̈nsulis Philippinis. (Cuming, n. ${ }^{\circ}$ 32.)

L. carvifolia, Wall.?

Filix ramosa, decomposita, 5-6 pinnata, subtriangulata; segmentis linearibus.

(Longueur, 50 cent.; les rameaux principaux ont plus de 36 centim. d'envergure; le stipe est lisse, de la grosseur d'une plume de pigeon; les divisions du rachis sont presque filiformes.) 


\section{*** Yervillis anastomosatis.}

\section{$\dagger$ Areolis exappendiculatis.}

A. Frondibus simplicibus aut palmatis.

\section{DORYOPTERIS, J. Sm.}

In Hook. Journ. bot., t. IV., p. 162.

Dory.opleridis spec., Kцотz., Liv., xx, p. 342 , Eudoryopleris.

Pteridis spec., L., Radd. - Litobrochice spec., Presl.

SPorothecis, sporangiis et indusiis pteridum; sporis rotundis.

Frondibes palmatis, pedatis, sagittatis, coriaceis, subopacis; nervillis pedatis, mesonevro et nervillis ebeneo colore, lucentibus; areolis uniformibus, obliquè elongatis; stipitibus longis, cortice aterrimo, crustaceo vestitis, ut in adiantis.

Filices erectce, Americance, vel Borbonicce aut Indica.

Diagnosis, Ноок. et B., Gen. filic., t. Lxv, B, p. 1 (fragmentum frondis). - D. huslata, J. Sr. (Pleris, Radd.)

Genus facie Pellæarum, sed nervillis anastomosatis et nervatione pedata frondium ab iis facilè dignoscilur.

Les doryopteris sont des pellca à nervilles anastomosées. Les frondes ont une forme pédiaire ou hastée, qui donne à ces plantes un port curieux : le nombre des espèces est assez restreint.

\section{ENUMERATIO SPECIERUM.}

Wallichii, J. Sm. - sagittifolia, J. Sm. (Pteris, Radd.*) - hastata, J. Sm. (Pteris, Radd.) - pedata (Litobrochia, Presl; Pteris, L., Langsd. et F.*; P. palmata et pedata, Willd., Plum.*, Petiv.*, etc.) - trifoliata (Pteris, Bory, Herb.) - Raddiana (Pteris pedata, var. $\gamma$, Radd.*) proealta, F. (Herb. Moug.) - articulata (an P. articulata, Klfss. in Spreng. 1v, p. 76?).

\section{SPECIES NONDUM DESCRIPTA.}

\section{Articulata.}

Frondibus pinnatis, basi bipinnatis, glaberrimis; stipite adiantino, suprà lavi, nitente; subtùs rufo-hirsutis; pinnis inferioribus articulatis, tachi et petiolis supernè glanduloso-turgidis; frondulis discoloribus, suboppositis, brevè petiolatis, basi cordatis, lobo inferiore latiori, apice crenulatis, oblusiusculis; mesonevro hirlo, suprà evanes- 
cente, angustissimo, marginibus repandis; fertilibus minoribus, acuminatis; sporotheciis universalibus, continuis; receptaculo anguslo, nigrescente; sporangiis anmulo $14-15$ articulato; sporis trigonis, fuscis.

Habitat in insulâ Borbonicu.

P'leris arliculata, Kaulf, Sieber, Syn. filic., 77, in schedul.

Filix triaugularis; pinnis horizontalibus; petiolis frondulorum gibbositate glanduliformi notatis; areolis Hewardire.

(Longueur, 30 eentim. et probablement plus; pinnules latèrales, 10 -11 eentim.; froudules . 5 - 6 centim. de longueur sur 2 de largeur; entre-nocuds, 2-4 centim.)

Sprengel (Syst. veg. w, p. 76 ) dit, en parlant dn $P$. articulala, que les frondes sont très-entières at les spornthèces interrompus; ce qui ne peut s'appliquer à ectte plante.

\section{B. Frondibus pinnatis.}

\section{ӭ7. LITOBROCIIIA, l.}

Litobrochia et Campteria, Prest. - Pteridis spec., Auct.

SPORотнесия, sporangïs el sporis pleridum.

FRохDiвus pinnatis vel bipinnalis, glabris, membranaceis; nerillis lenuioribus anastomosalis, in areolas hexagonoideas tìm universales, tìm partiales modì dispositis. Reliqua pleriduru.

Filices tropicales, herbacece, scepè magnce, divisa.

Diagnosis, Ноон. et B., Gen. filic., Lilobr. Endlicheriaua, Ноок, 1. Lxw, B (subgenus primumu), et L. biaurita (Campteriu), icon. cit. A (subgenus secuudum).

Icon. Iost.: lab. XI, A, fig. 6 (1. Eulitobrochia), Litobr. denticulatu, PR. - Fig. 7 ,

L. elata, F. - Fig. 8 (11. Campteria), L. Pseudo-Lonchitis, F.

Subgenera duo statuenda:

1.. EUцитоввосн1.t; areolis universalibus.

2. CAMPTERI.A; aceolis centralibus subnullis.

In subgenere Eulitobrochia areolce totam frondem impleut; in subgenere autem Campteria non inveniuutur nisi ad busin; reliquun nervillarum usque ad uurginem liberum manel.

Les lilobrochia sont de véritables pleris à nervilles anastomosées. Du reste, le port et l'aspect ne diffèrent guère; on les trouve dans les mêmes localités. L'Europe n'en possède aucune espèce. Nous rẻunissons dans ce groupe les litobrochir 
et les campleria de M. Presl, et nous ne leur donnons que la valeur d'un sousgenre. Le port est exactement le mêne, seulement dans le Campteric il n'existe qu'une aréole basilaire, c'est-à-dire située près du mésonèvre; les nervilles qui s'en détachent atteignent la marge et se bifurquent, en restant libres; tandis que dans le Lilobrochia l'anastomose des nervilles esı univerșelle et les aréoles ne cessent de se constituer que quand le segment fructifere se limite; il y en a donc d'autant plus qu'il est plus large. Toutefois les dernières nervilles, celles qui atteignent la marge, restent libres.

Ces fougères sont herbacées, cependant il en est deux ou trois espèces ligneuses, atteignant les proportions de petits arbres de 2-3 mètres de hauteur. Ex. le L. arborescens (Pleris arborescens, Nart. et Graleotı.). Toutes vivent sur la terre. On n'en connaît aucune qui soit aquatique.

\section{ENUMERATIO SPECIERUM.}

I. Elumobrocusa (nervillis omnibus anastomosantibus).

Chrysodioides, F. - Brasiliensis, Presl (Pteris, Radd.*, Arrabid.*) - denticulata (Pteris, Sw.: tristicula, Piadd.* an L. Brasiliensis varietas?') - contracta (Pteris, Lmrk.) - papyracea, F. - lertophy.lla (Pteris spinulosa, Radd.*; Pt. decurrens, Arrab.*) - Mexicana, F. - crassipes Pieris, Agardh; Pl. giganlea, Sicb., Syn. filic., n. ${ }^{\circ} 161$ ) - Kunzeana (Pteris, Ag.; Pt. podophylla, Kze. Pl. Pœppig.) - elata (Pteris, Agardh) - gigantea, Willd. - altissima (Pteris, Lmrk. non Poiret.) - aculeata (Pteris, Sw., Plum.*, Sloan.*, Pctiv.*, Iloult.*) - IVoodwardioides, Presl (allissima, Poir.; pellucida, Kaulf.) - Berteroana (Pteris, Ag.) - Hankeana, Presl, fragm.* (Pleris ampla, Kze.) - comans, Presl (Pteris, Schkh.*, Spreng.*) - splendens (Pleris, Klfss.) Karsteniana, Kże. (Pteris gigantea, Hortor.) - dimidiata, Presl (exclus. omn. synonym.) - arborescens (Pteris, Marl. et Galeolt.) - Borbonica, F. - Montbrisonis, F. - camptocarpon, F. Tussaci, F. - marginala, Presl (Pteris, Bory) - Orizabce (Pteris, Gal.) - intermedia, Presl (Pleris, BI.) - decurrens, Presl (Pteris, Radd.*) - podophylla (Pteris, Sw., Browne*, Buchoz*) - setifera, F. - microdictyon, F. - macilenta (Pleris, Less. et Pich.) - elegans (Pteris, Sw. incisa, Pısl (Pteris, Thunb.) - pallita (Pteris, Raıld.*) - Vespertilionis, Presl (Pteris, Labill.*) et var. flavescens - aurita (Pteris, Blum.).

1I. Camptrata (nervillis arcum unicum basilare formantibus).

Rottleriana (Campteria, PresI) - Balbisiana (Campteria, Presl) - Wallichiana (Campteria, l'resl.; Pt. umbrosa, Wallich.) - Pseudo-Lonchitis, Pres! (Pteris Woodwardioides, Bory non Presl, ex auctorilate Boryi in Herb. nostro) - triplicata (Pteris, Agardh.) - Kleiniana, Presl (P. geminata, Wall.) - Gardneri, F.

\section{SPECIES NONDUY DESCRIPTE.}

\section{Chrysonioides}

1. Euhtibrochi. (Lilobrochia, Presl.)

Frondibus glaberrinis, pinnatis, stipitibus supernè sulcatis; frondulis lanceolutis, incurvatis, brevissimé peliolatis, obtısis, basi rolındalo-cunertis; nervillis scalpluratis, hexagonoideis; mesoneuro robusto; sporotheciis universalibus; indusio la- 
liusculo; sporrangiis elliplicis, brevè pedicellatis; annulo lato $18-20$ articulato; storis crassis, trigonis, heteromorphis.

Inabitat in Americut Anstrali.

Filix sicritale subùs lucida, fucie Chry'sodii scalpturat?.

(Longueur totale deg la fronde, moins le stipe, 25 centim. : des froudules, 18 centim. curiren sm $16-17$ millim. de large.)

\section{PIPIRICE.}

Fondibus pinnatis, basi bipinnalis, allemis, ghluberrimis; rachi profundè canalicu-

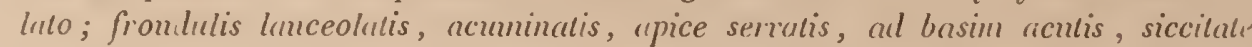
jupyruceis, pellacidis, membrunaceis, hucilis, petiolo mesoneuroque snbtis caunliculatis; nervillis areolas hexagonoiderrs, incequales (costales latıs, marginales minores), formantibus; sporolheciis angustissinis, continuis; indusio consistentii ot colore laminarnm, receplaculo crasso, fusco; sporangïs ovatis; mmulo 16.18 arliculato; sporis nigrescentibus.

Hubilut in Anericat merilionali (Gardner).

Filix elata, papyracea, frondulis remolis, exactè lanceolatis, acuminatis.

Longueur lutale, inconnuc; des frondules iuférientes, 28-30 ecutinn. sur 3\%, centim. de linge": les pétioles mesurent de 9.11 millim.)

\section{Mexicist.}

Frondibus supernè piunatis, infernè bipinnatis; rachi glubro, suprè cunuliculato; frondulis angustè lunceolatis, snborpositis; in euden fronde peliolntis, sessilibus, counatis vel ucuminatis; acumine extenso, remotè servato; nervillis creberrimis; areolis basalibus brevibus, sequentibus angustis longisque; indusio conrolori; sporotheciis spissis, contimuis; receptaculo lineari, angusto; sporangïs ellipticis; ammulo 20-22 articulato; sporis trigonis, colorntis; sporangiastris piliformilns, pellncidis, ciltinis, passim strungulatis.

Habitut in Mexico (Onxaca) et in Movâ Anduhusî́.

P'teris grandifolia, Mart. et Galcotti, n.0 6376 .

Filix fornosa, semi-bipiunatu, glabra, siccitale fnscescens; fromlulis fertilibus sunu rimam longitudinalem, murginalem impressis.

(Longucur de la froude, moins le stipe, 40 centim. enviren; les plus lungeres frondules attteignent emiron 16 centim, sur $15-17$ millim. de large; l'entre-ncent mesure 3 centin. Nons comptons 9 paires de folioles daus la partic pinnéc el dix paires de frondules dars les divisioun secondaites: Ies terminales sont phlus longnes quic Ies latérales.)

\section{BORBONICA.}

Frondibns pinnato-piunatifulis, stipite favescente, suprà Intè crunaliculato; pimnis pinnutifulis sessilibus, terminalibus latioribus, longiùs pedicellatis, acruninatis, apicer serratis; segmentis profande divisis, lunceolatis, oblusiusculis, apice crcunlatis, simu 
angısto; nervillis tenuibus, marginem non attingentibus, apice incrassatis, areolis pinuarum arcıatis, extensis, areolis segmentorım subhexagonoideis; rhizomate repente, pollicari, fibrilloso; sporotheciis brevibus; indusio lato, membranaceo; receptaculo nullo; sporangiis ellipticis, magnis; annulo 18-20 articulato, articulis discretis, spissis, intensè rubris; sporis magnis, trigonis, opacis; sporangiastris nullis.

Habitat in insulâ Borboniâ.

Filix delicatulr, translucilla, glaberrina; segmentis eleganter crenulatis.

(Longueur totale, 75 centim. Le stipe est à la fronde :: 2 : 1. Pinnules, 12 centim. sur 4 ecntim. d'envergure. Les segments ont environ 2 eentim. de long sur 7 millim. de large; les entre-nœuds mesurent 4 centim.; le rhizome atteint la grosseur du doigt et conserve les débris des stipes anciens.).

\section{MONTBR ISONIS.}

Frondibus antissimis; pinnellis ovato-lanceolatis, sessilibus, segmentis lanceolatis, obtusis, integris, sinuatis, incequalibus, curvulis, glabris pellucidisque; stipitibus et mesonevro helveolis; sporotheciis marginem non attingentibus; indusio lato, receptaculo nullo; sporangiis elliptico-obliquis, magnis, pedicello latissimo; annulo lato, 18-20 articulato; sporis majusculis, irregularibus, triedricis, succineo colore, marginalis.

Habitat in insulit Borbonici. (Montbrison.)

Filix iusignis, siccitate flavidula, nervillis tenuibus, rufescentibus.

(Longueur totale, ineonnue; pinuelles, 25 centim. sur 10 eentim. d'envergure. Les entre-nœnds mesurent environ 16 centim.; les segmenls ont de 9-11 millim. de large; le sinus qui les sépare est étroit et aigu.)

\section{Canptocarpa.}

Frondibus $3-4$ pinnatis, amplis, rachi stranineo, flavidulo, glabro, trisulcato; pinnellis sessilibus, longè acuninatis, acumine sterili; segmentis abbreviatis, discretis, curvatis, obtusis, ovatis; sinu lato, obtuso separatis, apice serrato, sterili; mucrone rostrato, spinescente rigido; areolis basalibus angustis, flexuosis, nervillis tenuibus, colorutis;sporotheciis curvatis; indusio crasso, latiusculo; sporangïs ellipticis; annulo 20 -22 articulato; sporis trigonis, lavibus; pilis sporotheciorum (sporangiastris ?) citrinis, subtorulosis strangulatisque.

Habitat in Columbia, colonia nomine Tovar. (Moritz, n. ${ }^{\circ} 47$. )

Pteris (Litobrochia) Orizaba, Klo!zsch, Linn., xx, p. 342 , non Galeolli.

Filix magna, glabra, siccitnte virilula.

(Longueur de la pinnule terminale, 42 centim.; elle porte $14-15$ pinnelles; pinnule inférieure divisée à la base, 25 eentim., avee une pinnelle terminale de 11 centim.; pinnelles latérales, 10-11 centim.; elı:ergure, 18-19 millin.; entre-nouds, 3 eentim.)

\section{Tussaci.}

Frondibus amplis, bipinnatis, rachi glabro, helveolo, subcanaliculato, in parte superiori angusto, alato; pinnis allernis, brevè stipitatis, acuninatis; seguentis curvatis, 
aculis, serralo-mucronulatis, latis, simu latiusculo, areolis basilaribus curvatis, angustissimis, nervillis scalpturatis; majusculâ longè petiolutâ; sporolheciis basalibus, indusio lato, margine receptaculariformi; sporangiis ovatis; annulo 18 articuluto; sporis irregulatim trigonis; sporangiastris intestiniformibus, citrinis, strangulatis.

Hubital in insula $S_{0}^{\circ}$-Domingo. (De Tussac.)

Filix glabra; siccitate helveolî.

(Longueur totale, incommue; elle est sans doute considérable. Les pimules atteignent environ 20 centim. sur 3 centim. d'envergure; les segments ont 5 millim. de large sur le double environ de hauteur; les sporothèces occupent la moitić de la partie inférieure du segment fructifère. I!s sont légèrement arqqués.)

\section{SETIFERA.}

Frondibus pinnatis; pinnis piunatifidis, glabris, tachi helveolo, suprà trisulcato, duos fasciculos rasorum litteram on eversam simulantes ferente; pinnis remotis, lanceolutis, segmento terminali, longè acuminato; segmentis lanceolatis, fulcatis, setı tenui, longissinat lerminatis, simu luto, rolnndo separatis; sporotheciis apicem serratum uon attingentibus; indusio latiusculo, firno; sporangiis ovoideis; pilis coucatenatis, succineo colore imunixtis; aunulo angusto, 18-20 articuluto; sports trigonis, lavibus.

Habitat in Mexico, super montem ignivonum S. Martini, circá craterem. (Galeotli, n. 6571.)

Filix glabra, distinctissima.

(Longueur totale 1 metrc: les deux plus grandes pinnules, 20 centim. ; les segments de la base, 2 centim.; les entre-nœuds ont en moyenne 6 centim. de hauteur; les sinus, 3 millim. de largen: les segnents mesurcut senlement 4 millim.; le stipe atténué, et presque filiforme vers le hant, alteint la grosseur d'une plume d'oie vers le bas.)

\section{IA. Microdiction.}

Frondibus pinnato-pinnatifidis, rachi subtrigono, in parte superiori canaliculuto; pinnis pinnatifıdis, acumünatis, brevè petiolatis, alırnis; segmentis lanceolutis, curvatis, basi leviter dilatatis, obtusis, crenatis, simu dilatato, areolis basilaribus angustis, sequentibus minutis; sporotheciis crassis, marginem non altingentibus; indusio angustissimo, spurio, receptaculiformi, margine crasso nigroque; spo. rangiis ellipticis; annulo 18-20 arliculato; sporis trigonis, nigrescentibus; sporangiastris intestiniformibus.

Habitat in insulis Philippinis. (Cuming, sine numero.)

Filix eluta, in anbitu ovoidea, obscura, slipile helveolo.

(Longucur totale, probablement 1 mètre: les pimules de la base out environ 9 centim. de long: leurs derniers segments tendent à la forme pimnatifide; les médians ont presque le donble de cette longucur, avec une envergure de 4 centim.; les pinnules sont séparées par un intervalle de 3 centim.; elles sont trés-régulièrement espacées; Ic stipe alteint la grosseur d'une plume d'oie.) 


\section{Gardent.}

2. Campteril, Presl.

Frondibus divisis, rachi rufescente, subtùs canaliculato, glabro; pinnulis longissimis, petiolatis, subpinnatis, caudatis, pectinatis; segmentis horizontalibus, usque cul costam partitis, linearibus, crassis, crenulatis, obtusis, repandis, sinu lutissimo, apice sterilibus, basi dilatatis; areolis basalibus angustissintis, difficilè discernendis, circò mesonevron rima indicatis; sporotheciis crassis; indusio latiusculo; margine receptaculiformi; sporangiis ovatis, pedicello tenni; annulo $16-18$ articulato; sporis trigonis, nigrescentibus.

Habitat in Zeylanicâ insula. (Gardn., n..$^{\circ}$, Herb. Moug.)

Filix ampla; stipite et rachi rubescente, nitente; pinnis longissinis, remotis.

(Longueur totale, inconnue; des pinnules, 38 - 40 centim.; envergure, 6 centim.; largeur des segments, 4 millim.; du sinus. près de 5 millim.)

\section{HETEROPHLEBIUM, F.}

Pteridis spec., Aucr.

SPoRothecis pteridum; sporangïs maximis, pyriformibıs; annulo ferè completo, $26-28$ arliculato; sporis trigonis.

Froxdibes pinnatis, exaltatis; frondulis linearibus; nervillis pinnatis, primium liberis, deindè, et circa marginem, in areolis hexagonideis anastomosatis; stipitibus et rachi stramineis.

Diagnosis : Lab. x1, A, fig. 9-12. (H. grandifolium, F.)

Genus monotypum, fucie Pteridum pinuatarum; in Antillis (S. Domingo et Martinici) vigens.

A Litobrochia differt, nervillis basi liberis, ad marginem solim coalitis.

Ce genre est monotype, à frondes extrèmement amples, dont toutes les divisions sont libres. Les frondules qui atteignent souvent 50 centimètres de longueur, n'ont pas moins de 4 a 5 centim. de largeur; le rachis est robuste, lisse, couleur de paille; le stipe forme une grosse souche qui s'élève au-dessus du sol. Les sporothèces bordent les frondules sans être plus larges que dans les espèces à segments étroits. Les nervilles, très-déliées, très-rapprochées el d'apparence colorée, lorsqu'on les regarde par interposition, ne forment d'aréoles que près de la marge; elles sont nombreuses, irrégulières et assez. petites. Le spécimen que nous possédons, ayant ses fragments réunis et mis en rapport atteint à peu près trois mètres de longueur. C'est l'une des plus grandes fougères que nous connaissions; aucune espèce des 
genres Pteris et Litobrochia n'acquiert ces dimensions, en conservant rigoureusement ses frondules libres, comme il arrive à l'Helerophlebium.

\section{SPECIES.}

Grandifolium (Pleris, L., Plum.*, Petiv.*, Sloan.*, Schkh.*).

\section{计 Areolis appendiculatis.}

\section{AMPHIBLESTRA, PresI.}

Tentam. pterid., p. 150.

Pteris talifolia, Нusв. et B.

Sровотнесі1, sporangïs el sporis pteridum.

Froxbibus membranaceis, amplis, Iriangularibus, segmentis tripartitis, pinnatifudis, acutis, cordatis, incquilaleralibus, repando-sinuatis; nervillis pinnatis, distantibus, venis curvulis conjunclis; venulis in areolis minoribus appendiculatis; appendiculis reclis aul incurvis, apice liberis; slipite circiler tredecim fasciculos vasorum ferente.

Diagnosis : tab. xl, B, fig. 1, 4-8. (A. Intifolia, PresL.)

Genus monolypum Columbiam inhabitans; filix herbacea, glabra, ampla.

Habitat in Columbiâ.

La nervation de l'Amphiblestra est analogue à celle des gymnopteris (acrostichées), des drynaria (polypodiées), des bathrnium (aspidiées), des selliguea (antrophyées). Le type est un très-belle fougère, rare dans les herbiers, d'un port tout particulier; elle appartient à l'Amérique tropicale et a été figurée avec soin dans les suites à Schkulir (II, tab. CXVIII), par Kunze. Le stipe est parcouru par treize faisceaux vasculaires, dont deux antérieur's comprimés plus grands, les autres épars, arrondis et plus petits.

SPECIES.

Latifolia, Presl (Pteris, Kze.*). 


\section{S. 2. Indusium curvatum, breve, lunulatum : LONCHITIDE \&E.}

\section{LONCHITIS, Linn.}

Gener. Pl., n. ${ }^{\circ} 1177$, Emend.

Sровотнесіs in sinubus sapè solitariis, rarò marginalibus modò Pleridum, semper meniscioideis el plis minisve curcalis; indusio lenui, membranaceo crassoque, nunc caduco, nunc persistente; sporangiis amplis, pyriformibus; annulo lato, 14-18-20 arliculato, arliculis latissimis; sporis ovoideis, reniformibus, episporio papillato.

Frondibes pinnatis, pinnis pinnalifidis, segmentis rolundis, villosis glabrisque; pilis arliculatis, nodulosis, strangulatis; nervillis in areolas inoequales hexagonas disposilis.

Filices molles, decompositce, magnce, ut plurimuin in insulis Africanis et in promontorio Bona Spei vigentes; pauca Americance australes.

Diagnosis : Schott, Gen. filic., t. Lxvi1, A. (L. hirsuta, Sieber, Presl, Tentam. pterid., t. v1, fig. 29. [Nervatio sola.])

Tab. nostr.: XI, A, fig. 13, L. tomentosa, F. (Sect. stipitis.)

Facie Pteridis hirsuta; nervatione Litobrochice.

Ce genre se rapproche de l'Hypolepis, mais les fructifications se développent à la base du sinus formé par deux des segments les plus voisins. Il résulte de cette situation que chaque sporothèce appartient pour la inoitié à chaque segnınt. Dans le genre Pleris, on ne retrouve pas ce caractère. Les sporothèces sont narginaux et toujours distincts, même quand les deux sporothèces de chacun des côtés de la lame se rendent dans le sinus; ils s'y rencontrent sans devenir cependant confluents. Quelques espèces ont, indépendamment des sporothèces fixés au sinus basilaire, des sporothèces narginaux; exemples: L. Madagascariensis, Hook., macrochlamys et Lindleyana; mais même alors ils prennent toujours naissance et s'appuient constamment sur la base des échancrures des segments qui sont sinués. Cette disposition toutefois les ratlache aux ptéridées.

M. Presl a réuni, dans sa Pteridographie (p. 161), les genres Hypolepis et Lonchilis pour constituer un petit groupe, celui des ptéridées, se basant sur la forme semilunaire des indusium qui se retrouve dans les deux genres. Il nous a semblé plus convenable de rattacher le Lonchitis aux ptéridées et l'Hypolepis aux cheilanthées. Ce dernier genre reproduit dans beaucoup d'espèces le type des aspidiées auxquelles il eût été possible de le réunir. Quant au Lonclitis, nous hésitons d'autant moins 
a lui conserver la place que nous lui donnons qu'il existe un petit sous-genre parni les pleris, le Lonchilidium, dont les sporothèces interrompus rappellent la forme de ceux des vrais lonchilis. Ajoutons que les faisceaux vasculaires qui parcourent le stipe de ces fougères, forment aussi des zones bizarrement combinées. Sur neuf espèces de lonchilis que nous énumérons ici, six appartiennent à l'Afrique australe et à son archipel; trois habitent l'Amérique tropicale.

\section{ENUERATIO SPECIERUM.}

surita, L. (1'lum.*, Pcliv.*) - slabra, Bory (Schlecht.*) - stenochlamys, F. (glabra, Kze.* non Bory) - Vatalensis, Ilook., fragm.* - pubescens, Willd. (Schkh.*, Hook., fragm.*) Lindeniana, Hook. fragm.* - Madngascariensis, Ilook., fragm** - tomentosa, F. - inacrochlomys, F.

$\cdot$

\section{SPECIES NONDLM DESCRIPTE.}

I. Strivochloiys.

Frandibus tripinnatis, amplis, pilosis, pilis sparsis, acicularibus, articulatis; rachi exnsperuto, helveolo, profnndè canuliculato; pinnis distantibus, longissimis, acutis . rachi alato; nervillis alarum anastomosantibus, parallelis, sporangïferis longissimis; segmentis subpinnatifulis, sinuatis, marginibus ciliatis, pellucidis, nervillis ad marginem liberis; sporotheciis parvulis, angustis, indusio angustissimo; pilis internis brevibus, contortis (sporangiustris:?); sporangiis ovatis; annulo 14-16 articuloto; sporis ovoideis, pellucilis.

Habitit al promontorium Bonce Spei. (Drège.)

Lonchilis glabra, Kze., in Acotỵl. Afric. austr.; Linn., 1x, Ejust., die Farnkr., p. 15.2 , tal. tru, non Bory.

Filix magnn, caudice repente, pilis sparsis vestita.

(Longueur tolale, inconnuc; des pinnulcs, 50 centim.; enrergure, 18 centim.; segments, 15 millim.)

lous les auteurs ont réuni celte plante au L. glabra de Bory, espèce glabriuscule, à seginents raides, aigus, terminés par un asscz long mucron, ayant des indusium assez amples; les menbranules ailées sont beaucoup plus larges, les nervures plus grosses et les arćoles plus courtes. Yous ćlablissons ces différences sur le spécimen de Bory. récolté par ce botaniste pendant son rovage.

\section{MACROCHLAMYS.}

Frondilus pinnato-pinnalifidis, lanuginosis, pilis articulato-nodulosis; segmentis profundè sinuatis, oblusis; sporolheciis latiusculis, sapè margines duas invadentibus; indusiis crassis, latis, siccitale subcrispis; spornngïs ovalis; annulo 14-16 urticuloto; sporis reniformibus, papillosis.

Hobitat in Brasilici. (Blanchet.)

Filix magna, cinereo-tomentosa; nervatione Litobrochice, indnsiis P'teridum senl semper in sinubus affixis.

(Fispece très-lemarquable, que nous ne possédons pas entièrc.) 
III. Tonestosa.

Frondibus tri-quadri-pinnatis, rufo-tomentosis; pilis acutis, bi-tri-articulatis; stipite et. rachibus rufis, angustè canaliculatis; pinnis extensis, lanceolatis; pinnulis pinnutis, apice pinnatifidis, brevè stipitatis; pinnulis inferioribus oppositis, centralibus alternis, superioribus adnatis; sporolheciis lutis, margimibus simnatis, omnibus fertilibus; sporangiis tabacinis, ovoideis; annulo 16-18 articuluto; piïs internis longis, contortis, pellucidis; sporis vitreis, ovoideis.

Habitat in insulâ Tos beh Madagascariensi (Pervillié), et in insulî́ Borbonici.

Filix altissima, tripinnata, cinereo-tomentosa, nervillis crassis, fuscis.

(Longueur des principales divisions, 50 centim.; des pinnules, 9 centim. sur 3 de largeur; lc stipe attcint la grosscur d'une plume de cygnc; le rachis des pinnules est gros conime celle d'un pigeon.)

Celtc belle espèce ne se rapporte pas à la figure du $L$. madagascariensis, domice par M. Hookeı (Sw. filic., II, t. 87); cllc cst tomenteusc; le tomentum est roussìtre; les pinnulcs diffèrent de forme a ansi que les sporothèces; lcs arćoles ont anssi une autre disposition el d'antres dimensions.

\section{Considérations générales sur les Ptéridées.}

Le groupe des ptéridées renferme neuf genres, ayant, arec un port semblable, des analogies nombreuses. Les frondes s'étalent considérablement et justifient, mieux que la plupart des fougères, l'origine élynologique du nom qu'elles portent

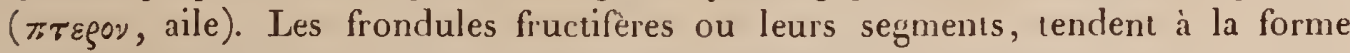
linéaire ou lancéolée; elles se garnissent de sporothèces allongés, toujours continus et étroits. Les indusium sont soulevés tout d'une pièce par les sporanges a l'époque de la maturité. La déhiscence a lieu de dedans en dehors, comne dans les lomariées et les adiantées, avec lesquelles toutefois il n'est pas possible de les confondre, tant le port offre de différences. Les sporanges s'attachent, tantòt à l'aisselle de l'indusium, et dans toute l'étendue du poitt sur lequel il naît, tantôt sur les nervilles, mais dans une étendue extrêmement restreinte. Les sporothèces sont exactement marginaux, souvent universels, c'est-à-dire, s'élevant de la base au sommet où ils sont confluents; quelquefois partiels et laissant le sommet stérile, quelquefois aussi plus spécialement fixés sur le sinus des lobules, et réduits dans leurs dinensions, au point de ressembler à un peiit fer à cheval (Lonchitis); mais même alors ils ne se bornent pas toujours, et la mêne fronde montre des sporothèces qui s'étendent fort au delà de ces limites. Les spores ont une forme ovoïde, trigone, et par exception ovoïde.

Les frondes sont glabres, quelquefois chargées de poils, presque jamais d'écailles; le stipe et les nervures prinaires sont analogues à ceux des adiantes "dans les genres Pellac et Doryopteris; ce stipe de couleur pâle, plus rarement foncée, est exceptionnellement de couleur d'ébène dans les genres Pleris, Litobrochica, Heterophlebium et Lonchitis; sa couleur est brune noirâtre inférieurement dans 
l'Amphihlestra. Le nombre de faisceaux vasculaires qui parcourent le stipe est en général très-considérable, et leur arrangement d'une bizarrerie extrême.

La nerration est libre dans plusieurs genres. Le Pellaca rappelle celle de l'Hémionilis; le Doryopteris celles de l'Hymenodium et du Nevrocallis; l'Amphiblestra, celle des drynaria, le Lonchilis, celle des woodwardia et des lilobrochia. Il n'existe aucun genre à nervilles conniventes, le Monogonia de M. Presl ne paraissant pas susceptible d'être conservé; voici nos raisons :

Le type, filix lusilania non ramosa, lonchilidisfolio, Tournef., Instit., p. 537. liguré tab. 513 du même ouvrage, est bien certainement un Pleris. Quoique la planchie laisse à dẻsirer, cependant on reconnait l'indusium marginal. Elle est réduite dans ses proportions. On ne peut rapporter celte figure au $P$. argula, Sw. trouvé aux Açores et peut-être même en Portugal. Il ne paraît pas que la plante ait été revue depuis Tournefort.

Limé n'en a pas parlé dans le Species, Lanıarck (Encycl. bot., p. 722), se contente de traduire la phrase de Tournefort, en ajoutant que la plante est intérieurement fructifiẻe, circonstance sans valeur, puisque presque toutes les polypodiacées sont dorsiferes. Swartz (Syn., p. 99) n'en dit pas plus, et Willdenow (Filic., p. 379) le copie en changeant ou plutôt en modifiant quelques termes.

La plante que nous avons eue sous les yeux, provenant de l'herbier de cet illustre botaniste, n'est pas la mêtne que celle de la planche de Tournefort; les segurents des frondes sont plus allongés et entiers. Leur disposition les montre arqués. Cette fougère, étudiẻe par M. Presl, a servi à établir un genre nouveau dans le groupe des ptéridées, le genre Monogonia, caractérisé par une nervation comnivente. Les nervilles sont pinnées et celles de la base se réunissent à leurs correspondantes pour former un angle. Si, comme nous somnes disposé à le croire, II. Presl a vu la plante fructifiée, il n'y a plus rien à dire; mais alors ce ne serait plus la plante n. 19,986 de l'herbier de Willdenow, car elle est à l'état stérile.

Ce spécimen, qui a été vu par ML A. Braun, a paru à ce botaniste sigace devoir être rapporté au Polypodium lelragonum (Goniopleris telragona de M. Presl), et nous adoptons pleinement cette opinion. Elle sera celle des personnes qui youdront comparer ce Goniopteris avec le prétendu Pleris paluslris de Poiret.

Le groupe des ptéridées se lie aux lomariées, quoique ces plantes soient fort différentes de port; aux vittariées, quoiqu'elles soient indusiẻe et aux cheilanthées par le genre Lonchitis, dont la nervation est réticulée. Ces rapports se déduisent surtout des organes carpomorphes, car la pliysionomie générale est absolument différente; elle sépare ce groupe de tous les autres. La plupart des plantes qui en font partie, montrent dans les sporothèces, mêlès aux sporanges, des poils intérieurs, rubanés, pellucides, obtus et contournès; peut-être sont-ce des pédicelles de sporanges, dont l'évolution n'a pu atteindre à la formation du sacculus. 


\section{S. 2.Sporothecia nervillam unicam occupantia : CHEILANTHEAE.}

Erectæ, squamigeræ, lanatæ, teneræ, multidivisæ; lobulis ultimis rotundatis; gymnosore et angiosoræ in speciebus ejusdem generis.

I. Acervis paucis, remotis; influsio orbiculari:

HYPOLEPIDEA.

\section{ADIANTOPSIS, F.}

Hypolepidis spec., Ноок.

Adianti et Cheilanthis spec., L., Thunb., Sw., Willd., Kze., Press, Pohr, etc.

Сровотпесп parvulis, uninervillatis, oligocarpicis; indusio orbiculari, tenuissimo, lateribus libero, integro, rarò funbrialo; sporangïs brevissimè pedicellatis, ovatis; annulo 16-20 articulato; sporis rotundis vel obscurè trigonis. Froxdibus bi- seu tripinnatis, triangularibus radiatisque; stipitibus et rachibus adiantorum; frondulis symetricis ( $A$. capensis), dimidiatis ( $A$. radiata) continuis (in specieb. pluribus) articulatis (.1. paupercula); nervillis liberis, flabellatis.

Filices herbacea, inermes, glabra, tropicales; aspectu adiantorum.

Diagnosis : (vide Kunze, die Farrenkr., n, tab. 127 [optima]).

Ce genre, qui prend place à côté de l'Hypolepis, en diffère par le port, mais aussi par des sporothèces formés d'un fort petit nombre de sporanges garnissant toute la marge et jamais confluents. L'indusium est mince, orbiculaire, attaché à la base par une faible surfice et libre par ses côtés. Les hypolepis sont de grandes fougères sur-décomposées qui tendent à l'arborescence et dont les stipes ligneux et robustes portent des aiguillons. Les segments sont pinnatifides et crénelés, tandis que les adiantopsis sont pinnés. Il n'y a d'exception que pour l'A. Capensis, qui, en outre, a des indusium frangés.

ENUMERATIO SPECIERUM.

Capensis (Cheilanthes, Sw., Schlechtend.*) - chlorophylla (Cheilanthes, Radd.*) - pauperculn (Adiantum, Kze.*; Ilypolepis, Hook.*) - radinta (Adiantum, anct. Pluk.*, Sloan.*).

Dubix : spectabilis (IIypolepis, Presl; Cheilanthes brasiliensis, Rard.*). 


\title{
62. HYPOLEPIS, Bernh.
}

\author{
Presl, Tentam. pterid, p. 161
}

Lonchilidis spec., L. - Dichisonice spec., Sprevg. - Cheilanthis spec., Sw. ct Atct. - Adianli spec., Borr. - Aspidii spec., Ecкцo..

Sporotnecus subglobosis, dislinclis, ad uarsinem sinuum laciniarum frondis

silis; indusio marginali spurio, tenuissimo, semi-orbiculalo, scarioso, rario aborlivo, ex margine orlo; sporangiis subrolundis, ovalibus; annulo $12-16$ arliculalo; sporis ovoideis, subreniformibus, fuscis.

FRoxdbus decomposilis, leneris, segruenlis crenulalis; nervillis pinnalis, maryinem allingentibus; slipilibus rufescenlibus.

Filices anulissime, tri-quadri-quinque-pinnatc, herbacere aut subarborescentes, terrestres, inermes vel aculeate, tropicales.

Ihingnosis: Hogk. et Baukr, Gen. filic., t. Lxw1, A (Cheilanthes conmulatu, Kze.) et B (Hy.polepis repens, PresL). PresL, l. cil., I. vi, fig. 24, et Tab. nostr., XII, fig. 3 (fragutentum).

Ce genre se rapproche du Lonchilis, groupe des ptéridées, par la forme de lindusium; mais au lieu d'occuper le sinus, ce tégument est attaché au sommet d'une nervure qui l'en éloigne et le rend latéral. Il ne peut être confondu avec le Cheilanthes, ayant un indusium de forme bien déterminée, recouvrant des sporothèces toujours distincts et arrondis. Lorsque l'indusium des hypolepis est combé, il en résulte un groupe de sporanges ayant l'aspect globuleux de celui des polypodiées, tandis que dans le Cheilanthes les sporothèces bordent la marge et sont tous confluents. Le port des fougères appartenant à ces deux genres, est absolument différent. Les hypolepis ressemblent à de grands alhyrium. Les frondes sont extrêmement amples; les pétioles et leurs divisions souvent armées d'aiguillons, et les stipes tendent à l'arborescence. Quelques espèces ressemblent à des alsophila et à des cyalhea; mais les sporothèces sont autrement organisés.

Les hypolepis vivent particulièrement sous les tropiques; ils sont glabres, rarement velus et presque jamais écailleux. L'espèce la plus voisine de l'Europe croìt en Abyssinie.

\section{ENUMERATIO SPECIERUM.}

Repens, Presl (llook. el B., fragm.*, Ilook.; Lonchitis, L.) - Boryana, Presl. (Adiantum Ilicksonioides, Bory in Herb. Kiz.) - anthriscifolia, Presl (Cheilanthes, Willd., II., I1. 20,128) trichodes (Polypodium, Rcinw.) - Smitliil, Mong. IIcrb. (II. repens, J. Sm. non Presl) - tenuifolia, Beruh. (Presl, nerv.*; Dryopteris, Rumph.*; Trichomanes, Burm.*; Cheil. arborescens, Sw., Hook., fragm.*) - commutata (Hook., Gen. filic., fragn.*; Cheilanthes, Kze.) - nigrescins, 
Hook., Syn. filic.* - Endlicheriana, Presl (Cheilanthes Dicksonioides, Endl., Kze.*) - Sellowiana, Kl. (Luschnath, PI. Bahienses, n. ${ }^{\circ}$ 18) - aspera, Presl (Cheilanthes, Klfss.) - Schimperi (Cheilanthes, Kze.*) - Bergiana (Cheilanthes, Schlecht.*) - Eckloniana, Presl (Aspidium, Eckl. P!. Cap., n. ${ }^{\circ} 100$; Cheilanthes aspera, Kze.) - hostilis, Presl (Cheilanthes, Kze.) - rarallelogramma, Pres! (Cheilanthes, Kze.) - Helenensis (Cuming, pl., S. Helena, n. ${ }^{\circ} 433$ ).

\section{SPECIES NONDUM DESCRIPTE.}

I. Sнiтн11, Moug. Herb.

Frondibus decompositis; stipitibus divaricatis et rachibus aculentis, aculeis robustis, apice fuscis, deflexis; rachi pinnularum tenuissimo; segmentis glabriusculis, pinnatifidis, crenatis; crenis rotundis, incequalibus, scepè decurrentibus; sporotheciis paucis, oligocarpicis, ad sinum segmentorum sitis; indusio tenui, scarioso; sporangiis parvis, ellipsoideis, pedicellatis; annulo $11-12$ articulato; sporis parvulis, fuscis, rotundis.

Habitat in insulis Philippinis.

Hypolepis repens, J. Sm. non Presl. (Cuming, Filic. Philipp., n. ${ }^{\circ}$ 271.)

(Longueur totale, 1 mètre; les pinnules, 20 centim. et plus; celles-ei, presque opposées, s'écartent du rachis à angle droit.)

Cette fougère ne peut ètre rapportée à l'H. repens de Presl, plante américaine depuis longtemps connue.

\section{Helenensis.}

Frondibus amplis, bipinnato-pinnatifulis; rachi subtìs canaliculato, flexuoso, rufo, glutinoso, pilis glandulosis brevibus, articulatis, siccitate rigidis, exasperato; pinnis lanceolatis, pinnulis sessilibus, segmentis pinnatifdis, lobulis fructiferis inarginibus incurvatis; sporotheciis rotundis, magnis, dorsum nervillarum occupantibus; indusio nullo; annulo lato, ferè completo, $12-13$ articulato; sporis ovoideis, reniformibus, papillatis.

Habitat in insula Sancta Helena. (Cuming, n. 433.)

Filix formosa, prolifera, glutinosa, rufescens, glabra, pilis articulatis, succineo colore, articulis fuscis cooperta; sporotheciis polypodiorum.

(Longueur d'une prineipale division, 45 eentim.; des pinnules, 14-15 centim.; des pinnelles, 3 centim.; nous en comptons une vingtaine; chaeune d'elles porte un nombre presque égal de segments pinnatifides.)

Est-ee bien là un Hypolepis? 
II. Acervis multis, approximatis, sapè confluentibus.

A. Erolutio frondium definila (lerminata): EUCHElLANTHE\&.

\section{MYRIOPTERIS, F.}

Cheilanthis spec., Auct. var.

Sporotuecis totam partem laminarum invadentibus; sporangüs rolındis, cum pilis rufts, tim v'iltatis el continuis, lim nodosis el nodulosis immixlis; anmulo 20 arliculalo; indusio scarioso, contiuno, infrì marginali, plìs minuisve lalo, non rarì deficienle: slomale sub to nerioso, nercis crassis, approximatis inter quinlum el sextum solulo; sporis upacis, rolundis vel trigonis, in aquâ erumpentibus et sporulas rolindas, lemissimas emiltentibus.

FroxDıses decomposilis; froudulis orbicularibus, pilosis; pilis stguamiformibus; lobulis fructiferis crassis, bullatis cucullatisque, marginibus replicatis; newillis: flabellalo-pinnatis, bifurcatis, tenuissimis el agrè discernendis.

Filices Mexicance el Peruviana, erecter, squamose, decompositu.

Diagnosis : tab. Xul, fig. 1 (M. mursupianthes, F., Mexic., Galeotti, n. 6256 , (t Berlandier, n. 414); fig. 2-4, fragmenta specierum rariarmm.

Ce genre, dont les espèces appartiennent en grande partie aux cheilanthes, avait été entrevu par M. Presl, qui en avait fait le deuxième sous-genre de son Cheilanthes, sous le nom de Physapleris. Nous lui donnons une plus grande extension. Les myriopteris sont des fougères herbacées, élancées, at frondes surdécomprosées. Les lubules peuvent tous devenir fructifères; ils affectent la forme arrondie et s'anincissent en une sorte de pétiole; les marges se recourbent pour se modifier en un indusium qui manque assez souvent. Dans le $M$. marsupianthes, l'origine de ce tégument protecteur est très-singulière. Les sporanges sont sous-cuticulaires, et soulèvent, dans toute son étendue, la cuticule du lobule, laissant seulement vers sa hase une fente qui sélargit peu à peu. Des poils nonbreux roussàtres, articulés et intestiniformes, sont toujours mêlés aux sporanges, comme dans les jamesonia, auquel ce genre confine. Ces fougères ont une grande tendance à se charger de poils et d'écailles; celles-ci sont parfois si abondantes (M. scariosa) qu'elles cachent les lobules dont elles ne permettent pas de juger la forme; elles semblent les unir entre eux et leur donner une plus grande amplitude.

Dans les véritables myriopteris, lindusium est très-apparent; dans les autres espèces, la marge se replie sur les sporanges, mais de deux manières, en for- 
mant un bourrelet très-contracté, la lame, restant plane; ou bien en se repliant largement des deux côtés pour donner à la frondule l'apparence d'un petit fruit arrondi. Cette frondule s'ouvre au centre à la maturité.

\section{ENUMERATIO SPECIERUM.}

1. Eumyropteris. (Indusiata.)

- Marsupianthes, F.* (Cheilanthes lentigera, Mart. et Gal., non auct.) - villosa, F.* - minor, F. (Cheilanthes, Mart. et Gal.*) - tomentosa (Cheilanthes, Lmrk.).

2. Chelcavthasprum. (Margine in indusii loco.)

Scariosa.(Cheilanthes, Klfss.) - paleacea (Cheilanthes, Mart. et Gal.*) - lentigera (Ch. lentigera, Siw.) - gracilis, F.* (Cheil. vestita, Kielıl non Sw.) - induta (Cheilanthes, Kze.) - contractu (Cheil. hirta, $x$, contracta, Kze.) - intermedia (Cheil. hirta, $\beta$, internedia, Kze.).

\section{SPECIES NONDUM DESCRIPTÆ.}

I. Marsupinsthes, tab. XII, $A$, fig. 1 (fragmenta).

Frondibus lanceolatis, tripinnatis; rachi rufescente, squamoso; squamis angustè linearibus piliformibusque; pinnis incurvatis, sessilibus; frondulis lenticuliformibus, bullatis, subtùs glaberrimis, virescentibus, margine incrassato; indusio infrà marginali, latiusculo, tenui, bursiculam simulante; sporangiis ovoideis, sessilibus, tomento continuo, fulvo, planiusculo, contorto, copiosè immixtis; annulo 20-22 articulato; sporis trigonis oratisque.

Habilat in Mexico (Pic d'Orizaba, allit. 3400 met.).

Filix insignis; squamis rufts obsita, lobulis regularibus, distinctis, bursiculiformibus.

Cheilanthes lentiger, Mart. et Galeotli, n. 6256 , non Auctor.

(Longueur totale, 34-36 centim., dout le stipe fait la moitié; pinuules, 22-26 inillim.; nous en comptons 20 paircs. Les lobules sont trc̀s-distincts les uns des autres et glabres; le tomentum fauve, qui abonde dans les sporothices, n'est pas articulé.)

Le véritable Ch. lentigera cst quadripinné; le lobule terminal est plus grand que les antres: tous sont poilus; les rachis se chargent de squames assez amples et de nature searieuse; les marges se replieut sur les sporothèces sans changer de consistance; il n'y a point d"indusium.

II. VIllosi, tab. XXVIII, fig. 3.

Frondibus lanceolatis, tripinnatis, stipite et rachi hirsulissimis, pilis longissinis, viltatis, flexuosis; pinnis curvatis, bipinnatis; frondulis roundis, bullatis, glabris, terninali maximá, margine crasso; indusio lato, albido, tenui; pilis internis contortis, acutis; sporrangiis globulosis, sessilibus; annulo 20 et plus articuluto; sporis globulosis.

Habitat in Mexico (altitnd. 2000 metr.), Galeotli, n. 6478.

Filix hirsuto-lanata; lanâ in slîpile crassâ, in rachi mollissimâ longâque.

(Longueur totale, $35-36$ centim.; Ies pinututes atteignent 35 millim. sur 16 millim. d'envergure. Nons comptons au deli de 20 paires de pinnules; elles sont sćparées par un iutervalle de 15 - 20 millini.)

Le M. marsupianthes est écailleux et non poilu. Le M. minor, qui a un autre port a des frondules erénelćes en leur pourtour. 
III. MiNOR.

Frondibus tripinnatis, stipitibus rachibusque hirto-lanatis; pinnis divaricatis, frondulis rotundis, cuneato-petiolatis, in ambitu crenulatis, contpressis; rhizonute repente; indusio latiusculo, tenuissimo, infrii margiriali; sporotheciis depauperctis; tomento futvo, pilis longissimis, contortis formuto; sporis trigonis.

Habitat in Mexico (Ouxaca, Galeotti, n. ${ }^{\circ}$ 6464; Tampico, Berlandier, n. 414).

Filix parvula, ovata, bi-tripinnata.

Cheilanthes minor, Mart. et Galeott., p. 75, tab. xxı, fig. 1.

(Longueur totale, 14-16 centim. sur 4 centim. d'envergure; nous comptons 10-15 pinnules: (He est très-différente de la précédente par le port et la forme des lobules.)

IV. Gracilis, tab. XXIX, fig. 6 .

Frondibus subtripinnatis, pinnis distantibus, stipitibus capillaceis, glaberrimis, adiantinis, basi squamas paucas ferentibus; frondulis suboppositis, sessilibus; terminalibus majoribus, ommibus ovoideis; fertilibus bullutis, lanâ nıolli, tenui, longâ vestitis; spo. rotheciis pilos internos gerentibus, nuargine crasso laminarum coopertis; indusio nullo; sporangiis globulosis, sessilibus; annulo latissimo 20 et plìs rerticulato; sporis muxinis, atris, lavibus, subtrigonis.

Habitat ad rupes circè Hillsboro, in Americî septentr.

Filix ca'spitosa, parvula, lanata; lobulis paruulis, ovoideis.

Cheiknthes vestita, Riehl non Sw., n. 529.

(Longueur, 5-6 centim., dont le stipe fait la moitié. Nous comptons 5-6 paires de pinnules.)

\section{PLECOSORUS, F.}

Cheilanthis spec., Kunz., Analect. pter., p. 35, t. xxiı, bona, excl. sporangiis et sporis.

SPOROTIECIS laminam tolam tegentibus, propter margines reflexos partim absconditis; sporangiis rotundatis, pilis squamosis immixtis; annulo $14-18$ articulato; stomate 10-11 nervato; sporis ovalibus, subdifformibus, nigrescentibus.

Froxdbus pinnatis, segmentis pinnarum crenatis; marginitus reflexis, plicatis, leviter scariosis; venulis pinnatis, in totâ longitudine proliferis; rachi validè squamoso v'el nudo. 
Filices speciosce, squamosce, erecte; pinnis approximatis; Mexicance et Peruviance; facie Aspidiorum.

Diagnosis : tab. xul, fig. 1: 1. P. Mexicanus, F. (Cheilanthes speciosissima, KzE., l. cit.); и. P. Peruvianus, F. (fragmenta).

Genus paradoxuın; inargine plicato, scepè scarioso, spurium indısium simulante.

Le genre Plecosorus tient aux cheilanthes par la disposition de la marge des frondules fertiles, repliées sur les sporanges, et tendant à être légèrement scarieuses.

Le mode de plicature de ces marges et la division des frondules en lobules arrondis, ainsi que la présence d'un grand nombre de poils mélangés aux sporanges, le rapprochent des myrioptcris; nuais le port de ces fougères est spécial dans le groupe des cheilanthées. Elles rappellent certaines grandes espèces de nephrodium. Le P. Mexicanus est abondamment couvert d'écailles qui passent par des transitions insensibles à la condition piliforme. Le P. Peruvianus est seulement velu.

M. A. Braun, auquel nous devons un spécimen du Cheilanthes speciosissima venant de M. Karwinski, l'a accompagné de cette note: videtur mihi generis proprii typus, et cette remarque faite par un botaniste aussi sagace, justifierait au besoin la formation de ce genre.

\section{ENUMERATIO SPECIERUM.}

Mexicanus (Cheilanthes speciosissima, A., Br., Kze.) - Peruvianus (Acrostichum, Ruiz, Herb.)

\section{Peruviancs.}

\section{SPECIES NONDUII DESCRIPTA.}

Frondibus bipinnatis, stipitibus et rachibus depressis, sulcatis, pilosis; pilis intestiniformibus, concatenatis, longissimis, pinnis sessilibus, obtusis, lanceolatis; segmentis latè reflexis, obtusis; nervillis suprì impressis, pedicellutis, pilis marginibus crenatis, cum sporotheciis ovatis immixtis, indusio critentibus; annulo $16-18$ articulato; sporis ovoideis.

Ilabitat in Peruviâ. (Pavon, dedil nobis Matrit., ann. 1809.)

Filix insignis, herbacea, Phegopteridis facie, lanceolata; stipitibus flexuosis.

Acrostichi spec., Ruiz, in Herbar. nostr.

(Longueur, 45 - 50 centim.; le stipe est un peu plus court que la fronde; les pinnules atteignent 5 centim. ; elles ont près de 2 ccutim. à la base. La marge des Jobules, repliée sur les sporanges, a presque deux millim. de largeur.) 


\section{ERIOSORUS, F.}

Acrostichi spec., Ruzz.

SPOROTHECIIs sub-universalibus, continuis, lanâ densâ vestitis; sporangiis nervitlaribus, elliplicis; stomate 5 nervalo, nervis incqualibus, rectis; annulo $18-20$ arliculato; sporis trigonis, crassis, nigrescentibus.

Froxibus pinnalo-pinnatifidis vel bipinnalis, segmentis oblusis, margine subcrenato reflexo; filamentis tomenti articulatis, intestiniformibus, aliquandoque nodulosis; fasciculo v'asorum stipitis unico ac transversè elliptico.

Filix Peruviana; flexuoso-scondens, in omnibus partibus densè lımatr.

Diagnosis : tab. xuı (E. scandens, F.; Acrostichun, Ruv, Herl). nostr., Peruvia). Nothochlona eriophora, F. (fragmentum ad comparandum).

Le port du type de ce genre est si remarquable et s'èloigne d'une manière si complète de celui de toutes les autres fougères, qu'on ne peut se dispenser de le regarder comme établi sur des bases solides. Le stipe est flexueux et probablement grimpant; il est arrondi et couvert très-abondamment de poils, les uns noduleux et les autres articulés. On les retrouve sur les frondules auxquels ils donnent une épaisseur considérable; ils sont mêlés aux sporanges, fort longs et d'une couleur rougeâtre très-prononcée. Dans le genre Ceterach, dont toutes les espèces sont dressées, ce sont des écailles qui recouvrent les lames; dans le Plecosorus les marges sont scarieuses et repliées sur les sporanges; dans les nothochlcena, de port tout différent, les sporanges sont marginales.

L'Eriosorus pourrait prendre place dans les hémionitidées, si l'on avait seulenrent égard à la disposition des sporanges attachées sur la presque-totalité de l'étendue des nervilles; mais le port et les organes accessoires, qui ont aussi leur importance, semblent justifier la place que nous lui donnons parmi les clıeilanthées, à côté du Nothochlana.

\section{SPECIES.}

Genus monotypum; vide diagnosim generis.

\section{SPECIFS DUBIO GENERE.}

Riciziaxes, tab. XIII, fig. 2 (fragmenta).

Frondibus lanceolutis, basi pinnoto-pinnalifulis, supernè pinnalifidis; rachi et stipite lonugine cinnamomeo colore abundè vestilis; piunis suprà glabris, sublìs tomentosis, lanceolatis, sessilibns; segmentis ovoideis, oblusis, apice serratis; sporothecïs 
laminam universè tectantibus, margine leviter reflexo; sporangiis ellipsoideis; annulo 18-20 articulato; sporis trigonis, lcvibus; pilis internis vittatis, contortis, pellucidis.

Habitat in Peruviâ.

Acrostichum, Ruiz., in Herbar. nostr.

(Longueur de la fronde sans le stipe, 30 eentim.; les pinnules mesurent 40-45 millim. sur une largeur de 9-11 millim.)

Cette plante, extrèmement eurieuse, se rapproche du Gymnogramme par la disposition des sporothèees qui sont nervillaires; l'épais tomentum mêlé aux sporanges, et la marge qui se replie légèreInent sur les sporothèees, en font une Cheilanthée. Est-ce bien là un Eriosorus? Le port du tıpe de ee genre n'est pas le mèıne, mais l'organisation des sporothèees ne différe pas.

\section{ALEURITOPTERIS, F.}

Allosori, Pteridis et Cheilanthis spec., Auct. var.

SPOROTнесіIs rolundis, depauperatis, apicem nervillarum occupantibus; sapè in lineâ angustâ ordinatis; sporangïs $2-3$ in eâdem nervillấ sedentibus, pedicello brevi; annulo 20 articulato: sporis trigonis, reniformibus; indusiis in ambitu liberis, basi connatis, contiguis, amplis, crispis, scariosis, rarò fimbriatis.

Froxdibus pinnato-pinnatifidis, bipinnatis, lanceolatis seu triangnlaribus; pinnulis inferioribus pedalis; paginâ inferiori pulvere vario colore tectâ, nisi in nervillis primariis; stipitibus fusco-badiis, lavibus; nervillis et venulis pinnatis, sinuatis.

Filices erecte, herbacere, fusciculate, ut plurimùrm Indicer; pauca in Abyssiniti et in insula Borboniâ vigentes.

Diaguosis : tab. xı, fig. 2 : 1. A. furiuosa, F. (Cheilanthes, Kavlf.) ; 2. A. dealbutu; 3. Hypolepis repens, Pr., fragmenta ad comparandum.

Les espèces, renfermées dans ce genre, se rapprochent des ceropteris par la nature de la sécrétion céracée qui recouvre les fiondes. Elles ont plutôt le port des pteris que celui des cheilanthes. L'indusium est scarieux, marginal, très-développé, crispé par la dessiccation. Il en existe dans tout le pourtour des divisions de la fronde et elles peurent devenir fertiles. Ces fougères sont toujours glabres; le stipe est pareil à celui des adiantum, noir, lisse et luisant.

La géographie des aleurilopteris est fort étendue; on les trouve au Mexique, a Ceylan, à Bourbon, aux Philippines; l'A. argentea croît en Sibérie, et l'A. deatbata, qui se trouve dans l'Inde, a été observé en Abyssinie par le voyageur II. Schimper. 


\section{ENLMERATIO SPECIERUM.}

1. Laminis subtits pulvere albo conspersis.

1rgentea (Cheilanthes, Kze.; Pteris, Gmel.*, Langsd. et $\mathrm{F}^{*}$ ) - argyrophylla (Pteris, Willd.: Cheilanthes pulseracea, Presl) - candida (Cheilanthes, Mart. et Gal.*) - dealbata (Cheilanthes farinosa, H. et Gr.*) - Indica, F. - Mexicana, F. (Galcolt., n. ${ }^{\circ}$ 6651.)

II. Laminis subtius pulivere flavidulo conspersis.

Sulfurea (Pteris, Cavan., Sw.)

I. IYDICA.

\section{SPECIES NONDUM DESCRIPTE.}

Froudibus lanceolatis, albo-farinosis, stipitibus el rachibus fusco-atris; pinnis subopposilis, lanceolatis, segmentis inferioribus usque ad costam liberis, ultimis longioribus, crenalis, subpedatis, omnibus lanceolatis, obtusis, mesoneuro flexuoso; sporotheciis remoliusculis, parvulis; indusiis minutis, pallidè roseis, orbicularibus; sporangiis crassis, pedicello brevi; anmulo lato, 18-20 articulato; sporis subtrigonis.

Habitat in Zeylonâ, Walker; iu Indiis orientalibus ad montes Nilghterries; A. Delessert.

Filix elata, facie Aspidii; pinnis distantibus, segmeutis remotis, inferioribus vix pedatis.

(Longueur de la fronde, 30 eentim. [le stipe est tronqué dans le spécimen dont nous donnons les dimensions]; envergure des pinnules, 9-10 centim.; elles ont 12 nillim. de large; nous en comptons une vingtaine; les segments sout sensiblement plus courts vers la partie supérieure: les deux inférieurs ont une longueur plus grande et comme les pinnules sout sessiles, elles prennent à la base une apparence déeussée [pinnulis decussatis.])

\section{Mexicaxa.}

Frondibus lanceolatis, elongalis, bipinnatis, laminâ inferiore granulis cerineis albillis coopertâ; stipitibus nudis, adiantinis, rufescentibıs; pinnulis lanceolatis, suboppositis, segmentis ultimis pedatis, pinnatifidis, obusis, onnibus crenatis; sporotheciis confluentibus; indusiis latis, undulato-crispis, scariosis, basi conniventibus; sporangiis subglobosis; annulo lato, $18-20$ articulato; pedicello brevi; sporis globosis, fuscis.

Habilat in Mexico (Oaxaca [Llano verde], alt. 2000 met., Galeotli, n. ${ }^{\circ} 6551$ ).

Filix elegans, facundissima, universè prolifera, indusiis continuis, connatis, latis crispisque.

(Longueur lotale, 40 centim.; des pinunles, 8 centim.; segments de la base, 3 centim.; intervalle séparant les pinnules, 4 centim.; le stipe et la fronde sont égaux en dimension. Nous complons 15 paries de pinnules.) 


\title{
67. CHEILANTHES, Sw.
}

\author{
Syn. filic., t. III, fig. 5-7.
}

Acrostichi, Nolhochlcence, Woodsice spec., Aucr. var. - Hypolepidis spec., Auct. recent.

Sровотнесиs subglobosis, marginalibus, discretis, confluentibus, marginem seı lobulos marginarum invadentibus; indusio spurio, membranaceo aut nullo, marginibus super sporangias revolutis; sporangiis ovoideis; sporis formâ varia; pilis vittatis, continuis, in pluribus speciebus strangulatis.

Froxdibes divisis, bi-tri-quadripinnatis, triangularibus aut lanceolatis; segmentis in lobos ovoideos divisis, siccitate perfacile crispis; laciniis rolundis, parvulis, basi divisis, stipitibus nigrescentibus, lanâ densâ saè vestitis, nunc lavibus, nunc asperis; nervillis pinnatis, liberis.

Filices cosmopolitance, herbacece, terrestres, rupicolce, multifida, frequenter hirsutce; determinatum difficillima; frondibus dissectis, opacis.

Diagnosis : Hook. et B., Gen. filic., t. cvı, B. - C. suaveolens, J. Sm., Prest, Tent. pterid., t. vi, fig. 15-17 (nervatio soln).

Genus arduum; speciebus pluribus ambiguis.

Les cheilanthes sont privés d'un indusium spécial; mais la marge, qui se replie sur les sporanges, devient souvent scarieuse, comme il arrive aux bractées florales, et elle simule alors un faux indusium, bien difficile à distinguer d'un véritable. Quelquefois il arrive que celte marge, ainsi repliée, ne se modifie en aucune manière; cependant les sporanges sont abritées comme si elles étaient indusiées, ce qui na pas lieu pour celles des nothochlacna, cachées dans l'épaisse villosité qui recouvre les laınes. Dans la plupart des espèces, les lobes fructiferes sont tellement étroits que toute la lame parait envahie par les sporanges. Les cheilanthes ont une grande tendance à se charger de poils, principalement le stipe. Les frondules, d'abord planes, se roulent sur elles-mènıes arec une grande facilité par la dessiccation; le port change, et la plante devient très-difficile à étudier et à reconnaître. Les frondes toujours dressées et plusieur's fois pinnées sont plus longues que larges. Ce genre diffère de l'Hypolepis, dont toutes les espèces portent un indusium apparent, limité dans ses proportions et hémispliérique. Les sporothèces qui entourent la marge dans le Cheilanthes, deriennent confluents; ils sont toujours distincts dans les hypolepis, grandes fougères, souvent épineuses et parfois arborescentes, aux frondes amples, au moins aussi larges que longues. Il s'éloigue du Myriopteris, dont il a le port, par l'absence de tout indusium rai et par celle de poils mêlés aux sporanges. (Consult. les planches analytiques.) 


\section{ENUMERATIO SPECIERUM.}

I. Frotdle tr seguevta GLabre vil GLatrescestrs.

1. Frondibus in ambitu triangularibus.

Micropteris, Sw.* (mala) - trianfula, Kze. - Sieberi, Kze. - tenuifolia, Sw. (Sehkh.*; Dry.opteris campestris, Rumph.*) - multifida, Sw. - Chilensis, F. (Allosurus hirsutus, Fl. cliil., non Presl) - angustifolia (Allosurus angustifolius, Mart. et Gal., PI. Mex., n..$^{\circ} 6330$, non PresI) - brachypus, Kze. - odora, Sw. (S.hhh.*) - ? elata, Kze. - Mysorensis, Wallich. - deltoides, Kze.

B. Frondibus in ambitu lanceolatis vel oratis.

Chcerophylla, Kze. - rufescens, Lmrk. - semiglabra (Nothochloena, Kze.*) - ? cuneata, Kliss. (Kze.*) - profusa, Kze.* - Mathewsii, Kze.* - aspidioides, F. (Galeott., n. ${ }^{\circ} 655$ i) - Grifjthiana, F., Griffith. (Indes) - Malaccensis, F. (Cuming, 11. ${ }^{\circ} 408$, Filic. Philipp.) - Alabamensis, Kze. - suaveolens, Sw. (Hook. et B., fragnz.*).

\section{Froxdze hisstie.}

Cornuta, Kze. - pariloba (C. hirla, var. parviloba, Kze.) - hirla, Sw. - ? vestita, Sw. (Sehkl.*, Kze.*) - viscosa, Lmrk. - glandulosa, F. - ? densa (Nothochliena, J. Sm., Kze.) - olivacea, (C. hirla, var. Kze.) - microphylla, Sw. (C. micromera, Link., Sloan.*, Plum.*).

\section{Chilessis.}

\section{SPECIES NONDUM DESCRIPTE}

Frondibns elatis, tripinnatis, in ambitu triangularibus, glaberrimis; slipitibus validis, rigidis, canalicnlatis, rnfescentibus, fasciculo vasorum mmico, litleram I simmlante peragratis; rhizomate repente, squamoso, squamis lanceolatis, inlegris, longissimè allenualis; segmentis ovalis, obtusissimis, basi sappè crenulatis, marginibus reflexis, scariosis, integris, indnsiiformibns; sporangiis maguis, elliplicis; anuulo latissimo, plano, 20-21 articulato; sporis globosis.

Habilat in Chili. (C. Gay.)

Filix insignis, robnsto, stipite elato, firmo, levvi.

(Longueur totale, 40 eentim. et plus; le stipe, qui atteint à la grosseur d'une plume de corbeau, est à la fronde :: $1: 5$; les pinnules inféricures dépassent 6 centim. de long; les segments n’ont qưun millim. de largeur.)

En vorant les stipes de fougères non arrondis, comme les rameanx, mais bien canaliculés, on doit en conelure que, quelque divisées que soient les frondes, leurs supports ne sont autre chose que des pétioles.

\section{I. A \glstifolia.}

Frondibus triangularibus; stipitibns aterimis, adiantinis; pinnulis inferioribus pedatis bipinnatisque; pinnulis intermediis pinnatis; supremis simplicibus; segmentis linearibus, terminalibus, longissimis; sporotheciis continuis, angustis; indusio villoso; sporougiis subrotundis; annulo 14-16 arliculato; sporis trigonis? 
DES POLYPODIACÉES.

Habital in Mexico (Cordillera, Vera-Cruz, Galeoti, n. 6330 ; Allosurus angustifolius, Galeotti non Presl).

Filix glabra, aspectu Onychii; segneutis ovato-linearibus; terminalibus condatis.

(Longueur totale, 27 - 29 centim., dont le stipe fait la moitié; pinnules de la base, 6 eentim. : le segınent, qui les rend pédiaires, a 3 centim.; les entrenœuds sont espacés de 2 eentim.; le rachis des pinnules est convexe vers la base et plane vers le haut.)

C'est la seule espèce à faux indusium villeux; elle a du reste un port qui l'éloigne de toutes les autres espèecs.

\section{ASPIDIOIDES.}

Frondibus bipinnutis, in aiubitu lanceolatis; slipite cylindrico et rachi aterrimis, pilosis; pilis articulntis, setaceis; pinnis lanceolatis, approximatis, emergentibus, curvalis, glabris; segntentis ovoideis, supernè auriculatis, dein basi subpüunalis, siccilute planis, in petiolum desiuentibus, terminali majuscula; sporotheciis margines laninarum et segmenta earum invadentibus; indusio continuo, tenui, pellucido; sporotheciis tabacinis, copiosis, brevè pedicellatis, ellipsoideis; annulo 16-18 arliculato; sporis crassis, uigrescentibus, rotundis, rariùs trigonis.

Habilat in Mexico (Prov. Oaxaca, San-Pedro Nolasco, Galeotti, n. 6557 , allitud. circiler 2600 met.).

Filix rufa, regularis, facie uspidiorum; pinuis approximatis; segmentis iuferioribus subpinnalis.

(Longueur totale, 30 centim.; envergure des pinnules, 6 eentim.; envergure des segments, 1 eentim.; intervalle des pinnules entre elles, $12-15$ millim. Nous en comptons une vingtaine, et elacune d'elles est ehargée d'une douzaine environ de segments. Ceux-ei sont entiers dans la partic supérieure de la pinnule, aurieulés, puis pinnés inférieurement.)

\section{Griffithiana.}

Frondibus bipinunlis, elongatis, in ambitu linenri-lanceolutis, apice pinnatis; stipitibus trigonis el rachibıs glaberrimis, rubellis; segmentis renotis, brevissimè petiolatis, brsi pinnatifidis, triangularibus, lobo terminoli majusculo: spocolleciis latiusculis; indusio spurio, convexo; spoirangïs ovatis; anuulo 18-20 articulato, pedicello brevissino; sporis crassiusculis, rolundis, leviter papillosis.

Habitat in Malncca. (Griffith.)

Filix elalı, glabra, basi bipinnata, sumunitate pinnuta; labitu proprio.

(Longueur des plus grandes frondes, $32-34$ eentim.; intervalle séparant les pinnules et les égalant en longueur, 2 centim.)

Espèce fort distinete, se rapproehant des pellaea, mạis privée de réceptacle et portant eles segments qui tendent à se séparer en lobules.

\section{MALACCENSIS.}

Frondibus pinnatis, ovoideis; stipitibus ebeneis, flifornibus, augustè canaliculutis, segmentis remotis, subpinnatifidis, lobalis; lobis rolundalis; frondibus sterilibus, brevio- 
ribus, amplioribus; segmentis obtusis; fertilibus longioribus, segmentis remotioribus, acutis; indnsio plano, latiusculo; sporangiis ovatis; annulo 16-18 articulato; sporis ovoideis trigonisque.

Habilat in Malacca. (Cuming, n. 408.)

Filix frondibus dissimilaribus, tenera, pellucida; nervillis fabellatis.

(Longueur tolale, 18-20 centim., dont le slipe fait la moitié.)

Celte curieuse espèce demande à ètre mieux connue; les frondes sout dissimilaires.

\title{
VI. Glandulosa.
}

Frondibus lanceolatis, tripinnatis, pilis glundulosis, septatis, pellucidis obsitis; stipite flaccido, rufo; raclii hirsutissimo; pinnis lanceolatis, ussurgentibus; segmentis hirtis, pimnatifidis; lobulis fissis; sterilibus planis, fertilibus bullato-crispis; sporangiis ovatis; indusio obsoleto; annulo $16-18$ articulato; sporis trigonis.

Habitat in Brasilin. (Claussen.)

Filix elata, hirto-viscosa; pinnis munerosis, contractis.

(Longueur totale, 54-60 centim., dont le stipe fait un peu moins de la moitié; les pinnules. redressées contre le rachis, ont de $6-7$ centim. sur 2 environ d'envergure.)

C'est l'une des plus grandes espèces du genre. Les poils sont de mème nature que ceux du C. viscosa, à fronde triangulaire, ayant un port tout différent.

\section{NOTHOCHLENA, R. Br.}

\author{
Prodr., p. 145. \\ Acrostichi spec., L. et Auct. - Cincinalis spec., Desv.
}

SPORothecis ad apicem venularum sitis, subuniseriatis, limbum angustum constitnentibus; sporangiis ellipicis; annulo $16-20$ arliculato; sporis globulosi., nigrescentibus, crassis, lavibus aut rugulosis.

FroNdibes pinnatis vel rarò bipinnalis, lanceolato-linearibus, ferè semper lanatis; pinnulis sinuatis, patulis; pilis stellatis, nodulosis, arliculato strangulatis; petiolis rufo-fuscis.

Filices pracipuè Americana, erectu, elastica, lanceolato-lineares; pinnis numerosis approximatis; species plures ad Cheilanthem tendunt.

Diagnosis: Ноок, et B., Gen. filic., t. Lxxv, A ( $N$. tenera, Hоoк.). Tab. nost., XIII, fig. 2; Nothochlena eriophora, F.

Dans les cheilanthes, avec lesquels les nolhochlana ont des rapports, la marge tend à devenir scarieuse, elle se replie sur les sporanges. Ici elle est toujours étalèe et ne forme janais de faux indusium; les sporothèces sont marginaux, con- 
tinus et nervillaires. Ces fougères ont la plus grande tendance à se charger de poils qui rendent tomenteuse la surface inférieure des lames. Les frondes sont allongées et presque linéaires. On y trouve des poils étoilés comme dans les niphobolus (Nolhochlcena sinuata et trichomanoides); ils sont quelquefois noduleux ( $N$. rufa et hypoleuca).

Ces fougères vivent au Mexique, à la Nouvelle-Hollande, aux îles Philippines, à Saint-Domingue, au Chili et au Brésil. Nous avons séparé de ce genre les espèces glabres, à frondules divariquées, subopposées, trifoliolées et à sporothèces tout a fait globuleux pour les réunir dans le genre suivant dont nous proposons ladoption.

\section{ENUMERATIO SPECIERUM.}

1. Squanose. - Sinuata, Klfss. (Kze.*; Acrostichum, Sw.) - loevis, Mart. et Gal.* - distans, Labill. - Eckloniana, Kze. - Marantoe, R. Br. (Ceterach, Cand.) - Galeottii, F. - Gillesï, F. (Cheilanthes squamosa, Hook. et Gr.*) - pumilio, R. Br.

2. Villos.e. - Trichomanoides, R. Br. (Pteris, Schkh.*) - mollis, Kze.* - rufa, Presl (Cheilanthes, Willd.) - hypoleuca, Kze** canescens, Kze. - invequalis, Kze.* - sulcata, Lmrk. (Kze.*) - lanuginosa, Dest. (Schkh.*; Acrostichum lanuginosum, Desf.) - Plukenetii, F. (Acrostichum velleum, Ait., Sw.) - eriophora, F.* (Gardn., n.* 2390.)

\section{GaleotTII.}

\section{SPECIES NONDUM DESCRIPTE.}

Frondibus lanceolatis, attenuatis, bipinnatis; stipite et rachi atris; squamis lanceolatis, laceris, rufescentibus, hirlis, suprà viridi-olivaceis, subtìs lactè rufescentibuls; pinnis lanceolatis, 25-30 jugis; segnentis sessilibus, lineari-lanceolatis, crenulatis, subpinnatifidis, oblusis, inferioribus longioribus; fusciculis vusorum duobus, angulatim apice conniventibus; sporolheciis marginaulibus; sporangïs pancis, distantibus; annulo 18 articulalo lato; pedicello brevissino; sporis magnis, fuscis, rolundatis.

Habilat in Mexico (Oaxaca, Capulalpan, altilud. 3000 met.; Galeotti, n. ${ }^{\circ} 6565$ ).

Filix insignis, aspidiiformis, squamoso-hirla, rufescens, bipinnata; pinnis inferioribus oppositis; internediis el superioribus allernis.

(Longueur de la fronde, moins le slipe, 30 centim. sur 8 d'envergure; pinnelles, 10-11 millim. Lintervalle qui sépare les pinnules est de $22-24$ millim.)

II. Eriophora, tab. XIII, fig. 3.

Frondibus triangularibus, palmatis, lanâ molli fulvâ, longissimâ vestitis, petiolis filiformibus, adiantinis, glaberrimis; lobis rolundis, interntedio sinuato, apice obluso; lateralibus brevioribus; rhizomate erecto; sporotheciis uervillaribus; sporangiis remotis; sporis rolundatis.

Habital in Brasilia. (Gardner, $\mathrm{n}^{\circ}$ 2390.)

Filix parvula, lanata; stipilibus grucilibus, flexuosis.

(Longueur totale, 6 centim.; frondes, 15 centim. en toutes dimensions. Le duret laineux qui la recouvre, est formé de poils faures, allongés et noduleux. 
$\doteqdot$ CInCINalis, Desv.

In Berol. Magaz., V, $3_{11}$ et seqq. (reduclumi).

Acrostichi, Pleridis, Gymnogranmes el Nolhochlecnes spec., Sw., Willd., Lmrk., Linn., Kaulf., Presl, etc.

Frovd be's ereclis, Iripinnalis, Iriangularibus; slipile lavi, adiantino; rachibus filiformibus, rigidis; pinnis divaricalis, subopposilis ; frondulis ovoideis, regularibus, integerrimis, opposilis, Irifoliolalis, glabris, ferè semper pulverecerineo colore adspersis, terminali maximâ; nervillis pinnatis; sporolheciis margrinanlibus, nudis, conlinuis, angustis; sporangriis cocciformibus, sessilibus, maximis; annulo crasso, coccineo, lato, superiori, 18 -20 arliculalo; slomate plurinervalo, mersis longissimis, parallelibus; sporis crassissimis, spharericis, laevibus, oculo nudo perspicuis.

Filices lenerce, tripimnale, brisceformes; frondulis inlegris, petiolatis, pulvere cernceo vestitis; slipitibus el rachibus adiantorum; in Americâ tropicali, Mexico, Peruvî et Chili vigenles.

Yous arons hésité longtemps à conserver ce genre, doniné par l'autorité des auteurs qui refusent d'en reconnaitre la validité; toutefois nous étions vivement frappé de la spécialité du port des espèces, que nous voulions y renfermer. Il est dans notre opinion que toute difference essentielle de port indique des différences organiques que l'on ne troure pas toujours, mais qui existent. Les cincinalis en offrent la preuve.

Les sporanges, comme toutes celles des vraies cheilanthées, sont portées sur un pédicelle extrèmement court. Leur forme est exactement globuleuse; le sacculus est ridé et ne renferme qu'un très-petit nombre de spores énormes, visibles à l'oil nu, arrondis et lisses. L'anneau couronne le sommet de ce sacculus et ne peut être reconnu ni comme latéral, ni comme vẹtical. Il est large, imite une bandelette, est à peine crénelé et présente un grand nombre d'articulations. L'élasticité dont il est doué, est extrême; il se débande avec force, chasse au loin les spores et déchire le sacculus. Le slona est formé d'un assez grand nombre de nervilles parallèles, longues et rapprochées.

Quoique nous ayons conservé le nom créé par. Desvaux, notre genre Cinciralis ne correspond pas exactement à celui que cet auteur arait formé (t. V, du Magàsin de Berlin). La plupart des espèces qui sont décrites ou énumérées dans ce recueil, prennent place parni les nothochlcena, où l'autcur, de son vivant même, les avait placées.

\section{LMUMERATIO SPECIERUM.}

Flavens (? Cincinalis, Dest.; Gymnogramme, Klfss.; Acrostichum, Willd.) - nivea (Vothochliena, Desv., Presl, Kze.; Acroslichum, Sw.) - tenera (Gill., Kze.*) - Fendlori (Molhochlena, Kze.*) dealbata (Nothoclena, Kize.*). 


\title{
B. Evolutio frondium indefinita: Jauesonie.e.
}

\section{JAMESONIA, Hook. et Grev.}

\author{
Icon. filic., t. 178 .
}

Pteridis spec., Cavan., Sw., Layrr. et Auct. plurim. - Gymnogrammatis spec., KL., etc.

SPOROTHECIs ad basim venularum insertis, planiusculis, demùm confluentibus; indusio e margine frondis veroluto oriundo, meinbranaceo, continuo, sapè sporotheciis remoto, frequenter nullo; sporangiis brevi pedicello donatis, cum sporangiastris viltatis immixtis; annulo $18-20$ articulato; sporis trigonis.

Froxdibus pinnalis, linearibus, frondulis rmultis, sapè imbricatis, sessilibus, subrolundo-cordatis, apice circinatis; nervillis liberis, pinnatis, bifurcatis, seu flabellatis, tenuibus.

Diagnosis : Ноoк. et B., Gen. filic., t. xilı. J. pulchr'a, Hoox. et Grev., loc. cit.; F,, tab. xil, fig. 5 (J. scalaris, KzE.).

Filices herbacece, erectce, rigida, fasciculatce; marginibus frondium convolutis; evolutione indefinitâ ; imprimis Peruviance.

Le port des Jamesonia est tellement distinct, qu'il permet de le reconnaitre à la première vue. Les frondes sont linéaires, à frondules si nombreuses que nous en comptons 170 paires dans le spécimen du J. scalaris, Kze., de notre herbier. Ces fiondules sont sessiles, ovoïdes ou cordiformes; les sporanges, conme dans le Myriopleris, sont entremêlées de poils roux, très-nombreux; l'indusium, ainsi qu'il arrive souvent dans les cheilanthées, est tantôt apparent et tantôt nul. Nous devons encore signaler l'évolution indéfinie des frondes comme caractéristique. Ce caractère, n'étant pas évident dans le $J$. adnata de Kunze (suites à Schkh., t. 133), lequel est en outre pinnatifide, n'est admis par nous dans ce genre que sous toutes réserves.

\section{ENUMERATIO SPECIERUII.}

Pulchra, Hook.* - scalaris, Kze.* - cinnamomea, Kzc.* - verticalis, Kzc.* -? adnata, hze.* - canescens, Kze. - bipinnata (Gymnogramme elongata, Hook.*; evolutio in icone indefinita). 


\section{Considérations générales sur le groupe des Cheilanthées.}

Les genres qui composent ce groupe sont plus complétement sẻparès par le port qu'ils ne le sont par l'appareil reproducteur. Ils ont une grande disposition à se charger d'ècailles et de poils, tendent à la station verticale, et, quoique rarement, se présentent à l'état ligneux. Les analogies que les cheilanthées offrent avec les autres groupes sont peu nombreuses; cependant le genre Hypolepis semble avoir quelques rapports avec le Lonchitis, mais par l'indusium seulement, et le Plccosorus se rapproche un peu du Nevrogramme, qui appartient au petit groupe des hémionitidées; mais ces rapports sont peu marqués.

On reconnaît, en étudiant les cheilanthées, combien est peu solide la base de classification empruntée à l'indusium. Parmi les genres qui les composent, l'Hypolepis, l'Aleuritopteris et l'Adiantopsis ont un indusium vrai, tandis que l'Eriosorus, le Plecosorus et le Nothochlacna en sont tout à fait privés; d'un autre côté le Cheilanthes, le Myriopteris et le Jamesonia renferment des espèces avec ou sans indusium, et sont pourtant très - étroitenent unies entre elles par tous les autres caractères. L'ambiguité du caractère, tiré de la présence ou de l'absence de ce tẻgument, est évidente dans tous les genres de cheilanthées, dont la marge se replie de dehors en dedans. Cette disposition est manifeste dans les genres Cheilanthes, Myriopteris, Plecosorus et Jamesonia. Les genres indusiés ont des lames qui restent planes. Exemples: Hypolepis, Adiantopsis, Nothochlana et Alcuritopteris.

Ce groupe curieux et difficile peut être subdivisé en trois sections : 1." Les hypolépidées, renfermant deux genres assez éloignẻs par le port. L'un, l'Adiantopsis, à espèces se rapprochant des Adiantım; l'autre, l'Hypolepis, dont les frondes décomposées rappellent celles des alsophilées; tous deux à sporanges pédicellées. 2. Les vraies cheilanthées (Eucheilanthece) auxquelles se rapporte tout ce que nous avons dit plus haut; plantes herbacées, laineuses, villeuses et plus rarenilent céracées; à sporanges très-courtement pétiolées et presque globuleuses, ayant, dans leurs frondes, une tendance manifeste à se diviser en frondules arrondies, de petite dimension. 3.” Jamesoniées; fougères élancées, linéaires, multifrondulées, à évolution indéfinie de la fronde, villeuses, à sporanges presque sessiles.

Dans les plantes de ce groupe, les spores ont une grosseur considérable et affectent presque toujours la forme trigone.

On trouve des cheilantliées dans toutes les parties du globe; nais moins en Europe que sous les tropiques. 


\section{§. 3. Sporothecia aut nervillce proliferce ad mesonevron obliquè currentia.}

Filices aspectu vario; oligomeræ, sæpè ceriferæ, ferè omnes tropicales.

Grammitidearum pars, Aspleniarice, Polypodiacece el Hemionitidece, Prest, Tentam. pterid., p. 206, 217, etc.

Hemionitidealum pars; Polypodiearum pars, elc., Gavdich., Voy. Uran. bot., p. 263.

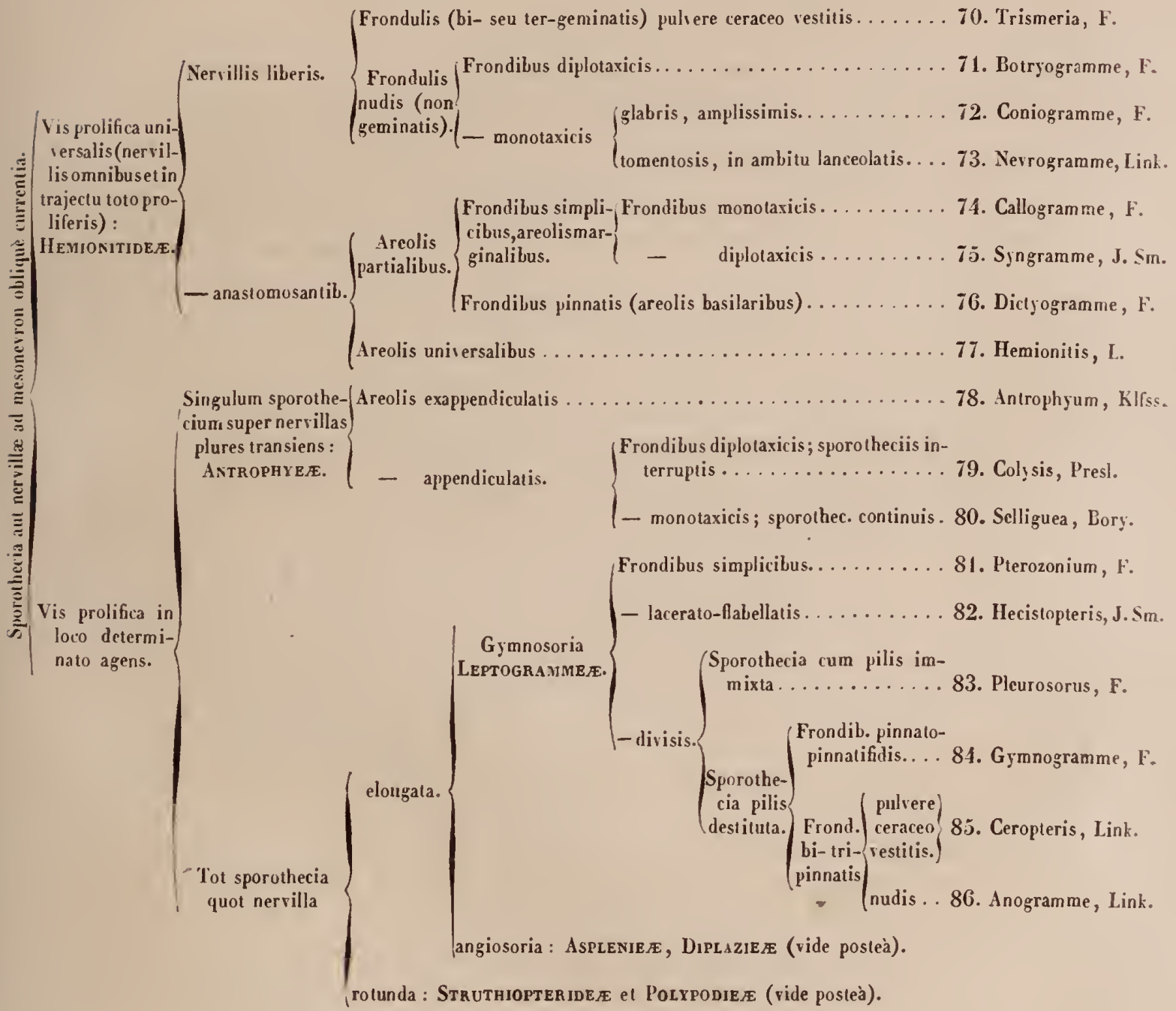


+ Vis prolifica unirersalis, ill est sporollecia laminas inleğrè restientia; nervillis onturilus el iı trajectu toto proliferis : IIE.HIOVITIDE.E.

Filices erectæ, plùs minùsve divisæ, feracissimæ, glalıre aut pilosa.

* Nervillis liberis.

\section{† Frondibus pulvere ceraceo vestitis.}

70. TRISIIERIA, F.

Acrostichi spec., Lix. - Gymnogrimumes spec., Beur., Desv, el Auct. pllais.

SPORотнесиs linearibus, depauperalis; sporangiis pyriformibus, maximis, subsessilibus; slomate 8 nervalo, angusto, nẹris crassis, brevibus, reclis; annulo, crasso, 18-24 arliculato, arliculis remolis; sporis crassissimis, Iriedricis, flaccidis, succineo colore.

Froxdibes pinnatis bipinnatisque, elatis, rigidis; rachi sulcalo, cbeneo-rufescente; pinnulis angustè lanceolatis, acutis, margine serrulatis; frondulis scep̀̀ bi-seu ter-geminalis; nervillis flabelliformibus, furcalis, creberrimis, laminis infernè pulvere ceraceo albo vel flavo densè vestitis; fasciculo v'asorum hippocrepidi seu oblusè quadrangulari al basi aperto, ramos duo breves emittente.

Filices erecter, elatce, rigide, Americance; frondibus pinnutis, frondulis folin Salicis viminalis referentibus.

Diagnosis : tab. xıv, A, fig. 1, T. argentea, et fig. 2, T. anrea, F.

A Coniogramme non longè distat; naturâ exsudationis et fubricâ sporangiarnum cum Ceropteridi affinis.

Les trismeria sont des fougères à frondes pinnées dont les frondules, à marges finement denticulées, ressemblent à des feuilles de saule. Elles présentent un caractère unique parmi les polypodiacées, celui davoir des pinnules pinnées, réduites a deux ou trois frondules, ce qui les fait parâtre trifoliées, surtout vers le haut de la fronde; inférieurement elles sont réduites à une seule frondule. Le stipe est rufescent, lisse et nu; la lame inférieure des frondules est chargèe très-abondanment de cette matière céracée, blanchı ou jaunâtre que nous avons signalée dans le Ceropteris, avec lequel toutefois on ne peut confondre le Trismeria, dont le port et la nervation sont absolument différents; chacune de ces molécules vue 
isolément au nicroscope, se montre sous l'aspect d'une glande claviforme dont le support est court et épais. Dans les jeunes pousses la sécrétion céracèe manque assez souvent.

\section{ENUMERITIO SPECIERUM.}

Argentea, F. (Acrostichum trifoliatum, Pohl, Pl. Brasil.) - aurea, F. (Acrost. trifoliatum, L. . Sch.h.*, Sloan.*, Petiv.*, Plum.*, etc.) - microphy.lla, F.

I. ARGENTEA.

\section{SPECIES NONDUII DESCRIPTE.}

Frondibus ovato-lanceolatis; stipitibus rubris, glaberrinis, sulcatis, nitentibuls; basi squamosis; squanis angustè lanceolatis, acuminatis; frondulis pulvere argenteo adspersis, alternis, basi bipinnatis, lanceolatis; frondulis duobus incequalibus, superioribus parvulis, marginibus serratis, serraturis oblusiusculis; fertilibus linearibus, acuminatis; sporotheciis brevè stipitatis, ellipticis; annulo 20 articulato; sporis magnis, triedricis, fuscis.

Habitat in Caraccas (Moritz); in Brasilia, Minas Geraes, Pobl.

Filix glabra; frondibus pulvere argenteo vestitis.

(Longueur totale, près d'un mètre; frondules, 10 eentim. sur 15 millim. de largeur; la supérieure de moitié plus petite dans toutes ses dimensions. Les pinnules sont bifrondulées et les denticulations très-marquées; inférieurcment les frondules se montrent isolées. Dans le $T$. aurea les pinnules sont fréquemment trifoliées, les frondules plus étroites, plus finement dentieulées, et les nervilles beaueoup plus rapprochées; la séerétion eéracée est d'un jaune très-prononcé.)

Nous appelons l'attention des botanistes sụr une espèce péruvienne à sécrétion blanchâtre, que nous voyons stérile dans l'herbier de notre savant ami M. le docteur Nougeot. Elle ressemble à une phanérogane. Voici sous quel nom nous la désignons :

II. MiCROPHYLLA.

Frondibus lineari-lanceolatis; frondulis argenteis, obtusiusculis, brevè petiolatis, inferioribus bipinnatis, frondulâ interiore parvulâ; marginibus remotè arguto-serratis; superioribus alternis, terminalibus longioribus; stipitibus brevibus, squamosis; squamis lanceolatis; sporotheciis ignotis.

Habitat in Peruviâ.

Filix terrestris, glaberrima, radice fibrosâ.

(Longueur totale, 30 centim., dont le stipe fait à peine la sixième partie; frondules un peu moins de 3 centim. sur 4 millim. de largeur.) 


\section{it Frondulis nudis.}

A. Frondibus diplotaxicis.

\section{BOTR YOGRAMUE, F.}

Allosuri spec., Kze., Lixwea, xu (1839); Mart. el Galeotri, Foug. du Mexiq., p. 47. Sporotuecus nervillaribus, laminau omminò instar acrostichearum tectantibus; sporanguis ellipssideis, bresé pedicellatis; annulo latiusculn, $16-18$ articulato: sporis triedricis.

l'кохDвтs dissimilaribus, supernè fructificantibus, glabris, subcoriaceis, supri decounositis, pinnis alternis, remotis, petiolatis; stipitibus curvatis fasciculum unicum curvatum ferentibus, versìs basin syuanosis; syuamis lanceolutis, Iongè acuminatis stranineisyue, rachi flexuoso, sulcato, glabro; frondulis: sterilibus, pleriminue ternatis, ovatis, obtusiusculis, serrulatis, glaucescentibus; nervillis flabellatis, marginem incrassatam exerentibus et mucrones sinulanlibus; fertilibus ad apicem pinnarun superiorarum terminalibus, sublinearibus, acunninatis, marginibus involutis.

Filix memorabilis, Mexicana; frondibus dissimilaribus, glaberrimis, slipitibus flexuosis, slramineis.

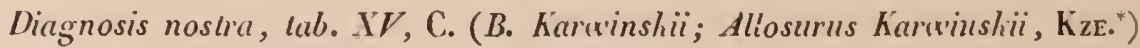

La fronde n'est fertile que vers la partie supérieure, comme il arrive dans l'Osmunda. Les frondules stériles sỏnt ovales, assez longuement pétiolées et obtuses. Les nervilles, après avoir traversé la lame, sortent de la marge et forment des espèces de mucrons robustes, couchés sur l'épaisseur de la lame qui est épaissie vers ses limites. Les écailles qui couvrent la base du stipe ont une couleur jaune-clair agréable; celles qui sont tout à fait inférieures prennent une teinte noire très-prononcée, mais leur base est roussâtre. Après la chute des écailles, la partie du stipe qui les portait est rude au toucher, et les cicatrices qu'elles y ont laissées sont visibles à l'œil nu. Les frondes fertiles, très-étroites, sont chargées de sporothèces à la manière des acrostichées.

Cette belle fougère, que l'on s'étonne de voir figurer parmi les allosirus, a des frondules dentées, voisines de celles des coniogramme, quoique plus petites.

Nous établissons notre diagnose sur un très-beau spécinen donné par M. Galeotti sous le n. ${ }^{\circ}$ 6351. Il a été recueilli dans le Mexique près de Yavesia, province d'Oaxaca, à une hauteur de 2400 mètres environ.

\section{SPECIES.}

Genus monotypum: vide diagnosin generis. 
B. Frondibus monotaxicis.

\section{CONIOGRAMME, F.}

Gymogrammes spec., Bun. - Giammitidis spec., Wall.

SPORотнеси angustis, depauperatis, superficialibus, marginem non altingenlibus; sporangiis rotundis; stomate lato, sub 8 nervato, nervis distantibus, longis, flexuosis; annulo spisso, articulis 14-24; sporis triedricis, lutescentibus.

FroIdines sape in eodem caudice pinnatis et bipinnatis; pinnulis lanceolatis, plis minusve angustis, inlegris, dentatis, seu tenuiter fimbriatis, acuminatis; mesonevro robusto, lavi; nervillis parallelo-furcalis, tenuioribus, apice incrassatis, onmibus proliferis; rachi helveolo, crasso; fasciculo vasorum in slipilibus unico, angusto, ferrum equinum simulanle.

Filices Indice, erecte, magnce, speciosissince, pauci-juga, glaberrima; frondibus vatiabilibus, basi bipinnatis apice pinnatis.

Diagnosis: tab. xuv, B, fig. 1, C. Javanica, F. (Gymnogr. Javanica, Bucu., Fl. Jav., t. xu.); fig. 2, C. serrulata, F. (fragmentum).

Formé aux dépens des gyminogramme, auquel il tient par la disposition des sporothèces, le Coniogramme en diffère tout à fait par le port et la nervation. Il renferme de très-belles fougères, grandes et robustes, bipinnées, parfaitement glabres, à frondules distantes, pétiolées, entières, acuminées ou finement denticulées; elles sont envalies par des sporothèces nus, nervillaires, étroits, qui s'arrêtent avant d'atteindre la marge. Le rachis est couleur de paille, aplati du côté inférieur, bombé en dessus. Les nervilles sont ténues, rapprochées, renflées à leur point de terminaison et flabelliformes.

On trouve ces plantes dans les Indes orientales et dans les îles de la mer des Indes : elles sont assez polymorphes.

\section{ENUMERATIO SPECIERUM.}

Serrulala (Gymnogramme, Blum.*) et var. caudala (Grammilis, Wall.) - Javanica (Gymnogramme, Blum.*) et var. nuacrophylla, Blum.* (Cuming, Filic. Philipp., 11. 86) - Serra, F.

SERRA.

\section{SPECIES NONDUM DESCRIPTA.}

Frondibus pinnatis, basi irregulatim bipinnatis; stipile helveolo, glabro, supernè trisulcato; frondulis omnibus proliferis, lanceolatis, acumiuatis, longè petiolatis, basi latis, cordatis, glaberrimis, membranaceis, mesonevro pilosiusculo, marginibus serratis, dentibus robustis, incrqualibus; nervillis furcatis, remotis, marginem allingentibus; 
sporolhecïs multò ante marginem terminatis; sporangüs magnis, ovoideis; annulo 18.20 articulato; sporis triedricis, scepè deformibus.

Habilat in insula Zejlanica. (Gardner, n. $\left.{ }^{\circ} 21 ; 1847.\right)$

Filix pimnata, basi pinnato-pimnatifida, difformi.

(Longueur totale prise à la base de la pinnule terminale, 40 centim.; le stipe fait moitic de lat grandeur totale; frondules, $15-18$ centim.; elles mesurent 30-35 millim.; le pétiole a 5-7 millin. de hauteur; nous comptons 7 nervilles par centimctre.)

On ne peut la confondre, ni avec le $C$. Jasanica, dont les frondules sont atténuées à la base (ct à narges entières, ni avec le $C$. serrulata, à frondules terninées en un prolongement caudiforme, dont les marges sont très-finement denticulées. Elle a uu port spécial qui permet de la reconnaitre tout d'abord.

\section{NEVROGRAMME, Link. (1811.)}

$$
\text { Spec. filic., p. } 158 \text {. }
$$

Gymnogrammes, Hemionitidis, Acrostichi, Asplenii spec., Aucr. var.

SPORотнесиs linearibus, venulas planè invadenlibus, sed marginem non allingentibus, ferrugineis, creberrimis; sporangiis brevè pedicellatis, rolundis; slomate 10-11 neriato, magno, inverso, subrhomboideo; annulo 14-16 arliculalo; sporis rolundalis, oroideis, parvulis, nigrescentibus (in Nevrogrammate pedatâ, Lk., (riedricis).

IRoxdibus pinnatis bipinnatisve, segmentis irregularibus, dentatis; nervillis flabelliformibus, approximatis, tenuibus; slipitibus lacibus, ebeneis; pilis in tolu. fronde sparsis, arliculatis, nodosis, concatenatis, strangulatis, rarò subconlinuis, apice sapè glandolosis; fasciculo solitario, tenui, rolundo.

Filices villoso-tomemtosce, erectce, divisce, rigida, siccitate fulvescentes; Americance.

Diagnosis: Lab. xıv, C, fig. 1, N. tomentosa, Lisk (Acrostichum, L.); cum fragmentis; fig. 2, N. rufu, Lא., el fig. 2, N. pedata, Lk.

Neurogramme habilu exteriori, sporangiis, sporis et pilositate proxima Hemionitidis.

Les nesrogramme sont des fougères tomenteuses, épaisses, à consistance molle, devenant fauves par la dessiccation; le système pileux est fort renarquable : il consiste en longs poils, les uns étranglès d'espace en espace, concaténés et terminés par un capitule solide et globuleux; les autres, noduleux, finissant en une longue pointe aiguë. Les stipes sont lisses et couleur d'ébène; les frondes pennées, bipennées ou pédiaires. Celles du $N$. tomentosa rappellent, par leur forme, les frondes du Pellaca hastata. Toutes les nervilles deviennent proliferes et les 
sporothèces s'arrètent avant d'atteindre la marge. Les spores ovoïdes ou arrondis dans presque toutes les espèces sont triédriques dans le $N$. pedalo, qui a aussi un port différent. Ces fougères vivent en Amérique.

ENUMERATIO SPECIERUM.

Rufa, Lk. (Hemionitis, Schkh.*, Stoan.*) - tomentosa, Lk.(Hemnionitis, Radd.*) - pedata, Lk. (Hemionitis, Sw.*).

\section{** Nervillis conniventibus.}

\section{** Nervillis anastomosantibus.}

+ Areolis partialibus.

A. Frondulis simplicibus.

\section{CALLOGRAMiME, F.}

SPOROTHECus linearibus, spissis, oblusis, longissimis, in partem liberam nervillarum excurrenlibus; sporangiis ovatis, anratis, sessilibus, ad basim pilis erectis, capile grloboso, involucralis; súmmale an gusto, 6 nervalo; anmulo $18-20$ articulato; sporis triedricis.

Hкохрівus simplicibus, monolaxicis, orato-lanceolalis, acuminalis, membraurceis, siccilate rnfescerlibus, margine undulato; slipilibus longis, badiu, supernè canaliculalis, fragilibus; nervillis relem irregularem ad marginem formanlibıs; areolis exappendiculatis; mesonevro robuslo; squamis basimm stipilum succineo colore, angustis, arliculalis, subcylindraccis, formô speciali et in aliis generibus munquam occurrentibus.

Filix Asiatica, prcestantissima, erecta, membrnuncea; rhizomate longè repente.

Diagnosis : Lab. xv, A. - Fig. 1, C. Ccecilice, F. - Fig. 2, Dictyogranune Juponica, F. (fragmentum ad comparaudum).

Ce genre est monotype et fondé sur une fougère à fronde simple; lancéolée, acuminée, à marge légèrement ondulée, rufescente par dessiccation. Le stipe est rougeâtre, purpurin et fragile comme celui des adiantum. Les nervilles sont parallèles, bifurquées, libres dans leur plus grande étendue, mais se réunissant près de la marge pour former une et plus rarement deux rangées daréoles inégalement hexagonales; le mésonèvre est rohuste; toutes les nervilles latérales deviennent prolifères, mais jamais les sporanges n'envalissent la partie réticulte 
de la lime. Le thizome est couvert de squames coniques, articulées, solides, terminces par un petit pénicille de poils; il est rampant. Cette plante a été recueillie à Singhapour (Inde transgangétique), par M. Cribdichaud, auquel nous unissent les liens d'une vieille amitié.

\section{SPECIFS.}

Cicciliu. (Vide suprit characteres et disquisiviones in genere.)

binnensions: longnem totale de la fronde fertile, 50 centim., dont le slipe fait les ${ }_{5}$ : largeur. 6 centinn. les frondes stériles de nolre spécimen sont moins grandes; nous comptons 6 nervues pur cention.; le rhizome est flexueux et de la grosseur lius plume ì écrire.)

\section{SINGRAMUE, J. Sm. (1845.)}

In Lond. Journ. bot. 1845 , IV, p. 168 .

Sponotnecus linearibus. depanperalis, in parlem liberam nervillarum evolulis; annulo $20-2$ f arliculalo, pedicello, mudo; sporis reniformibus seu ovalibus: sporantriastris nullis.

Froxdвcs simplicibus, diplolaxicis, membrunaceis, pellucidis, leneris, apice obluso, margine unduluto, infernè subcuneato; ferlilibus longrius peliolulis el anguslioribus; nervillis circi marginem anaslomosalis; mesonesro inforne fuscescenle, ad apicem eranescenle.

Filix Philippiuensis, erecta, tenera.

Diaguosis : tab. xr, B, fig. 1, S. vittuformis, J. Sм., l. cit.

Tervatione Callogrammes, sed habitu, texturî̀, nuditute pedicelli sporangiorum, sporangiastrorum absentiâ et sporis ovalibus, amplissimè ab ề differt.

Les frondes sont simples, les stériles oborées, ondulées, pellucides, niembratneuses; les fertiles lancéolées assez étroites, très-longuement pétiolées, opaques; la nervation est exactement la même que celle du Cullogrcrmme; mais dans ce dernier genre les frondes sont diplotaxiques, cartilagineuses, et les stipes ébénéens, les sporanges ont un pédicelle rameux; elles portent des sporangiastres; enfin les spores sont trièdres et non arrondis.

B. Froulibus pinnatis.

\section{DICTY OGRAMINE, F.}

SPORотнесиs limearibus, extensis, longè à mesonerro incipientibus, depauperalis, conlinuis; sporangiis globosis; ammulo 14 arliculalo; sporis trigonis; slomale sub) 6 nersalo. 
Frovdrbes coriaceis, glaberrimis, pinnatis, sapè in parte inferior bipinnatis; pinnis et pinnulis petiolalis, sessilibus aut adnatis, acuminalis, obtusiusculis, margine reflexo, serrulato; stipite brevi; nervillis ad mesonesron anaslornosatis, dein liberis et marginem non attingentibus, apicibus attenuatis, areolis biserialibus; costalibus brevioribus, sterilibus; intermediis longioribus, fertilibus.

Filix elula, Japonica; consislenliam el aspectum Coniogrammes, sed nervillas anastomosalas habens; nervalione Callogrammes, sed inversa; nam areolie basilares sunt . in Dictyogramme verò el in Callogramme, marginales.

Diagnosis : Kuxze, die Farrenkr., p. 39, t. cxw, sub Gymnogramme, el tab. nostr.xv, $A$, fig. 2; frons sterilis, ad demonsirandum nervillas anastomosantes.

Gymnogrammes spec, Desv. et Kze. - Hemionitidis spec., Thusв. et Sw. (nec Nevrogramme, nec Slegnogramme).

Le Dictyogramme ne diffère des coniogranme que par des nervilles anastomosées près du mésonèvre, tandis qu'elles sont libres dans tout le reste de leur parcours. La partie réticulée reste stérile (roy. Coniogramme pour de plus longs détails). Ce genre a, parmi les hémionitidées, la valeur de l'Heterophlebiuı parmi les ptéridées, ou celle du Schizoloma parmi les lindsayées. Kunze avait placé celte fougère parmi les espèces du genre Gymnogramme, l'un des moins naturels de la famille, tel que le comprenaient les auteurs.

\section{SPECIES.}

Genus monotypum: vide diagnosim generis.

\section{计 Areolis universalibus.}

\section{HEMIONITIS, L. (1764.)}

Spec. plant., p. 1535 , reduct.

Hemionilis sect. prima, Press, 'Tentåm. plerid.

SРоRотнесіs superficialibus, reticulatis, areolarum latera omnia sequentibus; sporangiis rotundis; annulo $14-18$ articulato; sporis ovoideis, papillatis; sporangiastris nullis.

Frovdibus palmatis vel cordatis, vel sagittatis, spissis, sapè pannosis, longè petiolatis, sapè proliferis; pilis fragilibus, articulatis, laminas vestientibus: nervillis in areolas exappendiculatas, hexagronas dispositis; rhizomate surculiformi, fibrilloso. 
Filices erfecte, villusar, molles, tomentosa, Antillance aut Indica, pilis articulatis nodulosis el strangulatis vestilu; petiolum seu stipitem lcrvam fusco-nitentem, ut in Alimtis prebentes; species tamen unica subglabrescens, coriacen.

Iliugnosis: Hook. et B., Gen. filic., t. Lxxir, B. (II. corlatu, Roxв.); - Lab. nost1. wv, D, H. sagiltuta, F, reducll.

IJemionitis naturâ pilorum, consistentia frondium el fubricâ sporangiorum cum Nerrogrammate congruil.

La consistance de la fronde, la nature des poils et l'universalite des sporanges qui envahiss nt la totalite des nervilles, rapprochent le genre Hemionilis du Tesrogramime, parmi les espèces duquel se trouvent une fougère à fronde pédiaire. Les sporanges suivent le trajet des nervilles et forment ainsi un résean continu très-élégant. Sur trois espèces qui constituent ce genre, il y en a deux proliferes, l'une vers la marge, $H$. palmala, l'autre à la base de la fronde, $H$. strgillata, F. On trouve les hemionilis aux Antilles et dans les Indes orientales. (Voy. Antrophyum.)

\section{EXUMERATIO SPECIERUM.}

H. palmala, Willd. (Lmrk.*, Plum.*, Sloan.*, etc.) - H. cordala, Rosb. (Hlook. el Gı.) sugillata, F.* (Hügel, 11.03573 et 3882 , Herb. Vindobon.).

\section{SPECIES NONDUY DESCRIPTA.}

Sacittita, tab. XIV, D.

Frondibus simplicibus, cartilagineis, spissis, opacis; slipitibus ebeneis, squamosis; squanis apice capilatis; sterilibus cordatis, longioribus, scepè proliferis, fertilibus sagitlatis; mesoneuro atro, supernè evanescente; sporotheciis universalibus; sporrugiiis pilis longis, subsquamosis immixtis, pedicello lato donatis; annulo 18 articulato; sporis papillatis.

Habilat in Asiû orientali. (Hügel, no ${ }^{\circ} 3573$ et 3882.).

Filix formosa, sugillarice facie; rhizomate repente.

(Longucur totale, 30 centim.; les fertiles portent prés de 40 centim.; le stipe est à la lant: $:: 3: 1$; les lames stériles ont un peu plus de 8 centim. jusquà la naissance du sinus, sur 6 de largeur, arec des oreilleltes qui mesureut 4 ccutim.; les lames fertiles dépassent 10 centin., et les orcillettes, qui ont 6 centim. de déreloppenent, sont pointues et extrèmement dirariquées.)

Le $11 .{ }^{\circ} \mathbf{2 8 5}$ des plantes de M. Cuming, rapporté des Philippines el déterminé par .I. J. Smilh comme étant l'II. curdala, semble différer de la planclie 64 des Icones filicum de M.M. Hooker et Gréville; le nom d'll. intermedia lui serait convenablement appliqué. Notre espéce, dont les frondes robustes et épaisses sont chargées de quelques poils raides el rongeìtres, ne peut ètre confondue ni avec l'Il. corlata, ni avec le $11 .^{\circ} 285$ de .I. Cuming. 


\section{Considérations générales sur le groupe des Hémionitidées.}

Ce groupe renferme huit genres, ayant pour caractère commun de porter des sporanges sur la totalité des nervilles. Des sporothèces universels couvrent donc toute l'étendue des lames, comme il arrive chez les acrostichées; mais ici les sporanges, au lieu d'être cuticulaires, sont nervillaires. Ces fougères ont des frondes simples ou divisées, à segments plus ou moins dilatés, ni lobés, ni crénelés, et encore moins pinnées ou multifides. Elles sont toutes herbacées, très-féraces, villeuses et à poils articulés, intestiniformes ou aciculés. On trouve des sporangiastres dans le Callogramme. Les rapports avec les groupes voisins ne sont pas nombreux. Les adiantées, les lindsayées et les ptéridées ont des sporothèces marginaux avec indusium; les cheilanthées, presque toujours indusiées, des sporothèces partiels, portés sur des lobes qui ne sont que la moindre portion des frondes; les antrophyées des sporothèces très-étendus, mais non universels; les leptogranmés des sporothèces qui tendent à se limiter, comme chez les polypodiées, quoique d'une manière moins marquée.

On trouve ces plantes dans les Indes orientales et dans l'Amérique méridionale, ainsi que dans ses îles. (Voy. la page 2 f de ce mémoire pour d'autres détails.) 
tt lis prolifica in loco determinato agens.

1. Singulum sporothecium super nervillas plures transiens: ANTROPHYEA.

Filices simplices ant vix divisa, glabre, erectx; sporothecia extensa, nuda, superficialia aut subimmersa.

$\dagger$ Areolis exappendiculatis.

78. ANTROPHYUM, Kaulf. (1824.)

Enum. filic., p. 198.

Antroplyyun, F., 1.e Ném. sur les fougères (Autrophyées).

Hennionilis el Antroplyi spec., Bun. - Antrophyi el Hymenodii spec., Press, Epim. bol. - Hemionitidis spec., Sw., Wind. - Poly-lcuium, Desv. - Anelinm, Spltgerrb., F., Mén. cil.

SPOROTHECIS linearibus, nunc superficialibus, nunc immersis (in Antrophyo citrifolio el pendulo alaxicè creberrimis); magna lanlimm lalera areolarum sequenlibus; sporangiis subrolundis; annulo 1 2-16 arliculato; sporis Iriedricis, vel saltem Irigonis; sporangiastris villatis seu cupuliformibus, aliquolies per p.xceptionem nullis.

Froxdres simplicibus, lanceolalis, obovalis, linearibus, integerrimis, opacis; venulis in areolas heragonoideas anastomosalis; appendiculis mullis; rhizomate repente; squamis cancellalis, radicellis lomenlosis.

Filices erecta ant rariùs pendulk', coriacece, arboricole', tropicales.

Diagnosis: Ноок. et B., Gen. filic., 1. cvu (Polyt(c'ninm lineatum, Desv.) et 1. cıx, A. Antrophyom plantagineum, KadLf, var. $\beta$ Lessosi.

Facie Hymenodii; ab organis vegetutionis Vittariurum proximum.

Ce genre, assez nombreux en espèces, ne renferme que des fougères à frondes simples, lancéolées, obovées et plus rarement linéaires. Par l'A. cilrifolium, il tend vers l'hymenodium (acrostichées) et par les A. linealum et lanceolatum, qui ne sont, à proprement parler, que des rillaria à sporothèces multisériaux vers les vittariées. On trouve dans ce genre une espèce paradoxale, l'A. cilrifolimm qui, au lieu d'avoir des sporothèces distincts, ne montre à la surface de la lame inférieure que des sporanges éparses, comme dans les acrostichées, groupe dans lequel nous l'avons fait figurer sous le nom d'Anelium cilrifolium. M. Presl la place aujourd hui parmi les espèces de notre genre $H_{y}$ menodium, dont elle a 
exactement la nervation; mais si nous considérons le port, la nature des appendices (radicelles) du rhizome, ses écailles cancellaires et la forme de ses spores, on ne pourra se dispenser de la réunir aux antrophyum.

Il y a plus, mais c'est un doute que nous exprimons ici, il se pourrait que les sporanges, que l'on voit épars à sa surface, ne lui appartinssent pas et qu'ils provinssent de quelques autres fougères avec lesquelles elle vit mêlée. Il nous a semblè que ces corps étaient plutôt posés que véritablement adhérents; ici nuls, là clairsemés, plus loin un peu plus abondants. Il faudrait étudier cette plante in loco natali pour en décider.

La dimension des antrophyum parcourt une grande échelle. Une espèce, l' $A$. nanım, dèpasșe à peine 3 centimètres, tandis que l'A. grigantentm s'élève 25 fois davantage.

\section{ENUNERATIO SPECIERUM.}

\$. 1. Sporotheciis immersis.

Callaefolium, Blım.* - Cumingii, F. - Lessoni, Bory* - senicosiatum, Blım.* (plantagineum, Blum.*) - elongatum, F. (pumilum, Blum., var.elongatum) - reticulatum, Klfss. (Schkh.*, Spreng.*; folcatum, BI.* - nanun , F. (obtusum, Blum.*, excl. synonym.) - plicatum, F.* plantagineum, Klfss. (Bor *) - pumilunı, Klfss. (parvulum, Bl.*) - Hookerianum, F. (pumilun , H. et Grev.*) - spathulatum, F.* - lineatun, Klfss. (Sw.*, Schkh.*, Hook. et B.*, fragm.) subsessile, Kze.* - Cayennense, Desv. (Kze.*).

S. 2. Sporotheciis superficialibus.

Latifolium, Blum.* - latipes, Kze. (F.*) - giganteum, Bory (F.*) - Boryanum, Klfss. non Blum. (Hook. et Gr.*, Bory*) - obtusum, Klfss. (Bory*) - lanceolntum, Klfss. (Schkh.*, Plum.*) - Galeotii, F.* (falcatum, Mart. et Gal.* non Blum. [statu imperfecto], F.*).

Citrifoliun , F. (Plum.*) - pendulunt, Lepr.

\section{S. 3. Sporotheciis sporadicis.}

Spec. rscrere. = Sessilifolium, Spr. - zosterafolium, F. (Hemionitis falcata, Willd.).

A. Frondibus monotaxicis; sporangiis interruptis.

79. COLYSIS, Presl. (1849.)

$$
\text { Epim. bot., p. } 146 .
$$

Selliguece spec., Prest, Tentam. pterid., p. 216. Hook., Icon., pl. 11, t. 204, etc. Bıcs., Filic. Jav, p. 124. - Grammitidlis, Polypodii, Drynarice, Hemionitidis spec., Auct. pluRim.

SPORотнесі1S dorso venularum superpositarum, inter duas venas in linecî angustâ, plùs minisve interruptâ dispositis; sporangiis ovatis; annulo $16-18$ articulato, crenato; crenis incequalibus; sporis oroideis subrotundisque.

Froxdibus monolaxicis, simplicibns aut pinnatifidis, membranaceis, siccitate rufo-fuscis, frondulis et segmentis lanceolatis, acutis; nervillis tenuibus, in areolas hexagonoideas unitis. 
Filices erecte, membranacere, integerrima, slabrce.

Diagnosis : Hоок. el B., Gen. filic., txxıv, A. (Sub Selliguea Wallichiana, Ноок.)

Le genre Colysis, créé par M. Presl, est au Selliguea, ce que notre gense Callogramme est au $S_{y}$ gramme du même botaniste. Linterruption des sporothèces n'est pas marquée au mêne degré dans toutes les espèces; mais le port et la consistance établissent des différences assez notables pour qu'elles puissent justifier la création d'un genre. Ici les frondes sont ninces, nuembraneuses, comme papyracées, décurrentes en pétiole et monotaxiques. Dans le Selligruea elles sont toujours simples, dures, opaques, diplotaxiques, arec des lames portées sur de longs pétioles.

\section{ENUMERATIO SPECIERLII.}

Hemionitidea, Presl (Selliguea, Presl [nervatio*]; Drynaria, J. Sm.) - macrophylla, Presl (Selliguen, Blum.*) - Wallichiana (Selliguea, Hook.*) - marginata, Presl (Selliguea, Meyen) pothifolia, Presl (Selliguea decurrens, Presl; S. pothifolia, J. Sm.; Grammitis, H. et Grev.*) tridacty-lis, F. (Cochinch., Gaudich.).

\section{计 Areolis appendiculatis.}

$B$. Frondibus diplotaxicis; sporotheciis continuis.

\section{SELLIGUEA, Bory. (1\$29.)}

Dict. class. d'hist. nat., t. XV, p. 344.

Selliguea, F., 1. Mém. sur les fougères (Antrophyées).

SPOROTHECus linearibus, continuis, super mesonesron obliquè cadenlibus, plures nervillas invadentibus; receptaculo nervilliformi, superficiali, parlim libero, parlim suprì venulas laminarum affixo; sporangiis crassis, lalè pedicello donalis; sporis osoideis, magnis.

Froxiвus simplicibus; nervillis anastomosatis; areolis appendiculalis, appendiculis harmalis, apice lurgidis; rhizomate repente.

Filices erecte, membranacer, opact, coriacer, margine integrce, glabca.

Diagnosis : Hoor. et B., Gen. filic., t. Lxxul. (Sub Loxogramme lanceolatĥ, PresL.)

Subgenus: 1." EesELLIGEeA; appendicibus multis.

2. ${ }^{\mathrm{m}}$ Loxogr.4.M.ME; appendicibus raris.

Les selliguea sont des fougères souples, assez délicates dans le sous-genre euselliguca, simples ou pinnatifides, glabres, a marge ondulée, aiguës, lancéolées ou it seginents lancéolés, rarement linéaires. Les sporothèces occupent, comme dans les antrophyum, le grand côté des aréoles et se continuent plus ou moins longtrmps en passant sur plusieurs d'entre elles. 
Dans le $S$. macrophylla de M. Blume, les sporothèces traversent les aréoles et se fixent sur les prolongements libres qui les parcourent. Il y a autant de sporothèçes que d'aréoles. Ces différences, très-notables, ont décidé MI. Presl à former le genre Colysis que nous arons adopté.

Le sous-genre Loxogramme diffère uniquement par ce caractère, de présenter des aréoles dépourvues presque en totalité d'appendices, qui cependant ne manquent jamais complétement. Cés fougères sont plus décidemment lancéolées, et les sporothèces, beaucoup plus fournis de sporanges, ouvrent avec le niésonèvre des angles plus aigus. Néanmoins il ne nous a pas semblé que ces caractères eussent une valeur générique.

La presque-totalité de ces plantes appartient aux Indes orientales et à ses îles. On en trouve plusieurs espèces aux Philippines et une seule au Mexique.

\section{ENUMERATIO SPECIERUY.}

I. Ecsculigira. = Feei, Bory* (Grammitis vulcanica, Blum.*) - pedunculata, Presl (Ceterach, II. et Grer.*; Hamiltoni, Presi) - heterocarpa, Blum.* - minor, F.

1I. Loxograyse, PresI = lanceoluta (Antrophyum, Blum.*; Grammitis, H. el Grev.*; Loxogramme, Presl, Hook. et B., fragm.*) - coriacea (Grammitis, Kllss.) - avenia (Antrophyum, Blun *) - Blumeana (Antrophyum coriaceum, Blum.*) - scolopendrina (Grammitis, Bory*; Sellig. flavescens, J. Sm., Cuming, n. ${ }^{\circ}$ 12) - involuta (Grammitis, H. et Gr.*; G. flavescens, Wall. non J. Sm.) - Mexicana, F. (Jingersen, Mexico, n. 945).

\section{Considérations générales sur les Antrophyées.}

Ces fougères ont des frondes simples ou plus rarement pinnatifies, à marge entière, affectant presque toujours la forme lancéolée. La nervation de l'Antrophyum est la même que celle de l'Hymenodium, du groupe des acrostichées; celle des genres Selliguea et Colysis a de l'analogie avec celle des bathmium (cyclodiées). Les appendices sont peu nombreux dins le Selliguea, sous-genre Loxogramme. Les sporothèces, allongés, courent obliquement vers le mésonèvre dont les aréoles suivent la direction; on ne les trouve dans l'Antrophyurn que sur les plans verticaux des aréoles, et non transversalement comme dans le genre Herrionitis. Ils sont superficiels ou, par exception, immergés. Des rapports nıarqués peuvent être constatés entre ce groupe et celui des vittariées. Les radicelles tomenteuses, les écailles cancellaires, les sporangiastres rubanés ou capituliformes se trouvent dans toutes les espèces du genre Antrophyum, dont les sporothèces sont immergés.

On trouve les antroplyyées dans les régions tropicales et équatoriales. (Consulter notre $4{ }^{\circ}$ Ménoire sur les fougères : Antrophyées.) 
II. Tot sporothecia, quot nervilloe.

1. Elongata, recla (vix miversalia).

A. Gymnosoria : LEPTOGRAMMEAE.

Hemionitidearum pars Presl, Tent. pterid., p. 217.

Filices aspectu vario, glabre, aut piloso-glandulosæ; ad polypodieas et ad asplenia tendentes.

$\dagger$ Frondibus simplicibus.

\section{PTEROZONIUM, F.}

Gymnogramme reniformis, Makt, Icon. select. Brasil., p. 88, t. xxw.

SPOROTHEcIs ereclis, anguslissimis, in rimâ lineari lamince superioris subinmersis; sporangiis ovalis, subbiseriatis, imbricalim adpressis, pilos involucrales ad apicem pedicellorum enillentibus; slomio anguslo, sub 8 nervalo; annulo lalo, 24-26 arliculalo; sporis Irigonis, lavibus, Iricoslatis, alris; sporangiastris paucis, clavaformibus.

Froxdib's reniformibus, glabris, opacis; nervillis flabellatis, liberis, aequalibus, furcalo-parallelis, tenuibus; peliolo longo, fusco, laevi nilidoque, fasciculis vasorum tribus ellipsoideis in slipitibus.

Filix Brasiliana, arboricola, simplex.

Diagnosis: tab. xv1, A, G. reniforme, F. (Gymnogrammes spec., 1. cit.)

Forma frondium omninò Adiantum reniforme, A. asarifolium et Lindsay:e reniformis.

Ce genre monotype est fondé sur une plante du Brésil, élégamment figurée par M. Martius. Elle est parfaitement distincte de tous les genres qui composent le groupe des leptogrammées. La forme des frondes rappelle celle de l'Adianturm reniforme et du Lindsaea reniformis, et la nervation est égalenent flabelliforme Les sporothèces, légèrement immergés, occupent le haut de la lame, mais sans atteindre la marge. Ils forment une bande noirâtre qui donne aux frondes fertiles un aspect très-remarquable.

\section{SPECIES.}

Genus monotypum; vide diagnosim generis. 


\section{it Frondibus lacerato-flabellatis.}

\section{HECISTOPTERIS, J. Sm. (1839.)}

In Hook. Lond. Journ. of botan., I, p. 139 .

Gymnogrammes spec., A. Sprexg., Tent. suppl. ad system. veget., p. 31. Kzt., Analecta, p. 11, t. vill, fig. 1.

SPOROTHECus superficialibns, linearibns, approximatis, nervillaribus, subconfluentibus, apicem nervillarum proliferarum non attingentibus, sporangiis subrotundis, brevè pedicellatis; annulo angusto, 24-28 articulato; pilis viltatis cum sporangiis immixtis; stomio angusto, $12-14$ nervato; sporis rotundis.

Froxdibes sessilibus, flabelliformibus, palmato-incisis, basi cuneatis, lacinuis: subbidentatis; nervillis rigidis, mesonevro nullo; rhizomate tenui repente.

Filicula Guyanensis, glabra, rigida, arboricola, inter muscos crescens; habitu proprio.

Diagnosis: tab. xvı , B, H. pumila, J. Sw. (Gymnogramme pumila, A. Spreng.), frugmenta analytica in icone Kunzei evulgata.

Genus Hecistopteris ab Acropteride non tongè distat, sed in Hecistopteride indusium deest.

Cette fougère naine, dont on avait fait un Gymnogramme, a un port tout à fait spécial; les frondes, cunéiformes, sont légèrement frangées ou dentées au sommet; le rhizome est filiforme et écailleux. Il existe entre cette plante et l'Acropteris quelques rapports èloignés, mais il n'y a pas d'indusium.

\section{SPECIES.}

Genus monotypum: vide diagnosim generis.

\section{计 Frondibus divisis.}

\section{PLEUROSORUS, F.}

Gymnogrammes spec., KzE., Analect., p. 12. - Asplenii spec.j PresL.

Sрокотнеси elongatis, subimmersis, lineari-ellipticis; sporangiis lateralibus, rotundatis; annulo lato, $16-18$ articulato; sporis ovoideis, nigrescentibus: stomio 6 nervato; nervis horizonlalibus, brevibus, incounalibus. 
Froxdbes pinnalo-pinnalifidis, subtriangularibus, oblusis, supernè sappè bipinnatifudis; pinruis alternis, remotis, segrmentis dentatis, laminis el rachibus pilos glandulosos habentibus; rhizomate crasso, surculiformi.

Filices parvule, Chilenses, Neo-Hollandicce, divisce, cinerere; rachi flexuoso; pilis strangulatis, articnlatis.

Diagnosis: tab. xw1, C, P. immersus, F. (Asplenium ciliaum, P'REst.)

Les pleurosorus sont des asplenium sans indusium : ils sont velus, pinnés ou bipinnés, à poils articulés et intestiniformes. Le rhizome est surculiforme. Les stipes ne portent qu'un seul faisceau vasculaire. Le Chili et la Nouvelle-Hollande sont les seules régions où les pleurosorus aient été trouvés.

\section{ENUMERATIO SPECIERUM.}

P. cunealus, F. (Gymnogr. subglandulosa, H. et Gr.*) - rutcefolüs(Grammitis, R. Br., H. el Gr.*, sub Gymnogramme) - papacerifolius (Gymnogramme, Kze.*). - immersus, F. (Asplenium cilintum, Presl).

\section{GIMNGGRAMME, Desv.}

In Berl. mag., V, p. 5o5, reductum et emendatum; non Hook. et Bauer.

Polypodii, Celerachis, Polyslichi el Gymogranmes spec., Auct. var. - Leptogramme, J. Ss., in Hook. Journ., ir, p. 51.

SPORотнесиs dorsalibus, semper distinctis, ellipsoideis, clongatis; sporangiis laxè approximatis; annulo $13-18$ arliculalo; sacculo sapè piloso, pilis rividis, continuis, divaricalis, crassis; sporis ovoideis, nigrescentibus.

Froxdbes pinnatifidis, scepius pinnatis, pinnalo-pinnatifidis; rhizomate surculiformi.

Filices erecte, divisc; Americance, Abyssinicr, habitu Phegopteridis et Aspidii.

Diaguosis : Hook. et B., t. ıxuı, fig. 7 (incontpleta). G. Lolta, Scru., Tab. nostr., xix, C, fig. 3. G. rufescens, F.

Genus arlificiale cum Phegopteride forsitan jungendum?

Les espèces de ce genre s'unissent aux polypodiées par les genres Phegopteris et Goniopteris dont elles ont le port, étant pinnées, à segments pinnatifides et bien plus rarement simplement pinnées, à segments à peine dentés. Plusieur's espèces (villosa, pilosa, tolla el plerioides) ont un sacculus chargé de poils en hameçon comme celui des goniopteris, dont les nervilles sont conniventes, et cette particularité indique une affinite entre ces deux genres. Les $G$. rufescens 
et cheilanthoides se rapprochent un peu des cheilanthes. Le caractère absolu pour ce genre est d'avoir des nervilles libres, pinnées, pouvant derenir toutes prolifères, non dans un point restreint, pour donner naissance à des sporothèces arrondis, mais dans une étendue assez considérable, ce qui les fait allongés; les sporothèces sont très-peu fournis de sporanges.

Dans le $G$. prolifera, les poils qui recouvrent le slipe et les rachis, sont courbés en hameçon, comme le sont ceux observés sur le sacculıs des espèces citées plus haut.

La géographie hotanique de ces plantes les montre éparses, surtout dans les régions tropicales.

\section{ENUNERATIO SPECIERUM.}

Pilosa, Mart et Gal.* - aspidioides, Klfss. (Celerach, Willd.*, Sw.*, Radd.*) - incisa, Mut. tt Gall. - tolla, Sehlecht. (Lowei, H. et Gr.*), Kze.* - cheilanthoides, Blunı.*, Kllss. (H. et Grev.*) - polypodioides (Ceterach, Radd.*) - I.inkiann, Kze. - rufescens, F., fragm.* - Plilipiinensis, F. - prolifern, F. - villosa, Lk. - pleroides, F., fragm.* - oblusala, B!.* - unila, Kzc.

\section{SPECIES NONDUII DESCRIPTIE.}

1. Ricifacens, tab. XIX, C, fig. 3 (frons parra).

Frontibus pinnatis, apice pinnatifulis, rufo-sericeis; stipile fusco, pilis longis, articulatis hirto; frondulis inferioribus subpinnalifidis, brevibus, oblusis; pilis rufis, selureis, articulutis onuslis; medianis el superioribus irregulariter dentalis billentatisque; sporotheciis depauperutis; sporangiis nervillaribus, sapè sparsis, nudis, magnis, brevè stipilatis; annulo $16-18$ articuluto, articulis spissis; sporis ovoideis reniformibusque.

Habital in Andibus Peruvianis. (Hathews.)

(Longueur totale, 34-36 centim.; 24 - 26 pinnules séparées par un intervalle d'environ 2 centinı: longueur des frondules, $3-5$ centiun.)

L'aspect soyenx roussàtre de eette espèce eurieuse, la brièreté des fiondules, la nature des poils, identique avec celle des myriogteris, la rendent très-distinete de toutes les autres.

\section{Pinlippixensis.}

Frondibus pinuntis, apice pinuatifulis, in ambitu ovato-lanceolatis, rachi et stipite depressis, siccitute uigro-funosis; frondulis remotis, lanceolatis, curvatis, sessilibus, obtusiusculis, subpinnatifidis, segmentis ovoideis, curvis, sinu lato; nervillis pinnalis, omnibus proliferis; sporotheciis ovoideis, spissis, usque ad upicem evolventibus; sporungiis ovoileis, pedicello lato, longiusculo; annulo $14-15$ articulato; utliculis remotis; sporis ovoideis.

Habitat in insulis Philippinis. (Cuming, $\mathrm{n} .^{\circ} 321$.)

(Stenosemia aurita, J. Sm., in Sched. speciminis nostri, verò ab errore.)

(Dimensious de la fronde saus le stipe, 36 centim.; pinnules, 9 centim., sur 15 millim. de largeur; l'intervalle, qui sépare ehacune d'elles, est de 4 ceutim.) 
III. Prollfera.

Frondibns pimnatis, Linceolatis, rachi et stipite phrniusculis, helveolis, cinereo-lomentosis; frondulis lanceolatis, pinnatifulis, npice serratis, in axillis gemmiparis, viviparis, suprì glabris, snbhis hirsutntis, pitis brevibus, linnatis; sporotheciis ellipsoideis al centrum nervillarum affixis; sporangiis ovoideis; Imnuto 11-15 articulnto; sporis ovoicleis.

Habitut in Americâ tropicnli! (Brasiliâ ?)

(Longueur totale, 75 centim. et plus: frondnles. 8-9 centim., sur 15 millim. de lirgeur; les cutre-uœuds ont un intervalle de 4 centim.)

\section{PTEROIDES.}

Frondibus pinnutis, apice abruptè pinnatifidis, ghtaberrimis, rachi canaliculnto; frondulis sessilibus, suboppositis, angustè lnnceolatis, tongissimè ucuninutis, acumine lineari, undulato, vix pinnalifidis, translncidis; nervillis simplicibus, pinnatis, curvatis, marginem subcilintan attingentibns, terminali longâ; nervillis bifurcatis; sporotheriis depauperntis, longis; sporangiis ovoideis; sacculo piloso, pilos hamatos ferente; sporis ovoideis.

Ilabitut in Brasilin. (Vauthier.)

(Longueur totale, 60 centim.; pinnules, 14-15 sur 2 de largeur; entre-nicuds, 3 centim. Fille ressemble à un Pteris par la consistance et la forme de ses frondules.)

\section{CEROPTERIS, Link. (1824.)}

Spec. filic., 1. 1 亿1.

Gyınnogranmes, Cincinalis, Acrostichi, Hemionitidis spec., Aıct. var.

Sporotnecus linearibus, depauperalis, superficialibus; sporangiis ovatis, subuniseriatis; annulo crassissino, $16-24$ arliculato; sporis maximis, episporialis, rotundalis, nudis, Irigonis.

Fкохрівеs piunato-pinnatifidis bipinnatisque, segnenlis ullimis sapaius dentatis, watis sen triangularibus; lanuinis pilos breves, cluralos, glandulosos, cerum fulcaru, roseam, albamque exsudanles, infernè ferentibus; petiolis lavibus, nudis, ebenaccis, alro-rufis: rhizomate surculiformi.

Filices magnitudine varia, erectce, validre, firmce, Americance, arboricolı; phures facie Pliegopteridis et Aspidiorum.

Dingnosis : Hoox. et B., Gen. filic., 1. xxxru. C. calomelcena, Presu, I. cil. (Acrostichun, L.), sub Gymnogrammate (bona, sed sporangia malè). 
L'exsudation jaune, blanche ou rose qui couvre la lame inférieure de toutes ces plantes, est de nature céracée, et cette sorte de cire végétale est soluble dans l'alcool et l'éther. Elle est produite par des glandes en massue, et présente sous le microscope l'aspect de petits filaments d'une ténuité extrême. Les sporothèces sont comme perdus au milieu de cette matière, mais en $\mathrm{y}$ regardant de près, il n'est pas difficile de reconnaître qu'ils sont linéaires, assez allongés, quoiqu'ils n'envahissent que le tiers supérieur de la nervure sur laquelle ils prennent naissance.

Les ceropteris ne sont pas les seules fougères qui se chargent de cette poussière céracée; on la retrouve d'une manière universelle dans les genres Aleurilopteris et Trismeria; un Anogramme présente cette particularité. Les frondes sont bipinnées.

L'Amérique seule réunit toutes les espèces de ce genre, et c'est principalement dans cette partie du monde que vivent les plantes à exsudation céracée.

\section{ENUMERATIO SPECIERUM.}

1. CөпуsоDı. = chrysophylla, Lk., Plum.* $-l$ 'Herminieri, Bory - Martensii, Bory (hybrida, Mart.) - sulfurea, Dest. - Massoni, Lk.

II. Argrria. = Dislans, Lk. - calomelena, Lk. (Acrostichum album, Arrab.*, Schkh.*) - Perusiana, Lk. - tartarea, Lk. (Gymnogr., Willd.*).

\section{ANOGRAMME, Link. (1824.)}

$$
\text { Spec. filic., p. } 137 \text {. }
$$

Gymnogrammes, Grammitidis, Acrostichi, Adianti, Hemionitidis spec., Auct, var. Monachosorum, KzE.?

Sровотнесліs crassis, ellipticis, dorsalibus, super nervillam proliferam extensis; sporangïs superficialibus, pallidis, laxè congestis; annulo 20-28 articulato; sporis nigris, lavibus, trigonis, oculo nudo perspicuis.

Froxdibus tripinnatis, novellis late flabellatis, folia Coriandri sativi referentibus; segmentis bifidis; nervillis flabellato-pinnatis; rachibus rufo-fuscis; rhizomate surculiformi.

Filices tenerrimce, pellucidle, glaberrima, erectce, arboricola, rupestres, non rarò in regionibus tropicorum scandentes, ramos retrofractos exhibentes; locos madidos amantes.

Diagnosis: tab. x1x, A, fig. 1. A. leptophylla, Lk. (Polypodium, L.), et A. refractı, F. (fragmentum).

Anogramme a Ceropteride non longè distut; Cystopterides Europace cum Anogramme analoga sunt, consistentia et nervatione. 
Ces fougères sont extrêmement délicates, pellucides, à divisions nombreuses, dressées et quelquefois grinpantes; se plaisant daus les lieux ombragés et humides; une d'elles se recourre d'une exsudation céracée de couleur rose $(A$ rosea, $\mathrm{F}$.). Sous avons dit, page 6千, que ce genre pouvait admettre l'Acrostichnm bifurcalum de Swartz, et nous en faisons $\mathrm{l} A$. paradoxa pour exprinter que cette plante est tout à fait embarrassante et difficile à classer. Pour accepter notre upinion, il serait nécessaire de voir les nombreux spécinıen de notre collection, indiquant les passages par lesquels passe cette plante pour devenir pinnatifide, simplement dentée qu'elle est parfois. Au reste, Kaulfuss et Kunze en font un Gymnogramme, et cette circonstance est d'un grand poids à nos yeux. Il est une espèce cosmopolite, l'A. leplophylla, Lk. L’ile Bourbon et l'Aniérique du sud en possèdent plusieurs espèces curieuses.

On peut trouver quil existe de l'analogie entre ce genre et le Cystopleris par la fronde, et avec le Ceropteris par la disposition des sporothèces.

\section{ENUMERATIO SPECIERLY.}

Leptophylla, L. (Gymnogramme, H. ct Grev.*; Grammitis, Sw.*, elc.) - A. refracta, H. (Gymnogramme, Kze.. mssc.) - Ruiziana (Gymnogramme, Klotzsch.) - petroselinifolia (Gymnogr., kl. [Linden, Columbia, n. ${ }^{\circ}$ 3]) - Alabellata (Gymnogr., Hook., icon.*) - Ottonis, F. (Gymnogramme, Kl., Columbia) - Schomburgkiana (Gymnogr., Kze., IIerb.) - luserpitiifolin (Gymnogramme, Kze. [Columbia, Moritz, n1. 95$]$ ) - chnrophylla (Gymnogr., H. et Gr.) - villosa, F.* (Brasilia, Claussen) - rosea, F. (Ilemionitis, Bory, Bourbon) - consfersa (G.mnogr., Kze.*, Guenzius, Cap.) - ? hispidula (Jamesonia, Kze.*) - ? paradoxa (Acr. dimorphum, II. et Gr.*: Marea furcans, Bory*) - ? dacallioides (Monachosorum, Kze**).

\section{Considérations générales sur le groupe des Leptoģrammées.}

Cês fougères nont pas, à heaucoup près, une plyysionomie identique. Le facies du genre Ptcrozonium rappelle, par ses frondes, celles des Lindsaya asarifolia et Adiantum reniforme. L'Hecistopleris a un facies qui lui est propie; le Pleurosorus se rapproche de l'Asplenium par des sporothèces auxquels il ne manque que l'indusium pour être identique. Le Gymnogramme a le port des phegopteris. Le Ceropteris celui des aspidinm; l'Anogramme a la consistance et la délicatesse de structure du Cyslopteris. Tel qu'il est constitué, ce groupe tend ver's les cheilanthées par le Ceropteris, vers les aspléniées par le gente Pleurosurus, t't vers les polypodiées par le genre Gymnogrammic. Toutefois il diffère des premières par l'absence de tout indusium et par l'extension que prennent les sporothèces, ainsi que par la nature du système pileux; des secondes par la nudité absolue des sporothèces, et des dernières par la forme de ces mêmes sporothèces, ainsi que par l'absence de toute espèce de réceptacle. 


\section{B. Angiosoria.}

\section{Indusium solitarium et laterale: ASPLENIEAE.}

Multiformes, rarò simplices, erectæ, divisæ, cosmopolitanæ, ferè semper glabre.

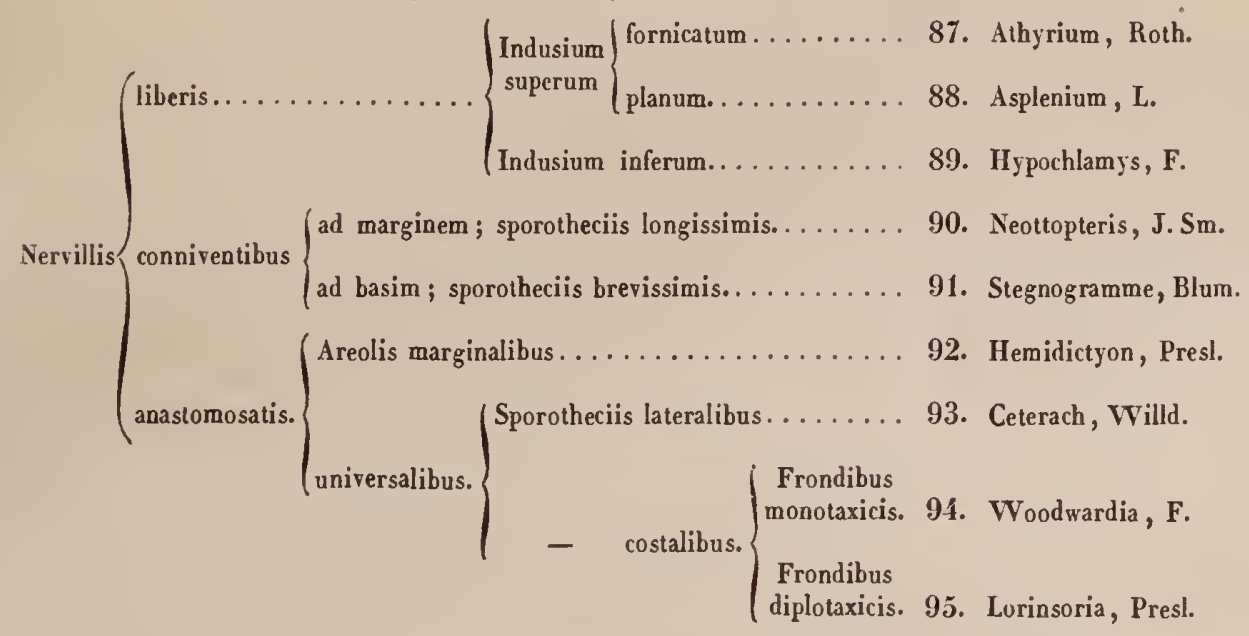

\section{* Nervillis liberis.}

\section{ATHYRIUM, Roth.}

Presl, Tent. pterid., p. 97 .

Asplenii spec., Kze., Waluch., Enduch. - Aspidii spec., Sw., Willd. - Allantodice spec., Kaulf. - Brachysorus, Presl, Epim. bot., p. 70.

SPORотнесII oxatis vel ellipticis, vel cylindricis, indusio gibboso laterali ant dorsali, sape reflexo,persistente, tenni ant crasso; sporangiis rolundo-ovatis; annulo lato, 12-14 articulato (in A. conchato el macrocarpo 18-19); sporis ovatis, subreniformibus.

FroNdibus divisis, segmentis dentatis; nervillis pinnatis, brevibus, marginem non altingentibus.

Fitices herbacèce, tenera, divisce, glabrescentes, erectre, terrestres aut rupicola, sytvicolre; fucie Aspidiorum, stipilibus helveolis, glabris. 
Diagnosis : Hook. el Bacer, Gen. filic., to xv. (A. australe, Presl.) F., Tab. XVII, C, fig. 1. Athyrium conchatum, F.

Differt ab Asplenio, indusio gibboso; sporothecïs semper brevioribus, ovoideis ant ellipticis.

Les alhyrum, fougères à texture délicate, souples, divisées, à segments dentés, ont le port des aspidinm et plus rarement celui des phegopleris. La forme de lindusium qui manque dans les phegopleris les sépare complétement des polypodiées. Le port et l'habitude générale les disingue des asplcnitum, mais ils s'en rapprochent beancoup par la nature de l'indusium, surtout lorsque ce tégument est court (abbreviahum), on peut constater leur caractère différenciel en s'assurant sil est plane ou bombé. Dans les alhyrum il est gibbeux et ovoïde.

La patrie de ces plantes, toutes herbacées, est très-étendue. L'Europe en possède plusieurs belles espèces. Elles se plaisent jarticulièrement dans les régions tempérées. Quand elles vivent dans les contrées tropicales, il faut les chercher sur les montagnes. L'Europe et l'Amérique en possèdent le plus grand nombre, et elles ont entre elles une analogie très-marquée. Elles sont d'une détermination difficile, et très-vraisemblablement les auteurs confondent plusieurs espèces disinctes sous les noms d'A. Filix-formina, d'Asplenioides et de Michauxï.

\section{ETUMERATIO SPECIERUM.}

I. Europr.x. = Ilalleri, Roth. (Aspidium fontanum, Selıhl.*) - fontanum, Presl (Aspidium, sw.; Polypod., Bolton*, Pluk.*) - crenatum, Ruprecht (Asplenium crenatum, Fries) - obosatum (Asplenium, Vir.) - Filix feemina, Presl (Aspidium, Selhkl.*, Black.*, Moris.*, Pluk.*, TabernaMont.*, Houltuyn* - incisum, F. - Corsicum, F.

II. Aвrssixic.. $=$ Schimperi, Moug.

11I. Azonice. = Axillare, Presl (Allantodia, R. Br.) - Azoricum (Allantodia axillare, var. Hoclistell, F.) - umbrosum (Lllantodia, R. Br.).

IV. Aurrucase. = A. America borealis. $=$ Thelipteroides (Asplenium, Mich.. Schkh.* $)-1 / i-$ chauxii (Asplenium, Spreng.) - asplenioides, Presl (Mephrodium, Mich.; Asplenium, Schkh.*) nngustum, Presl (Aspidium, Willd.) = B. America tropicalis. $=$ Galeottii (Asplenium Michauxii, Galeott. non $\mathrm{S}_{\text {preng. }}$ ), Mexico - macrocurpon, F., Mexico - conchatum, F., Mexico - sphterocarpon (Aspidium athyrioides, Mart. et Gal.*), Mexico - decurtatum, Presl, Brasilia. - Achilletefolium (Cenopteris, Mart. et Gal.).

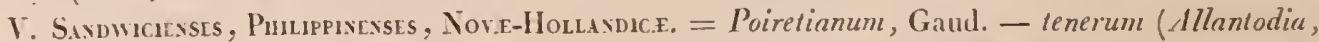
R. Br.) - Australe, Presl (Allantodia, R. Br.) - basilare (1)iplazium bresisorum, J. Sm.; Brachysorns, Presl, Comming, n. ${ }^{0}$ 153) - Sandxichianum, Presl - Gaudichaudii, F.

V1. Borbosic.e. = Scandicinum, Presl (Allantodia, Klfss.: Aspidiume, Willd. [sporce et sporangice in A. Puiretiano divers(r]).

1. Consictu.

\section{SPECIES NONDLY DESCRIPTE.}

Frondibus pinnatis, ovoideo-lanceolatis; stipitibus helveolis, ğlubris, rachi supernè alato; pinnis sessilibus, lanceolutis, acutis; pinnulis incisis, incisuris obtnsis; spo- 
rotheciis brevibus, distinctis, in quôque segmenta octo; indusio ingntsto, albidulo, submeniscioideo; sporangiis parvulis; annulo $12-13$ articulato; sporis reniformibus.

Habilat in Corsicâ. (F., 1845.)

(Dimensions : eelles de l'A. Filix-fomina. Lorsque eette espèce se troure dans les lieux ombragés, elle se dilate et se rapproche par le port de l'Aspidium dilatatum; elle semble voisine de l'Allantodia umbrosa. Cette fougère s'ćloigne considérablement de l'A. Filix-formina; dans cette dernière espèce le pédicelle des sporanges porte des sporangiastres ou poils pellucides, articulés, renflés au sommet en une sorte de eapitule, que l'on ne retrouve pas ici.)

\section{IxcISUM.}

Frondibus subtripinnatis, glabris, ovoideis, pinnis lanceolatis, acuminatis, pinnulis lanceolotis, acutis, sessilibus, pinnatiftlis; segntentis angustis, curvatis, apice profindè incisis; stipitibus et rachibus sulcatis, helveolis; sporotheciis basiluribus; indusio amplissimo, rufescente, curvato; sporrngiis ovoideis, pedicello latinsculo; annulo 14 articulato; sporis reniformibus, levibus.

Habitat in Gallia centrali. (F., 1805.)

(Dimensions: les mèmes que eelles de l'A. Filix-famina; les divisions primaires (pinnce) sont plus longues. Les pinnules sont profondément pinnatifides.)

\section{SCHMPERI, Moug. in litter.}

Frondibıs bipinnatis, lanceolatis, acutis, glabris; stipitibus helveolis, planis, suprì latè canaliculatis, flexuosis; pinnis incurvis, petiolatis, pinnulis elongato-ovoideis, segmentis discretis, profundè incisis, scepè bidentatis; squamis rhizomatis fulvis, lanceolatis, longissimè attenuatis, marginibus pauci-dentatis; sporotheciis brevibus; indusio curvulo, albidulo; sporangiis subrotundis, brevè pedicellatis; annulo cras. sissimo, vix crenulato; articulis spissis 12.13; sporis ovoideis, episporio translu. cido vestitis.

Habitat in Abyssiniâ. (Debra, altitud. 3000 metr.)

(Dimensions : un peu inférieures à celles de l'A. Fïlix-formina; pinnules, 8 centim. Le rachis est sensiblement flexueux.)

\section{Galeottil.}

Frondibus antilis, ovoideis, rachi flexuoso, latè canaliculato; pinnis longis, sessilibus, äcuminatis, pinutulis lanceolatis, acutis; segntentis apice incisis; sporotheciis subrotundis; inchusio curvulo; sporangiis parvis; annulo 11.12 articulato; sporis renifornibus.

Habital in Mexico. (Pic d'Orizaba, alt. 3000 metr.)

Asplenium Michauxii, Mart. et Galeott.,.$^{\circ} 6269$, non Auctor.

(Dimensions : 60 centim. et plus; divisions primaires (pinnce), 21 centim. sur $\mathbf{i}$ centim. d'envergure; pinnules, 8-11 millimètres Nous comptons au deli de 20 paires de pimnules sur chaque division prineipale. Port des grands aspidium.) 


\section{MLAROCARPON.}

Frondibus bipinnatis, stipite et rachi squnnosis, squamis creberrimis, ferrugineis, laceratis; pinnis lanceolatis, sessilibus; rachi plano, apicibus genmiferis; pinnulis incisis, basi pinnatifidis; segnentis incisis, pauci-dentatis, nulcronulatis; sporotheriis crassis, remotis; indusio lato, ovoideo; sporangïs ellipticis, magnis, pedicello tenui donatis; annulo 18-19 articulato; sporis reniformibus.

Habitat in Mexico. (Llano verde, Oaxaca, Galeott., n. ${ }^{0} 6555$, altitud. 2000 metr.)

Filix tenera, pellucida, siccitate viridis, genumifera.

(Dimensions : longucur totale, 80 centin., dont Ic stipc fait la moitié; divisions primaires, 12-14 eentim.; il en existe 12-15. Le rachis est sensiblement aplati; lc stipc, d'apparencc tomenteuse. est simplement écailleux. La plante se rapproche des darea, arec des segments plus larges.)

\section{Coxchatum.}

Frondibus elatis, ovoideis, bipinnatis, suprà pinnatis, stipite et rachi primario maculatis, glabris, suprà canaliculatis; pinnis lanceolatis, longissinè acuminatis, acumine caudato, serrato; pinuulis sublinearibus, dentatis; dentibus renotis, nervillis siniplicibus; sporotheciis crassissinuis, turgidis; indusio albidulo; sporangiis magnis, ovoideis, obliquis; annulo 18-19 atticulato; sporis subrotundis.

Habitat in Mexico. (Ad crateren Cerro Sancti Martini, Galeoti., n. ${ }^{\circ}$ 6569.)

Filix insignis, elata, glaberima, pinnulis integris.

(Dimensions : longueur totale, 1 mètre et plus; les divisions basilaires, 16-18 centim. sur 5 centim. de largeur; les segments ou pinnules sont décurrents sur le rachis et mesurent environ 4 millim. de largeur. Celte belle espèce est un peu dissidente; elle tend vers le genre Asplenium.)

\section{ViI. Gaudichaudi.}

Frondibus ovoideis, bipinnatis, pinnis lanceolatis, longè acunninatis, apice pinnatifidis; pinnulis sessilibus, obtusiusculis, basi solùn fructiferis; segnentis denticulatis; sporotheciis paucis, sublinearibus; indusio angusto; sporangiis ovatis; anuulo crassissino, $12-14$ articulato; sporis latè episporiatis.

Habitat in insulis Sandwicensibus.

Filix elata, ampla, glabra; stipite et rachi helveolis.

(Dimensions de la fronde sans le stipe, 40 centim.; des divisions principales (pinnce), 20 - 22 centim.; les pinnules, $3-4$ centim.; elle a le port d'un Aspidium.) 


\title{
88. ASPLENIUM, L.
}

\author{
Spec. pl., 1558 et Auct.
}

Asplenii el Tarachice spec., PresL.

Sровотнесиs linearibus, elongatis, ad latera nervillne specialis adnatis; indusio tenui, membranaceo, persistente, prius et posteriùs oblique seclo, in auriculas baseorum inverso, intis dehiscente; sporangiis ovoideis; annulo 20-28 articulato, pedicellis longis, torulosis, sapè articulalis; sporis ovoideis, subrenifornubus, atris, laevibus seu papillatis (sporangiastris villosis in A. serrato).

FroxDlbus variabilibus, sapè glabris, rarò simplicibus, ferè semper divisis, Iriphyllis, 1-, 2-, 3-pinnatis, aliquandò parenchymate depauperalis; segmentis ad formam linearem lendentibus, marginibus dentatis; nervillis liberis, pinnatis, in speciebus macrophyllis subparallelis, slipitibus duos fasciculos vasorum, angustè ellipticos ferentibus.

Filices erectıe, herbacece, scepè tenerce; genus vastissimum, in omnibus regionibus orbis terratum species habens.

Diagnosis : Hook. et Bader, t. xxx. (A. Rula-muratia, L.) Prest, Tentam., t. III, p. 11, 19, 23. Tab. nost., V, fig. 3 (A. Montbrisonis, F. fragmentum]), et lab., XVII, fig. 3 (A. Falx [pars]. Tarachia, PresL).

Hoc genus in speciebus macroplyllis, Neottopteridem, Hemidictyonem et Scolopendrium refert; speciebus parenchymate destitutis, Schizceam et nonnullis speciebus diplazium, fabricâ indusii sui.

Le genre Asplenium, le plus vaste de la famille des polypodiacées, renferme des plantes de toutes les formes et de toutes les dimensions. Elles sont en général très-robustes, assez raides; pinnées d'ordinaire, quoiqu’il y en ait d'entières, de palmées et de hi- ou même de tripinnées. L'indusium est sinıple, linéaire et axillaire à la nerville qui le supporte. Il n'existe aucune limite véritable entre ce genre et le Diplazium, surtout dans les espèces de ce dernier genre qui n'ont d'indusium double qu'à la base des pinnules et vers le rachis. (V. Diplazinutu.)

Les grandes espèces à frondes simples et lancéolées sont remarquables par la longueur des sporothèces; on trouve dans la plupart d'entre elles des sporangiastres ou poils internes mêlés aux sporanges, et elles sont souvent remarquables par la longueur du pédicelle qui les supporte; il n'en existe pas dans les autres.

On les trouve dans tous les climats. Ces fougères sont rarement écailleuses; quoiqu'elles aient quelques rapports avec les athyrium, leur physionomie est distincte.

Il existe, parmi les asplenium, un certain nombre d'espèces remarquables par la délicatesse de leur port et par leur facies qui les fait ressembler à des darea; 
nous les avons réunies en un sous-genre auquel nous avons inposé le non de Dareastrum, pour indiquer la principale de leurs affinités. Il est facile, toutefois, de les distinguer des véritables darea, à l'indusium qui est ovoide ou éloigné de la nrarge, et qui se détache, dans la plus grande partie de son étendue. Celui des darea, tout à fail narginal, reste fixé par les côlés; il se soulève, sans se délacher même, en devenant béant, et conserve la consistance de la lanıe, comme sill était endomarginal. (Voy. genre Darea.)

Le genre Asplenium renferme plus de deux cents espèces; les types sous lesquels on peut les ranger sont peu nombreus; nous en reconnaissons cinq, savoir:

1. Espèces simples, lancéolées, ayant le port des neollopleris; N'totTopteriDASTRE'M (A. serralum, Sw.).

2. Espèces anguleuses palmées, Hemioxitidastruy (A. palmalum, Lmrk.).

5. Espèces pinnées, pinnées - pinnatifides, ou plusieurs fois pinnées, EUASPLENIUM (A. Trichomanes, L., A. Adianlum-nigrum L., et la plus grande partie des espèces).

4. Espèces à frondes nervées, presque rachiformes, à segnıents incisés, aigus, -AcRopterinastRU: ( $A$. furcalum, Th.).

5. Espèces à frondes très-divisées, tendres, pellucides, portant de courts sporolhèces près de la marge des segments, DAREASTRUM (A. cicularium, Sw.).

Le genre Asplenium demande une monographie; beaucoup d'espèces ne sont pas encore illustrées; surtout celles à frondes amples. Il est des espèces mobiles dans leurs formes et très-difficiles ì caractériser neltement; tel est l' $A$. furcalum, fougère cosmopolite très-polymorphe; les $A$. aurilum, auricularium, regrulare, salicifolium, adianlum-nigrum, ne le sont pas beaucoup noins et domnent lieu a des réunions ou à des séparations quelque peu hasardées.

Tous possédons en herbier, et nous avons vu dans d'autres collections, beaucoup d'asplenium, qui nous ont semblé inédits el que nous n'osons décrire, de peur de doubles emplois; nous ne faisons exception que pour ceux qui nous ont présenté des caractères remarquables, ne laissant que point ou peu de doutes sur leur spécificité.

\section{ENUMERATIO SPECIERUM.}

I. Neottopteridastrey.

Serratum, L. (Schkh.*, Plum.*, Petir.*, Sloan.*) - integrum, F. - Surinamense, F. - Greillei, Wall. (H. et Grer.*) - ensiforme, Will. (1I. et Gr:*) - angustun, Sw. (Kze.*) - Raddii, F. (Vidus, Radd.*) - coriaceum, F. - Callifteris, F.* - crenulalum, Presl - Schomburgkianum, Kl.

II. Exasplenilu.

1. CALC.1SIC.E. = Palmatum, Lurk.* (Schhl.*, Tourn.*, Pluk.* [Hisp. Alger.]) - Trichomanes, L. (Plum.*, Schhh.*, etc.) - viride, Iluds. (Bolt.*, Moris.*, Schhh.*) - Petrarchce, DC. (11. et $\mathrm{Gr}^{*}$ ) - protensum, Schrad., Ibyss. - marinum, L. (Bolt.*, Moris.*, Schih.*) - Rutamuraria, L. (Black.*, Sclskh.*) - tenuifolium, Guss., Ital. - Breynii, Retz. (Germanicum, Willd., Wulf.*, Moris.*, Schhһ.*) - lanceolatum, lluds. - crenatum, Fries (Sibiricun, Kze.*) - fissum, 
Kitaib. - obtusum, Kit., Abyssin. - Serpentini, Tausch. - Adiantum-nigrum, L. (Fl. danic.*, Black.*, Bolt.*, etc.) - furcatum, Thunb., Abyssin. (Schkh.*, Pluk.*) - acutum, Bory (Grocia, Lusit., Hisp.) - Schimperianum, Hochst., Abyssin.

2. INDICE. = Elasticum, F. - varians, Wall. (H. et Gr.*) - Hohenackerianum, Kzc. - opacum, Kze. - concinnum, Wall. - furcatum, Thunb. (Schkh.*) - longipes, F. (Zeylon) - Serricula, F. (Zeylon) - caudatum, Forst., (Schkh.*) - Petersenii, Kze. (China).

3. AUSTRALASICA E'T NOVE-ZELANDICA. = Altenuatum, H. et Grev. - fabellifolium, Cav. - diodon, F. - decurrens, Willd. (obliquum, Labill.*) - sarmentosum, Willd. (obtusatnm, Labill.*) - obliquum, Forst. (Schkh.*) - lucidunt, Forst. (Schkh.*) - tenerum, Forst. (Schkh.*) - obtusatum, Forst. (Schkh.*) - bulbiferum, Forst. (Schkh.*).

4. OCEANICF. = Menziezii, II. ct Gr** (O-Wahu) - amblyodon, F. (Iles Viti) - laserpitiifolium, Lmrk. - caudalum, Forst. (Schkh.*) - elongatum, Sw. (productunt, Presl* [iles Marian.]).

5. PIIIIPPINENSES. = Varians, J. Sm. - resectum, Sm. - excisum, Presl - elongatum, Sw. (productum, Presl* [Cuming, n." 163]) - calophyllum, J. Sm. - persicifolinm, J. Sn. - oxyphyllum, J. Sm. - anisodontium, Presl - Meyenianum, Presl - longissimum, Reinw. truncatilobum, F. - laserpitïfolium, Lmrk. - gracile, F.

6. BoRBoniC_E, MAURITIANA, MADAGASCARIEISES ET HELENENSES = Chlonopteron, F. lineatum, Sw. - Mascarenhense, F. 一 argutans, F. - crectum, Bory - resectum, Sm. (H. et Gr.*) - intermedium, Klfss. - nitens, Sw. - setosum, Desv. (Madag.) - auritum, Sw. (Schkh.*) - protensum, Schrad. - firmum, F. (Sancta-Helena) - Serra, L. et Fisch.* - macrophyllum, Sw. - plumosum, Bory - dareifolium, Bory - Montbrisonis, F.* - bipartitum, Bory - falcatum, Lmrk. - cuneatnm, Lmrk. (Sloan.*, Schkh.*) - furcatum, Th. (Schkh.*)

7. CAPENSES. = Prionitis, Kze. - gemmiferum, Schrad. - anisophyllum, Kze. - Serra, Langsd. ct F.* - erectum, Bory (mutilatum, Klfss.) - monanthemum, Sin. (Houtt.*) - Dolabella, Kze. - lunulalum, Sw. - Doreyi, Kzc. (Tov. Guin.) - Dregeanum, Kze* — argutum, Bory furcalum, Th. (Schkh.*) - solidum, Kze. - splendens, Kze.

8. CANARIENSES. = Palmatum, L. (Pluk.*, Touncf.*, Lmrk.*, Schkh.*) - monanthemum, Sm. - anceps, Soland. (H. ct Gr.*) - acutum, Bory in Willd. - Canariense, Willd.

9. C'IILENSEs. = Trapezoides, Sw. - macrosorum, Bert. - consimile, Remi - hastatum, Klolsch.? (Palmilla, incol.) - Menziezii, II. et Gr.* - Neeanum, Kzc. - Fernandezianum, Kzc. - Magellanicum, Klfss. (H. et Gr.*).

10. CARIBEEE. = Alatum, H. ct B. (II. ct Gr.*) - rhizophorum, Sw. (Sloan.*, Pluk.*) - obtusifolium, L. (Plum.*, Petiv.*, H. et Gr.*) - abscissum, Kl. (firmum, Kze.non F.) - salicifolium, L. (Plum.*, Pctir.*, Sloan.*) - auricularium, Desv. (Brasiliense, Radd.*) - gibbosum, F. - cirrhatum, Rich. in Willd. - dinidiatum, Sw. - argutnm, Kz - regulare, Sw. - formosum, Willd. - lunulatun, Sw. (falcatun, Th. non Willd.) - dentatum, L. (Plum.*, Petiv.*, II. ct Gr.*) fragrans, Sw. (Pluk.*) - recognitum, Kzc. (Plumier, t. 46) - pumilum, Sw. (Jacq.*, Plum.*, Petiv.*) - Martimicense, Willd. (Plum.*, Peliv.*) - cuneatum, Lmik. (Sloan.*) — Schkhnriannm, Presl (loctum, Schkh.*).

11. GUYANENSES. = Schomburgkianum, KI. - allcopteron, Kzc. - Falx, Desv. (F.*) obtusifolium, L. (Ilook. et Gr.*).

12. Brasilienses. = Serra, Langs. et Fisch.* - decurtatum, Kze. - semicordatum, Radd.* auritum, Sw. (Schkh.*, Sloan.*) - mucronatum, Presl (laxum, Radd.*) - lamprocaulon, F. (semicordatum, Mart. et Galeot. non Radd.) - auriculariun, Desv. (Brasiliense, Radd.*) - repandulun,, Kze. - prilchellunt, Radd. - regulare, Sw. - formosum, Willd. - psendo-nitidum, hadd. - angustatum, Prcsl. - nigricans, Kzc.).

13. PERUVIANE. = Trapezoides, Sw. $($ Schkh.*) - tenellum, F. - fragile, Presl* (Stoloni- 
ferum, Pres!*) - lenue, Presl* - imbricalum H. et Gr.* - Karstenianum, Klolz. - Zamicefolium, Willd. $\left(K_{z e}{ }^{*}\right)$ - pumilum, Sw. - macilentnm, Kze. - formosum, Willd. - nigricans, Kze. - fabellulatum, Kze. - flabellatum, Klotz.

14. MEXICANE. = Pumilum, Sw. (Jacq.*, Plum.*; minimum, Mart. et G.*) - polymorphum, Iart. et Gal.* - Galeolıï, F. (incequilaterale, Mart. et Gal. non Willd.) - monanthemum, Sm. - pendulumF. (falcalum, Galcott.? non Willd.) - Feei, Kze., in litt. - gibbosum, F. - lamprocaulon, F. - oblusissimum, F. - helerochroum, Kze. - melanocaulon, Willd. - parvulum, Mirt. et Gal.* - formosum, Willd. - abscissum, Willd. - repandulum, Kth. - auritum, Sw. (Schkh.*, Sloan.*) - lacerum, Sclıl. - nigricans, Kz.e. - promorsum, Sw. (Pluk.*) - Mexicanum, Marl. et Gal.* - furcalum, 'Th. (Schkh.*) - dislans, F. - asfidiiforme, F.

15. BoREALI-AYERICAN.E. - Pinnatifidum, Nutt. - anguslifolium, Mich. (Schkh.*) - ebenum, lil. (Pluk.*, Moris.*, Schkh.*) - melanocaulon, Willd. - monlanum, Willd.

\section{Darcasrnus. (Tenera, pellacida, segmentis monocarpicis.)}

Macraei, H. et B.* - Dregeanum, Kze* - Schullworlhianum, Kze.* - cicularium, Sw. (Caenopleris, Thunb.*, Plum.*, Petir.*) - myriophy.llum, Presl - rachirhizon, Radd.* (radicans, Sw.?) -- adiantoides, Radd.* - foniculaceum, II. B. et Kth. (II. et Gr.*) - divaricalum, Kze.* - abrolanoides, Presl* - delicalulune, Presl. - bifissum, F. - Abyssinicum, F.

\section{SPECIES NONDUM DESCRIPT E.}

\section{Frondibus simplicibus. (Neotropteridastrum.)}

\section{SURINAMENSE.}

Frondibus siuplicibus, uneubranaceis, pellucidis, lanceolatis, basi angustioribus, ses- silibus, nargine dentuto-repandis, mesonevro crasso, inferuè uriangulari; uervillis temuibus, ulargineu non allingentibus; sporotheciis angustissinis, iucequalibus, cüci unesonevron nascentibus; indusio tenui, uembranaceo; sporangïs ovoideis, pedicello breviusculo; anmulo $20-22$ articulato, septis latis; sporis rolundis, nigrescentibus; pilis internis (sporangiasti is?) nullis.

Habilat in Guyanâ batavâ (Sucinam), Kappler.

Filix magna, facie Neollopteridis.

A. seiratum, L. var. Kze. (Kappler, n. 1736. )

A. angustum (forma latior.), Kze. non Willd.; Kappler, n. ${ }^{183, ~ b}$ (in Herbar. uostro).

(Dimensions, 85 centim. et probablement plus; largeur, 10-11 centim. Nous comptons en moyenne 5 sporothèces par centim.; ceux-ci atteignent $25-28$ millim. de longueur.)

Celte espèce est bien plus délicate que l' $/$. serratum. On ne trouve point mèlés avec les sporanges les poils articulés qui existent abondamment dans cette derniẻre espèce; les sporanges sont portées sur un pédicelle court, tic̀s-long dans l'A. serratum. Les bifurcations des nervilles sont sourent stériles.

Les espèces de cette division sont extrèmement difficiles à déterminer; voici comment nous les dislinguons :

1. Frondes à nuarges entières: A. integrifolium, A. lanciforme.

2. Froudes à marges créuclées: A. crenulalum, Presl (Guyane), ì sommet prolongé en une pointe crénelće, différente de l'A. Nidus de Raddi.

3. Frondes à inarges dentées-crénelées, ondulées; sans sporangiastres, $A$. Surinamense; avec sporangiastres, A. serralum.

Les $A$. coriaceum, callipteris et angustum sont faciles à reconuaitre. 


\section{INTEGRLYI.}

Frondibus magnis, lanceolatis, sessilibus, glaberrimis, margine siccitate convolutis, integerrimis; nervillis parallelibus, furcatis, narginem non attingentibus; sporotheciis angustis, longissimis, incequalibus, aliis à mesonevro remotiusculis, aliis magis approximatis, indusio angustissimo; sporangïs ovatis; pedicello longissimo infernè articulato, sulfureo colore; sporis rolundatis, episporio incequali cinctis.

Habitat in Guadalupú. (L'Herminier.)

Filix magna, siccitate pallidè olivaceâ, mesoneuro robusto.

(Dimensions : environ 1 inètre sur $\mathbf{1 1}$ centin. de largeur; les plus longs sporothèces atteignent 5 centim.; nous en comptons 26 sur une étendue de 4 centim. Presque toutes les nervilles sont fructifères.)

Cette espèce diffère de l'Aspl. Surinamense par des l'rondes plus consistantes, à marges entières. par des sporothèces plus longs et plus rapprochés, portant de longs pédicelles, enfin par des nervilles tendant d'une manière plus décidée à l'horizontalité.

On cultire dans les jardins une espèce à marge entière, bien plus petite, à spores moins longs et plus gros, à nervilles ourrant un angle de 45 degrés; nous lui donnons le nom d'A. lanciforme, et nous appelons sur elle l'attention. Nous lisons dans une note manuscrite de notre savant ami, M. le D. ${ }^{r}$ Mougeot, qu'elle est originaire de la Guyane.

\section{Callipteris.}

Frondibus simplicibus, lanceolatis, membranaceis, translucentibus, basi cuneatis, murgine undulato; stipile mesonevroque nitrrescentibus; nervillis simplicibus, patulis, pilos nigros, curvatos aliquos ferentibus, apice curvatis, pellucidis; sporotheciis mesoneuro ad marginem extensis; indusio tenuissimo, angusto, punctis minutis, atris marginato; sporis reniformibus?

Habitat in insulis Philippinis. (Cuming, n. ${ }^{\circ}$ 308.)

Filix elegans, translucida modùm Hymenophylli; formâ Scolopendrii.

Asplenium vittoforme, J. Sm. non Cavan.

(Dimensions, 32 centim. sur 25 millim. de largeur; le stipe s'élève it i centim. Les sporotheces occupent de chaque còté la moitié de la lame.)

L'A. vittooforme de Cavanilles, très-brièrement décrit daus Swartz, ue peut être rapporté ì cette espèce, qui semble avoir l'organisation anatomique du Callipteris de la tribu des diplaziées.

\section{Coriaceun.}

Frondibus simplicibus, rigidis, coriaceis, opacis, lanceolutis, utroque attenuatis, nuargine integro, siccitaie convoluto; sporotheciis angustis, longissimis; indusio angustissimo; nervilltâ prolifer $\hat{\imath}$ in receptaculo nigrescente mutat $\hat{a}$; sporangiis ovatis; annulo 18-20 articulato; sporis ovoideis, latè episporiatis.

Habitat in Mexico. (Galeotti, sine $\mathrm{n}^{\circ}$ )

(Dimensions, 24 centim. de longueur sur 12 millim. de largeur; les sporothèces qui se dirigent vers le mésonèrre, en formant un angle très-aigun, ont 2 centim. de long, ce qui est extrèmement considérable, si l'ou a égard à l'étroitesse de la fronde.)

Cette plante curieuse a le port d'un Pteropsis on d'un Drynaria, section des pleopeltis. 
V. FeEI, Kze.

\section{Euasplexicho,}

a. Frondibus rinnalis.

Frondibns pinnatis, squamulosis, lnnceolatis, radicantibus, rachi basi violnceo, supri helveolo; frondnlis $1 \mathrm{j}-18 \mathrm{jugis}$; fromlulis lanceolatis, hasi cuneato, subtriangularibus, infernè emarginatis, apice extenso, candiformi, serrato, sterili, margine denticulato, tentibns incrqualibns, imcisis; nervillis snbsintplicibns, remotis; mesoneuro tenui, pollinlo; sporotheciis crassissimis, ovatis; indresio amplo, albido; sporangïs rufescentibus, pedicello longissino; anmulo 24-26 articulato; sporis ovatis.

Mubitat in Mexico. (Galeotli.)

Asplenirm Feei, Kunz., in litteris.

(Dimensions : longueur totale, 58-60 centiu., dont le stipe fait le tiers; les plus longues piunules ont environ 8 centim. sur $12-14$ millim.; les entre-nonds mesurent un peu moins de 2 centim.; la forme des frondules rapproelie eette espèce de l' $l$. chloenopterum; plutòt erénelé que denté, et portant environ 14 paires de sporothèces, landis qu'il y en a à peine 9 paires dans l'esjèce qui nous oecupe. Celle-ci est mexicaine, l'autre croit ì Bourbon.)

VI. Mascarenuexse, F.

Fromlibres pinnatis, lanceolatis, stipite et rnchi sulcatis, fuscis; frondulis lanceolatis, longè acuminatis, semiserratis, acumine remotè serrato, basi cmmeato, in petiolum llesinente, infernè leviter emarginato; sporotheciis longis, linearibns; indnsio angusto; sporangiis rmbro-ferrugineis, pedicello gracili; anuulo 18-20 articulato; sporis parvis, ovorileis.

Habitat in insulâ Borboniâ ins. Mascarenhensi]. (De Montbrison.)

(Dimensions : longueur de la fionde seule, $54-56$ ecnlim.; des frondules, 11 ecntim. sur 15 millin. de largeur: elles ourrent aree le rachis un angle de 45 degrés; les entre-nouds sont espacés de 2 eentim.: la narge des froudules est à peine dentéc dans la moitié inféricnre.)

\section{Akgltars.}

Frondibus lanceolatis, pimnatis, ad upicem pimnatifulis, atlemalis, stipile pubescente, snprà plano, infrà strinto; frondulis lonceolatis, obtusis, subsessilibus, supernè uuricnlatis, infunis leflexis; nervillis fuscis, mesonevro pubescente; rhizomate recto, fibrilloso; sporothecris angnstis, longiuscnlis, remotis; sporangiis ovatis, pedicello lato; anmulo 18 articnlato; sporis ovoideis, latè et irregulatim eprisporiatis.

Habitat in insulà Borboniâ. (Sieber, 11. 246. Griffith.)

Asplenium formosum, Sieber non Willd.

(Dimensions : longueur totale, 32-34 centim., dont le stipe fail euviron les $\% / 5$ : frondules, 5 centim. snr un peu moins d’un eentim. de largeur.)

\section{Cillexopterox.}

Frondibus pinnatis, in ambitu lauceolatis, rachi et stipite sulcuto-squanosis; frondulis ovato-lanceolatis, subtriangularibus, acıminatis, glabris, brevè stipitatis, basi-obli- 
quis, infernè emargitatis, margine crenato-dentato, incisuris incequalibus; nervillis marginem non allingentibus; sporolheciis brevibus, ndultis confluentibus; indusio latissimo; sporangiis ovutis, magnis, pedicello longissimo; annulo 22-21 articu. lato; sporis subreniformibus.

Habilat in insulâ Borboniû. (Olivier.)

(Dimensions : longueur totale, 70 ecntin., dont le stipe fait un peu moins de la moitie; Iongrueur des frondules, 6 - 7 centim.; largeu à la hase, 9-11 millim.; entre-nœuds, 2 centim. Nous arons un spécimen ì dimensions de moitié inférieures. Les sporothèces aree leur indusium ressenblent au Coccus adonidum, L., qui se développe sur les plantes de nos scrres; on en troure $14-15$ sur chaque còté de la lame. I été donné par le muséum de Paris, sous le nom d'A. obliquum, Labill., espèce toute différente, trourée à la Nourelle-Zélande.)

\section{LONGIPES.}

Frondibus ovatis, glaberrimis, stipite et rachi flexibilibus, helveolis; frondulis ovatolanceolatis, longè stipitatis, acuminatis, marginibus crenatis, basi cuneatis; nervillis simplicibus, marginem non allingentibus, in partem mediam proliferis; sporolleciìs longiusculis, basi ad apicem decrescentibus; sporrangiis ovatis, pedicello tenui, longissimo articulntoque; annulo 18-20 articulato; sporis ovatis, brevibns.

Habilat in insulâ Zeylanicrî. (Colonel Walker.)

Filix glaberrimu; stipitibus tennibus, frondulis folin Sorbi Ancuparire referentibus.

(Dimensions : 22 - 25 centim. de longueur totale, dont le stipe fait la moitié; frondules, 8 centin. sur 15 millim.; pétiole, 9-11 millim.; entrc-nœuds, 11 - 13 millim.; sporothèes, 6 millim. Daus ın spéeimen les frondules inférieures sont tri-frondulées.)

\section{Gibbosum.}

Frondibus pinnatis, lanceolatis, gluberrimis, stipite et rachi lavibus; frondulis $1 \bar{i}-19$ jngis, petiolutis, lanceolntis, horizontalibus ant panlulium deflexis, acnminatis, crenulatis, basi inferiore cunentis, semi-cordatis, supernè auricnlatis, cristato-gibbosis, marginibus crenatis, crenis incequalibus; nervillis remotis, margmem non attingentibus; sporolheciis distantibns, angustis, ad auriculam insersis; sporangiis ovatis, brevè pedicellatis; annulo $18-20$ urticululo; sporis episporintis, in ambitn finbriatis, nudis snbreniformibusque.

Habitat in Gnndelupâ. (Perrottet.)

Filix valida, lobo cristnto, magno, superiore, insignis.

(Dimensions : Longueur de la fronde seule, 48 eentim.; elle se termine un peu brusquement un une frondule rétréeie, presque pinnatifide; le stipe est tronqué; frondules, T-9 eentim. de longrieur sur 2 centim. environ de large; entre-11œuds, 2-3 centim. Nous eomptons 7-9 paires de sporollièces; les plus longs atteignıent 12 millim. Cette fougère doit prendre placc à eôté de l'A. Fal $x$.)

\section{NI. Diodon.}

Frondibus pinnatis, lanceolatis, glabris, rachi supernè alato; frondulis ovalibus, cuneutis, suprà auriculatis, basi emarginatis, obtusis, profundè dentato-crenatis, 
crenis scepè bidentatis; sporotheciis ovoideo-elongatis, naturilate conniventibus, ad auriculas inversis; indusio albidulo, anguslo; sporangïs ovalis; annulo 18.20 arliculalo; sporis brevibus, oblique ovoideis.

Hubilal in insulis Philippinis. (Cuming.)

Filix lanceoluta; habilu Asplenii regulcuis, Sw.

(1)imensions de Ja fronde, qui est un peu arquée, 36 centim.; frondules, environ 3 centim.: les inféricures sont presque triangulaires et infléchies; largeur, 9-11 millim. Le rachis porte près de 40 paires de frondules.)

\section{NII. Serricuta.}

Frondibus pinnalis, rachi depresso, anguslè aluto, siccilale pallide-viridi; frondulis 5-6 jugis, lanceolatis, acuminutis, petiolutis, petiolo longiusculo, angustissimè alato, marginibus serralis, serraturis remolis, busi cunealis, acumine extenso, serrato; nervillis al narginem allingentibus; sporotheciis linearibus, latiusculis; sporangiis ovatis, pedicello tenui, longo; annulo 18 -20 atticulalo; sporis reniformibus.

Hubilal in insula Zeylanicâ. (G. Gardner, n. 30.)

Filix glabra, rigidula; rhizomate crasso, squmnis lanceolntis, margine strigillosis, obsito.

(Dimensions: longueur tolale jusqu’i la base de Ja frondulc tcrminalc, ริ0 centim.; fiondules, 1: centim.; elles sont scnsiblenent égales; largeur, 12 centim.; entre-nœuds, $3-5$ centim. Les sporothèces atteignent emiron 7 millim. de longueur.)

\section{NiII. Elasticlin.}

Frondibus pinnalis, lanceolatis, curvalis, elasticis, rachi squamuloso, nigro, depresso; frondulis aculis, crassis, opacis, basi ad apicen decrescentibus, angustè linearibus, cuneatis, supernè nuriculatis, dentibus remotis, profundis, terninali angusto , fertili; sporolheciis elongatis, imbricatis, lanuinam tolam invalentibus; sporangiis nuediocribus, ovatis; annulo 18-20 arliculnto; sporis ovalis, cum episporio irregulari obliquis.

Habitat in Indiis orientalibus. (Griffith.)

Filix rigida, spissa, elestica.

(Dimensions: lougueur tolale, 40 centim.; frondules horizonlales, ayant de 35 a 40 centiun. de long sur 7-8 millim. de largeur; les entre-nouds mesurent 9-10 millim. Nous comptons au deli de 30 paires de frondules, et sur cliacune d'elles de $7-9$ sporothèces, ayant 5 millim. de développement.)

\section{NIV. Pendelum.}

Frondibus pinnatis, linearibus, longis, glaberrinis, stipite alato, flexibili el rachi allintinis, lavibus; frondulis angustè lanceolatis, longè acuminatis, arguè serratis, bnsi cunealis, supernè auriculatis; nervillis marginem non allingentibus, oplosilis, suprenuis. alternis; sporolheciis anguslis, curvatis, ad auriculan inversis, mesonevro flexuoso approxinatis; sporangiis parvulis, pedicello articulato; annulo 16 - 18 articulato; sporis minutis, ovoideis. 
Habitat in Mexico (Cordillière de Veracruz), ad filices arborescentes pendula, in sylvis. (Galeotti, n. ${ }^{\circ}$ 6107.)

\author{
Asplenium falcaum? Marl. et Gal. non Willd.
}

(Dimensions : longueur lotale, 70 centim., et très-probablcment plus; frondules, 5 centim. sur 7-8 millim. de largeur; intervalle des cntre-nœuds, $15-17$ millim. Nous comptous plus de 30 paircs de frondules sur le spécimen que nous décrivons; le stipe cst très-souple. Cette fougère doit èlre placée à còté de l'A. erectum, Bory.)

XV. Lamprocaulox.

Frondibus pinnatis, lanceolato-linearibus, glabris, stipite et rachi fusco-nigris, glabris; frondulis sessilibus, crassis, obtusissimis, ovoideis, grossè crenatis, infernè mar ginatis, supernè gibbosis, ultimis deflexis; sporotheciis angustis, centealibus, distantibus, distinctis; sporangiis ovatis; annulo 18.20 articulato; sporis ovatis, fuscis.

Habitat in Mexico (Llano verde; Oaxacn), Galeotti, n. 6340.

A. semi-cordetum, Mart. et Gal. non Radd.

(Dimensions, 45 centim. [le stipe ne parait pas complet]; pinnules centrales, 2 centim. sur 8 millim. Nous comptons 26 paires de frondules. La terminale est caudiformc, flexueuse ct fructifère.)

\title{
XVI. Firuen.
}

Frondibus pinnatis, rigidis, stipite et rachi firmis, glabris, canaliculatis, rufo-fuscis, glabris; frondulis incequaliter dentatis, lanceolatis, acuminatis, basi cunentis, iufernè emarginatis, brevè petiolatis, teruninuli pinnatifilâ ; nervillis tenuibus, pellucidis, purpurascentibus; sporotheciis crassis, longis, unesonevro approxinutis, confluenlibus; sporangiis ovoideis; aunulo 18-20 articulato; sporis fuscis, ovoideis.

Habitat in insultî Sanctâ Helenâ. (Greville, Herb. clar. Mougeot.)

(Dimensions : longueur totale, 26 - 28 centim.; dont le stipc fait lc tiers; pinuules, 5 -6 centim. sur 1 nillim. de large; cntrc-nœuds, un peu moins de 2 centim. Nous comptons 12 paires de frondules; cclles du centre sont étalées, presque à angle droit.)

\section{XVIJ. Oвtesissinum.}

Frondibus pinnatis, linearibus, glabris, stipite brevi, adiantino, frondulis subpetiolatis, diutidiatis, obuusissinnis, brevibus, crassis, opacis, argutè serratis, monocurpicis, "upproximatis; sporolleciis solitariis, crassis; indusio lato, subuarginali; sporangiis ovatis, pedicello longissino; annulo 18-20 articulato; sporis magnis, ovoideis, fuscis.

\section{Habitat in Mexico. (Galeotti, n.0 6446, partim.)}

Filix glabca, linearis; ad A. Trichomanoidem referens, sed monocatpica et robustior. Asplenium monanthenum, Mart. et Galeotti non Smith.

(Dimensions : longucur totale, 25 centim.; le stipe cst court, rougeàtre et luisant. Nous comptons près de 50 paires de frondules, et cliacune d'elles mesurc à pcine 6 millim.; elles sont distinctcs jusque vers le sommet de la plante.) 
IVIII. GRICHE.

b. Frondibus bi-aut tri-pinnatis.

Frondibus gracilibus, basi bipinuatis, "quice caudatis, serratis; rachi filiformi, alato, nigrescente; frondulis petiolatis, anriculatis, angulato-dentatis, cuneatis; sporotheciis angustis, ad auriculau inversis, curvatis; sporangiis ovalis; annulo $16-18$ uticuluto; sporis reniformibus.

Hubitat in insulis Philippinis. (Cuming, sine numero.)

Filix tenera, delicatula; fiondulis divisis, angulatis.

(Dimensions : longueur tolale, 17-18 eentim.; slipe filiforme assez eourt; frondules, 10-12 millin.: les inféricures. eourtes, plus dislantes et anguleuses.)

\section{TEXflicin, F.}

Frondibus tenerrinis, grluberimis, tripinnalis, segmentis monocarpicis, limeraribus, bi- sen tri-fuccatis; stipite capilliformi, rachi depresso; sporotheciis pulicuri:ormibıs, subsolituriis; indusio angusto; sporangüis mediocribus, ovatis, pedicello tenui; unnulo 18 articuluto; sporis orato-reniformibus, fuscis.

Habilut in Quito. (Jameson, 18 亿8.)

Fïlix tenera, dissectu, glabra; siccitate viridis.

Dimensions : 30-35 centim. de longueur totale; elle est simplement piuréc an sommet: les segments sont sétacés; les divisions primaires ont environ 7 cenlin.)

\X. Мохтвкіsonis, tab. VI, $\boldsymbol{A}$, fig. 3 (fragm.).

Frondibns bipinnatis, ovatis, apice abruptè decrescentibus; stipite glabro, nigrescente, rachi squanuloso; pinnis flubellatis, bipinnalis, acuminato-dentalis; segmentis irreguluriter dentulis, inferiorihus oralis, cuneatis; rhizomate crasso, squanoso, frondes sparsas ferente, squamis lanceolatis, longè acmuinatis, integris, rele temuissino; sporotheciis apluoximatis; indusio amplo; sporangiis ovatis; annulo 18 - 20 arliculato, pedicello isevi; sporis ovoideis.

Habitat in insulâ Borbonici. (De Montbrison.)

Fïlix al A. nigricans, Kze., tendens; squanis cancellatis vestila.

(Dimensions : fongueur totale, 28-30 centinn.. dont le stipe fait près de la moitić; les piunules centrales atteignent $\mathbf{7}$ centinn.: elles décroissent brusquement vers le sammel, qui est simplement pinné.)

\section{Distais.}

Frnudibus bipimato-pinnatifudis, ovatis, amplis, giabris, stipite sulcuto; ruchi tenui, flexuoso, helveolo; pinnis lanceolatis, stiptitatis, remotis; pinnulis petiolatis, dein sessilibus, decurrentibus, acuminatis; seguentis calloso-dentalis; sporotheciis linearbus, angustis, approximatis; sporangiis ovalis; amnulo 18-20 atlicululo; sporis exactè ovoideis. 
Habitut in Mexico (Galeotti, n. 6579 ), ad craterem del Cerro San Mratiu.

Filix magna, dilatala, glabra, aspectî Atlyriorum.

(Losgueur totale, 70 centim., et très-probablement plus; entre-nouds, 7 centim.; divisions primaires, 18 centim.; pinnules inférieures, $4-5$ sur 15 millim. de largeur.)

XXII, AspidIFormE.

Frondibus elatis, bipinuatis, ovoideo-lanceolatis, glabris, apice pinnatifidis, rachi tenni, pinnis semi-pinnatis, acnunatis, pinnulis inferioribus stipitatis, dein sessilibus, postei coadnnatis, crenato-undulatis; sporotheciis curvantibus, ultim is inversis; sporangiis ovatis, brevè petiolntis; annulo 14-16 arliculato, septis remotis; sporis ovoideis.

Habitut in Mexico. (Tepitongo, Galeotti, n. ${ }^{\circ}$ 6483.)

Filix veuusta, elata, pinnis carvatis, semi-pinnatis; stipite fuscescente.

(Dimensions : longueur de la fronde seule, environ 60 centim.; nons comptons une vingtaine de paires de divisions primaires, séparées par des entre-nœuds de 6 ecntim.; elles mesurent $17-18$ ceustim. à la base de la fronde; les pinnules inférieures ne dépassent pas 4 ceutim. sur $7-8$ millim. de largeur.)

X XIII. Bifissum.

\section{Dareastruy.}

Frondibus subtripinnatis, teneris, flaccidis; pinnis debilibus; segmentis linearibus, oblusis, bifidis, monocarpicis; slipile fliformi, lavi, fusco; sporolheciis ovalis, parvulis; iudısio rufescente; sporangiis ovoideis; anunlo angusto, 18-20 articulato; sporis brevè ovatis.

Habitat in Cubai. (Linden, 1888.)

(Dimensious, 16 - 18 centim.; divisions primaires courtes; segments linéaires bifides. Il est trèsvraiscmblable que ecte plante aequiert des proportions supérieures.)

\section{Abyssinicum.}

Frondibus tri-pinnatis, ovoideis, ieneris, pellucidis; stipitibus flaccidis, lavibus, lucidulis, pulchrè castaneo colore; thizonıale crasso, longo fibrillosoque; squamis cinereis, lanceolatis, acnminato-setaceis, margine integro; rachibns depressis, pallidis; pinnis bi-piunatis, sessilibus, allernis, acuminatis; pinnulis ovatis, segnentis ovatis, inferioribus dicarpicis, superioribus monocarpicis, 1-2 crengtis, obtusis; sporotheciis ovatis; iudusio flaccido; sporangils brevè stipilatis; anuulo 18-20 articulato; sporis ovoideis.

Habital in Abyssiniâ, locis umbrosis medice regionis montis Sillice. (Schimper, 11. 679.)

Filix tenera, flexibilis, pellucida, aspectı Aspl. cicutarii.

Asplenium Abysinicum, F.

cuneatım, in schedulâ Schimperi (iter Abyssinicum). 
(Dimensions : longueur totale, 50 centim., dont le stipe fait la moitié; divisions primaires, $\mathbf{7}-8$ centim. sur 3 centim. d'envergure; les pinnelles mesurént $13-14$ millim.; le stipe est assez gros, ulliantin, violet, lisse, brillant. Celte conleur se continne dans la fronde pour s'effacer vers les $\%$ supériens de son étenduc; le rhizome, clargé des débris des pélioles, est au moins gros comme le pouce: les écailles ont de $10-11$ millin. de longueur.)

\section{\$9. HYPOCHLAMYS, F.}

Diplazii, Aspidii el Asplenii spec., Presl et Acct. Plurim.

Sровотнесиs ovoideis, elliplicis, nervillas ommes invadenlibus; indusio fornicalo, membranaceo, persistente, infero, sporangias el nervillam proliferam legente; sporangiis subrolundis, superis, ab indusio nervillâ separatis, super lalus superius nervilla proliferce silis; sporis ovoideis, nigrescenlibus (in H. pectinata). Froxdres pinnalifidis, frondulis elongalo-lanceolalis, lobulis oblusis, subarcualis; nervillis liberis, pinnalis; fasciculis vasorum duobus, stralum leverm, exlius curvalum simulantibus.

Filices divisa, flexibiles, aspectu Atlıyriorum; ferè onnes Antillance, unica species Philippinensis.

Diagnosis nostra: tab. xwn, C, fig. 2. (H. pectinata, F.)

Ce genre, dont les espèces ont le port des alhyrium, diffère de toutes les fougères angiosores par la situation de son indusium, attaché au-dessous de la nervure; les sporanges occupent la partie supérieure. Ce tégument protecteur se redresse, devient bombé et recouvre tout à la fois la nerville et les sporanges, celles-ci, au lieu d'ètre situées à l'aisselle de l'indusium, en sont séparées par toute l'épaisseur de la nerville dont elles occupent le côté supérieur. Il résulte de cette organisation singulière que les sporanges, à l'égard de la nervure, sont supères, tandis que l'indusium, au contraire, est infere.

\section{ENUMERATIO SPECIERUM.}

11. Tussaci, F. - pectinala, F.* - squamulosa, F. - Sorgonensis, F. (Diplazium, Presl ; Asplenium ambiguum, Schkh.*)

\section{SPECIES NONDUM DESCRIPTE.}

I. Pectixata, tab. XVII, C, fig. 2.

Frondibus elatis, ovatis, bi-pinnatis, glabris, stipitibus infernè quadranguluribus; pinnis excurvatis, lanceolatis, sessilibus, acuminatis, apice pinnatifulis; pinnulis lanceoIntis, connatis, obtusis, dentatis, apice paululium dilatatis, dentibus obtusis; nervillis 
remotis, sinticibus, basi fructiferis; sporotheciis ovalis, brevibus; indusio crustrceo, semi-ovalo, fornicato; sporangiis ovatis; annulo 16.18 articulato; articulis crenatis; sporis ovoideis, episporio irregulari scrpè vestitis.

Habitat in Sunto-Dogningo. (De Tussac.)

Filix magna, mullipinnata; segmentis (pinnulis) horizontalibus.

(Dinrensions : Ia fronde seule mesurc 70 centim.; les plus grandes partitions (pinnox) ont 20 centim.; nous en eomptons 24 paires; les inférieures sont opposées et séparées par un entrc-nœud de 4 centim.; Ics segments natteignent pas le rachis; ils ont une dircction horizontalc et 2 eentim. de longueur sur 6 millim. de Jargeur.)

\section{Tussaci.}

Frondibus bipinnatis, lanceolatis, glabris, rachi helveolo; pinnis lanceolatis, apice caudatis; segmentis ovato-elongatis, oblusis, argutè serratis; nervillis simplicibus, rubellis; sporolheciis ovatis, confluentibus; indusio crustaceo, fornicato; sporangiis ovatis, pedicello brevi; annulo 16-17 articulato; articulis spissis; sporis ovatis, crassis.

Hubitat in Santo-Domingo. (De Tussac.)

Fillix facie Allyrii Filicis-famince.

(Dimensions : longueur de la fronde sans le stipe, 45-50 centim.; Ies divisions primaires, 13 centim., sur 2 centim. d'envergure; largeur des segments , 2 - 3 millim.; entre-nœuds, un peu moins de 3 centim.; 26 - 28 paires de froudules, chargées chacune d'un même nombre de segments.)

\section{Sevamulosa.}

Frondibus bipinnatis, in anbitu ovatis; stipitibus helveolis; squamis sparsis, subovoideis, fulvis; pinnis lanceolatis, incurvatis, petiolatis, laciniis seu pinnulis elongato-ellipticis, obtusis, serratis, squanosis, basi connatis, remotiusculis; nervillis simplicibus, in partem medianam fertilibus; sporotheciis ovoideis; indusio squamiformi, membranaceo, tenui, pellucido, fornicato; areolis latis, irregularibus; sportangiis ovatis; annulo 18 - 20 articulato; sporis ovoideis.

Habitat in Santo-Domingo. (De Tussac.)

Filix magna, squanulosa; pinnis longissimis, incurvalis.

(Dimensions, 1 mètre et plus; divisions primaires, 25-28 centim.; segments, 4 centim. d'cnvergurc, sur 4 millim. de large. Une vingtainc de partitions, étalćes dès le point d'insertion, courbes et longuement acuminćes; 30 segments environ, un peu écartés et légèrement arqués. la basc est élargie. La naturc de l'indusium suffirait seule pour earactériser eette espèec.) 


\title{
** Vervillis conniventibus.
}

\section{NEOTTOPTERIS, J. Sm.}

\author{
In Journ. bot. Hook., IV, p. i 175 .
}

Thamnopteris, Pless, Epin. bot., p. 68.

Asplenium, sect. prima: Thamnopteris, Presu, Tentam. pterid., p. 105. - Asplenii spec., Sw. et Willd.

Sporotnecus linearibus, anguslis, continuis, incepualibus, approximatis, parallelis, mesonevro adhcerentibus; indusio angusto, plicato, nervillầ prolifer $\hat{a}$ incrassatâ; sporangiis rolundis, oroideis, pedicello longo, villato donatis; annulo 20-22 arliculato; sporis ovoideis, nigrescentibus, episporio papillato vel spinuloso lectis.

Provdrus simplicibus, amplis, lanceolatis, glabris; mesonevro robusto; nervillis parallelis, ad marginem uniarcuatis.

Diugnosis: H. et Bucer, Gen. filic., L. cxuı, B, N. Nïlns, J. S.s. (Asplenimm Nidhs, L.)

Hoc genus ad Asplenimm fricie tendit, sed ab eo differt frondibus magnis, simplicibus, tanceolatis, et nervillis ad margines laminarum coalitis.

Les fougères, renfermées dans ce groupe, ont des frondes siniples d'une longueur considérable, dépassant souvent un mètre sur une largeur qui rarement excède $12-16$ centim. Elles forment des touffes imitant un vaste cône renversé. C'est au milieu de cet abri de frondes robustes et pourtant souples, que sourent les oiseaux établissent leur nid, circonstance exprimée par le nom générique et par le nom spécifique de la plante-type. Les nervilles parallèles sont extrêmement déliées et très-rapprochées; les sporothèces, linéaires et très-étroits, se développent près du mésonèvre sans janais atteindıe la marge. Ils sont quelquefois tous de même longueur et donnent à la fronde un aspect singulier; mais ordinairement ils sont inégaux, plus petits et plus grands par alternance. La famille des fougères n'en présente d'aussi longs que dans les asplenimm à frondes entières, tel est l' $A$. serratum, sur lequel nous en mesurons qui atteignent cinq centimètres. Ces asplenium ont le port des neoltopleris, mais la manière dont les nervilles se réunissent en arc à la marge, est une circonstance remarquable et suffisamment déterminante, comme caractère générique; d'ailleurs le port n'est pas absolument le même, et les frondes, au lieu d'ètre éparses sur le rhizome, forment de larges rosettes dressées. Peu d'espèces ont été jusqu'à présent figurées, ce qui laisse beaucoup de vague dans leur détermination.

M. Presl est le premier auteur qui ait établi ce genre comme subdivision du genre aspleniun ; mais M. J. Smith le prenier en ayant fait un genre distinct sous le nom de Thamnopteris, nous avons dî le suivre de préférence. 


\section{ENUUERATIO SPECIERUMI.}

Vidus, J. Sm. (Breyn.*, Moris.*, Hook. et Bauer*, fragm.*) 一 stipitata (Thamnopteris, Presl) - squamulata (Thamnopteris, Presl) - Mauritiana (Thannopteris, Presl) - phyllitidis, J. Sm. orientalis (Thamnopteris, Presl) - simplex (Thamnopteris, Presl) - tveniosa (Thamnopteris, Presl) pachyphylla (Thamnopteris, Presl) - ovata, J. Sm. - rigida, F. - stenocarpa, F. - elliptica, F.

I. RIGIDA. .

\section{SPECIES NONDUM DESCRIPT.E.}

Froudibus lanceolutis, aculis, coriaceis, rigidis, siccitate atro-rufesceutibus, opacis; nervillis crebertinis, angulum $45^{\circ}$ cum mesonèvo crasso, cancaliculato metientibus; laminis punctis minutissimis, creberrintis coopertis; sporangiis linearibus, longis, basi mesonevron ferè altingentibus, longiovibus, tres-quadrantes lateris lamiularum occupantibus; sporangïs rufescentibus, rotındis, junioribus clavafornibus, longè pedicellatis; annulo 17-18 arliculato; sporis ovoideis, episporialis.

Habitat in China (Macao), J. S. Henslow.

(Dimensions : longueur totale, un peu moins d'un mètre, sur 10-11 centim. de largeur au centre: le mésonèvre, à la base de la fronde, atteint la grosseur du doigt d'un enfant; il est largement cavalieulé du eôté supéricur; uous eomptons 21 sporothèees sur une hauteur de 3 centim., et eenx-ci mesurent quelquefois 5 eentim.; presque toutes les nervilles sont fertiles.)

Le $N$. Phyllitidis, J. Sm., est aussi raide, mais plus étroit, à nervilles plus éeartées, l'indusium est aussi beaucoup plus large. Nous eomptons 12 nervilles sur 3 centim. d'étendue, tandis qu'il y a 21 sur la mème Jargeur dans le $T$. rigida; les sporothèees s'avaneent plus près de la marge, ete.

\section{Stemocarpa.}

Frondibus lanceolatis, obtusiusculis, inargine repaudis; uervillis tenuissinnis, creberrimis; sporothecis subcqualibus; unesonevro approxinatis, brevibus, quartan pratem laninarum invadeutibus; sporangïs et sporis Neotlopteı idis rigidle.

Habitat in insulis Plilippinis. (Cuming, sine nuntero.)

(Dimensions : longueur totale, ineonnue; largeur 10-11 eentim. Le mésonèrre n'est pas canaliculé; nous comptons 35 nervilles sur un espaee de 3 centim.; sporothees, $14-15$ millim. de longueur.)

Cette curieuse espèce, à sporothèees rapproehés et sensiblement égaux, a un port remarquable : que l'on retroure dans une autre espèce, venant également des Philippines, et que nous indiquons plus bas.

\section{Eishptica.}

Froudibus elliptico-ovatis, acutis, sericeis, pellucidis, matginatis; mat'gine incrussulu, discolori; mesonevro suprà prominente, infrà squanululoso; nervillis lentuissinis, crebertinis, subhorizontalibus; sporotheciis breviorilus, quintam parten luminurum occupantibus; indusio allgusto; sporangïs et sporis N. rigidle, sed minoribus.

Habitut in insulis Plilippinis. (Cuming, sine numero.) 
(Dimensions : longueur totale. 50 centiu., sur 14 de largenr: les sporotheces mesurent de $12-15$ millim. : les marges décrivent deux courbes cxtrêmement ménagées; 35 nervilles et 25 sporotheces sur 3 centim. de largeur; le ticrs inférieur de la fronde est stérile.)

Le I. Mauritiana, que M. Presl dit ne pas avoir vu complet, est unc forgère robuste, ayaut un mésonère de la grosseur du doigt à la base; elle est largement lancéolée, acumince et sessile; les plus longs sporothèes atteignent 40 et mêtme 45 millim.; on peut compter de $8-9$ nervilles par centim. Dans le $\mathbf{Y}$. playllitidis les sporothéees touelient presque la marge; ils sont très-écartés.

\title{
91. STEGNOGRAMUE, Blum.
}

\author{
Filic. Jav., P. 172 .
}

I'olypodii spec., WaLuch. - Hesochlecha, R. Bu. in Horsfield's pl. Javan. et J. Sis. Spharostephanos, KzE., die Farrenkr., I, p. 20. - Gymnogrammes spec., Bцcм., Fl. Javi, p. 98.

Sporotheciss oblongis, dorsalibus; indusio angusto, crasso, villoso, persistente, internè dehiscenle, ad nevillam lurgidam adharenle; sporangiis subrolundis, glandnlis pedicellatis, aureis, rolundis immixtis; annulo 20 arliculato; sporis obscurè Irigonis.

Froxdbes pinnalis, pinnulis pinnalifidis, acuminalis; nervillis pinnalis, primariis basilaribus in angulum conniventibus.

Filices insignes, erecke, pinnalo-pinnatifidce, Indica; facie Aspidiorum; sporolheciis elongatis ul in Granmilide; indusio Asplenii, sed angustiore, sporangia incompletè vestiente.

Diagnosis: Hook. et Baver, Gen. filic., to xxiv. - S. aspidioides, Blcm., l. cil.

Le genre-Stenogramme est, dans le groupe des aspléniées, ce qu'est le Nephrodium parmi les aspidiées. Il a, comme on peut le voir dans la synonymie, servi de type aux genres Spharostephanos et Mesochlaena. M. Blume a fait du Stegnogramme une fougère indusiée. M. Presl ne lui reconnaît pas d'inclusiunı; M. Blunı seul a raison, ainsi que nous en pouvons juger d'après un spécinen authentique du Slenogr. aspidioides des rives du Gange, dont lindusium ne diffère pas de celui des asplenium. La deusième espèce, dont M. J. Smith a fait son genre Spharoslephanos, a la mêne nervation que la précédente, et l'indusium en fait également une aspléniée. Cependant cette membrane est d'une mollesse remarquable, bordée de glandes dorées, double et dorsifere.

\section{ENLMER.ATIO SPECIERLM.}

Ispidioides, Blum. (Gymnogramme, Blum.*) - Mesochlepna (Mesochleena, R. Br.; Spharostephanos asplenioides, J. Sm., in Ilook. Gener. fil., Kzc. ${ }^{*}$ ) - Moluccuna (Mesochliena, R. Br.) - Jaianica (Mesochliena, R. Br.). 
DES POLYPODIACÉES.

\title{
*** Nervillis anastomosantibus.
}

\section{IEMIDICTYON, Presl.}

\author{
Tentam. pterid,, p. 110.
}

Asplenii spec., Accr. var.

Sporotheciss linearibus, longissimis, angustis, incequalibus, indusio tenui, membranaceo, persistente; sporis ovoideis, crassis, nigrescentibus, episporio tuberculoso.

Froxdubes simplicibus, vel pinnatis, pinnis lanceolatis, brevè peliolatis, acutis, basi cordatis, apice acutis, maryine dentatis; stipitibus validis; nervillis circà mesoneuron parallelis, dein anaslomosatis el areolas irregulares formantibus; nervillâ tenui, margines frondium ambiente, nervillis ormnibus ad eam confluentibus.

Filices magnce, glabrescentes, tropicales, herbacea.

Diagnosis : H. et Bauer, Gen. filic., t. Lv, A. (H. marginalum, PresL, loc. cil., I. III, fig. 24 [nervatio].)

Ce genre est monotype; il se rapproche du Neollopteris et des asplenium à frondes simples, par la disposition et le développenent considérable des sporothèces. Ici les frondes sont pinnées, opposées et cordées à la base, et la nervation est anastomosée. Les aréoles se constituent vers le tiers supérieur de la lame; elles sont irrégulières et sans appendices. Après avoir formé ces mailles, elles vont se réunir à une nervure marginale très-distincte et assez robuste. Cette fougère, aux larges dimensions, appartient à la végétation de l'Amérique du sud et de ses iles.

SPECIES.

Genus monotypum: vide diagnosim generis.

\section{CETERACH, Willd.}

Spec. pl.; Filices, p. 136.

Gymnogrammes spec., PResL, sect. 3, B, Ceterach. - Acrostichi spec., L. Sw.

SPовотнесиs linearibus, indusio tenui, angusto, lateri exteriori nervillarum adharente; sporangiis breviler slipilatis; annulo ferè completo, $22-24$ articulato: articulis congestis; sporis opacis, ovoideis, episporio papillato. 
Froxdres piunalifudis, bi-lripinnalifudisque, segmenlis undulalis, oblusis; nervillis basi liberis, circà marginem confluenlibus; areolis raris, difficilè perspicuis; slipilibus robuslis, fuscis, squamosis; laminis inferioribus squamis fulis, imbricalis integrè teclis.

Filices herbacere, squamose, coriacere, lucide, breves, rigider, rupestres; Europare, Atlanticar, Africance; stipitibus talidis, squanis nerviltas et indusinm oblegentibus.

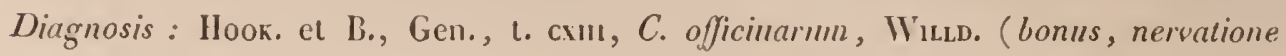
exclusa.)

Facie propriat; hoc genus Vothochternce et Cheilanthi affine est, sed ì primo presentia indusii differt, et à seciendo sporotheciis, non marginem, sed discmm occupuntibus. Indusinun verum exstat, quemvis diri paradoxum; nervillc anastomosontur in C. officinarum et Capensi, sed in omnibus areotas existere incertum est.

A voir les celerach couverts d'écailles abondantes, à frondes étroites, dont les lobes sont arrondis, coriaces et opaques, on serait tenté de les rattacher aux cheilanthées, mais la présence d'un indusium, toutefois très-difficile à reconnaître, el que cependant nous sommes parvenus à constater, les place parmi les aspléniées. L'opacité de la fronde ne permet de reconnaitre les aréoles quavec infiniment de peine. Nous les avons distinctement obserrés dans les C. officinarum et Capense. Le port des celerach est tellement distinct, qu'il est possible de grouper les espèces en consultant seulement leur facies.

\title{
ENUMERATIO SPECIERUM.
}

Oficinarum, Willd. (Grammitis, Schkh.*; Asplenium, Black.*, Berger*, Moris.*, Plum.*, elc.)latifolium, Bory* (sub Asplenio) - Capense, Kzc.* - cordalum (Gymnogramme, II. el Gr.*).

\section{WOODWARDLA, F.}

\author{
Smith, Act. Taur, V, p. 411, t. 9 , p. 5 (partim).
}

W'oodweardica el Doodya, Presl, R. Br. el Aucr. var.

Alichistea, Presl, Epim. bot., p. 71.

Sporothecns ovoideo-elliplicis, oppositis, areolam basicam, scrobiculatan occupantibus; indusio crasso, inflato, convexo, obtuso; sporollicciis irregulariler rolundis, crassis, pediccllo longo; annulo in W. radicanti 16-18 articulato, articulis vix crenulatis; sporis rotundis, subreniformibus papillalisque.

Froxblbus lum pinnalifidis, lum pinnatis, aul pinnalo-pinualifidis; segmentis argutè serratis, serraluris rigidis; nervillis rufescenlibus, areolatis, areolâ proliferâ basilari, supernè curialî, coleris inurqualibus, liexagonoideis. 
Filices lerrestres, herbacea, statırâ variâ, una vivipara, omnes rigida el glabrescentes. Europcere, Cunarienses, Anstratasica.

Diagnosis: Hoor. et B., Gerı., t. xv11, WV radicans, Sw. (bona sed ornala; sporangia mala, annulıs ab errore completus); t. Liv, A (Doodya Kinthiana? Gavd.). Presl, Tentam., t. 111, p. 6, 7, 12 (Woodivardia) et t. III, p. 18 (Doodyra), nervalio. - F., t. xw11, $A$, fig. 1, $W$. radicans, et fig. 2, $W$. lunutala, F. (Doodya).

In Woodwardià radicante sporothecia areolas proliferas ferè implent; in W. caudatâ, connexâ, divite et asperâ (Doodyce spec. auctor) sporolhecia minorem partem areolarum occupant; in $\mathrm{W}$. asperầ el divite scepè sporolhecio biseriolia sınt.

Nous réunissons les genres $I V$ oodwardia et Doodya des auteurs; la nervation est la même, et nous ne voyons de différence que dans les proportions. En effet, dans les fougères de ces deux genres, il y a des aréoles spéciales et basilaires; les sporothèces les occupent entièrement dans le premier et partiellement dans le second. Cette différence ne peut nous sembler suffisante. La patrie des $W$ oodwardia est extrêmement étendue. L'Europe possède le $I V$. radicans, Java le

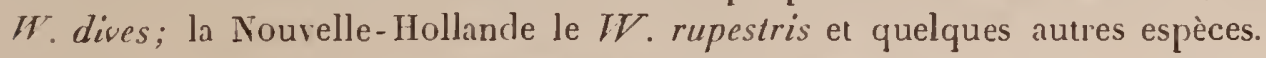

\section{ENUMERATIO SPECIERLM.}

I. Etwoodwardia. = Sporotheciis lunulatis; indusio fornicato. = Radicans, Sw. (Schkh.*) et la var. $\beta$ Mexicana. - Japonica, Sw.

II. Dooprt, anct. - Sporotheciis lunulatis; indusio subplano. = Caudata, R. Br. - dives (Doodya, Kze.*) - lunulata, R. Br. - aspera (Doodya, Hook.*) - Kunthiana (Doodya, Gaudich.*) - connexa (Iloodya, Kze.*) - blechnoides, Cunngh. - media, R. Br. - virginica, Sw. (Pluk.*).

\section{LORINSORIA, Presl.}

Epim. bot., p. 72 .

Woodivardice sper., Auct. Plurim.

Acrostichi spec., L. - Osmmnde spec., WaLt. - Onoclece spec., Micax.

Sporotueciss parallelis, elongatis, linearibus, allernatim dispositis, venam internam occupantibus et seriem unicam formantibus; indusio coriaceo, fornicato; sporangiis outatis, pedicellatis; annulo $18-20$ articulato, crassu, leviter obliquo; sporis ovatis, lavibus, admodium magrnis.

Froxdibls dissimilaribus; sterilibus herbaceis, translucidis, pinnatifidis, vix. basi pinnatis, frondulis et segrmentis oblongo-lanceolatis ant pinnatifidis; nervillis tenuibus; areolis costalibus majoribus, areolis laminarum subhexagonoideis; fertilibus pinnato-pinnatifidis, rigidis, frondulis uniareolatis, areolis fructiferis alternis; rhizomate repente; fasciculis vasorum in stipite sterilium, tribus, tenuibus.

Filices Americance septentrionales, heteromorpher, divisa.

Diagnosis nostra: Lab. xvil, $B$. 
L'hétéromorphie des frondes diffërencie suf̣̣samment ce genre du genre $I V$ oodwardia; mais en outre la nervation n'est pas exactement semblable; les aréoles sont ici bien plus nombreuses, et quoique les nervilles atteignent la marge, elles ne se réunissent pas avec elle pour lui donner plus d'épaisseur; enfin les frondes stériles sont moins grandes et tendent à la disposition pinnatifide. Elles ont, avec celles de l'Onoclea sensibilis, une analogie très-grande. Le genre Doodya, te] quill était constitué, semblait unir le $I$ oodwardia radicans aux Lorinsoria. L'anneau nous a paru un peu oblique.

\section{ENUMERATIO SPECIERLYI.}

L. areolala, Presl, l. cil. (IVoodix. onocleoides, Moris.*. Pluk.*, Schkh.*, F.*) - L. Ihelypteroides, cjusd. (IV. thelypteroides, Pursh.).

\section{Considérations générales sur le groupe des Aspléniées.}

Le genre Asplenium présente quelqu's espèces faciles à confondre avec les diplazinm, parce qu'elles portent à la hase des frondules ou de leurs divisions des sporothèces, dont la situation semble inverse de celle des autres, les indusium étant déliscents de dehors en dedans. Mais en y regardant de près, on peut s'assurer quils rentrent dans la loi commune. En effet, cette particularité n'est éridente que sur l'auricule des frondules; or, ces appendices devant être considérés conme des frondules, arrêtées dans leur développement, le lobule, auquel elles sont réduites, se comporte comme s'il était un segnent distinct et produit une ou deux paires de sporothèces dont les extérieur's sont placés dans un ordıe renversé relativenent à celui qui régit la frondule mère. C'est la tendance d'un segment de fougère pinnée ì devenir indépendant el à constituer une nouvelle pinnule. Ces espèces, regardées comme ambiguës, ont tour ì tour fait partie des aspleniium et des diplasium; tels sont, par exemple, les A. palmatum, Serra, falcalıum, aıritım et beaucoup d'autres.

Cetle particularité a servi tout récemment de base au genre Tarachiu, regardé par M. Presl comme intermédiaire entre les genres Diplazium el Scolopendrimm. L'explication que nous en donnons, faisant rentrer les plantes qui la présentent dans la loi commune aux asplenium, rend suffisamment compte de l'impossibilité oil nous nous trourons d'adopter le genre proposé par le sarant auteur. Les sporothèces sont done les uns à l'égard des autres dans un ordre parfait qui laisse nom de Tarachia (тcęcén, disordo), sans application réelle.

I. Presl, Epim. bot., p. Fo, a créé sur le Diplazinm brevisorum de W. J. Snith un genre Brachysoris qui ne nous semble pas différer de l'Allyrium, ayant, comme cette aspléniée, un indusium en voùce, seulement les sporothèces sont attachées sur les nervilles ou à la base de leurs bifurcations et jamais sur le trajet de la branche bifurquée. 


\title{
II. Indusia opposita nervillas duas sejunctas occupantia : SCOLOPENDRIEAE.
}

\author{
Nerviliis liberis................ 96. Scolopendrium, Sm. \\ - anastomosantilus; areolis regularilus........ 97. Antigramme, Presl. \\ - irregularibus....... 98. Camptosurus, Link.
}

\section{* Nervillis liberis.}

\section{SCOLOPENDRIUM, Smith.}

Act. Taur., V, p. 40, t. 9 , fig. 2.

SPORотнеспs linearibus, plìs minùsve angustis, binatim sppositis, inferiore super venulam superiorem affixo; superiore in venulâ inferiori silo; ambobus line $\hat{a}$ rectâ, nervilliformi separatis; indusio proprio, angusto, persistente; marginibus liberis, contiguis, cum indusio proximo conniventibus; sporangiis ovoideis, longo pedicello donatis; annulo 20 articulato; sporis rotundo-ovoideis, episporio rugoso vestitis.

Froxpibus simplicibus, lanceolatis, rarius pinnatis, sapè basi appendiculatis; nervillis subparallelis, bifurcatis, marginem non attingentibus.

Filices lerrestres, rupestres, crassce, cosmopolitana, loca umbrosa amantes, simplices ant rarius pinnatce.

Diagnosis: Ноок. et B., Gen. filic., t. Lvi, B (niediocris). S. officinarum, Sмтнн.; PresL, Tentam., t. 1\%, fig. 15-16 (neruatio). F., tab. xvII. D, fig. 3. (S. minus, F.)

Scolopendrium ad Asplenium tendit; frondes Scolopendrii officinalis in hortis facitè polymorphar; S. Durvillei frondes heleromorphas simplices pinnatifidas aul bipinnalifidas habet; autem Scolopendrium Krelsii sporollıcia biformia producit, aliis sporolhecia Scolopendrii, aliis Lomarice sporolhecia referentibus (ex Kunzeo).

\section{ENUNERATIO SPECIERUII.}

Officinarum, Sm., et variet. plur. inter quas: macrosorum, F., hort. Argentin. et bifidum (apice bifido; Corsica) - Hemionitis, Sw. (Schkh.*; Hemionitis peregrina, Tournef.*, Moris.*, Petiv.*) cordatum (sagittatum, DC.) - minus, F.* - longifolium, Presl. - Durvillei, Bory (Kze.*) Krebsii, Kze.* (olim Onychium) - pinnatum, J. Sm.

\section{SPECIES NONDUII DESCRIPTA.}

Mists, F., tab. XVII, $D$, fig. 3.

Frondibus latilatis, oblusiusculis, basi subcordatis, infernè angustatis; slipile squamoso, squamis lanceolatis, longè acuminatis; nervillis tenuibus, creberrimis, fur- 
catis; sporolheciis ovoideo-elongatis, distantibus, centralibus; sporangiis ovatis; annulo 18-20 articulato; sporis subrotundis.

Habitat ad montes Pyreneos?

Filix parvula, stipite breviusculo; nervillis creberrinis.

(Dimensions, 6 centim. de longueur, sur 18 millim. de largeur; le stipe, 8-9 millim.; 8-9 paires de sporothèces situćs au centre de la fronde.)

Nous avons reçu cette charmaute petite espèce arec des plantes du midi de la France; nous la croỵons pyrćnéemue, sans pouroir l'assurer.

\section{** Yervillis conniventibns.}

\section{*** Vervillis anastomosantilus.}

\section{ANTIGRAMME, Presl.}

Tentam. pterid., p. 120, non J. Sm.

Scolopendrii spec., Acct. plurim.

SPOROTHECl1s, sporangiis et sporis Scolopendrii.

Froxdвts simplicibus, integerrimis; nervillis basi liberis, circì marginem reliculatis; areolis exappendiculatis, subhexagonis, intermediis majoribus.

Filices herbacere, coriacere, terrestres, tropicales.

Diagnosis: Ноoк. et B., t. wvil, A. A. repanda, PresL, l. cit., t. Iv, fig. 9 et 10 (uervatio).

Genus Scolopendrio affine, sed nervillis aunstomosatis; longè distat à Camplosuro, habitu, nervatione et situ sporothecior unt.

\section{ENUMERATIO SPECIERUM.}

Repanda, Presl (Scolopendrium repandum, Presl; Sc. ambiguum, Radd.*) - lancifolia, Presl oblongata, Presl - Douglasii (Asplenium, H. et $\mathrm{Gr}^{*}{ }^{*}$ ) - populifolia, Presl - subsessilis, F.

SUBSESSILIS.

$$
\text { SPECIES NONDUM DESCRIPTA. }
$$

Frondibus simplicibus, lanceolatis, repandis, coriaceis, rete anastonosato, circì mesonevion constituto; sporotheciis angulum $35^{\circ}$ cum mesonevio metientibus, longis, augustis, scepè duobus superpositis et tunc superiori nbbreviato; indusio angusto, rigido; sporangiis parvulis, ovatis; sporis subrotundis.

Habitat in Brasiliâ. (Gaudichaud.)

Filix stricta, margine repandâ, subsessilis, apice in specinimibus uobis conspectis fortuiter bilobato. 
(Dimensions, 20-22 centim. de longueur totale sur 4 centim. de largeur; le stipe est très-cour.) On ne peut reconnailıc celte espèce ni dans la description faite par Raddi du Scolopendrium ambiguun, ni la rapportes à la figure qu’il en a donnćc.

\section{CAMPTOSURUS, Link.}

Asplenii spec., Аuct. var.

SPOROTHEans oblongis vel linearibus, sparsis; in aceolis costalibus el super venulas marginantes solilariis; indusiis lenuibus, albidulis, brevibus, parle inferiori et superiori nervillarum alternatiun adnatis; sporangiis subrotundis vel subglobosis, longè pedicellalis; annulo 20-24 arliculato; angusto, articulis approximalis; sporis ovoideis, epispurio translucido veslitis.

FRoxdibes simplicibus, subhastato-auriculatis; nervillis areolatis; areolâ basilari conicâ; cateris hexagonalibus.

Filix Americana, herbacea, terrestris, tenerrima, apice sapè radicans, glaberrima.

Diagnosis : Ноок. et B., Gen. filic., t. Lvi. C. rhizopliyllıs, Lk., loc. cit.

Cette jolie fougère est bien voisine du genre Scolopendriuru; elle en diffère par la nervation, mais les sporothèces, qui ne sont pas toujours opposés, sont écartés comme dans les asplenium, auxquels beaucoup d'auteurs ont lattaché le genre Camplosurns.

Genus monotypun : vide diagnosim generis.

\section{Considérations générales sur les Scolopendriées.}

La mobilité que les plantes de ce petit groupe présentent dans leurs frondes, paraît se retrouver dans la disposition que peuvent prendie les sporothèces. Ceux du Scolopendriun Krebsii, Kze., s'offrent sous deux états : normaux et anormaux. La figure donnée par Kunze (tab. LXXIV, C, Die Farrenkr.), montre cette curieuse fougère sous l'aspect d'un Lomaria. Les sporothèces se dirigent suivant le trajet du mésonèvre, se superposent les uns aus autres, deviennent confluents et ne semblent plus former que deux lignes continues, composées cependint d'autan de parties qu'il y a de nervilles. Nous ignorons si ces transmutations sont fréquentes. Le $S$. Krebsii que nous cultivons, ne nous a rien offert encore de pareil. (Voy. p. 26 pour d'autres particularités d'ensemble.) 


\title{
III. Indusium bivalve, aut abortu univalve, valvis oppositis, dorso comniventibus: DIPLAZIEAE.
}

\author{
Diplaziex, Presl, Tent. pterid., p. H1, tab. III et IV.
}

Herbacex, aut subarborescentes, simplices aut sapiìs divisa, ample, erectre, tropicales, speciosæ.

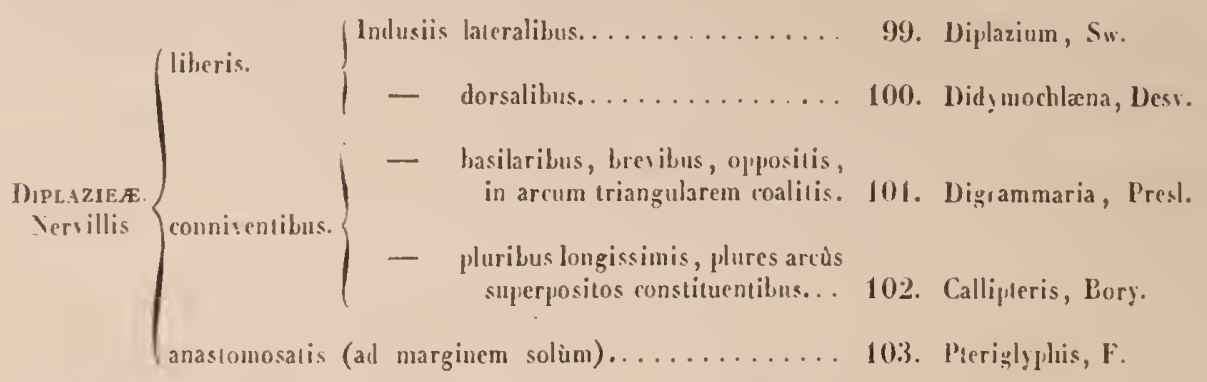

* Nervillis liberis.

A. Pinunlis sen segmentis symetricis.

\section{DIPLAZIUM, Sw.}

Syn. filic., p. 4 .

Aspleuii spec., Аист. уав. - Lolzea Klolzsch, Liмxхa, 1817 , p. 358.

SPORотиғсп plis minusve linearibus; indusio incequali, bivalvi, aul per aburlum mivalvi; dorso, seu latere nervillarum affixo. In dehiscentia sapè resupinato: sporangiis ovoideis, in latere superiori el inferiori sedentibus; annulo lat", $14-16$ arliculato, arliculis crassis; sporis ovoideis, subreniformibus.

FroNDibus simplicibus aul divisis; nervillis pinnalis.

Filices herbacer, rarius arborescentes, tropicates, magnor.

Diagnosis: Hook. et B., Gen. filic., I. Lv, B. Dipl. plantagineum, Sw.; striatum, Sw., el radicans, Priss (fragmenta). P'kesL, Tentam., xiv, fig. 1-5 (nervatio). F., Lab. xvi, D, fig. 1. Dipl. Malaccense, Prust.

Diplazium Asplenium est indusio Livalvi; species plures in duobus generibus ab auctoribus confunduntur; apud Dipluzium in juventute aliquando sunt indusia univalviu. Lotzea Cl. Ktotzschi, Diplazium verum est, cum indusio funbriato. 
Les diplazium sont de grandes et belles plantes, quelquefois arborescentes. Quoique le caractère basique soit facile à constater, ce genre tend vers les genres Alhyrium et Asplenium. Les indusium ne sont pas tous doubles; sourent même chaque pinnule fructifere n'en présente qu'un seul. Il est donc alors asplénoïde; ainsi s'explique la confusion qui règne dans la synonymie. Lorsque les sporothèces sont courts, ils se rapprochent de la forme ovoïde et ressemblent plus ou moins à des athyrium. Il faut soigneusement les examiner pour constater le genre.

S'il arrive que les sporothèces soient simples, c'est le sporothèce externe qui avorte vers la partie supérieure de la fronde; mais vers la partie inférieure de la fronde ou des frondules, c'est le sporothèce interne qui se montre. Le seul moyen possible de liniter convenablement ce genre, est de regarder comme diplazium toute fougère ayant des sporothèces à large indusium, les uns avec déhiscence externe, les autres avec dẻhiscence interne, altachés tous sur la même nerville. Cénéralement la base des frondes ou des frondules est diplazioide, tandis que leur sommet tend à la disposition asplénioïde. Il n'existe que fort peu d'espèces dont tous les sporothèces soient doubles.

Les diplazium sont des fougères tropicales; l'une d'elles est alimentaire; l Europe n'en possède aucune espèce.

Il existe dans ce genre vaste et difficile deux coupes faciles à faire; $10^{\circ}$ espèces ayant, avec une nervation simple, le port des callipleris; $20^{\circ}$ espèces ayant le port des asplenium ou celui des aspidium.

Les fougères appartenant à la première section sont des diplaziuu, puisque les nervilles sont libres. M. Hooker, Gen. filic., LVI, B, en a jugé autrement. Ce botanisie place parmi les anigosonium (callipleris) le Diplazium sylvalicum de Swartz, se basant sur le port, sans se préoccuper de la nervation : ce qui n'a rien en soi de déraisonnable; nais pour suivre loutes les conséquences de ce principe, il ne fallait pas admettre comme type du diplaziun le $D$. planlagineum, qui a aussi le port des callipteris.

On trouve dans les herbiers un assez grand nombre de formes quil n'est pas possible de rapporter à des espèces connues; nous décrivons uniquement celles qui nous ont paru avoir des caractères bien tranchés, encore ne les donnonsnous qu'avec réserve.

\section{ENUMERATIO SPECIERCM.}

1. Calloptenidastrum. = Plantagineum, Sw. (Schhh.*) - Lanceum, Presl (Thunb.*; Asflenium subsinuatum, H. et $\mathrm{G}_{\mathrm{r}^{*}}^{*}$ ) - castanecefolium, Sw. - Boryanum, PresI (lanceum, Bory*) - grandifolium, Sw. - Hilsenbergianum, Presl (sylvaticum, Sieber; Anisogonium, Hook. et B.*? ?) - callipteris, F. - paradoxum, F. - elatum, F. - repandun,, F. - fraxinifolium, Don.

II. Eudiplaziuм. = Cultratum, Presl - juglandifolium, Sw. (Schkh.*, Sloan.*) - petiolare, Presl - extensum, J. Sm. (Cuming, Fil. Phil., n. ${ }^{\circ} 336$, partim) - porrectum, J. Sm. (Cuming, Fil. Phil., n. ${ }^{387}$ ) - radicans, Presl - Malaccense, Presl (F., fragm.*) - chlororachis, Kze. - 
mulilum, Kze. - pabescens, Lk. - lasiopteris, Kzc. - actrale, F. - Shepherdi, Lk. - biserratum, Presl - nuriculnlum, Klfss. - deflextm, J. Sin. - dubium, Lk. - coudatum, J. Sin. (Philippin., Cuming, 11. 158 ) - obiusum, Klfss. - strintum, Presl - Sandwicense, Prcsl - Sorgonense, Presl - elongentum, F. - patens, l'resl - Tiussaci, F. - expansum, Willd. - vestitum, Presl (Cuming. Fil. Phil., 11. 336, partim) - coudatum, J. Sin. - arborescens, Sw. - Elienum. J. Sm. (Cuming, Plilipp., 11. ${ }^{159)}$ - Meyenianum, Presl.

\section{SPECIES NONDU U DESCRIPTE.}

I. C.illipteris.

\section{Callipteridastrum.}

Frondibus...., tuchi profundè sulcuto; fiondulis petiolatis, lanceolutis, acutis, busi subtruncato-cordatis; marginibus dentato-repandis, dentibus callosis, brevibus; mesonevio rufescente, suprà canaliculalo, glubro, subtùs squanoso; squamis flaccilis, lanceolatis, fimbriatis; nervillis pimnatis, longis, tenuibus, liberis, furcatis, marginen attingentibus, et callositatem parvulau formantibus, ramo superiori solim prolifero; sporolheciis anguslis, circì mesonevion evolventibus, vix median partem luminarum percurrentibus; indusio angustissimo; sporangiis crassis, perlicello luto; annulo 11 articulato, articulis crassissimis, incequalibus; sporis elliptico-ovoideis.

Habilat in Cubî, Linden, n. 233. (Herlb. Lenormand ex Mougeot.)

(Dimensions : longueur des frondules, 19-20 centim., sur 4 contim. de largeur; lc péliole ue s'élève qu’ì 6 millim.; Ies sporothèces atteignent 9-11 millim. Cettc plante, très-distinctc, dont nous ne rojons qu'un fragment, est sans doute de grande dimension.)

\section{PARADOXUY.}

Frondibus subbipinuatis, glubris, rachi supè̀ sulcato; pinnis brevissimè petiolulis, membranaceis, pellucidis, fulvis, acuminatis, apice crenutis, aliis pinnatis, aliis pimatifidis, segmentis obtusis aut acuminatis; nervillis pimatis, dissimiluribus, tunc liberis, "t in Diplazio, tunc coalitis, "ul in Cullipteride, sed ataxicis; sporotheciis angustis, indusio convexiculo; sporangiis mediocribus, subronundis; anunlo 14-15 articululo; sporis reniformibus.

Hubital in insulı Zeylanichı. (Gardner, n. 36. )

Dimcusions : Frondes principales (partitions), celle qui est piunćc, 25 ccutim., sır 10 - 11 d'envergure; les segments sont libres juscrüi la base, pour se souder de plus eu plus complétcment el dercuir indistinctes; les partitions piunatificles ont à peinc 18 contim. sur 4 centim. de largeur.)

Cettc plante est bizarrc; les partitions de la basc des frondes sont pinnécs, longues, à segnients aigns au sommet et à ncrvilles soudées vers la marge, puis brusquement pinnatifides, plus étroitcs. bien moins longues, anant presque tontes lenrs nervilles libres.

\section{Elatey.}

Frondibus elatis, pinnatis, apice pimnatifidis, longè cauduto-sertatis, in anzbitu lanceolatis, slipile bicunaliculato, fusco; rachi subquadrangulari, inarginalo; fusciculis zasorum tluobus, ungustis, basi contortis; frondulis lanccolatis, brevi petiolutis, 
infernè subtruncato-cuneatis; marginibus acuminatis, acnmine prolongo, serrato; marginibus serrato-collosis; mesonevro tenui, plano, fuscescente, nervillis pinnatofurcalis; sporotheciis angustis, circà nesonevron evolventibus; sporangïs subrotındis; annulo lato, 14-15 articulato; sporis reniformibus.

Habital in insulı̂ Zeylanicâ. (Gardner, n. ${ }^{\circ}$ 34.)

Filix fornosu, magna; frondulis teneris, membranaceis, pellucidis.

(Dimensions de la frondc seule, 72 centim. Si l'on admet que le stije a la moitié de cette dimension, cette espèce s'é!èrerait à plus d'un mètre. Frondules, 15 centim., sur un pen moins de deux, arec des entre-nouds de 5 centim. à la base de la fronde; la partie supérieure pinnée atteint 15 centim.; nous comptons 16 paires de frondules libres; la moitié inférieure des frondules est plutòt ondulée que dentée; lc sommet des nervilles se détache en blanc près de la marge de la lame supérieurc, cc qui est sans doute accidentel.)

\section{Repandum.}

Frondibus ...., rachi crasso, sulcalo, fusco-rubro, glabro; frondulis subsessilibus, oblongo-lanceolatis, vix dentatis, menbranaceis, papyraceis, nuarginibus repandis, mesoneuro tenui; nervillis furcatis, longissinis, tennibus, ad marginem curvalis, coalescentibus; sporotheciis incrqualibus, latiusculis, indresio ungusto, fusco; sporangiis crassissinis, ellipticis, pedicello lato; annulo spisso, 14 articulato, articulis latis, remotis, obliquis; sporis ovoideis, episporio latissimo, diaphano involutis.

Habitat in Cubâs Linden, $\mathrm{n}^{\circ} 4$.

(Dimensions : frondules, 27 centim. de longucur sur 6 centim. de largeur; les nervilles forment une courbe prc̀s du mésonève et s'étendent à plus de 3 centim.; les sporothèces n'en occupcnt qu'environ la moitié.)

Les nervilles s'unissent à la marge, comme dans le Schizocœena, et cette circonstance pourrait suffrre, si elle était rigoureusement appliquée, pour établir un nowreau genre.

\section{Acutale.}

\section{Eudiplaziun.}

Frondibus lanceolatis, pinnotis, opice pinnatifidis, peliolatis, glabris; rachi tenui, flexibili, helveolo; frondulis curvatis, bosi pinnatifidis, in acumen longum serratum desinentibus, segmentis ovoideis, obtusiusculis, dentalis, remotis, superiore liber $\hat{\imath}$, najore; nervillis pinnatis, spinescentibus, nuargine exsertis; sporolheciis curvotis, inferiore multim longiori; indusio lato; sporangïs rolundo-obliquis; amnulo 16 articulato; sporis subreniformibus.

Habilat in Mexico. (Galeotli, n." 6289.)

Dimensions: longueur, 47-50 centim. sans le stipe; nous comptons $15-16$ paires de frondules libres; celles-ci ont 12-14 centim. de longueur sur 15 millim. de largeur; la pointc qui est lièsdistincte, atteint 4 centim.)

\section{Elongatum.}

Frondibus pinnato-pinnatifilis, stipite et rachi profundè sulcatis, pilosiuscnlis, in. anbitu lanceolato-ovatis; frondulis vix apice coalitis, lanceolatis, sessilibus longè 
acuminatis; segmentis ovatis, obuusis, dentatis; nervillis ferè omnibus simplicibus; sporotheciis extensis, angustis, curvalis; sporangiis subrolumlis; annulo crasso, 14-16 articulato; sporis nigrescentibus, ovoideo-reniformibus.

Habilat in Mexico. (Pellapa, Galcolti, n. ${ }^{\circ}$ (6171.)

Filix magna, mulli-pinnala, Rexibilis; facie Aspidiorum.

(Dimensions, 1 mètre et plus; partilions (pinna ), 12 eentim. sur $30-35$ eentim. de largeur. Kous comptons 24 paires de pinnules.)

\title{
III. Tessici.
}

Frondibus pinnalis, amplissimis, in ambiul ovalis; rachi suprà sulcalo, fasciculo vasorum angusto, continuo, peripherico, formun stipitis simulante; pinnis brevissimè petiolatis, squamosis, basi pinnalifadis, apice aculis, marginibus serratis, mesonevroque flexuoso; segmentis oblusis, paululim falcalis, nervillis pinnatis, furcalis, curvatis; sporolheciis breviusculis, mesonevro connexis, basilaribus diplazioideis, superioribus asplenioideis; sporangïs magnis, subrotundis; annulo crassissino, 14-15 articulato; articulis remotis; sporis reniformibus.

Habilat in insulâ Santo Domingo. (De Tussac.)

(Dimensions: grande fougère, s'élevant probablenrent à plus d'un mètre; frondules (finme), 85 centim., sur 7 de largeur, airec des entre-ncends mesurant 5 ecntim.; $6-7$ paires de frondules: chaque segment porte de $8-9$ sporothèes, ayant de 4-6 millim. de déreloppement ehaeun.)

Nons arons eetle plante de Sieber, sous le nom d'Asplenium costale, Sw. (11. ${ }^{\circ} 36$ I), Ind. occid.

\section{B. Pinnulis dimidialis.}

\section{DIDYMOCHLANA, Des:.}

\author{
In Berol. Mag., $Y$, ı. 7 , fig. 7 .
}

.Honochla'na el Didy.mochlcena, Gaudicis. - Hippodium, ejusd. - Ceramium el Tegularia, Reıw. - Hysterocarpus, Lavgsn. msc. - Aspidii spec., Sw., Syn. filic., p. 252 .

Sporotuecus oblougo-elliplicis, oblusis, ad focmam elongalau tendenlibus; "picem nervilla abbrevialce occupantibus; indusio crasso, palulo, elliplico, medio cristae peominentis, longiludinalis affixo; sporangiis lalecalibus, opposilis, priuno superiori, allero inferiori; annulo $14-16$ arliculalo; sporis ovalibus, episporiu rugoso.

Froxplous slipilatis, coriaceis, bipinnalis, amplissimis; pimnulis subdimidialis, ; nervillis flabelliformibius; ferlilibus brevioribus; fasciculis vasorun in slipite frondium mulis. 
Fïlices arborescentes, amplee, Brasiliance, Philippinenses, Antillance; pinnulis pinnas Adiuntorun rejerentibus.

Diagnosis : Hook. et B., Gen. filic., t. vu (optima). PresL, Tentam., t. 11, fig. 23 (nervatio).

Les frondes de ces belles fougères sont attachées à un tronc assez élevé; elles unt de 5 à 6 pieds de longueur. Il est peu de genres aussi nettement caractérisés. A voir ses frondules dimidiées et auriculées supérieurement, on serait tenté de le rattacher aux néphrolépidées; nıais ici l'indusium est bivalve, libre dans touı son pourtour, ni réniforme ni cordiforme, et fixé sur le dos de la nerville qui se soulève lègèrement en une sorte de crête; à la maturité des sporanges il est libre dans le sens de la longueur, persiste et se montre alors distinctement bivalve.

ENCMERATIO SPECIERUII.

Sinuosa, Dest. (Mart.*; Diplaz. pulcherrimum, Radd.*; Adiantum fruticosum, Arrab.*) - dimidinta, Kze.*).

\section{** Nervillis conniventibus.}

\section{DIGRAiLiaria, Presl.}

Tentam. pterid., p. 116.

Microstegice spec., Prest, Epim. bot., p. 90.

Diplazii spec., Aucr. var.

Asplenii spec., Auct. var.

Sновотнесліs linearibus, in venis infimis bilaleralibus, sen duplicibus, in reliqui: unilateralibus, indusio plano; sporangiis ovalis; annulo $14-18$ arliculalo; sporis reniformibus.

Froxorbe's decomposilis, amplis; nervillis infirmis, una opposilâ vel duabus, in arcum aculangulum anaslonosalis.

Filices Indica, Philippinenses, Borbonicke, ficie Aspidiorum el nervatione Goniopteridis.

Diagnosis: Hoor. et B., tab. Lv1, B. PresL, talb. w, fig. 12 et 17 (conditio nervationis). F., tab. xvill, A, fig. 2. (D. robusta.)

Le port de ces plantes est voisin de celui des alhyrinm et des aspidium avec la nervation des goniopleris, des slenogranmme et des nephrodium. Elles sont toujour's herbabées, mais très-grandes; les derniers segments tendent à la forme arrondie. L'une d'elles est comestible.

\section{LNUMERATIO SPECIERUM.}

Lisculenta (Nicrostegia, l'resl) - ambigua, Presl (Rheed.*, Schkh..*, Hooh.*) - robusta, I. (fragmentum*). 
RoBUSTA.

\title{
SPECIES NONDUM DESCRIPTI.
}

Frondibus amplis, stipite robusto, helveolo; pinnis lougissimis, basi pinnutifudis, ad apicem integris, segmentis obtusissimis; nervillis pinuatis, basilaribus oppositis , conniventibus, sed non semper; ad margines arcûs augulatos constituentibus; sporotheciis piunutis, arcuatis, distinctis, coalitis, fuscis; sporangiis ovatis; anuto 14-16 articulato; sporis irregularibus, nigrescentibus.

Habitat in insuli Borbonia.

(Dimensions: longueur des pinnules, $35-38$ centim., sur 6 centim. de largeur; le misonerve est robuste: le pétiolule (stipelle) mesure $\mathbf{i}-8$ millim.)

\section{CALLIPTERIS, Bory.}

\author{
Bory in Voy., l. I, p. 282.
}

Callipteris, Prest, Epim. bot., p. 88. - J. Sм. in Hook., Journ. of botan., II, 409. Anisogonii spec., Prest, Tent. pterid., p. 116.

Diplazii el Asplenii spec., Acct. var.

Sровотиесиs linearibus, longissimis, angustissimis, alipuandio confluentibus, infimis diplazoideis, superioribus asplenioideis; indusio temui, membranaceo

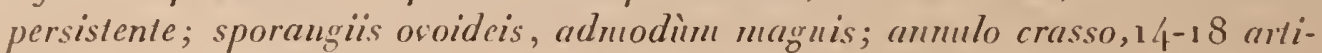
culato; arliculis remotis, pedicello latè villalo; sporis oroideis episporiatis. Froxdibes simplicibus, frequentius piunatis vel bipiunatis, amplis; frondibus lanceolatis, dentalis; nervillis oppositis, pinnatis, curvatis, longissinis, gracilibusyue, in arcuis triangulares superpositos anastomosantibus; caudice scepè spiumloso.

Filices herbacert aut rariùs arborescentes, tropicales, prastantissima.

Diagnosis: Hoок. et B., Gen., L. Lvi, A (Anisogonium decussalum, PresL). F., tab. xvin, D, fig. 2. (Callipteris prolifera, Bor.)

Les fougères adınises dans ce genre tendent à devenir arborescentes. Les frondes sont amples, plusieurs fois pinnées; à lobules arrondis; les nervilles, simplentent pinnées, sont semblables à celles du genre Goniopteris, et conniventes d'après le même système. Toutes sont prolifères et dans toute l'étendue de leur parcour's. Ce sont des diplazium, sauf la connivence des nervilles.

Ces fougères sont remarquables par le bel aspect que prennent les frondes ferliles; à les voir couvertes de sporanges qui suivent le trajet des nervilles, à la unanière des Coniogramume on les croirail élégamment ciselées. 
EAUMIERATIO SPECIERUIY.

Ovata, J. Sm. (Oxygonium, Presl* et Hook.*) - pinnatifida (Diplaziun, Kze.*) - prolifera, Bory (Anisogonium decussatum, Presl, nervat.*) - syliatica, Bory (Diplazium, Schkh.*) - attenuata, Presl - undulosa, Presl (Plum.*, Petiv.*) - Serampuresne (Anisogonium, Presl) - serrulata, (Microstegia, Presl) - microphylla (1)iplazium, Desr.*) - elegans, J. Sm. - Zollingeri, Presl.

\section{*** Norvillis circat marginem in areolas anastomosantibus.}

\section{PTERIGLYPHIS, F. (1813.)}

Fẻe, X. congr. scient. de France, I, p. 178 .

Ochlogramma, Prest, Epim. bot., p. 93.

Oxy.goninem, Prest, Tentam. pterid., p. 117, tab. Iv, fig. 7 (nervatio); non Hoox. et Bacer, Gen. filie.

Callipteridis spec., J. Ss., in Ноок. Journ, of bol., 111, 409. (Exct. synonym.)

\Ронотнесиs linearibus, angustissimis, elongatis, milateralibns, oppositis; indusio

lineari, plano, duplici, rarius simplici; sporangüs seriatis, erectis, ovoideis. brevè pedicellatis; annulo crasso, 14-15 articnlato; articnlis obliqnis; sporis ovoideis, episporio irregnlari alatis.

Froxdibus panci-pinnatis, slipite rigido, nigrescente, canaliculato, paleaceo, basi sulcato; frondulis oblongo-lanceolatis, acuminatis, repandulis, angustissirrie revolutis, acuminatis, petiolatis, petiolo subdecurrente, mesonevro atro, basi hirto-squamoso; nervillis basi flabellatis, furcatis, approximatis, ad marginem areolas uni- ant bi-seriatas formantibus.

Diagnosis: F., tab. xvin, B. (PresL, lo cit., sub Oxygonio [nervatio]).

Cette belle fougère avait été élevée par nous, à la condition de genre, dès l'année $\mathbf{1 8 4 5}$, et nous avions mis sous les yeux des membres du congrès scientifique de Strasbourg, un dessin accompagné de la diagnose que nous reproduisons ici. Kunze, auquel nous en avions référé, nous écrivit que cette plante était une forme pinnée du Diplasium alismafolinm de Presl, et qu'il l'avait reçu. à l'état de fronde simple de M. Cuming, tel qu'elle a été figurée par M. Presl dans ses Reliquice Haenckeance, sous le nom de Diplazium alismafolium. C'est cette mème fougère qui plus tard a servi de type au genre Oxygonimn, fondé en 1856 dans le Tentamen pteridographice du même auteur. Tout récemment la forme pimnée, regardée comme distincte de la forme simple, vient de servir à l'établissement du genre Ochlogramma, savamment décrit par l'habile professeur de Prague, dans les Epimelia botanicx. Il résulte de cet exposé que le 
genre $O \cdot x$ gonmum n’a plus de raison d'être, la première espèce étant un Callipleris, et la seconde un Pleriglyphis.

II. Presl regarde cette belle fougère comme intermédiaire entre les scolopendriées et les diplaziées. Nous la croyons bien mieux placée dans le premier de ces deux groupes, les sporothèces étant opposécs sur des veines différentes. C'est par exceplion que le contraire se présente.

\section{SPECIES TYPICA.}

El.fgaxs, F, tah. XriII, B.

Vid. charact. generis.

Habitat in insulta Luzon Philippinarum. (Cuming, n. ${ }^{\circ} 116$. )

Ochlogranme Cumingii, Prest, 1. cil.

Cullipteris alismafolia, J. Sis., l. cil., exclus. symonym.

Diplazium alisma folium, Prrst, Reliq. Henck., p. 49, tab. viu, fig. 3 (fronde simplici). Oxy-gonimm alismafolium, Ejusd. Pterid., p. 118.

(Dimensions: longueur totale, $34-35$ centim., dont le stipe fail un peu moins de la moilie; frondule terminale, 25 centim.; les latérales, 19-80, sur 6 centin. de largeur. Nous complons de 4-5 paires de frondules, inégalement distantes; les sporothèces ont tout près de 3 centim.)

\section{Considérations générales sur les Diplaziées.}

Tous croyons utile de parler encore de ce groupe dont nous avons donné, 1. 26 , les principaux caractères. On doit regarder les diplaziées comme des aspléniées doubles; le genre Diplazium surtout est tellement analogue à l'Asplenium qu'on peut à peine tracer les limites des deux genres. Le caractère fondamental des diplaziées n'est évident que d'une nıanière générale. Nous arons déjà fait remarquer que les sporothèces de la base de chaque frondule, ou même parfois de ses lobules, sont doubles en effet, tandis que ceux du sommet sont simples et tout a fait semblables à ceux des aspléniées. Ces plantes sont donc mixtes; tantôt le caractère asplénoïde domine en elles et tantôt le caractère diplaziö̈de. Il arrive encore que les deux sporothèces qui devraient être opposés, ne se développent pas, et l'on voit avorter, ou bien le sporothèce infere qui devient asplénioide, ou hien le sporothèce supère qui, quoique simple, est cependant alors diplazioide. (Voy. Aspléniées.)

Y̌ous arons admis cinq genres dans ce groupe; parmi eus le Didymochlaence semble anomal; il tient en effet des crcladiées par un indusium dorsal, mais il est allongé et se soulève par les côtés, étant ainsi véritablement bivalve; les frondules sont inéquilatérales, tandis que dans tous les autres genres leur forme est ymétrique. Les genres Callipteris et Pleriylyphis ont un facies spécial et sont 
d'une beauté vaiment remarquable. Plusieurs diplaziées atteignent la proportion de pelits arbres, de port extrèmement élégant, à frondes souvent très-amples et tiès-souples. Les Philippines, les quatre îles d'Afrique et le sud de l'Amérique possèdent la plupart de ces plantes curieuses; aucune d'elles ne vit en Europe.

\section{Sporothecia curvata, in dorsum renularum transversarum curvatarum erulgata: MIENISCIEAE.}

Magnæ, divisæ, erecta, terrestres aut rariùs palustres, multinervatæ; nervillis scalpturatis.

A. Nerrillis pinnatis; venulà curvatå apice appendiculatà, rectà..... 104. Meniscium, Schreb.

B. Yervillis pinnalis; renulas irregulatim anastomosantes emittentes.. $†$ Dryomenis.

\section{* Nervillis liberis.}

\section{MENISCIUM, Schreb.}

Gen. pl., n. ${ }^{\circ} 1630$.

Polypodii, Asplenii et Hemionitidis spec., Acct. var.

SPORотнесns superficialibus, suprà venulas speciales curvulas nascentitus; sporangiis ovalis, sacculo in parle superiori pilos duos laamalos saepè ferente; annulo $13-18$ arliculalo; sporis reniformibus.

Froxdвes pinnalis, rarò simplicibus, in eâdem specie v'ariabilibus; nervillis emergenlibus, pinnalis, apice liberis, venulas pinnalas in arcum Iriangularem proligerum, plis minusve aculun anastomosalis el venulam secundan liberam, clavalam, cmillenlibus; slipilibus fasciculurn vasorunu hippocrepidiformenr unicum ferentibus.

Filices tropicales, erecte, pinnatce, herbacere, feracissimce; paucis speciebus subarborescentibus.

Diagnosis : Scнотт, Gen. filic. fisc., III, fig. 2. (M. sorbifolium, W ILLD., [oplima]). Ноoк. et B., Gen. filic., I. xt. (M. palustre, Radd.)

Genus nervatione et habilu Goniopteridi affine.

Ce genre, fort remarquable, est parfaitement distinct. Il renferme des plantes presque toujours herbacées, arborescentes par exception. Les frondes sont pinnées; 
une seule espèce se présente quelquefois simple, mais par avortement des frondules latérales. Celles-ci tendent à la forme lancéolée; les marges sont ondulées ou crénelées. Les frondes fertiles et stériles ont la mème forme, à la seule exception du M. Guyanense, à frondes fertiles, beaucoup plus petites que les stéiłles. Lorsque les spornthèces croissent très-rapprochés les uns des autres, et qu'ils portent un grand nombre de sporothèces, ils deviennent confluents et la plante ressemble alors à un Lomariopsis.

Le sacculus de la sporange se couronne de deux poils translucides et recourbés en hameçon. Ce sont les espèces des îles Philippines qui offrent surtout ce caractère. Ces poils se retrouvent avec les mêmes formes sur les lames de ces mèmes fougères. Dans la plupart des autres congénères, des poils longs, raides et pointus croissent mêlés arec les sporanges; mais ils n'y adhèrent que très-exceptionnellement.

Nous avons dit (p. 26) que certains goniopteris portaient aussi des poils sur le sacculus des sporanges. On peut dire que ce sont de véritables meniscium, quant à la nervation et au port; aussi croyons-nous utile de les énumérer à la suite des rais meniscium, sauf a les reproduire plus tard, quand il sera question des goniopleris.

\section{ENUVERITIO SPECIERLII.}

1. Sacculus pilos hamatos ferens. $=$ Triphyllum, Sw. (Spreng.* [sterilis], Ilook. et Gr.*. Kzr.*) - Cumingii, r. - cuspidalum, Blum.

B. Sacculus pilos destitutus. $=*$ Sporotheciis hirsutis. $=$ Kapplerianum, F. - Salzmanni, F. Iungersenii, F. - Guy anense, F. - rosirntum, F. $=*$ Sporotheciis pilos destitutis $=$ Sorbifolium, Willd. (Langsd. et F.*; reliculatum, Sehkh.**) - reticulatum, Sw. (Plum.*, Petiv.*) - palustre, Radd.* (llooh. et B.*) - macrophy.llum, Kze.*

Species milii non visue: Angustifolium, Willd. - arborescens, II. et Bonpl.

Gonioplerides nerratione menisciorum. = Repanda, F. - Rivoirei, F. - crenata, Presl - meniscioides, F. - crenato-dentata, $\mathrm{F}$.

\section{Comisgli.}

\section{SPECIES NONDLY DESCRIPTE.}

Frondibus trifrondulatis, stipite et rachi pilosiusculis; frondulis luteralibus sessilibus, suboppositis, obliquis, acuminatis, marginibus repandis, terminali majore, basi latè cuneato; mesonevris hirsutis; laminâ superiori glabrâ, laminâ inferiori pilosâ; pilis hanatis rigidis, brevibus; sporotheciis angustis, distinctis, villosis; sporangïs ovatis; aunulo 13-14 articulato, sacculis pilos hanatos duos ferentibus; sporis ovoideis.

Habitat in insulis Plilippinis. (Cuming, sine numero.)

(In herbario Weebirmo dicitur : crescit in Malacca.)

(Dimensions: longueur tolale, prise i la base de la pinnule tcrminale, 15 centim.; celle-ei a 20 centim., sur plus de 4 centim. de largeur; les latérales, 13 centim., sur 3 centim.; nous avous des spécimens de proportion beaucoup moindre el comptons de 8-10 sporothices sur chaque còté de la lane; les poils qui recourrent les lames et eeux qui se déreloppent sur le saceulus, out cractement la ucme forme.) 
Les frondules du M. triphyllum sont hastées it la base, relues seulement sur les nervilles; les sporothèces, plus gros, sont aussi plus courts et moins nombreux; les poils, en hameçon, se montrent presque exclusirement sur les sporanges.

\section{KAPPLERIANUM.}

Frondibus pinnatis, ovoideis, slipite helveolo, glabro, elato; infernè triangulari; rachi suprà profundè canaliculato; frondulis lanceolato-linearibus, repando-crenatis, acuuninatis, subsessilibus, basi cotundatis; nervillis pinnatis, creberrimis, arcubus approximatis; sporotheciis hirsulissinis, spissis, connexis; pilis longissimis, albis, rigidis; sporcugïs ovatis, glabris; anuulo 15-16 articulato; sporis crassis, rolundis.

Habilat in Guycauâ Batavoruu. (Suriuam, Kappler, n. ${ }^{\circ} 828$; in schedulâ: M. sorbifoliun, Willd. ex Kunzei.)

Filix elala; siccilate flavidula, frondulis approximalis.

(Dimeusions : longueur tolale, 1 mètre, dont le stipe fait environ les $3 / 5 ; 13$ paires de frondules, ourant arec le rachis un angle de 45 degrés et séparées par un entre-nœud de $22-23$ millim.; elles ont de 12-14 centim. de longueur sur 15 millim. de largeur et sont sensiblement égales. Nous comptons 6-i reines arquées sur chaque moitié de la frondule et près de 80 uervilles pinnées.

Dans le M. sorbifolium, fort différent sous d'autres rapports, les sporothèces sont absolument glabres.

\section{IIf. Salzuaris, F.}

Frondibus pinautis, vachii subtrigouo, villoso; pinnis 12 jugis, suboppositis, lunceolatis, acutis, scepè brevè acuminatis, unargine cepaudis, cilialis, supcì glabris; mesouevro canaliculato, subvilloso, subtins hirsutulo; sporotheciis nervillas non attingentibus, abbrevintis; sporangiis brevi pedicellatis; annulo 13-14 articulato; sporis ovoideis.

Habital in Bulitî, locis linmidis. (Salzmann in Herls. Mougeot.)

(Longueur de la fronde entière, 45 centim.; de la partie pinnulifère, 28 centim.; longueur des frondules, 8-10 eentim. sur 2 centim. de large: distanee des entre-nœuds, 25 millim.)

Celte fougère a été déterminée par II. Gréville, conme étant l'A. sorbifolium, dont elle diffère beaucoup. Les pinnules sont presque opposées, courtes, pointues, mais non acuminées, couvertes de poils coniques, particulieremeut sur le stipe et les nervures. L'intervalle des nervilles n'a guère qu'un millimètre, et nous comptons sur une scule pinuule, de 10 centim. de longueur, prés de 60 rangées de sporothèces: ccux-ci sont couıts, épais, et n’atteignent point les nervilles, sur lesquelles s'appuient les veinules eourbes, fructifères; elles restent toujours distinctes.

\section{If. JuTgerseNH.}

Frondibus piunatis; rachi iufernè plıno, supernè sulcato, fusciculum unicuın stipitis, lilleram grcecam $\Pi$ refereule; frondulis lineari-lanceolatis, petiolatis, in acunen lougun termiualis, margiuibus creunto-repandis; nervillis pinuatis, scalpucatis, accubus vix curvalis; sporotheciis crassis, brevibus, centralibus, distiuctis; sporotheciis ellipticis; annulo $15-16$ articulato; sporis ovoideis.

Habital in Hexico. (Jungersen, $\mathrm{n} .^{\circ}$ 917.) 
(Dimensions des frondules, 28-30 cculim. sur 22-30 millim. de largeur; nous complons près de 100 nervilles pinnées el sur la largeur 10-12 arcéaux fruetifères; l'appendice perpendiculaire se détaehe en rose ì la surfaec supérieure de la fronde dans le spécinen que nous sonmeltons ì la diagnose.)

\section{GLYANENSE.}

Frondibus ovalis, slipite rigido, valido, sulcato, basi curvato; rhizomate lignoso, fibrilloso, rachi sulcato; frondulis acuminatis, inferioribus jeliolatis, superioribus sessilibus, glaberrimis, membranaceis; nervillis el venulis scalpturatis, appendice recto ad apicem incrassulo; sterilibus majoribus, oblongo-lanceolatis; margine repandis; fertilibus minoribus, undulatis, lanceolatis; sporotheciis crassis, approximalis, confluentibus, pilosis; pilis longis, rigidlis, acicuiariformibus; annulo 12-13 arliculato; pedicello lato; sporis ovoideis.

Ilabital in sylvis paludosis, ad annes Conana el Gabarel. (Guycuna Gallici, Leprieur, 1835, in schedulâ $M$. sorbifoliumı)

Filix amplu, siccilule rufescens, frondibus dissimilaribus.

(Dimensions: longueur lotalc, 80 centim. ct sans doulc plus; les frondules stériles alteignent jusqu’à 26 eentim. sur plus de 6 centim. de largeur; clles portent environ 40 nervilles pinnécs cl $15-17$ reinules arquées; les fertiles ne dépasscut gućres 12 centim. sur nu peu moins de 2 eentim. de largeur; le nombre des nervilles pinnées el celui des areeaux fructiféres étant le mème sur une longueur moitié moindre; ils sont consćquemment beaucoup plus rapprochés. Le slipe ne renferme qu'un scul faisceau vasculaice en forme de fer à clicral.)

Celle espc̀ce se rapproche du M. macrophyllum, Kze., à sporolhices glabres et à frondules fertiles; portant 10-11 sporothees seulement sur eliaque moitic des lames, el celles-ci sont bealleoup' plus larges.

\section{VJ. Rostratey, lab. XVIII, fig. 3.}

Frondibus amplis, pinnatis; stipite, rachi, mesonevris, nervillis et venulis helveolis, glabris; frondulis oblongo-lanceolatis, brevè peliolatis, mesonevro valido, marginibus crenatis, crenis rostratis, rostro incurvo, calloso; sporotheciis angustis, centrum venulke prolifere occupantibus, semper distinctis; sporangiis ovatis; annulo 18 -20 articulato, glabro, apice pe.licellormu sapè appendiculuto; sporis ovoideis.

Habilut in Brasilici. (Gardner, $\left.110^{\circ} 1905.\right)$

Filix formosa; nervillis el venulis scalphuratis; crenis rostralis noluta.

(Dinensions des frondules, 26 - 28 centim. sur 4 ecnlim. de largeur; elles portent jusqu’ì 70 ucrilles pinnées; ces nervilles donnent naissance, cn se recoubant, au bee (rostrum), qui accompagne chaque erćnılation; nous comptons de 17-20 veinules frucliféres; on troure dans le raehis un faisecau vaseulaite en forme de fer à clieval, un peu déprimé vers le haut. Nous avons vu quel(jues sporanges à anncau cuticr, ayant jusquä 30 anticulations.) 
II. le D.r Mougeot vient de nous communiquer l'espèce suivante, que nous regardons comme nouvelle, et qui doit prendre place à còté du $M$. reliculatum, Sw.

Chrisodioides.

Frondibus ovatis, rachi crasso, villoso, sulcalo; frondulis tanceolatis, petiolatis, margine repandis, apice brevè acuminatis, basi rotundatis, nervillis scalpturatis, areolis ab appendice recto dimidiatis; mesonevro pubescente, procipuè ad partem superiorem; sporolhecïs crassis, brevibus, turgidis, approximatis, confluentibus; sporangiis ellipsoideis; annnlo $16-18$ articulato; sporis renifornibus.

Habitat in America australi. (Collect. Pamplin., in Herls. cl. Moug., n. 5.5.)

Filix formosa, feracissima, aspectû Chrysodii vulgaris, $\mathrm{F}$.

(Dimensions des frondules, 17-19 centim. de longueur, sur 25-28 millim. de largeur: chaque rangée est composée d'envirou 10 ou 12 sporothèces, et nous en comptous au delà de 60 sur chaque moitić de la lame.)

Nous indiquons, sans toutefois le proposer définitivenent, le genre suivant, qui prendrait place à còté du Meniscium.

\section{* Nervillis anastonosantibus.}

Drynarice spec., J. Sis.

$\div$ DRMOMENIS, F.

SPOROTHECIS curvalis, tunc conlinuis, tunc interruplis, nudis, super dorsurn nervillarnm curvalarum silis; receptaculo crasso, elongato, gibboso, elliplico, plirs minizve curvalo; sporangiis reclis; annulo 14 arliculalo, pedicello lalo; sporis subrolundis.

Froxdrous diplotaxicis; sterilibus amplis, membranaceis, trifoliatis; frondulis terminalibus majoribns, trilobatis, basi cordalis, margine repandis, infuni: auriculatis, obliynis, subpedalis; nervillis pinnalis, Iransversalibus, curvalis, minulis; areolis irregularibus, parvulis, appendiculatis; appendiculis curvalis; fertilibus longioribus, pinnalis; frondulis remolis, lanceolalis, lerminali Irifoliala, acuminalâ; nervillis conformibus, stipite longo, canaliculalo, slrialı: rhizomate crasso, lignoso.

Filix Philippinensis, magna, glabra.

Dingnosis nostr., tab. xvi1, A, fig. 1.

Cette fougère curieuse, recueillie par M. Cuming et distribuée sous le n.". . a été nonmée par M. Smith Drynaria menisciifolia. Il est certain qu'il existe entre cette plante et les drynaria une analogie véritable, c'est pourquoi nous lui arons donné le nom de Dryomenis, forme des premières syllabes des mots menisimm et drynaria. Le spécimen que nous possédons est altéré; sans celle circonstance, nous eussions fait passer ce genre de la condition provisoire à la condition definitive.

Le Dryomenis Phynalodes se rapproche, par la nervation, des balhminm et du Drynaria Phymalodes. Toutefois la disposition trifolièe des frondes stériles et leur ampliturle l’éloignent de ces genres. 
3. Sporolhecia rolunda vel ellipsoidea, rarò subelongala; renula prolifráa ad mesonerron obliquè tendens.

A. Gymnosoria.

1. Lamina frondiun fertilimu convolutie, silipuiformes rel bacciformes:

STRLTHIOPTERIDE.

Vlagna, valide, diplotaxicæe, frondes fertiles rigidx, convolutæ; indusio paradoxo.

A. Bacciforma. Nerillis liberis. 105. Struthiopleris, Willd.

B. SILIQUUAFORMIA 106. Onoclea, L. 107. Ceratodaclylis, J. Sm.

\section{A. BICCIFORMIA.}

\section{* Nervillis liberis.}

\section{0ว. STRUTHIOPTERIS, Willd. (1810.)}

Spec. pl. (Filices), p. 288.

Osmunde spec., L. - Onoclea, Bersн.

Sporotuecus dorsalibus, nudis, in medio venulce insertis, approximatis, confluentibus; receptaculo punctiformi; sporangïs ovatis; annulo $16-18$ articulato; sporis brevibus, ovalibus.

Froxdurs sterilibus, in circulo dispositis, pinnatis; pinnis pinnatifudis; nervillis pinnatis, venutis simplicibus, fertitibus sensim minoribus, insigniter revolutis,

- rigidis, confertis, contralibus et tardius evolutis; venulis trifurcatis, brevihus; rhizomate repente.

Filices erectce, repentes, terrestres, Europace et Americance boreales.

Diagnosis: Hook. et B., Gen. filic., to xıx. S. Germanica, Wıьtd., loc. cil.

Struthiopteris, frondibus sterilibus, faciem Nephrodii Filicis maris habet; fertilibus, Onoclex sensibilis fertiles refert; sporothecia frequenter indusiuta sumt, procipuè in frondibus fertilibus que ultima apparent, astate oul finem vergente.

Les struthiopteris sont des fougères vigoureuses, dont les frondes stériles croissent en cercle autour d'un rhizome globuleux, assez considérable, en formant d'élé- 
gants panaches, gracieusement étalés; elles paraissent les premières et au printemps; plus tard, et au centre de la touffe, se montrent les frondes fertiles, qui sont raides, et ne participent en rien à la grâce du port des frondes stériles.

Quoique le rhizome soit globuleux, il fournit dans son pourtour des rejets vigoureux qui plongent en terre, et s'écartent à des distances souvent considérables de la plante-mère; ils sont pour cette plante l'un des principaux moyens de nuultiplication.

L'espèce-type de ce genre, le Struthiopteris Germanica (Willd.), qui, pour Linné, était une Osnionde, et pour Swartz un Onoclea, abonde en Suède, en Russie, en Autriche, et dans presque tout le nord de l'Europe; elle s'avance au sud jusque vers les bords du Rhin. On la cultive, comme plante d'agrément, daus les jardins anglais.

Le $S$. Pensylianica (Willd.) ne diffère de l'espèce européenne que par les segments obtus de ses frondes. On peut le regarder comme douteux.

\section{ENUMERATIO SPECIERUII.}

Germanica, Willd. (Osmunda, Gumn.*, Fl. Danica*) - Pensylvanica, Willd.

\section{** Nervillis conniventibus.}

\section{*** Nervillis anastomosantibus.}

\section{ONOCLEA, L. (1764.)}

$$
\text { Gener., n. } .^{\circ} 1177 \text {. }
$$

Calypterium, BеRкн. - Angiopteris, Мıтсн.

SPOROTHECus globosis, magnis, approximatis, deminu confluentibus; indusio orbiculato, concavo, reliculato, venoso (an epidermide inferiore soluto?); sporangiis cieberrimis, receptaculo conico insertis, breviler stipitatis, nigris, subrotundis; annulo vix crenulato, $28-32$ articulato, articulis latis; sporis ovalibus.

Froxnıвs diplotaxicis; sterilibus profundè pinnatifidis; nervillis hexagronis, cxappendiculatis; fertilibus bipiunatis, pinnulis sessilibus, in globum contractis; nervillis crassis, pinnatis, prominentibus, rigidis; thizomate repente.

Filix Boreali-Americana, tenera, erecta, terrestris.

Diagnosis : Hook, et B., t. Lxrxu. O. sensibilis, L. 
Ce genre ne renferme qu'une seule espèce, qui croît en pleine terre dans nos jardins, sil elle fructifie assez facilement; elle est herbacée et traçante comme le Strultiopteris. Nous regardons l'indusium comme douteux.

\section{B. SILIQUEFORMIA.}

\section{CERATODACTYLIS, J. Sm. (185i.)}

In Gener. filic. Hook. et B., t. XXXIt.

SpOPOTHECıs laxis, superficialibus, dorsalibus, ad bifurcationem nervillarum pinnaturum sedentibus, per confluentiam linearibus, receptaculo nullo; sporangiis rotundis; annulo ferè completo, sub 20 articulato; sporis trigonis; indusio spurio, intus deliscente.

Froxdibls pinnatis, pinnis sterilibus, alternis, oblongo-ellipticis, basi obliquis, serrulatis, venosis; venulis subsimpliciler aut dicholomo-ranosis; ferlilibus contractis, linearibus, subfalcatis, sapè ternatis, marginibus revolutis, membranaceis, indusiformibus, dorsum pinnula totum tegentibus.

Filix erecta, Mexicann.

Diagnosis: Honk. et B., l. cil. C. osmundoides, J. Sis., l. cil.

Ce genre, fondé par. II. J. Smith, n’a qu'une seule espèce originaire du Mexique, oil elle a èté récoltée par N. Lambert; elle nous est inconnue.

\section{Considérations générales sur le groupe des Struthioptéridées.}

Nous avons réuni dans ce petit groupe les fougères ayant des frondes fertiles et stériles absolument différentes, à pinnules prolifères plus ou moins conplément roulées sur elles-mêntes, de manière à prendre la forme d'une baile. Le caractère qui peut faire penser qu'il est artificiel, se déduit de l'existence, che\% quelques-unes de ces plantes, d'un indusium qui ne se retroure pas chez les autres. Cependant on peut regarder ce tégument comme douteux, même dans les genres oi l'on admet sa présence. Dans tous les cas ce groupe forme un passage très-naturel des fougères gymnosores aux fougères angiosores. La nervation est libre ou anastomosée. Ce sunt de grandes plantes dont une seule, type du groupe, le Struthiopteris Germanica, Willd, vit en Allemagne dans les lieux montueux, sans quill ait été possible, nalgré tout ce qu'on a tenté, de le naturaliser dans les Vusges; cependant il n'est pas rare dans la Forêt-Noire. Les autres struthioptéridées virent dans l'Anérique septentrionale. (Voy. p. 26.) 


\section{Laminn frondium planæe sen rarissimè plicatæ, munquim revolutie:}

POLIPODIEE.

\section{Herbaceæ, erectæ aut pendulæ, ut plurimùm arboricolæ, multiformes, cosmopolitanæ.}

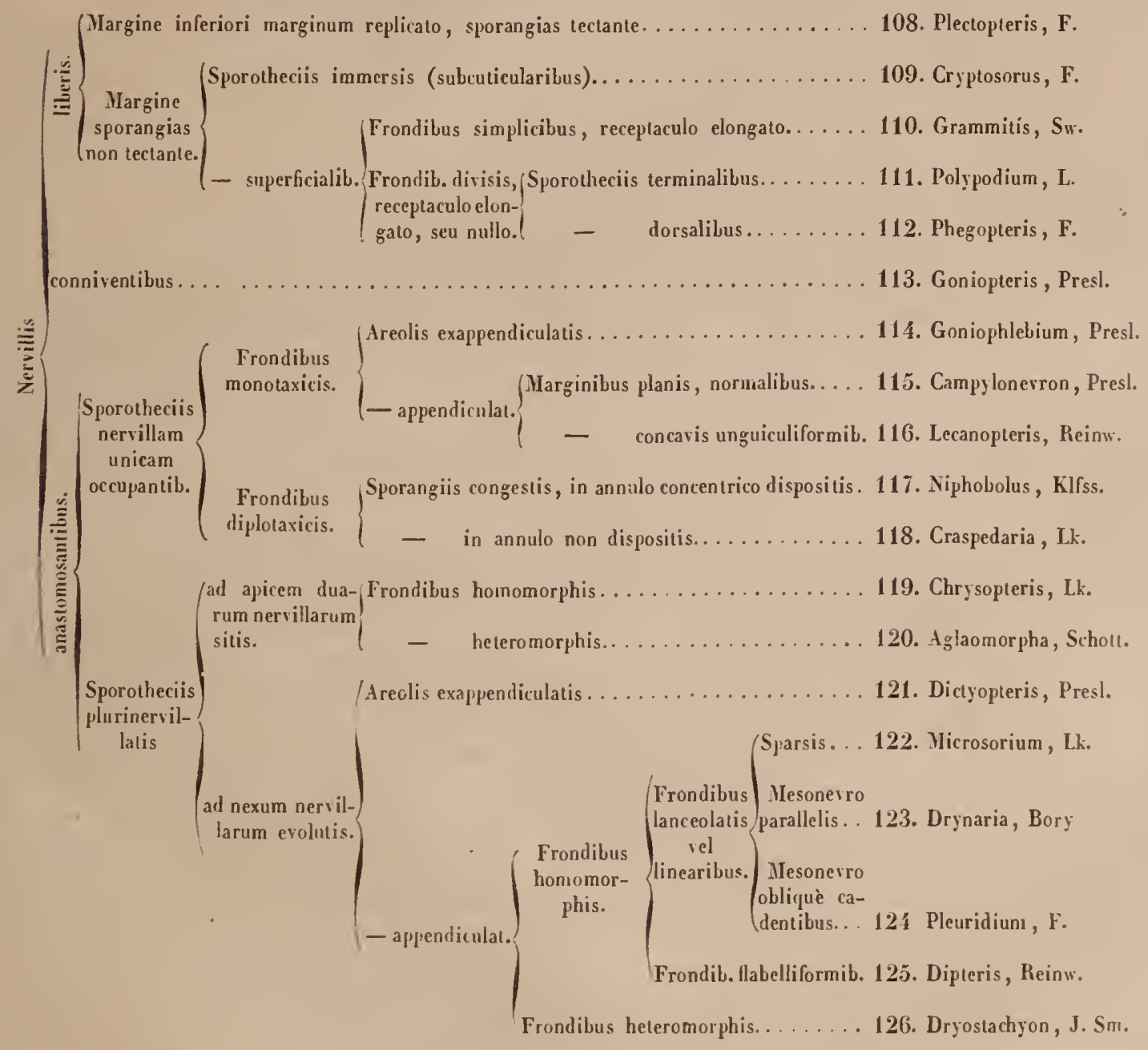




\section{* Vervillis liberis.}

1. Margine inferiori marginum replicato, sporangias tectante.

\section{PLECTOPTERIS, F. (1845.)}

Congr. scient. de France, X. ${ }^{\circ}$ session, t. I, p. 178.

Grammitidis spec., J. Sw.

SPorotnecio unico, subgloboso, apice nervilla incrassato insidente; margine inferiori lamince basi leviler aucto, sursim flexo, subcucullato, involucri vicem gerente; sporangiis oroideis; annulo $10-11$ articulato; stomio undulato, subIo nervato; sporis ovoideis.

Froxdirus pinnatifidis, linearibus, brevè stipitatis, fasciculatis, in parle inferiori (sterili) crassè serratis, in superiori (fertili) pinnatifidis, sinubus rotundatis, alternis, omnibus proliferis; nervillis pinnatis, distantibus, simplicibus; rhizomate subrotundo.

Filix parvula, tenera, erecta, Philippinensis.

Diagnosis: tab. xıx, B. P. gracilis, F. (Grammilis cucullata, J. S.м. non Butм.)

Ce genre monotype, établi sur une petite foug̀̀re distribuée par M. Cuning sous le n." 206, a le port des polypodes voisins du $P$. Trichomanes. Mais la nerration est réduite à sa plus grande simplicité, chaque lohe ne recevant qu'une nerville assez grosse, obtuse, et qui se termine assez loin de la marge. Les sporothèces ellipsoïdes sont cachés par la marge inférieure qui se soulève de bas en haut sur le mésonèvre, et constitue ainsi une sorte d'involucre à valves inégales. Dans quelques pecites espèces de polypodium la marge se recourbe aussi sur les sporothècés; mais la rangée supérieure de ces groupes est nue; au reste, la nervation diffère et ne permet pas de méconnaitte ce genre curieux. Nous le regardons conme distinct du Calymmodon de M. Presl, établi sur le Grammitis cucullata de MM. Nees et Blume, fougère que n'a pas vue le savant auteur. Lit figure assez médiocre que nous avons sous les yeux se rapporte bien plutòt à un Xiphopteris qu'à tout autre genre, et elle n'a aucun rapport véritable avec notre plante. Il nous semble donc impossible, dans l'état actuel de nos connaissances, de conserver le genre Calymmodon, destiné à prendre place à còté du genre Pleclopteris, sil arrive que la plante-type soit mieux connue.

\section{SPECIES.}

Genus monotypum: vide diagnosim generis. 
B. Margine sporangias non tectante.

A. Sporangiis immersis (subcuticularibus).

\section{CRYPTOSORUS, F. (1843.)}

Congr. scient. de France, X. ${ }^{e}$ session, t. I, p. 178

Polypodii spec., Buum., Enum. pl. Javæ, p. 128.

SPOROTHECIIS ovoideis, apicilaribus, inmersis, sub culiculâ nascentibus; sporangiis subroluudis, parvulis; stomio lato 18 nervalo; nervis parallelibus, crassis; annulo $11-12$ arliculato; sporis rolundis, nigresccntibus.

FroNDibus elongatis, lanceolalo-linearibus, pinnatifidis; segmentis apice solium fertilibus, culiculâ maluritate sporangiarum fissẩ dilatatấque; fissurâ lineari, marginibus labiiformibus, incrassatis, scepè coloratis; labiis in C. Dionæâ ciliatis; ciliis horizontalibus aperturam velantibus; nervillis pinnatis, crassis, marginem non allingentibus; fasciculo vasorum unico, rhomboidali in quâcumque slipile.

Filices elasticre, pectinatce, arboricolce, Javanenses el Philippinenses; fucie polypodiorum; frondem elasticam, pectinatam habentes.

Diagnosis : tab. xıx, C. C. Dionaea, F.; fig. 2, C. elaslicus, F. (fragm.); fig. 3, Gymnogramme pubescens, F. (fragnentum ad comparandum).

Ce genre, dont nous ne connaissons que deux espèces, a le port des polypodium pectinés, et les sporothèces occupent aussi le sommet de nervilles simples. Le caractère distinctif qui motive la formation d'un genre, se déduit de la situation des sporanges, naissant au-dessous de la cuticule inférieure pour se mettre en rapport avec la lunière; ils la fendillent et il en résulte une ouverture béante à peu près ellipsoïde et à marges épaissies. Les groupes que forment les sporanges sont épars, distants, peu nombreux, situés principalement vers le sommet des lobules. Dans le $C$. Dioncea, l'ouverture du méat est bordé de cils convergents, et qui se ferment à la manière des poils de la feuille du Dioncea muscipula, L.

Quelques polypodium ont des sporanges logés dans une dépression de la lame; mais c'est une fausse immersion, car ils sont superficiels et non souscuticulaires. 
C. Dionæa, F* - Blumei, F* (Polypodium obliquatım, Blum., l. cit.).

Dıox.

\section{SPECIES NONDUY DESCRIPTA.}

Frondibus lanceolatis, pectinatis, profundè pinnatifulis, membranaceis, stipile rachinue nigrescentibus, hirtis; segmentis linearibus, oblusis, horizontalibus, approximatis, basi decrescentibns, glabris; nervillis crassis, simplicibus, abbreviatis; sporolheciis apicitaribus, prucis, eltipticis, immersis, culicutô tabiornum fissurce ciliatâ; ciliis rigidis, radiantibus; sporangiis ovatis; annulo 12 articulato; sporis ovatis.

Habilat in Java. (Lobb., n. ${ }^{\circ}$ 270.)

Filix elegams, pectimata, stipile brevi, fasciculum vasorum unicum ferente.

(Dimensions: longueur totale, 30 centim.; envergure, 3 centim. Nous comptons euviron i0 paires de segments.)

B. Sporangiis superficialibus.

a. Frondibus simplicibus, receptaculo elongato.

110. GRAMNITIS, Sw. (1806.)

Syn. filic., p. 21.

Polypodii spec., Auct. Pluris. - Mecosorus, K. Lis., t. 20 , p. 40 亿.

SPOROTHECus uniscrialibus, mesonevro plis minisse approximatis; receptaculo crasso, sublineari vel elliptico; sporangiis rotundis, pedicello longo, sapè arliculato donatis, dorsalibus aut subapicilaribus; annulo crasso, articulis inaqualibus 10-12, sacculo frequenter ad apicem piloso; pilos 2 aut 3 longissimos, divaricalos, rigidos emillente; sporis niorrescentibus, rotundis.

Froxdibes simplicibus, linearibus, integris, petiolatis, venulis bifurcatis, rammlu superiori ad basim fertili.

Filices erectre, parve, piloso-squamose, ratins glabra, arboricoler, Javanice, VeoHollandica, Sandwicenses, pancre Americance.

Diagnosis : Hook. ct B., Gen. filic., L. LXXu (G. furcala, L. et Grev.). Icon. nostr. : N, $A$, fig. $3, G$. Magellanica, I.

Ce petit genre ne diffère que bien peu du polypodinm; le port est toutefois distinct. Tous les grammitis ont des frondes simples, à marge entière, linéaires, terminées en pointe ì leurs deux extrémites, d'ordinaire velues, portant de chaque 
côté du mésonèvre une rangée de spores allongés-linéaires ou ovoïdes. La forme du réceptacle détermine celle des sporothèces; cependant il arrive quelquefois qu'ils prennent une disposition arrondie; mais si l'on enlève les sporanges on peut s'assurer que le réceptacle tend au moins à l'ellipse; celui-ci est situé le long du trajet des nervilles, ou, ce qui est bien plus rare, au-dessous de leur sommet. Souvent le sacculus est chargé de poils comme dans le Goniopteris, le Meniscium et la plupart des gymnogramme, dernier genre à côté duquel il eut pu être placé sans inconvénient, s'il ne nous eût semblé qu'il se rapprochait plus des polypodiées que des leptogrammées, ayant avec les pleopeltis une affinité incontestable.

On trouve les grammitis aux Philippines, à Java, à la Nouvelle-Hollande, aux îles Sandwich, au détroit de Magellan. Une ou deux espèces sont américaines.

\section{ENUIIERATIO SPECIERUII.}

Longa, F. (Lobb. Java, n. 271) - fasciculata, Blum.* et hirta, Blum.* (vix differunt) - limbata, F. - tenella, KIfss. (Kze.*) - Billardieri, Willd. (Kze.*) - Magellanica, Desv.*-crassa, F. - parietina (Polypodium, Kı., Kze.*) - linearis, Siv. (Schkh.*; Asplenium, Jaeq.*) - marginella, Siv. (Sehkh.*) - punctata, Radd.* - congener, Blum.* - pilosiuscula, Blum.* - pusilla, Blım.* - Zejlanica, F. - furcata, Hook. et Gr.* (Ilook. et B.*).

I. Loxga.

\section{SPECIES NONDUM DESCRIPTE.}

Frondibus longissimis, linearibus, utrinquè attennatis, marginibus integerrimis, rtpandis, stipile brevi, filiformi; laminis glabriusculis; sporolheciis suprà impressis, ramos superiores nervillarum bifurcatarum occupantibus, circà mesonevron evolvenlibus, ovoideis, distinctis; recepluculo elliptico; sporangiis ovoideis, sacculo piloso; annulo 12-13 articulato, pedicello longo; sporis globulosis, nigrescentibus.

Habitat in Javî. (Lobb., n. 271.)

Filix elata, linearis, angusta, flexibilis, fasciculuta.

(Dimensions : longueur totale, 24-26 centim., sur 7 -8 millim. de largeur; le stipe est const.)

II. Livibata.

Frondibus fasciculatis, linearibus, oblusinsculis, undulatis; nervillis simplicibus, tenuibus, marginem non attingentibus, mesoneuro tenui; margine line $\hat{\imath}$ aterrim $\hat{\imath}$, lnciduli notato; sporotheciis ovoideis, centralibus; receptaculo elliplico; sporangiis rolundis, parvis; annulo 12-13 articulato; sporis nigrescentibus, incequalibus, roundis.

Habitat in insult Gundalupâ. (Perrotet.)

(Dimensions : longueur des frondes, 10-11 eentim., sur 5-7 nillim. de largeur; les sporcthéces; assez rapprochés, sont eependant toujours distincts; ils oecupent le tiers supérieur de la fronde, sarss en atteindre le sommet.) 
III. Crassi.

Frondibus lineari-lunceolatis, crassis, opacis, basi in petiolum rutlenuatis; nervillis pinnatis, angulum $40^{\circ}$ cum mesonevro mctientibus, surculo squamoso, squamis magnis, lanceolatis, inlegris, acuminatis, fuscis; sporotheciis dorsalibus, ellipticis, scepè confusis; receptaculo lineari, longiusculo, rimerformi; sporangiis crassis; annulo 12-13 articulato, crenis crassis, distuntibus; sporis rotundatis, globulosis, nigrescentibus.

Habitat in Novat-Hollandia nemorosis. (Lord Amkland.)

Filix rigida; frondibus fasciculatis; mesonevro robasto, siccitate flavescente.

(Dimensions, $15-17$ centim., sur 15 millim. de lirgeur; les réceptacles atteignent 5 millim.: les écailles, 10-11 millim. de longueur.)

\section{ZeYLanica.}

Frondibus lanceolatis, undulatis, acutis, membrunaceis, fasciculatis; nervillis flabellatim bifurcatis, ramis subcqualibus, superiore prolifero; rachi filiformi, piloso; pilis horizontalibus, rufescentibus; sporotheciis subroundis; receptaculo ovoideo; sporculgiis ellipticis, pedicello longo; annulo 12-13 articulato; sporis irregulariter ovoideis.

Habilat in insulâ Zeylonâ. (Gardner, n. 56.)

Filix membranacea, margine undulatî, aliquando laceratâ.

Dimensions : longueur des frondes, $15-1 \mathbf{i}$ ceutim., sur 1 centim. de largeur; le stipe a enviren 3 centim. de hauleur; les frondes ne sont fructifiées que vers le sommet.)

6. Frondibus divisis; receptaculo elongato seu nullo.

\section{POLYPODIUII, L. (1764.)}

Polypodium, Prest, sect. 1. (Speciebus paucis exclusis.)

Lepicy-stidis spec., J. Sw., Hook. Jonrn. bot., w, p. 56. (Spec. squamosce.)

SPOROTHECIIS rolundis vel ovoideis, ad apicem venulae simplicis aul ramuli superioris venularum furcalarum silis; receplaculo ejusdem formce quam sporolhecia, sapè lanlùm punclum lranslucidum, glandulosum exhibenle: sporangiis auratis, rolundalis; annulo $11-12$ arliculato; sporis ovoideis, reniformibus, episporio crasso, nigrescente vestitis.

Froxрıвеs pinnalifidis, rarissimè pimnalis, fragmenlis allernis, sapè oblusis, linearibus, venulis simplicibus aul bifurcalis, ramis incequalibus, marginem non allingenlibus, apice incrassalis; rhizomate repente.

Filices in toto orbe sparse, erecte aut pendulce, arboricolcr, squamigerce, staturit mediocri.

Diagnosis : Hook. et B., Gen. filic., I. Lxxis, B. - Polyp. vulgare, L. - Icon. nostr., $\mathrm{xx}, \mathrm{A}$, fig. 2. $P^{\prime}$. australe, $\mathrm{F}$.

Genus vastissimum : Ctenopteridem, Goniophlebium et Calymmodontem referens. 
Ce genre, autrefois le plus nombreux en espèces, a été démembré et considérablement réduit. Il renferme surtout les fougères à frondes pinnatifides, à nervilles libres et à sporothèces attachés au sommet d'une nerville simple ou bifurquée. Le réceptacle est constitué par le sommet niême de la nerville qui se renfle, devient pellucide et se colore en rouge. Quelquefois ce renflement est à peine sensible, et l'existence du réceptacle est hypothétique. Ces fougères ont une grande tendance à se charger d'écailles; certaines espèces en sont couvertes si complétement, qu'on ne peut voir ni la disposition des nervilles, ni le point d'attache des sporothèces; elles appartiennent au type fourni par le $P$. vulgare. Les polypodium sont dressés ou pendants; quelques espèces pectiniformes ont une élasticité si prononcée qu'elles conservent leur courbure native d'une manière indéfinie. Les frondes sont quelquefois articulées et presque toujours attachées sur des rhizomes rampants couverts d'écailles.

Sur quarante-cinq espèces de polypodium renfermées dans noțe herbier, trentesept sont pinnatifides, à marges entières; deux pinnatifides, à marge dentée; une seule est pinnée-pinnatifide; une seule bipinnatifide; deux pinnées, une bipinnée et une à frondes simples. On voit que si dans le Phegopteris les frondes tendent à être composées, dans le Polypodium elles se montrent simplement polytomes, et cela d'une manière à peu près universelle.

\section{ENUMERATIO SPECIERUII.}

A. Simplices. = Scolopendrioides, I. cl Grev.* - var. apice divisa: trifurcatum, L., Plum.*, Peliv.*

B. Divisce. = Mullifidum, Bory (Kze.*).

C. Pinnatifida. = 1. Glabræ. = vulgare, L. (Sclskh.*), variat lobis acutis aut obtusis (icones multce in variis operibus). B. Cambricum, Desv., Schkh.* [statu sterili]) - austrnle, F.* opacum, F. - Scouleri, II. el Gr.* — Virginianum, L. (Plum.*, Pluk.*, F.* [nervatio]) - argyratun, Bory - Paradisice, Langsd. el F.* - afine, Marl. el Galcoll.* - camplonevron, F. — biserratum, Mart. et Galeoll.* - macrocarpon, Presl* (Pleopelis pinnatifida, H. el Gr.*). = 2. Villosa = Chnoophorunt, Kzc. - pubescens, Gillics in IIook. et Gr.* - pilosissimum, Mart. et Galcolt.* - subcrenatum, Ilook.* = 3. Squamosa (Lepicystis, J. Sm.). = Incanum, L. (Pluk.*, Morı.**. Schkh.*) - lanosum, F. - rhagadiolepis, F. - microlepis, F. - lepidopteris, Langsd. et F.* hirsutissimum, Radd.* (Bory*) - Eckloni, Kzc. - squanatum, L. (Plum.*, Peliv.?*) - tridens, Kze.* - lanigerum, Desv. (laxum, Presl.*).

D. Trichomanoidea; ferè omnes pendulae. = Nanum, F. - trichonanoides, Sw. (Schıklı*) - parvulum, Bory - delicatulum, Galeott.* - Serricula, F. - ferrugineum, Galeolt.* - pendulum, Sw. (Schkh.*) - Perusianum, Desv. (Ilook. el Gr.*) - rigescens, Bory (IIook. el Gr.*) - l'llernunieri, F. - ellipticosorum, F. - moniliforme, Sw. (Schhh.*) - cultratum, Willd. - gracile, II. ct Gr.* (Plum., Lab. 85) - saccatum, F. - pachysorum, Kze. - jubaforme, Kifss. - Plumula, Rade.* - suspensum, L. (Plum.*, Pctiv.*) - subfalcalum, Blum. - anfractuosum, Kzc. - tenuiculım, I: - leucosticta, F. - nutans, Blum. - Pecten, F. - crispatum, L. (Plum.*, Pluk.*) - fabelliforme, Sw. (Plum.*) - pectinatum, L. (Schklı.*, Plum.*, Pluh.*) - papillosum, Blum. (Cuming. 11. 185) - Schkuhrii, Radd.* - taxifolium, L. (Plnn.*, Peliv.*) - pulchrunt, Galeolt.* filipendulafolium, F. 
E. Pinnata bipinnatifide subbipinnataque. A. Glabre. = Heteromorphum, II. et Gi.* - hastufolium, Sw. (llook. et Gr.*) - procurrens, Kze. (ramosum, Palis. Beaur.*) - tenellum, Forst. Schhlı.*) - Cubense, F. - fallax, Sehlceht. - macrosorum, F. - achilleafolium, Klfss. (Kizc.*) Finniculum, F. - Billardieri, F. (Grammitis heterophylla, Labill.*) - curratun, Sw. - Friedrichsthalianum, Kze.* - Lindenianum, Kze.* - pilipes, Ilooh.* - murorun, Ilook.* - rude, Kze. (Alsophila pilosa, Marl. el Gal.*). = B. Squamosx. = Cancellatum, F.

\section{SPECIES MONDLII DESCRIPT $\mathrm{E}$.}

\section{Pinvatifine.}

* Glabre.

I. Alstrale.

Frondibus pinnalifidis, glabris, sapè irregulatìn pinnatifidis; seginentis lineari-lanceolatis, alternis, oblusè dentalis, repandis, dentibus oblusis, acuminatis, basi decurrentibus, mediunis et infunis subpinnatifulis crenatisve, segmentis obtusissinis, crenis incequalibus, dentatis, stipitibus levibus, rufescentibus; sporotheciis serialibus, opposilis, ovoideo-rolundatis, amplis, rufidulis, apice nerville elliptico receptaculiformi; sporis ovoideis, magnis, mberculatis.

Habilat in Sardinia, in Corsicâ (Rcquien), Teneriffa (Bory).

I. enlgare, var. Canbricun, Herb. Moug.

Longueur totale, 40 - 45 centim.; des plus longues pinnules, 11 - 13 centim.; plus grandé larzeur it la base, 2 eentim.; sporothices, au nombre de $20-24$ paires, distants les unes des autres de 5 centim.; les sinus ont un pen plus d'un centim. d'ouverture; je compte 20 paires de pinnules 'ur je spéeimen que j’ai sous les yeux.)

Celle espèee, donnće comme la variété Cambricum du P. vulgare, nous semble différente; elle est plus grande; ses pinnules produisent des segements obtus et non aigus; les nervilles alteignent presque la marge; les spores, beaucoup plus gros et plus réguliers que dans le $\boldsymbol{P}$. vulgare, sout fortemeut tuberculeux; les sporothèces sont écartés les uns des autres; les éeailles du rhizome ne se terminent pas en une longue pointe aeuminće et la nervation est différente.

\section{Op.acun.}

Frondibus profundè pinnatifidis, apice caudatis, slipitibus longissimis, rufescentibus, lucidis, rachi nigrescente; segmentis lineari-lanceolatis, obtusissimis, crenatis, distantibus, basi contractis, squanas sparsas laceralas ferentibus; nervillis furcatis, difficilè perspicuis; sporotheciis crassissinis, rolundis, superficiem totam lamince invadentibus; sporangiis ovalis; annulo $12-13$ articulato, pedicello tenui; sporis lavibus, crassis, ovalibus.

Habilat in Neridâ; altitud. 2300 metr. (Funcke et Schlim, n. ${ }^{0} 1579$. )

Filix longè repens, opaca, eleganter crenata, stipite tenui, flexuoso, sub adiantino, angustè canaliculato.

Dimensions: longueur totale, 30 ecntim. et plus; le stipe ou pétiole fait la moitié de cette dinension; les segments ont environ 3 eentim. de longueur, sur 5-6 millim. de largeur; ils portent de 5.6 paires de sporothèees; le rhizome est rameux, droit, noirâtre, écailleux et de la grosseur l'une plume doie. Celte espèee se rapproche un peu du P. vulgare el espèces roisines.) 
III. Cayptosevrox.

Frondibus pinnatifidis, abruptè terminatis, stipite gracili; rhizonate squamoso; squamis rufescentibus; segmentis remotis, linearibus, rachi puberulo; nervillis abbreviatis, mesonevro undulato, fusco; sporotheciis parvilis, terminalibus, sporangiis parvulis; annulo 11 articulato; sporis nigrescentibus, ovoideis rotundisque, leviter in ambitu irregularibus.

Habitat in Cubat. (Linden, 1886.)

Filix flaccida, tenuis; segmentis cum rachi angnlum $450^{\circ}$ inetientibus.

(Dimensions : celles du $P$. vulgare, L. Les segments, au nombre de 20 paires environ, sont remarquables par leur peu d'épaisseur; ils mesurent environ 2 centim.; le mésonèvre serpente dans la lame, et chacune des cotorbures reçoit la nerville prolifère, qui est fort courte; plusieurs espèces ont un mésonèrre ondulé, mais aucune ne l'a d'une manière aussi marquée; le rlizome est gros comme une plume de pigeon. Les frondes croissent écartées les unes des autres.)

\section{Laxosum.}

** Squamosce.

Frondibus linearibus, segmentis obtusis, contortis, opacis, cartilagineis, siccitate subcontortis, suprà pilis albis, longissimis, basi squamis, sparsis onusto; subtìs lanâ molli, rufescente longâque densè obsitis, segmentis superioribus solìm fertilibus; sporotheciis crassis confluentibusque, $3-4$ in qnoque segmento; sporangiis ovatis; annulo 12-13 articnlato; sporis crassis, ovalibus.

Habitat in Clili. (Herb. Nougeot.)

Filix singnlaris, elongata; segmentis brevibus, legumina viciarum ant ervorum referentibus.

Dimensions : longueur de la fronde (le stipe est tronqué), 30 centim., sur 21 - 23 millim. d'ellvergure; les serments mesurent à la base 8 millim.; ils sont arqués et rappellent la consistance et mème la forme des légumes de quelques espèces des genres ercum ou vicia. Nous comptons 40 paires de segments.)

\section{Rhagadiolepis, F.}

Frondibus pinnatifidis, stipite depresso et rachi squamosis, segmentis linearibus, suboppositis, acutis, assurgentibus, suprà glaberrimis, suprà densè squamosis, squamis adpressis, niveis, in ambitu luceris, centro colorato; sporotheciis rotundis, magnis, liermesinis, basi squamis cincto; laminâ totâ proligerâ; sporangiis ellipsoideis; annulo 12-13 articulato, pedicello longissimo, vittato; sporis ovoideis subreniformibusque.

Habitat in insula Cubâ et in Mexico. (In sylvis dictis de Yerba Buena, Linden.)

Filix elegans, squamosa, spissa, segmentis remotis.

(Dimensions : longueur totale, 20-24 centim.; celle des segments est de 3 centim., sur un peu moins d'un centim. de largeur). [Le spécimen que uous décrivons, ne peut donner une idée exacte des dimensions.]

Kunze, auquel nous avous communiqué cette plante, a écrit cette note: Filix mihi haud nota, nec in collectione Lindeniana visa; est polypodium e sectione Pleopelidis; dernicre conclusion, qui ne peut ètre admise, les nervilles étant libres et les sporothèces libres de toutes écailles. 


\section{Mickolepis.}

Frondibus pinnalifidis, longè slipitatis, slipilè el rachi squamosis, rhizomate repente, fibrilloso, crassiludine pemnce columbince; semmentis oppositis, ellipticis, horizontalibus, suprà glabris, subuìs densè squan!osis; squamis parvulis, imbricatis, subroıundis, longè acuninalis, centro fuscis, acumine liberis; sporolheciis rotunlis, approximatis, subsenis, labacinis; sporangüs rolundis; annulo lato, 12-13 articulato; sporis ovalis, reniformibus levibusque.

Habilat in Americâ Australi. (Collect. Pamplin, n. ${ }^{\circ} 38$, Ilerl). Mougeotiano.) Filix repens, parva, frondibus remolis; segmentis exactè opposilis.

(Dimensions : longueur totale, $6-\bar{\tau}$ eentim., dont la noitić est occupée par Jes segments fiondulaires; l'envergure est de $7-8$ millim.; nous eomptons de 9-11 segments; il s'en trouve $3-4$ cn une étendue d'un centim. Jolie espèce, très-distinete du $P$. incanum.)

VII. Yaxcai.

\section{TкісномамоіDE.}

Frondibus fusciculutis, linearibus, hirsulis, rachi hirlo; segmentis ovoideis, concuvis, crassis, opacis, monosoris, approximatis; sporolheciis rolundis, crassis, solitatüs in quoque segmento; sporangïs magnis, rolumdatis, pedicello longo; annulo lato, 14-15 articulato; sporis ovalibus.

Habitat in Guyant. (Leprieur, Herb. cl. Moug.)

Filix parvula, rigida, hirla.

(Dimeusions : longueur totale, à peine 5 eentin., sur 3 millim. d'envergure; les segments descendent jusqu'au bas du stipe; nous en comptons environ 8 sur unc étendue d'un centim.)

\section{Vili. Serricula.}

Frondibus crespitosis, rigidis, linearibus, acutis, sessilibus, dentuto-pinnatifudis; denlibus inlegtis, angulutis, obutusiusculis; lamina pilis paucis criniformibus hirkti; sporalheciis costalibus, in quâque dente solitariis; sporangiis ovoideis, pedicellatis; sporis subrolundalis, allis; rlizomate fibrillis nigris, plumosis onuslo.

Habilat in Antillis (Guadalupî), L'Ilerminier; Perrottet.

(Petite fougère dont les fiondes naissent en touffes sur un rhizome dressć. La longueur des frondes est de 16 eentim., sur 5 eentim. de largeur; Ies dents sont un peu ćloignées, obtuses, triangulaires; (quelques poils roides lićrissent leur surface; rus au mieroseope, ees poils sont continus.)

IX. L'Hervisier I.

Frondibus pinnatifudis, pendulis, lanceolutis, pectinatis, rachi villoso, pilis muis, divaricalis; rachi hirsutulo; segmentis horizontalibus, oblusiusculis, approximatis, elliptico-lanceolalis, terninali cauliformi; mesonevro flexuoso, atro; nervillis crassis, brevibus, omnibus ferlilibus; sporolheciis rolundis, apicem nervillarum incrassatum coronantibus; sporangiis ovoideis; annulo 12-14 articulalo; sporis irregularibus, subroundis.

Ilabilat in Guadalupit. (Perrottet.)

Filix elegans, peclinata, mullipartita, infescens. 
(Dimensions : Tongueur totale, 28-30 centim.; envergure, 3 centim.; le slipe est à la fronde :: 1: 5; nous comptons 65-70 segments sur clraque fronde el 8-10 sporothèces sur chaque cóté de la lame des segments; le rhizome est gros comme une plume d'oie et muni de longues fibrilles.)

\section{Ellipticosorim.}

Frondibus pinnalifidis, linearibus, pendulis, nollissimis, cilialis, ciliis longissimis, paucis, brisi decrescentibus; segmentis oblongis, oblusis, basi sterili latioribus, horizontalibus, approximatis; llizomale parvulo, brevi, stipile basi lannginoso; sporotheciis ellipticis, crassis, obliquis; receplaculo nullo; sporangiis ovatis, pedicello tenni; anmulo 14-16 articulıto; socculo ad partem superiorem pilos rigidos, 6-8, longissimos tenuissimosque ferente; sporis ovoideis.

Habitul in Merida; altitul. 2000 metr. (Funcke el Sehlim, n. 960.)

Filix dendricola, sıspensı, mollissina; sporotheciis leptogrammearum; sporangiis sacculo hirsulissimo notalis.

(Dimensions : Iongueur totale, 45 centim. et probablement plus, sur 30 - 35 inillim. d'envergure; nous comptons jusquà 80 paires de segments, et sur chacun d'eux de $7-10$ paires de sporothèces : très-rapprochés, mais non confluents et très-allongés; la base des segments fructifères est stérile. Espèce très-curieuse el très-distinete.)

\section{Saccatum.}

Frondibus linearibus, fusciculutis, pinnalifulis, subsessilibus, uulis; segnentis creberrimis, profundis, oblusis, horizonlalibus, glabris; nervillis simplicibus, apice - frucliferis; sporotheciis rotındis, immersis, distinctis, suprà intpressis, in depressione laninse nascentibus, margine revoluto subabsconditis; sporangiis rotundis, parvis, pedicello tenui; annulo 12-13 articulato, sacculo perfacilè soluto; sporis subrolundis, parvis.

Habitat in Antillis (Guadalupi, Perrottet); Martinica (M."1e Rivoire).

Filix parva, elongala, sporangïs immersis, marginibns segmentorum reflexis.

Dimensions : Jongueur totale, 20 centim., sur 10-13 millim. d'envergure; segments rapprochés ; nombreux; nous en comptons jusqu’à 60 paires.)

Cette espèce se rapproche du Calymmodon par ses sporothèees à demi-cachés par le repli de lá marge des lobules, et du Ctenopteris par des sporanges en apparence enfoneés dans la lame; mais malgré cette apparence ils sont suprn-cuticulaires. (Voy. Calymmodon et Ctenopteris.)

\section{Texticelun.}

Frondibus pinmatifidis, ovato-elongatis; stipite brevi, tomentoso; rachi piloso, pilis rigidis, acutis; rhizomate repente; segmentis complanulis, membranaceis, tenuibus, oblusissinis, glabris, angulum 50 cum rachide metientibus; nervillis simplicibus, abbrevialis, apice globoso, turgido, fet tili; mesonevro flexuoso, nigrescente, sporolheciis remotis, dislinctis, apiciluribus; lomina in parte prolifer $\hat{\imath}$, leviler depressci; sporangiis parvulis, pedicello brevi; annulo 11 articulato; sporis parvulis, ovoideis, rolundis, nigrescenlibus.

Habitut in Guadulupî. (L'Herminier.)

Filix dendricola, tenuis, complanata; sporotheciis suprà impressis. 
(Dimensions: longueur lolale, 15-16 eentim.; le stipe esı d la fronde :: $1: 5$ ou à 6 . Les plus zrands segments alteignent 2 eentim.; nous en comptons une singtaine. Celle espèec est renarquable par le pen d'épaissem de ses lames.)

\section{IIII. Lel costicta.}

Frondibus peudulis, linearibus, pilosis, pilis rufescentibus; slipile filiformi, cylindrico; segmentis oblusis, lanceolutis, nervillis brevibus, simplicibus; mesonevro flexunso, uigrescente, ud apicem evanescente; sporotheciis subsenis, rolundis, infernè lumimam inquinantibus; receptaculo uullo; sporangiis ovoideis; annulo crussn, incruali, 1\$-15 arliculuto; sporis rolundalis, sporulis minulissimis repletis.

Ilabilul in (Muilo. (Jameson.)

Filix longiusculı, flexibilis, angust' pilis rufis coopertı.

Dincusions : longueur totale, 30 centim., sur $22-84$ millim. denvergure; nons comptons de 15-50 segnents, remarquables par les points blane de neige, qu'ils portent en dessus el qui correspondent aux sporothèees; la eulieule, décolorée et derenue seariense, se délache très-facilement dr ces impressions punetiformes.)

\section{NII. PECtEx.}

Frondibus fusciculalis, pinnulifudis, curvatis, elasticis, ovoideis, stipile et rachi lomenlosis; segmenlis horizontalibus, ruchim allingentibus, angustè lanceolatis, oblusiusculis, glabcis, integerrimis, subopacis, nevvillis apice ferlili, translucido, lurgiulo; sporolheciis crassis, circi nuarginem evolventibus; sporangiis rolundis; anuulo spisso, 12-13 arliculato; sporis ovoideis.

Habilut in Meridâ (Colunubiu), Linden, n." 239.

Filix elastica, pectiuata; rhizomale surculiformi.

Dimensions longneur totale. $15-17$ centim., sur 22-24 millim. l'ensergure: le slipe noiritre est a la fronde :: $1: 2$ : nous comptons ensiron 30 paires de segments.)

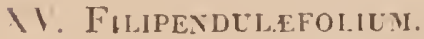

Frondibus frusciculatis, lanceolutis, pinnalifulis, curvulis, elaslicis, slipile bievi el ruchi flexuoso pilosis; pilis rufescentibus, palulis; segmentis profundè incisis, dentibus oblusiusculis, subhorizonlalibus, .excurvalis, oblusis; nervillis brevissimis, apice lurgido, glanduloso, pyriformi, fruclifero; uesonevro flexuoso; sporolleciis subroıundis, 5-jugis, apicilacibus; spotungïs parvis, pedicello lenui; anuulo 9-10 urliculalo; sporis rotundalis.

Habilat in Javit. (Lobb, n. ${ }^{\circ}$ 269.)

Filix elegans; segmentis ad formam pinnatifidum tendentibus.

(1)imensions : longueur totale, 13-14 eentim., sur a centim. d'curergue; les scgments (nous en complons environ 30) sont légèrement recuurbés en delıors; ils portent quatre dentienlations pofondes: qui leur clonnent me apparence pinnatifide.) 


\section{XVi. Cciberse.}

\section{Pinvate yel pinvatifide.}

Frondibus ovatis, pinnatis, hirsululis, articulatis; rhizomate repente, crassitudine penna anserince, squamis basi rotundis, in acumine longo abruptè terminatis obsito; stipite helveolo, lcevi; frondulis lanceolatis, obtusiusculis, dentato-crenatis, basi inaqualè cuneatis, pilosiusculis, nervillis dichotomo-flabellatis, nigrescentibus, ramo primario basilari fructifero; sporotheciis crassis, rotundis, apicilaribus; receptaculo apice nervillce turgidce, translucida, ovatce formato; sacculo, circì amnulum, pilos longos, flaccidos ferente; sporis ovoideis, sporulos rotundos inserentibus.

Habilat in Cubâ. (Linden, sine numero.)

Filix dendricola, repens, pinnata; frondulis oppositis, supremis connatis.

(Dimensions : 18 centim. de longueur totale, mesnrée sur notre spécimen, mais nous la croyons plus grande; frondules, 5 centim. de longueur, sur 1 millim. environ de largeur; entre-nœuds . 2 centim.; les écailles sont très-remarquables; elles ont une base arıondie, du sommet de laquelle part une longue pointe acuminée; les spores sont des kistes pleins de sporules et leur nombre est immense.)

\section{MaCrosoruy.}

Frondibus ovoideis, basi tripinnatis, suprà bipinnatis; rachi complanato, squumis cancellatis, ovatis, integris, paucis, sparsis onusto; stipite tarticulato; rhizontate cylindrico, squamoso; segmentis, aliis pinnatifidis, aliis crenatis, obtusis, remotiusculis; sporotheciis crassissinis, terminalibus, tabacinis, scepè ad axilla squcunarum crescentibus; sporıngiis amplis, pedicello tenui; annulo crasso, 12-13 articuluto; sporis magnis, ovoideis, lutescentibus.

Iltrbitat in Quito, Jameson, 1845.

Fïlix lıbitu proprio; sporangiis unagnis, lobos fructiferos ouminò tegentibus; squumis pleopeltidcarum.

(Dimensions : longueur totale, 32 centim.; divisions lalérales, à la base de la fronde, 5 centiu., leurs principaux segments mesurent de $13-14$ millim.; la grosseur des sporothèces est démesurée, si on la compare aux segments qui les supportent; le rhizome est gros comme une plume de pigeon; il est parcouru par une dizaine de faisceaux vasculaires, à peu près disposés en cercle.)

\section{IVili. Fuxiculuir.}

Frondibus profundè pinnatifulis, lanceolatis, abruptè terminatis, glabriusculis; stipite et rachi fuscis; caulibus longè repentibus, contortis, intermixtis, intricatis, funiculun sinulantibus, crassitudine fili emporetici, passim gemmiferis; segmentis angustè lanceolutis, obtusiusculis, dentatis; nervillis unifurcatis; rano superiori breviusculo, fertili; sporotheciis sub quinque pariis, parvis, distinctis, lcetè fulvis; sporrangiis ovoideis; unnulo 13-14 grticulato; sporis ovouleis, subreniformibus.

Habitat in Cubu, Linden, n. 1885.

Filix singuluris, longè repens; caulibus intricutis. 
(Dimensions : la pliule entière a plus d'un demi-mètre; les tiges émettent des frondes mesurant environ 15 centim.; les segments atteignent à peine 15 millim.; Je sommet est brusquement terminé par un segment profondément denté, linéaire et caudiforme.)

\section{Caxcellatey.}

Frondibus ovalo-lanceoialis, bipinnalis; slipile, rachi et lumina inferiori squamosis; squamis ovalis, imbricatis, in umbilu laceratis, puncto coloruto nolatis; pinnis pinnalis; segmentis linearibus, suprì viridi-olivaceis, slaberrimis, remolè dentalis, dentibus oblusis, omnibus proliferis; sporolheciis subrolundis, terminalibus; squumis circumdulis; sporangiis subrolundis; annulo crasso, 12-13 arliculato; sporis magnis, ovoideis, tavibus, lutescentibus.

Habilal in Cubat. (Linden.)

Filix speciosa; pinuis el segmentis decussatis, cancellatis; squanis planis, imbricatis, adpressis coopertu.

(Dimensions : longucur totale, 20-22 centim.; principales divisions, environ $2-3$ centim.; segments inférieurs, 8-9 millim.; le slipe est à la fronde :: $1: 5$; les spores sont remarquables par leur grosscur.)

\section{PHEGOPTERIS, F.}

Polypodium, §. 2. Phegopleris, Prest, Telltam., p. 179 (parlim).

Polypodii species, Auctonus.

SPOROTнEcus rolundis, in dorso medio venularum simplicium aul bifurcalarum silis, ferè semper parvulis; receplaculo subnullo vel eliam nullo, parle nervillarum proligerâ nec incrassalâ, nec glandulosâ; sporangiis el sporis Polypodiorum.

Froxdвes pinnalo-pinnalifidis, bi-seu rarò Iripinnalis, nec simplicibus, nee pinnalifidis, nec pedalis; nervillis pinnalis, simplicibus el furcalis.

Filices erectce, magna, sapè mullisectce, palula, flexibiles, terrestres, cosmopolilana', in Europâ plures, ad regiones tropicas mulıce; quarum species difficitè delerminantur.

Diagnosis: tals. xx, A, fig. I. Pheg. decursivè pirnala, F.

Hoc genus hubilu generali, silu sporangiorum, numero fusciculorum vasorum in stipile, longè distal à Polspodio.

Les phegopteris sont de grandes fougères à frondes plus ou moins divisées. bien plus rapprochées des aspidium que des polypodium. Elles ont une grande souplesse, et les derniers segments se terminent obtusément. Les stipes sont assez. minces, canaliculés et de couleur pàle. Toutes les espèces de ce gemre avaient étè placées par les auteurs parni les polypodium, et cependant elles ont un port bien 
différent. Les sporollèces sont nus dans les deur genres, nerrillaires el arrondis, mais dans les phegopleris ils naissent roujours au-dessous du sommet de la nerville, quoique parfois ils s'en rapprochent beaucoup, tandis que dans les polypodium ils occupent l'extrémité de la nerville qui se constitue en réceptacle. Comme par exception, deux ou trois espèces onl des sporothèces terminaux, mais le port les rattache suffisamment au genre dans lequel nous les faisons figurer.

Ce genre cosmopolite est nombreux en espèces. Toutes se rapprochent plus ou moins du Polypodium Phegopleris. Il règne encore de lincertitude sur la détermination piécise de plusieurs espèces; beaucoup d'entre elles n'ayant pas encore èté figurées.

Sur cinquante-quatre espèces de phegopleris que renferme notre collection, vingt-quatte sont pinnées avec des frondules pinnatifides, huit hipinnées, quinze tripinnées, cinq quadri- ou quinque-pinnées et deux pinnées à pinnules courtes.

\section{EAUMERITIO SPECIERIII.}

1. EUROPAEE. = Polypodioides (Polypod. Phegopteris, Scink $*$ ) Oreopteris (Aspidium, Sw., Selıh..*; Polypod., Ehrh.*. IIoffm.*, Bolt.*) - Dryopteris (Polypod., Roem.*, Bolt.*, Schkh.*) - calcarea (Polypod., IIoffm.*).

2. INDICA. $=$ Ornala (Polypod., Wall.) - decursive -pinnata (Aspidimn, Kze.) - mitens, F

3. OCEANIC.E. = Lunulata (Polypod., Forst., Schk1..*) - neriosa, F. - obscara (Stenosemia, J. Sm. ?).

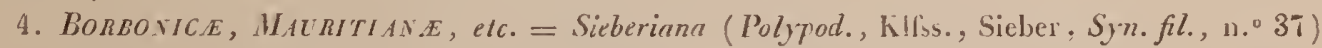
- aspidioides (Polypod., PresI) - scalpturata, F. - lanata, F. - straminea, F. - thelipteroides (Polyp., Sieber, Syn. filic., n1. $\left.{ }^{\circ} 50\right)$ - ammifalia (Polypod., Poir.) - crinita (Polyp., Pois., Ilooh. et Gr:* - elata, F. - Helliana, F. - Montbrisoniana, F.

5. AMERICANE AUSTRALES: insula et terga firma. = Aspleniifolia, Sw. (Plum.*, Pelis.*an Polypod. spec.?) - flaso-punctata (Polypod., Kilfss.) - cordata, F. - tenella, F. - concinne (Polyp., Sw.) - leptoptera, F. - rngulosa (Polyp.. Labill.*) - subincisa (Polyp. Willd. ciliata, F. - tetragona (Gal., n.. 6321) - Slomei (.tstidium, Kzc.) - polystichiformis, F. adenochrysa, F. - ampla (Pulyp., II. el BI.) - Galeottiii (Polypodinn, Maul.*) - sancla (Pluk.*, Sloan.* - effusa (Adiantun, Sloan. - splendida (Polypod., Kllss.) - spectabilis (Polypod., Kilss.) - Prionitis (Polypod., Radd.) - macroplera (Polypod., KIfss.) - Blanchetiana, F. - Tijuccana (Polyp., Radd.*) - connexa (Polypod., Mart.*) - caudain (Polypod., Radd.*) - perforate, F. divergens (Polypod., Jacq.*, Selihlı.*) - macrosora (Pulyp. subincisum, Mar..* non Willd.) formosa (Polyp., Radd.*) - axillaris (Polyp., Radd.*) - epierioides, F. - lirsuta, 1. - Portoricensis (Polypodium Portoricense, Spr., in Act. nor.); Polyp. Portoricense, ejusct. , in Sy.st. est Goniopteris Portoricensis, Presl.

6. BorEALI-A.MERICANE. = Calcarea (Polypod., atuet.) - hexaEonoptera (Polypod., Mieh.. Hook. et $\left.\mathrm{Gr}_{\mathrm{r}}{ }^{*}\right)$.

\section{Texeitha.}

\section{SPECIES NONDLM IJESCRIPT.E.}

Frondibus fuscicnlatis, pimnatis; slipite capilliformi, brevi glubroque; frondulis superme auriculato-partitis, glabris, laetè viridibns; nervillis simplicibus, teneris, pellncidis; 
sporolheciis parvulis; sporangiis ovotis; unnulo lato, 13-14 urticulato; sporis reniformibus, lutescentibus.

Hubitat in insulì Cubut. (Linden.)

Filix pusillu, pellucide, glabro, aspectu aspleniorum e sectione trichomanoideurum.

(1)imensions: Jongucur totale, 1 centim. : Ies lirondules ont ì peine 5-6 millim. de lanteun . sur 2 de Jargeur. C'est une des plus petites fougères du groupe.)

\section{Cordita.}

Fromlibus pinnatis, lanceolutis, glubris; richi et stipite tennibus, ulbidulis, pubescentibus; rhizomute repente; frondulis ellipsoilleis, obtnsis, basi cordutis, brèè petiolatis, "pproximatis; nervillis furcatis; sporothecuis parvis, unl bifurcationem nervitlurrun ferè semper sedentibus; sporangïs ovalis; amnulo 12-13 articulato, crenis gibbosis; sporis ovoileis.

Habilut in insulâ Cubâ. (Linden, n. ${ }^{\circ}$ 1873.)

Filix teneru, uspectu polypodiorum.

(Dimensions : longueur totale, 20 centim.; stipe assez cont ; 22-24 frondules. ayant 16-17 millim. de longueur, sur 5 millim. de largeur; le rhizome est fibrillens el gros comme lejpetit doigt d'un cnlant.)

III. NĖR Vos.I.

Frondibus pinnatis, linearibus, acruminatis; stipite el rachi brevibus, villoso-tomentosis; frontulis ovato-falcatis, obtusissimis, brevissimè petiolatis, basi subcorlatis, supernè auriculatis, in ambitu crenato-repandis; nervillis teunibus, furcutis, suprii scalpturatis; sporotheciis rolındis; receptaculo mullo; sporangiis rolmndatis; annulo 13-14 articulato, lato; sporis brevibus, ovoideis.

Habilat in insulis Philippinis. (Cuming, sine numero.)

Filix parva, angusta, slubra, fasciculata.

(Dimensions : longucur totale, $22-24$ centins., sur cnviron a centim. de largeur; le stipe est presque filiforme, el n’atteint guères que $2-4$ centim.; nous comptons une trentaine de Raires $^{\text {ale }}$ segments; les sporothèces ne sont pas nombrenx.)

\section{LEPTOPTERA.}

Froudibus pinnato-pinnutifidis, elongato-ovalibus, basi decrescentibus; rachi el stypite glabris; pinnulis angustè lanceolatis, sessilibıs, acuminatis, curvatis, mesonevro supra canaliculato, marginibus hirtis, pilis brevibus; segmentis obtusis, ovatis; nervillis simplicibus, rubellis, glubrinsculis; sporotheciis parvis, depauperatis, sı pè confluentibus; sporangiis ovatis; annulo 13-14 articulato; succulo pilos ilnos conicos, breves, rigilos ferente; sporis ovoideis, fuscis.

Ilabitat in Santo Domingo. (De Tussac.)

Filix stricta, glabrinscula, succulo piloso ab omnibus aliis speciebus distincta.

(Dimensions: longucur de la fronde, 50 centin.; des pinuules, séparées par un entre-nerud de $2-3$ centim., $6-\mathbf{T}$ centim. sur 1 centim. denvergure: nons en comptons plus de 30 .) 
V. ADENOCHRYSA.

Frondibils pinnato-pinnatifidis, ovato-elongatis, decrescentibus; ruchi et stipite glabris, sulcatis; pinnulis horizoutulibus, lanceolotis, sessilibus, acuminatis, pectinatis; segmentis ovatis, obtusinsculis, apice sterili; nervillis crassiusculis, simplicibus, marginem attingentibus; laminnt punctis creberrimis, aureis, nitentibus, minutissinis adspersi; sporotheciis dorsalibus, sed apicem nervillarum approximatis, parvis; sporangiis rotundis; annulo $13-14$ articulato; articulis spissis; sporis lcevibns, ovoideis reniformibnsque.

Habitat in. Antillis. (Martinicâ, M."He Rivoire; Porto-Rico, Bertero.)

Filix formosa, magna, flexibilis, transhucida; punctis aureis laminurum notata.

(Dimensions : longueur totale, 80 centim.; la pinnule seule, 65 centin.; près de 40 pinnules horizontales, acuminées, ayant 2 centim. d'envergnre; nous comptons sur chacune d'elles une trentaine de segments qui se chargent de 8-9 sporothèces, à sporanges làchement unies entre elles.)

\section{BLANChetiaxa.}

Froudibus pinuato-pinnatifulis, in amıbitu ovato-elongrttis; rachi suprà trisulcuto, squanuloso, helveolo; frondulis subsessilibus, semi-oblongis, acuminalis; segmentis ovalibus, subfalcatis, piloso-squanuulosis; nervillis 9-11, apice denticulatis, tenuibus, curvis, nuarginem attingentibus, omnibus in partem medianam proliferis; sporotheciis rotnudis; sporangiis rotundis, pedicello brevi; annulo 14-15 articulato, vix crenulato; sproris ovoideis.

Habitat in Brasilici (Bahia), Blanchet, n. 2928.

Filix elola, habitu Aspidii falciculati, Radd.

Dimensions : la fionde, sans le stipe, 50 centim.; les frondules, 10-12 centim. sur 2 centim. d'enrergure; une vingtaine de pinnules et pour chacune d'elles une vingtaine de segments; les froudes fertiles présentent sur leurs lames nu grand nombre de points dorés, qui sont peut-ètre des glandes ou une malière exsudéc (roy. Ph. adenochrysa). Le Ph. vestita (Polypodium, Presl), qui se rapproche de notre espèce, est abondamment convert d'écailles plates et blanchâtres; les nerrilles sout bien plus écartées.)

\section{ViI. Scalpturata.}

Frondibus pinnato-pinnatifidis, lanceolatis; stipite cinereo-tomentoso, suprà profindè et latè canaliculuto; pinnulis rigidis, lanceolatis, sessilibus, suboppositis, acuminatis, rochi toncentoso, basi decrescentibus; nervillis simplicibus, curvatis, villosis, scolpturatis; segmentis obtusiusculis, basi accrescentibus, duobns inferioribus longioribus, decussatis, sporotheciis parvulis, rotundatis, scepè confluentibus; receptaculo rouındo, parvilo; sporangiis subrotundis, crassitudiue mediocri; aunulo 12-13 articulato; sporis ovoideis reniformibusque.

Habitat in insulis Madagascariensi et Borbonici.

Filix venustu, robnsta; stipitibus et rachibus toncentosis; pinnulis extensis, patnlis. $V$ ariat. fronilulis el nervillis plìs minìsve pilosis. 
(Dimensions: longueur totale, 1 mètre: pimules inférieures, 16 centim., sur un peu plus de deux ecntin. de largeur. Nous eomptons au delà d'une trentaine de pinnules, séparées par un entrenoud d'environ 3 eentim.; elles sont opposées, el comme les inférieures sont plus longues, elles forment une eroix avee leurs correspondantes (pinnis decussatis); les segments sont en meme nombre et larges de 3 millim.; le stipe est gros eomme une plume de ergne.)

\section{Nitexs.}

Frondibus bipinnalo-pinnalifidis; rachi squanoso; pinnis trimguluribus, pinnulis lanceolatis, actmminalis, basi pinnatis; segmentis ovalis, cunealis, argule dentatis, subtirs nilentibus; nervillis tenuibus, furculis; sporolheciis rolnndis, remolis; receplaculo puncliformi, prominente; sporangiis ovoideis; annulo 14 articulato; arliculis lalis; sporis ovoideis, nigris.

Habilat in insulà Zeylanicá. (Colonel Walker.)

Filix infernè nitens; ad polysticha tenderis.

(Dimensions d'une pimnule prineipale : longueur, 28 centim.; elle est bi-piuncée et mème tripinnće à la base; les pinnnles sont au nombre de 20 ; la lame supérieure a pris, par la dessicci-

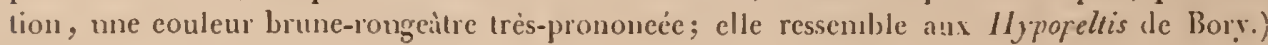

\section{LaNaTA.}

Frondibus bipinnalo-pinnalifutis; stipile el racli cinereo-lanatis, pilis strigillosis, mollibus; pinnis ovalis; pinnulis lanceolutis, sessilibus; segmenlis ovalis, oblusissimis, infunis rachi coadmnalis; nervillis furcalis, rano superiori sub apice fertili; sporollieciis rolındis, scepè confluentibus; sporangiis laxè aptroximalis; annulo lato, 1.2-13 arliculato; sporis ovato-irregularibus, nigrescentibus.

Habikat in irsula Borbonici. (De Montbrison.)

Filix mollis, densè villosa, basi bipinnalo-pinnalifuda, apice pimnalo-pinnulifudu.

(Dimensions: longueur de la fronde, $42-45$ centim.; les divisions pinuaires, 18-20 eentim.: les pinnules, 5 eentim., sur 1 centim. de large; entre-ncends inférieus, $\mathbf{T}$ eculinn.)

\section{Straminea,}

Frondibus bipinnalo-pinnalifidis, palulis, triungularibus; rachi glabro, lavi, stramineo; pinnis ovoideis, sessilibus, suboppositis; rachi supernè ferrugineo-lomentoso; pinnulis profındè pinnalifdis, acumninalis; segmentis $3-4$ crenutis; rachi et nervillis pilosis; sporolheciis rolundis, remotiusculis; sporangiis ellipsoideis; annulo 12-13 urticnlato; sporis ovoideis el reniformibus.

Habilat in insulti Borbonici. (De Montbrison.)

Filix ınagna, extensa; rachibıs sıpernè canaliculatis; sulcis tomento ferrìgineo replelis.

(Dimensions : grande comme le Pteris aquilina; divisions primaires, 36-40 centim.; entre-nouds, i-8 ecntim.; nous comptons une trentaine de pinnules sur chaeune d'elles; eclles-ci atteignent 4 eentim.; elles portent 10 segments environ, et ehaque segment deux séries composces de $3-1$ sporothèces; le stipe est jaume, rougeatre ct souvent maculé.) 
XI. Polistichiformis.

Frondibus bipinnatis, apice pinnatis, ovato-lanceolatis; stipite et rachi helveolis, glabris, squanosis; frondulis ovalis, cuneatis, subdimidiatis, supernè gibbosis, oblusis, crenatis, infernè integris, apice el gibbositate aristatis; sporolheciis rotundis, kermesinis; serie superiori completâ, serie inferiori interruptâ; sporangiis ouatis; annulo 14-16 articulato; sporis ovoideis.

Habitat in Santiago de Cuba, ad montem vulgò dictum Liban. (Linden, $\left.n .{ }^{\circ} 1874.\right)$

Filix omninò aspectu polystichi, sed sporotheciis mudis.

(Dimensions : Iongueur totale, 40 centim. dans notre spécimen et probablement plus; le stipe est à la fronde :: $1: 2$; les pinnules out environ 5 centim., sur 15 millim. d'enrergure.)

Cette plantc, radicante au sommet, est un véritable Polystichum à sporothèces nus.

\section{Elata.}

Frondibus elatis, amplissimis, tripinnalis; slipile rachique helveolis, canaliculutis; pinnis ovato-lanceolatis, rachi apice alato; pinnulis lanceolatis, subsessilibus; segmentis subpinnatifidis, elongalo-ovoideis, obtusis, glabriusculis, parallelis; nervillis furcalis, squamosis; squamis linearibus, albidulis, integris, sparsis; sporolheciis 5-6, rolundis ; receptaculo crasso, gibboso, duro; sporangiis ovoideis, longè pedicellatis; annulo 13-14 arliculalo; sporis ovoideis.

Habital in insula Borboniâ. (De Montbrison.)

(Dinensions : celles du Pleris aquilina, L.; divisions primaires, 40 centim.; de longueur avec un rachis ailé vers lc $1 / 3$ supérieur; pinnules, 9 centim., sur 2 de largeur, séparées à la base par un entre-nœud de 25 millim.; clles sont très-ouvertes; nous comptons une vingtaine de pinnules, et sur chacmue d'elles 14-16 segments, ayant 4 millim. de largeur.)

\section{Helliaxis.}

Frondibus tripinnalis, amplissimis, in ambilu triangularibus, universè villosis; stipitibus rufo-cinereis, trisulcatis; pinnis elongato-ovalis; pinnulis lanceolatis, obtusiusculis, basi integris; segmentis profundè crenatis, obtusissimis; sporolleciis $5-7$ pariis, rolundatis, salis magnis, semper distinctis; recephenlo nullo; sporangiis ovoideis, magnis; annulo spisso, 14.15 articulato; arliculis latis, sporis ovoideis.

Habitat in insula Borbonici. (De Hell.)

Filix maxima, decomposita, hirsuta, rachi et stipite depressis cinereisque.

(Dimensions : longueur des principales divisions (pinnce), 50 centim.; elles portent de $24-28$ piunules distantes de 25-28 millim.; celles-ci ont environ 8 centim., sur 25 millim. de largeur: les segmeuls sont au nombre d'unc quinzaine.)

Nous dédions cette espéce à MI. le contre-aniral de Hell, ancien gouverneur de Bourbou, qui a laissé dans cette ile les sourenirs les plus honorables.

\section{XiV. Montbrisoniana.}

Frondilus tripinnatis, amiplissimis; stipite el rachi robustis, sulcatis, squamulosis; pinnis pinnato-pinnatis, acuminatis, pyramidatis; rachi tomentoso; pinnulis lanceolatis, 
sessilibus, obtusiusculis; segutuento ultimo, inferiori et sa'pè segmentis infinis cuu rachi condunatis; segunentis onnibus ovatis, integris, nargine leviter repandis, glubris; mesonevro hirsutulo; nervillis simplicibus, marginem non attingentibus, remotis; sporothecüs 5-6 crassis, distinctis; sporangiis ovatis; annulo 12 -13 atticmlato, articulis spissis; sporis ovoideis.

IIabitat in insultâ Borbonict. (De Montbrison.)

Filix magna, robustı, firma, opaca.

(Dimensions: longueur des principalcs divisions (pinna), $42-45$ eentim., sur $13-15$ dienvergure : les pimules dépassent le nombre 20; elles sont séparées par des entre-nœuds de $22-26$ millim.)

Parmi les espèces nouvelles à rattacher à ce genre se trouvent encore :

1. Le Phegort. cilnata : Frondibus pinnatis, frondulis lanceolatis, acuminalis, sessilibus; segmentis obtusis, curvatis, ciliutis; nervillis simplicibus goniopteridis, sed basi liberis, omnibus proliferis.

Linden, Cubâ, n. 270.

2. Le Phegort. perforata : Frondibus pinnatis; pinnis lanceolatis, acumilnatis; segmentis linearibus, viridibus, obtusis, repandis, apice dentatis; laminis perforatis modo Hyperici perforati.

Herbier de M. Mougeot provenant du professeur hickx, sous le nom de l'olypodium autifolium, Presl, ap. Nyst. Herb.

(Celte espèce très-curieuse, dont la patrie nous est ineonnue; est remarquable entre toutes ses rongénères par les pores translucides dont elle est eriblée.)

3. Le Phegopt. hirsuta : Frondibus tripinnatis, hirsutis; pinnis acuminatis; segmentis oblongis, obtusis, dentaiis; sporotheciis rotundis, depunperatis (facie aspidiorum). Mexico, Funcke et Schlim, n. 975.

4. Le Phegopt. eprertodis: Frondibus bipinnatis; rachibus et mesonevris subtus glabris, supernè brevè lanatis.

Linden, Cubâ, no. 282 et 412.

\section{** Vervillis conniventibus.}

\section{GONIOPTERIS, Presl.}

Tentam. pterid., p. 18 .

Polypodii spec., Auct. - Gymnogrammes spec., Bums.

Sporotrecus in medio dorsi venarum insedenlibus, oppositis, globosis, parris: receptaculo aut submullo aut distincto et lunc subrolundo; sporangiis ovali:, 
pedicellatis; annulo $12-18$ articulato; sacculo sapè pilos acutos, rigidos ferente; sporis ovatis, subreniformibus, episporio crasso, nigroque vestitis.

FRONDıBs pinnatifidis al pinnatis, rarò simplicibus; pinnis lanceolatis; subintegris, crenatis dentatisve; venulis utriusque infimis, in arcum acutum anastomosatis.

Filices tropicales, erecto, rariùs pendulce, aliquandò proliferce, scepè pilosce, pilis stellatis.

Diagnosis : Ноок. et B., Gen. filic., t. xxxvill. G. crenata, PresL, loc. cit., t. vil, fig. 9.11 (nervalio).

1. UNIJEGEE; id est una tantìm nervilla basilaris connivens.

11. MULTIJUGEA; id est nervilla plures conniventes.

Goniopteris nervatione et habitu Menisciis affinis; sed sporotheciis lateralibus, binis, distinctis, globulosis, nec arcuatis.

Les goniopteris sont dans le groupe des polypodiées, ce que le genre Nephrodium est dans celui des aspidiées. Cette analogie est surtout marquée pour les espèces pectinées-que renferment les deux genres. Cependant ce genre, considéré dans son ensemble, se présente avec des segments plus grands, se rapprochant bien plus de la forme ovale lancéolée que de la forne linéaire ou ovale-linėaire. Le sacculus, glabre dans les nephrodium, est presque toujours velu dans les goniopteris. Il en est de même des meniscium et de plusieurs espèces de gymnogramme. Ces fougères sont médiocrement grandes, de consistance assez molle; il en est plusieurs qui deviennent radicantes et prolifères sous l'empire de diverses circonstances dont la principale est la chaleur humide.

Sur trente espèces que renferme notre collection, vingt sont indigènes de l'Amérique tropicale; les Indes orientales en réclament trois, les Philippines cinq, l'Afrique australe deux. Sur vingt-deux espèces de nepltrodium il n'y en a au contraire que trois qui soient américaines; dix sont indigènes des îles Philippines, cinq de Bourbon, le reste est asiatique; une seule espèce vit au Cap.

La nervation est connivente, et le nombre des nervures qui se trouvent ainsi disposées varie; tantôt la basilaire seule se soude avec sa latérale, tantôt toutes s'unissent. Or, comme le prolongement qui naît au sommet de l'angle s'élève jusqu'ä l'angle supérieur, chaque aréole est divisée en deux parties symétriques. Cette disposition donne aux espèces qui y sont soumises un aspect tout particulier: elles semblent tendre vers les meniscium. On peut tirer parti de cette modification pour diviser le genre Goniopteris en deux sous-genres.

\section{ENUMERATIO SPECIERUM.}

A. Paucijugatce; I- 2 nervilla conjugata. - Simplices. = Incisa, Presl - scolopendrioides, PresI (Plum.*, Petiv.*, Pluk.*) - Pinnatifidx. - A ginis, F. - ferax, F. - subtetragona, Presl (Polypod., 
Sclıkh.*; vix differt a G. telragonâ) - patens, F. - lucida, F. - tetragona, Presl (Filix non ramosa, Sloan.*, Plum.*) - megalodus, Presl (Polypod., Schikl.*) - Berleriana, Presl (Sieber, 11. ${ }^{\circ} 168$ ) - submarginalis, Presl (Polypod., Langsd. el F.*) - Lobbiana, F. - asplenioides, Piesl (Polypod., Sw., Sloan.*) - asymelrica, F. - replans, Presl (Polypod., Sw., Sloan.*, Pluk.*) pennigera, Presl (Polypod., Presl*, Sloan.*, Pluken.*) - cheilocarpa, F. - Madagascariensis, F. - fraxinifolia, Presl (Polypod., Jacq.*) - pilosa, Presl (Polypod., Schkh.*) - prolifera, Presl (Meniscium, Sw.). - Subbipinnatx. = Asterolhrix, F. (Linden, Cnba, 11. ${ }^{\circ 1917}$ ) - arislala, F. (Cuming, Philipp., 11. ${ }^{20}$ ).

B. Mullijugala; nervillae omnes connivenles. - Repanda, F. - mollis, F. - crenala, Presl (Ilooh. et B.* [fragm. analy .] , Plum.*) - meniscioides, F. (prolifera, J. Sm.) - barbala, F. (aspera, J. Sm.; Cuming, Philipp., n. 172) - crenato-dentala, F. - aspera, Piesl non J. Sm. (Polypodium, Presl*).

\section{AFFiNis.}

\section{SPECIES NONDUM DESCRIPT£.}

Frondibus pinnatifidis, infernè pinnatis, basi et apice decrescentibus, petiolo et rachi

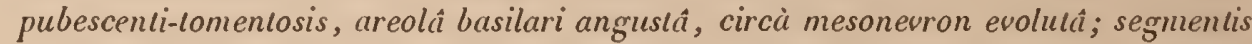
subfalculis, incequalibus, ad centrum crenatis, oblusis, suprì glabris, infrò ad mesoneuron et nervillas hirtis; pilis brevibus, stellatis; nervillis tenuibus, uniarcualis; arcubus venulun rectam, marginem atlingentem, emillentibus; sporolheciis parvulis, pluriseriatis; sporangiis ovoideis; annulo 14-16 articulato; sporis ovatis.

Habilat in Guadalupâ. (Bertero.)

(Dimensions: longueur totale, 40-44 centim., sur 6 d'envergure au centre; les segments ont environ 1 centim. de largeur; ceux qui occupent le bas de la fronde, sont plus écartés, ovales, mucronés et très-courtement pétiolés.)

Cette plante a élé délerminée sous le nom de Polypodium Domingensis, Spr. (Goniopleris scolopendrioides, Spr.), par Kunze; clle en diffère beaucoup. Dans la plante de Sprengel Ies sporothèces sont bisériaux et les nervilles beaucoup plus serrées; enfin les segments sont ondulés, ct non crénelés.

\section{Ferax.}

Frondibus pinnatifidis, busi et upice decrescentibus, radicantibus; rachi pilos breves, stellatos ferente; segmentis lanceolatis, argutè serratis, incqualibus, rigidis, opacis, centralibus, ounibus proliferis, inferioribus et superioribus dentatis; nervillis uniarcuatis; sporotheciis utrinque uniseriatis, parvulis; sporangiis ovalis; annulo. $12-13$ articulato; sporis ovoideis.

Habilat iu Goladalupâ. (L’Herminier.)

Filix singularis, feracissima; segnentis frondium onnibus radicantibus; novellis lineraribus.

(Dimensions : Iongueur totale, 70 centim.; les scgments du centre alleignent 10 centim.; ceus du somuet sont inégaux et horizontaux; ceux de la base finissent en une membrane décurrente sur le pétiole; les frondules vivipares, qui se développent au sommet, ont jusqu’ì 10 centim.; ccus qui se fixent à l'extricuté des segments latéraux, ont nne forme lancéolée et sont fasciculces.) 
III. LOBBIANA.

Froudibus pinuritis, glaberrimis; stipile valido, canaliculato; ruchi quadranguluri; froudulis rigidis, angustè lanceolatis, membranaceis, inciso-dentatis, sessilibus, upproximatis, uniureolatis; sporotheciis globulosis, nervillas iuferiores occupantibus; sprorangiïs densè congestis; anuulo 14-15 articulato, sacculo glabro; sporis crrssis, ovoideis.

Habilat in Java, Lobb., n. 276.

Filix magna, eleguns, multifrondulosn.

(Dimensions: la fronde, sans le stipe, 75 centim.; les frondules s'étendent à 18 centim. emiron, sur 2 centim. de large; nous en comptons 33 . Un autre spécinen de la mème fougère. et tronqué, a des frondules plas étroites et dentées en scie.)

\section{Chemocarpa.}

Frondibus piunato-pinnatifidis; stipite el luchi grlubris; piunulis liueuribus, profunute crenatis, rculis, suprà glubris, sublìs pilosulis; nervillis unioreolatis; sporotheciis subutarginalibus, conniventibus; sporangiis magnis; annulo 1.5-16 arliculatn, "1rliculis distantibus, sncculo glabro; sporis nigrescentibus, episporintis.

Habilat in Brasilici. (Claussen, n. 112 ; Gardner, n. ${ }^{\circ} 53$. )

Aspiliun conssunguiueun (Cyclosorus, Lk.), Kze., Herb. Vindob. et Fl. ined. Brasil. Kze., in litteris.)

Filix elata, gigantea.

(Dimensions: longueur totale, 1 mète 53 centim.; frondules, au nombre de 30 paires, 16 centim., sur 12-14 millim. de largeur; entre-nœuds inférieurs, 7 cenlin. : 33-36 crénulations; le stipe égale la lame en longueur.)

\section{NaDigascakiexsis}

Fronlibus pinnalis; slipile et rachi glubris, helveolis; frondulis membranaceis, tronslucidis, lineari-lauceolutis, longè acuminatis, sessilibus, creurtis; sinubus crenarum ope membranule pellucidce coulitis, glabris; nervillis basilaribus, areolus durs constimentibus; mesonevro flexuoso; sporotheciis ellipticis, dorsalibus; sporrungiis magnis; annulo $14-1 \hat{0}$ atticulato, lato; sporis ovoideis.

Habiut in iusulâ Madagascuriensi. (Goudot.)

(Dimensions: longueur des frondules, 26-30 ccntim., sur 2 centim. dans leur plus grande largeur; elles se terminent insensiblement en une pointe allongée, ondulce; nous comptons unc cinquantaine de nervilles pimnées, à pen près horizonlales, légèrenent courbées au sommet.)

\section{Repaxda.}

Frondibus pinnatis, paucifroudulutis; slipite, ruchi et nervillis hulveolis; frondults elonguto-ovoideis, basi cuneutis, upice ubruplè caudatis; uarginibus tepandis, sıperuè argutì et incequaliter dentutis; mesonevro sublìs convexo, piloso; laninî superiori gluberrima , lanuiun inferiori pilosâ; areolis approxinutis, lineolâ rectâ dinndintis; sporotheriis crussis, rolundis, inter siugulan areolan biserialibus, distiurtis; 
sporangiis parvulis, rolundis; annulo $12-13$ articulato; sacculo $6-10$ pilos longos ferente; sporis renifornibus.

Hubital in Pulo-Pinang, Cochinchinâ. (CI. Gaudichaul.)

Dimensions: longueur totale, $80-90$ centim.; longueur des frondules, 18-19 centim., sut $3-t$ eentim. de largeur: nous comptons 45 uervilles pinnées de clraque còté de la lame.)

UI. MolLis.

Frondibus pimnalis, panci-frondulatis, flexibitibus; frondulis membranaceis, mollibus, ovato-elongatis, abruptè acuminatis, brevissimè petiolatis, in medio crenatis; suprì parcè pilosis, sublìs pilosissinis, pilis albidulis, rigidis, circà mesoneuron creberrimis et patulis; nervillis pinnatis, distantibus, venula rectâ in areolis libera; sporotheciis inter singulam areolam biserialibus, renotiusculis; sporangiis purvulis; annulo 14-15 articulato; sacculo glubro; sporis ovoideis.

Habitat in Tabasco. (Linden, n. 1499 , inter plantationes Theobromatis Cacao.)

Duneusions : longueur des frondules, 24 - 26 centim., sur 5 de largeur enriron; nous comptou prics de 45 nervilles pimnées de eliaque còté de la frondule; le mésonèvre est assez délié.)

\section{IIII. Crexito-dextata.}

Frondibus pinnatis, in ambilu ovalis; rachi helveolo, glaberrimo, lavi, quadrangulari; pinnis lanceoluto-linearibus, sessilibus, basi obliquè rotundis, apice caudato-curvatis, creuatis, crenis rostratis; mesonevro prominente, callali augustissimo supernè notato; "lervillis scalpturatis, curvatis; venulis temuissimis, omnibus conniventibus, "reolis appendici recto dimidiatis; sporolheciis $12-13$, minutis, distinctis; receptaculo parvulo, elongato; sporangiis ellipsoideis; annulo latissimo, 12.13 articulato, 1ix crenulato; sporis ovoideis, fuscis.

Habilat ad ripas Gangis, circà Calcuttann.

Filix elegans; rachi flexuoso, siccitute lutescente.

(Dimensions : longuenr de la fronde, sans le stipe, 30 centim. et plus; les pinnules mesurent 20 - $\$ 2$ centim. de longueur, sur $\mathbf{2 5}$ millim. de largeur. On compte au dela de 60 crénulations, lont 54 sont fertiles. Le caleul suirant pent sembler curieux; en évaluant à 10 paires de sporothèces chaque sistème de nervation, on arrive à trourer sur une seule pinnule 1,080 groupes: or , comme il existe en morenne 15 pinnules, on trouive un total de 16,200 sporollicees par fronde; chaque sporothèce, ì son tour, étant formé d'au moins 20 sporanges, en contient 3:4,000; ur, chaque sporange, à son tour, renfermant au moins 20 spores, le ehiffre total des corps repro(lucteurs sélève ì $6,480,000$. Beaucoup tle fougères donneraient un résultat décuple.)

IX. BчRBAT.

Frondibus pinnatis, subovatis; stipitibus et rachibus profundè trisulcatis, pilis criniformibus, longissimis, nigrescentibus, basi bulboso persistente vestilis; pinnis longissimis, linearibus, crenatis; crenis apice curvatis, brev̀̀ peliolatis, acumine. longo, angusto, inlegro, flexuoso terminatis; mesonevro valido, glıberrimo, flavescente; nervillis tenuibus 2-3, ultimis conniventibus, ferè onmibus al basim fructiferis; sporolheciis circà mesonevron evolventibus, sapè confluentibus; spo- 
rangiis ovatis; annulo 16-17 articulato; pedicello longo, tenui; sporis ovoideis, utris, papillatis.

Habitat in Philippinis. (Cuming, n..$^{\circ}$ 172.)

G. aspera, J. Sm. non Presl.

Filix robustu, formosa, pinnis linearibus et rachi crinito notatis.

(Dimensions : longueur des pinnules, 36 -40 centim., sur 25 millim. de largeur; la pointe entière 4 centim.; nous comptons jusqu'a 75 crénulations; les poils, semblables à des crins, dépassent 12 millim.: ils sont très-durs, lorsqüils quittent le rachis: ils $\mathbf{y}$ laissent une base proéminente noire. qui leur donne une grande rudesse.)

Cetle belle fougère n'a aucun rapport avec la figure qui représente le Polyrod. asperum, telle que la donue M. Presl (Reliq. Hoenk., tab. III, fig. 4). En admettant que ce soit là en effet la plante de Roxburg (in Herb. Linn. Societ.), le nom derait être changé.

X. Rivolrei.

Frondibus pinnatis, stipite sulcato, rigido, supernè hirtò; frondulis lanceolutis, subpetiolatis, acuminatis, crenulatis, hirtis, asperis, hirsutulis, ciliatis; terminali petiolatâ, magis crenatá; sporotheciis subsenariis, tabacinis; sporangïs rotundis; succulo piloso; sporis ovoideis, episporiatis.

Habitat in Guudalupâ.

Dimensions : longueur des frondes stériles, 16 -18 centim.; les fertiles, beaucoup plus longues, ont un rachis de près de 30 centim. de hauteur; frondules, au nombre de $3-4$ paires, atteignant $9-10$ centim., sur $15-18$ millim. de largeur.)

Le nom spécifique de celte belle fougère est destiné à rappeler le nom de $\mathrm{IN}^{{ }^{{ }^{\mathrm{e}}}}{ }^{\mathrm{e}}$ Richard, uée Riroire, qui, aux Antilles, dans ume mission, toute de dérouement et de bienfaisance, a su récolter une foule de belles plantes, arec le discernement d'un botaniste habile.

A ces espèces nouvelles on peut encore ajouter:

1. G. patexs: Frondibus pinnatis, nervillis frondularun remotarum, 3-4, conuiventibus; stipite sulcato (ad G. tetragonam tendens). (Guenzius, Sw., Port. natal. in schedulî Aspidium patens.) :

2. G. Lccida : Frondibus pinnatis, lucidis; stipitibus et rachi puberulis, supernè pinuatifidis; frondulis sessilibus, crenatis; sporotheciis pluriseriatis; uervillis basilaribus fructiferis. (Guadelonpe.)

3. G. Asruetrica : Frondibus pinnato-pinnatifidis; segmentis in apice frondium incqualibus, longis. (Plilippines, Cuming, $\mathrm{n}^{\text {os }} 51$ et 102.)

4." G. asterothrix : Frondibus pinnutis, apice pinnatifulis; pilis stellatis coopertí. (Cuba, Linden, $\left.\mathrm{n} .^{\circ} 1917.\right)$

5. G. aristata : Frondibus pinnatis, pinuis basi pinnatifidis; segmentis crenatis; crenis aristatis. (Plilippines, Cuming, n. $^{\circ}$ 239.)

6. ${ }^{\circ}$ G. MExıscombes : Frondibus pinnatis, irregulatim crenatis; nervillis omnibus conniventibus; areolis ab appendicibus rectis partitis; sporotheciis creberrinis; succulo sporangiarum nudo, etc. (G. prolifera, J.Sm. non Presl; Philippines, Cuming, n. ${ }^{\circ}$ 168.) 


\title{
*** Vervillis anastomosatis.
}

\section{A. Sporotheciis nervillam unicam occupantibus.}

\section{$\dagger$ Frondibus monotaxicis.}

d. Areolis exappendiculatis.

\section{GONIOPHLEBIUM, Presl. (1836.)}

\author{
Tentam. pterid., p. 185 (anclım).
}

Polypodii spec., Auct. var. - Synanmic, Presl, I. c., p. 212.

SРОнотиесп rolundis, uni seu pluriseriatis, superficialibus aul subinmersis; ad apicem v'enula infima, libere, axillaris et basilaris, nec non ad sunmitatem nersilla liberce, super angulos, conniventiấ nervillarum duarum formatos, nascentibus; sporangiis ovalibus; annulo lato, 12-16 articulato; articulis spissis; sporis maximis, lavibus, episporiatis, reniformibus, obliquè oralibus, rarissimè ovoideis.

LRoxnвes pinnalis seu pinnalufidis, rarius simplicibus; pinnis angustè lancen. latis, acutis; verulis apici fertili, turgido, in arcum triangularen, acnumm, unastomosatim subeuntibus; infunâ liberâ, ex axillâ areolà costalis nascente; rhizomate repente.

Filices evectre, e'alidae, tropicules.

Iniaguosis: Hoor. el B., 1. xw (Marginaria verrucosa, Hlook.), el 1. Lrx, B (II. neriifolia, P'rest), 1. cx. (Symammia triloba, Priss) Prist, loc. cil., 1. vi, fig. 13-14 (nervationes). - Diagnosis nostra: tab. xx, B, fig. 2. G. ensiforme, F. Polypodimm, Тнuхв., et xwr, B, fig. 2. G. nerïfolium, F. (fragmentum).

Hoc gemus habilu nonnularum speciernu, ad Polypodia tendit.

Le genre Goniophlebium renferme des fougères robustes, nues, lisses, luisantes, transparentes, simples, pinnatifides et pinnées. Les unes se rapprochent des polypodium, quoique plus grandes; les autres des chrysopteris. La nervation est extrèmement élégante et très-régulière; les aréoles polygonéales, superposées et à pans droits ou plus rarement courbes, émettent une nerrille libre, isolće, dont le sonmel devient fructifere; celte nerville nait, tantôt à la basc et du côté interne de l'aréole, tantòt au sonmet de l’anģle, constitué par la soudure de deux nervill's latérales, ce qui rapproche ces espèces des goniopleris, qui toutefois n'om jamain de sporothèces terminaur. 
Les frondes varient, de la forme simple linéaire, à la forme ovale-lancéolée. Les frondules des espèces pinnées et les segments des esjèces pinnatifides ont souvent de grandes dimensions qui leur donnent un aspect extrêmement remarquable. La plupart des espèces qui constituent ce beau genre appartiennent au continent américain ou à ses îles. Elles sont pour la plupart dendricoles, et leur rhizome, cliargé de nonibreuses écailles, est difforme et rampant. Les frondes y sont ariiculées.

\section{ENUNERATIO SPECIERUM.}

1. Simplicia. $=$ Glaucothy llum $($ Polypodium, Kze.* $)-$ serpens $($ Poly.podium, Sw. $)-$ solutum (Polypod., Kl., Kr.." ${ }^{*}$.

B. Pinnatifida. $=1$. Sporotheciis ovalibus (Synamnia, Presl). = Californicum (Marginaria et Synanımia, Presl, H. et Baner, fragm. anal.*). = 2. Sporotheciis rotundis = translucens (Polypod., Kze.) - Catharince (Polypod., Langsd. et F.*) - eleutherophlebium, F. - loriceum (Polypod., L.) arcuatun, F. - falcarium (Polypod., Kze.) - chnoodes (inarginaria, Presl) - ramosum (Polypod., Kze.) - semipinnatifidum, F. - ensiforme (Polypod., Kze. [die Farrenkr., tab. 54, ad sinistrum]) - attenuatum, Presl (Polypodium dissimile, Schkh.*) - elatum, F. — areolatum, PresI - vacillans, (Polypod., Kze.).

C. Pinnate. $=$ Neriifolium (Polypod., Sehkh.*, Radd.*, H. et Bauer, fragm.*) - neniscifolium (H. et Bauer, fragm.) - pachynecron, F. - distans (Polypod., Radd.*) - Reinwardtianum, R. de Virièse - allo-runctatum (Polypodium, Radd.*) - argutum, J. Sm. (Polypod., Kze.) - Pleopeltis, F. - pallens, Presl - ornatum (Polypod., Klotzsch.) - verrucosum (marginaria, H. et Baner* [boma sed ornata]) $\rightarrow$ grandidens, Kze. - gladiatum, F.

\section{SPECIES NONDUY IESCRIPT £.}

\section{Eleеctherophlebium.}

Frondibus pinnatifulis, ovato-lanceolatis; stipite et rachi helveolis, glabris; segmentis approximatis, usquè ad ruchim liberis, obtusis, apice decrescentibus, undulatis, ullimis deflexis; nervillis nigrescentibus, scalpuratis, flexuosis, furcutis, rarò coudunutis; fertili axillari, longiusculi ; sporotheciis uniseriatis, rotundis, crassis; receptaculo ovoideo, tenui, fusco; sporangïs ellipticis; annulo $12-13$ articulato; sporis reniformibus.

Habitat in Meriela, altitud. 2 j00 netr. (Funke et Schlim, n. ${ }^{\circ}$ 1102.)

Filix magnitudine et fucie Polypodii vulgaris, $L$.

\section{Arcuatum.}

Frondibus pinnatifulis, glabris; rhizomule crassitudine penne unseris; rachi plano; segmentis lanceolatis, latusculis, arcuatis, inferioribus deflexis, nervillis trunslucentibus, busiluribus hexagonoideis; sporotheciis orbicularibus, subbiserialibus; suprì inquinantibus et puncto rufescente notatis; receptaculo prominente, rotundo; sporangiis ellipticis; annulo 12 articuluto, arliculis crassis, crenulatis; sporis reniformibus.

Habilat in insula Martinicensi. (M1. "1e Rivoire.)

Statura Polypodii vulgaris, L.; aspectus G. falcarii. 


\section{SEmipingatifidum.}

Frondibus apice sinualis, crenalis, rolundis, parte inferiori pinnalis, incequnlibus, oblnsinsculis, stricte marginatis, crenis inaqualibus, stipite et rachi helveolis; nervillis omnibus anastomosantibus; fertilibus liberis, apice receptaculiformi urgido, albidnlo; sporotheciis crassis, approximatis; sporangiis ovoideis; annulo. 12-14 articnlato, pedicello tenui; sporis reniformibus, lavibus.

Habital in Nov. Granalensi circà Pamplonam, altitnd. 2500 metr. (Funtic et Schlim, n.0 1363.)

Filix semi-pinualifida, apice lancerformi, aculo; aspectu irreguluri.

(Longucur totale, 37 centim.; la fronde seule, 25 ; envergure, 6 centim.; la partie supericure, simple ou lobéc, mesure 12-13 centim, : les plus grands segments ne dépassent pas 10-1: millin. de Jargeur.)

IV. Elaturi, F.

Frondibus profundè pinnatifidis, glubris, in unbitu lanceolatis; rachi suprì cumuliculato; segmentis lanceatis, marginibns repandis, apice aculis, basi decurrentitus. pellucidis, membranaceis, mesonevro villoso; sporolheciis biserialibus, salis purvis, remolis, centralibus, ad apicem turgidmm receptaculi elliplici, translncilli, coloratique sitis, sublus impressis; sporangïs ovoideis; amnulo 11 -12 articnlato; articulis remolis, crassis; sporis ovoideis.

Habilat in Cubâ. (Linden, n. ${ }^{\circ}$ 1890.)

Filix elata, glubra, membranacea; sporolheciis miseriatis.

(Dimensions : longueur totale, 80 centim., dont le stipe fait la moitić; les plus grands segments atteignent 12 centim., sur 15 millim. de largeur; ils sont séparés les uns des autres par un sinus de 4 centim. de largeur et portent cnviron 20 paires de sporothèces.)

\section{Pleopeltis.}

Frondibus pinartis, squammlosis, extensis, evolntione indefinitu; frondulis linearibus, brevè pedicellatis, argutè serratis, horizontalibus, membranaceis, pellucidis; areolis marginalibus minutis, basi leviter contractis, subtruncalis, apice acuminalis, acnmine circinato; sporotheciis rotundis, squamis peltatis supernè tectis, snprè inquinanlibus; sporangiis et sporis ignolis.

Habital in Javio. (Lobls, 11. 263.)

Filix excelsa, upice frondium el frondularmm circinato nolata.

(Dimensions : Jongueur de la fronde, sans le stipe, 80 centim.; des frondules, 10-12. sur 1 centim. au plus de large; elles sout au nombre de 40 environ. Cette fougère est, avec les jamesonia, la scule qui ait un déreloppement indéfini; c'est aussi la seule du genre à sporothicces couverts d'écailles peltées.)

Nous trourons dans I'herbier de M. Mougeot (Collect. Pamplin., n. ${ }^{\circ} 8$ ) une belle fongere de litmérique du sud, que nous rattachons à ce genre sous le nom de Goniophlebium glatintum; elle est remarquable par la longueur de ses frondes, qui dépassent sourent 24 centim. el qui sont courbées en forme de glaive. Elte a de grandes dimensions et prent, en se desséchant, une teinte jaune très-prononcce. 
B. Areolis appendiculatis.

\title{
115. CAMPYLONEVRON, PresI. (1856.)
}

\author{
Tentam., p. 189 .
}

Cyrtophlebium, R. Br.; J. Sn., in Journ. bot. Hook., IV, p. 59.

Polypodii spec., Auct. var.

SPOROTHECns rolundis, globosis, parvis, superficialibus, in apicent aut dorsum venula infimae axillaris sedentibus; sporangiis ovatis; annulo $12-14$ articulato, articulis spissis; sporis reniformibus, obliquè ovalibus, lulescentibus, laevibus. Froxnibes simplicibus aut pinnatis, nudis, nervatis; pinnis lanceolatis, glaberrimis; nervillis pinnatis; venulis in arcum curvatis, anastomosatis, infirmi axillari liber $\hat{a}$, turgidâ, apice proligerâ; rhizomate repente.

Filices erecte, arboricolce, integrce, glabre; in Americat australi vigentes.

Diagnosis: Ноor. et B., Gen. filic., t. LXı. C. repens, PresL, loc. cit. (Polypodium, L.)

Affinis Microsorio et Goniophlebio.

Ce genre, formé aux dépens des polypodium, renferme des plantes à frunde. simples et comme par exception pinnées; elles sont grandes, lancéolées, presque toujours entières, nues et lisses; la nervation, tout à fait caractéristique, consiste en un mésonèvre robuste duquel partent des nervures pinnées, évanescentes près de la marge; elles sont unies entre elles par des vénules courbes qui se chargent a leur tour de prolongements droits, au nombre de deux ou de trois, renflés à leur sonmet globuleux, pellucide et d'un aspect glanduleux. C'est là que naissent les sporothèces, toujours distincts el semblables à ceux des polypodium.

On ne peut confondre ce genre avec nul autre. Les espèces qui le composent sont cependan: confuses. Les auteurs ayant eu seulement égarrl à la forme, sans se préoccuper de la nervation, n'ont pas eu de caractères spécifiques solides. Pou:tant les nervilles seules peuvent fournir des moyens certains de détermination; elles forment des courbes plus ou moins prononcées, se présentent écartées ou rapprochées, et les appendices qui prennent naissance sur ces nièmes courbes sont courts ou allongés, souvent assez mêne pour partager les aréoles en deux parties égales.

En combinant ces caractères, on peut arriver facilement à des déterminations rigoureuses. Ce moyen est facile, et nous le recommandons aux botanistes qui voudront arriver à des déterminations précises.

\section{ENUMERATIO SPECIERUII.}

A. Simplices. $=$ Angustifolium (Polypodium, Sw., Radll.*) - taniosum (marginaria, Presl) Jamesonii, F. - Cubense, F. - bresifotium, Lk. - crispum, F. - minus, F. - Xatapense, F. - 
Phillitidis, Presl (Plum.**, Petiv.*) - lanciforme, Piesl (P'olypod.lapathifolium, Radd.*, Plum.*) — nitidum, Kllss, - caspilosum, Lk. - repens, Presl' (Plum.*, Petiv., II. et Bauer [fragm. analyl.])

- coslatum (Pulypod., hze.) - Moritzianum, F. - sphenodes, Kltz. (Moritz, Columb., 11. ${ }^{\circ} 304$ )

- Sieberianum, Presl - polyanthum, Presl - oligophlebium (Polypod., Kze.) - undulalum, Presl

- laerigalum, Presl (Polypod., Cavan.).

B. Pinnala. = Decurrens, Lk. (Radd.*).

II. Klotzsch (Linncea, 20, p. 397) énumcre les espèces suivantes, que nous n’arous jamais vues : Amphostenon, Kze. (Merida, Moritz, 120 ) - solutum, Kl. (Colmubia, Moritz, n. ${ }^{\circ} 309$; Hartweg, n. ${ }^{\circ}$ 1493) - nodosum, Kl. (Columbiı, Moritz, 11. $\left.{ }^{\circ} 310\right)$ - leucorhizon, KI. (Colunb., Moritz,

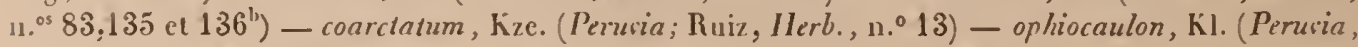
Dombey, $120^{\circ} 41$; Herb. Paris.) - chrysopodum, Kl. (Columbia, Moritz, 11. 134.)

\section{Malapexse.}

\section{SPECIES NONDLII DESCRIPT L.}

Frondibus lanceolutis, gluberrimis, basi cuneuto-rotundatis, marginibus undulutis; nervillis pinnatis, areolas biseriales inserenlibus; arcubus remotis; sporotheciis globulosis, distantibus, inter nervillas sappè quadriserialis, remotis, puncto nimuto, niveo, supernè indicatis; sporangïs rotundis; anmulo crasso, 12 articuluto; sporis reniformibus, lutescentibus.

Polypodiun Phyllitidis, Mart. et Galcolt., Fil. Mexic., p. 30, non L.

Habitat in Xalapâ Mexicanorum. (Galeotli, n. ${ }^{\circ}$ 6273.)

(Dimensions : longueur totale, 70 centim., sur 40-45 millim. de largeur.)

Ciest la seule espèce qui présente deux rangées d'aréoles entre chaque intervalte nervillaire; aussi les sporothèees s'étendent-ils fréquemment sur quatre rangées. La base des frondes n'est pas décurrente sur le pétiole.

\section{MoritziaNtur.}

Frondibus lanceolatis, brevè acuminalis, infernè cuneatis, glaberrimis, nitentibus, mesonevro valido, rufescente, suprà plano, subtùs subtriangulari, basi repandis; nervillis pinnatis, angulum $80^{\circ}$ cum mesonevro metientibus; venulis arcûs irregulatìn curvatos formanlibus; uppendiculis $2-4$ rectis, sapè cum arcubus superioribus coalitis; areolis irregularibus, frequenter dimidiatis; sporotheciis 10-12, rolundis, parvulis; sporangiis anmulum 12 articulatum ferentibus; sporis reniformibus.

Ilabilat in Caracas. (Moril\%, n..$^{\circ}$.)

Filix magna, basi cuneata, marginibus undulatis.

(Dimensions : longueur totale, 75 ecntim., sur 8-9 eentim. de largeur; nous comptons pres de 90 nervilles latérales; les aréoles sont sensiblement difformes et de grandeur inégale.)

\section{Mixts.}

Frondibus sessilibus, lanceolatis, longè acuminatis, falcatis, subpapyraceis, trans. lucidis, glabris, marginibus crispis; hizomate tenui, repente; sporolheciis parvis, 
rotundis, depauperatis; sporangiis rolundis; annulo crassissimo, $12-13$ acticulato; sporis crassis, lavibus reniformibusque.

Habitat in Americâ australi.

Filix repens, membranacea, longè acuminata; marginibus incequalè dentatis; rhizomate crassitudine pennce columbince.

(Dimensions : longueur totale, 24 centim., sur 13-14 millim. de largeur; on compte 6 nerrilles sur une étendue de 2 centim. de hauteur et 4 rénules curvinerres sur la largeur totale des frondes. Cette espèce n'est petite que relativement.)

Parmi les espèces nouvelles à frondes simples on peut encore indiquer:

1. Le G. cubtnse, F. (Cuba, Linden, n. 1912): Froudibus angustè lanceolatis, basi et apice attenuatis; sporotheciis, aliis suprò nervillan liberis, aliis super nervillas curvatas anastomosuntes positis.

2. Le G. Jaseson, F. (Quito, Jameson) : Frondibus lanceolatis, in petiolum brevem attenuatis; areolis latis, nervillis proliferis longissimis, apice punctiformi, pellıcido terminatis; sporotheciis remotis; rhizomate contorto.

3. Le G. CRISPUM: Frondibus lanceolatis, aculis, margine crispis, venulis curvalis, uppendiculos duos liberos emiltentibus (Poly.p. nitidum, KzE.; Martius, Brasil., n. 303 , non Kufss.); variat. staturâ el consistentiâ.

\section{LECANOPTERIS, Blum. (1830.)}

Enum. pl. Jav., p. 120.

Onychium, Resww. in Syllog., 112.

SPORотнеспs ovalibus, subglobosis, magnis, ad apiceun denlium curlilagineorum el excavalorum frondium silis, siccilate reflexis; receptaculo ovali, suborbiculalo, latissimo, concaviusculo, pilis oblecto; sporangïs maximis, ovalibus, pedicello longissimo latoque; annulo lalissimo, 15-16 arliculato; sporis crassis, loer ibus reniformibusque.

Frovdrus lineari-lanceolatis, pinnalifidis, lacinuis oralo-subrolundis, incisodenlalis; nervillis pinnalis, dislantibus, apice proliferis; venulis in areolas.s hexagonoideas anaslomosalis.

Filix Javanica et Philippinensis, coriacea, erecta, facie propria.

Diagnosis : in Hoor. et Bauer, Gen. filic., t. cx, B. L. calnosa, Blus., loc. cit.

Ce genre présente une singularité d'organisation qui l'a fait considérer par II. Pres! comme type d'une section de la tribu des polypodiacées. Les sporothèces 
naissent a l'extrénité des lobules du segment supérieur des frondes, et celles-ci sont pinnatifides. Cette extrémité se dilate, se creuse légèrement, devient un peu cartilagineuse et reçoit un sporothèce nu, composé d'un très-grand nombre de sporanges très-longuement pédicellées. La figure donnée par MM. Hooker et Bauer rappelle la disposition de l'appareil fructifère des peltigera et des nephroma. Il est dit dans l'exposition des caractères de ce genre, que le réceptacle est couvert de poils très-longrs (undique pilis obtectımi), ce qui n'est pas exact. Les pédicelles des sporanges ont été pris ì tort pour des poils, et quoique M. Hooker ait reproduit la plurase de M. Presl, sa diagnose, qui est très-bonne, n'en fait pas mention.

Le Lecanopleris carnosa de Blume est une petite fougère de 20 centimètres environ de hauteur; ses segments sont elliptiques. Quoique M. Presl ait cru devoir la rapprocher du Calymurodon, on ne peut lui trouver avec cette plante aucune véritable analogie et son port est tout à fait spécial. Beaucoup de fougères élargissent leurs sommets ou leurs segments fructiferes. Exemples les vagimularin, xiphopteris, onychium et pleurogramme; mais ici la modification de la fronde est extrêmemtnt prononcée.

SPECIES.

Cienus monotypum; vide diagnosim generis.

\section{计 Frondibus diplotaxicis.}

\section{NIPHOBOLUS, KIfss. (1824.)}

Entm. filic., p. 124.

Polypodii spec, L. et Atcr. - Cy.clopliorus, Desr., Journ. de bot., I, p. 19. Candollea, Mins., in Buff. Hist. nat., ed. Déterr. - Craspedaria spec., Lk., Filic. sp. 118.

SPOROTHECns superficialibus, sapè iummersis, rolundis elongatisque, in grros, "el in aumulos dispositis, remolis, approximatis, mni aut nultiserialibus, fere semper partem superiorem lamiuarum occupartibus; sporangiis ovalibus, pyriformibus, subrhomboideis, pedicello tenui, longo donatis, accumbentibus ef versus centrum assurgentibus, pilis stellatis, immixlis: anmulo $14-18$ articulato, arliculis latis; sporis crassis, ovoideis, subreniformibus, mudis, tuberculatis, opacis, nigrescentibus.

Frovdıres simplicibus, rarissinue divisis, coriaceis, opacis; ferlilibus el sterilibus sapè diversis; vernulis difficilè perspicuis, in areolis minulis, irregularibus, appendiculatis coalitis: rhizomate repente, radicellis tomento bresi, fusco coopertis. 
Fïlices arbocicolce, repentes aut scandentes, rigida, opaca, ferè semper tounentosa simplices, aut raciüs parlila, ferè on nes Indicre, paucce Australasica.

Diugnosis: Ноок. et B., Gen. filic., t. Lxxmı. (N. Penangianus, Ноок.)

Genus heleroclilum; pilis Nevroplatycerotis; venulis Pleopellidis el Gymnopleridis; sporothecis uniserialibus ut in Polypodiis; Pleopellidibus, elc., mulliseriulibus ul in Pleucidiis, indislinclis el confluentibus ut in Acrosticheis, elc.

Le genre Niphobolus est certainenent l'un des plus difficiles de la famille des polypodiacées. Toutes les espèces ont un port semblable; ce sont des fougères raides, coriaces, opaques, simples, lancéolées et parfois linéaires, couvertes de poils étoilés qui envahissent les sporothèces. Il y a une ou deux espèces glabres; les rhizomes sont déliés, rampants et portent des radicelles rameuses, à rameaux divariqués, couver's de poils courts et noirâtres. Cette disposition est universelle. Les frondes sont diplotaxiques et par exception monotaxiques. Cette particularité demande à ètre confirmée, sur le vivant, pour les espèces dissidentes. Ce qui rend ces plantes vraiment hétéromorphes, c'est la disposition des sporothèces écartés ou rapprochés, enfoncés ou superficiels, formant une ou plusieurs séries. Le caractère commun à toutes est d'avoir des sporothèces constitués de sporanges accombantes, c'est-à-dire, imbriquées ou appliquées les unes sur les autres par leur partie ventrale. Disposées ainsi en cercle, elles laissent au centre un vide qui indique l'endroit où finit cette spire contractée, circonstance exprimée par l'épithète de perlusus, donnèe à l'une des espèces lts plus anciennement connues. Ce genre a des analogies, par ses poils, avec le nevroplalyceros, et renferme une espèce à fiondes divisées en longues lanières qui rappelle le port de ce genre curieux.

M. Presl, observateur sagace, avait formé trois sous-genres dans son genre Niphobolus (Tentam. plerid., p. 201), Niphobolus, Cyclophorus et Scylopleris, par suite de l'appréciation qu'il avait faite des différences que présentent les spornthièces, superficiels ou enfoncés, distincts ou effus. Dans ses Epimelice bolanicre (p. 124 et suiv.), cet auteur a été plus loin, et le genre Niphoholus lui a fourni huit genres, savoir: Niphobolus, Cyclophorus, Guleoglossa, Scylopleris, Spharoslichum, Polycampium, Apalophlebia et Gyrosorium, auxquels il convient de joindre le Macropelihus, fondé sur l'Hymenolepis platyrynchos de Kunze. Nous n'osons formuler aucun jugement sur ces genres, qui n'ont point été illustrés par des diagnoses. Il est à craindre que les différences, principalement tirées de la disposition des nervilles, quoique bien constatées par l'auteur, ne soient pas toujours suffisammient appréciées par les hotanistes.

Voici quels sont les caractères de ces genres. Nous les présentons sommairement.

1. Nıрновоцus : sporothèces immergés, disposés en lignes obliques, posés sur un réceptacle proéminent, contigus et attachés au sommet contracté d'une fronde fertile, différente des stériles. 
2. Cyelophorus : sporothèees immergés ou semi-immergés, globuleux, eontigus, trèspetits, formant de 2 à 5 séries; le réeeptacle est plane, un peu eonvexe; les frondes stériles et fertiles sont de même forme.

3. Galeogrossa : sporothèees superfieiels, attachés au sommet d'une veinule libre, globuleux, eonfluents, donnant à ees plantes l'aspeet d'un acrostichum; réceptacle punetiforme; frondes diplotaxiques, hétéromorphes; les fertiles entièrement envahies par les sporanges.

4. Scytopteris : sporolbèees très-serrés; glolsuleux, superfieiels, petits, confluents; rappelant les acrostichum; réeeptacle légèrement eonvexe; fronrles diplotaviques; sommet de la fronde fertile, contracté et linguiforme au point fruetifére.

j. Spherostichum : sporothèees eouvrant en entier une fronde nullement modifie, prenant l'aspect d'un acroslichum; réceptacle verrueiforme, hémisplı́rique, proéminent; frondes monotariques; nervilles primaires pinnées.

6. P'olveaspiun: sporothèees superficiels, très-nombreux, sériaux, globuleux, apieilaires ou dorsaux; sporanges longuement pédieellées; réeeptaele ponctiforme, convese; nervilles pinnées, robustes, parallèles; arćoles formant des paralléloğrammes; frondes diplotaxiques.

7. Apalopulisia: sporothèees superficiels, très-nombreux, épars, annulaires, formés l'un petit nombre de sporanges eourtement pédicellées; réceptacle ponetiforme faisant saillie; frondes monotaxiques; nervilles pinnées, parallèles; vénules trèsrameuses; sporothèees oceupant le sonmet de rénules de $3 .^{e}$ ordre.

8. Grrosoriun : sporothèees très-nombreux, contigus, épars, petits, annulaires, enttourés de poils tomenteux; réceptacle ponetiforme saillant; frondes monotaxiques portant les sporothèees vers leur sommet qui est contraeté; nervilles et rénules semblables, formant des aréoles oblongues et hexagonales.

Le gemre Microlerus, fondé sur le Polypodium negleclum de M. Blume, nous semble tout à fait dissident.

Voici comment l'auteur distribue les espèces de ces diver's genres; nous n'énumérons que celles dont les figures sont connues, sauf un très-petit nombre d'exceptions.

\section{ENUIERATIO SPECIERLII.}

1. Niphonotus. = Carnosus, Blum.* - adnascens (Polypod., siv.*) - elongatus, Blım.* varius, Klfss. - pertusus, Spr. (Polypod., Roxb.*; varius, Blum.*) - caudatus, Klfss., Blum.* - spissus, Klfss. - rupestris, Spr., H. cl Gr.* - bicolor, II. cl Gr.* (Polypod. magnifolium. Bory*; Polypod. stellatum, Schkh.*).

2. Crсьорнолеs. = N. glaber, Blum.* - puberulus, Blum.* - albicans, Blum.* - fluccigrer, Blum.*

3. Galfoglossa. = N. nummulariafolius, J. Sm., F.* (Acrostichum, BI.*) - rotundifolius, F.* (Acrostich. numnnularioef., var. $\beta$, BI.*) - obovatus, Kzc. (Acrostich., Blım.*).

4. Scrropin: 1 1. Scytopteris (acrostichoides, Presl; P'olypodium, Sicb., Syn. filic., n. ${ }^{\circ}$ 94).

5. Spi.erosncuè. $=$ V. acrostichoides, J. Sm., F.* (neriat.).

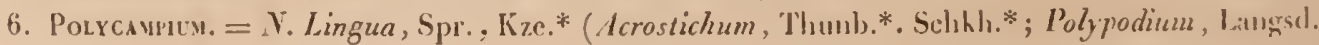


et F.*, Kze.*) - Penangianus, Hook.* (Hook. et B.*, fragm. analyt.) - haslatus, Kze. (Acrostichum, Thunb.*, Houtt.*)

7. Apalophlibia. $=N$. costatus, Presl* (nervat.) - venosus, Blum.*

8. Grnosonsum. = N. Africanus, Kze.* - Samarensis, F. (Cuming, Philipp., n. $\left.{ }^{\circ} 323\right)-$ fissus, B1.*

†. Microterus, Presl. = N. neglectus (Polypod., Blum.*).

\section{CRASPEDARIA, Lk. (1841), reductum.}

Spec, filic., p. 117 , rediucta.

Marginarice spec., PresL, secl. \$. 1, Pleurogonium, Tentam. pterid., p. 187. - Polypodii spec., Auct. plurim.

Lopholepidis spec., J. Sw., in Hook. Journ., IV, p. 56.

SPORотиеспIs rolundis, magnis, biserialibus, approximalis, subconfluentibus; receptaculo crasso, ovoideo; sporangïs ovoideis, cum syuamis scepè immixtis et ad basim venula infuma, liberce sedentibus; annulo crasso, $12-16$ articulato, vix dimidiam partem sacculi amplectente; sporis subgloboso-ovoideis, rarissimè reniformibus, nigrescentibus, lavibus.

Frondius simplicibus, heleromorphis; sterilibus oralibus, ellipticis obovatisve; fertilibus spathulatis, linearibus; venulis furcatis; ramo superiore libero prolifero; inferiore, prcecipuè circà marginem, cum analogo coalescente et areolas subhexagonoideas formante: rhizomate ramoso, repente, funiculiformi, syuamoso.

Filices scundentes, arboricolce, Americance, rariù Indica.

Dingnosis : Ноок. et Bacer, 1. u (sub Marginariâ piloselloide).

Craspedario affinis est sporangiis et sporis Niphobolo, sed nervalione divergit.

Ce genre, à frondes diplotaxiques, a un port parfitiment distinct que l'on retrouve dans deux ou trois espèces de niphobolns. Il se rapproche des drynaria, section des pleopeltis, par des squames mêlées aux sporanges, mais ces écailles étant lancéolées et non peltées, ne peuvent, en se développant, former une couche continue, simulant une sorte d'indusium. Les frondes se chargent d'écailles, pareilles à celles des pleopellis. Faisons remarquer que la présence des écailles dans les sporothèces est l'indice qu'elles se trouvent aussi sur les lames. Dans le Craspedaria vaccinifolia, ces écailles sont remplacées par des poils. Une espèce dissidente, parfaitement glabre, et que nous avions par cette raison désignée par l'épithète de calva, a servi de type à M. Presl pour constituer son genre Microterus (Epim. bot., p. 124). Le port, tout spécial de la plante, rend parfaitement compte de celte détermination. Dans le C. cıspidiflor fertiles-s'amincissent vers le sommet qui seul devient prolifère. Celte particularité, très-fréquente chez les niphobolıs, est ici exceptionnelle. 
Les craspedaria sont des fougères rampantes, à tiges presque filiformes, écailleuses, chargeees de frondes écartées. On les trouve au pied des arbres, sur les écorces, ou nıêlées aux mousses, aux hépatiques et aux lycopodes.

\title{
ENUMERITIO SPECIERUM.
}

1. Euchasprdanrf. = Piloselloides, Lk. (Plum.*, Petiv.*; Marginaria, II. et Bauer [fragm. unaly. z.* - ciliata, Lk. (Polypodium, Desi.; var. Ilostmanni, Pl. Surinam., $11 .^{\circ} 324$; frondibus lanceolntis) vaccinifolia, Lk. (Polypodium, Langsel. et F.*) - lagopodioides (Polypodium, Jaeq.*) - aurisela (Polypodium, Radd.*) - cuspidiffora (Polypodium, Reinw.*) - veronicarfolia, F. - calia (Microlerus, Presl).

11. Cripsivus. - Nummularia (Marginaria el Cirypsinus, Presl; Drynaria, J. Sm.).

III. Dissidestrs : facie craspedariarum, sed frondibus homomorphis et ad goniophlebia accedentes. $=$ Serpens (Polypodium, L., Plum.*, Petiv.*; Marginaria, Presl) - Surinamensis, F.

Nous désignons comme nouvelles les deux espèces suivantes:

1. Veronicafoula : Frondibus ovatis, petiolatis, folias Veronicce Acymi referentibus, crispis, undulatis; fertilibus majoribus, lanceolatis, obtusis; sporotheciis rotundis; rlizomate cepente, tenui, squemroso.

(Espèce bien distinete, ressemblant à quelques-mes des pelites espéces rampantes de véroniques d'Europe.) [Herbier Mougeol, provenant de Ramond de la Paz, Cuba.]

2. Surivanexsis : Frondibus ovatis, lanceotalis, acuminatis, translucidis, uervillis scutpturatis, brevè stipitutis, siccitate cufescentibns, distantibus; rlizonate teuui, Iongè repente, squamoso; sporolheciis uniseriatis.

(Fougère des forêts humides de la Guyane centrale, réeoltée par II. Leprieur, qui lni a clomé le nom de Polypodium Surinamense. Les frondes ont jusqu’à $T$ centim. de longneur, sm15-17 millim. dans leur plus grande largeur.)

\section{B. Sporotheciis plurincrillatis.}

a. Sporotheciis ad apicem duarum uervillarum evolutis.

\section{CHRYSOPTERIS, Lk. (1\$41), reductum.}

\author{
Spec. filic., p. 120.
}

Phlebodinm, R. Br., J. Ss. et Hook. et B., Gener. filic. - Polypodium, sert. v, Euphlebodium, KLzscr., Limnera, xx, p. 402.

SEOROTUECIS rolundis, superficialibus, uni aut pluriserialis, ad apiceme duarnu venularum conuiventium, sitis; receptacnlo ovali-rolundo, prominulo: sponangiis ovatis, longè pedicellatis; annulo 13-1' articulato; sporis ovato-reniformibus, lavibus vel rarò tuberculosis.

l'Rosdbus pinuatifidis, grlabris, lavibus; laciniis lanceolatis, amplis; sinn lato separatis; nervillis crassis, emergentibus, areolas hexaconos, irregulares, 
efformantibus, areolâ basilari sterili; rhizomate repente, squamoso; fasciculis vasorum 5-7 puncliformibus et incequalibus in slipite.

Filices amplae, arboricolce, peliolate, Americance.

Diagnosis: Ноок. et B., t. Cxı. C. aurea, Lisk, l. cil. (sub Phlebodio).

Habilus nonnullarum specierum Chrysopteridis; ad Goniophlebia el Drynarias tendit.

Belles et grandes fougères, à rhizome rampant, couvert d'abondantes écailles, mais ayant des frondes lisses et glabres. Celles-ci sont pinnatifides, à segments lancéolés-linéaires ou lancéolés-pointus, laissant entre eux de larges sinus arrondis. Les sporothèces sont presque ronds: ils s'étendent sur une ou plusieurs rangées et s'attachent à un réceptacle elliptique, naissant au point de jonction de deux nervilles donnant naissance, en se réunissant, à une aréole conique, libre de toute adhérence, avec son entourage. La nervation, très-élégante, se dessine en relief sur les lames pour former des hexagones à pans droits. Toutes les espèces que nous avons vues sont américaines.

Ce genre se rapproche, par le port, de plusieurs espèces de goniophlebium, mais chez celles - ci les sporanges naissent au sommet d'une nerville isolée. Dans les drynaria ils s'attachent sur un plexus nervillaire et les aréoles sont appendiculées.

\section{ENUMERATIO SPECIERUM.}

Aurea, Lk. (Polypodium, Sehkh.*; Phlebodium, H. et Baner [fragm. analyt.*], Plum.*, Peti.**) - trilobata , F. - sporadocarpa , Lk. (Polypod., Willd.) -dulcis (Polypodium, Sw. Plum.*, Petiv.*) - decumana (Poly.pod., Willd.) - glauca (Polypodium aureum, Mart. et Gal., Mexic., n. ${ }^{\circ} 6413$ ). non L. - dictyocallis, F.

\section{Dictyocallis, F.}

\section{SPECIES NONDUM DESCRIPTA.}

Frondibus pimnato-pinnalifidis, stipite fusco, glabro, nitente; fronduiis latè lunceolatis, oblusiusculis, nembranaceis, sessilibus, scepè commatis; marginibus incrassulis, creualo-dentalis; areolis serialibus, conformibus, aspectû imbricalis, venulas rechus 2 - 3, apicè comnivenles inserenlibus; sporolheciis rolundis, crassis; areolis férè omnibus ferlilibus; sporangiis ovoideis; anmulo 11 arliculalo; sporis reniformibus, utberculosis.

Hubitat in Guyanâ gallicâ. (Poiteau.)

Filix nervatione pulcherrima; rhizomate mulli-fibroso; fromlulis subpapyraceis.

(Dimensions : longueur des stipes, 12-14 centim.; frondules, 24-25 eentim.; la terminale, souvent trifrondulée, est plus longue que les antres; largenr, 5 centim.; la marge porte une quarantaine de erénulations.)

Nous trouvons dans le riche herbier de fougères de notre honorable ani, M. le D. ${ }^{\mathrm{r}}$ Mougeot, une espèce, qui serait la plus remarquable du genre, si la forme sous laquelle nous la voyons élait constante; nous la décrivons succinctement, pour attirer sur elle l'attention. 
Cunysopteris тrulobita : Frondibus trilobatis, lobo terminali, longiori; omnibus obtusissimis, margine repandis, cartilagineis, opacis; nervillis scalpturatis; sporotheciis centralibus, uniseriatis; stipile brevi; rhizomate repente, squanis lactè fulvis, lanceolntis, longè acuminalis.

Habilat in America australi. (Collect. Pamplin.)

(Dimensions : longneur du stipe, 3-4 eentim.; segment médian, 8-9 eentim., sur 17-18 millim. de largeur; segments latćraux, 5 -6 centim., sur 12 millim. de largeur.)

\section{AGLAOMORPHA, Schott. (1855.)}

Gen. filic., fasc. IV, fig. 4 .

Psygmium, PresL, Tentam. pterid., p. 199, tab. vill, fig. 20 el 22. (1836.)

SPOROTHECIS parvulis, rolundis, alternis, singulum lobum segmenlorurn occupanlibus; receplaculo hamispharico, ex apicibus venarum coadunatis nascente; sporangiis ovalibus, longè pedicellatis; annulo incomplelo, sub 12 -arliculato; sporis reniformibus.

Froxdrats pinnalifıdis, disparibus; slerilibus densè venulosis; nervillis pinualis; inter se in areolas parvas, irregulares, appendiculalas unilis; pinnis infernè slerilibus, supernè abruptè angustioribus, ferlilibus; segrnentis uni- aut bipinnalifidis, linearibus, venis bifurcatis duabus, ad apicem ferlilem coalilis.

Filix persingularis, Plilippineusis, erecla, glabra.

Diagnosis : Sснот, l. cil. (optima). Ноoк. et B., Gen. filic., 1. хсı. A. Mejeniana, Sснотт, l. cil.

Ce genre curieux a des caractères tellement tranchés qu'il s'isole de tous les autres. La fronde, pinnatifide vers sa moitié inférieure, et tout à fait senblable à celle du Drynaria Phymatodes, se rètrécit brusquement pour former des segments linéaires, élargis à la base, pinnés et lobés, à lobes hémisphériques, devenant proliferes près de la marge. Le spécimen que nous possédons ( . $^{\circ} 49$, Filic. Philipp., Cuming) a 75 centimètres de hauteur. Nous y comptons quatorze paires de segments stériles alternes et vingt-cinq paires de segments fertiles, sous-opposés et quelquefois bifurquès au somntet. M. Schott en a donné une savante analyse, et Kunze une excellente figure (die Farrenkr., t. 81).

SPECIES.

Genus monotypum: vide diagnosim generis. 
b. Sporolheciis ad nexum nervillarum evolutis.

† Areolis exappendiculatis.

\section{DICTYOPTERIS, Presl (1836), reductum.}

Tentam. pterid., p. 194, tab. VIII, fig. 6, 7 et 13 (fragm.)

Polypodii spec., Reinw., Bory, Presl.

Sрокотнесп marginalibus, uniseriatis, superficialibus, rolundis, ovoideis, sapè in lineain continuam confluentibus; receptaculo elongalo, prominente, ad 1 rajectum venularum, in areolis connexarum, silo; sporangiis parvis, longo pedicello donatis; annulo 12-13 articulato; slomio nononervalo; sporis ovatis, imembranaceis.

Frondbus sparsis, pinnalim divisis, glabris, membranaceis, pinnulis crenalis; venis pinnatis, venulis anastomosatis; areolis inaqualibus, inter se coalitis, ad margines minoribus; areolâ basilari elongatâ; appendiculis nullis.

Filices Philippinenses, magnce, tenerce; facie Aspidiorum.

Diagnosis: tab. xxı, A, fig. 1, D. pteroides, Presl, et fig. 2, D. macrodonta, Press.

Ce genre, qui semble ne diffèrer des sagenia que par l'absence d'indusium, ne renfer'me qu'un nombre très-restreint d'espèces à frondes amples et flexibles. Les frondules sont ovales, lancéolées, les pinnules acuminées, à sommet pinnatifide. Les nervilles forment des aréoles irrégulières, celles de la base, plus longues que larges, sont constituees par une courbe. Il n'y a pas d'appendices. Dans le D. macrodonta, les sporothèces occupent toute la largeur de la lame; dans le $D$. pteroides ils sont absolument marginaux; distincts dans la première espèce, confluents dans la seconde. On ne les trouve qu'aux Philippines.

\section{ENUMERATIO SPECIERUM.}

Macrodonta, Presl (Cuming, Philipp. , n. $\left.{ }^{\circ} 9\right)$ - Pteroides, Presl (F. [fragm. analyt.* $]$; Cuming, , Philipp., $10^{\circ} 171 ; \mathrm{F}$. [fragm. $\left.]\right)$.

t† Areolis appendiculatis.

* Frondibus homomorphis.

122. MICROSORIUM, Link. (1822.)

Specin. filic., p. 135.

Plymatodis spec., Prest, Tent. pterid., p. 195, tab. vui, fig. 14. - Poly podii spec., Aucr. SPOROTHECus superfucialibus, creberrimis, alaxicis, super trajectum venularum anastomosarum positis; sporangiis ovatis; annulo lato, 13-15 articulato, arti- 
culis spissis; slomio 8 nerralo, undulalo; sporis reniformibus, ovoideis, brevibus lacibusque.

Jroxnв́s simplicibus aut irregulariler divisis pinnalifidisque, glaberrimis; pe. liolis brevibus, laminâ marginalis, margine inlegerrimis; mesonevro robuslo; nervillis pinnalis, inler se ope vernarum curvarum coalitis; venulis areolas parvulas, appendiculalas efformanlibus; appendiculis recurvis, punclo prolifero, lurgido translucidoque lerminalis.

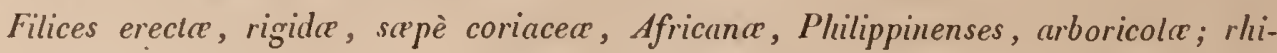
zomale repente.

Diaguosis : tab. xx, B, fig. 1, M. irioides, F. non Accr.; fig. 2, M. longissimum, et fig. 3, M. irregulare.

Genus Campylonevro affine; sed venula infima libera deest et sporothecia alaxica sunt; non longè distal à Drynariâ, sed habitu, nervatione et silu sporotheciorum diversum est.

Ce genre curieux est, entre tous, caractérisé par la disposition ataxique de ses sporothèces attachés sur les nervilles qui toutes paraissent susceptibles de devenir proliferes. Comme la nervation forme un réseau extrêmenent petit, il s'ensuit que les frondes portent des myriades de sporothèces. Ainsi un centimètre carré, mesuré sur la fronde du Microsorium irregulare, en porte environ cinquante. La surface totale pouvant être évaluée à 150 centimètres, il y aurait donc sur une seule fronde 7500 sporothèces.

Le genre Microsorium est peu nombreux en espèces. On n'en troure aucune en Amérique; Bourbon, le Cap et les Philippines sont leur patrie. On cultive, dans les jardins botaniques, une espèce à frondes polymorphes par la culture : elles sont épaisses comme les rameaux aplatis de certains caclus. Reconnue conme distincte par Link, elle a été réunie par quelques auteurs au $\boldsymbol{M}$. irioides, et snivant nous, à tort.

\section{EAUMFRATIO SPECIERUM, CUM CHARACTERIBUS DISPARIBUS.}

\section{А. Еuмicrosorium.}

1. IrIones, F.* : Frondibus lanceolalis, magnis lalisque; mesonevro valido; sporis subreniformibus. (Polypod. irioides, Poir., Guenzius, Port natal, Bourbon.)

2. Irregltare, Lk., F.* : Frondibus crassis, variabilibus; annulo crassissimo. (Polypodium irioides, Lark. non Hook. el Grev.)

3. Loxgrssmcм, F.* : Frondibus longissimis, acuminatis, nembranaceis, areolis basilaribus amplis, marginalibus parvis. (Drynaria, J. Sm.; Cuming, Pl. Plilipp., n. ${ }^{\circ} 66$. )

4. Sessile: Frondibus sessilibus, angustis; venulis curvantibus, approximatis, basi laninarum gemmiferis. (Polyp. sessile, Kaulf.; Sieber, no. ${ }^{.03}$ 1, 38 et 287; Philipp., Cuming, n. 21 ; Hook. et Grev., tab. cxxv, exclus. synonym.) 
B. Dissidentes.

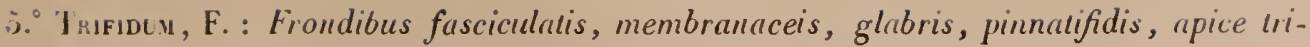
fidis, lateralibus bifulis; segmentis acuminalis; sporotheciis depauperatis, difformibus, pedicello longo. (Gaudichaud, Manille; Cuming, Philipp., n. 31 . [Aspidium irrigıum, J. Sm.])

6. Palмaтc: : Frondibus pinnatifidis, glabris; segmentis renootis, linearibus, acuminatis; sporolleciis eltipticis, rotundis, planiusculis, nigrescentibus, multiseriatis sparsisfue. (Cuming, Philipp., n. 52; Drynaria palmata, J. Sm. [in D. palmatâ, J. Sm., Cuming, n. $^{\circ} 126$, in hierb. nost., sporothecia biserialia sunt.])

Ces deux dernières espèces qui ne peurent appartenir ni au genre Aspidium ni au genre Drynaria, n'ont pas le port des vrais microsorium, les frondes flant divisées et le pétiole très-allongé et libre; cependant les sporothèces, par. leur disposition ataxique et les nervures par leur manière de s'anatomoser, ne permeltent pas de les placer ailleurs.

** Frondibus monolaxicis.

\section{DRYNARIA, Bory (1828), emendatum.}

Dict. class. . articl. Polypode.

Polypodii spec., Auct.

Pleopeltis, Hсмв. et Boxpl. et acctorty.

Pleopeltidis, Dictyopteridis et Plymmatodis spec., PrEsL, Tentam. pterid., p. 181 el seq\%.

SPOROTHECIS elliplicis, rarius rolındis, immersis, aliquandò superficialibus, uni aut mulliseriatis, supernè rinâ, depressione, concavitate seu gibbầ indicatis : receptaculo carnoso, promimente, rolundo, elliptico, elongato, lineari; syuamis peltatis, frequenter teclis; sporangïs ovalibus aul pyriformibus, sape squarnigeris, aut rarius piligeris; annulo crasso, 12-13 articulato; articulis latis; sporis reniformibus, lavibus, pallidi-lutescentibus, episporio delapso.

Froxnıcs coriaceis, opacis, simplicibus, acutè lanceolatis, sen pinnatifidis, rarissimè pinnatis, glabris aut syuamas lanceolatas gerentibus; venulis orunibus anastomosatis; areolis inavualibus, hexagonis; appendicibus rectis aut cursatis; rhizomate repente, siluamoso.

Filices tropicales, arboricola, rigida, erectce.

Diagnosis gen.: Ноок. еt B., 1. cit., 1. xvin (Pleopeltis muda, Ноок.), 1. цxхı (Dictyopteris altemuata, Prest), t. Lxxul (Microgranıme persicariafolia, PrEsL). Tal). nost., xxı, B; fig. 1, D. Plyzmalodes, F., et fig. 2, Goniophlebium ensiforme, Prest. (fragmentum ad comparandum). 
Ce genre, trej-nombreus, renferme des fougères ì frondes sinples, lancéolees ou pinnatificles, à segments allongés, linéaires ou lancéolés. Le réseau nervillaire est fo:mé de nailles nombreuses, dont les dernier's éléments consistent en appendices libres, diversement recourbés. Les sporothèces arrondis ou plus rarentent ellipsoïdes, sont assis sur un plexus de nerrilles déliées, appartenant à plusieurs aréoles. La plupar des espèces à frondes simples ont des écailles pelıées qui rroissent ave les sporanges. Celte particularité a semblé suffisante à quelques auteurs pour créer ou pour conserver le genre Pleopellis, dont le nom consacre cette particularité. Nous n'arons pas cru possible de les innter, autrement il aurait fallu donner aux sporangiastres et aux poils une importance quils ne peurent aroir. Tous n'arons conservé le genre Ploppellis que comme sous-genre. Il renferme presque toutes les espèces ì frondes simples.

Les drynaria sont des fougères robustes, sourent coriaces et opaques, tendant à la forme lancéolée et se divisant en longues linnièrt's peu nombreuses quand il arrive qu'elles passent à l'état pinnatificle. Les rlnizomes sont écailleus et rampints.

Les espèces à frondes simples se rapprochent des grammitis par la forme woïde des sporothèces; les espèces pinnatifides on quelquefois le port des chrysopleris touttfois ces analogies sont éloignées.

On troure ces fougères dans les régions tropicales.

\section{ENUIERITIO SPECIERCII.}

\section{Pteopeluts, II. et B. (SF:orothecin in jusentule squamis lecta.)}

1. Simplices. = Percussa, II. et Gr.* (Polyrodium, Radd.*, Langsd. et F.*) - Pangusiala, Piesl (Niphobolus spherocephalus, II. et Gr.*) - excasala (Polypodium, Bory) - ?'macrosora, Presl (Niphobolus macrocarpus, Hook. et Arnolt.*) - phlebodes (Polyjodium, Kizc.) - Billardieri (P'olyiudium, R. Br.) - nuda, Hook.* (Ilooh. cl Baue1* [fragm. analy\%]) - comprach, F. - vestitu, I. - macrocnipa (Polyrod., Bory) lanceolala, Presl - Prieurei, F. - lepidola, Presl - elonganta (Synammia, Prest*: frag

2. Jivisa el pimnalifida. = Angusla, II. et B. - torulosa, F. - slenoloma, F. (G.aleolt., 11." 6532- Radliana (Polypodium pleorellidifolium, Radu.*).

\section{ECDRTaR1. (Sporathecia semper nuda.)}

A. Simplices. = Ottoniana (Phymalodes, Presl) - Zeylanica, F. - Schomburnthiana (Polyjudrum, Kzc.*) - oraln (Polypod., II. el Gr.*) - Thouiniana (Polypodium, Gaudich.*) - dubin. J. Sm. (Cuming. 11. $0^{\circ}: 4$ ) - slenophylla, J. Sm. (Cuming, 11.0 1:2 [an genus distincl..”]) oades (Pulypodium, kze.) - cordifolia (Polypod., Mart. el Gal.*) - longifrons (Polyrod., Wall.*. 11. ct G1*) - revoluta, J. Su1. (Cuming. Plilitp., $11{ }^{\circ} 24 \mathrm{~T}$ ) - Browniana, Polyp. allemalum, Ii. Br., Diclyopleris, II. et Bauc1*, fragm.) - persicarixyolia (Microgranme, Presl*. nerv.) lycopodioides (Polyrodium, L., Schhh.*, Plum.*) - ileorhylla, Lh.

B. Pinnalifide. = Fulia (I'olyp., Mart. et Gal.*) - flaucina (Polyp., Mart. el Gal.*) - nrauteosa (Poly.p., 11. et Ga1.*) - lomarioides (J. Sun., Cuming, Phil., n. ${ }^{\circ}$ 212) - rubila, J. Sm. - rustulato

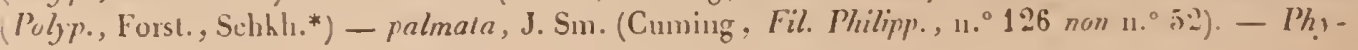


matodes, F.* (Phymatod. vulgaris, Presl, Kze. , ab errore cum Polyp. ensiformi mixta, ad dextram*) - scandens (Polypod., Forst., Schkh.*) - grossa (Polypod., Langsd. el F.*) - quercifolia, Bory (Polypod., Schkh.*) - hastata (Polypod., Thunb., Kze.*) - tridactylis (Polypod., Hook. et Gr.*) - glauca, J. Sm. - latifolia (Polypodium; Schkh.*) - afinis, J. Sm.

C. Pinnatce. = Pinnata, F.

\section{SPECIES NONDUM DESCRIPTA.}

\section{Vestita.}

\section{Pleopeltis.}

Frondibus simplicibus, crassis, opacis, longè peliolalis, sparsis; caulibus repentibus, crassiludine pennce columbre; laminis lanceolatis, oblısiusculis, squamosis; squaniis supernè sparsis, infernè densè imbricalis; mesoneuro nigrescenle, plano; sporolheciis paucis, marginalibus, crassis, ovoideis, immersis; sporangiis elliplicis, magnis, pedicello longo; annulo $16-17$ articulalo, lenui; sporis lavibus, magnis, lutescentibus, exaclè ovoideis.

Habilat in Mexico. (Galeotli.)

Filix repens, frondibus distantibus, conformibus.

(Dimensions : longueur totale des frondes, 6-8 centim., sur 5-7 millim. de largeur; le péliole a 13-14 millim. de longueur; les écailles sont orbiculaires et portent au centre une large tache noire. Quoique cette plante soit courerte d'écailles de même forme que celle des Drynaria, sect. Pleopeltis, arec lesquels on ne peut se dispenser de la placer, les sporothèces en sont dépourvus.)

\section{Prieurei.}

Frondibus linearibus, aculis, in peliolum brevem altenuatis, crassis, carlilagineis, squamis planis, fimbrialis vestilis; ferlilibus angustioribus; rhizomate repente, lenui; sporol/teciis ovalis, apicem luminarum invadenlibus, nagnis, marginem excedentibus, in sulco elongalo sitis; sporangïs ellipticis, longè pedicellatis; annulo crasso, 13-14 arliculalo; sporis ovoideis, brevibus lavibusque.

Habital in Guyanâ gallica (Leprieur); nec non in insula Marlinica (M."le Rivoire).

Filix parva, rigida, crassa, aculn, repens.

(Dimensions : longueur totale, 6-7 centim., sur 3 millim. de largeur; 9 -11 sporothèces, occupant le haut de la fronde.)

\section{Torulosa.}

Frondibus pinnalifidis; slipile fusco; rizomale repente, undulalo, squamis rigidis, nigris, aciculariformibus vestilo; segmentis rigidis, linearibus, apice allenualis, squamis anguslis, fuscis conspersis; frucliferis aspectu loruloso; sporolheciis ovalis, crassissimis, geminato-conuiventibus; receplaculo sublineari, crasso, promineule; sporangiis longè elliplicis; annulo crasso, 12-13 arliculato; sporis lcevibus, renifornibus.

Habilal in Cubâ. (Linden, sine numero.)

Filix rigida; mesonevro ebeneo; sporotheciis lannina latioribus. 
(Dimensions: longueur totale, $22-23$ centim.; le stipe en fait un peu plus de la moitié; segments, 5-6 centim. sur 3 millim. de largeur. Ces segments, dans leur partie décurrente . sont fertiles; on peut compter jusqu'i 12 paires de sporothèces, et ceun-ci sont hors de toute proportion avec les lames qu'ils débordent considérablement; la forme des sporanges est singulière; nous n'en commaissons point qui soient aussi allongćes.)

\section{Stexolona.}

Frondibus pinnatifidis; stipilibus tenuibus, glabris, longis; rhizomate crassiludine pennce passeris; segmentis longissimis, flexibilibus, linearibus, longè altenuatis, assurgentibus; marginibus crispis, subùs parcè squanosis, usque ad costrm fruclicuntibus; receptaculo angusto, nigrescente; sporotheciis crassis, ovoideis, distinclis; sporangiis ellipticis; annulo 13-15 atliculato; sporis curvatis reniformibusque.

Habilat in Mexico. (Talea, altitud. $15-1600$ met.; Galeotti, n. ${ }^{\circ}$ 6j32.)

Filix segmentis angustissimis et longissimis, in trajectu toto proliferis.

(Dimensions : longueur totale jusquau sommet du segment terminal, 32-34 centim.; $6-8$ paires de segments presque opposćs, ayant jusqu'i 15 centim. de longueur, sur $3-4$ millim. de largeu seulement; nous en possédons de beaucoup plus petits, trifides et fructifères; il existe jusqu’ả 30 paires de sporothèces, occupaut jusqu'au sommet de la pointe des segments ; cette pointe est nudulée.)

\section{T. ZEILANICA.}

\section{Eudryyaria.}

Frondibus longè acuminatis, lineari-lanceolatis, utrinque attenuatis, opacis, curtilugineis, glabris, margine siccilate revolutis, petiolo larvi, urticulato mesonevroque helveolis; rhizomate repente, crassiludine penuce columba'; sporotheciis crassis, orbicularibus, labacinis, laninis superioribus, ob sporolhecia opposilu, depressione elongatâ impressis; sporangiis magnis; annulo lato, 12 articulato, articulis crassis ; sporis lavibus, lutescentibus, crassis, reniformibus.

Habilat in iusultî Zeylauicrî. (Colonel Walker, 1846.)

Filix rigida, acuminata, opaca; habitı D. percussx, sed sporotheciis diversissimis.

(Dimensions : longueur tolale, 32 centim.; elle est variable; largeur, 15 millim.; le réceptacle est ovoïde, brunàtre, proéminent et comme cornć; les sporanges sont làchement réunies: uous ue royons d'écailles, ni dans les sporothèces ni sur les lames.)

\section{VT. Piniata.}

Frondibus pinnatis, glaberrinis; frondulis siccilute lutescentibus, lanceolutis, superioribus linearibus, ommibus serrutis, obtusiusculis, basi cuneatis; nervillis scalpturulis, areolis mimutissimis; sporotheciis uniseriatis, centralibus, rolundis, immersis, suprà gibbositate indicatis; sporangiis ovoideis; annulo 11 - 12 articulato, pedicello longo; pilis internis (sporangiastris?) longis, apice penicellatis; sporis reniformibus.

Habitat in Philippinis. (Cuming, n. 263.)

Filix rigida, glaberriua; froudulis perfacilè solutis. 
(Dimensions des frondules inférieures, 15-17 centim., sur un peu moins de 2 centim. de largeur; les dépressions, dins lesquelles sont reçues les sporanges, ont une profondeur relative assez grande; elles bosscllent la lame supérieure et forment de petits cônes, discolores au sommet; la présence de sporangiastres, mêlés aux sporanges, est dans ce genre un fait très-rare.)

Nous désignons encore comme espèce nouvelle la fougère de Sainte-Hélène, distribuée par M. Cuming sous le n. ${ }^{\circ} 431$, et nous lui donnons le nom de Drynaria (Pleopeltis) compacta. Elle est très-épaisse, cartilagineuse, lancéolée, opaque, couverte d'écailles roussâtres sur l'une et l'autre lame; elle se charge, vers le sommet, d'un très-petit nombre de gros sporothèces arrondis, un peu enfoncés; les sporanges s'attachent sur un réceptacle ovoïle.

\section{PLEURIDIUM, F.}

Phymalodis spec., PresL, Tentam. pterid., p. 196 , sect. secunda, pars prima; Pleuridium (1836).

Sровотпесі1 rotundis, hemispharicis, inter venas binas pinnatas, uni aut biseriatis, receptacnlo placentiformi, depresso, atro, superficiali; sporangiis ovatis, in P. crassifulio ad parten superiorem sacculi pilos ereclos, obtusos ferenlibus; annulo 13-14 articnlato; sporis lavibus, reniformibns.

Froxdrus simplicibus, lanceolatis, maraine integris, peiiolatis; nervillis primariis pinnatis, venulis primariis irregnlariter anastomosatis, cum appendiculis liberis, apice pellucido, glanduloso.

Filices rhizomate repente, erectce, rigida, arboricolce, Americance et Philippinenses; facie Campyloneuri et Microsorii.

Diagnosis : Scнотт, Gen. filic. (optima). Ноок. et B., Gen. filic., t. xхıx, snb Ply'mutode (mediocris); Pleuridium crassifolium, LK., l. cit.

Le genre Plenridirm esı fondé sur une fougère à fronde simple, épaisse, connue de Linné et cultivée dans nos jardins sous le nom de Polypodium crassifolinm. Elle est très-vigoureuse et portée sur un rhizome rampant et difforme; on la trouve sur les arbres. Elle a été observée en Amérique. Nous avons placé à còté d'elle comme congénère, le Polypodium rupestre de M. Blume. Ces fougères ont une nervation assez compliquée. Les nervures qui se détachent du mésonèvre sont pinnées; elles montrent, dans l'intervalle qui les sépare, deux rangées de sporothèces : cliacun d'eux est posé sur un plexus de nervilles. Les appendices nervillaires sont renflés à leur sommet. Le réceptacle est arrondi.

Les plenridium ont de l'analogie avec les campylonevron par la forme générale de la fronde; mais les sporothèces ne sunt pas fixés sur une nerville libre 
et la nervation est différente. Dans le Microșorium les sporothèces sont ataxiques; ils forment dans les drynaria des séries parallèles à la côte médiane, au lieu de se diriger obliquement vers elle; circonstance parfaitement expliquée dans le Pleuridium, par la présence de nervilles latérales pinnées, le long desquelles, les sporothèces se dirigent. Link avait donné à ce genre le nom d'Anaxelum, plus anciennement attribué par Grertner à un genre de synanthérées, adopté par Cassini et de Candolle; il était donc impossible de le conserver.

ENUMERITIO SPECIERUII.

Crassifolium (Anaxetum, Lk.) - rupestre (Fil. Philipp., Cuming, 11. 245).

\section{DIPTERIS, Reinw.}

Polypodii spec., Aucr.

Syllog. Pl. nov., pl. II, 3.

SPOROTнECIS superficialibus, parvulis, creberrimis, sparsis, secundium nerillas pinnalas nascentibus; sporangiis ovalis; annulo latiusculo, 12-14 arliculato: seplis elevalis; sporis oblongis; sporangiastris pedicellatis, cyalhiformibus (ex Kunzeo).

Frovdubs profundè biparlilis, suborlaucis; segmenlis palmalo-lacinialis, serralis, dicholomo-nervosis; venulis reliculalis; sporangiis cum glandulis sublurbinalis immixtis; pedicello tenui, longissino instructis.

Filix insignis, erecta, arboricola, opaca, coriacea, indica, cum aliis nullo modo comparanda.

Diagnosis: D. conjugata, Reıw., l. cit. (KzE., Analect., p. 16, t. x.)

Il est facile de reconnaitre ce genre à ses nervures prinaires flabelliformes e t a l'absence du mésonèvre. La fronde est profondément divisée en deux parties qui tendent à s'appliquer l'une contre l'autre par leur lame supérieure. Les segments digités sont crénelés et terminés en pointe. La nervation a quelque analogie avec celle des nevroplat,ceros. Les sporothèces sont extrêmement nonbreux, trèspetits, superficiels, posés sur un réceptacle ponctiforme naissant sur un plexus nervillaire. Les dernières aréoles sont d'une grande ténuité. Kunze a figuré les sporangiastres mélangés aux sporanges, sous un grossissement trop peu considérable.

\section{SPECIES.}

Conjugata, Reinw. (Polypodium Wallichii, Hook. et Grev.*, Icon. Filic., 1. 168 et 169). 
DES POLYPODIACÉES.

Frondibus heteromorphis.

\section{DRYOSTACHYON, J. Sm. (1841.)}

In Hook, Journ. of botan. III, p. 399

Polypodii spec., ReIsw.

SPOROTHECIIS magnis, ovoideis, approximatis, conniventibus, sed semper distinctis, inter venas costaformes sedentibus; receptaculo nullo; sporangiis ovalibus, ad basim sacculi, 3-7 pilos continuos, obtusos gerentibus; annulo crasso, 15 - 16 arliculato; articulis spissis (Dryostachyon pilosum; J. Sm.); sporis ovoideis.

Frovdibus sessilibus, rigidis, cum rachi articulatis, pinnatifidis; segmentis sterilibus lanceolatis; fertilibus linearibus; nervillis pinnatis; venulis areolas parvas cum appendicibus, apice turgido, formantibus.

Filices rigidce, coriacece, opacce, Philippinenses, habitu peculiari. Genus distinctissimum.

Diagnosis : Ноок. et B., Gen. filic., t. xcv. (D. splendens, J. Sм., l. cil.)

Le genre Dryoslachyon est nettement caractérisé. Les frondes sont modifiées vers la moitié supérieure de la fronde; lancéolées vers la base, elles deviennent linéaires et s'allongent vers le sommet. Les marges sont entières; les sporothèces, très-rapprochés et souvent fort gros, ont un réceptacle ovoïde; la nervation est semblable à celles de plusieurs drynaria; les dernières aréoles sont très-petites. Des nervures transversales droites, flexueuses et très-rapprochées, unissent les nervilles costales qui sont pinnées. Les segments fertiles montrent aussi ces nervilles transverses, et entre chacune d'elles se fixent les sporothèces; le sacculus est pileux.

Le port des dryostachyon est raide et peu gracieux. On trouve ces fougères aux Philippines et aux îles Célèbes. Elles n'ont de comınun, avec le genre Aglcomorpha, que la métamorphose brusque des frondes vers la partie qui devient fertile.

\section{ENUMERATIO SPECIERUM.}

Pilosum, J. Sm. (Cuming, 11. 90$)$ - splendens, J. Sm. (Cuming, 11. $\left.{ }^{\circ} 87\right)$ - caudatum (Polypodium, Reinw.). 


\section{Considérations générales sur le groupe des Polypodiées.}

Ious avons déjà patlé de ce groupe, p. 27; nous ajouterons ce qui suit:

Le groupe des polypodiées est placé au centre de tous les autres, et il a avec plusieurs d'entre eux, soit par les organes reproduits, suit par les organes de la nutrition, quelques points de contact. Il est nombreux en genres et en espèces; la nervation se modifie beaucoup, et l'on peut y reconnaîre la presque-totalité des contbinaisons connues; cependant les nervures ne se soudent jamais à la marge comme dans les.genres Olfersia, Lomariobotrys ou Neottopteris, et lorsque les nervilles se constituent en aréoles, celles-ci sont presque toujours appendiculées. C'est surtout avec les aspidiées qu'elles semblent inarcher parallèlement, de sorte que l'on pourrait dire, ou bien que les polypodiées sont des aspidiées à sporothèces nus, ou bien que celles-ci sont des polypodiées indusiées.

Beaucoup de genres ont une plyysionomie propre qui suffit pour les caractériser nettement : tels sont les genres Calymmodon, Microsorum, Lecanopleris, Niphobolus, Aglaomorpha, Dipteris, Dryostachyon. Les genres les plus nombreux sont les Polypodium, Phegopteris et Drynaria; quatre d'entre eux sont nonotypes: Calymmodon, Lecanopleris, Arlaomorpha, Dipteris, et quatre autres oligotypes: Ctenopteris, Dictyopteris, Pleuridium et Dryostachyon.

En se représentant ce groupe comme central, on le voit tendre vers les acroslichum, par les frondes lancéolées des microsorium et des pleuridium; vers le nevroplatyceros, par les poils étoilés des niphobolus; vers les pleurogrammées par l'élongation marquée des sporothèces du gence Grammitis; ver's les aspidiées par la composition des frondes des Dictyopteris; enfin vers les alsophilées par le genre Phegopteris qui a le même port, quoique les stipes soient herbacés et les frondes plus petites.

Les polypodiées n'ont qu'une faible tendance à se diviser'; un très-grand nombre portent des frondes simples et pinnatifides. Il n'est pas précisément rare d'en trouver qui soient pinnées et à frondules pinnatifides, mais rien ne l'est davantage que de les trouver décomposées. Les auteurs, en décrivant les sporothèces des fougères appartenant à cette tribu, s'accordent à les déclarer sphériques; ils offrent cependant cette disposition bien rarement, étant presque constamment elliptiques ou ovoïdes, soit par eux-mêmes, soit par leur réceptacle. 


\section{Indusium superum : EPICILLAIIIDE $\boldsymbol{E}$.}

\section{In ambitu liberum.}

A. Peltatum : CYCLODIEAE.

Aspidiariæ, Presl, Tentam. pterid., p. 82, ad exclusionem Didymochlænæ.

Erectæ; simplices aut divisæ, cosmopolitanæ; multiformes.

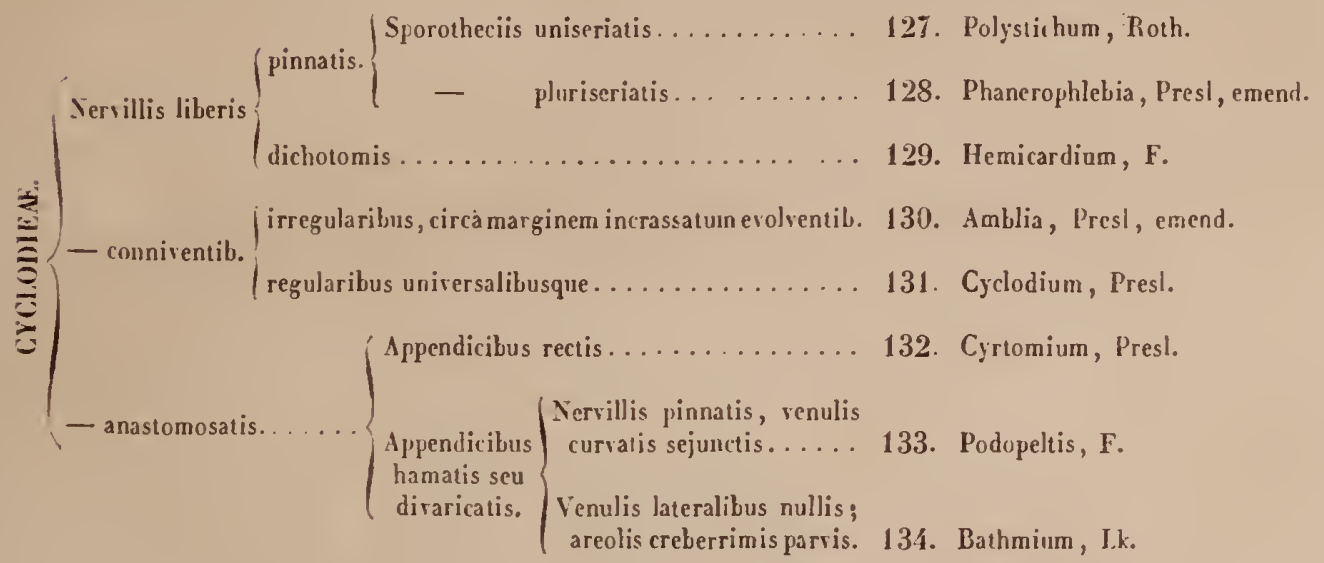

127. POLYSTICHUII, Roth. (1788.) [Schott.]

Aspidii spec., Auct. Plcrim. - Hypopellidis spec., Bory. - Nephrodii spec., PresL. - Teclaria, Cav. - Rumohra, Radd, etc.

SPOROTHECIIS orbicularibus, serialibus, inter costam et marginem silis, super ramulum superiorem vence sedentibus, rarò subapicilaribus; receptaculo (nersilla turgida) consexo, minuto; indusio stipilato, peltato, suborbiculari, super dorsum receptaculi imposito; sporangiis longè pedicellatis, in ambitı receptaculi affixis; annulo $14-24$ articulato; sporis ovoideis, brevibus, scepè papillatis.

Froxdibes pinnatis, pinnato bi-tripinnatifidis; venulis liberis, pinnatis, exsertis, in mucrones subaculeatos mutatis; segmentis frondium rigidis, acutis; stipiti bus sapè squamosis; rhizomate crasso.

Filices herbacere, cosmopolitance, dentatce, rigidce, corincea. 
Diugnosis : Sснотт, Gen. filic., Fasc. II, 1.,Iv (optima). (P. Lonchitis). Ноок. ct B., Gen. filic., t. xlvuI (P. lobatum, PresL). Prest, Tentam., p. 82, t. 11, fig. 7, 13 (nervatio sola).

Ce genre, très-bien caractérisé, de port particulier, quoique voisin de quelques aspidium, n'est pas universellement adopté, et c'est à bon droit qu'on s'eı étonne. Ce sont des fougères dressées, à frondules ovoïdes, portant sur la marge et au sommet des mucrons spinescents plus ou moins allongés; les nervilles, pinnées, décrivent des courbes rentrantes. Les sporothèces se frxent sur le trajet d'un ramuscule qui se détache de la principale veinule. L'indusium est attaché par son centre à un petit support ou columelle. Si ce support est grêle, le tégument se sépare; sil résiste, il couronne les sporanges et reste plane ou se recoqueville suivant sa consistance.

Ce genre est nombreux en espèces; nous ne croyons pas qu'il en existe moins de soixante. On les trouve dans tous les pays, mais l'Europe n'en possède qu'un petit nombre. Elles s'élèrent assez haut vers les pôles et prospèrent dans les paýs froids. Le Polystichum acrostichoides présente ce caractère particulier d'avoir des frondes rétrécies ver's le sommet qui se recourre complétement de sporothèces; ceux-ci devenant confluents, donnent à la plante l'aspect d'un aspidium; une espèce est hizophore et deux autres prolifères, les noms spécifiques qui leur ont été donnés en témoignent. Nous en possédons une qui rappelle dans la forme de ses frondules les feuilles de l'Ilex: aquifolium (Toy. plus loin P. ilicifolinm, F.)

\section{ENUMERITIO SPECIERLY.}

1. Frondibus pinnatis. = Rhizophyllum, Presl - ? glandulosum, Presl (Aspid., II. et Gr.*) falcatum, F. - Lonchitis, Roth. (Schkh.*, Fl.dan.*, Pluk.*, Schott., fragm.*) - cyphochlamys, I: - ilicifolium, F. - acrostichoides, Schott (Aspid., Sw., Schhh.*) - mucronatune (Aspidium, Schlkh.*, Sloan.*) - auriculalum, Presl (Schhh.*, Burm.*) - trapezoides, Picsl (Polypod., Sw.. Sloan.*).

B. Frondibus bipinnatis. = Rhomboideum, Schott. - marginatum, Schott. (Astidium, Sw., Plum.*) - pungens, Kllss. - lobalum, Presl (Schkh.*, Pluk.*, Ilook. et Bancr, fragm.*) - aculealum, Roth (Schkh.*); var. $\alpha$, spinosunz; $\beta$, Taygeti; $\gamma$, hastulalum, Tenor. - Brannii, Spenn. nngulare, Presl - arisialum, Sw. (Schkh.*) - Sieberianum, Presl (Aspid. vestitum, Sich.) - oblusum, J. Sm. - ordinalum, Kze., sub Aspidio (Linden, $10^{\circ} 489$ ) -- gelidum, Kize. (Linden, n. ${ }^{\circ} 498$ ) - Wauritianum (Hypopeltis, Bory?) - heterolepis, I. - radicans, Sicb. (N. Holl.. 11. 104) - viviparum, F. - polyblepharum, Rö̈m. (sub Aspidio) - vestitum (Aspidium, Sw..

- Schkh.*) - varium (Aspidium, Sw.) - triangulum (Plum.*, Petir.*) - mucroulfolium, Kze. (Aspidium, Blum.). - ? inerne, F.

C. Frondibus tripinnatis. = Elegans, Remy (Fl. Chil, ined.) - squarrosum (IIypopeltis, Bory) stramineum (11ypopeltis, Bory) - incisum, $\mathrm{F}$. (Cuming, Philipp., n. ${ }^{\circ} 146$, in Herb. nostr. ab errore) - setosum (Aspid., Langsd. et Fisch.*) - corinceum, Roth. (Schhh.*, Langsd. et Fisch. ; Pl. valdi polymorpha) - - chlcnosticla , F. - mohrioides (Ispidium, Bory) ins. Falhland - tenerum, F. coniifolium, Pıesl (Aspid. carvifolium, Kze.) - cnudatum, Sw. - muricalum (Plum.*, Petiv.*).

D. Frondibus quadripinnatis. = Amplissimum, Presl - discretun, J. Sn. 


\section{Falcatey.}

\section{SPECIES NONDUM DESCRIPTE.}

Frondibus pinnntis, lanceolalis, glabris, stipile et rachi tenuibus; frondulis lanceolatofalcatis, acuntinatis, glnbris, auriculatis, brevissimè petiolatis, infernè cuneatis, in anbitu dentatis, mucronatis, apice, auriculti et dente majori inferiori aristatis; aristis multò longioribus; sporotheciis rotundis, remotis, super laninam superiorem leviler impressis; indusio tenui; sporangiis ovoideis, pedicello lato; annulo 14-16 articulıto; sporis ovalibus, episporiatis.

\section{Habilat in Santo Doningo. (Port-au-Prince, L’Épagnicr.)}

(Dimensions : longueur totale, 25-87 centim.; frondules, 3-4 eentim.; sur 1 eentim. de largeur; le stipe et le rachis ont le diamètre d'un gros fil. Nous eomptons 20 paires de frondules, séparées par un entre-nœud, ayant au centre environ 15 millim.)

\section{Ciphochlayis.}

Frondibus lanceolatis, fasciculatis, stipite rachique squamulosis, squamis mollibus, margine strigillosis; frondulis pedicellatis, ovalibus, aculis, rigidis, mucronibus crassis, brevibus; inferioribus rhomboideis, basi Iruncatis, sursùm auriculatis, paucicrenatis; rhizonate crasso, squanis lanceolatis, nigrescentibus, lucidis; sporotheciis globosis, crnssis, approximatis; indnsio umbonato, cupuliformi, caduco; sporangiis variabilibus, roundis, obliquis, ellipticis; annulo 14-16 articulato; sporis ovalibus, episporicutis.

$$
\text { Habital in Cubô. (Linden, n. 2175.) }
$$

Filix rigida, opaca; indusio cupuliformi notata.

(Dimensions : longueur totale, 30 centinı. el sourent moins, sur 4 eentim. d'envergure; une vingtaine de pinmules sont altachées à la fronde qui est pinuatifide au sommet.)

\section{Ilicifolicy.}

Frondibus piunatis, linearibus, fasciculntis, virgatis, stramineis, glaberrinis, apice sapè radicrntibus; frondulis remotis, pedicellatis, rhonboideis, novellis subquadrangularibus, omnibus ad angulos aristatis; aristis longis, setaceis; sporotheciis crassis, rotındis, paululum inmersis, 1-6 in utroque latere laninarum; indusio perfacilè delapso; sporrangüis ovoideis, longè pedicellatis; annulo 18-19 articulato; sporis ovalibus, episporiatis.

Hubilat in insulâ Cubâ. (Santiago; Linden, n. 2193.)

Filix singularis, aristata, virgata.

(Dimensions : longueur totale, $42-48$ centim., sur 3 eentim. d'envergure; 34 paires de frondules; stipe radieant au sommet.)

\section{Heterolepis.}

Frontibus bipinnatis, lanceolatis; stipite striato rachique squamosis; squunis biformibus, aliis linenribus, longis, unicoloribus, aliis ovalibus, carinatis, in medio fuscis; 
pinnis angustè lanceolatis, aculis, rigidis, apice serrato-pinnatifidis, frondulis ovulis, in acumen rigidum terminatis, inferiore multò majore auriculatâ, rachim tectante; nervillis scalpturatis; sporotheciis $3-4$, apice solitariis; indusio orbiculari, tenui; sporangiis mediocribus, rolundis; unnulo 11-16 arliculato; sporis rolundis, episporiatis.

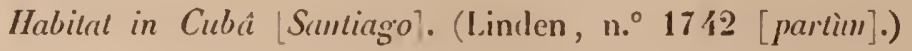

Filix bipinnata, pilis biformibus el segmento inferiori multò majore notaln.

(Dimensions : longueur totale, 50 ecntiun.; les pinunles ue dépassent guc̀re 45 millim.; la fiondule terminale basilaire atteiut 1 centim.)

\section{Niviparum.}

Frondibus mixtis, infermè bipinnatis, supernè pinnatis, virgatis, radicanti-viviparis; rachi valido, canaliculato, rufescente, squanis lanceolatis, acuminatis, ad centrum nigrescentıbus; frondulis oblusis, inferioribus basi pinnalis, segnentis mucronalis, mucronibus brevibus, crassis; frondulis superioribus, subrhomboideis, sursim auriculatis, crenulatis, apice mucronatis; sporolheciis \$-6 remolis, suprì impressis; indrusio orbiculari, fusco-rufescente, sporangiis rolundis; annulo 14 artirulato; sloris parvis, nigrescentibus.

Habital in Cubî $[$ Santiago]. (I.inden, n.० $1742[$ partim $]$.)

Filix virgata, apice ralicanti, semi-bipiunata, flexibilis.

(Dinensions : 36 centim. de longneur totale, sans le stipe; les pinnules inférieures ont 22.26 millim. de longneur, sur 1 centin. de largeur i la base; les pinuules inféricures varient de $1-2$ centin.; il existe une quarantaine de paires de piunules euviron.)

\section{Vi. Chloenosticta.}

Frondibus bipinnatis; stipite anguloso, striato, busi squamoso; squamis lanceolutis, nitentibus, linearibus, fulvis, succineo colore, ad rachin pallidioribus; pinnulis angustè linearibus, acutis, glabris; frondulis ovatis, crenatis, spissis, opacis, nucronatis; segnentis fructiferis parvis, sporothecia duo ferentibus; indusio gibboso, centro macula nigrâ notato; sporangïs magnis; annulo 18 articulato; sporis crassis, nigris tuberculosisque.

Habilat in alpibus Nove Hollandice. (L'Hotschy.)

Filix rigidn, pinnulis brevibus, ad apicem solùn fructiferis, indusio in centro nigrescenle notalc.

(Dimensions : longneur, 36 centim.; dont le stipe fait le tiers; pinnules, 5.6 centim., sur 1 centim. d'envergure.)

\section{il. Texerty.}

Frondibus tripinnalis, ovulis; stipite gracili, busi squamis angustis, piliformibus hirı; rachi glabro; nervillis bipinnatis; pinnis lanceolatis, pimnulis ovatis, segmentis ovalis, argutè serratis, muticis, glabris; sporotheciis rolundis, remolis; receptuculo 
punctiformi, fusco; indusio parvo, perfacilè caduco; sporangiis ovatis; annulo 16.17 articulato, pedicello latissimo, villato; sporis ovoideis.

Habitat in Brasilici. (Claussen.)

Filix flexibilis, tenera,pellucida, glabra; segmentis acutis, muticis.

(Dimensions : longueur totale, 30 centim. au plus; le stipe cst à la fronde :: $2: 1$; divisions pinnaires, 7 centim.; les segments, oroïdes et pétiolés, ont environ $4-5$ millim. de longueur.)

L’espèce suivante, qui est dissidente, mérite d'être indiquée.

? INERME.

Frondibus pinnato-pinnalifdis, glabris; frondulis lanceolatis, aculis; subpinnatifidis, apice crenatis; crenis obtusissimis, nervillis abbreviatis, tenuibus simplicibusque; sporolheciis crassis, dorsalibus, suprà impressis; indusio fusco, siccilate crispo; sporangiis ovalis; annulo 16-18 articulato; sporis ovalis.

Habilat in Guyanâ gallicâ. (Leprieur, $\mathrm{n} .^{\circ} 188$, Herb. clar. Mougeot.)

(Dimensions : longueur de la fronde, 40 centim.; des frondules, au nombre de 14 paines, 12 centim., sur 3 centim. de largeur; entre-nœuds, 4 centim.; l'indusium, en redressant ses bords par l'effet de la dessiccation, se rapproche plus ou moins de la forme quadrangulaire.)

\title{
128. PHANEROPHLEBIA, Presl (1856), emendatum.
}

\author{
Tentam. pterid., p. 84.
}

Aspidii spec., Auct. plurim.

SPORотнесіs orbicularibus, ad dorsum venula lateralis sitis; indusio peltato, parvulo, centro affixo, caduco; sporangïs subrolundis; annulo $14-16$ articulato; sporis ovoideis, succineo colore.

F'RONDibes pinnatis, frondulis lanceolatis, aculis, petiolatis, pallidis; nervillis liberis, furcalis, marginem incrassalum, carlilagincum, argulè dentalum allingentibus, denlibus mucronalis, pungentibus; rhizomate horizontali, synamis magnis onuslo.

Filices pinnatce, Mexicance.

Diagnosis : F., Lab. xxıt, B, fig. 2.

Quoique nous adoptions ce genre de M. Presl, nous ne lui reconnaissons pas les mêmes caractères. Cet auteur déclare que les nervilles sont anastomosées, et c'est ainsi qu'il les représente (tab. 11, fig. 19). Or, l'Aspidiurn nobile de I. Schlechtendal a des nervilles parfaitement libres, ainsi que nous pouvons le voir dans le spécimen authentique provenant de Kunze, qui a donné de cette fougère une excellente figure (Die Farrenkr., t. LXVII). Les nervilles y sont représentées libres, ainsi qu'il le fallail faire. En comparant la figure 19 de la 
pl. II, et la fig. 22 de la pl. VII, l'une se rapportant à l'Amblic et l'autre au Phanerophlebia, on les voit à peine différentes, et cependant si M. Presl arait eu entre. les nains l' $A$. nobile, la condition des nervilles n'aurait pu lui échapper. Il denreure donc douteux pour nous que ce botaniste liabile ait connu la plante de M. Sclilechtendal, qui permet de voir avec la plus grande netteté la disposition du système vasculaire de la fronde, ses frondules laissant facilement passer la lunière.

M. Kunze trouve que le Phanerophlebia nobilis de M. Presl se rapproche beaucoup de son Amblia jugrandifolia, mais il admet avec raison de notables diffèrences.

\section{ENUNERITIO SPECIERUM.}

Vobilis (Phanerophlebia nobilis, Presl? Aspidium, Schlecht., Kze.*, F.*, Hook. et Bauer, Gen. filic., tab. XLIX, A (fig. Presliana) - pumila (Aspidium, Mart. et Gal.*, n.. 6251).

\section{HEHICARDION, F.}

Aspidii spec., Accr.

$C_{3}$ clopellidis spec., J. Su., in Bot. mag., 1846.

Sporothecus rotundis, bi aut triserialibus, dorsalibus aut subapicilaribus, ramos superiores nervillarum occupantibus; indusio rolundo, crasso, pedicellato, siccitate in ambitu crispalulo, sapè delapso; receptaculo punctiformi, durissimo: sporangiis ovatis; annulo 14 articulato; sporis ovoideis.

Froxdbes pinnalis, pinnulis sessilibus, acuminalis, sapè crenatis, basi senicordatis, lobulo inferiore curvalo stipitem tegente; nervillis ter qualerque dichotomis, liberis, rigidis, apice subturgidis; fasciculis vasorum yualuor, didynamis (in Hemicardio crenalo); stipite sulcato.

Filices erecke, pinnata, Asiaticae.

Diagnosis: tal. xxı, fig. 1, H. crenalum, F., et fig. 2, H. Cumingianum, F. (fragm.).

Le non donné à ce genre s'applique à la hase des frondules dont la base inférieure est auriculée et comme semi-cordée. Ce lobule se redresse, s'applique sur le rachis en laissant une surface vide qui simule une ouverture arrondie; on retrouve cette organisation dans toutes les espèces; les frondes sont pinnées, à frondules sessiles, lancéolées, aiguës, acuminées, glabres, un peu ondulées et très-rapprochées. Ce sont des fougères de l'Inde et des Plilippines, ayant le port de la fronde fertile des lomariopsis (acrostichées).

\section{ENUIERATIO SPECIERUII.}

I1. Tephrolepis (Aspidium semi-cordatum, Sw., Plum.*) - Cumingianum, F* - crenalum, F.* - subhastatum (Amboyna, Labill., Merb. Weeb.) - Cochinchince (Gaudich. in Merb. Moug.). 


\section{Crenitum.}

\section{SPECIES NONDUM DESCRIPT $Æ$.}

Frondibus pinnatis, in ambilu ovatis, stipite et rachi sulcatis; frondulis allernis, elliptico-elongatis, abruptè acuminatis, glabris, acumine falcato, undulato, marginibus crenatis, deorsum rotundatis; sporotheciis parvulis, $2-3$ serialibus, subterminalibus; sporangiis longè pedicellatis, ovatis; annulo 13-14 articulato; sporis ovoideis.

\section{Habitat in Cochinchiná. (Tourane, Gaudichaud.)}

Filix elata, frondulis membranaceis, translucidis, aspectu lomariopsidis.

(Dimensions : Jongueur totale 75 centim.; pinnules 10 centim. sur 16-18 millim. de largeur. Les entre-ncuds ont, vers la base de la fronde, de $4-5$ centim. Nous comptons une quinzaine de frondules environ.)

Dans l'A. semi-cordatum, $\mathrm{S} w$. , les frondules sont plus longues, plus étroites, presque opposées, opaques, à marges entières; elles se terminent en pointe par une décroissance menagéc; la base supérieure, au lieu d'être arrondie, est tronquée; les sporothèces ne sont pas terminaux, mais bien attachées vers la base du rameau fructifère de chaque nerville, de sorte que la plus grande partie de ce rameau est libre.

\section{Cumingianum.}

Frondibus pinnatis, lanceolatis, siccitate fuscis, rachi sulcato, squamuloso-piloso; frondulis lanceolatis, falcatis, acutis, sessilibus, approximatis, alternis, margine repandis, incequaliter cordatis; auriculis inferioribus latioribus, auriculis superioribus brevioribus, latus superius rachidis tectantibus; sporotheciis minutis, 4 seriatis, dorsalibus; sporangïs el sporis ut suprà.

Habilat in insulis Philippinis. (Cuming, n..$^{\circ}$ 68.)

Filix eluta, multifrondulosa, glabra; siccitate fuscescens.

(Dimensions : de la fronde, sans le stipe, qui nous est inconnu, 60 centim.; des frondules centrales 10 centim. sur 18 millim. de large, séparées les unes des autres par des entre-nœuds de 25 millim. Les oreillettes supéricures et inférieures recouvrent, les unes, le còté supérieur, et les autres, le côté inférieur dı rachis. Les premières cachent l'oreillette inférieure des frondules immédiatement attachées au-dessus d'elles. Les frondules inférieures sont obtuses et plıs courles.)

\section{AMBLIA, Presl [rectiùs AMBLYA] (1856), emendatum.}

Tentam. pterid., p. 84 .

Aspidii spec., H. et Bonpl.

SPORотнесі1s rolundis, ad dorsum venula lateralis sitis; indusio rolundato, parvulo, caduco, ad centrum affixo; receptaculo prominente; stomio angusto, 7-8 nervato, nervis crassis, incequalibus; sporangïs ovoideis; annulo 12 articulato; sporis obscurè reniformibus, intùs sporulas inserentibus. 
FRONDIBCS pinnalis, pinnis petiolatis, crenato-dentatis, acuminalis; nervillis dicholomis, basi liberis, circà marginem in arcuis anastomosalis, seplem fasciculis vasorum in slipile: quinque superioribus minoribus : duo inferioribus woide is nuajoribus.

Filix herbacea, Mexicana, pinuata, erecta; fucie Cyrtonii proxima.

Diagnosis: tab. xxu, fig. 1, A et B; A. juglandifolia, Preš, l. cil., t. 1 , fig. 19 (nervalio); ab Ноок. et Bater, Gen. filic., t. xLv, reproducta (incomipleta).

L'indusium de l'Amblia existe, et nous avons pu en constater la présence arec la plus grande facilité. C'est donc probablement pour avoir examiné un spécimen trop avancé que M. Presl, si bon observateur, ne l'a pas vu. Cette fougère curieuse n'est donc ni un Polypodium ni une polypodiacée, mais bien une cyclodiée, l'indusium étant fixé au centre et orbiculaire. On ne peut la confondre avec le Phanerophlebia dont les nervilles sont libres. Kunze établit les rapports existants entre le Phanerophlebia nobilis et l'A mbia juglandifolia : il les juge différents, mais voisins. Il persiste à faire de ces plantes, à indusium orbiculaire, fixé au centre, des aspidium dont lindusium réniforme est attaché près du sinus; cette opinion est inadmissible.

SPECIES.

1. juglandifolia, Presl (Polypod. juglandifolium, H. B.*; Galeott., Pl. Mexic., n. ${ }^{\circ}$ 6443).

\section{** Vervillis conniventibus.}

\section{CICLODIUM, Presl. (1856.)}

Tentam. pterid., p. 85.

Aspidii spec., Auct. var. - Nephrodii spec., J. S..

SPORothecIIs puncliformibus, in medio venarum insidentibus, globosis; indusio orbiculato-pellato; sporangiis pedicellatis; annulo crasso, 16 arliculato; sporis reniformibus.

Frovdruts pinnalis; venulis pinnatis versùs latera connivenlibus, areolis venulâ erectâ, ab angulo superiore innatî, partitis.

Filices herbacere, piunatce erecke.

Diagnosis: Hook. et Baver, Gen. filic., t. xux, A; C. confectum, Presl, I. cil., I. II, p. 20 et 21 (nervatio).

La nervation des cyclodium a quelques rapports avec celles de plusieurs meniscium. Des nerrures de deuxième ordre, qui sont fructiferes, se détachent du 
mésonèvre et vont s'unir à leurs voisines, en formant des angles. Du sommet de chacun de ces angles s'élève une nerville droite qui se prolonge jusqu'à la base de l'angle supérieur et ainsi successivement, pour diviser compléiement les aréoles en deux moitiés égales. Les frondules sont grandes, lancéolées, acuminées, à narge un peu ondulée, glabres et courtement pétiolées. Les spores sont rèniformes.

\section{ENUMERATIO SPECIERUM.}

Confertum, Presl* - meniscioides, Presl (conditio nervationis*, F.*, frons sterilis; Aspid. confertum, II. ct Gr.* et H. et Bauer*, F., frons steril.*, sub Soromane integrifolio) - abbreviatum, Presl.

\section{*** Nervillis anastomosatis.}

\section{A. Areolis exappendiculatis.}

$B$. Areolis appendiculatis.

\section{CYRTOMIUMI, Presl. (1856.)}

Tentam. pterid., p. 86 .

Polypodii spec., L., 'Тнunв. - Aspidii spec., Auct, var.

SPOROTHFCns puncliformibus, sparsis, in medio dorso nervilla liberce sitis; indusio orbiculato-peltato, sporangiis ovoidcis, longè pedicellatis: annulo ferè coimpleto, 14-16 articulato; sporis rotundis, ovoideis, episporio tuberculoso vestitis.

Frovibus pinnatis, crassis, frondulis ovatis, falciformibus, obliquis, venulis in areolas hexagonales dispositis, venulam reclam proligeram, apici lurgidaur, includentibus.

Filices indicce, robuste, erecte; affines quidem Polystichiiis, sed parum.

Diagnosis: Ноox. et Baver, Gen. filic., t. xux, B; C. caryotideum, Prest, l. cit., t. II, fig. 26 (nervatio).

Ce genre ne renferme jusqu'à présent que deux fougères de l'Inde, ayant une physionomie presque semblable. Le $C$. falcatum, le seul que nous ayons sous les yeux, a des frondes pinnées assez longues, dont le rachis, couvert de nonibreuses et belles écailles fauves, se charge de frondules courtement pétiolées, longuement acuminées, ondulées, falciformes, coriaces, opaques et parcourues par des nervilles épaisses qui constituent des aréoles sériales, surmontées de une ou deux droites. La souche est dressée et assez considérable; M. Hooker dit que celle-du C. caryotideum, dont il a donné une bonne figure, est rampante. 
Falcatum, Presl (Polypodium, L., Thunb.*, Pluk.*, Houtt.*) - caryotideum, Presl (Aspidium, Wall., Hook. et Gr.*).

Aspidii spec., WaLl.

\section{PODOPELTIS, F.}

SPOROTHECIS rolundis, parvulis, approximatis, inler yuasyue nervillas pinnalas, 5 -seriatis nascentibus, indusio minuto, peltato, siccitate crispatulo tectis; sporangiis magnis; annulo lato, 12 articulato; stomio lato, inceyuali, sub 10 nervalo; sporis rotundis, latè marginatis, reniformibus.

Froxdibus simplicibus, integris, lanceolatis, nervillis pinnatis, inter se ope venularum transversalium, curvalarum coalitis; appendicibus areolarum recurvis; thizomate repenle; crassiludine penne columbine; slipite fusciculis lateralibus vasorum lacrymaformibus peragrato.

Filix herbacea, erecta, integerrima, Indica.

Diagnosis : tab. xxm, A, fig. 1 ; P. Singaporiana (Aspidium, Wir.t.)

A Bathmio differt, nervatione el silu sporotheciorum.

Ce genre ne renferme qu'une seule espèce à fronde simple et ovale-lancéolée, se terminant en pointe vers ses deux extrémités. Les nervilles latérales sont pinnées, assez nombreuses, réunies par des latérales légèrement recourbées, émettant des veinules qui s'anastomosent et deviennent fructiferes. Le nombre des sporothèces est si considérable que nous en pourons compter plus de soixante dans lintervalle de deux nervilles pinnées; or, comne il en existe plus de trente de chaque côté de la lame, nous avons environ 5600 sporothèces pour cliaque fronde, et en admettant que chacun d'eux soit constitué de douze sporanges et que dans chaque sporange il y ait seulement cinquante spores, nous arrivons ì un total de plus de deux millions de germes reproducteurs.

Le Podopeltis a quelques rapports avec les bathmium à frondes simples; mais la nervation et la disposition des sporothèces ainsi que le port, en font un type parfaitement distinct.

SPECIES.

Singaporiana (Aspidium, Wall., Hook. et Gr.*, Kze.*).

\section{BATHМIUI, Lk. (184..)}

$$
\text { Spec. fil., p. } 114 \text {. }
$$

Aspidii el Polypodii spec., Аuct. - Bathmii spec., Lk.

SPORoTneciss hamispharicis, biserialibus; receptaculv elevato; indusio orbiculari, primim plano, deinde inflexo, centro pellatim affixo, receptaculimm glo- 
bosum occupante; sporangïs densissimis, longè pedicellatis; annulo sub 15 arliculalo; slomio lalerali, 4 nervalo; sporis reniformibus.

Frondibs rarò simplicibus, ferè semper lobato-pinnalis, pinnulis infimis parlito-pedatis; nervillis pinnatis; venulis subimmersis, crassis, anaslomosatis, areolis appendiculatis; stipitibus glabris, lavibus.

Filices amplce, variabiles, herbacere, nervillis primariis pedatis; siccitate virescentes seu rufescentes; tropicales, sapè arboricola; aborlu non rarò gymnosorea.

Diagnosis : Sснотт, Gen. filic., fig. 1, t. $11 ;$ B. trifoliatum, Lk.; PresL, Tentam. pterid., p. 87 (nervatio).

Ce genre renferme de grandes et belles plantes, souvent aussi larges que hautes, presque toujours divisées, pinnatifides, trifoliées ou pinnées, avec des frondules inférieures pédiaires. On trouve les sporothèces à l'état nu et à l'état indusié dans une seule et même espèce. (Voy. Pleonemia et Sagenia.) Faute d'avoir constaté l'intégrité de l'indusium, ces plantes ont été confondues avec les aspidiunı, même pour les espèces cultivées dans les jardins. Pour les voir tels, il faut les observer de bonne heure. A la maturité des sporanges, ce tégument, qui est extrêmement délicat, se relève sur son point d'attache et devient presque crêpu, offrant 3, 4 ou même 5 replis durs, que la macération dans l'eau ne peut assouplir: Cette particularité se retrouve dans le Cardiochlona, mais d'une manière bien moins marquèe. Les ballımium ont, avec les espèces de ce genre, des rapports marqués, mais ici l'indusium est circulaire et fixé sur un large réceptacle de mème forme. C'est parce qu'il y adhère très-fortement qu'il est persistant. Celui des cardiochlona, libre jusqu'au sommet du sinus, devient lobé ou cordiforme à la base; il est plus facilement caduque et s'attache sur un réceptacle linéaire ou manifestement allongé.

A l'exemple de Link, nous conservons le nom d'aspidium aux fougères à indusium réniforme, renfermées dans le genre Lastrea de M. Presl. Nous agissons dans cette circonstance comme nous avons agi pour le genre Acrostichum, afin de ne pas surcharger les synonynies.

\section{ENUMERATIO SPECIERUM.}

A. Frondibus simplicibus. = Macrocarpon (Polypod. plantagineum, Jacq.*, Plum.*) - sinuatum, F. - ? undulatum (Drynaria, J. Sm., Cuming, 11. 250) - ? subfalcatum (Drynaria, J. Sm., Cuming, n.*113).

B. Frondibus ternatis. = Ebeneum, F. - trifoliatum (Asfidium, Sw., Jacq.*, Peliv.*, Plım.*, Sloan.*) - heracleifolium (Asfidium, Willd., Mart. et Gal.*) - alatum, Presl (Aspidium, H. et $\left.\mathrm{Gr} .^{*}\right)$.

C. Frondibus pinnatis. = Repandum, Presl (Sagenia platyphylla, J. Sm.).

D. Frondibus bipinnatis. = Billardieri (Aspidium sinuatum, Labill., Sertum ausiral.*). 


\section{MACROCALPON.}

\section{SPECIES NONDUM DESCRIPTE.}

Frondibus simplicibus, ovalo-ellipticis, utrinque acutis, margine repandis; apice scepè viviparis; siccilate fusco-olivaceis, pellucidis, petiolo nudo; mesonevro flexuoso; nervillis lateralibus undulatis, subhorizontalibus; areolis irregularibus, latiusculis; rhizonate crasso, lignoso; sporotheciis crassis, rolundis, indusio amplo; sporangiis crassissimis, rolundis; annulo spisso, 12-13 articulato, septis sulfureo colore; sporis ovalibus, latè el irregulatim episporiatis.

Habitat in Guyanâ gallicâ. (Caỷenne, Poiteau.)

Filix glabra, translucida, olivacer, crassitudine sporolheciorum notata.

(Dimensions : 53 eentim. de longucur totale sur 9 eentim. de largeur; le pétiole atteint 23 centim.)

Nous connaissons cette plante à l'état gymnosore (stalu polypodino) et nous la rattachons alt Polyp. plantagineum de Jacquin, figuré par cet anteur et par Plumier.

\section{Sinuatuy.}

Frondibus ovoideo-lanceolntis, luridis, simuato-lmudulatis, apice subaculis, viviparis, basi decurrentibus, sinubus latis, obtusis; nervis lateralibns flexuosis, suboppositis; sporotheciis biserialibus; indusio delapso sen abortivo; sporangiis orbiculuribus, crassis; annulo amplo, pedicello lato.

Habilat in Gujanâ. (Leprieur.) V. S. in Herb. Moug.

Affinis cum B. plantagineo, sed margine undulato-sinuato, sublobato, repando el lenulis crassioribus.

(Frondes : $35-45$ centim. de longucur; stipe 10-14; la plus grande largeur est de 6- 7 ; intervalle des nerrures secondaires, 15 à 20 millim. Chaque lobe ou sinus correspond ì une wervure secondairc. (Déerite sur plusieurs spécimens.)

La consistanee, la couleur, la forme générale sont les mèmes; mais la marge est ici ondulúce, sinueuse dans tons les spéeimens que nous avous vus, et eette cireonstanec, qui ne peul ètre regardéc eornme accidentelle, est organique.

\section{EBexeun.}

Frondibus ternatis, frondulis lateralibus dintdiatis, sessilibus, extùs pinnatifudis, terninali majore pinnatifidâ; segmen tis undulatis, obtusiusculis; stipite et rachi adiantinis, lcevibus, nitentibus; nervillis lateralibus rufescentibus, pubescentibus; venulis crassis, areolis minutis; sporolheciis crassis, remotis, indusio rufidulo; sporangiis et sporis ul suprà.

Habitat in insulâ Madagascariensi (Nos-Beh), nec non in insuli Borbonia.

Filix anpla, formosa, siccitate rufescens; stipitibus, rachibus et busi mesoneviorum adiuntinis, lucentibus.

(Dimensions : longueur totale 70 centim. sur 20 d'entergure. Le pétiole est aussi lougg que la fronde. Le segment terminal et les segments latéraux ont plus de 20 centim. de hauteur.) 
Cette espèce se rapproche du $\boldsymbol{B}$. trifoliatum par la disposition de la fronde; mais clle en diffère par la nervation, la couleur du stipe et celle du rachis.

Nous possédons une espèce de Bathmium cultivée dans les jardins botaniques de Belgique, ì laquellc l'épithète de villosum serait très-convenablement appliquẻe; clle est sinuée, créneléc vers le haut des segments et couverte de poils grisâtres.

\section{Considérations générales sur le groupe des Cyclodiées.}

Les genres que renferme ce groupe ont un port assez différent et aucun ne présente une physionomie qui ne puisse se retrouver ailleurs, à la seule exception peut-être du genre Polystichum, dont les nervures sont prolongées en une pointe raide presque spinescente. Ajoutons que le Bathmium se rapproche beaucoup des cardiochlocna, et que le Podopeltis n'est pas sans rapport avec les microsorium, du moins quant à la nervation.

Nous indiquons parmi les cyclodiées, pour prendre place entre le Polysltchum et l'Hemicardion, un genre que nous n'osons pas constituer définitivernent, la description que nous donnons de l'espèce type, la seule que nous connaissions, le fera suffisamment connaitre à titre provisoire.

\section{PELTOCHL.ENA NEPHRODIFORMIS.}

Frondibus pinnatis; stipite longo, trisulcato, squamuloso; frondulis sessilibus, lanceolato-linearibus, apice obtusiusculis, basi truncatis, marginibus crenatis, crenis incequalibus; mesonevro suprà canaliculato, marğine lineari, subcristato; nervillis pinnatis, liberis, abbreviatis; sporotheciis dorsalibus, supernè impressis, rotundis; indusio crasso, orbiculari, undulato, centro affixo, pedicello rigido, longiusculo, sporangiis subglobosis; annulo crassissimo, 9-10 articulato; sporis ellipticis, fuscis.

Habitat in Guyanâ Gallicâ. (Leprieur, 1810 ; Herb. elar. Houg.)

Filix elatu, pinnata, facie Neplurodii.

(Dimensions : longucur totale 90 centim.; du stipe, 50 centin.; 24 frondules environ, inesulint 12 - 14 ccutim. sur 15 millim. de largeur; 40 crénulation; 24 paires de frondules; cutrenœuds distants. de 2:-25 millim. Les nervilles n'altcignent pas la marge, et presque toutes sont lertiles.)

Celte fougère s'ćloigne tont à fait des Polystichum par lc port et de l'llemicardium par la nerrat(iinir et la forme des frondules. 
2. Indusinn! reniforme, sublieniispharicullı aut cordalum.

B. Sinu affixum: ASPIDIEAE.

Aspidiace.e, Presl, Tent. pterid., p. 70.

Aspidiearum pars, Gaud., Voy. de l'Uranie, p. 261.

Vilices multiformes, cosmopolitanæ, flexibiles, sæpè teneræ, decompositæ.

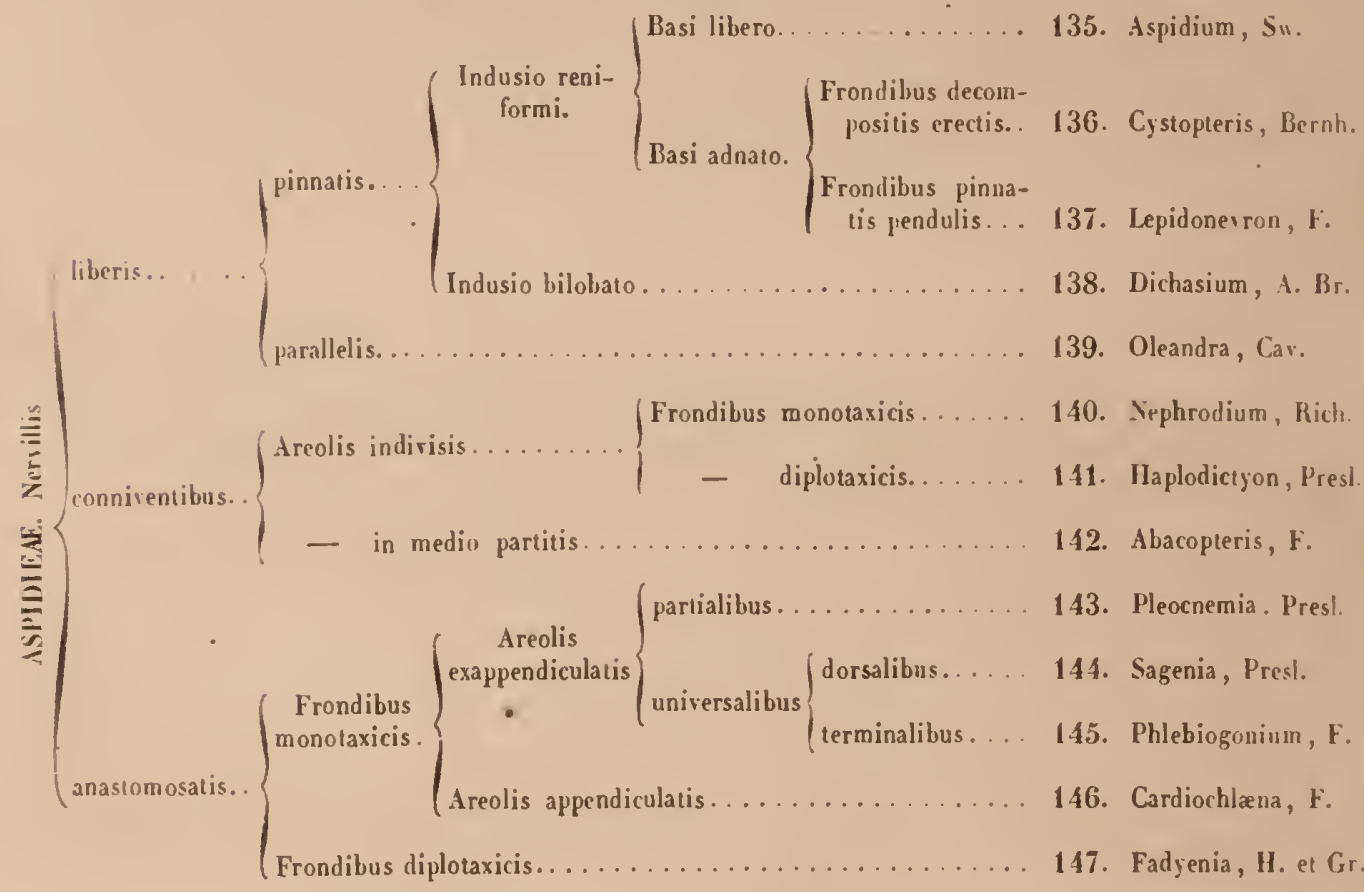

Genera ulteriùs judicanda cum aspidio affiniu.

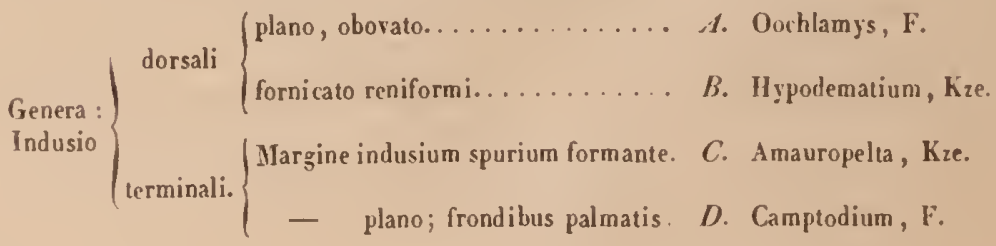




\section{* Nervillis liberis.}

A. Pinnatis.

135. ASPIDIUM, Sw. (1806), emendatum.

Syn. filic., P. 51.

Lastrea, Prest, Tent., p. 72. - Dryopteris Anaxs, Scнotr. - Polypodii, Polystichi, Thelipteridis, Neplrodii spec., Accr. var.

SPoRотнеси rolundis, nervillaribus, dorsalibus, rarissimè apicilaribus; indusio plano; sporangiis rolundis, ovoideis; annulo non elastico flexuram servante, mulliarticulalo aliquandoque complelo, arliculis 18-30; sporis subrolundis, ovoideis seu obscurè reniformibus; indusio reniformi, glabro seu hirsulo, sinu adharente.

Froxnıbs pinnalo-pinnatifidis, bi seu tripinnalis; nec pedalis, nec pinnalifidis; nervillis liberis.

Fïlices magne, decomposite, erecte, sı̈pè glabriusculce, cosmopolitance, terrestres.

Diagnosis: Ноок., Gen. filic., t. xur, A. - A. Filix mas, Sw.

Affine Phegopteridi, sed sporotheciis indusintis; Nephrodio, sed nervillis liberis. Inter. Amauropeltam et Aspidium cix differentir tantum exstat. Sporothecia marginalir suut in Amauropeltâ ut apud Aspidtum marginale et terminalia ut in pluribus speciebus aspidiorum. Non vidimus dıo indusia sed ınuın. Indusium spurium a Kunzeo admissum, nobis marginem rejlexum videtur.

Ce genre est extrêmement vaste et d'une diagnose en général facile, en ce qui concerne le genre; il n'en est pas de mẻme des espèces. Ce sont de grandes fougères herbacées presque toutes bi- ou tripinnées, ayant le port des phegopteris. Les sporothèces occupent le trajet moyen des nervilles ou plus rarement leur sommet. Les indusium cordiformes offrent une échancrure plus ou moins marquée. Ils s'attachent au sommet du sinus par un point plus ou moins élargi, et c'est sur ce point, qui sert de réceptacle, que les sporanges se développent. L'indusium est très-large dans l' $A$. fraggans, très-étroit au contraire dans l'A. cauldalum et dans l' $A$. noveboracense, nince et fragile dans le plus grand nombre des espèces, épais et noirâtre dans les $A$. melanochlanıs et melanoslictum, et presque orbiculaire dans l'A. cyclochlariys.

\section{ENUMERTTIO SPECIFRLH.}

1. CACC.1SICE. = Thelipteris, Sw. (Schkh.*, Fl. Dan.*, IIoriss. . etc.) - Filix mas, Siw. (Schkh.*, Blach.*, Bolt. , etc.) - afine, F. et Mer. - fragrans, Sw. (Tephrodium, H. et Gr.*; - cristatum, Sw. (Schkh.*, Afzel.*) - rigidum, Sw. (Schkh.*) - remotum, A. Braun - pallidum (Nephrodium, Boı**, Cracia) - spinulosum, Sw. Schkh.*, Fl. Jlan.*, Pluk.*, clc.) - dilatatum, Sw. (Schkh.*. Boli.*, Pluk.*, ctc.). 
2. INDICA. = Ferrugineum, F. - trichotomum, F. - paradoxum, F. - Zeylanicum, F. macrochlamys, F. - Malaccense (Lastrea, Presl). - impressum, F.

3. YOKA-HOLLANDICE. = decompositum, Kze. - hispidum, Sehhh.*

4. PIILIPPINENSES. = Verrucosum, Presl) - prolongum, F. - speciabile (Lastrea, J. Sn.) - Philippinum (Lastren, Presl) - propinquum (Lastren, J. Sm.) - membranaceum (Lastren, J.Sm.).

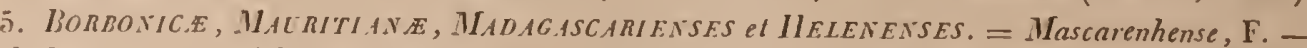
yclochlamys, F. - Madngascariense, F. - oppositum, Kllss. - Boryanum, Willd. - grande, F. - leucopis (Lastrea, Presl, Cuming. 11.0 114) - cognatum (Lastrea, Presl, Sancta-IIlelena) Tapoleonis (Lastren, Presl, Sancia-Helena).

6. CARTises. = Triste, Kze. - Iregei (A. Thelipteris, Kze. non Sw.) - incequale, Sehlecht. - catopterum, Kze. - athamanticum, Kze.

i. CANARIENSES. = Fonisecii, Lowe - elongatum, Sw.

8. C.1RIBAE.E. = Pennigerum, Sw., Hispamiola (Schkh.*) - conspersum, Schrad., Ilispaniola, Cuba - deltoideum, Sw. - sanctoides, F. - confuens, F. - patens, Willd., Ilispaniola, Cube (Shhh.*, Sloan.*) - imcisum, Sw. (Schhh.*, Sloan.*, Plum.*) - tenuiculum, F. - cicutarium, sw., Gundel. et Cuba (Pluk.*) - consobrinum, Bory, Guadel. - pubescens, Sw. - Tussaci, F. Ilispanioln. - Srrengelii, KIIss. - melanochlamys, F., Cuba - villosum, Sw. Petiv.*. Plum.* sloan.*) - formosum, F. (Pelir.*, Plum.*, Sloan.*) - angescens, Lk. (Petir.*, Plum.*, Slonn.*, Kz.c.*)

9. GUTANENSES. = Ciculurium, Sw. (Pluk.*).

10. BR,ASILIENSES. = Conspersum, Selirad. - Kaulfusii, Lk. - falciculntum, Radd. - "abbreviatum, Sehrad. - expansum, Mart. - cicutarium, Sw.

11. Collmblane el MEXICANA. = Crimitum, Mart. el Gal. - formosum, F. - melanostictum, Kze. - exlensum, F. - nemophy.llum, Kze., Caracas - radicans, F., Caracas - augescens, Lk., Venezuela.

12. BoREALI-AMERICANE. = Noveboracense, Sw. (Sehkh.*) - narginale, Sw. - Goldiamum, llook.* - internedium, Willd. - Lancastriense, Sw. (Schkh.*).

\section{SPECIES NONDLII DESCRIPTE.}

\section{Texiceluni.}

\section{Frondibus piNinato-pixisatifidis.}

Frondibus pinnato-pinuatifidis, lanceolutis, glubris; pinuulis lanceolatis, sessilibus, suboppositis, multipartitis, pectinatis, in acumen longum serralum terminatis; segmentis linearibus, obtusis; nervillis simplicibus, omnibus proliferis; sporotheciis dorsalibus, sed margine approximatis, parvis; indusio reniformi; sporangiis parvulis, brevè pedicellatis; aunulo crasso, 14 articulato; sporis magnis, lavibus, ovoideis.

Habitat in Cubâ $P$ Linden, n. 2.

Filix formosa, elata, plana, segmentis tenuiculis el nervillis simplicibus notata.

(Dimensions : longucur de la fronde seule 75 eentin.; des plus grandes pinnules $18-20$ centin. sur 24-28 millim. de largeur. Nous comptons plus de 30 pinnules presque horizontales, el chaeune d'elles est partagée en 40 segments environ, ouverls ì angle droil, très-ininees, à nervilles simples, tontes fructifères, it l'exception des 2 on 3 dernières; il y a 13-14 paires de sporothcees fort petils.)

\section{SiNctoines.}

Frondibus pinnato-pinnatifidis, lineari-lanceolatis, pilosis, pinnulis lanceolutis, superioribus condunalis et inferioribus sensinu brevioribus, subopposilis, acuminatis 
ommibus sessilibus, rigidis, subdecussatis; sporotheciis dorsalibus, fulvis; indusio reniformi, glabro; sporangiis subglobosis; annulo crasso, 13-14 articulato; sporis ovoideis, lavibus, fuscis.

Habilat in Guadalupâ ad montem Soufrière. (Duchessaing, 1851; Herb. cl. Mougeot, sub Polypodio sancto.)

Filix rigida, lanceolata, phegopteridis facie.

Dimensions : longueur totale de la fronde $40 \mathrm{centim.;}$ une quarantaine de pinnules lancéolées, linćaires, ayant à peine 6 millim. de largeur; rappelle, par le port, le Phegopteris sancta, et c'est pour consacrer cette ressemblance que nous avons imposé à celte fougère le nom spécifique sanctoides.)

\section{Coxfluevs.}

Frondibus pinnato-pinnalifidis, lineari-lanceolatis, lirtis, pilis cinereo-albidulis; pinnulis lanceolatis, sessilibus, suboppositis, acutis, siccilate margine integro, revoluto, superioribus inferioribusque sensim brevioribus, ultinis remotioribus, omnibus excurvatis; sporolheciis confluentia dorsalibus; indusio reniformi, subfimbriato, caduco; sporangiis subglobosis; annulo crasso, 13-14 articulato; sporis magnis, ovoideis, vilteis.

Habilat in Americî australi. (Collect. Pamplin, n. ${ }^{\circ} \mathbf{7 5}$, sub Nothochlonâ, Herb. Moug.)

Filix rigida, angusta, pinnulis brevibus exterius curvatis.

(Dimensions : Jongueur de la fronde 45 centim. sur 6 centim. d'envergure; les pinnules, au nombre de 30 à la base, ont un centim. environ de largeur. Sc rapproche de l' $A$. sanctoides, avec lequel toutefois il est impossible de le confondre.)

\section{Ferrugineum.}

Flondibus pinnalo-pinnatifidis, lanceolatis, rachi rufo-hirto, adiantino, aterrimo, lucente; pinnulis sessilibus, lanceolatis, acutis, basi oppositis, segmentis oblusissinis, pilosis, pilis intestiniformibus; sporotheciis rotundis, terninalibus, satis magnis; indusio basi cordalo, crasso plicatoque; sporangiis rotundis, pedicello longissimo munitis, sacculo parvulo; aunulo lato, 12-13 articulato; sporis rotundis, crassis.

Habilat in Indiis orientalibus. (Griffith.)

Filix staturâ mediocri, pilis intestiniformibus et stipite adicntino aterrimo nolata.

Dimensions : longucur totale 40 centim.; une dizaine de pinnules ayant en longueur $\mathbf{7}$ centin. su 16 - 18 millim. de largeur.)

\section{Paradoxum.}

Frondibus pinnatis, subtriangularibus, basi bipinnatis; stipite, rachibus el mesoneviis hirsulis; pinnulis scepè bifidis, duabus ultimis pendulis, longis, stipite pacallelis; uervillis lenuibus; venula bifurcatâ, è mesonevro orlä, in sinubus omnibus; segmentis obtusis, iutegris, apice tantum fertilibus; sporotheciis marginalibus, ter- 
minalibus, paucis, nigrescentibus; indusio cordato, siccilate crispato; sporangiis ellipsoideis, sporis ovatis.

Habital in insula Zeylanicá. (Gardner, n. 52.)

Filix lenera, membranacea, pinnulis sapè bifidis el dubus infinis pendulis, stipiti parallelis, nervillis solitoriis in sinu evolutis notata.

(Dimensions Jongucur de la fronde 35 centim.; des divisions inférieures 16 centim. : les deux pimules inférieures pendantes, mesurent 12 centim. sur 3 centin. de largeur. On trouve an-dessous du sinus, formé par les segments, une uerville bifurquée, à rameaux arqués, naissant attachice au mésonère de la pinnule et en delors du système de la nervation des segments.)

II. R.sDIC sis.

\section{B1- tRIPINNato-PINNatifidis.}

Frondibus bipinnato-pinnatificlis, in ambitu ovatis, supernè radicantibus, stipite et rachibus depressis, glabris, pinnulis lanceolatis, acuminatis, basi pinnatis, in medio sessili-decurrentibus; apice pinnatifulis; pinnellis ovatis, acutis, segmentis dentalis; nervillis simplicibus; sporotheciis dorsalibus, indusio vix cordato, spisso, fusco-rubro; sporangiis orbicularibus, pedicello 1-2 sporangiastra clavata ferente; annulo 14-15 articulato; sporis ovoideis.

Habitat in Caracas. (Linden, sine numero ex Herbario Lessertiano.)

(Dimensions: longueur totale de la fionde 45 centim. el probablement plus; pinnules inlëtieures 20 centim. sur 8 d'envergure ì la base. Nous en comptons 12 à 13 paires jusqu'au point wi elles se réunissent pour former une pointe pinnatifide; elles sont séparées par un entre-noend de $\mathbf{T}$ centim. vers le bas de la fronde.)

\section{Melaxochlamis.}

Frondibus bipinnato-pinnatifidis, stipite et rachi paleaceis; squamis linearibus, longissimis, attenuatis, fulvescentibus; pinnis remotis, flexuosis, livoricatis; pinnis angustis usque ad costan divisis; sporotheciis subapicilaribus, rotundis, approximutis; indusiis planis, crassis, cordiformibus, subimbricatis, margine pellucido, basi spisso aduatis, ad centrum atro-fuscis, in ambitu rufescentibus; sporaugiis ovoideis; annulo 15-16 arliculato; sporis ovoideis.

Habitat in Cuba (Suntiago, al nontem Liban. [Linden, n. 1865.])

Filix squamosa, distinctissima, partitionibus onnibus remotis, indusio centro niguescente, in ambitu rufescente notata.

(Dimensions : longueur totale, 75 centim.; 15 paires de pinnules ayant environ 15 centim.; ('lles sont écartécs, ì rachis grêle et portent des pinnelles distantes, à segments presque entièrement courerts par 3-4 paires de sporothèees, dont les indusium sont presque imbriqués; elle ue déprassent pals 1 centim. de largeur, sur 5-6 millim. d'envergure. La plante est grêle, mais très-prolifère.)

\section{Extexsen.}

Froudibus tripinnatis, amplis, ovatis; stipite fusco et rachibus helveolis, Icrvibus, squamulosis; pinnis sessilibus, ovato-lanceolatis, apice pinnatifidis; pinnellis lanceolutis, 
acutis, segmentis elongatis, dentatis, obtusissimis; nervillis tenuibus; sporotheciis dorsalibus, rotundis; indusio vix cordato, spisso, puncto atro, centrali notato; sporangiis lenticulariformibus; pedicello pilos breves duos ferente; annulo angusto, $16-18$ articulato; sporis ovoideis, papillatis.

Habitat in Mexico. (Linden, $\mathrm{n}^{\circ}$ 6457.)

Filix expansa, tenera, flexibilis; sporotheciis $A$. melanochlamydis, sed fronde diver. sissima.

(Dimensions : longueur totale, 1 mètre, sur 50 centim. d'envergure à la base; pinnelles, 8 centim., sur 25 mill. de largeur. Nous comptons 15 paires de pinumles jusqu'au point où la fronde devient pinnatifide.)

\section{Macrochlamys.}

Frondibus tripinnatis, ovatis, ruchi squamoso, helveolo; pinnis lanceolatis; segmentis omnibus inucronatis, ovatis, supernè auriculatis, pellucidis, glabris; sporotheciis terminalibus; indusio membranaceo, amplo, cordiformi, siccilate rufidulo; sporangiis ...., sporis rotundis.

Habilat in insula Zeylanicâ. (Colonel Walker.)

Filix ampla, tenera, habilu polystichi.

(Dimensions de la fronde : longueur totale, 40 centim.; des principales divisions, ouvrant un angle de $45^{\circ}$ avec le rachis, 20-22 centim.; les derniers segments mesurent de $11-13$ millim., sur 3 à 4 mill. de largeur.)

\section{d. Grajde.}

Frondibus tripinnatis; stipite fusco, nitido, crassitudine digiti minoris; rachibus tenuibus, helveolis; pinnis longis, lanceolato-ovatis; pinnulis basi pinnatis, sogmentis ellipsoideis, dentatis, remotis, obtusissimis crassisque; sporotheciis dorsalibus, 4-5 paribus; indusio cordiformi, spisso, glabro; sporangiis ovatis; annulo 13-14 articulato; sporis brevè ovatis.

Habitat in insulâ Borboniâ. (De Montbrison.)

Filix gigantea, robusta, firma, pirnis remotiusculis.

Dimensions : s'élcre au moins à la hauteur du Pleris aquilina d'Europe.)

\section{Trichotonum.}

Frondibus triternatis, tripinnatis; stipite et rachibus fuscis, glaberrimis, sulcatis; pinnulis sessilibus, lanceolatis, supernè coalitis, acutis, glabris, segmentis oblusissimis; nervillis pinnatis, tenuibus, apice fructiferis; fasciculis vasorum in stipite multis, duobus majoribus; sporotheciis rotundis, apicilaribus; indusio cordato, spisso, persistente; sporangïs subrolundo-obliquis, latè pedicellatis; annulo latissimo, 13-14 articulato; sporis ovatis.

Habitat in Cochinchinâ. (Tourane, Gaudichaud.)

Filix insignis, distinctissima. (Kunz. in litteris.) 
(Dimensions : longueur de la fronde. 40 eentim., sur un dércloppement en largeur presque égal. Les divisions inférieures primaires ont environ 24 centim. La plante est diviséc à la lase en trois branches opposées; la centrale se continue en se trifurquant encore une fois; les latérales se subdiviseut cu trois parties également trifurquées vers la partie supéricurc.)

\section{Formosum.}

Frondibus triangularibus, quadrinunuatis; segmentis angnstis, oblusè dentatis; stipite lougo, glabro, helveolo, sulcalo, basi squanas fulvas, longas, upice tortili ferente; sporotheciis crassis, ovatis; indusiis magnis, subcordiformibus, fulvis, sinu contracto ruluatis; sporangiis longè pedicellatis, ellipticis; aunulo crassissimo, obliquo, 13-15 atticulato; sporis ovatis.

Habitat in Cubâ. (J. Linden, 2115.) Yavesia el Pellapa Mexicanorum. (Linden. n. ${ }^{\text {os }} 6563$ et 6473.$)$

Fïlix elegaus : aspcctu polystichorun froude dissecta; indusio fulvo, lavi, maguo, supid̀ segurenta ungusta sedente.

(Dintensions : longueur totale, 75 eentim. et plus, sur $24-28$ eentim. d'enrergurc; Ic stipe est it la fiondc :: $3: 2$. Les grandes partitions sont remarquables par lcurs rachis filiformes; les derniers segments sout étroits, allongés et glabres. Les indusium out un assez grand dćveloppement. Le spéeimen de Cuba est plus petit et les indusium ont une conleur fauve brunàtrc dans le spécimen mexieain.)

Les espèces suivantes nous paraissent aussi devoir prendre place dans les species.

1. Mascarenhexse: Frondibus pinnalo-pinuatifidis, stipile el rachi sublonentosis frondulis sessilibus, lanceolatis, aculis, basi truncatis, crenatis; mesonevro el nervillis hirtis; ihizomate repente, sulcato; sporotheciis terminalibns, rnfis. (Insulî Borbonici, Dc Montbrison.)

(45 centim. de longueur sur 11-12 d'envergure.)

2. Madagascariense: Fiondibus pinuato-pinnatifidis, tachi sulcato, helveolo, pubescente; frondulis sessilibus, pinnatifidis, ad apiceut tantun frucliferis, segmentis monocatpicis; thizounate repente; sporotheriis crassis, terminalibus, latè fulvescentibus. (In insulâ Madagascariensi crescens.) Staturî A. mascarenheusis suprà descriptu.

3. Cyclochlasys : Fiondibus pinnato-pinnatifidis, multifrondulosis; rachi sulcato, mefidulo; frondulis piunatifidis, lanceolalis, patentibns; segnentis 10-11; sporolhecin biserialia ferentibus; sporotheciis parvulis; indusio ferè orbiculato. (İ insulti Botboniâ, De Montbrison.) Facie A. conspersi; altitud. 80 centint., latitud. 2 1 ceutulu.

1.' Inpressum : Frondibus piunato-pinnatifulis, rigidis; rachi el mesonevris cinereo-tomentosis; pinnulis suboppositis, lanceolatis, acnuninalis, horizonlalibus, feracissinis, ultimis deflexis; sporotheciis crassis, approximatis, suprà impressis; indusiis cordutis, hirsulis. (In insulâ Zeylanicâ; Gardner, n. ${ }^{\circ}$ 49.)

(Longueur totale, 60 eentim., sur 18 centim. d'envergure; les pinuulcs, assez rapproclices, ont 15-17 millim. de largeur.) 
5. Zey laniclu: Frondibus bipinnatis, amplis, mollibus; stipite et rachibus squamulosis; segmentis margine repandis; sporotheciis dorsalibus; sporangïs laxè unitis. (In insulci Zeylanicâ; Gardner, n. 61.)

Espece assez rapprochée par le port des Allantodia (Athyrium) de Ténériffe.

6. ${ }^{\circ}$ Tussacı : Frondibus tripinnatis; stipite et rachibus passim squanosis, squamis umplis, tanceolatis, pinnis sessilibus; ultimis segmentis apice tantùm dentatis; sporothecuils dorsulibus. (Species magna, fucie Aspidii dilatati Europa. Sancto Domingo, De Tussac.)

Les petits groupes suivants sont des modifications de l'Aspidium. Les botanistes auront plus tard à statuer sur leur valeur générique.

\section{A. OOCHLAMYS, F.}

SРовотнеспs submarginalibus, rolundis; indusiis oboralis, basi obluso allenualis, super nervillam incrassalam sedentibus, in ambilu solulis; sporangïs subrotundis; annulo crassissimo, 14-16 articulato; sporis magnis, reniformibus.

Froxulbes aspidiorum pinnatorum.

Filix Martinicensis, pinnato-pinnatifida; pinnulis hasi decrescentibus, oppositis, rigidis, glabris; stipitibus helveolis, pubescentibus.

O. Rivorrer, F.

Celte jolie fougère, à laquelle nous donnons le nom de MI. ${ }^{\text {He }}$ Rivoire, qui l'a réeoltée à la llartinique, est assez délicate et remarquable par ses frondes décroissantes du centre au sommet el du centre ì la base; elle se termine en une longue pointe; ses pinnules sont opposées et sessiles; elle rappelle le port de l'Aspidium Thelipteris.

\section{B. HYPODENATIUN, Kze. (1837).}

Analecta pteridogr., P. 45.

Nepltrodii spec., Don, Decass.. Pl. Aral. Heur., p. 18.5.

Lastrece spec., Prest.

Aspillii spec., WalL.

Sporothecls ovoideis, semper dislinclis; receplaculo puncliformi; indusiis basi receptaculiadnatis, reniformibus, fornicatis, scariosis, villosis, in medio sulcatodepressis, persistentibus; sporangiis rotundatis; annulo 15-14 articulato; sporis nirrescentibus, magnis, ovoideis.

Froxpıвs decompositis; segmentis ultimis rotundis, dentatis; nervillis pirnati., in medio proliferis.

Filices magna, Abyssinice et Indica, nec non in Graciâ inhabihntes.

Diagnosis : H. onustum, KzE., l. cil., tal,. xxvill.

L'indusium est d'une nature un peu différente de celle de l'aspidium; mais le port est absolument le même. On ne peut conserver ce petit groupe comme 
genre, et une circonstance se présente qui justifie celte opinion. Sur trois espèces 1' Mypodenalium l'une est indienne, lautre abyssinienne et la dernière grecque. Que des genres aussi vastes que l'Aspidimm, le Pteris, l'Asplcnimm ou le Polypodimm soient cosmopolites, on le comprend, mais qu'un seul genre occupe des latitudes aussi differentes, semble un fait tout i fait improbable.

\section{EIUNERATIO SPECIERUN.}

1)nustum, hzc.* (Asfidium ericarfon, Wall. - Ruprellianum, Kze.* (Schimper. Pl. Mb.ss., 11. 358) - nisale (Asprilium nisale, Bory, Ti!ngetus).

\section{AMALROPELTA, K\%e. (1840).}

Die Farrenkr., p. 86 et 109 .

SPokUtuecus lermimalibus el marginalibus, orbicularibus, planis: indusio busi subcurdalo-reniforme, coriuceo, rmoruloso, in ambilu solulo; sporangiis oralis; unnulo crassissimo, 14 articuluto; slomale angruslo; sporis reniformibus, nudis, episporiulis conformilurs.

FRoxDrbes pinnalo-pinnalifidis; pinnis sessilibus, ullimis segmenlis subpinnalis, longissime allenualis; nervillis pinnalis, laleralibus simplicibus el furcalis; margine prolifero, subcremaio-revolulo.

Filix magna, Antilluma, habiu Aspidiornun; glumdulis rolundis, anereis conspersu:

Diagnosis: Kuxze, loc. cit., t. L.. (A. Brentelii, ejustl., p. 109.)

Amurropelta genus est indusio simplici umenitum; margo laminarum subcrentus, parlim abscondit sporothecia, sed servat semper et aspectum el uaturam proprian. triffert ab aspidio, indusiorum forma et situ.

\section{CAMPTODIUM, F.}

Aspidium pedatum, Desv., I'rodr. in Mém. soc. Linn. de Paris, v, p. 244; Kunz., Die Farrenkr., p. 179, t. Lxiv.

SPOROTHECIS ad apicem nervilla sedenlibus; indusio lalo, adnalo, reniformi, simum tolum occupante, in ambihu solulo; sporangiis ocalis; sporis triedricis (ex Kunzeo).

lRoxdibes pedalis, corruceis, glabris, basi cordalis; segmentis lateralibus, ascendentibus, falcalis, oblusis, lobo terminali rhomboideo, pinnalifido; slipile flexuoso, cbeneo; rhizomate valido, radicoso.

Habital in Santo Domingo (De russac) [in Herb. nostr.]; in Janaica (W edel.); in insulâ Bolıou (Viti), Gaudichaud (in Ilerb. nustr.).

\section{Pedatci, F.}

Cette fougère sélère à 18 cenlim. de hauteur (Viti) el à 14 centim. (Guadelonpe). Elle est alljondlhui parfaitement connue, tres-exactement decrite. "t tress-hien figure par .1. Kunze (l. cit.). 


\section{CYSTOPTERIS, Bernh. (1806.)}

In Schrad. R. Journ. 1806 , p. 49, เ. II, fig. 7 .

Cystea, Sмiтн, Engl. bot.

Polypodii spec., L. - Allyytii spec., Rúth., Prest. - Aspidii spec., Аuct. plurim. Hymenocystis, A. MeYER.

Sровотнесп dorsalibus, puncliformibus, in serie simplici disposilis; receplaculo 'ix ullo; indusio fornicalo, laceralo, strialo, tenuissimo, flaccido, basi rolundo affixo; sporangis paucis, subrolundis; annulo 14-16 arliculato; sporis ovalibus (in C. fragili muricatis).

Froxdics bi-tripinnalis decompositisque; segmentis aculis, tenerrimis, facite marcescentibus; nervillis tenuibus, furcatis.

Fïlices cosmopotitance, in humidis crescentes, erecta; facie Aspidiorum sed teneriores.

Diagnosis : Scнотт, Gen. filic. (optimn) [typus], Fasc. 11, l. ॥I; Hoor. et B., l. cit, 1. LII, B (typus); C. frugilis, BerNh.

Le port de ces plantes est absolument le même que celui des aspidium à frondes décomposées; cependant la consistance a plus de délicatesse. Ce n'est donc pas dans les organes de la nutrition quil faut chercher les différences qui séparent les cystopteris de ces plantes, mais bien dans les sporothèces dont l'indusium n'est ni cordiforme ni attaché au sommet du sinus, ni libre dans son pourtour. Ce tégument protecteur dans les cystopteris est déchiré antérieurement, quelquefois linguliforne et fixé à la hase qui est élargie. C'est là que s'attachent les sporanges, et celles-ci le soulèvent dins toute son étendue à la seule exceprtion du point d'attache. L'organisation anatonique de lindusium du c;slopteris se trouve parfaitement indiquée par M. Schott (pl. citée). Il est formé de cellules allongées, parallèles, formant des rangées inégales qui lui donnent, vu à la loupe, une apparence déchiquetée, même quand il est dans toute son intégrité.

Le Cystopteris differe du Davallia par le port, et plus essentiellement par un indusium superficiel, libre dans sa plus grande étendue, sommet et cótés compris.

Ces fougères se plaisent dans les lieux lıumides des forèts ombragées.

\section{ENUMERATIO SPECIERUII.}

Dentata, J. Sm. (Polypod., Dichs.*); var. Pontederce (Polypod., Scguier*) - Rhatica (Aspidium, Siv., Schkh.*) - bulbifera, Bcrnh. (Schklı.*, Pluk.*, Moriss.*, elc.) - Caucasica (Ilymenocystis, C. Mey) - funarioides, Scholl - acuta, F. (Ispid. fragite, Mart. et Gal., nou Sw.) - fragilis, Bernh. (Schkh.*, Scholl, Ilook ct Baue**): var. Abyssimica, Azorica, Chilensis, Mexicana - regia (Cystea, Sm.) - montana, Lk. (Schkh.*, Jacr.*) - rufescens, F. - bresinersis, F. - tenuis, Scholl - villosa, F. - afinis (Leucostegia, J. Sur.). 


\section{BRETNERTIS.}

\section{SPECIES NONDUM DESCRIPTE.}

Frondibus tripinnatis, fasciculatis, in umbitu lunceolutis; pattitionibus distuntibns; stiputibus et rachibns filifornibus, rillosis; pinnulis in ambitu subtriangularibus; pinnellis ovatis, segmentis pellucidis, ovoideis; nervillis à margine remotis; sporotheciis depauperatis, terminalibus subterminalibusque; indusio parvulo; sporangiis et sporis ul suprà.

Habitul in Cubâ? (Linden, n. 1876. )

Filix tenerrina, pellucida, flexibilis.

11. Ric FesCENS.

Frondibus tripinnatis, in anbitu ovalibns; stipitibus flexuosis, flifornibus, squanosis, squunis rufescentibus ad basim stipitis homonallis, dein sparsis; rachibus pilosis; pilis strigillosis, brevibus; pinnulis oblongis, basi pinnalifdis; segnentis ovalis, pellucidis; sporotheciis terminalibus, rufescentibus, depauperatis; indusio rufescente, purvulo; sporangiis lenticularifornibus; anmulo luto, 14-15 articnlato; sporis ovoideis.

Habitat in Cubci. (Linden, n. ${ }^{\circ} 187 i$.)

Fillix venusta, pellucida, ad rachides squunosa villosaque; sutucî́ mediocri.

(Dimensions : longueur tolale, 18 -20 centim. Les pinnules de la base, 4 eentim.; la pinnelle inficience est plus grande que les autres.)

\section{ACETA.}

Frondibus tripinnutis, glaberrimis, in umbitu lanceolatis; partitionibus approximutis, acutis, rigidulis, segmentis ultunis crenutis; sporotheciis ovatis, dorsalibus; indusiis anulis, cancellatis, segmenta fertilic excedentibus; frondibus sterilibus latioribus; sporangiis unagnis; annulo lato, 16-18 articulato; sporis ovoideis.

Habilut in Mexico. (Pic d'Orizaba, Galeolti, n. ${ }^{\circ}$ 6260.)

Aspidium fragile, Mart. el Gal., Fil. Mex., p. 67.

L'Aspidium fragile des hesbiers, Sw., réunit, suivant nous, plusicurs espèces distinetes, mème pour les spécimens curopéens, et il serail intéressant de les ćtudier arec soin. C'est ainsi : $1 .{ }^{\circ}$ que 1'. 1. fragile, var. fumarioides de MII. Martens el Galeotti (Fil. mexic., n. ${ }^{\circ} 6259$ ) serait reconnu pour une espèce différente du C. fumarioides de M. Presl, el pourrait ètre nommé mexicuna." 2. que le C. fracilis (Filic. ined. du Chili) deviendrail un C. chilense? $3 .^{\circ}$ celui d'Alyssinic (Schimper, n." 123i), un C. Abyssinica? 4. celui de Fạal aux Aęores (Collect., C. Hoehsielter). un C. Azorica? ele. 


\section{LEPIDONEVRON, F.}

Vepholepidis spec., Auct. recentior. - Nephrodii, Aspidii, etc., spec., Аuct. plukim. SроRотнесиs ad apicem nervillarum sitis; indusio spisso, orbiculato, cordato, reniformi; sinu subcentrali affixo, in ambitu ferè libero, maturitate supernè plicato; receptaculo crasso, gibboso, duro; sporangiis mediocribus; annulo 12 13 ariculato; stomio lato, sub 7-nervato; nervillis remotis; sporis reniformibus. Froxdibes pinnatis, elongatis, pinnis lanceolatis, ferè semper acutis, rarò supernè auriculatis; nervillis pinnatis, creberrimis, tenuibus, deorsìm flabellatis, marginem non attingentibus, apice turgidis; stipitibus arliculatis? fasciculis vasorum in numero variabile; apud L. longifolium septem : tribus majoribus, uno superiori et duobus lateralibus, quatuor intermediis minoribus; in aliis speciebus tribus vel quatuor.

Filices elongatce, angustce, elongatce, erectce aut pendentes, tropicales.

Diagnosis : tab. xxm1, C; fig. 1, L. punctulatum, F.; fig. 2, indusium Nephrolepilis exaltati ad comparandun.

Differt à Nephrolepide indusio in ambilu libero, sinui subcentrali affixo," coriaceo; receptaculo prominente, magno, rolundo.

Fougères à frondes pendantes, souples, toujours pinnées, étroites, pecliniformes, allongées; frondules courtes, étroitement lancéolées, souvent arquées, se détachant facilement du rachis, sur lequel elles sont courtement rattachées. Les sporothèces occupent le sonmet d'une nerville qui se termine avant d'arriver à la marge. Les indusium sont à peu près orbiculaires ou très-courtement réniformes : ils s'attachent vers leur tiers inférieur et se montrent libres dans tout leur pourtour. Ce caractère les sépare des nephrolepis, ceux-ci ayant un indusiunı attaché par une large base toujours soudée à la nerville. Cette analogie établie, on ne peut confondre ce genre avec nul autre. Ajoutons qu'a la maturité des sporothèces l'indusium se soulève de tous les côtés d'une manière régulière; il replie ses bords seulement dans le nephrolepis attaché par une large base. Ces plantes sont tropicales.

\section{ENUMERATIO SPECIERUM.}

Bidenlalum (Vephrodium, Presl) - punclulalum (Aspidium, Sw.) - rufescens (Aspidium, Schrad.) - acuminalum (Aspidium, Willd.) - hirsululum (Aspidium, Schkh.*) - volubile (Nephrolepis, J. Sin.) - longifolium (Aspidium, Pohl) - oblusalum, F. - distans, F. - biserratum (Nephrolepis, Scholt*) - biauritum (Nephrolepis, Presl) - trichomanoides (Nephrolepis, PresI).

\section{Obtesaten.}

\section{SPECIES NONDUM DESCRIPTI.}

Frondibus linearibus, pinnutis, pendulis; rachi squamuloso, canaliculato; frondulis approximatis, sessilibus, linearibus, obtusinsculis, serratis, basi inferiore truncatis, 
sursiun acutis; sporolheciis intupressis, puncto calcareo supernè indicatis; iuclusio siccilate rufo; sporangiis rolundis; annulo 14 articulato; sporis ovatis seu rarius reniforinibus.

Habitat in Brasiliâ (Blanchet, sub nouine Aspidii exaltati donavil); Sancto Domingo (De Tussac).

(Dimensions : très-longue fougère, souple, garnie d'une très-grande quantité de frondules rapproehées, mais non imbriquées; l'extrémité, dans une étendue de 30 eentim., en porte près ile 40 paires.)

\title{
II. Distals.
}

Frondibus lanceolato-linearibus, peudulis, tongissintis; frondulis renotis, lanceotutis, acuminatis, brevè petiolatis, basi truncatis, sursùn gibboso-auriculatis, nesonevion squamuloso; nervillis apice incrassutis, supernè puncto nigro indiculis; sporothecuis distantibus; sporangiis ovalibus; annuto 12.13 articulato; sporis lavibus, parsulis, ovatis et reniformibus.

Habitet in Sancto Domingo. (De Tussac.)

(Dimensions : très-grande fougcere dout les frondules ont $12-14$ centim., sur $12-15$ milliu.: elles sont inférieurement séparcés par un entre-nœud de 2.3 eentim. Nous comptons jusqü ï 36 sporothèees sur chaque moitić des lames.)

\section{DICHASIUI, A. Bram. (1811.)}

\author{
Flora, 1841, p. 710.
}

Lastrere spec., PresL, Tent. pterid., p. 76.

Aspidii spec., KzE. et Auct. var.

SPOROTHEcus rotundis, distinctis; receptaculo punctiformi, prominente, rufo, dorsum venularum occupante; indusio biscutelloideo, crasso, substipitato, parte superiori affixo; sporangiis fasciculatis, pedicellis latis, vittatis; annulo 12 -articulato; stomio sub 12 -nervato, nervis leriter flexuosis; sporis ovoideis, episporio vestitis, opacis el subluberculosis.

Frovdrus pinnato-pinnatifidis; nervillis pinnatis, impressis, marginem attingentibus, in medio trajectu proliferis; rachi sulcato, squamis basi solutis, rufescentibus amplissimè vestito; fasciculis vasorum in stipite quatuor superioribus, minoribus, et duobus inferioribus, majoribus.

Filices Mexicance; una species indica orientalis; facienn gerens Aspilii, sed diversissima, ob indusiun nec orbiculatum, nec cordiforme, nec reniforme; sed biscutetloideun; ob frondium consistentian firmant, nervillas tenues, imuersas, pellucidas, rufescentes.

Diagnosis : tab. xмm, B, fig. 1. D. pruallelogrumunun, A. BR., fig. 2. D. patentissimuı, A. Br. (sectio stipitis). 
lous plaçons ce genre, qui rappelle les aspidium, dans le groupe des aspidiées, parce qu’il nous semble voir dans l'extrème division de l'indusiuu, qui se partage en deux parties, une exagération de la disposition cordiforme.

\section{ENUIERATIO SPECIERUII.}

Parallelogrammum, A. B. - patentissimum, A. Br. (Aspidium Donianum, Spreng.).

B. Nervillis parallelis ad marginem in arcu coalitis.

139. OLEANDRA, Cavan. (180\%.)

Prælect., n. 623.

Aspillii spec., Atcr. - Neuronia, Don. - Ophiopteris, Reısw.

SPOROTHECIS reniformibus, nervillaribus, mesonerro approxinalis, receptaculo, angusto, sublineari; indusio sinu obliquè affrxo, meniscioideo; sporangï. ventricosis; annulo lato, 14 arliculalo; sporis renifornibus.

Froxdacs simplicibus, lanceolatis, integris, membranaceis, subpapyraceis, pellucidis; nervillis parallelis, furcalis, tenuibus, monosoris; peliolo articulalo, super surculunı flexuosuu, syuanigerum nascente; arliculis à surculo, seu caudice repente, pliss minusie remotis.

Filices repentes, Indicre el Americana.

Diagnosis : Ноок. et B., l. cil., t. xLv, B, O. pilosu.

Genus nalurale; habilu proprio, frondibus simplicibus acrosticha paululiun referens.

Ce genre curieux et parfaitement distinct rènferme des plantes à frondes simples, entières, lancéolées, aiguës, articulées sur un stipe rampant, souples, transparentes, à nervilles serrées, pellucides, parallèles, se réunissant à la marge pour former un arc à très-court foyer. Circonstance qui a échappé à la sagacité de M. Presl, et que n'a pu constater M. Hooker, dont la diagnose citée laisse ainsi une lacune qu'il ètait utile de remplir. La disposition des nervilles et leur soudure, à défaut d'autres caractères, sépareraient suffisamment l'Oleandra du Nephrolepis et du Lepidonevron. Les frondules de l'Amphidesuium rappellent les frondes de l'Oleandra, et dans ces deux genres, du reste très-différents, les sporothèces forment, près du mésonèvre, plusieurs rangées irrégulières, longitudinales.

On trouve ces plantes dans les Indes orientales et dans ses îles. Deux espèces jusqüici ont èté observées aux Antilles; l'une d'elles a des frondes élevant leur articulation à près de ; centimètres au-dessus du rachis qui reste chargé de longs 
débris caudiformes, tronqués et évasés au sommet ( $O$. nodos $\iota$ ). Ce caractère est aussi très-marquẻ dans l'O. Wallichii, Presl, des Philippines.

Le nom d'Oleandra, imposé à ce genre par Cavanilles, ne rappelle la forme des feuilles du Nerion Oleander que d'une manière éloignée et ne peut s'appliquer à leur disposition ternée.

\section{ENUMERATIO SPECIERLM.}

Cumingii, J. Sm. (Cuming, Fil. Plilipp., n..$^{0} 60$, partim) - macrocarpa, Psesl (Cuming, Fil. Philipp., n. ${ }^{\circ} 60$, parlim) - mollis, Presl (Cuming, Fil. Philipp., n. ${ }^{\circ} 94$, partim) - neriiformis, Cavan. (Kze*, Bory*) - Phyllarthron (Aspidium, Blum.) - musxfolia (Aspidium, Blum.) Moritzii (Aspidium, Kze.) - lomatopus (Aspidium, Kze.) - Wallichii (Aspidiun, IIooh.) hirtella, Miq. (Kze.*) - nodosa, Car. (Aspidium, Schkh.*, Plım.*) - articulata, Presl.

\section{** Vervillis connivenitibus.}

\section{NEPHRODIUII, Rich. (1820.)}

In Mich., Fl. bor. Amer., 11, 266.

Polypodii spec., L. - Polystichi el Aspidii spec., Aucr. - Lastrece spec., Borr. Cyclosorus, Lא.

SPOROTHECIS puncluformibus, in seriem simplicem dispositis, pliss miniusve "pproximalis, rarò confluenlibus; indusio reniformi, plicalo, parculo, scepè pilifero, sinubus affixo; receplaculo reniformi seu puncliformi; sporangiis ovalis; annulo sapè completo, 1 S-20 arliculato; sporis ovalis, verruculosis. Froxdibes pinnatis seu pinnalifido-pinnatis; nervillis simplicibus, pinnatis, curvulis, infunis coadunalis; areolâ v'enulam reclam, ad apicem ferente.

Filices erectre, scepè tenerce, glabrce aut hirsute, cosmopolitance.

Diagnosis : Sснотт, Gen. filic. (optima). Ноок. et B., I. cil., t. хьvil. V. molle, Sснотr. E., tab. xvil, C; $N$. leuconeuron (fiagm.).

Genus affine Phegopteridi habilu, sed nervatione diversum; sporotheciis minorilus, indusio tectis.

Les nephrodium sont de véritables aspidium à nervilles basilaires des pinnules conniventes. Toutefois l'indusium est plus petit; les espèces sont bien moin, nombreuses et toutes étrangères à notre continent. Quelques-unes ont un port spécial, d'autres rappellent celui des aspidium, au point de permettre, même i des yeux attentifs, de les confondre. Ajoutons que beatcoup dautres semblent ètre des goniopteris indusiès. 
Les espèces qui composent ce genre se présentent sous trois aspects différents; l'un, qui les rapproche des aspidium et des Phegopteris molle, violascens, nympluale; le second, qui les, fait ressembler aux Phegopleris Oreopleris, Eckloni, Pohlianum; le troisième et dernier, qui leur est particulier et che\% lesquelles les lobules sonı unis par une membranule blanchàtre: Maurilicumum, leuconevron, microcarpon, plectochlona. Ces dernières espèces forment un groupe distinct, qui peut constituer un sous-genre sous le non de Pleclochlienea, nom destiné à rendre compte d'une disposition singulière de l'indusium qui est plissé en son centre.

\section{ENUIERATIO SPECIERUII.}

1. AMERICAN.e. = Molle, Schott (Schkh.*, Jacq. *) - Pohlianum, PresI - aurescens, Lk. chrysolobum, Lk. - deltoideum, Presl (Aspidium, Sw.) - denticulatum (Aspidium, Sw.) - violnscens, Lk. (Brasil., Seneg.) - quadrangulare, F. - abbreviatum, F.

2. INDICE. = Oreopteris, F. - obtusatum (Pteris, Willd.*) - gongy-loides, Schkh.* - parasiticum (Sw. Rhced.*) - terminans (Asridium, Wall.) - conionevron, F. - Amboinense, Presl (Aspidium, Willd., Rumph.*) - glandulosum, Presl (Zollinger, 11. os 2608 et 2920) - Benoitianun, Presl (Moluq.) - impressum, Blum. - decurtatum, hzc. (Jar.) - unitum, Schott (Schklı.*. Petiv.*, Barın.*).

3. CAPEASES. = Eckloni (Aspidium, Kze.).

4. Borbonic.e, Mavritiav.e, elc. = Leuconerron, F.* - caudiculatum, Picsl (Sieb., Syn. fil., n.。 47) - plectochlona, F. - microcarpon, F. - Mauritianum, F. - lucens, Bojer - dicarpum, F.

5. PhilipPINEySES. = Attenuatum (Lastrea, J. Sm.) - mucronatum, J. Sm. - Hilsenbergii, Presl (Sieber, Sj`n. filic., n. ${ }^{\circ} 49$ - hirsutum, J. Sm. (Cuming, n.॰ 82) - diversilobum, Presl (Cuming, ${ }_{11} .^{05} 51$ et 102) - Smithianum, Presl (Cuming, n. $\left.{ }^{\circ} 279\right)$ - mullilineatum, Piesl (Cuming, 11.03 $182 \mathrm{ct} 278$ ) - latifolium, Presl (Cuming, Fil. Plit., ${ }^{\circ 0}{ }^{\circ 5} 16$ et 298) - angustifolium, Presl (Cuming, $10^{\circ} 268$ ).

6. NoV.E-HoLLANDIC.E. = Propinquum, R. Br. - Shepherdi (Aspidium, Kze.).

\section{SPECIES NONDUM DESCRIPTE.}

\section{Dicarpum.}

\section{Facie Phegopteridis.}

Frondibus pinnatis, stipite et rachi villosis, helveolis; pinnis (frondulis) ungustè lunceolatis, patulis, sessilibus, acuminatis, sent-pinnatifudis, villosis, translucentibus; nervillis tenuibus, basiluri tuntim coalitu; ; segmentis obtusissimis, ud busin dicrapicis; sporolheciis rotundis; indusio glabro; sporangïs mediocribus, rolundis; annulo angusto, $16-18$ articulato; sporis reniformibus.

Hubitat in insulâ Borboniâ. (De Montbrison.)

Filix habitu, stuturn, consistentî, omninò Phegopteridi polypodioidi sinilis.

On croirait avoir sous Ies ycux le Phegopteris polypodioides; mais les nervilles basilaires sunt unics, et il n’existe sur chaque segment que deux sporothèces attachées aux deux nervilles amastomosantes.

Prés de cette espèce vicnt se placer le N. Griffithianum, à stipe grèle, à pinnules écartées, sous- 
prétiolées, crénelées en leur marge et ne portant que 3 ou 4 sporothèces arrondis. Est-ce là son état habituel? Le rhizome est rampant, de la grosseur d'une plume à éerire. Cette plante vit sur la terre, à Ceylan, où elle a été récoltée par M. Griffith. Les dimensions de notre spécimen sont inlérieures à celles de l'espéce de Bourbon, déerite plus haut.

\section{OREOPTERIS.}

\section{Facie P. oreopteridis.}

Frondibus pinnatis, glabris, ruchi sulcato; frondulis alternis, lanceolato-linearibus, acuminatis, brevè stipitutis, pellucidis, dentutis, dentibus mediam partem attingenlibus; sporotheciis dorsalibus, crassis, marginalibus; nervillis inferioribus sterilibus; indusio tenui, persistente; sporangiis parvulis; annulo 13.14 articulato, pedicello tenui; sporis brunneis, ovatis, papillatis.

Hubitat in insulis Plitippinis (Cuming, n. $\left.{ }^{\circ} 48\right)$; nec non in insuli Zeylunicâ. (Walker.)

Filix elegans, ferax, nervillis tenuibus, facie Phegopteridis Oreopteridis.

Dimensions : longueur de la fronde mesurée à la base de la frondule terminale, 30 eentim. : 1: paires de froudules; les plus longues mesurent 18.20 eentim., sur 15 millim. de largeur.)

Le spécimen de Ceylan porte seuleneut 5 paires de nervilles sur elaque segment, tandis quail en existe 7 sur ehaque segment du spéeituen des iles Philippines.

\section{A BbREviatcr.}

Froudibus pinnatis, in ambitu ovoideis, glabris, stipite rachique lavibus, helveolis; frondulis upice abruptè pinnutifulis, lanceolutis, acuminatis, petiolatis, crenatis, basi cuneatis, glabris; nervillis longis; areolâ unicâ cum "ppendice longissimâ, apicilari; sporotheciis dorsalibus, rotundis; receptaculo (nervilla in loco prolifero turgidu) elongato, sublineari; indusio perfacile cuduco, reniformi; sporangïs lenticulariformibus; annulo lato, 14-15 articuluto; sporis ovatis.

IIabitat in Brusilia. (Blanchel; in herbario clar. Nougeot; an Aspidium abbreviutum, Schrad.?)

Fillix glabra, frondulis petiolatis, fronde abruptè petiolatî.

(Dimensions : longueur totale, 80 eentim., dont le stipe filit la moitié ; frondules, 16 centim., sur 25-28 millim. de largeur; entre-uœuds, 3 centim.; $10-12$ paires de frondules. Le sommet dans sa partie pinnalifide mesure 13 eentim.)

Le n. 325 (Fl. du Brésil), désigné sous le nom d'Aspidium abbreviatum, Sehrad., se lermine aussi par un sommet pinnatifide. Il est plus grand et ses frondules tendent à la forme pinnatifide. Les nenilles sont généralement libres, mais il y en a aussi d'anastomosées. Ce sont peut-être deux formes de la même espéee: ce qu'on pourra décider plus tard.

\section{Facie profria.}

11. Leccuserrox, F., tab. X VIII, C, fig. 3.

Frondibus pinnatis, stipite cinereo, lanuginoso, profundè et angustè canaliculuto; rachi tomentoso, latè canaliculato; pinnis longis, lineari-lanceolatis, sessilibus, apice serratis, basi abruplè abortivis; segmentis ellipticis, sıprà glabris, subtìs villosis, punctis 
rubris, minutis, creberrimis coopertis; nervillis curvatis, oninibus cum nervillis proximis menubranula rubescente, hirsulti coalitis; sporangiis dorsalibus, sed parten superiorem nervillarum occupantibus, distinctis; indusio fulvo, glabro, sinu plicato; sporangiis ovatis, magnis; annulo crasso, 13-14 arliculato, sacculo supernè piloso; sporis subrolundis, lavibus, nigrescentibuls.

Habitat in insulâ Borboniâ. (Olivier.)

Filix elata, rigida; nervillis pinnarum entersis, albidulis.

(Dimensions : longueur totale, 1 mètre; des pinunles, 15 ccntim., sur 15 millim. de largenr: entre-nœuds, 25 millim.; les pinnules centrales sont courbées en dehors; inmmédiatement au-dessous des plus grandes, commcncent les pimnules qui restent à l'état rudimentaire, et sont plus écartées; ellc prend place à côté du $N$. plectochlena; mais elle en diffère par la nervation, par les dimensions, l'incidence des pimnules, etc. Les nervilles sont toutes soudćes par l'intermédiaire d'une membranule qui, en dessous, revêt l'apparence d'une nerville. Quoiquc celtc espècc soit glandıleuse comme le $\mathrm{N}$. glandulosum des Philippincs, elle est tout à fait différente.)

\section{PhectochleENa.}

Frondibus pinnatis, ovatis, hirsulis; rachi contpresso ; pinnis sessilibus, linearibus, approximatis, assurgentibus, acuminatis, crassis, opacis, suprà glubris, subtìs cinereo-villosis; lobulis infinis, ubruptè abortivis, oratis, membranulâ pellucidâ, usque ad tres partes coalitis et punctis rubris adspersis; nuarginibus crassis, reflexis; nervillis omnibus fertilibus; sporotheciis parvulis, connexis, dorsalibus, imbricatis; indusio catuoso, lcevi, glabro, reniformi, plicalo; sporangiis ovatis, opacis, crassiludine mediocri; annulo 12-13 articulato, sacculo glabro; sporis reniformibus, fuscis.

Habitat in insulti Borboniâ. (De Hell.)

Filix rigida, multipinnata, hirsutans.

(Dimensions : Jongucur de la fronde, 36 centim.; des pinnules, 9 centim., sur 8 millim. de largeur; 24 paires de pinnules, onvrant avec Ic rachis un angle dc $35^{\circ}$ environ. Eıtre-nœuds un peu moins de 15 millim.)

\section{MICROCARPON.}

Frondibus pinnatis, stipite, rachi et mesonevris cinereo-pilosis; nervillis tenuibus; pinnulis linearibus, palulis, superioribus angulum $45^{\circ}$ metientibus; lobulis ovatis, punctis rubris, minutissiniis adspersis; segmentis apice reflexo, cucullato, mentbranulit continut inter se unitis; sporollectiis dorsalibus, ninutis, distinctis; indlusio plicute; sporangiis .....; sporis crassissimis, rotundutis, lavibus, fuscis.

Hubital in insula Borboniâ. (Olivier.)

Filix flexibilis, multipinnata, pinnulis approxinatis et sporotheciis minulissimis notatu.

(Dimensions : longueur de la fronde, 32 centim.; des pinnules ou frondules, $8-9$ ccntim., sur 6 millim. de largeur, séparées par des entre-nœuds d'un centim. Nous comptons au delà de 乏0 paires de pinnules. Prend place à còté du $N$. plectochloena; en differe par des pinnules ćtalées, plus rapprochées, par des sporothèces toujours distincts et beaucoup plus petits, par une membranc continue unissant toutes les nervilles. 


\section{MaERITHYIM.}

Frondibus pinnalo-pimatifidis, glabris, rachi robusto, profundè sulcato, helveolo, luvi; pinnis longissimis, sessilibus, ncuminutis, apice serratis, basi subcunealis; nervillis arcuatis, simplicibus, tenuibus; segnentis lunceolatis, obtusiusculis, falcatis, usque ad median portem et ullrà liberis, membramulâ pellncidâ coalitis; nervillis temuibus, 2-3 coalitis, omnibus proliferis; sporotheciis dorsulibus et centralibus; indusio purvulo, glabrescente; sporangiis ovalis, lenticulariformibus, pancis; annulo 13-11 articulato; sporis reniformibus ovoideisque.

Inubitat in insulta Mauritii. (De Montbrison.)

Filix magna, formosa, ferax, pinnulis semi-pinnatifidis, nervillis helveolis.

(Dimensions : tics-grande fougère, dont les pinnules ont 32-36 centim. de longueur; sur un peu moins de 4 contin. de largeur: entre-nouds $4-5$ centim. Nous complons sur une senle pinnule pres de 60 scroments de chaque còté du mésoncire.)

\section{Coxioserrox.}

Frondibus pimnutis, rachi subquadrangulari, glabro; frondulis linearibus, longissimis, longè acuminalis, pectinatis, segntentis oblusis; nervillis lumince superioris grunulis creberrinis, rotundis, albidulis, contiguis coopertis; sporothecuis dorsalibus sed margine approxinuatis, conniventibus; indusio crasso, siccilate crispo, persistente; sporolheciis lenliculariformibus, parvulis; annulo 18-20 arliculato; sporis rotundis, fuscis.

Hubitat in insulâ Zey-lanicû. (G. Gardner, n. ${ }^{\circ}$ 51.)

Filix pinnata; frondulis (piunis) subopposilis, longissimis; nervillis pulvere granuloso, persistenle coopertis.

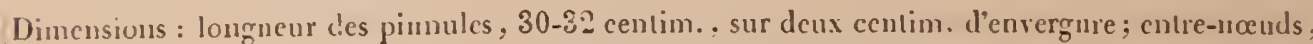
35 millim. Nous complons près de 75 segnients sur les plus longues pinnules. Le mésonévion ('st jaunàtıc el nu.)

\section{QLadraigelare.}

Frondibus pinnalo-pinnatifulis, stipite el rachi quadrangularibus, helveolis, pilosiusculis; frondulis pinnatis, acuminutis, lanceolatis, villosis, sessilibus, basi subtrmncatis, mollibus, segmentis obtusis; nervillis siniplicibus, areolâ busilari solitariâ; sporotheciis dorsalibus; indusio hirto, parvo, persistente; sporangïs parvis, lenticularifornibus; annulo 14-15 articulato; sporis leviter renifornibus.

Habilal in Guyanâ gallicâ, in sylvis paludosis ad riprs amnis Mont-Tigre.

(Leprieur, 182, in Herb. clar. Moug.)

Filix elata, flexibilis, villosa, mullifrondulosa; stipite rachique quadrangularibus.

Dimensions : longueur tolale, près d'un mètre; lc slipe est un peu plus courl que la frondc; pimules, 24 et plus; mesurant 12-14 centim., sur 2 centim. de largeur; entre-næuds, 25 millim.) 


\section{HAPLODICTYON, Presl. (1849.)}

Epim. bot., p. 50.

Nephrodium Bhumei, J. Sı., in Ноок. Journ. bot., III, 411 (excl. synonym.).

Lastrece spec., J. Sm., Enum. Fil. Cumingii.

SPOROTHECus globosis, infrà medium dorsum vence arcuformis inserlis; indusio reniformi, sinu affixo, cilialo, caduco; sporangïs longè pedicellalis, lenticulariformibus; annulo ferè tres quartas parles sacculi amıleclante; sporis...

FRoxdibus heleromorphis, pinnatis; nervillis pinnalis, ramosis, infimis opposilis, in arcum sublriangularem anastomosatis; venulis superioribus furcatis, in fronde fertili liberis, in sterili ramo transverso connexis; frondibus sterilibus usque ad medium pinnalifidis, segmentis oralo-oblongis; fasciculis vasorum in stipite duobus, teretibus; frondibus fertilibus, basi pinnatis, stipite longiusculo; segmentis ovatis, obtusis; venulis tenuibus in arcum triradiatum anastomosatis, reliquis liberis, furcalis.

Filix Plilippinensis, hirsuta, pinnatifida; rhizomate repente.

Exsiccat., Cususg, Fil. Philipp., n. 322.

Icon. nost., xvu1, C, fig. 2. (Conditio nervatiouis.)

Ce genre, dont nous ne possédons qu'un seul spécimen en médiocre état, est établi sur la diagnose donnée par. M. Presl. Le port de cette fougère, la manière dont s'anastomosent les nervilles et l'hétéromorphie des frondes, la séparent suffisamment des neplırodiurn; peut-être devrait-on ajouter à ce genre l'Aspidium exig"utı!n de J. Smith, sounis aussi à l'hétéromorphie, à frondes velues, pinnéespinnatifides, et qui est égalenıent indigène des Philippines.

ENUMERATIO SPECIERUM.

Ileterophytlum, Presl (F., nervat.*) - ?exiguum (Aspidium, J. Sm.; Cuming, Fit. Phitipp., 11. 251).

\section{ABACOPTERIS, F. (1845.)}

Congr. scient. de France, X. ${ }^{e}$ session, t. I. ${ }^{\mathrm{er}}$, p. 178 .

Cyclodii spec., Tentam. pterid., 85, t. 11, fig. 21.

Aspidiii spec., Bucr., Enum.; KzE., in bot. Zeit., v1, 260.

Nephrodii spec., J. Ss., in Hoor. Journ. bot., in et Iv; P'ResL, Epim. bot.

Sровотнесиs rolundo-oralis, dorsalibus; indusio parso, reniformi, sinu affixo; receptaculo durissimo, angustè elliptico; sporangïs ovatis, longè pedicellatis; annulo 14-16 arliculalo; sporis reniformibus. 
Frохривеs pinnalis, rarò el aborlu (?) simplicibus; frondulis lanceolatis, acuminatis, basi cordalis Iruncalisyue, marogrinibus undulalo-crenatis; nervillis scalpluratis, pinnalis, tenuibus, inler se ope venularum lateralium, ferlilium coalitis; arcolis pluribus inler se superpositis, in segmentis subquadranguluribus parlitis.

Filices nervatione meniscioidece, indusio aspidiacea, inter meniscium et goniopteridem collocanda. A Nephrodio longè distant.

Diagnosis: tab. xvm, C, fig. 1. A. Philippinarum, F.

Ce genre est facile à caractériser. La nervation est bien plus voisine de celle des meniscium que de celle des groniopleris. Les nervilles pinnées émettent des vénules courtes qui s'unissent à leurs correspondantes pour former des angles obtus; du sommet de ces angles part une nerville assez robuste qui les unit tous, en divisant les arẻoles en deux parties symétriques, reproduisant assez exactenıent la figure d'un quadrilatère, d'un rhombe ou celle d'un trapèze. Chaque nerville pinnée étant considérée comme un système complet, serait le mésonève d'une frondule si la fronde était partagée; comne elle est indivise et seulement crénelée, elle montre deux ordres de nervilles, les dorsales et les suturales, ainsi qu'il arrive lorsque se soudent les feuilles carpellaires.

Les sporothèces sont arrondis, indusiés et situés sur chaque vénule, ce qui ne permet pas de confondre ce genre avec le meniscium. Toutes les espèces que nous connaissons ont pour patrie les Indes orientales et les îles des mers dı Sud.

\section{ENLMERATIO SPECIERLM.}

Elegans, F.* (conditio nervationis) - Philiprinarum, F., Congr. scient., l. cit. (Nephrod. latifolium, J. Su.; Cuming, n. $\left.{ }^{\circ} 16\right)$ - simplicifolia (Nephrodum, J. Sm.) - truncata, F. (Cuming . n.. 298 [partim $])$ - glandulosa (Cyclodium, Presl, Tentam.; Nephrodium, cjusd., Epim.).

\section{Eleggans.}

\section{SPECIES NONDCM DESCRIPT'E.}

Frondibus simplicibus aut trifolintis, Innceolatis, repando-crenatis, acuminatis; sy-stemate vasculari pubescente; stipite tenui, helveolo; nervillis pinnatis, scalpturatis, curvatis; venulis arcûs regulares constituentibus; areolis quadrangularibus, parvis; sporotheciis rolundis; indusio ferè orbiculato; sporangiis ovoideis; annulo 14-16 articulato, sacculo duos plos humatos ferente; sporis reniformibus.

Habitat in Cochinchina. (Gaudichaud.)

(Dimensions : longueur, 33 centim., sur $5-6$ centim. de largeur; le slipe est :: $2: 1$; quelquefois la lane fait moitić de la dimersion totale.)

\section{Truscatem.}

Frondibus pinnutis, rachi subtomentoso, frondulis sessilibus, acutis, ovato-lanceolatis, basi truncatis; mesonevro pmberulo; nervillis tenuibus, venulis subtus vix perspicuis; 
sporotheciis elongatis; receptaculo extenso; indusio piloso; sporangïs ovatis; annulo lato, 14-16 articulato; sporis reniformibus.

Habitat in Philippinis. (Cuming, n.? 298.)

(Dimensions : 24-25 centim. à la base de la frondule terminale, plus longue que les latérales: celles-ci mesurent 14-15 centim., sur 2 -3 centim. de largeur.)

Kunze, dans une note manuscrite, avait reconnu que celte fougère n'était pas l' $A \cdot$ glandulosum de I. Blume. Nous constatons qu'elle n'a aucun rapport avec le Nephrod. latifolium de M. J. Smith; distribué sous Ic n.॰ 16 par M. Cuming.

\section{$\dagger$ Frondibus monotaxicis.}

A. Areolis exappendiculatis.

\section{PLEOCNEMIA, Presl. (1856.)}

Tentam. pterid, , p. 152.

Aspidii spec., Auct. varior.

Sporothecis rotundis, serialibus, terminalibus aut dorsalibus; indusio parvulo, reniformi; sporangiis ellipticis; annulo $16-18$ articulato; sporis ovoideis, fuscis, papillatis; pilis aureis, mastoideis, cuun sporotheciis sapè intermixtis. Froxdibes lanceolatis, bipinnatis, pinnis lanceolatis, approximatis ; segmentis areolâ basilari coalitis; nervillis tenuibus.

Filix arborescens, Plilippinensis, magna, rigida, erecta, paradoxa; facie ferè Aspidiorum, scepè indusiis abortivis el tìm gymnosora.

Diagnosis : Hoor. et B., 1. xcrı (optima). P. leuceana, J. Ss.

In icone suprà laudato Hoolieri, nervatio frondis sterilis libera indicata est, ex errore; nullu differentia extat inter frondem sterilem frondemque fertilem.

Ce genre présente cette singularité d'avoir des individus d'une même espèce arec ou sans indusium, indusiés ou nus, et par conséquent appartenant tout aussi bien aux polypodiées qu'aux aspidiées. Celte bizarre anomalie a-t-elle lieu sur les frondes d'un même rhizome ou sur des individus séparés? c'est ce que nous n'osons décider. Nous possédons dans notre lerbier, sous le nom de $P$. leuceana, quatre spécimens, tous des Philippines et provenant de M. Cuming, parni lesquels les n. ${ }^{\text {os }} 34$ et 107 sont indusiés, tandis que les n. 33 et 289 , ainsi qu'un autre spécimen sans numéro, indiqué seulement comme une fougère ell arbre (tree), sont privés d'indusium, et cependant telle est l'analogie de forme qu'on doit les regarder comme absolument congénères. C'est cet avortement de l'indusium, qui explique comment il s'est fait que M. Presl ait donné dans son Tentamen au genre Pleocnemia une place parmi les polypodiées, opinion 
d'abord acceptée par M. Hooker, qui en a fait plus tard une aspléniée, sans toutefois reconnaitre le double état sous lequel se trouvent les sporothèces de celte plante; M. Presl (Epim.bot., p. 50) a reconnu que la présence d'un indusium réniforme était la condition nornale de ce genre, et il l'a placé parmi les aspidiées.

Les espèces de pleocnemia, distribuées par M. Cuming, présentent un grand désordre dans les étiquettes qui les désignent; aussi allons-nous donner leur ènumération en suivant M. Presl, quoiqu'il nous semble que nos espèces et les siennes ne soient pas rigoureusement correspondantes.

\title{
ENUMER.TTIO SPECIERUM.
}

Conjugata, Presl (Asridium, Blum.) - Cumingiana, Presl (Cumming, Fit. Philipp.. 11. ${ }^{\circ} 33$ et 10i) - leuceana, Presl (Cuming, n. ${ }^{\circ} 34$ et 289).

\section{SAGEMA, Presl. (1856.)}

\author{
Tentan., p. 86 .
}

Polynlictyi spec., Ejusd., Epim. bot., p. 52 et 259.

Microbrochis, PresL, l. cil., p. 50.

Aspidii, Neplerodii, Dicty-opteridis el Polypodii spec., Aucr. pucn!y.

SPOROTHECus rolundis, sparsis, super receplaculum rolundum, gibbosum crassumque nascenlibus; ad apicem, seu ad dorsum nervilla silis; sporangïis rolundis, indusio reniformi lectis; annulo 13-1 i arliculalo; sporis ovoideis, subreniformibus.

Froxpıns divisis, mullibus, glabris; areolis irregularibus, exappendiculatis, basilaribus longis, angustis, brevibus, subrectis; fasciculis vasorum quindecim, sparsis ovoideisyue, quorum octo basilares punctiforues.

Filices Asiatica, rarius Americnnce, Madagascarienses, anple, divisce.

Diagnosis : Hook. et B., Gen. filic., t. tu1, A. S. macrodonta, F. (Aspidium coadhnulum, Walr.). Presi, i. cil., t. II, fig. 22.25 ; cum inllusiis ex errore peltatis, nam certissimè reniformes stmt. Tal,. nostr., xxiv, A, fig. 1.

Facie Dictropterilis, sed indusinte. Indusinm aliquamlò abortivum; proplereci in Cunningii Filic. Plilipp., $10^{\circ} 9$, sub uomine Polypodii el Aspidii ab auctoribus recentioribus determitutum furit.

Differt à Cardiochlu'na, Bathunio et Podolepide habitu geuerali; sporolheciis apici venulce liberce sitis; ob nervationem Goniophlebii proximun foret.

Le genre Sagenia renferme de grandes espèces de fougères à frondes trèsétalées, décomposées en lobes lancéolès. Elles sunt dressées, plus rarement grinpantes, ayant un rhizome asse\% considérable, rampant et écailleux. Les sporothèces 
sont fixés sur le trajet d'une nerville, libre dans une seule espèce (Surugeniu radicans, F.) et faisant partie d'une aréole dans le plus grand nombre des espèces. La nervation est réticulée, non-seulement près du mésonèvre, mais dans toute l'ètendue de la lame. Les aréoles, d'une inégalité narquée, ne portent point d'appendices libres. Il differe du Pleocnernia, dont les espèces ressemblent à des aspidium, par l'universalité des anastomoses et par un port distinct; du Cardiochlacna, par des aréoles non appendiculées et par des frondes pinnées ou décomposées, ni pédiaires, ni palmées. Nous avons donné à l'espèce principale de ce genre le nom de $S$. macrodonla, pour indiquer son analogie avec le Diclyopleris macrodonta, fougère à sporothèces nus, mais très-voisine de ce Sageniu par la fionde.

\section{ENUIIERATIO SPECIERUM.}

Macrodonta, F. (coadunata, J. Sm.; Aspidium, Hook. et Grer.*) - gemmifera, F. - Hippocrepis, Presl (Polydictyum, ejusd., Hook. et Gr. [fragm.*], Plum.*) - Mexicana, F. - varia, Presl sorbifolin, Presl - apüfolin (Microbrochis, Presl; Aspidium, Schkh.*).

\section{GEMMIFER A.}

\section{SPECIES YONDUII DESCRIPTÆ.}

Frondibus latè ovatis, pellucidis, pilosiusculis, pinnato-pinnatifidis; rachi helveolo, gemmas globulosas, geminatas, hirsulas, crassiludine seminis Pisi salivi ferente; segmentis lanceolatis, acuminalis, pinnalifidis, crenatis; pinnis inferioribus conformibus sed petiolatis; nervillis tenuissimis, areolis incequalibus; sporotheciis venulum liberam, brevem occupantibus; sporangiis subrotundis; annulo 13-14 articulato, pedicello pilis translucillis, 2-3 coronato; sporis ovoideis.

Habitat in insulâ Mladagascariensi. (Pervillie.)

Filix magna, gemmifera, flexibilis, pellucila; ruchibus el mesoneuris helveolis.

(Dimensions : de la fionde sculement, 54 centim.; pinumles. 24 eentim., sur $12-14$ centim. d'euvergure. Les sporothèces écartés arrètent leur développement au nivean du sinus que lorment les segments pinnulaires.)

II. Nexicara.

Frondibus latè ovatis, apice pinnatifidis, centro pinuato pinnatifulis bipinnatisque, bust tripinnatis, rachi intensè rufo, glabro, canaliculato; frondulis et pinnis acuminatis; segmentis crenalis, areolis polygonoideis, subregularibus; sporotheciis dorsalibus rotundis; indusio parvulo; sporangiis rotundis; annulo $12-13$ urtirulato; sporis ouralis, latè episporialis.

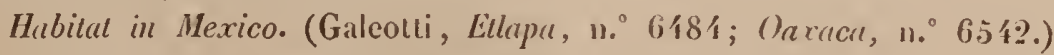

Filix basi tripinnata, glabra, flexibilis.

(Dimensions : longueur de la fronde, 45 eentin. Les divisions inférieures, 25 centim. Les segmenls externes, bien plus longs que les internes, atteignent 10 ceutim.) 
145. PIILEBIOGONIUM, F.

SPOROTIECHs immersis; receplaculo (nerilla apice lurgida) py riformi, apicilari; indusiis planis, reniformibus, siccilate crispis, marginibus assurgentibus, triseu quadriguetris; sporangiis ovalibus, pedicello tenui; annulo 13-14 articuleron; sporis ovoideis, episporiatis.

Froxdвсs bipinnatis; pinnis el frondulis remolis, basilaribus longè stipitatis, ommibus apice pinnatifidis, glabris, siccilate rufts, sporolheciis sublis inpressis; stipitibus lavibus, nigrescentibus, profundè sulcatis; quatuor fasciculus "rrsorum ferentibus : duobus superioribus elongrato-ovoideis, dnobus inferiuribus puncliformibus; nerillis anaslomosatis, omnibus sporangaiferis; areolis heragonoideis, venulâ rectâ, axillari, liberî, prolifer $\hat{\imath}$ notatis.

Filix indica, erectu, decompositu, feracissima.

Diagnosis: tab. xww, A, fig. 2.

La nervation est voisine de celle des goniophlebium. Claque aréole renferme un sporothèce qui en remplit l'aire presque entièrentent. Il prend massance à l'angle interne d'une aréole régulière hexagonale. La surface inférieure est bosseltete par les sporothèces, ce qui lui donne un aspect tout particulier. Cette fougère a un port spécial très-distinct de celui des autres aspidiées.

P. impressum (Grifilh., Pl. Indic., n.. 34 ).

\section{SPECIES.}

B. Areolis appendiculatis.

\section{CARDIOCILENA, F.}

Potydictyi spec., Press, Epim. bot., p. 52.

Asplenii el Potypodii spec., Accr. - Aspidii spec., \$. 2. Buthnium, parlim, Prest. SPORAxGus rolundis, biserialibus, superficialibus aut leviter impressis, indusiatis, aliyuondio nudis; receptaculo irregulari; indusio cordiformi, centro affixo, siccitate triquetro, crispo; in C. macroph, llấ reniformibus el orbicularibus: sporangïs magnis, longè pedicellatts, pedicello supernè $2-3$ pilos saepè ferente; annulo 13-18 articulato; stomio angusto, sub 8 nervato, nervis brevibus, inceryualibus; sporis oroideis, reniformibus, latè mermbranaceis.

l: RохDibes pinnatis, basi pedatis; pinnulis amplis, lanceolatis, crenalo-incisis; venulis in areolas parulas, irregulares, cum appendicibus rectis ant harmatis dispositis; slipitibus lacvibus, infernè profundè canaliculatis, aliquandò ebeneis; fasciculis vasorum septern: quinume superioribus puncliformibus, duobus inferiuribus ovoideis. 
Filices tropicales, magnce, membranacece.

Diagnosis : talı. xxıv, B, fig. 1; C. macroplyylla, F. (Aspidium, Sw.; Polypodium, WIıLD.); fig. 2, Goniophlebium neriifolium, F. (fragmentum), ad comparandım.

Duo subgenera statuenda:

§. 1. Lobochletad : Apicilaria.

f. II. Evc.ardochlema : Dorsalia.

Species Cardiochlance in herbariis fere omnibus, cum Aspidiis immixtce. Genus indusio cordiformi et areolis appendiculatis planè distinctum; frondibus satis polymorphis.

Ce genre est nonbreux en espèces et suffisamment caractérisé. Les frondes ont une nervation pareille à celle des gymnopteris (acrostichées), des drynaria (polypodiées), des balhmium (cyclodiées). Ce sont de grandes et belles plantes qui vivent dans l'Amérique tropicale, aux Philippines et dans quelques parties de l'Inde. Les frondes, assez élancées, se divisent en frondules ou en segments largement lancéolés, acuminés, sinueux ou crénelés à la marge. Dans deux espèces des îles Philippines, les stipes rappellent par la couleur et la consistance ceux des adiantées.

Il existe entre ce genre et le Bathmium de nombreuses analogies. Les firondes sont divisées de même : elles ont une consistance pareille et une même nervation. L'appareil fructifère seul diffère dans ses parties essentielles. L'indusium, au lieu d'être échancré en cœur ou lobé, est entier dans le bathmium, fixé au centre sur un receptacle arrondi. Les sporanges viennent toutes adhérer sur cet axe en. rayonnaut dans son pourtour; l'indusium les abrite également dans tous les points de la circonférence. (Voy. Bathniumn.)

\section{ENUMERATIO SPECIERUN.}

A. Sporotheciis serialibus. = Alata, F. - Menyanthidis (Polydictyum, Presl; Aspidium, J. Sın.) - locis, F. - sinuosa, F. - macrophylla, fragm.* (Aspidium, auct., Peliv.*, Plum.*), el var. plures: distans (Brasilia); crenala (Caraccas), Morilz - ampla (Guadel., LHItiminier).

B. Sporolhecicis alaxicis. = Trilobala, F. - confuens, F. - subbipinnatifida (1spid. microsorum, Presl).

I. Alata.

\section{SPECIES NONDUII DESCRIPTE.}

Frondibus pinnatifidis, glabris, rachi squamuloso, bicanaliculuto; segmentis remotis, lanceolatis, acuminutis, pellucillis, longè decurrentibus, marginibus untulatis; superioribus trifidis; inferioribus bipartitis; mervillis temuibus, leviter inupressis; sporotheciis ovatis, biserialibus, ad apicem nervillce liberce sitis et sapè sessilibus; indusio plano, tenui, eleganter cordiformi; spornngiis ovalis; annulo $12-13$ articuluto; sporis ovoideis.

Habitut in insulis Philippinis. (Cuming, n.0 118.)

Filix singularis; segmentis remolis, tongè decurrentibus.

(Dimensions : longneur de la fronde, 50 centim.; des segments. 16 centin.. sur 25 millin. de largenr; l’intcrvalte qui sépare les segments inférieurs est de 8 - 9 centim.) 
II. L.tVIs,

Frondibus linnatifidis, basi pinuatis, ghabris, membranaceis; frondulis at segmentis lcrvibus, translucidis, acuminatis; inferioribus pedato-partitis, terminali trifidi ; rachi syuamuloso; nervillis flexuosis, apice pvanescentibus; venulis crassis, fuscis; areolis subquadrangularilus, uppendicibu bifurcato-ranosis; sporotheciis biserialibus, reniformibus, ad apicem nerville brevis, libera evolventibus; indusio tenui, plano; sporoileciis subrolundis; annulo lato, 10-11 articulato; sporis ovoideis.

Habilat in insulis Philippinis. (Cuming, sine numero.)

Filix formosa, alata, glubra, apice trifida, basi pinnata.

(Dimensions : longueur totale de la fionde, 42 centim.; segmeuts latéraux, 21 centim., sur aे centim. de largeur. Le sommet de la fronde est piunatifide; mais les deux dernières partitions cout masifestement pinnées . surtout l'inférieure, qui a un court pétiole.)

\section{SiNiosa.}

Frondibus ovatis, apice pinnalifidis, basi pedatis, intermediis petiolatis; slipile el rachi rufo-fuscis; seginentis frondulisque oppositis, acuminatis, grossè crenulis, simuosis; inferioribus exterius pinnatifidis; nervillis tenuibus; appendicibus areolarum longissimis; sporolhecils remotis, tune dorsum nervillce areolarum, tunc apicem nerville liberce ocrupantibus; sporangiis ovoideis, pedicello pilis pluribus capitatis coronato; sporis ovalibus.

Ilubitat in insulis Philippinis. (Cuming, sine numero.)

rilix anupla, basi pellata, apice pinnatifida, dein pinnatı.

(Dinnensions : Jongueur de Ja fronde, 40 centim. Le sommel, qui cst pinnatifide; mesure 18 centim. Les segments se raceourcissent brusquement vers le haut; les frondules laterates ont 14-15 ecutim. de longueur sur 4-5 de largeur: la dernicie paire est plus longue et plus large.)

11. Trilobata.

Frondibus trilobatis, glabris, cordatis, lobo terminali magno, lateralibus acuminatis, obtusiusculis, marginibus repandis; petiolo lcovi, glubro, rufescente; nervillis rufilulis, angulun $10^{\circ}$ cum mesonevro metientibus, apice evanescentibus; areolis incequalibus, polygonalibus; sporolheciis creberrimis, irregularibus, rotundis, ellipticis elongatisque, scrpè nudis, suprà nervillam incrassalan sedentibus; indusio reniformi aut semiorbiculari; sporotheciis rotundis; annulo lato, extenso, 12.13 articulato; sporis ovoideis.

Hubitat in Antillis Gallicis.

Filix glabra, membranacea; petiolo el nervillis rufescentibus.

(Dinensions : longueur tolale, 40 centim., sur 16-18 d'envergure. Les sporothèces sont tresunulbreux et sporadiques. Le stipe égale la fronde en longueur.)

1. Coxplexs.

Frondibus pinuatis; frondulis acuninatis, oppositis, terminalibus, triangularibus, basi pimnatiftlis, infmnis divisis, exterius pinnatifidis, marginibus repandis; stipite el rachi 
glubris, helveolis, striatis; nervillis crassis, in areolas parvulas, irregulares anastonısal is; sporotheciis creberrimis, ataxicis, incequalibus, scepè confluentibus; indusio incrquali, parvulo, scepè deficiente; sporotheciis ovalibus, pedicello angusto; annulo 13 -14 articulato; sporis ovoideis, latè episporiatis.

Habitat in insulâ Guadalupâ. (L'Herminier.)

Filix feracissima, pinnata, magna, glabra; nervillis crassis, fuscescentibus.

(Dimensions: longueur totale, 50 centim.; celle des frondules inférieures, 20 centim.; des intermédiaires, 16 centim.; largeur, de 4-6.)

\section{计 Frondibus diplotaxicis.}

\section{FADYENIA, Hook. et Baner. (1842.)}

Gener. filic., t. LIII.

Aspidium proliferum, Ноок. et Grev., Icon. filic., t. xсvı.

SPORотнесus serialibus, in fronde lineari el ad apicem nervillarum nascentibus, magnis, suborbicularibus; indusio magno, cordalo, basi profundè bilobalo: sporangiis rotundis; annulo lalo, 14-16 arliculato; sporis ocoideis.

FRoxdies sterilibus, lanceolalis, sessilibus, apici allenualo proliferis; venulis pinnatis, superioribus cum proximis oppositis, areolas hexagonas constituenlibus; ferlilibus lineari-ligulatis, oulusis, basi attenuatis; rhizomate fibroso.

Filix crespitosu, simplex, tenera, Cubensis et Jamaicensis.

Diagnosis: Ноок. et B., l. cit.; F. prolifera, Hook. et B., Gen. filic., t. LII.

Ce genre inonotype est le seul du groupe qui ait des frondes diplotaxiques. Les nervilles forment des aréoles dépourvues d'appendices.

\section{Considérations générales sur le groupe des Aspidiées.}

Les aspidiées sont des polypodiées indusiẻes; elles en ont le port et très-souvent la nervation. Cependant elles tendent à diviser leurs frondes d'une manière plus complète. Ainsi sur douze genres qui composent ce groupe, il n'en est que deux qui aient des frondes entières, encore les espèces y sont-elles peu nombreuses; tandis que sur les dix-neuf genres renfermés dans les polypodiées, six ont des frondes simples et deux des frondes mixtes avec beaucoup d'espèces à frondes indivises.

Les aspidiées ayant un port spécial, sont les seuls genres Oleandra et Fadyenic. Les autres ont des analogues dans d'autres groupes, notamment dans les 
ménisciées, les polypodiées, les néphrolépidèes, les cyclodiées, et même dans les leptocarpidées : exemple le genre Anogramme. Ajoutons que le genre Oleandra rappelle exactement la nervation des calophyllum, et que le Fadyenia se rapproche des craspedaria par le port, quoique de loin.

Il est bon de constater que ces analogies sont loin d'être des sinvilitudes, abstraction même faite de l'indusium. Celui-ci n'est jamais orbiculaire: il s'attaclie au sommet ou sur le dos d'une nerville et en son centre, sur un réceptacle linéaire assez allongé. Les sporanges viennent s'y fixer, mais ne peuvent constituer des sporothèces arrondis, comme on le remarque dans les cyclodiées. Ces groupes sont nécessairement interrompus à la base et peu fournis au sommet du réceptacle, qui est à peine renflé. L'indusinuru est fugace ou persistant, glahre ou velu, souvent crispé par dessiccation. Les spores ont assez. universellement la forme arrondie.

Le genre Aspidiun est l'un des plus nombreux de la fanille, et les espèces quil renferme sont souvent d'une détermination difficile. Il est avec le genre Cystopteris le seul qui renferme des espèces européennes, presque toutes sont tropicales. LOleandra est remarquable par des frondes simples, articulées sur un stipe grimpant; le Lepidonevron pend aux arbres sur lesquels il vit. Le Pleocnernic est la seule fougère ligneuse du groupe.

5. Indusiun hasi lato affixum, sulo orbiculare ant reniforme : IEPIIROLEPIDE.E. Tephrodiariearum par's, PresL, Tentam. pterid., 1. 75. Aspidicarum pars, Auct. var.

Herlsacex, elongate, pendulx aut rarius erectie, pimnatifidæ, subpectinate, glabre, arboricolæ, tropicales; ma species tuberifera; nervillx semper libere.

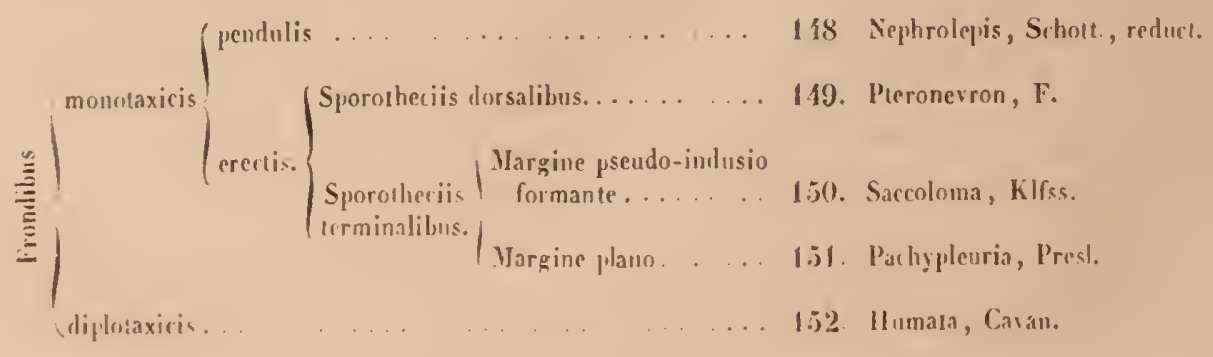


148. NEPHROLEPIS, Schott. (1854), reductum.

Polypodii, Davallice, Humatce, Aspidii, Nephlrodii et Nephrolepidis spec., L., J. S»., Prest, Cavan, etc.

SPORотнесіI rolnndalis, ad apicem glandulosum ramulorum secundarium abbrevialorum nervilla obliquè silis; receplaculo parvulo, puncliformi aul transversè ovoideo, nervillâ lurgidâ nascenle; indusio lenui, obliquè affixo, hemisphcerico, cordalo, reniformi, basilalâ, nunquàm solul $\hat{a}$, adhcerenle; sporangiis snbovoideis, slomio subynadrinervalo; annulo 14 arliculalo; sporis ellipsoideis vel reniformibus.

FRONDIBCs pinnalis; frondulis supernè auriculalis, brevè pedicellatis aul sessilibus, arliculalis, apice denlalo-crenulalis; nervillis bifurcalis, rammlis incequalibus, inferiore longiori slerili, omnibus ad apicem glandulosis el pellncidis; fasciculis vasorum in slipile variabilibus, sapè ternis; rhizonate crasso; slipilibus basi fuscescenlibus, fasciculalis non arliculalis.

Filices longissimer, pendentes, arboricolce, pectinater, multipinnulatee, scepè subtìs punctatce, tropicales.

Diagnosis : Sснотт, Gen. filic., fig. 1, І, ш1. Ноок. et B., Gen. filic., t. xxxv. N. exultata, Prest, Tab. nost., xxv, fig. 1. N. tuberosa, Press, cum analysi tuberculi, et tabs. xxill, C, fig. 2 (sporotheciunt).

Facies et nervatio Lepidonevri, sed indusio basi affixo et integrè inhcrente vliffert; Ditvalliceis affinis est. N. tuberosa filix notissima, quce sola profert tubercula ovoidea, multigemmata, subterranea, subtranslucida, nuco subsolido repleta.

Les nephrolepis sont de grandes plantes pendantes, pectinées, très-longues, ètroites, à frondules souvent arquées, articulées, facilement caduques, à nervilles renflées au sommet, qui est glanduleux. Une espèce est tubéreuse; on les trouve attachées aux arbres dans les régions tropicales.

Il existe entre ce genre et le Lepidonevron des rapports nombreux; c'est le mênse port et la même structure de frondes, mais dans le Nephrolepis les indusium, toujours réniformes, sont attachés obliquement par une large base qui ne se sépare janais de la lame. La déhiscence est donc incomplète, tandis qu'elle intéresse toute la circonférence du tégument dans le Lepidonevron. (Voy. p. 301.)

La fronde des nephrolepis est en général beaucoup plus longue; les frondules, bien plus nombreuses, sont aussi plus rapprochées, et souvent même au point d'être imbriquées.

\section{ENUMERITIO SPECIERUM.}

Tuberosa, Presl - imbricata, Presl - undulata, J. Sm. - obliterata (Nephrodium, R. Br.) pendula (Aspidium, Radd.) - exaltata, Presl - Schkhurii, Link.; et var. $\beta$ minor; Linden (Cuba, 11. 1882). 


\section{PTERONEVRON, F.}

Humate spec., J. Si.

Nephrodii et Davallice spec., Accr.

Davallia sect., S. 2. - Pachypleuria, partim, PresL, Tentam. pterid., p. 128.

Sporotuecis Iateralibus, ramulis nervillarum superiorum receptaculi locum lenenlibus, marginem non allingentibus; indusio crasso, reniformi, basi adharente, ad ambritum libero; sporangïs congeslis, elliplicis, longè pedicellatis, pedicellis latis, fasciculatis, stomio angrusto el annulo crasso, 12-15 arliculato donatis; sporis ovoideis, luberculosis.

Froxdibes pinnatifidis, Polypodia referentiburs; segmentis spissis, apice dentatis: nervillis liberis, in sterilibus furcatis, in fertilibus simplicibus; rhizomate repente.

Filix erecta, pinnatifida, Philippinensis, stricı, glabra; nervillis Gleicheniam referens.

Diagnosis: Tab. xxv, B, fig. 1. P. parallelım, F. (Davallia, Wact.; Nephrodium Gaimardianum, Gacb.)

Le Pteroneuron est une fougère à fronde pinnatifide, raide, dont les segunents sont horizontaux. Les nervilles sont libres, parallèles, bifurquées, épaissies et applaties; les sporothèces sont situés près de la marge. L'indusium est épais, fortement fixé par sa base; il est absolument semblable à celui des nephrolepis. Les nervilles des frondes qui restent stériles sont bifurquées et recourbées de dedans en dehors; celles qui deviennent fertiles sont simples en apparence, mais on peut reconnaitre, à la courbure brusque de ces mêmes nervilles, que le rameau interne se continue, et que le rameau externe, qui avorte, est remplacé par le sporothèce. Celui-ci, en apparence axillaire, est en réalité terninal, puisqu'ou le trouve attaché au point de développement d'une nerville rudimentaire.

SPECIES.

Parallelum (Davallia, Ilook.; Nephrodium Gaimardianum, Gaudich.*).

150. SACCOLOMA, Klfss. (1824.)

Enum. filic., P. 124.

Neuropteris, Desr. - Davallia, Subgenus Sacconon.t reductum, Hоок., Spec. filic., p. 170 .

Sporothecus apici venarum dilatato insertis, planiusculis, transversis, demim, contignis, lineam submarginalem formantibus; indusio transwersè v'rulvalo e.z- 
trorsim aperto; sporangiis ovalibus; annulo 16 arlicululo; sporis trigonis ocalibusyue.

Froxdibus pinnalis, membranaceis, pellucidis; pinnis lanceolatis, incequalibus, upice dentatis; nervillis parallelo-furcatis.

Filix erecta, magna, pinnata, Americana; facie nonnullarum specierum Litobrochict.

Dingnosis : Ноок. et B., Gen. filic., t. Lviı, B. S. elegans, Kaulf., I. cit. Tub. nost. xx, B, fig. 2 (fragmentum).

Nous réduisons ce genre-à trois espèces seulement, et nous les séparons des davalliées, nous fondant sur cette consideration que les indusium sont attachés à la base et libres dans leur pourtour, ce que la diagnose, donnée par MII. Bauer et Hooker exprime clairement. N. Hooker, dans son Species filicum, ne fait plus du Saccoloma qu'un sous-genre du Davallia et il y a fait entrer beacoup' d'espèces qui sont pour nous, pour la plupart, des Microlepia à sporothèces cyathiformes, dont les indusium, attachés par les côtés, ne deviennent libres que vers le sommet.

\section{ENUMERATIO SPECIERUYI.}

Lilegans, Klfss.* (Hook., Gener. Fil.*; F., fragm.*; Neuropteris, Desv.*) - Imrayana (Datrallia, Honk.*) - Hookeriana (Davallia, Wall., Hook.*).

\section{PACHYPLEURIA, Presl. (1849.)}

Epim. bot., p. $9^{8}$.

Scyphofilix, Асв. du P'т. Tн., Gener. Madagasc., n. ??

Davallia, \$. II, Pachypleuria, Prest, Tent. pterid., p. 128.

Davallice et Humata spec., Desv., J. Sis.

Adianti spec., Lisv., Supp. 146.

Sровотнеси lerminalibus, in sinu denlium sitis; indusio suborbiculari, sericro, nitente aul reniformi, orbiculalo, basi rolundo latè affixo; sporangïs parvulis, pedicellis fasciculatis; annulo $10-11$ articulalo; sporis subglobosis.

Froxdres pinnalifidis, bipinnalis, pedatis, coriaceis, conformibus; nervillis liberis, apice clavalis, inferioribus angulum aculissimum aperientibus; vemulis tenuibus; rhizomate longè repente, squanis acuminatis hirlo.

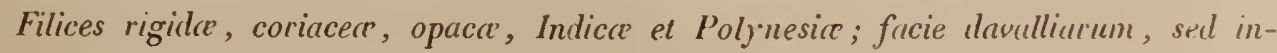
dusio libero.

Ce genre, que nous plaçons dans les néphrolépidées, a, par les frondes, le port des davalliacées, et il est même assez voisin des Davallia. Le caractère qui 
nous a déterminé a lui donner la place quil occupe ici est tiré de l'indusium. Ce tégument, libre seulement vers le sommẹt dans les davalliacées, n’est fixé dans le Pachypleuria que par sa base. La nerville étant élargie vers le point fructifere, onre une plus large surface d'insertion, ce qui explique comment il arrive que l'indusium, inférieurement arrondi, s'attache dans une plus grande étendue que dans la plupart des néplrolépidées.

Il diffère du Pleronzeron par des sporothèces terminaux et par des frondes pinnatifides à segments entiers, ayant une direction horizontale, les fertiles à nervilles simples, les stériles à nervilles bifurquées.

\section{ENUMERATIO SPECIERUM.}

Angustata, Presl (Davallia, Wall., II. et Grev.*) - pedata, Presl (Dacallia, Sw., Blum. ct Tees*) - sessilifolia, Presl (Davallia, Blım., Kze.*) - pecinata, Presl (Dasallia, Sm., Ilook. et Gr.*)

- lepida, Presl (1)acallia Cumingii, Hook., Sp. fil.*).

\section{HUMATA, Cavan. (1801.)}

Prælect. botan., n. 678 et 679 .

Sporotıecus super dorsum dentium frondium nascentibus; indusio orbiculato, dimidio superiori libero; sporangïs ovoideis; annulo profundè crenulalo, 1 2-13 articulato; stomio 6 nervalo, colorato, spisso, evidenter ex aunuli unodificalione proveniente; sporis ovoideis, luberculosis.

Froxidics sterilibus integris seu leviter crenulatis; nervillis pinnalis seu flabelliformibus; ferlilibus minoribus, dissimilaribus, crenulatis pinnalifidisque; slipile duobus fasciculis vasorum peragralo.

Filices Indica, repentes, arboricolcr.

Diagnosis: H. pinnatifida, C.rv., l. cil. - Hook. et B., L. cxiv. Diagnosis nostru, lab. xxv, fig. 1. H. ophioglossa, Cav., Pralect., n. 678.

Differt à Pachypleuriâ frondibus dissimilaribus; nervillis temuioribus, apice non clicuatis.

Le port de l'Humata, genre oligotype, est semblable à celui des craspedaric (polypodiées); mais les nervilles sont libres, bifurquées et étalées en éventail. Les frondes fertiles sont épaisses, opaques, ovoïdes, à base légèrement cordiforme et constamment pédicellées dans l'H. helerophylla; lancéolées, acuminées et pourvues d'un long pétiole dans l'H. pinnalifida; les frondes fertiles, dans ces deux espèces, tendent à la forme pinnatifide.

\section{ENUMERATIO SPECIERUMI.}

11. ophioglossa, Cavan., (Davallia heteroplyylla, Sm., Sw. , etc.: Cuming, Philipp., n. ${ }^{\circ} 335$, in Merb. noslr.) - H. pinnalifida, Cavan. (Davallia, Sw., IIook. et Grev., Icon. Filic., 1. 230, exclus. synon.; Ilook. et Bauer, Gen. filic., I. civ, $\Lambda$; exclus. synon. 


\section{Considérations générales sur le groupe des Néphrolépidées.}

Les néphrolépidées établissent un passage très-naturel entre les aspidiées et les davalliées : elles diffèrent des premières par un indlusium attaché par une large base qui le retient même à la maturité des sporanges et des secondes par ce même indusium cordiforme et non cyathiforme. Quatre genres seulement le composent. Le Nephrolepis, qui a le port du Pleronevron; le Pleronevron, qui tend vers les Davallia; les Saccoloma et Humala, dont le port est spécial. Ces fougères, très-élégantes, sont pendantes ou rampantes. L'une d'elles est tuberculeuse, Nephrolepis tuberosa; la forme pectinée clomine parmi les espèces. Toutes vivent sous les tropiques.

\section{Indusiun in ambitu adherens el anticè apertun : DAVALLER.}

Herlacex, nervose, crectæ, rigidx.

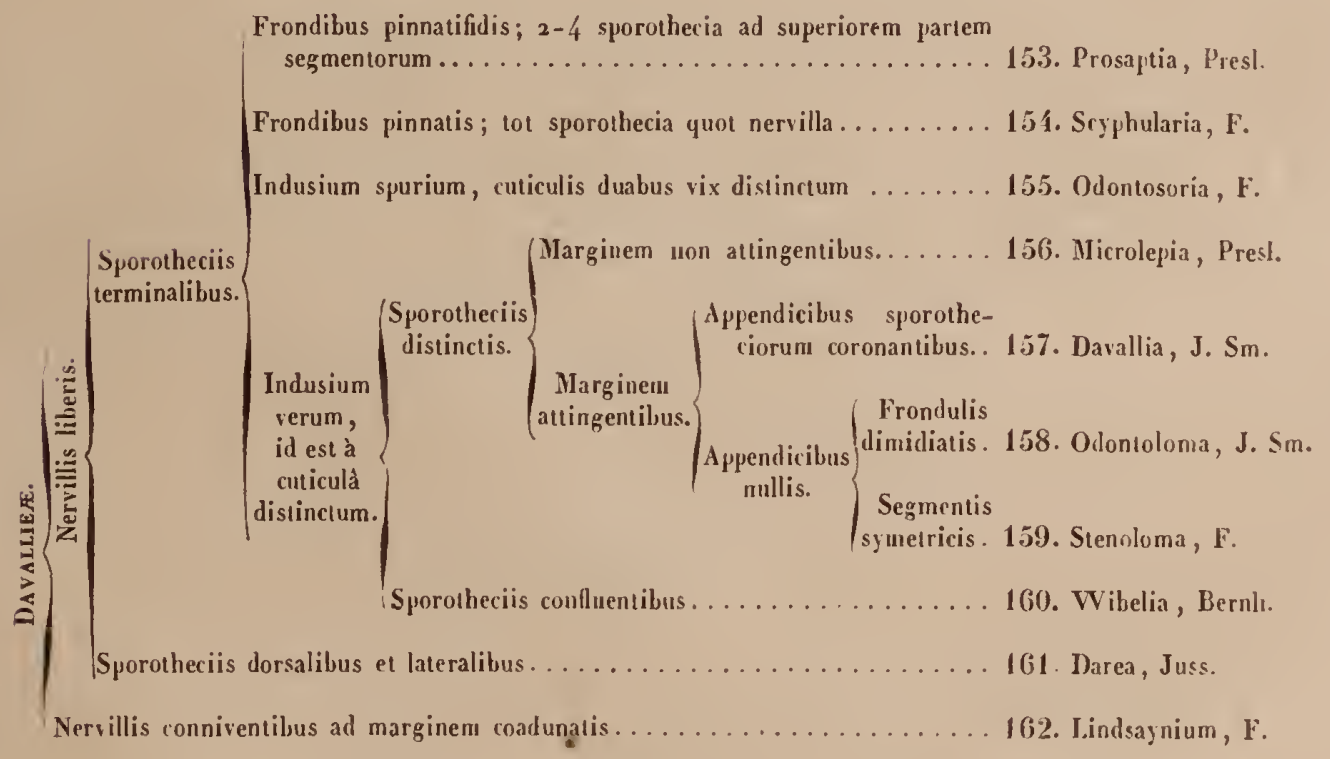


* Nervillis liberis.

\section{$\uparrow$ Sporotheciis terminalibus.}

\section{PROSAPTIA, Presl. (1856.)}

Tentam. pterid., p. 165 .

Druvalliar spec., Acct, plerin.

SPORотнесп1 elliplicis, ad apicem nervilla silis, marginalibus, endophyllis; culiculis duabus indusiiformibus, gibbosis, vix modificatis, supernè dilalatis; receplaculo minuto; sporangïs longè pedicellatis, ocalibus; annulo $10-11$ arliculato; stomio latissimo, sub 8 nervalo; pedicello flexuoso ; sporis rolundis: ovalis, nigrescentibus, granulis repletis.

Frovdibes pinnalifidis, laciniis ad apicem frucliferis.

Filices Indicre, erectre, rigidı, elasticre; fucie ferè Polypodii vulgaris.

Diagnosis: Prest, l. cit., t. vi, p. 19, 25 (nervatio sola), el Diagnosis uost., tab. Irvi, A, fig. 1. P. conligua, Buch. (Davallia, Mlver.)

Le type de ce genre est le Prosaptia pinnatifida de M. Presl, indigène des iles Plilippines, distribué par M. Cuming sous le $n .^{\circ}{ }_{261}$. Ces frondes sont raides, coriaces, pinnatifides au centre, et seulement crénelées à la base, se continuant sur le pétiole en décroissant successivement; les segments sont ciliés de poils raides et étoilés. Il est difficile d'apprécier les motifs qui ont fait placer le Prosaplia par M. Presl à côté du genre Villaria. Sans doute le docte auteur s'est cru autorisé à agir ainsi, parce qu'il n'existe pas de véritable indusium dans le genre Prosaptia; mais la situation terminale et intérieure des sporanges lui donne une place bien plus naturelle dans les davalliées.

\section{ENUMERATIO SPECIERUM.}

Emersoni, Presl (Dasallia, H. et Gr.*) - contigua, Presl (F.*; Davallia, Sw. , H. et Gr. $\left.{ }^{*}\right)-$ Preslii (Daiallia, Hook.).

\section{SCIPIICLARIA, F.}

Davallice spec., Accr.

Parestic spec., Press, Epim. Jot., p. 99.

SPORотнесиS scyphuliformibus, lenticulariformibus, apice nerilla simplicis, exteriùs arcuate, adnatis; receptaculo parculo; indusio spurio scyphuliformi, gibboso, à cuticulâ vix modificatâ formato; sporangiis longè pedicellatis, bast 
coalitis, pedicello continuo, viltato; stomio sub 7 nervato, latissimo, nervis flexuosis; sporis reniformibus, crassis.

Frovdres pinnatis, pinnis lanceolatis, terminali longiori; nervillis in laminis sterilibus, bifurcatis; in fertilibus, simplicibus.

Filices Juvanicce el Plilippinenses, erecta, coriacece, opacce; rhizomate repente, squamis nigris vestilo.

Diagnosis : tab. xxvı, B, fig. 1. S. pentaphylla. (Davallia, Bucss, KzE., Die Farrenkr., II, 1. crin.) Dicksonia tenera, MART. (fragmentum, ad comparandum).

Le genre Scyphularia est fort distinct entre tous les genres de ce groupe intéressant. Il ne renferme jusqu'ici que deux espèces à rhizone rampant, hérissé d'écailles noirâtres et longuement acuminées; les frondes s'y trouvent attachées à longs intervalles : elles sont pinnées, ternées et parfois simples, comme il arrive par avortement à la plupart des frondes ternées; les frondules tendent à la forme linéaire ou lancéolée; elles ont une consistance cartilagineuse et ne se laissent pas pénétrer par la lumière.

\section{ENUMERATIO SPECIERUM.}

Pentaphylla (Davallia, Blum., Hook., Kze.*; Zollinger, Pl. Javan., n.0 1778) - triphylla (Jraillia, Hook.*).

\section{5.. ODONTOSORIA, F.}

Sровотнесиs terminalibus, endoplyyllis, ad apicem venulae sitis, post lapsum sporangiorum scyphum vacuum simulantibus; indusio crasso, spisso, vix ì culiculâ dissimili; sporangiis pyriformibus; slomate lato, 10 nervato, nervis approximatis; annulo crasso, $10-20$ articulato; sporis globosis, magnis, flavescentibus, umbilicatis cristatisque.

Froxdibcs decompositis, flexuosis, scandentibus, aculeatis; segmentis crenatis, dimidiatis; nervillis flabellato-furcatis; stipitibus angulatis, aculeatis, fasciculo vasorum solitario trajectis.

Filix facie Lindsnyarum, scandens, glabra, volubilis, armala, Americana.

Diagnosis : 1. xx v11, B, fig. 1, B, O. uncinella (Davallia, KzE.); fig. 2, Stenoloma dumiosum, F. (Davallia, Sw.) [ad comparandum?.

Differt à Davalliâ, nervalione, habilu generali, sporarum el sporangiarum formâ.

Ce genre ne renferme qu'une seule espèce grimpante et presque sarmenteuse; les stipes, tortueux et rameux, portent de courts aiguillons; elle est glabre dans toutes ses parties. Les sporothèces naissent dans le mésonèvre qui se creuse en godet. La cuticule supérieure se soulève et constitue un indusium bombé qui s'ouvre antérieurement à la manière d'un calyce. Il se distingue du Stenoloma, 
à côté duquel le port tend à le placer, par des frondules plus larges, ni cunéifornes, ni linéaires, ni dichotomes. Cettẹ fougère est indigène de l'Amérique tropicale.

\title{
SPECIES.
}

O. uncinella (Dacallia uncinelta, Kze.*).

\section{MICROLEPIA, Presl. (1836.)}

\author{
Tentam. pterid., p. 12.
}

Microlepia el Lencostegice spec., Prisi et J. S.

Deunstïltia, Berviı, in Schrad. Journ., 1801.

Crenopteridis spec., Wilıb., Phytogr., cum iconib.

Sрокотнесі ss subrolundis, depressis, cyalhiformibus, submarginalibus, nunyuim resupiualis, ad apicem venula marginem non allingentis affixis; indusin semi-orbiculari, scarioso, anterius truncalo, venulis marginalibus mullis; sporotheciis ovalibus; annulo lalo, 20-28 articulalo; sporis trigonis, rarò ovralibus. FroNmbes pinnato-pirnatifidis, aut tri-bipinnatis, segmentis ultimis plis minùsve denlalis; nervillis liberis, tenuibus.

Filices erecta, plurisecta, tropicales, fucie Aspidiorum.

Diagnosis : Ноок. et B., Gen. filic., 1. Lviı, A. M. incequalis, Prest, I. cil., 1. W, p. $21-13$.

Differt à Davalliâ habitu et absentid appendicium cornigerum, sporollecin amplectrantium.

Ce genre, composé d'espèces à frondes décomposées et à segments dentés ou lobés, a le port des dicksonia. Il en diffère par des sporothèces cyathiformes et par un indusiun attaché par les côtés dans toute son étendue, s'ouvrant au sonmet sans se redresser. Les nervilles fructiferes n'atteignent que rarement la marge des segments; les sporothèces restent par conséquent intra-marginaux et couchés; leur partie antérieure, tronquée, vient souvent s'affleurer à la marge. Ce genre est très-voisin des dcovallia, à côté desquels il faut définitivemen le placer. Il en diffère par des sporanges à peine exsertes, par des sporothèces prenant naissance sur des nervilles de troisième ordre, se dirigeant vers les sinus des derniers segments intra-marginaux; ces plantes sont aussi moins féraces et leurs spores trigones.

\section{ENUMERITIO SPECIERUII.}

Nigricans, Presl (Dacallia incequalis, Kze.) - rhomboidea, Presl, fragn..* - trichosticha, J. Sm. (Dacallin, Hook.; Cuming, Fil. Phit., n..0 328) - decurrens (Dasallia, Ilook. fragm.*; Cuning. Fil. Phil., n. ${ }^{350}$ ) - Khasiyana (1)asaltin, Ilook., fragm.*) - strigosa, Presl (Dicksonia, Sw. 
hze.*, Hook., fragm.*) - polyantha (Davallia, Hook., fragm.*) - Plumieri (Dicksonia, Hook.*, Plum.*) — Lindeni (Dicksonia, Hook., fragm.*) - villosa (Davallia, Wall., Hook., fragm.**) calvescens (Davallia, Wall., Hook., fragm.*) - hirla (Davallia, Kllss.; Dicks. Kaulfussiana, Gaud.) - ? lonchitidea (Davallia, Ilook., fragm.*) - flaccida (Dicksonia, Sw., Sehkh.*; Dennstädtia, Bernh.*) - multifida, Presl (Crenopteris Japonica, Willd.*) - hirsuta, Presl (Leucostegia, J. Sm.; Davallia ciliata, Hook., fragm.*) - alata, J. Sm. (non Davall. inøequalis, Kze.) tenuifolia (Leucostegia afinis, J. Sm. [partim], Cuming, Fil. Phil., n. ${ }^{\circ} 215$ ) - Galeotii, F. caudala, F. - ademalosa? (Funk. et Sehl., "1. ${ }^{\circ}$ 1224) - incisa, F. - mollis, F.

\section{GALEOTTII.}

\section{SPECIES NONDUM DESCRIPTE.}

Frondibus subtripinnatis, ovatis, glaberrinis, slipile lavi et rachibus canaliculatis, pinnulis acuminatis, ultimis segmentis ovalis, denlatis, glabris, oblusiusculis; sporolheciis parvis, indusio culicula vix diverso submarginali; sporangiis crassis, lenliculuribus; annulo latissimo, 24-26 arliculalo; sporis obscurè trigonis rolundisque.

Habitat in Mexico. (Teotalengo, Galeotti, n. 6526.)

Filix glabra, segmentis symetricis, glaberrimis, siccitate lcctè virescenlibuts.

(Dimensions : longueur de la fronde, 45 centim., des principales pinnules, 20 eentim.; sur 6-7 centim. d'envergure; nous en comptons 19 paires distinctes presque jusqu'au sommel; celte espéce est très-différente de la précédente.)

\section{Caudata.}

Frondibus subquadripinnatis, glaberrimis; stipitibus helveolis, sulcatis; rachibus tenuibus, helveolis, apice filiformibus, flexuosis, pinnis subbipinnatis, caudalis, caudâ longissimâ, lineari, denlalo-incisâ; ullimis segmentis dimidialis, remolis, infernè inlegris, supernè incisis, basi longè cuneatis, incisuris monocarpicis; sporotheciis submargiualibus; indusio crathiformi, à cuticula vix distincto; sporangiis paucis; annulo lato, creutulato, 18-20(?) arliculato; sporis trigonis.

Habilat in Mexico. (Teolalengo, Galeott., n. 6527.)

Filix mugna, siccilate viridis, partitionibus el segmentis remotis.

(Dimensions : longueur totale, sans le slipe, 82 eentim.; une vingtaine de pinnules, dont la plus grande a près de 20 eentim.; les piunules sont terminées par une pointe ayant 5 ou 6 centim. de longueur; les derniers segments sont très-étroits et mesurent 2-3 millim.)

Le genre Microlepia, qui renferne les davalliées à sporothèces couchés, bombés, terminaux, non protégés latéralement par des appendices nervillaires, comıne dans le Davallia, et qui jamais ne sont redressés (résupinés) conme dans le Dicksonia, est destiné à s'accroître considérablement. Quoique nous ayons réduit à deux le nombre des espèces nouvelles que nous décrivons, nous aurions pu facilement en décrire davantage; telles sont les espèces suivantes que nous nous contentons d'indiquer: 
1. M. oedexitosa, Funk. et Sehlim. Venezuela, n. 1221. Remarquable par ses spurothèces fortement bombés et très gros, occupant le rameau supéricur de la nerville externe, eclui qui se dirige vers les sinus lobulaires; elle est grande "t plusieurs fois pinnée.

2. 11. 1xcisa. Grande fougère de la Guadeloupe à pinnelles ovales profondément incisées, à sporothèces terminaux extrêmement petits. (Hert. Mouor.)

3. H. solus, de Bourbon, à pinnules flexibles et entièrement eouverte de poils blancs, mous et strigilleux; à stipe et rachis rougeâtres, à sporothèces petits, n'alteignant pas la marge.

157. DAVALLIA, Sm. (Sw., 1S01), reductum.

Stenolobus et Davallia spec., Prese, Tentam. pterid., P. 127 et 129.

"V'ibelice spec., Berwu., in Sehrad. journ., 1801.

Microlepice et Leucostegice spec., J. S»., Enum. filie. Cusnsar.

Trichomanoidis spec., L., Forst. Prodr. fl. Insul. austr.

P'arestice spec., Prest, Epim. bot., p. 99.

SPокотнесіs pyxidalis, subrolundis, ore marginali, processis $1-2$ elongalos, laterales, corniformes, oblusos ferente; indusio firmo culiculâ laminarum vì. modifucalâ formato; sporangiis elliplicis, exserlis; annulo 14-16 arliculalo; sporis reniformibus, crassis.

Froxdbes sapè Iriangularibus, bi-pluriesque pinnalo-seclis, laciniis ullimis anguslis, scepè bifidis; ramis incequalibus; nervillis pinnalis; rhizomate crasso, syuamigero.

Filices erectıe, patulce, multisectce, iu Europâ australi, Africâ septentrionali, Asî̀ et America tropicali crescentes.

Diagnosis : Ноок. et B., Gen. filie, t. xxvi. (D. pyxidutu, Cavan.)

Inter Davalliam et Stenolobum uulla differentiu essentialis exstat, uisi in dimensione sporotheciorun, apud Stenolobum longiorum. Hoc genus differt à Leptopleuriut, Pachypleutiâ, Pteronevro, Hunata el Nepltrolepide indusio ad apicem aperto et lateribus numquàm liberis.

Nous réduisons ce genre à un certain nombre d'espèces de port semblable, dont le type est le Davallia Canariensis, L. Elles ont des frondes surdécomposées, à segments fructiferes vers le sommet ou latéralement. Les nervilles se chargent de sporanges longuement pédicellées, qui partent du même point et sortent du sporothèce pour se mettre en rapport avec l'air et la lumière; lindusium est bonbé, attaché par les côtés et s'ouvre vers le haut comme dans le Microlepia. Les sporothèces, largement tronquées antérieurement, présentent latéralentent, tantòt un et tantôt deux appendices cornus qui s'élèvent plus ou 
moins et sont traversés par une nerville peu distincte du point où s'atlaclse l'indusium, avec lequel souvent même confinent ces sporothèces. Cette disposition donne aux davallia fructifères une apparence singulière, qui les fait reconnaitte entre tous les autres genres.

\section{ENUIERATIO SPECIERUM.}

Vestita, Blum. (Hook., fragm.*) - solida, Swv.. (Schkh.*, Hedw.*; Stenolobus, Presl, fragm.*) - elegans, Sw. (Hook.*; Dav. bidentata, Schkh.*) - nitidula, Kze (Hook., fragm.*) - Griffithiana, Hook. (fragm.*) - bullata, Wall. (Hook.*, fragm.*) - chcerophylla, Wall. (Hook.*, fragm.*; Leucostegia ligulata, J. Sm.) - Novce-Zelandice, Colens (Hook., fragm.*) - falcinella, Presl* - menibranulosa, Wall. (Hook., fragm.*) - elata, Sw. (Sclikh.*, Bernh.*, Hook., fragm..*) - Mauritiana, Hook. (fragm.*) - pyxidata, Cavan. (Hook., fragm.*) - Fejeensis, Ilook. (fragm.) - Canariensis, J. Sm. (Hook., fragni.*) - Amboynensis, Hook. (fragm.*; Dicksonia straminea, Bory) - Lindleyi, Hook. (fragm.*) - Vogelii, Hook. (fragm.) - gibberosa, Sw. (Schkh.*) - parvula, Wall. (Hook. et Gr.*) - Lindeni, Hook. (fragni.*) - Schimperi, Hook. (fragm.* F., tab. xxuı, fig. 4) - ? concinna, Schrad. (Kze.).

\section{ODONTOLOMA, J. Sm. (1838?)}

In Journ. bot., Hook, reduct.

Saccolomatis spec., Presl, Tentam. pterid., p. 125.

Dicksonice, Davallice, Adianti, Aspidii, Aucr. var.

SPORотнесі1s hemispharicis, terminalibus, apicem nervillos unicae aut rarò duarum nervillarum coronantibus, suprà dentes laminarum sitis, continuis aut rariùs interruptis; indusio spurio, culiculâ inferiori constituto; sporangiis. crassitudine mediocri; annulo $10-11$ articulato; sporis rotundis, parvulis.

FRONDıus pinnatis, segmentis bifidis aut dichotomis, linearibus; nervillis flabellatis, furcatis, distantibus; caudice repente, incequali.

Filices scandentes, facie Adiantorum Lindsayarumque, Indiarum aut Africre australis insularum incolce.

Diagnosis : Ноок. et B., Gen. filic., t. cxıv, B. Tab. nost., xxvı, A, fig. 2. (O. Boryanum, J. Ss.)

C'est sur l' $O$. Boryanum que nous établissons le caractère de ce genre fondé par II. J. Smith. L'O. pulchellum, J. Sm, est un peu dissident, et l'O. Parkeri, Hook, en diffère à peine; quant à l' $O$. hemipterum, c'est peut-être un individu jeune de l'O. Boryanum.

\section{EIUMERATIO SPECIERUM.}

O. Boryanum (Davallia, H. et Gr.*; Saccolonia Boryanum, Presl, fragm.* - pulchellum, J. Su. . F.*, Field. et Gardn.* (Cuming, n. ${ }^{\circ}$ 217) - ? hemipterum (Davallia, Bory*, in Voy. Berang. [sterilis]) - Parkeri, Presl (Davallia, Hook.*) - adiantoides, Presl (Saccoloma, Presl ; Davallia adiantifolin, Hook.). 


\section{STENOLOMA, F.}

Lindsece spec., Willd., Sp. plant. (F. Filic.).

Davallice spec., Hоoк., Spcc. filic., tom. I. ${ }^{\text {er }}$

Sporothecus marginalibus, depressis, ad apicem laciniarum anguslarum sitis; indusio scarioso, tenui, dentalo, supernè hianti, subbivalvi, super 1-2-3 nervillas sedente; sporangiis pyriformibus, magnis; annulo 16-24 articulato; sporis ovoideis, lavibus.

l'roxdibes decompositis, segmentis ultimis integris, elongato-cuneiformibus, glaberrimis, 2-3 nervalis; rachibus elongatis, helveolis; rhizomate (saltem in $S$. clavalî) repente; pilis intesliniformibus, strangulatis, rufescentibus.

Filices erectre, glaberrimce, tenerce, tropicales.

Iniagnosis nostr. : tab. xxwn bis, A, fig. 1, S. Schlechtendalii; fig. 2, Bhumeanum; fig. 3 , clavatum; fig. 4, aculeatum; fig. 5, P Lindsayoides; fig. 6 , fumarioides.

Fougères délicates, à long stipe glabre, lisse et jaunâtre, portant des rameaux filiformes, auxquels s'attachent des segments cunéiformes, dilatés pour recevoir le sporothèce revêtu d'un indusium un peu frangé en ses bords et fixé sur deux ou trois nervilles très-déliées. Ce genre n'est pas sans analogie avec l'Odontosoria du groupe des davalliées. Il en differe par ses sporothèces simplement recouverts d'un indusiun appliqué sur les sporanges et séparable par le sommet et par les côtés, tandis qu'il est pyxidiforme dans l'Odontosoria, bombé et déhiscent antérieurement.

On troure, parmi les espèces de ce genre, une plante embarıasante et qui peut-être pourrait servir de type à un genre distinct. Les botanistes la connaissent sous le nom de Lindsaya microphylla. Elle a un port spécial et ne peut rester avec les lindsaya, dont elle diffère beaucoup. La cuticule, formant indusium, est modifièe des deux côtés et dentée élégamment au sommet. (Voỵ. tab. IIVII (bis), fig. 5.)

\section{ENUMERATIO SPECIERLII.}

Schlechtendalii (Daiallia, Presl) - Blumeanum (Odontoloma, J. Sm.; Davallia, Ilook., fragm.*) - aculeatum (Davallia, Sm., Plum.*, Sloan.*) - fumarioides (Davallia, Sw., Schkh.*) - dumosum (I)asallia, Sw.) - ? Lindsayoides (Lindsay*a microphylla, Sw., H. et Gr.*) - clawatum (Sw.; Dasallia venusta, Schkh.*) - retusum (Davallia, Caran.) - tenuifolium (Davallia, Sw. . Presl, fragm.*) - ? Goudolianum (Davallia, Kze.). 
160. WIBELIA, Bernh. (1804.)

In Schrad. Journ., 1801 , p. 122, t. I, fig. 2.

Davallice spec., Cavar., Hoor. - Saccolomatis et Microlepice spec., Prest. - Microlepice spec., J. Su.

SPOROTHEClıs intrà-marginalibus, elongatis, transversis, sapè binis, ad apicem latè hiantibus; indusio spurio, fornicato; sporangiis pyriformibus; annulo lato, 16-18 articulato; sporis ellipticis, vix reniformibus.

Froxdibus pinnatis; frondulis elongatis, irregularibus, flagellatis, linearibus; nervillis pinnatis, simplicibus aut bifurcatis; sporotheciis ad nervillas simplices solitariis, sed ad nervillas bifurcatas geminis.

Filix indica, pinnata, rigida, glabra, fronduiis incequalibus.

Diagnosis : tab. xxvu bis, B. (Wibelia pinnata, Bernh.)

Les frondules sont symétriques ou dimidiées, et portent sur l'une et l'autre narge des sporothèces attachés au sommet de chaque nervure. Lindusiun est intra-marginal, concave et assez consistant. Il persiste, et comme il confine de très-près avec celui qui naît sur le même lobule, il rend facile la confluence des sporothèces; ceux-ci prennent alors la forme allongée 1 . Cette plante appartient au moins autant aux davalliées qu'aux lindsayées; elle est raide et terminée par des frondules inégales.

\section{ENUNERATIO SPECIERUNI.}

W. pinnata, Bernh. (Hook.*; D. fagellifera, II. et Gr.*; Davallia, Cavan., F.*, fragm.) bipinnata (Dav. Luzonica, Hook., fragm.*) - pectinalis, F. (Lindsaya dubia, Kze.*. Hook.*). Javer.

Nous regardons, comme nouvelle, l'espèce suivante, que nous signalons a l'attention des botanistes.

IV. JAVE.

Frondibus pinnatis, glabris, stipite subquadrangulari; frondulis linearibus, integris, repandis, incequalibus, abruptè decrescentibus, angulum $40^{\circ}$ cum rachidi metientibus, crenatis, acumninatis, basi cuneatis, passim subauriculatis; nervillis scalpturatis, bifidis, ramis duobus fructiferis; sporolheciis parvis, à margine frondis iemotis; sporolheciis minutis; annulo 14-16 articuluto; sporis subreniformibus.

Habilat in Javâ. (Kollmann, Herb. cl. Mioug.)

Filix extensa, in ambitu lanceolata, flexibilis, glabra.

(Dimensions; longueur totale, 70 centim.; stipe et rachis déliés; frondules (les plus longues). 15 -16 centim., sur 5 millim. à peine de largeur; entre-nouds, 25 millim. de largeur. Les froudules se redressent rers le stipe; la terminale est fortement crénelée.)

1. La planche des Icones filicum de MIM. Hooker et Greville ne rend pas comple de ectte organisation. 


\title{
计 Sporotheciis dorsalibus et lateralibus.
}

\section{DAREA, Juss. (1789.)}

\author{
willd., Spec. pl., Filic., p. 295.
}

Cernopteris, Bergu., non P'resL, Epim. bot., p. 262.

Asplenii spec., Presl, Acct. var. - Conopleridis spec., Acct.

Sровотиесиs oroideis, clongatis, linearibus, solitariis, marginalibus aul submargrinalibus; indusio plano, tenui, crasso, convexo, lateribus affixo, anterius solulo; sporangïs ovalibus, pedicello arliculalo; slomio quadrinervalo, brevi; annulo 18-20 arliculato; sporis ovalibus reniformibusque, episporio crislaformi vestitis.

Frovdres varie divisis, segmentis ullimis linearibus, sapè bifidis, rigidulis anl mollibus; stipitibus stramineis seu fusco-badiis, lenuibus; nervillis pinnatis marginem allingentibus; rhizomate crasso, fibrilloso.

Filices tropicales, herbacea, terrestres, glaberrimce, semper divisce, rarò viviparce. Facie in plurimis, Aspleniorum, in paucis, Davalliarum; confines inter Asplenia. et Dareas; determinatu perdifficiles.

Diagnosis: tab. xxw1, C, fig. 1, D. incrqualis, Wııь.; fig. 2 et 3 , partes aliarum specierum; fig. 4, Davallia Schimperi, Ноок., ad comparandum.

Ce genre se rapproche des asplenium, et cependant nous le plaçons à une grande distance des aspléniées; c'est qu'il nous a semblé que, indépendanment des différences notables de port qui les rapprochent des davalliées, l'indusium, comme dans les fougères, appartenant à ce groupe, n'est débiscent que vers le sommet, les côtés restant parfaitement adhérents. Il s'ouvre, en devenant béant, par simple dilatation, en simulant une fente. Les davallia s'unissent aux darea par les Dav. Lindenii et Schimperi, ayant, l'une et l'autre, l'organisation des davallia, au point de faire hésiter auquel de ces deux genres il convient de les rapporter.

II. Presl, Epim. bol., l. c., a rélabli le genre Canopleris de Bergmann, pour y renfermer l'O. Japonicum de Kunze, que nous persistons à laisser parmi les ony.chium.

\section{EIUMERATIO SPECIERLI.}

Furcata, Willd. (Cenopteris, Bergm.*, Schkh.*, Jacq.*) - rutcefolia, Willd. (Cenopleris, Bergn.*, Thunb.*) - scandens (Asplenium, J.Sm.) - ? palmata, Kifss. - flaccida, Willd. (Thunb.*, Schkh.*, sub Canopteride) - vicipara, Willd. (Cenopleris, Bergm.*) var. faniculacea, Sieber - incequalis, Willd. (Cenopteris, Bory) - appendiculata, Willd. (Coenopteris, Labill.*) - odontites, Willd. (Canopleris odontiles, Thunb., Schhh.*) - bifida, Klfss, , in Sieb. (intermedia, Klfss.) - rhizophy.lla, 
Will. (Cenopteris, Thunb., H. et Gr.*, Sloan.*) - cicutaria, Willd. (Canopteris, Thunb.*, Petiv.*, Plum.*; Asplenium, Sw., H. et Bauer*) - myriophylla, Willd. (Coenopteris, Sw.) - foecunda (Asplenium, Kze.; Cenopt. vivipara in hortis variis, non Darea vivipara, Bergm.) - ? thalictroides (Conopteris, Loud.?) - ? Millefolium (Cuming, Pl. chil., n. $\left.{ }^{\circ} 324\right)$.

\section{** Vervillis conniventibus ad marginem coadunatis.}

\section{LINDSAYNIUM, F.}

Lindsayce spec., J. Sr.

SPOROTHECIS interruptis, marginalibus, ad apicem furcalurae nervillarum sedentibus; stomate 8 nervato, nervis inaqualibus, obliquis; indusio tenui, membranaceo; sporangiis ovatis; annulo 14 articulato; sporis trigonis.

Froxdisus bipinnatis, pinnis linearibus, pinnulis obliquis, supernè articulatis, subsessilibus; nervillis paucis, scalpluratis, bifurcatis, ad marginem incrassaIum coalitis; stipitibus stramineis, fasciculo vasorum unico elliplico peregratis.

Fitix Malaccensis, rigida; fucie Lindsayce, sed nervatione diversa.

Diagnosis : tab. xхиı bis, C. (L. rigidum, F.; Lindsaya, J. Sм., Ноок.")

Ce genre monotype est facile à reconnaitre à ses frondules dimidiées, entourées d'une forte nervure marginale qui provient du pétiolule, et unit tout le système vasculaire. Les nervilles sont en relief et bifurquées; les sporothèces n'occupent que le sommet des découpures antérieures de la frondule. Il n'y a ordinairement qu'un seul, mais parfois on en compte deux.

\section{Considérations générales sur le groupe des Davalliées.}

Nous n'avons que peu de particularités à ajouter à ce que nous avons dit page 29. Ces fougères sont, après les hyménophyllacées, les plus délicates de toutes les plantes qui composent cette vaste classe. Elles ont, avec les lindsayées, des rapports évidents par l'indusium, surtout lorsqu'il s'allonge par confluence des sporothèces. Exemples : Odontoloma et Wibelia. Le Darea n'est pas sans analogie avec le genre Asplenium. On retrouve le port des polypodium chez le Prosaptia, et Je Microlepia ressemble à des athyrium. Mais ces rapprochements se bornent aux frondes. La fructification, bien étudiée, montre ces plantes assez étroitement groupées. Elles sont exclusivement tropicales. 


\section{Indusium inferum membranaceum : IIIPoCILLAIIDEE.}

Filices herbaceæ, rarò arborescentes, erectæ, amplæ, ferè omnes decomposita.

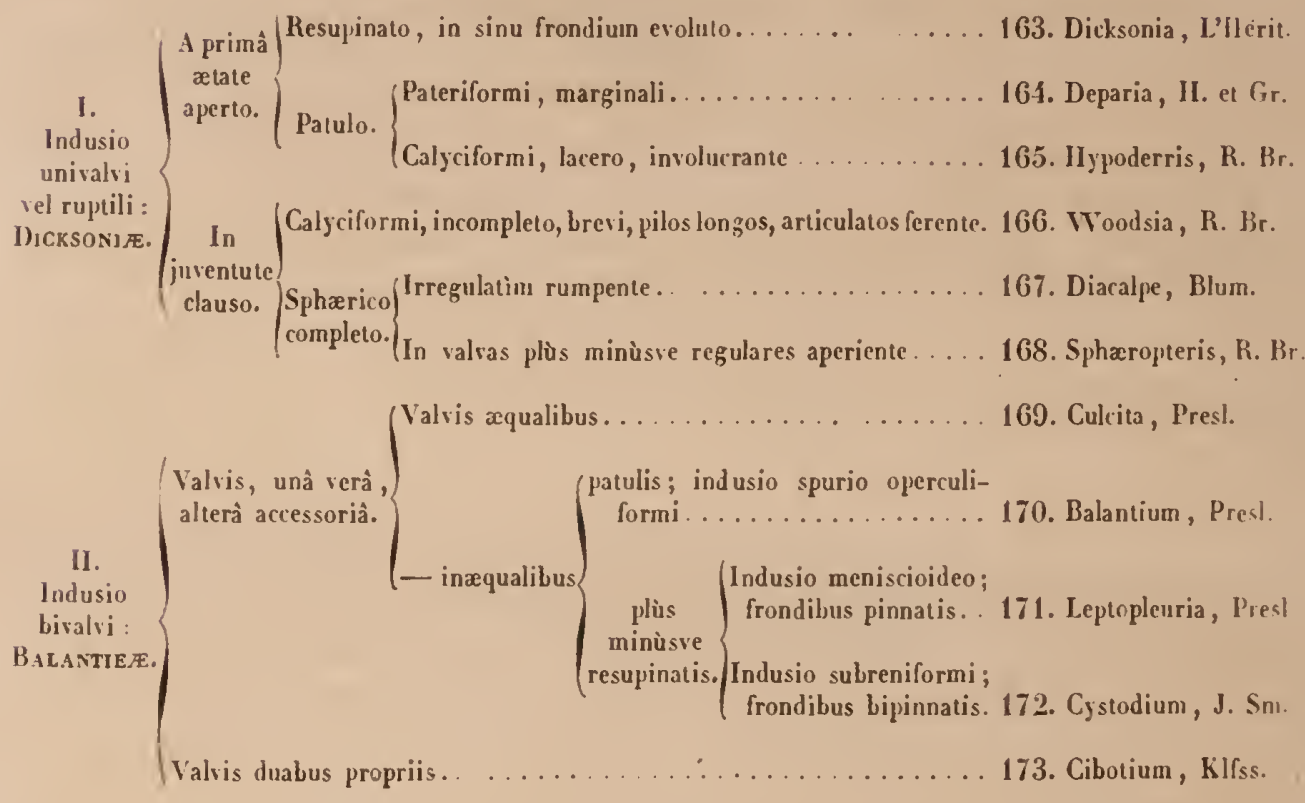

\section{Univalve: DICKSONIEAE.}

\section{A. Indusio cupuliformi, à primâ xtate aperto.}

\section{DICKSONIA, L'Hérit. (1788.)}

Sertum anglicum, p. 30.

Balantii spec., PresL, Tentam. pterid., p. 134.

Patruia, Press, l. cit., p. 137. - Sitolobium (nelius sitobolium), Desv., dnn. soc. Linn. de Paris, v, 262. - Adectum, Lk. - Microlepice spec., PreSt, l. cit., p. 124. - Neplirodii spec., Desv. - Trichomanoidis spec., Forst. prodr.

Sрокотнеслs resupinatis, cupuliformibus, ad apicem venularum sitis, marginulibus, in sinu laciniarum nascentibus, apice horizontali latè apertis; indusio membranaceo, molli, paterceformi, integerrimo, brevi, persistente; receptaculo punctiformi, minimo; sporangiis ovatis; annulo 18-28 articulato; sporis tri gonis, rarò cordiformibus vel ovatis, nigrescentibus. 
Frovdibus decompositis, herbaceis, amplis; venis pinnatis, tenuibus, pinnatim ramosis.

Filices tenerce, erectce, glabrce aut villose, Iropicales; facie Aspidiorum et Davalliarum.

Diagnosis : Hook. et B., t. Lxi, A. D. tenera, PresL, l. cit., t. v, p. 6 et 7 (nervatio). Tab. nostr. xxvı, B, fig. 2, fragmenta ejusdem plantce.

Genus Dicksonia in duo subgenera dividendum:

1. EUDICKSovia.

11. Sitolobiem.

Subgenus Sitolobium filices arborescentes includit; nescio an genus sit proprium? sed sporas verè labet Dicksoniearum.

Genus habilu Aspidiorum et Hypolepidum. Sporotheciis resupinatis, id est statu aperto, cum laminis verè parallelis. Limiles generis Diclisonice latiores quum in Specie filicum cl. Hookeri esse debent.

Ce genre nombreux renferme des fougères herbacées et quelques espèces ligneuses : elles ont toutes de grandes frondes décomposées et surdécomposées, glabres et parfois épineuses. Les sporothèces sont cupuliformes, mais au lieu d'être couchés et de s'ouvrir dans le sens de l'axe de la nerville, comme dans les microlepia, ils sont dressés et s'ouvrent par leur sommet qui serait parallèle à la cuticule inférieure s'ils n'étaient redressés. Tel que nous le comprenons, ce genre répond assez exactement au Palania. Dans la jeunesse de ce sporothèce, l'indusiunı est de même nature que les deux cuticules dont il paraît se détacher en se dressant. Le genre Davallia serait bien près du Dicksonia, s’il ne conservait avec la fronde un parallélisme parfait.

\section{ENUMERATIO SPECIERUM.}

Distenta, Kze. - Pavoni, Hook. (fragm.*; Plum.*) - adiantoides, HI., B. et Kth. (Hooh., fragm.*, Plum.*) - cicutaria, Sw. (Sloan.*, tenera Mart.*, Hook., fragm.*; Patania erosa, Presl, fragm.*) - expansa, Klfss. - dissecta, Sw. (Schkh.*) - apiifolia, Sw. (Hook., fragm.*) - rubiginosa, Klfss. (Hook., fragm.*) - punctiloba, Hook. (pubescens, Schkh.*) - Smithii, Hook. (fragm.*) - neglecta, F. (Guming, n. ${ }^{*} 108$, partim) - anthriscifolia, KIfss. (Hook., fragm.*) deltoidea, Hook. (fragm.*) - cuneata, Hook.* (Sitolobium, J. Sm.) - scabra, Wall. (Hook., fragm.*) - asperula (Polypod., J. Sm., Cuming, I. ${ }^{\circ}$ 63) - stenochlcena, F. - dubia, Gaud. (Balantium Brownianum, Presl) - Zippeliana, Kze. (scandens, Hort.) - Moluccana, Blum. (Lobb. Pl. Jav., n.0 260) - Mathewsii (Deparia, Ilook., fragm.*) - obtusa, Moritz.

\section{NegLeCta.}

\section{SPECIES NONDUM DESCRIPTA.}

Frondibus subquudripinnatis, rachibus pilosis, supernè obtusè canaliculatis, rufo-vinosis; pinnis lunceolatis, acuminatis, segmentis angustis, inciso-pinnatifidis, obtusis; sporo- 
theciis crassis, marginalibus; indusio cupuliformi persistente; sporangiis ovatis; (nnnulo 24-28 articulato; sporis trigonis reniformibusque.

Habitat in insulis Philippinis. (Cuming, $\mathrm{n}^{\circ} 108[$ partim].)

(Dimensions : une des grandes partitions, 38 eentim.; des pinnules, 5 - 6 eentim., sur 15 millim. environ d'envergure; nous en comptons environ 40 paires sur la partition que nous possédons. et sur chaeune d'elles une vingtaine de segments jusqu'au point où clle devient pimnatifide.)

\section{Stenochleva.}

Frondibus quadripinnatis, villosis, siccitate flavidulis; pinnis ovoideis, pinnellis lanceolatis, acuminatis, segmentis ultinis infernè integris, dimidiatis, supernè crenalis. crenis dentalis; sporotheciis submarginalibus; indusio brevi, tenui; sporangïs ovoideis; annulo 14 articulato; sporis trigonis.

Habilat in insuld Borbonia. (De Montbrison.)

Filix expansa, mollis, hirsuta.

(Dimensions : longueur d'une pinnule basilaire, 40 centim.; les pinnelles, qui sont eourtes. 18 eentim., sur 6 d'envergure; entre-nœuds, 4 eentim.)

\section{DEPARIA, Hook. et Bauer. (1842.)}

Gen. filic., t. XLIV.

Dicksonice spec., Kadlf. - Cibotii spec., Prest.

SPOROTHECns hemispharicis, marginalibus, exserlis, in dentibus venarum sitis; indusio infero, pateraformi, membranaceo, ecidem texturâ quam frons; ore dilatato, sublacero; receptaculo parso; sporangiis rolundis; anmulo 16 articulato; sporis ovoideis, nigrescervibus.

Froxdacs pinnatis, pinnis elongatis, profundè pinnatifidis; venulis simplicibus aut rarius furcatis.

Filix Sandwicensis, ampla, membranacea; facie Aspidiorum.

Diagnosis : D. prolifera, Ноок. еt B., l. cit.

Differt à Balantio indusio pateriformi uec bivalvi.

Le type de ce genre, dont les auteurs avaient fait un Dicksonia, est indigène des îles Sandwich; il a été très-bien figuré par MM. Hooker et Greville (Icon. filic., t. 154). Nous regardons le genre Deparia comme monotype. M. Hooker en décrit cependan deux espèces (Spec. filic., p. 85); mais nous voyons un Dicksonia dans le D. Mathewsii du Pérou admis par cet auteur. 
B. Indusium inrolucrale lacerum, basilare.

165. HYPODERRIS, R. Br.

In Wallich., Ic. pl. Asiat. rarior. in not.

SPORотнесп biserialibus, globosis, ad angulos confluentes venularum insertis; indusio calyciformi, membranaceo, reticulato, ad marginem fimbriato; receptaculo minuto, ferè obsoleto; sporangiis ovoideis; annulo subcompleto, 14 articulato; sporis margine crenulato circumdatis.

Frovdibus simplicibus, subcordato-auriculatis, acuminatis, pinnatim venosis, venis alternis, parallelis; nervillis pinnatis, undulatis, venulis reticulatis.

Filix insulce Trinitatis, simplex, membranacea, subcorduto-curiculata.

Diagnosis : Hook. et B., Gen. filic., to 1. H. Brownii, J. Sx.

Cette fougère est très-rare et peu connue; nous adoptons le genre dont elle est le type, d'après ce que M. Hooker en a fait connaître dans ses ouvrages; car I. R. Brown, qui en est le fondateur, ne l'a indiqué que sommairement. Elle a le port du Bathmium trifoliatum.

SPECIES.

Brownii, J. Sm. (Hook.*).

C. Indusium globulare, antè evolutionem clausum, dein irregulariter apice apertum.

166. WOODSIA, R. Br. (1815.)

In Linn. Transact., XI, t. 173 .

Pliysematium, KLFss, in Flora 1829.

Polypodii, Aspidii, Nephrodii et Acrostichi spec., Accr. - Alsophilae spec., Srrexg.

SpoRotuecus globulosis, dorsalibus; indusio membranaceo, primuim sporothecia undiquè tegente, dein irregulariter rupto et ad apicem lacerato, laciniis articulatis, elongatis; sporangiis rotundis, brevè stipitatis; annulo 16-18 articulato, articulis remotis; sporis crassis, ovoideis et reniformibus.

Froxdibes bipinnati-sectis, villosis, pilis articulatis; nervillis pinnatis.

Filices erecta, Americance, facie Aspidiorum et Phegopteridum. Geuns Hymenocystis habitn et indusii structurô, proximum est Pliysematio (cfr. Cy'stopteris, Веrs....

Diagnosis : Hook. et B., Gen. filic., t. cxix. (Woodsia hyperborea, R. BR.) 
In Physematiis legitimis sporothecia tardè aperiuntur et irregulariter rumpuntur ; in Woodsiis auctorum, sporothecia citiis dehiscunt et apicem lacerato-pilosum habent. Species omnes eundem aspectum offeruni, sed teslante indusio, in luo subgenera dividendie sint.

Woodst.t; indusio in lacinias elongalas articulutus partito.

Purst.u.ATLA; indusio apice irregulariter lacerato.

A l'exemple de M. Hooker, nous réunissons les genres Physematium et Woodsia, car il ne nous a pas semblé qu'il y eût des motifs suffisants pour les séparer, autrement que comme sous-genres. M. Hooker en adopte trois : le Physematium à involucre tendant à la forme globuleuse, dans lequel il fait entrer I'Hymenocystis de M. A. Meyer; le Perrinia, Hook., à involucre presque hémispliérique, et le vrai $W$ oodsia à involucre patériforme.

Quoiqu'il y ait lieu à réunir les plantes qui, aujourd'hui, composent le genre Woodsict, on doit déclarer qu'il n'est pas tout à fait naturel.

\section{ENUMERATIO SPECIERUM.}

1. Woons1A. = Itvensis, R. Br. (Engl. bot.*) - hyperborea, R. Br.* (Iingl. bot.*) - glabella R. Br. (Ilook.*).

B. Physruati. = Mollis, J. Su. $($ Physematium, Kze.*) - Guatemalensis, Ilook, fragm.* J'erusiana, ILook., fragm.* - Cumingiana (Physematium, Kze.) - elongata, Ilook., fragm.* - Perriniana, Hook. el Gr.* (Polypodium, Schkh.*) - incisa, Gill. (H. et Gr.*; Physematium, kz.e.).

\section{DIACALPE, Blum. (1830.)}

Enum. pl. Jav., p. 24 1.

Plysemalii spec., Kze., Analect. - Cyslopteridis spec., Prest. - Aspidii spec., Will., Catal., 359.

SpоRотнесиS globosis, sparsis, dorsalibus; indusio sessili, spherico, primum integro, deindè vertice irregulariter erumpente; receptaculo paroulo; sporangiis rolundis, brevè pedicellatis; annulo incompleto, 16-18 articulalo, vix apicem sporangiorun altingente; sporis ovoideis, subreniformibus.

Erovdres tripinnatis seu decompositis; nervillis liberis, pinnatis, tenuibus.

Filices ample, herbacea, tenerce, Javanica el Madagascarienses; affinis Aspidio et phegopteridi.

Diagnosis : Hook. et B., Gener. Filic., t. xcıx.

Typus : D. aspidioides, Buw.

Le port de ces plantes rappelle exactement celui des grandes espèces d'aspidium et de phegopteris. Les fougères qui en font partie, appartiendraient au pre- 
mier de ces genres, si l'indusium était réniforme et attaché par le sinus, elles rentreraient dans le second si les sporothèces étaient nus. Le caractère générique n'a donc point influé sur les organes de la nutrition, ce qui, d'après nos idées, en diminue la valeur.

\section{ENUMERITIO SPECIERUM.}

Aspidioides, Blum., Hook. et Bauer, l. cit.* - Madagascariensis, F.

\section{MaDaGaSCARIEISIS.}

\section{SPECIFS TONDLM DESCRIPTA.}

Froudibus anplissinis, tripinnatis, stipile et rachibus helveolis, profundè sulcatis; partitionibus prinariis, ovatis, pinnis lanceolatis, subsessilibus, pinnellis horizontatibus, sessilibus, suprà rachim decurrentibus, profundè dentatis, obtusissimis, horizonlutibus, dentibus omnibus proliferis; pitos strigillosos ferentibus; sporothecïs globutosis, rufescentibius, dorsalibus; sporangiis ovatis; annuto 11.12 articulato; sporis ovoideis aut obscurè reniformibus.

Habitat in insula Nos Beh Mudagascariensium. (Pervillié.)

(Dimensions des divisions ou partitions primaires, 40 centim., sur 17 d'envergure, nous constous 16-18 paires de pinunles, et sur chacune d'elles $13-14$ segments.)

\section{SPHEROPTERIS, Wall. ( 1821.$)$}

Pl. Asiat. rarior., I, p. 42 , t. 48.

Peranema, Don., Prodr. Fl. Nepal., p. 12.

Sporothecis pedunculatis, globosis, in medio dorsi vence infumce superioris sitis; indusio globoso, coriaceo, involucrante, clauso, verticali, ad centrum in duas partes subaquales partito, rete cancellato; sporangiis pedicellatis, receptaculo communi convexo insidentibus; annulo 20 articuluto; sporis oroideis, tuberculosis.

Froxprbes decompositis, herbaceis, venulis liberis, apice clavatis; nervillis pinnatis, marginem non atlingentibus.

Filix Nepalensis, erecta.

Diagnosis: Filic., Scнот, Gen. filic. Fasc., I, t. 1 (optiuu); Ноок. et B., Geи. filic., t. xxII. (S. barbata, IVALL., testè Hoor., loc. cit.)

Nous retrouvons encore ici le facies d'un aspidium, mais avec des sporothèces pédicellés. L'indusium a une tendance à s'ouvrir, non pas d'une manière constamment bivalve, ainsi que l'exprine la diagnose donnée par MII. Schott et Hooker, nais par simple rupture. Les figures de la diagnose de M. Hooker 
semblent renchérir sur ce caractère, en montrant un sporothèce qui, s'il s'ouvrait, d'après le système exprimé par la figure donmée, serait évidemment trivalve; or l'indusium n'est ni bivalve ni trivalve; s'il en était ainsi, sa déliscence ne serait autre chose qu'une séparation normale de parties organiquement dislinctes, tandis que cette enveloppe cède à la pression exercée par les sporanges; elle se fend alors à peu près en son nilieu; c'est donc une déchirure et non une déhiscence régulière. Le nom spécifique barbata, donné au type, est assez. peu caractéristique. Les stipes et les rachis portent des écailles étroites comme un très-grand nombre de fougères.

\title{
SPECIES.
}

Barbata, Wall.*, Scholt, Diagn.* (Peranema cyathoides, Don.).

\section{Indusio bivalvi: BALANTIEAE.}

a. Valvis duabus; una rera, altera accessoria.

\section{CULCITA, Presl. (1\$56.)}

\author{
Tentam. pterid., p. 135.
}

Dichsonice spec., L’Hérit., Sert. Anglic. - Balantium, Kavlf. non Prest.

Sронотнесns hemisphericis, magnis, marginalibus, ad apicem venulce incrassata sitis; indusio bivalu, fornicato, valvis aqualibus, alris, semilunatis, patentibus; receptaculo lineari, cristaformi; sporangïs osatis; annulo crasso, 18 articulato; sporis ovoideis.

FRONDIBTS pinnato-decompositis; venis pinnatis, simplicibus aut furcatis.

Filix Maderensis; facie Davallice; differt ì Balantio valvis duabus propriis.

Dingnosis: Ноok. et B., l. cit., tab. Lx. Prest, Tent. pterid., t. v. p. 5 (nervatio). C. macrocarpa, Prest, l. cit.

Ce genre monotype diffère du Balantium, 1. par les valves de l'involucie qui sont égales et de même origine; $20^{\circ}$ par un involucre linéaire et dressẻ en une sorte de crête. La plante-type découverte par L'Héritier, avait été placée dans le genre Dicksonia; Kaulfuss voyait en elle un Balantium. Elle n'a été jusqüici trouvée qu’à Madère. La grosseur de ses sporothèces lui a mérité le norn de C. macrocarpa que lui a donné M. Presl. Le stipe est parcouru par un seul faisceau vasculaire très-délié et qui suit exactement les contours de ce support. 


\title{
170. BalaNTIUM. Presl. (1856.)
}

\author{
Tentam. pterid., p. 134 (reductum).
}

Balantii et Cibotii spec., Kaulf., Enum. - Dicksonice spec., L'Hŕrir. - Davallice spec., Acct. var.

Trichomanoidis spec., Forst., Prodr., Fl. insul. austr.

SPOROTHECIS globulosis, marginalibus, ad apicem venularum sedenlibus; indusio bicalvi, valvis incequalibus, patulis; vero semilunari, inlerno; spurio seu accessorio, operculiformi, convexo; receplaculo globoso, magno, hispidulo; sporangiis rolundis; annulo 24-26 articulalo; sporis crassis, obscurè trigonis; pilis sporotheciorum apice glanduloso-masloideis.

Froxdibes pinnalo-decompositis; venulis pinnalis, inferioribus furcalis.

Filices ampla, herbacece aut subarborescentes; Sanctie Helence, Nova Zelandice, Nova Hollandice, et Brasilia incolce.

Diagnosis : Нoor. et B., Gen. filic., t.·xx. B. auricomum, Prest, bona.

Les balantium sont de grandes et belles fougères atteignant quelquefois aux proportions de petits arbres. Les frondes acquièrent un dèveloppement considérable. M. Hooker ne veut voir dans ce genre qu'une simple division de son genre Dicksonia, dans laquelle il fait entrer les genres Culcita, Leptopleuria et Cystodium. Nous n'hésitons pas à regarder ces genres comme distincts. Le $B a$ lantium semble nettensent caractérisé par un indusium bivalve, dont la valve fausse ou cuticuléenne a la forme d'un opercule.

\section{ENUMERATIO SPECIERUM.}

Auricomum, Klfss. (Dicksonia arborescens, L'Hlérit., Klfss., fragm.*, Hook. et Bauer, fragm.*) - antarcticum (Dicksonia, Labill.*; Cibotium, Klfss., fragm.*) - Karstenianum, Kltz. (Venezuela) - Berleroanum, Kze. (Dicksonia, Hook., fragm.*) - fibrosum (Dicksonia, Colens, Hook., fragm.*) - lanatum (Dicksonia, Hook., fragm.*) - squarrosum, Kze. (Dicksonia, Sw., Schkh., fragm.*).

\section{LEPTOPLEURIA, Presl. (1856.)}

Tentam. pterid., p. 136.

Dichsonice spec., BORY.

SPOROTHeCıs marginalibus, globosis, exsertis, apice nervilla incrassato sitis; receptaculo puncliformi; indusio bivalii: vero coriaceo, semilunari, concavo, demiirn patulo; accessorio, dente frondis excreto efformalo; sporangiis 
rolundis, pedicello ramoso; annulo anguslo, 14-16 articulato; sporis reniformibus.s.

Froxdrus coriaceis, pinnatis, pinnis sessilibus, oblongis; venulis tenuissimis, apice punchum magnum, albidum gerente.

Filix Borbonicu, herbacea; facie Nevrolepidis.

Diagnosis: Hook. et B., Gen., L. Lx, B; L. abrupta, PresL, I. cit.

Differt à Cystodio habitu, nervatione, fabricâ annuli sporangiorum, formâ spororum, etc.; sed structurâ indusiorum maximè affinis est. A Puchypleuriâ longè distat prcesenticî indusii duplicis.

L'espèce qui seule constitue ce genre, a le port des nephrolepis, et comme ces fougères, pend aux arbres. Elle s'éloigne donc beaucoup, par les organes de la nutrition, des genres au milieu desquels on lui a donné place. L’indusium est semilunaire; les frondes pinnées, à frondules sessiles, portent à la marge des sporothèces assez écartés. Celles qui sont fertiles ont des dimensions supérieures : elles se recourbent vers le sommet et deviennent plus étroites. Les frondes se terninent souvent d'une manière brusque, et le nom spécifique rend compte de cette particularite.

\section{SPECIES.}

Abrupta, Presl (Dicksonia, Bory*, Hook. et Bauer, fragm.*).

\section{CTSTODIUII, J. Sm. (1858.)}

In Hook. et Bauer, Gen. filic., t. XCVI.

Dichsonice spec., J. Ss., in Rees' Cycl., vol. vil.

SPOROTHECIs marginalibus, exsertis, globosis, venulas terminantibus; indusio duplici : interno vero, subreniformi, parvo, planiusculo: externo accessorio, concavo, cucullato, indusium internum includente; sporangïs ovoideis; annulo latissimo, 24-28 arliculato; sporis ovoideis.

Froxibes bipinnatis, pinnis lanceolatis, pedatis, pinnulis lineari-lanceolatis, acuminatis, subfalcatis, dentatis, dentibus soriferis; nervillis simplicibus red rariìs furcatis.

Filix Moluccana, ampla, affuis Leptopleurice, sed habitu et nervatione diversu.

Dingnosis: Ноoк. et B., Gen., l. cit. C. sorbifolium, J. Ss., l. cil, bonu.

Ce genre est voisin du Leptoplenria; mais ici le système vasculaire consiste en nervilles bifurquées qui atteignent la marge en devenant coniques à leur sommet; dans le Leptopleuria elles se terminent avant d'arriver à la marge et forment un 
point globuleux : elles sont plutôt parallèles que pinnées. Les frondes sont dressées, bipinnées; les stériles et les fertiles semblables: le Cystodium n'a aucune analogie avec les nephrolepis, et se rapproche bien plutôt du Wibelia, quoique bipinné. Enfin la valve fausse ou cuticuléenne est réniforme et non méniscioïde.

SPECIES.

Cystodium sorbifolium, J. Sm. (Hook. et B.*, Hook.*).

b. Valvis duabus propriis : CHBOTIE 2 .

173. CIBOTIUM, KIfss. (1824.)

- Enum. filic., p. 229 .

Pinonia, Gaudich., Voy. de l'Uran., p. 369. (1826.)

SроRотнесns depresso-globosis, marginalibus, sed introrsim reflexis et ad apicem venularum sitis; indusio bivalvi, coriaceo, valvis subcequalibus, interiore paululim minore; receplaculo parvulo; sporangiis ovoideis; annulo extenso, latissimo, 20-2' arliculato; sporis trigonis, nudis, vitreis, episporio vestilis, fuscis.

Froxdibus decomposito-pinnatis, saepè subtìs glancis; nervillis pinnatis, simplicibus aut furcatis.

Filices herbacece et arborescentes, amplae, rigida, spinose, Sandwicenses aut Americance tropicales.

Diagnosis : Hook. el B., Gen. filic.; t. xxv. C. Schiedei, in Linnæa, v, p. 616.

Ces belles fougêres n'ont été jusqu'ici trouvées qu'aux îles Sandwich et aux Philippines; une seule espèce a été découverte au Mexique par MM. Schiede et Galeotti. Leurs frondes acquièrent une grande amplitude : elles sont décomposées, pinnées, raides, glabres et souvent glauques en dessous. Elles tendent manifestement à l'arborescence. Les valves ont une consistance solide, et elles paraissent être toutes les deux de nature particulière. M. Hooker, dans l'excellente diagnose qu'il a donnée de cette plante dans son Genera filicum, représente l'anneau des sporanges presque complet, il est seulement très-étendu; les poils que la planche citée donne à l'état d'isolement, sont attachés à la base des pétioles et ne paraissent être autre chose que des sporanges arrêtées dans leur développement.

\section{ENUMERATIO SPECIERLM.}

Glaucum, Hook. et Arn. (Hook., fragm.*) - glaucescens, Kze.* - Assamicum, Hook., fragm.* - Chamissoi, Klfss.* (Pinonia splendens, Gaud.*) - Menziezii, Ilook., fragm.* - Schiedei, SchI. et Cham. (Hook., fragm.*). 
Le genre suivant, qui certainement appartient à ce petit groupe, demande à être mieux connu.

\section{$\doteqdot$ PAESIA, A. Saint.Hil.}

Voy. Distr. des diam., I, 38 r. Endlich, Gen. supp, p. 1350.

Sровотнесіs sublinearibus aut rotundis, submarginalibus; indusio in juventute clauso, plano, membranaceo, tenui, in valias ducas dehiscente: valiấ accessoriầ è cuticulẩ proveniente : valîa verâ minori, suborbiculari propriấ; sporis.....

Froxdates tripinnatis; pinnulis palulis; nervillis pinnatis, liberis.

Filix Brasiliana, ampla; facie Pteridis.

Genus mihi ignotum.

\section{Considérations générales sur les Dicksoniées et les Balantiées.}

Il est à remarquer que ces fougères, qui constituent le dernier groupe des cathétogyratées, ne renferment que des plantes à physionomie peu tranchée. Par les frondes, on croit voir des aspidium ou des phegopleris; c'est l'organe reproduit qui les différencie et les caractérise. Les dicksonia ne sont pas très-distincts du Microlepia; les woodsia ressemblent à des phegopteris. Le Leptopleuria rappelle les nephrolepis, le Cyslodium, les wibelia, l'Hypoderris, les bathmium. A l'exception du Dicksonia, les genres sont peu nombreux en espèces, et plusieurs d'entre eux sont monotypes. Le caractère qui rend ce groupe distinct de tous les autres est d'aroir un indusium infère, tandis quill est supère dans tous les groupes indusiés dont il a été jusqu'ici question. 


\section{Annulus sporangiorum eXcentricus : HELLCOGYRATE.}

\section{Sporollecia dorsalia : CIITIIEE.}

Polypodii spec., L. et Auct. vak.

Filicum gyratarum pars, R. Br.

Cyathece, Gaudich., partim.

Alsophilacece, Cyatheacece, Press, etc.

Erectæ, excelsæ, arborescentes, spinescentes, frondes amplæ, multisectie.

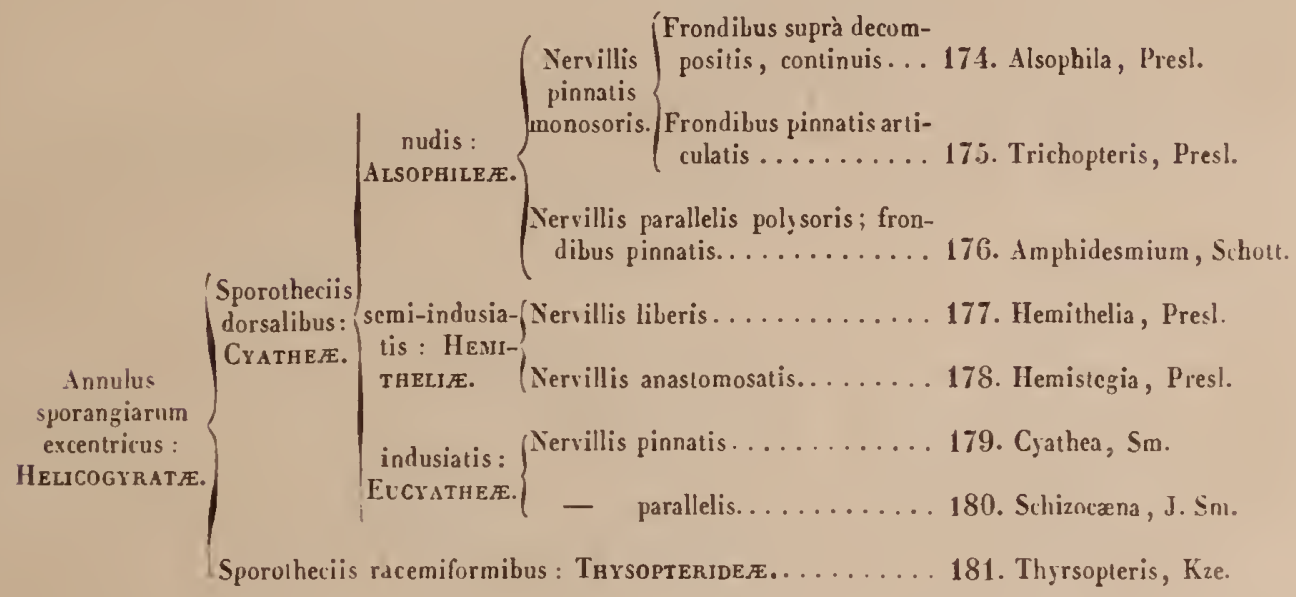

1. Sporotheciis nudis (Gymnosoria): ALSOPHILER.

* Vervillis pinnatis, monosoris.

174. ALSOPHILA, R. Br. (1840.)

Prod. Fl. Nov. Holl. - Presl, Tent. pterid. - Ejusd., in Die Gefässb. im Stip. der Farrnkr., p. 32.

Cyalhere, Chnoophorce spec., Kavif. et Auct. - Polypodii spec., L.

Arachniodes, Buus., Enum. Filic. Jav., t. 11, p. 241.

Gymnosphera, Ejusd., l. cil., et Ноок. et B., Gen. filic., 1. xхı.

Lophosoria el Dichorexia, PrisL, Die Gefissb., p. 36.

Sровотнесіs rolundis, prominentibus, in medio dorsi aut in furcaturấ venularum sedentibus, nudis; receptaculo gibboso, globoso aut obovato, integro 
aul biparlito, grlabro ant villoso; sporangiis ovalis, aliquolies sporangiastris brevibus, apice clacalis ins/ruclis; annulo lalo, sapè obliquo, sed non semper, 1 $0-18$ arliculalo; sporis episporio vestitis ovalis, nudis Iriedricis.

Froxibes decomposilis, facie Phegopleridum vel Aspidiorum; slipilibus sapè spinosis; venulis pinnalis, liberis, simplicibus aul sapius bifurcalis.

Filices arborescentes, erectre, tropicales; cicatricibus stipitum in ordine spirali senario, $(1 / 6)$ disposilis.

Dingnosis: Ноoк. et B., Gen. filic., 1. Ix (A. excelsa, R. Br., non Sw.), et t. c (Gymnosphicra squanulata, Bцсм.).

Hic locus essel Lophosorice (Prist, Die Gefissbild., P. 36), generis cujus venulce ad apicem non liberce sunt, sed in arcuis marginales ancistomosantur. Character recognilu difficilis el in pluribus speciebus à Clar. Preslio nolatis paradoxus.

Ces fougères arborescentes, toutes tropicales, ne se trouvent guère dans les herbiers qu'à l'état de fragiments. Elles ont le port des aspidium et des phegopteris, et comme il arrive quelquefois que l'obliquité de l'anneau est peu ou point marquée, on ne trouverait aucune raison de ne pas les placer parmi les polypodiées, si leur consistance, constamment ligneuse, et l'arrangement des faisceaux vasculaires du stipe ne suffisait pour les différencier nettement.

Nous avons indiqué dans l'énumération des espèces celles qui se rattachent aux genres Dichoresia et Lophosoria de MI. Presl, sur la validité desquels nous ne sommes pas encore fivé.

L'Alsophila pilosa de MII. Martens et Galeotti est pour nous un Polypodium; II. Presl en fait le type d'un genre noureau placé parmi les grammitidèes, sous le nom de Glaphyropteris rudis. C'est une fougère difficile à classer.

\section{ENUMERATIO SPECIERUM.}

I. A.sopıu. = Venulis liberis el receptaculo semper integro. = Blanchetiana, Pres! (Blanch., Herb. bras., n. ${ }^{\circ}$ i ) - pracincla, Klfss. (Mart., Bras., n. ${ }^{\circ} 391$ ) - squamulala, Blum. (Hook., Gen. fil., fragm.*) - alata, Kze. - australis, Rob. Brown. (Ilook., fragm.*) - glabra, Blum. (Gymnosphara) - Glauca, J. Sm. (Ilook., fragm.*) - selosa, Klfss. - armala, Pres! (Sivarlziana, Mint.*) - ferox, Piesl (arniala, Mart.*; Polypod., Radd.*) - Miersii, Ilook.* - leucolepis, Mart.* - hirla, KIfss. (Mart.*) - plualerata, Mart.* - lepifera, J. Sm. - crinita, Ilook.* - comosa, Wall. (Ilook., fragm.*) - caudala, J. Sm. (Hook.*, fragm.*) - compla. Mart.* - acula, Presl - Smithiana, Presl - contaminans, Wall. (Hook., fragni.) - dealbala, Presl - villosa, Kze. (C)alhea, II. B. K.*) - plagiopteris, Mart.* - paleolala, Mart.* - rigidula, Mart.* - pycnocarpa, Kze.* - nigra, Mart.* - atrovirens, Presl. (Langsd. et F.*) Mexicana, Mart.* - Millefolium, Desr. (Plum, , tab. 33) - excelsa, R. Br. - oligocarpa, F. , Funck. et Sclil., n." 1002 - infesta, Kze. - squanata, Kl.

11. Dicuonхu. = Receptaculo in duas Hemisphoeras apuales concavas dehiscente = Gigantea, Wallich. (Polypodium, Wall.; Gymospherra, J. Sm.) - latebrosa, Wall. (Polypod., Wall.*.

III. Lopmosonı. = Venulis ad marginem excurrentibus, arcum formantibus. = Pruinala, KIfss. (Polyp. griseurn, Schhh.*) - affinis, Presl. 


\section{TRICHOP'TERIS, Presl. (1836.)}

Delic. Prag. 1, 172 (Trichipleris), et Die Gefässb., p. 32, tab. VI, fol. 11-13 (secliones stipilum).

Clinoophorce spec., Kautr. - Clinoophorce et Alsoplillee spec., KzE. el Mart. Polypodii spec., Roth, Radd., etc.

SPOROTHECIS rolundis, confluentibus, in medio dorso venulae silis, lineam recIanı subcontinuam formantibus, $2-4$ serialibus; receptaculo sessili, globoso, areolato, pilis longis hirlo; sporangiis subsessilibus, pyriformibus, obliquis; annulo 18-20 arliculato, obliquo; sporis trigonis.

Frondrus coriaceis, bipinnatis, pinnis cum rachi arliculatis el deinde deciduis, peliolatis, venulis pinnatis, simplicibus aut basi furcalis, apice incrassatis.

Filices arborescentes, caudice octangulari, 6 - 8 metrali; insertione stipilum in ordine spirali duodenario ( $1 / 12$ ); planlæe procipuè Brasilienses, fucie Amphidesmui.

Dingnosis : Schотт, Gen. filic., Fasc. I, 1. v (optima); Ноок. et Grev., Gen., 1. xxхıv. T. cxcelsa, PresL, l. cit.

Dans ce beau genre, bien distinct du précédent par le port et la disposition des sporothièces, les frondes sont bipinnées, à marge entière, lancéolées et remarquables par la disposition linéaire des sporothèces, naissant sur le trajet moyen de toutes les nervilles. Celles - ci sont paralléles : elles se recourbent dès la base, en émettant deux ou trois branches qui atteignent la marge dans laquelle elles vont se perdre. Les frondules sont lancéolées, acuminées, longuement pétiolées et articulées; les sporothèces croissent très-rapprochés, et comme ils se développent à la même hauteur, ils forment des lignes continues qui donnent à la série l'apparence d'un tanitis, disposition appréciée par Roth, lequel nomma l'espèce principale Polypodium Tanitis. Le réceptacle, après sa chute, laisse sur la lame une cicatricc elliptique déprimée au centre.

M. Hooker (Syu. filic., p. 35) réunit en une seule espèce les T. excelsø et denticulala de Mi. Presl.

\section{ENUMERATIO SPECIERUM.}

Elegans, Presl*, Tent. pterid., p. 59 (Alsophila, Mart.*) - excelsa, ejusd.*, Del Prag., 1, 172 (Alsoplila, Marl.*: Polypod. Corcosadense, Radd.*) - denticulata, cjusd.*, Tent. plerid., p. 59. 


\title{
* Vervillis parallelis, polysoris.
}

\section{AMIPHIDESHIUM, Schott. (1834.)}

\author{
Gen. filic. in notis.
}

Polypodium Parlieri, Hoor. et Grev., Icon. filic., ccrsul, sub Melaxy A. - Metuxya, Presl. - Alsoplitle, Chnoophorce, Aspidii el Polypodii spec., Auct. var.

Sporotuecus ovoideis, uno aut duobus in dorso cjusdem venula, mesonevro approximatis; receptaculo prominente, ovoideo, elongato, pilis longis, crinitis onusto; sporangiis amplis, subpyriformibus; annulo subverticali, amplo, 20-22 articulato, articulis latis; pilis numerosis, articulatis, longis intermixtis; sporis obscurè trigonis.

FoxDIBts pinnalis, frondulis remotis, arrectis, lanceolatis, apice dentato-crenatis, abruptè acuminatis, coriaceis, glabris; venulis prominentibus, parallelis, simplicibus, rarius furcatis, marginem incrassatmm attingentibus, rachi profundè canaliculato.

Filix Guyanensis, rigida, erecta, arborescens. (Ex Poiteau.)

Diagnosis: Ноoк. et B., Gen. filic., tab. xul, B. (A. Parkeri, Presh, sub Metaxici iostratâ, PresL.

Les frondules de l'Amphidesmium ressemblent à des frondes d'oleandra, et sont également articulées. Les sporothèces se dirigent perpendiculairement comne dans le genre Trichopteris, ınais ils sont rapprochès du mésonèvre, et la même nerville peut en porter deux et mème trois. Les nervilles se rendent vers la marge oì elles ront se perdre. Nous avons dit que ce caractère ne constituait pas à nos yeux une véritable connivence. La figure donnée par M. Presl (Tentam., pl. 1, fig. 5) attribue à ces nervilles une disposition qui n'est pas réelle, cal elles atteignent la marge. La figure 2 de la planche XLII $B$ du Genera de MII. Hooker et Bauer est exacte, cependant il ne faut pas croire ì l'existence dune nerville marginale cxcurrente, mais uniquement à l'épaississement d'une marge fiisant bourrelet. Le point d'insertion des sporanges (le réceptacle) est ovoide, allongé et blanchàtre après la chute de ces organes.

\section{ENUMERATIO SPECIERUM.}

Parkeri, Presl (Polypodium, H. et Gr.*; Chnoophora rostrala, Mart.*; IIIetaxia, Presl [fragm.*]). 


\section{B. Sporotheciis semi-indusiatis, id est indusium internum dimidiatum ferentibus : HEMITHELIEAE.}

\section{* Nervillis liberis.}

\section{HEMITHELIA, Presl. (1836.)}

Die Gefässbild., p. 41 .

Cnemidarice, Cyathece, Alsophilce spec., Auct. var. - Polypodii el Aspidii spec., Linn., Sw., ete. - Disphenia, PrESL, l. cit., p. 40.

Amphicosmia, Gard.

Sporothecis globosis, basi vence infimce, seu dorso medio venularum insidenlibus; receptaculo sessili, globoso, vel subpyramidali; sporangïs pyriformibus, brevè pedicellatis; annulo lato, slomate multinervato; indusio dimidiato, concavo, squamiformi; sporis triedricis.

Frondibus suprà decompositis, amplis, squamis sparsis, adspersis; nervillis pinnatis, simplicibus, in dentem frondis excurrentibus; stipite arboreo.

Arbores inermes aut aculealox, frondibus amplissimis, ferè semper tropicales.

Diagnosis : Hoor. et B., Gen. filie., t. xц11, A (H. Capensis, R. Br.), tab. xxı. Alsophila aspera, R. Br. (Disphenia).

In hoc genere Alsophilac proxinı, indısium sapè reducilur ad squaman, basim receplaculi occupantem; hace squama indusiiformis; vix differt ab eis quac in lamina infernè sparsce sunl.

Ce genre unit le groupe des alsophilées aux cyathées. L'indusium est situé près de la nerville et réduit à moitié; on pourrait rigoureusement le considérer conıme une sorte d'écaille; sauf ce caractère, qui a suffi à tous les auteurs pour le conserver, on döit voir, dans les espèces qui le composent, de véritables alsophila, ayant des feuilles extrêmement amples, souvent aiguillonnées et portées sur un stipe arborescent de dimensions variables. C'est peut-être la difficulté dans laquelle on s'est trouvé de pouvoir choisir entre le Cyaihea et l'Alsophila pour y placer convenablement les fougères à indusiun dimidié, qui explique la nécessité de la conservation du genre Hemilhelia.

\section{ENUMERATIO SPECIERUMI.}

I. Euhemrelı. = Receptaculo indiviso. = Integrifolia, Kl. (speciosa, Hook. Spec. filic.*, fragm.) - speciosa, Klfss. (Cyalhea, II. B. et K.) - Hookeri (horrida, Hook., Spec. filic.*, fragm.) Imrayana, Hook.* - Capensis, R. Br. (Hook.*, fragm.; Presl, Cond. nerval.) - Walkera (Cyathea, Hook.*) - Hostmanni, Hook.* - Guyanensis, Hook.* - ? Parkeri, Hook.* - Beyrichiann, Pr. (Cyathea, Hook.*) - ?allernans, Hook.* - macrocarpa, Presl (Blanchet, Pl. Bahiens., n. ${ }^{\circ 1} 17$ et 3227) - exlensa, Presl (Cuming, Pl. Philipp., n. ${ }^{\circ 179}$ ). 
1I. Disphexia. = Receptaculo bipartito, segmentis clasatis disergentibus (ex Preslio). = Arborea (Cyathea afinis, Schkh.*; Serra, Willd., Ilooh.*, fragm.) - muricata (Cyathen, Willd., Plum.*, Petiv.*) - aspera (Cyathea, Sw., Plum.*) - aculeata (Cyathea, Willd., Ilerb.; Disphenia, Presl*. Cond. neri.).

\section{** Vervillis conniventilous.}

\section{HEMISTEGIA, Presl. (IS47.) [auctum.]}

Hemistegia, Microstegmus et Aclinophlebia, Press, Die Gefissb., p. 46 at 48. - Cnemillarin, Press, Die Gefässb., p. 41. - Hemithelice et Cnemillarice spec., PresL, I. Br., etc. - Cyathece spec., Alcr. pleris. - P'olypodii spec., Lis.

Sporotheciss minulis, globosis, medio dorso venulurum inserlis; v'enulis omnibus proliferis; receplaculo globoso, prominenle, fusco, glabro, ad basim inlernam, indusium plis minisse dimidiahum, cupuliforme, scariosum, irregulariler fissum aut lacerum ferenle; sporangiis ovoideis; anmulo 12-14 arliculalo, arliculis obliyuis, stonale subdecem nervalo; sporis trigonis et irregulatim reniformibus.

Froxdвr's amplissimis, pinnalis, furmis; pinnulis profunde pinnalifudis, laciniis falcatis, venulis furcalis, infunis in arcum v'enuliferum constitutis, areolers subtriangulares rachidi proximas efficienlibus.

Filices subarborescentes ut phurimum aculeater, Antillana et Guyranenses, una I'anamensis.

Diagnosis: Tab. xxvı , fig. 1; 1. Hemistegin grandifoliu, PresL; 11. H. hourida, F. (Actinophlebia, PrtsL). Hook. et B., Gen. filic., 1. Ir Hemistegia [Cnemidariu. horrida, PresL).

Differt à Cyatheri nervatione anastomosticâ et habitu. Genus Cnemidaria, apud P'reslium (Dic Gefissb., l. cit.) servatum est, vera nobis videtur Hemistegia; nam indusium non est integrum, ut cit Clur. Auctor, sed dimidiutum, quod ab icone Martii laudatâ probatur. In H. grandifoliat nerville sapè basi liberce sunt; indè genus Microstegnus Preslii.

Ce genre, avec des nervilles anastomosées à la base du rachis et des sporothèces protégés par un indusium incomplet, a une grande analogie avec l'Hemilhelic, et l'origine étymologique rend compte de cette particularité qui leur est commune; par les frondes, il tend à se rapprocher du Schizocana. En adoptant le genre Henrislegia créé par. M. Prest, nous y avons juint les genres Aclinophlebia et Microslegnus. Les veinules, dans le premier de ces deux genres, atteindraient la marge pour s'unir, ce qui n'aurait pas lieu pour l'Hemislegia, $€ \mathrm{t}$ dans le second les veinules de la base seraient libres, comme elles le sont dans l'Memislegin et l'Actinophlebia. Nous re doutons pas de la réalité de ces caractères, mais outre 
qu'ils n'impriment aucun changement à l'habitude extérieure, il nous a semblé trouver sur les neemes espèces des modifications pareilles à toutes celles qui sont rendues spéciales pour chacun de ces genres.

Nous signalons comme nouvelles, 1. un Hemislegia lucida, communiqué sous le n. ${ }^{\circ} 6537$ par M. Galeotti, qui l'a récolté au Mexique (à près de 2000 mètres d'élévation). Les frondes pinnées et se terminant par une pointe pinnatifide, ont très-vraisemblablement plus de 2 mètres de longueur; le stipe est gros comme le doiğ; sillonné et épineux, il est couvert d'écailles furfuracées. Les frondules acuninèes atteignent jusquà 45 centimètres sur 4 d'envergure : elles sont crénelées et luisantes en dessus. Cette fougère est fort belle.

2. Un Hemistegia repanda récoltè à Cuba par M. Linden et que nous avons sans numéro. La pinnule que nous possédons est pinnatifide, à segments crénelés, ondulès; la côte médiane est rougeâtre, étroite et canaliculée; la base des sinus est traversée par une veinule droite et un peu anguleuse.

\title{
ENUMERATIO SPECIERUM.
}

I. Eunemistrgia. = Speciosa (Cnemidaria, Presl) - obtusa, Presl (Hemithelia, KIfss.; Cnemidaria, Presl*; conditio nerv.) - Kohautiana, Pres! (Cnemidaria, Presl; Sieber, Fl. Martin., n. ${ }^{0} 375$; ejusd., Fl. mixia; n. ${ }^{\circ} 31$ ) - grandifolia, Presl (Hemithelia, Hook.*, fragm., Plum.*) - marginalis (IIemithelia petiolata, Hook.*, fragm.*, non KIfss.) - Willdenowii (Cyathea grandifolia, Willd.; Microstegnus grandifolius, Presl).

II. Actisoluleris, Presl. = Horrida (Actinophlebia, Presl; Cyathea commutata, Spreng.*, Plum.*) - spectabilis (Hemithelia obtusa, Hook., fragm.*, non KIfss.; Hemithelia [Cnemidaria] subincisa, Kze.) - repanda, F. - lucida, F. (Linden, Cuba; Galeott., Pl. mexic., n. ${ }^{\circ} 6537$ ).

\section{Sporotheciis indusiatis (Angiosori): EUCY ATHEAE.}

\section{Indusio completo.}

\section{* Vervillis pinnatis.}

\section{CYATHEA, Sm.}

\author{
Act. Taur. V, p. 417 .
}

Sporaxgus globosis, superficialibus, in medio dorso ant ad nervillarim basim affixis; indusio infero, involucrante, magno, scarioso, irregulariter rumpente; receplaculo globoso, clavalo, vel disciformi, scepissirnè hispido; sporangïs pyriformibus, sessilibus vel breviler pedicellatis; annulo ferè semper obliyno, 16-18-24 arliculalo; sporis trigonis, triedricis, lavibus, incequalibus nigrisque. 
Frovdrues decompositis, amplissinis; nervillis pinnalis, simplicibus, frequenter furcalis; candice tereli, aut irregulariler angulato, cicalricibus stipitum in ordine senario dispositis.

Filices uopicales, arborescentes, "ut plurimùn aculealce.

Diagnosis : Hoox. et B., Gen. filic, t. xтu (Cy’alh. elegans, Heward.; C. Grevilleana, Mart.), et t. xuI , A.

Les cyathea ont le même port que les alsophila, mais les sporothèces, nus dans ce dernier genre, sont indusiés dans les cyathea. Cet indusium est extrèmement mince, pellucide et fragile; c'est par la pression qu'exercent les sporanges lors de leur complet accroissement qu'il faut expliquer la rupture irrégulière de ce tégument, ainsi que sa prodigieuse ténuité.

\section{ENUMERITIO SPECIERLII.}

Serra, Willd. (Hook., fragm.*) - discolor, Bory, Ile de Fr. (in Herb. nostr.) - Grevilleana, Ilart. - Commersoniana, F. - cuspidata, Kze. (Ilook. fragm.*) - Perillliana, F. - divergens, Kze. (Ilook., fragm.*; Presl, Cond. vasorum in stijite) - vestitn, Mart.* - hirtula, Mart.* Schanschin, Mart.* - Gardneri, Hook.* - Lindeniana, Presl (Linden, n. ${ }^{\circ}$ 1022) - J)regei, Kze. (Hook., fragm.*) - Burkei, Ilook., fragm.* - canaliculata, Willd. (Iook., fragm.*) - excelsa, Sw. (Ilook., fragm.*; Presl, Cond. vasor. in stip.) - Mexicana, Sehlecht. (Galeott., n. ${ }^{\circ} 6335$ ) - aurea, Kl. (Mexicana, Kl.) - spinulosa, Wall. (Hook., fragm.*) - integra, J. Sm. (Hooh.*) - petiolata, J. Sn. - medullaris, Sw. (Spharopteris, Bernh.*) - glauca, Bory (Boubon) dealbata, Rich.*

\section{CoMyersoviasa.}

\section{SPECIES YONDLY DESCRIPTE.}

Frondibus .... ad apicem piunatis, pinnalifdis, glabris, rachibus flexuosis, infrà lavibus, glabris, rubris, supernè tomento rufo, brevi vestitis; pinnulis sessilibus, upproxinatis, aculis, lanceolatis; segmentis ovoideo-elongalis, oblusis, apice dentatis, nervillis bifurcatis; sporotheciis in bifurcationibus nervillarum sitis.

\section{Habilal in insulâ Mauritii, Commerson, n. 1773.}

(Dimensions : le fragment que nous possédons est la partie supérieure d'une fronde; il mesure 37 centim.; les pinnules inférieures ont de 16-17 eentim. de longueur, sur 3 eentim. d'envergure; les segments sont fruetifères presque jusqu'au sommet; les raehis flexueux, eolorés en rouge, et les sporothèees qui envahissent presque tout le segment, earactérisent eette plante, qüil faudrait etudier dans son lieu uatal.)

\section{Pervilliaja.}

Frondibus decompositis, stipite el rachi helveolis, subundis; pinnulis lanceolutis, sessilibus, acuminatis, segmentis usque ad costan liberis, linearibus, elegunter crenutis, acutis, apice sterilibus, horizontalibus; nervillis bifurcatis, sculpluratis, litteran gracam $\Upsilon$ referentibus et ad bifurcationes fructiferis; sporolheciis rolundis, approximatis; 
indusio amplissimo, scarioso; receptaculo punctiformi, durissimo, albo; sporangïs amplis; annuto 18-20 atticulato; sporis triedricis.

Habitat in Nos Beh Madagrascariensium (Pervillié), el in insulâ Borboniut.

Filix formosa, dilatata, segmentis eleganter crenatis notatr.

(Dimensions : longueur des pinnules, 34 centim.; enlre-nœuds, 4 centim.; 40 paires de segments environ; les inférieures mesurent un peu plus de 3 centim., sur 4 millim. de largeur; nous ne connaissons pas la fionde entière.)

Tous possédons en herbier un Cyalhea de l'ile de France, récolté par M. Bory en 1802 , et portant le nom de $C$. discolor. Les segments sont glauques inférieurement et verdàtres en dessus, à marge parfaitement entière; ils sont sessiles, un peu cordiformes et attachés par la base vers le haut de la pimnule qui les porte; les nervilles, déliées et trifurquées, deviennent fertiles à leur point de bifurcation. Les rachis se couvrent de squamules courtes, de couleur ferrugineuse. Les nervilles, bifurquées dans le $C$. Commersoniana, sont ici trifurquées.

Le genre Cyalhea est destiné à s'accroître, mais on ne peut le faire qu'avec réserve. Nous possédons plusieurs fougères des Philippines, des Antilles et du Mexique destinées très - vraisemblablement à constituer des espèces nouvelles, cependant nous n'osons les décrire de peur de doubles emplois.

\section{** Nervillis parallelis.}

\section{SCHIZOCENA, J. Sm. (1838.)}

In Hook. et Bauer, Gen. filic., t. 2.

Cyathece spec., Ноoк., PresL.

SPOROTHECIs globosis, superficialibus, medio dorso nervillarum inserlis; indusin infero, involucri faciem gerenle, scarioso, irregulariler rumpenle; receplacult, puncliformi; sporangiis subsessilibus, pyriformibus; annulo vix obliquo, $16-18$ articulato; sporis trigonis.

Frovibus simplicibus ant pinnatis, slabris, frondulis lanceolatis, peliolatis, basi rotundatis, arliculis deciduis, margine undulato, apice dentato; nervillis fuscis, prominulis, tenuibus, aequalibus, furcato-parallelis, marginem atlingenlibus (et lunc coalitis? ).

Filices herbacea, erecte, ampla, tropicales; caudice uonnunquim arboreo, inermi; sporolleciis, involucro, receptaculo, sporangiis et sporis Cyalhere; sed frondium nervatione el habitu diversissimice sunt.

Diagnosis : J. Sy., Hoor. et B., l. cil. Sclizocann Brunonis, J. Sx. (delitscentia indusii mala). Tab. nost., xxvin, ter B. 
II. Hooker n'a pas cru devoir adopter ce gerre, non plus que M. Presl dans ses derniers ouvrages. Cependant, et malgré tout ce que ces autorités ont d'imposant, nous le croyuns tout a fait distinct et par le port et par la nervation. L'innenu n'a que très-peu d'obliquité et le réceptacle est à peine visible.

\section{ENUMERITIO SPECIERUM.}

Iinualn (Crathea, Hook et Gr.) - Brunonis, J. Sm. (C)athea, Wall.) - Gaudichaudii, I.

Cracticitald DH.

\section{SPECIES YONDUM DESCRIPTA.}

Frondithes pinnatis, rachi helveolo, angustè canaliculato; frondibus aculis, basi ro. tundis, leviter cunentis, marginibus undulutis; nervillis lenuissimis, circà mesonevron bifurcatis, mousoris; sporolheciis rolundis, approxinatis, alternis, super nervillas ad altitudinem in quâcumque eorum varinbilem crescentibus, tùmque multiseriatis lubendis; sporanguiis tongè pyriformibus, sessilibus, duos pilos ad basim sacculi ferentibus; sporis trigonis.

Hubitut in Cochinchina, Pulo-Pinang. (Cl. Gaudichaud.)

Filix formosissina, rigida, glaberrima, frondulis brevè petiolatis, patulis.

(Dimensions : longucur des frondules, 14 centim., sur 20 - 24 millim. de Jargeur; cntre-sıcuds. 1 ccutim.).

\section{Sporothecia racemiformia : THIRSOPTERIDEE.}

\section{Arlıores excelsæ; frondibus, amplis.}

\section{THYRSOPTERIS, Kze. (1854.)}

\section{Die Farrenk., ८.}

Chontr, Molina, Chili, 156.

Ponicularia, Collia, Mém. acad. de Turin, xwox, 33, t. Lxıv?

Sровотнеси pedunculalis, globosis, subsecundis, in rachibus frondis ferlilis, biIripinnale sedentibus; indusio infero, globoso, hemispherico, coriaceo, ore aperlo, inargine flexuoso; receptaculo magno, globoso, spongioso; sporangiis sessilibus, imbricatis; annulo magno, subobliquo, 16-18 articulalo; sporis trigonis.

Froxdres suprì decomposilis, nilidis; nervillis pinnalis, liberis; pinnis sterilibus el fertilibus in ecidem stirpe: parte sterili lacinuis planis, cunealis, parle fertili laciniis racemiformibus. 
Filix arborescens in insulâ Juan Fernandez crescens.

Diagnosis : Hook. et B., Gen. filie., 1. xuw, A; T. elegans, KzE., l. cil.

Ce que nous allons dire de ce genre, se rattache au groupe tout enier. Il est parmi les hélicogyratées ce que le Struthiopleris ou l'Onoclea sont parmi les cathétogyratées. Les frondules fructifères occupent la partie supérieure des frondes et ne sont pas séparées sur des pieds différents. Le Sphceropleris, qui porte des sporothèces pédicellés, semble un passage vers le Thyrsopleris. Ceute fougère curieuse est surdécomposée, corrace, luisante; les derniers segments fertiles sont obscurément dentés, cunéiformes et lancéolés.

\section{Considérations générales sur le groupe des Hélicogyratées.}

L'obliquité de l'anneau n'est pas dans ces fougères un caractère aussi important qu'on veut généralement le croire, et nous l'avons déjà fait remarquer page 29 de cet ouvrage. Quelques espèces, dans les genres nombreux, ont un anneau semblable à celui des cathétogyratées, et il n'y aurait aucune raison de ne pas les en distraire, si l'arrangement des faisceaux vasculaires dans le tronc et le tronc lui-mêne, ne permettaient de reconnaitre le lien qui les unit entre elles. La détermination des espèces est difficile. On ne les trouve qu'en fragnents dans les herbiers, et il n'est guère possible de constater les modifications que peut présenter une seule et mênre espèce. On doit de grands éloges à II. de Martius, qui a donné le port de plusieurs d'entre elles, et qui en a reproduit un grand nombre par la gravure. Les troncs eux-ntèmes ont été savamnient étudiés dans leur structure anatomique. L'étude de ces fougères lie la botanique oryctologique avec la botanique moderne, et la géologie leur emprunte d'utiles comparaisons.

N. Presl a cherché dans les coupes horizontales du stipe les moyens d'arriver à une meilleure circonscription des genres et à une distinction plus rigoureuse des espèces; ce savant botaniste a étendu ce genre de recherches à d'autres groupes. Nous ne croyons pas que le résultat désiré soit obtenu; il faut encore attendre pour se prononcer, quoique nous soyons bien plus près de nous prononcer pour la négative que pour l'affirmative.

La plyysiononie de ces plantes n'a, pour la plupart des genres, rien de spécial; les deux plus nombreux, Alsophila, Hemithelia et Cyalhea, rappellent les grandes espèces d'aspidium et d'alhyrium; l'Amphidesmium est un oleandra pinné 
quant aux organes de la nutrition; les genres Hemistegia, Schizocaena et Trichopleris ont un facies plus tranché. La nervation n'offre jamais cette complication si remarquable dans certains genrés de polypodiées et d'aspidiées. Les nervilles ne forment que bien peu d'anastomoses. Yous avons dit ailleurs que les nervilles atteignant la marge et paraissant se confondre arec elles, ne fournissaient pis un caractère suffisant pour motiver la création d'un genre, et c'est ce qui explique comment il se fait que nous n'ayons pas adopité certains genres établis jar M. Presl.

Les hélicogyratées réclament une monographie; mais elle ne peut guère ètre entreprise avec succès que par un botaniste voyageur, qui décrira les espèces sur place et qui en fera connaitre le port. Ce genre de travail ne peut convenir que difficilement aux botanistes sédentaires. 


\title{
GENRES ET SOLS.GEVRES
}

\author{
NON ADOPTÉS OU OMIS DAIS LES SINONIMIES.
}

Acrophones, Presl, Tent. pterid., p. 93, tab. III, fig. 2. Cystopteridis spec.? Javallia nodosa, Hook., Spec. filic., p. 157. Nous n'arous jamais vu cette plante.

Acrivioptrnis, J. Sm. Adiantopsidis spec., F. (Adiantum radiatum, L.)

Aupionadesiev, Desv, Annal. soc. Linn., Paris, VI, 335. Adenophorus, Gaud.

Aupeloptrris, Klfss. Toenitis, sect. 1. ${ }^{\text {a }}$

Antsocanpium, Presl, Epim. bot., p. 58. Genre à plaeer parmi les eyclodićes, après le genre Cyclodium, dout il diffère surtout par ee que ses frondes fertiles et stériles sont de mème forme. Nous u'arons jamais vu le type de ee genre, sur la validité ducquel nous n'osons nous prononeer.

Ahgrrociosma, J. Sm., Subgenus Nothochlena.

Atactasia, Blum. Enum. pl. Jav., p. 134.

BeLvisia, Mirb. Mymenolepis, Kifss.; et Asplenii spec. Anct.

Beplarocalisa et Ctexochlesa, divisions élablies par Kunze, dans le genre Aspidium, pour les espèces à indusium velu ef à indusium lacinié.

Botryorialles, IIortul. Polybotryer spec., Auet.

Calovirayos, Presl. Subgenus 2. ${ }^{u m}$ Gymnogrammes. Il représente le genre Ceropleris de Link, saul quelques espèces.

Chiloptens, Presl; sect. 2.", generis Grammitidis, ejusd.

Colposoria, Presl; sect. 3." Mavallice.

Crevoptras, Blum. Subgenus Polyjodii, Anel.

Diagramia et Paragramia, Enum. filic. Jave. Ces deux sous-genres du Polypodium sont devenus pour cet auteur : le premier le genre Sellignea, le seeond le genre Drynaria.

Dicracoptrns, Mart. , C'ryplog. Brasil., p. 67 , sect. 3." generis Alsophilae.

Dicraxoptemis, Blum. Subgenus Polypodii.

Dicryoclosscy, J. Sin. IJymenodii spec., F. Acrostichum, L.

Diprenis, J. Sm. Subgenus Mrynarix, Auet.

Dryoptelis, Adaus; et Dryorteris, Presl ; sect.1. ${ }^{\circ}$; Lastrece, Phegopteridis spec., $\mathbf{F}$.
Drcrimis, J. Sm. Mrynarice spec., F. Dictyopteridis spec., Presl.

Ertocrosua, J. Sm. Subgenus Nolhochlience.

Glaphyroptenis, Presl. Polypodii spec., Auet.

Haplophlemia, Mart., Crypt., 67. Mlsophiloe, sect. 1. a, Presl.

Haplopteris, Presl, Tentam. plerid., p. 141 , tab. V, fig. 21. Ce n'est point un Blechnum, comme le reut Endlicher, ear les sporanges ne sont point eostales; ni un tceniopsis, eomme l'cerit M. J. Sunith, ear il existe un indusium. Ce genre doit rester daus les incerta jusqu’à ee que la plante-type, qui est extrèmement rare et que peu de botanistes ont vue. soit mieux eonnue.

IItrenogosiun, Presl, Epim. bot., p. 142. Nous possédons le 11. 289 (Foug. de Cuming), qui a servi de type à ee geure; il diffère éridemnıent de la plante, portant le mềne numéro dans la eolleetion de M. Presl; les sporothèees sont arrondis et les nervilles libres. Le n.$^{0} 321$ déterminé ainsi que le précédent, eomme uı Stenosemia aurita de II. J. Smith, et qui est un véritable Pleocnemia aurila, semblerait ètre l'Heterogonium de notic auteur, quoiqu'il ne reproduise pras exaetement les figures 1 et 2 de la planelie 94 du genera de IIII. Hooker et Baner. Nous regardons eomme bien diffieile de eroire iei à l'hétéronıorplie des frondes fertiles et stériles, et à la dissimilitude de la nervation. Cette eireonstanee peut se présenter lorsque les frondules fertiles sont linéaires. II est sans exemple qu'elle se produise dans les fougères dorsilcres, à frondes pinnées-pinnatifides, dont les frondules sont dilatées. Il faut s'assurer de ee fait, et en attendant regarder l'Heterogonium eomme un Gymnogramme. La planehe, citce de III. Hooker et Bauer, donne les détails de trois plantes différentes, dont aueune n'appartient au genre Stenosemia analysé.

Histioptr.ris, Agardlı. Subgenus Pteridis, duet.

IIYalolipis, nom proposé par Kunze pour l'IIymenolepis, comme plus eonvenable. 
Hrurnolema. Nom domé d'abord an gemre $/ l_{y}$ menocystis, E. Mey. devenu un Cystopteris.

IIrucsorous. Gaud., Voy. Freyc. bot., 3i9, gense senlenent indiqué, lequel réunirait plusieurs de nos especes de Stenolome.

Incacssanra, Gaudich., Voy. de la Bonite, Allas (sans terte). Ce genre comespond exactement at genre Egenolfia de II. Schott, fondé en 1834. Trois especes ont ité figurées :

1. L. montann. Eqenolfia montana, roisin de l'E. marginata (lals. 118).

2. L. "ppendiculata. Egenolfa Gaudichaudiana, F. (tab) 119)

3. L. rhizophylla. Fgenolfa Ilamiltoniona, silsolt (tit). 120).

Lı.picisris, J. Sm. Subgenus Goniophlebii, J.Sm. Lrpicitosus, J. Su. Subgenus Nothochleence.

Jomariolin, Presl, Epim. bot., p. 154 et 263.

Ce gemre formé aux dépens des lomaria cl que nous arons seulenent indiqué dins la synonymie de ee genre, esl, suivant l'auteur, eatractérisé par des sporothèces privés d'indusinn. Cependant M. Presl y lait entrer le Lomaria L'Ilerminieri, chez Icquel l'inclusium existe l'une manière tout aussi évidente que dlans lat plupart des autres espèees. Dislinguer un indusium fatux d"un vrai est close souvent diflieile. Le savant auteur s'exirime ainsi : imblusium mullum, cum margo tenuior et pallidus numquam replieatus, sed planus indusium dici nequit; or, dans le Lomaridium L'Jerminieri, ta maroe est replice jusque vers le mésonèrre el mème modifiée daus sal forme d la base. Le caractèrc admis ne nous semble pas suffisaut pour motirer la formation d'un geme qui, dans tous les eas, ue pourait recevoir le Lomaria L'lierminieri.

Lopholrprs, J.Sm. Subgenus Goniophlebii, J.Sm. Lytonevunox, Kifss. Subgemus Doryopteridis.

Notocalfia, Presl. Subgenus Cyaiheer, ejusd.

())osiosonil, Presl; sccl. 4. ; cum Oclontosoria nostri non coufert.

Oxopreris, Neck., Elem., 11.0 1721. Asplenii spec., Auct.

()rнovoloma, Lk. Cheilantlis sjec., Auct.

PLexisicu, Piesl. Tentame pterill., p. 109 , lab. 111. fig. 13. Asplenii spec., Btum., Wall.
Podrilema, R. Br., mssc. Sphreropteris, R. Bi.

Polsgnaua, geme senlement indiqué par M. Presl (Epim. bot., p. 156), dans le groupe des lomariées.

Puovoprenis, Wall., Cal., "1. ${ }^{\circ}$ 184. Spheropteris, R. Br.

Proferca, Presl, Ejim. bol., p. 259. Le type de ee genre qui apparticnt au groupe des cyclodiées, ne nous est pas eomun.

Proxfmutu, Presl, Efim. bat., p. 258. Les espices de ce genre, qui prend place parmi les aspidices, nous sunt inconnues; elles n'ont point été figurces.

Prcsononta, P'resl, Ephim. bol., p. 100. Ce genre est fondé sur le Pteris opaca de M. J. Sunith. plinte des Philippines, distribuce sous le 11. 342; nous ne volons pas en quoi elle cliffère des autres pteris. Le port est le nuème ainsi que l'organisiltion. Les icinules sont trèsdélices, tris-rapprocluces et parallèles, le faiscean vasenlaire aurait me forme particulière: mais ees caracteres se retronvent diuls d'autres pteris, et nous nous sommes assuré que rien n'était plus variable que da clisposition des faisceaux vaseulaiues daus ce gente; dans le P. opere il cost en lorme de fer at clicrat. (Vou. tab. $\mathrm{Xl}, \mathrm{\Lambda}$, fig. $2,3,4,5,8$ et 13.)

PYrrmosis, Miib., In Bull. soc, philom, , ill IX. 70. Niphoboli spec.

Ragloptcins, l'resl, Tent. pterid., 1). 95, 1. 1II, fig. 9 et 10. II. J. Smith eroil que la fronde stérile el la lionde fertile, dont II. Presl at dounce des liagments, n'appartiennent pas à la plante, et que le fragnent fertile seul se rattache à l'Onoclen sensibilis; il ajoute quil a su dans l'herbier de V. Lambert l'excmple d'une méprise semblable. Celá opinion nons semble fondéc et nous pensons que ee gुenre doit disparaitie.

Salpiglexs, J. Su, , in Linncea ex errore pro Salvichluena.

Schellolepis, J. Sm. Subgenus Goniophlelvii. J. Sm.

Srlfsinum, Kunz. Davallice spec., Auct.

Solrwopteris, Wall., Msc. in Endlich. Gencr., p. 59. Loxogramme, Blum.; Selliguee Subgenus Loxogramme. 


\section{LISTE ILPIIBELTIOLL}

\section{DES OUVRAGES ICONOGRAPHIQLES CITÉS DANS CET OUVRAGE.}

Irzeutes (1.). Acta Holmice, 1787. (Afzel.*)

Anrabani (A.). Floroe Fluminensis icones. Parisiis, 18:7; 11 rol. in-fol. (Arrab.*)

Aublet (Fusée). Histaire des planies de la Guyane fransaise. Paris, $1774 ; 4$ vol. in- $4 .^{\circ}$ (Mubl.*)

Basks (J.). Reliquice Horstoniance. London, 1781. (Banks.*)

Benviandi (J. J.). Dans le Journal de botanique de Schrader, 1799 et suiv. (Bernh.*)

Bergerit (J.). Flore des Pyrénées. Pau, 1803. (Bergeret.*)

Brackwell (Lady E.). Curious herbal containing 500 culs, etc.; 173 I : in P. (Black.*)

Butve (C. L.). Flore Jave (Filices). Bruxellis, 1828-1829, in-fol. (Blum. .)

Bucve ct Neis. In Act. nova curios, natur., t. XI.

Boltos (J.). Filices Britannice, 1705 ; in-fol. (Bolt.*)

Bory de Sarvi-Tixcexr (J. B. G.). Voyage dans les qualre rrincipales iles des mers d'Ifrique. Paris, 1804. (Bory.*)

Bony de Sirvo-Incent (J. B. G.). Fougeres et familles voisines, dans la partie botanique (Cryptogamie) du Voyage de .1. C. Belanger. Paris, 1831 et aun. suir.

Bory de Sistr-Viserst (J. B. G.). Exploration scientifique de Morée; 1835 [botanique].

Breyx (J.). Icones rariorum et exoticar. plantarum; il1-4. ${ }^{\circ}$ : 1689. (Breyn.*)

Browse (P.). The civil and natural history of Janurice; 1756.

Bunusv (J.). Flora Malabarica; ill-fol. Amsterdam, 1769. (Burm.*)

Destatx. Journal de bolanique. Paris, 1808-1814 [passim]. et aussi dans le Magasin de Berlin et les Aunales de la Société Linnéenne de Paris. (Desv.*)

Desvaux. Prodrone de la famille des fougeres (Annales de la Société Linnéenne de Paris, 1827); in-8.

Dryavder (J.). In Linn. transact., III, 39 ; tab. III-X. (Dryand.*)

Eurhant (F.). Beiträge zur Valurkunde, etc.; 1787-1792. (Ehw.*)

Fé (A. F. A.). Mémoires (1.4) sur la famille des fougeres. Strasbourg, 1844-1852; in-fol.

Flona Davica; in-fol. (Oeder et Auct. var.: 1761: se continue). (FI. Dan.*)

Gacoichacd (M. Ch.). Voyage de l'Uranie, partie botaniqne. Parris. 18:6; in-4." (Gaud.*)
Gazdichaud (M. Ch.). Voyage de la Bonile; partie bolanique, sans texte. Paris, 1836-1837; in-fol.

Gsmeux (P. F.). Otia botanica. Tubing., 1761. (Gmel.*)

Guvira (J. E.). Flora Norwegica. 1766, in-fol. (Ginn.*)

Iofmaxx (G. F.). Deutschlands Flora (Cryptogamie). Erlang.. 179j; in-12. (Hoffn.*)

IIombrox et Jice. Voyage au pôle sud (Cryprogamie).

Hookrr (W. J.) et Grevilue (R. K.). Icones filicum; 2 vol. in-fo!. Londini, 1831. (Hook. el Grer, *)

Hooker (IV. J.). Exolic Flora. Londini, 8 rol. in-8. $.^{\circ}, 1823$. (IIook.*)

Hooker (J. W.). Species filicum, being descriptions of all know ferns..... 1841; se continue. (Hook.*)

Hooker (IV. J.) et Bater (F.). Genera filicum or illustrations of the Genera of ferns. London, 1838 ; rand in -8 .

IIotrux (MI.). Des Ritlers von Linné PfanzenSistem, nach der Anleitung des IIoutluynschen IVerks; in-8. Nürnberg, 1777-1778. (Houtt.*)

Husuboldt (Al.) et Boxplaxd (Im.). Nora genera et Species plant. Amer. aquinoclialis. Parisiis, in-fol., 1817-1825. [Filices.] (Humb. et Boupl.*, II. Bonpl.*, H. B. et Kth.*)

JacQus (X. J.). Collectanea ad botanicam, chemiam et historiam naturalen. Vindobone. (Jaeq. *)

Kicterss (G. F.). Enumeratio filicum quas in itinere circi terram le git clar. 1. de Chamisso. Lipsia, 1824, in-8. (Kifss.*)

Kuvze (G.). Analecia pleridographica, seu descriptio et illustratio filicum aut novarum, aut minus co nnilarum. Lipsioe, 1837. (Kze.*)

KuxzE (G.). Die Farrenkriuter in kolorirlen 1 bbildungen naturget reu erlautert nnd beschrieben (Schknlur's Farrenkräuter; Supplément. Leipzig, 1841-1851). (Kze.*)

Labilarmine (J. J.). Nove Mollandice plantarum specimen; in-4..$^{\circ}$ Paris, 180t-1806. (Labill.*)

Labillarouĺre (J. J.). Sertum Austro-Caledonium in-4." Parisiis, 1824.

Lamarck. Encyclopédie (botanique), I-IV; 1783 1796. Paris, in-4. (Lmrk.*)

Lasgsdonfa (G.) et Fischir (F.). Plantes recueillies pendant le voyage des Russes autour du 
monde. Tubingue, in-fol., 1810. (Langsul. et Fisch.* . L. el lisch.*)

liwer (C.). Imanilates academices: Acrostichum. Disserlatio X. IIolmia, I. I, 1749. (L.*)

Marmiss (M.) el Galootio (H.). Mémoire sur les founires du Mexique. Bruxclles, 1842? in-4. Acad. ros. de Bruxelles. (Mart. et Gal.*)

Mantus (C. F. Ph.). Icones plantarum cryplogamicarum quas in itinere annis 1817-1820 per Brasilizm collegil el descripsit Martius. Monachii, 18:8-1831, in-fol. (Mart.*)

Houssos (R.). Plantarum historia universalis; Oxoniensis; 3 vol. in-fol.; 1680. (Ioriss.*)

Irelen (O. F.). In Valurforscher; st. 21. (Yull.*)

Pilisot in Bratiols (1. M. F. J.). Flore des royaumes doware el de Benin. Paris, 18051810, in-fol. (Palis. Beaur.*)

Pint-Thocars (Anbert du). Descriplion el esquisse de la flore de l'ile de Tristan d'Acunha. Paris, 1804, in-8. (Pet. 'Th.*, Aub. P. TH..*)

Prerisn (J.). Opera hisloriam naluralem spectunlia; 3 vol. in-fol. Plerigraphia Americana, t. II, Londini, 1764. (Petiv.*)

P'ukmer (L.). Opera omnia, in sex tomos divisa. Londini, in-fol., 1720. (Pluk.*)

Poumun (C.). Tractalus de filicibus americanis (Traité des fougères de l'Ancérique). Paris. 1705 , in-fol. (Plum.*)

Plumer (C.). Description des plantes de l'Amérique arec leurs figures. Paris, in-fol., 1713 , texte francais. (Plum.*)

Porrer. Article Acrostichum; Encyclopédie méthodique, partic botanique. Paris; in-4. ${ }^{\circ}, 1810$. Supplément. (Poir.*)

Prisl (C. B.). Delicice Pragenses. Pragee, 18:22, ill-8. (Presl et Pr.*)

Presl (C. B.). Tentamen plerilographice seu genera filicacearum, prisertim juxti venarum decursum el distributionem exposila. Prage, 1836.

l'r.tsL C. B.). Reliquie Ilankeana, seu descripliones el icones plantarum, elc. Filices, fasciculus prinus. Praga.

liadm (J.). Plantarum Brasiliensiunt nowa genera el species nove, vel minus cognilce. Florentice, 18:25. (Kadd.*)
Rerzus (1. J.). Fasciculus 1-6 obseriationum bolunicarum. lipsice, grand in-fol., 17791791. (Relz.*)

RuE Ine (II.). IIortus Indicus ,Malnbaricus. $12 \mathrm{vol}$. in-8. Amstelodami, 1794. (Rherl.*)

Ricunad. Flore de la Nourelle Zílande. (Rielı.*)

Runpuncs (G. E.). Ilerbarium Amboinense; T part. in-fol. Ainstelodani, 1739. (Rimuph.*)

Salisbur (R. 1.). Transacl. of linnean soc., vol. VIll-X. (Salisb.*)

Scukenr (C.). Bolanisches IJandlbuch oder Krrplogamische Gersächse, elc. Leipzig, 1815. in-4. (Schhh.*, Schk.*)

Schlcchtrval (D. F. L.). Adumbraliones planiarum. Fascic. 4. Berolini, in-1. ${ }^{\circ}$ La $1 .^{\text {re }}$ livraison est eunsacrée ans fongères. (Schlecht.*)

SEBA (Mb.). Locuplelissimi rerum naluralium, etc. Amsterd., 1734. (Seb.*)

Seguier (J. F.). Planle Veronenses; in-8. ${ }^{\circ}, 1745$. (Seguier.*)

Stonx: (J.). Catalogus plantarum quee in insula Jamaicn proceniunt; pars prima. Londini, in-8. , 1696. (Sloan.*)

Sprescll (C.). Anleilung zur Kenntniss der (jewaichse, elc. Ifalle, 1802 el 1804. (Spreng."

Swartz (O.). Synopsis filicum, earum genern of species systemalici complectens. Kilice, 1806. in- $8 .^{\circ}$ (Sw. *)

Tabren.emostanes (Jac.). Icones, elc.; 1588. (Tibernicmont.*)

Thunbrig (P.). Flora Japonica. Leips., 1784. (Thunb.*)

Tounvront (J.). Instiutiones Rei herbaria; 1700. (Toumef:*)

'Tupre (P. J. F.). Mlas du Diclionnaire des sciences nalurelles de Lecrault; 1816-18:29. (Тur.)*)

Vall (M.). Symbola bolanica, sive planturum tam earum quas in ilinere collegil P. Forshal, quam aliarum recentius detectarum exactiones. Ilafn., gr. in-fol., 1790-1794. (Vahl.*)

Willdivow (C. II.). Phylographia seu descrip. liones rariorum minus cognilarum planlarum. Erlang., 1794. (Willd.*)

Wrerris (F. X.). Plantarum rarior descripliones. lips., in-4.", 1805. (Wulf.*) 
Listr indiquune, commer complément, la date de la création des divers genres.

Wencophorns. Gaud. 1826.

inligramme l'resl. 1836 .

isplenium, L. 17G'.

thinrirum, Roth. 1788.

Collipteris, Bory. 1804.

C'amploserese L. Li. $181 \mathrm{~L}$

cascbeeria, hilss. 1824 .

Celerach Willd. 1809.

Cincinalis: Cincinnalis, Dest. 1810.

ruspiellaria, F. 1851.

ryelleen . Sn. 1790.

Dirlymorhlena. Desv. 1810.
Digiammaria, Près]. I830. Diplasium, Sw. 1500. Dipteris, Reinw. 18 ?8. Doryopleris, J. Sm. 1842 Goniopleris, Presl. 1836. Gymnogramme, Dest. 1810. Hemidictyon, 1'resl. 1836. Hexardia, J. Sm. I8'1].

Hypoderis , R. Br. $1818 \%$ Hypolepis, Bernh. 1799\% Jamesonit, H. et Gr. 18.31 . Jamesonige, H. et G
Lonchilis, L. 1737 .
Lorinsorir l'res. 1819.

Veniscium, schrrib. 1759

Neollopteris, J. Sm. 18 '?

Fothochlence. R. Br. 1810

ochropteris .J. Sm. 18 '?

Onychinem, hiltss. 1824.

Phorolobus, Desv. 181 t.

Pleurograinme, l'resl. 1836.

Schisolepton, F. 1851 .

Scolopendrium. Smith. 1790.

Stegnogretmme, Blum. 1830.

xiphopteris, hiles. 18 ?'

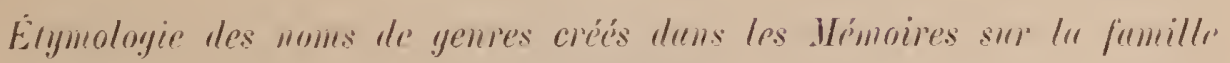 des Fongines.}

thacopleris. Vervilles formant des areoles mesque (mindrilateres i la maniere des cases d'un damier

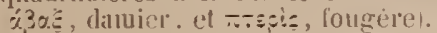

Irlicentopsis qui se rapproche par l'aspect de l' thermtum xós:-oy, adiuntum, et o's:e, aspect, apparence I.

deurilopleris. Hougcure il lanes infirieures courertes d'une poussirale larinellse rizjoo\%, farine; trevis, lougure.

Botryogremme. Fontrire it friclification lineaire disposece en soltes de grappes ßó-p's, grappe: үрхuн , ligne.

crollogramme. Fonsire a finctification lineaire. èleganment dispost: (xólisos, beate; rpurur, limile .

cremptodium. Fongère dont l'indusium est fortement fleclii au centre (x.gu-s-b; plic, courbe .

ramlinelilena. Fougère ì sporothèces pontant un

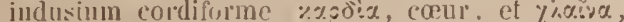
[mic|le [indusiun]].

Cheiloleplor. Sporanges reenes dans un itroil caual;

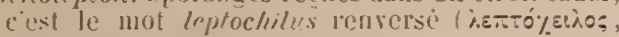
canal etroit.

('mysorlium. Foncere it frourles fertiles, convertes de sporauges d apparence dore r.pusos; or

rouiogramino. Fougère à sporanges pell serres, paraissant ejalpillées sur la lame comme unc

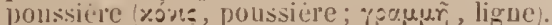

(iryplosomes. Les sporotheces baissent dans le mesonère et ils! sont caches $x_{0}-\pi=\omega$, je eache; swros, anlas [sorns ou sporothece] !

Cuspiduria. Frondes dont les divisions sont $\mathrm{en}$ pointe cuspis. pointe.

Diclyogramme. Fongẻre a frnctilication lincaire et at

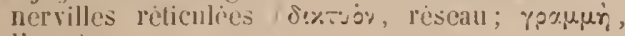
limuc i.

inryomenis. longere athoricole ayant des sporoilieces meniscioüdes el des nervilles réticulecs $1 \delta p^{\circ}=$, rlene, pont arbice, el privr, lune.

Eriosorzes. Sporothèces formis de sporanges et de

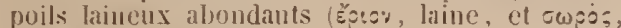
antas de sporotheces!.

Hemicurlion. Les frondules sont a demi cordecs

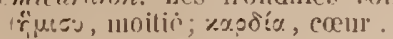

Heleronerron. Tervilles formant des areoles integulieres žspos, different, et yejpso nerf nervilire, I.

Heterophlebrum. Hẻme signilication que Heleronevron; les arcoles sont de grandeur et de forme

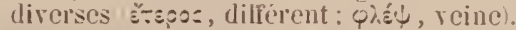

Hymenodium. fiente a rijeces membraneuses juri, memblanc

Hypoclifamys. Indisium at!ardee sous la nervure (j-5, solls, el yizuije, chlamyde, indusium!.

Lepieloneron. La nerville porte in indusium arant

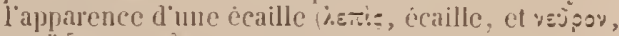
nerl" [nervire) !

Lindsaynim. Geure se rapprochant par le port du gente Limelsuyre Lindsay, nom dïltomme .

Lomarioljol\%s. I.nmaria à fructification disposice en

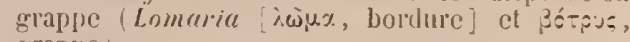
grappe 1.

Lomeriopsis. Fougcie sc rapprochant par l'aspect extiriem du Lomaria; genre chez lequel les sporothèces forment deux liames continus qui bordent les lames Lomaria i.w. s., bordure, et b'st: apparence ).

Myrinpteris. Fongere divisice en un nombre con-

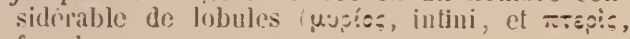
follgère!.

Fervocullis. Fougère remarquable par la beauté de

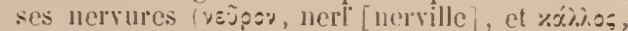
beante'?

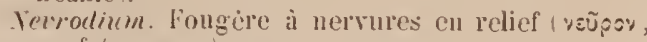
nerf (nervine)

Odontosoria. lougète à sporolheces atlachés a l'extrémite dime nerville qui traversc me denticu-

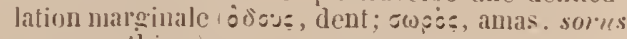
ou sporothice \%

Oochlamys. L'indusimn est exactencut oroüde wör, wuf, ct yiquis, clulanyde indusinm?

Phegopleris. Hot il mot fougere du lidte. Ce gemie a pour type le Polypodinm l'hegopleris des an-

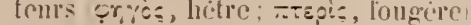

rhecbiognnium. C"est le nol Goniophedrum renrerso; il signific nervilles se remuissant pour former des angles 1 phét, reine. et ;wrix, angle/. 


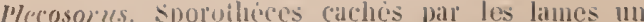

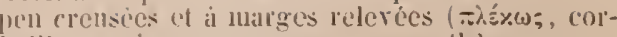
beille; z(1) 50 , allits. sorus oul sporotliecel.

pectopteris. liougere dout la laue se leplic pour ralchel les sporantes ( riex-os, qui se plic, at -r.epis, fungrile .

Pexerlinm. Laltaiche des sporotheees est laterale -ieveor, coto

Pleurosores. Sporolheces attachies sul de coite de la

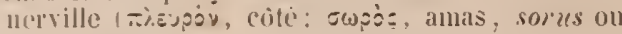

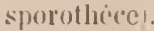

Porlopellis. L'indusimu, qui est en bouclicl. est supuporti an (ecutie pall mn support assez long

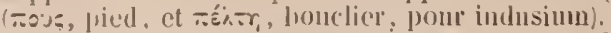

Pleviglyphis. Sprorotheres et nervilles en l'elief

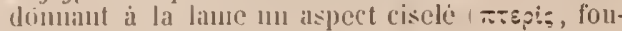
give el ris-si, je grave

Plerenceron. lougèce dont les nervilles sont dila-

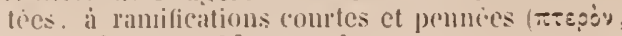

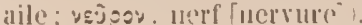

Plero:onium. Sporothices formant une zoue distincte antour d'une fronde orbiculaite ( $\pi$ sepis. longere: ¿́wr, zỏnel.

scllisolepton. Sillon lecevant les sporanges daus un sillon a yant liluparence dinne lente étroite je feuls, et rex-s=, délie. frès-citroit.

scyphularir. Fougères dont les sporothèces. munis d'un indusimm, ont la forme d'un verte sxśps:, relice il boirel.

soromanes. Fongeres ayant une tendance trisgrande it se cliarerer de sporanges / כwpos, amas. sorus ou sporotliece, et pryíx, minie).

Stenofoma. Fongères à frondes partagees en seg-

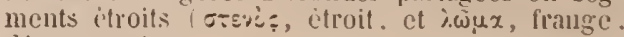
diconjurce).

Trismeria. Fougere a frondules divisces par trois cós, trois, et $\mu$ épos, partic

Vayimularir. Fondes fertiles formant mue gaine pom recevoir les sporanges. (rogimula. petite galue 1

\section{ADIITIONS ET CORRECTIONS.}

l'agures. l.ıpnes.

6 31. An licu de press ae 170. plus exactement 181.

1' 26. Daus le tableau des plantes tilicoüdes et daus quelques antres endroits le unot angiosore est unal a propos imprimc par $y$.

43 18. Faites disparaitre de l'émuméation des especes l'terostichum dimorphum. dout nons avons fait un anogremme, par les raisons dednites pages fi et 18 i.

i5 17. Fiffacez les mots compris entre les denx parentheses.

25. An lieu de agno mme;o lisez magno mumero.

j. An lien de lleux lisez cinq.

20. Au lien de emeioribus lise\% cemuibus. Cette fante se reproduit encore ailleurs.

7. Au lien de Mnlyeerotis spec. lisez Plalycerii spec.

5. Supprimez la prenticre espèce inmmeric qui est un leplochilus.

16. du lieu de plus minuse proximum lisez plus minuse mesoneren proximnm.

73 36. Le Blechnum pectinatum, Hook, est émmeré a tort denx fois; il ell est de méme. pange 2l í, liguc ?. dı Diplazium caudalum, J. Sus.

í 11. Le Blechnum menetulatum. Sw. . est sans donte la mème plante que le Lomeria punctulale de Kumze. Le B. Vilobum, Presl, est indiqué parmi les Blerhmum et parmi les Lomaria. Ciest nne plante de transition. qui mnit les deux genres; il semble néammoins qu'elle soit micux placic parmi les Btechnum.

89 T. An linu de basi lisez basim.

10j 13. Supprimez de l'énumération le limlsayn rigullı, J. Sul

120 33. In lien de anyusta. J. Sm., lisez pallens, J. Sm.

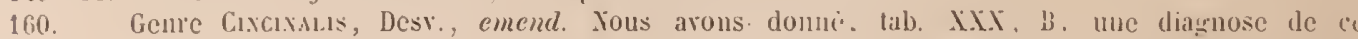
genle, distinct dn . Tohochtana par le port et par le singulier mode de division des frondules qui rappellent l'épillet des brisa; mais il en diflère i peine par les organes reprodnits. l.es sporanges unt la mène siluation, et, comme dans ee gremre, elles sout attachices sur les nervilles et pres de la marace. les fromdules, nues rets la lane superiente. sont couvertes

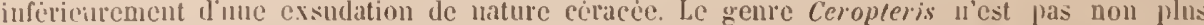
tres-idoiguc dn Cincinatis; pourtant le port et l'arlugement des sporanges. formant des serries lincaires qui descendent rer's le centre des libues. séparent suffisimment ces deud genres.

16. 16. Au lien de duo lisc\% duos.

186 20. An lien de Aspidium, tontanum, Sw. . lise\% Isprolinm fonlanum, Willd.

191 35. Au licu de argutum. li., lisez argutuns, l:. 
Pages. Lignes.

$192^{\circ} 1$ '. Au licu de Asplenium Mrereei, H. et B. lisez Hook. et Gr.*

205. Genre 93. Ceterach. Willd. Nous arons cru devoir donner une analyse nourelle de ce goenc, dans lequel ne parait point exister d'indusium. Sous avions cru le contraire; mais ce que nons regardions comme tel, n'est autre chose que la nerville réceptaculairc renilćc et chargèc des débris de pédicelles de sporangiastres fasciculcs i leur base. Nous nous sommes en outre assmé qüil n'y arait d'anastomoses que dans les $C$. officinarum et lalifolium. Yous avons dit it tort Capense. Les $C$. Caperese et cortalum, ayant des nervilles libres. devraient done disparaitre de ec genre pour derenir des yymnogramme, si l'on roulait soukment avoir égard it la nerration; cependant le port est tellement scmblable qu'on ne peut guère les séparer des rais ceterach. (Voy. la planche XXX, A, pour l'intelligence de ce qui prècéde.)

231 17. .tu licu de C. elusticus lisez C. Blumei.

= 18. Au licu de pubescens liscz rufescens.

237 30. Au lieu de suprà densè squamosis lisez injò̀ ulensi squamosis.

258 8. Yons avions compris parmi les Campylonceron Ic C. solulum, sul l'alitorite de V. Kilotzsch, qui, Ie premicr, a fait connaitre cette fougère; mais la figure, lounce par liunze. nous a dèmontrè que c'était un rẻritable Goniophlebium. ( Yoy. p. 255.)

261 12. Le Craspeclariu serpens, placé parmi les espèces dissidentes, est au nombre de ces plantes ambiguës, réclanées par deux genres et qui ne sont conrenablement placées ni dans l'un. ni dans l'autrc. Yous le mettons définitivement parmi les goniophlcbium. Il fant done le faire disparaitre des plantes comprises dans lénumération des craspedreria.

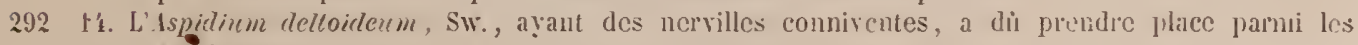
vephleocliem.

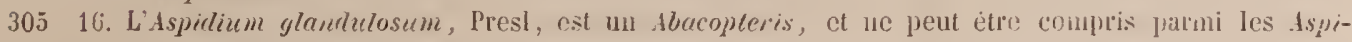
dium. Noy. 1). 310.

333 1. Supprimez te Darea cieularia, Sw. et Willd., qui est un Asplenium de la division des Drreastrum, p. 19?.

= 3. Au licu de Darea vivipara, Bergul., lisez Ccenopleris vicipara, Bergm.

352 13. Le Cyalhea serra, Willd.: doit disparaitre de l'énumèratlon des especes. M. Hooker le decrit conme un Cyathea; mais II. l'resl, dont nous adoptons l'opinion. cu fait un Irisplenia. (qui, pour nous, est un sous-genre de lillemislegia.

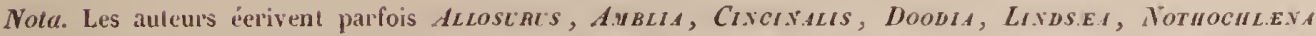

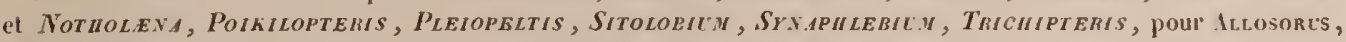

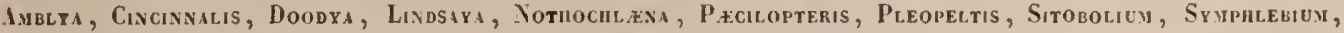
Trichoptenis. Les désinenees en gramme sont aussi sourent orthographiées gramuma. 


\section{LISTE ALPIIABÉTIQLE DES PLIITES}

\section{FIGUREES EN TOTALITÉ OU EN PARTIE DANS LES PLANCHES DE CE GENEII.I.}

Am.sopteris, tah: AVIII, C.

I'hilippinarum, fig. 1.

ICROPTEIS, tal,. II, I.

australis, fig. 2. (Atiniopteris, l..) septentriunalis, fig. 1.

ICROsticnit: M, tab. I, I.

andicola, fiz. ‘.

lior anum, fig. 2 .

Yathewsii, fiy. fo.

Ieridense, fig. .;.

ophioglossoides, fig. j.

rabulolepis, fig. 1.

Schomburgkii, fig. 7

ACTIYIOPTERIS, I.k., ioj. Acropteris.

АIEvориокт:s, tab. $\backslash, 1$.

bipinnatus fig. I.

AIIATTIy, 1ab, .II, B, el tab. XXIX. rardiuchlæna, tab. VI, fig. 2. (Apotomia.)

macrophyllun, ,ab. XI, fig. 3. (Synechia.)

radicans, tal,. I.IIX, fig. 2

AI.E:RITOPTEIS, tal. III, B

dealtuata, fig. 2.

Parinosa, fig. I (reduct.).

IYli.t. tab. XIII, li.

juglandifolia, fig. I.

I III-IIIBLESTR.1, tal). II, B.

latifolia, fig. $1,4-8$.

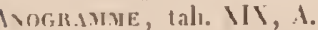

leptophilla, fig. I.

refracta, fig. 2.

LSPLENIUy, tab. III et XVII.

Falv, tal). H1l, C, fig. 2. (Tarachia.)

Moutbrisonis, tab. 11, 1, fig. 3. Iтпгкеч, tab. VVII, C.

conchatum, fig. I.

BIECHNopsis, Presl, ioy. Blechnum.

BIECHN' 1 , tal. $1, \mathrm{~B}$.

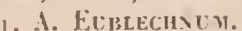

caudatuu et extensum, fig. 1'. glandulusum, fig. 11.

Valaciense, fig. I.3.

13. Bitecinopsis, Press.

scriulatum, fig. 15.

2. VIesotilevi, l'resl.

liastatuII, fig. 12.

BotTuogr.iuve, tal. . IV, C. Karwinskii.

Calcitteris, tab. IVII, D.

prolifera, lig. 2 .

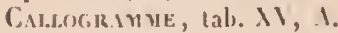

Cæciliæ, fig. ।.

Carmochl.exa, tab. X.MI, B. macrophylla, fig. 1 .

Ceteraci, tal, Ifis, 1.

Capense, fig. 4 .

cordalum , fig. 3.

latifolium, fig. 1.

officin arum , fig. 2 .

Cheiloleptos, tab. III, C.

IBlume anum.

Cincisalis, tab. VIX, B. flavens.

Coviogr.s.me, tal. XIN, B.

Jasanica, fig. I.

serrulata, fig. 2.

Criptosorus, tab. XIK, C.

Dionæa, fig. ı.

clasticus, fig. 2.

Cuspibaria, tab. IIII, A.

fircata, fig. 2.

subpinnatilida, fig. 1.

tricuspis, fig. 3.

Darea, lab. IIIII, C

iıxqualis, fig. I.

flaccida, fig. 2.

iivipara, fig. 3.

D.M.A.LIA, tab. WIII, C.

Shimperi, fig.

DeN digglossa, tah. VII, B. quercifolia, fig. 2.

subquinquefida, lig. I.

taccæfolia, fig. 3.

Dichasiuv, tab, I.III, B. parallelogramumu, fig. I.

patentissimum, fig. 2.

Dicksovia, tal). MVII, B.

tenera, lig. 2.

Dictyograyme, lal. $\mathrm{Xl}$, A.

Japonica, fig. 2.

Dictyopteris, tal. .Ni, 1.

macrodunta, fig. 2 .

pteroides, fig. I.

Digrayvaris, tab. CIIII, $b$.

robusta, fig. 2.

Diplazitu, tal. IVII, D.

Valarcense, lig. 1.

DR YMog Loss's, tab. IS. piloselloides, lig. 2.

subcordatum, fig. I.

Drvikia, tal. XII, B.

Phymatodes, fig. 1 .

1)RIOVENIS, tal, IVIII, A.

P'himatodes, fig. 1.
ERIOSORU's, tab. XIII, IB.

Ihnizianus, fig. 2.

scandens, fig. I.

Gateoglessit, P'resl, roj. Nipliobolus.

Govinpilemivn, tal. IVI et MIV. eusiforme, tab. XII, I3, fig. 2. neriifolinı, Ial. IVIT, B, fig. 2.

Gr.ıмvitis, tal. XI, I.

Vagellanica, fig. 3.

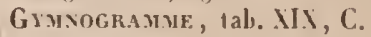
rufescens, fig. 3 .

II.IPLDICtro:, lab. IIIII, C.

heterophillum, fig. 2

IIECISTOPTERIS, tali. II, li. pumila.

Henicardinx, tal). IVII, I.

crenatum, fig. 1

Cumingianum, fig. 2.

Heuoxitis, tals. (II, b). sayiltata (reduct.).

HFuistegil, tab. IIIII (ter), I.

grandifolia, fig. 1 .

horrida, fig. 2.

IIETEROVETRo\, tal. I 1,1

disersifolium, lig.:

IIfterophlebum, Ial. II, I.

grandifoliun, fig. y-12.

Huv.tт, tal, IIII, I.

ophioglossa, lig. I.

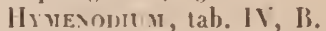

(rinitum, fig. 1 (reduct.).

Kunzeanum, fig. 2 .

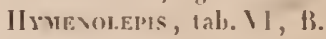

umicronata, fig. 1.

opliog lossoidles, fig. 2.

IIY POCILA UIYs, 1ab. II II . C.

pectinata, fig. 3.

IIrpol.teps, tab. MII.

repens, fig. 3.

Juvesovil, tal. \II, I.

scalaris, fig. i.

l.EPToCHIL.ts, tal. III, h.

avillaris.

I.EPIIOYETRO , tal, IVIII, C.

punctulatum, lig. 1.

LINDS.IYA, tab. II, B, el 111 III.

crenulata, F., tal., CitIII, lig. 2

multifrondulosa, tal). .1. YIII, fig. I.

polymorpla, lal). XI, fig. y et io.

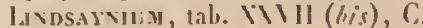

rigidum.

l.ITnikocilia, tal. VI, 1. 
denticulată, fig. 6 .

elata, fig. 7.

2. Campteria

Pseudo-lonchitis, fig. 8.

Loviria, tal, V, B.

attenuata, fig. 6 .

callosa, fig. $\%$.

Gueinzii, fig. 9

lieterophylla, fig. Ј.

lanceolata, fig. 2.

L'Ilerninieri, tab. I, B, fig. \{.

Ilagellanica, fig. 10.

punctata, fig. 4 .

Spicant, fig. I (arl Doodiam transiens).

spissa, fig. 8 .

striata, fig. 3.

I.MMARIOBOTRIS, tab. $\mathrm{V}, \mathrm{A}$

Icleniana, fig. I.

Ioviariopsis, tab. I, B.

erythrodes, fir. 1.

Sinthii, fig. 3.

sorlifolia, fig. 2

Loxchitis, tab. XI, A.

tomentosa, fig. 13.

Lorivsokia, tab. XVII, b.

areolata.

Nevisciuni, tab. XVIII, B.

rosiratum, fig. 3.

MESOTHE.A, Presl, voy. Blechnum.

Microsoluvi, tal, If, P.

irioides, fig. I.

irregulare, fig. 3

Iongissimun, fig. 2.

Movogramme, tal. IX, C.

lincaris.

Mrriopteris, tal). III, NXViH et

IIII.

induta, .III, $A$, fig. 3 .

gracilis, tab. IXIS, fig. 6.

lentigera, tal. XII, fig. 4.

marsupianthes, tal. SII, fig. I.

tomentosa, tab. XIi, fig. 2 .

villosa, tal,. XXVIII, fio. 3.

Nefhnonum, tab. XV'́lI, C.

leuconerron, fig. 3.

Nephrolepis, tab. XXIII et MIV.

cxaltata, tab. XXIII, C, fig. 2.

tulscrosa, tab. XIV, $\Lambda$.

Nevrocallis, tab. IV, A.

præstantissima, fig. 1.

Nevrodium, tab. VIII, C.

lanceolatum.
Neyrogramie, tab. XIV, C.

tomentosa, fig. 1-3.

Niphobolus, tab. IX, A. nummulariæfolius, fig. 3. (Galeoglossa, Presl.)

NотноснцжхA, tab. XIII, B. eriophora, fig. 3.

OCHROPTERIS, tab. XIIX.

angusta, fig. 3.

pallens, fig. 5 .

peltigera, fig. 4 .

ODontoloma, tab. XIVI, A.

Boryanum, fig. 2.

ODostosoria, tab. XXVII, A.

uncinella, $\mathbf{b}$, fig.

Orrcituri, tab. VII, C.

auratum, fig. I.

Capense, fig. 2.

Phaxerophlebia, lab. XIII, 1. nobilis, fig. 2.

Phegopteris, tab. XI, A. decursivè-pinnata, fig. 1.

Phlebiogonion, tab. XITY, A. immersum, fig. 2.

Phorolobus, tab. VII, D. crispus, Desr.

Plecosorus, tab. XIII, A. Ylexicanus, fig. 1 .

Peruvianus, fig. 2.

Plectorteris, tab. SIX, B. gracilis.

Pleurogramieg, tab. X, C. myrtillifolia.

Precrosoncs, tals. XVI, C. immersus.

Podopeltis, tab. XNIII, A. Singaporiana.

Polrpodius a, tah. I et XI. australe, tab. XI, A, fig. 2. fallax, tab. X, A, fig. 2 .

Prosaptia, tab. XXVII, A. contigua, fig. I.

Pteriglyinis, tab. XVIII, B. elegans.

Pteris, tab. XI, A.

aquilina, fig. 3 .

cretica, lig. 1 ct 2.

longifolia et chrysocarpa, fig. 5. serrulata, fig. 4 .

PTERONETRON, tab. XXV, B. parallelum, fig. 1.

Pterozonivir, tab. XVI, 1 reniforme.

RHIPIDOPTERIS, tab. II, A. peltata iar. feniculacea, fig. 1

sphenophylla, fig. 2.

SAccoloni, tab. XIT.

clegans, B, fig. 2 .

SADleril, tab. VII , 1.

cyatheoides, fig. I.

Souleytiana, fig. 2

SAgENIA, tab. NAIY, A.

macrodonta, fig. I.

Salpichlexsa, tal. V, B.

Finlaysoniana, fie. 17.

Patersonii, fig. 18.

scandens, fig. 16

Schizocavi, tals. IVIII (ler), li.

Brunonis.

Schizoleptox, las. VIII, B.

cordatum, fig. I.

SCHIzoloma, tal. SII

Jar $x$, fig. I.

Scolopevdricu, tal, IVIf, ().

minus, fig. 3.

Scrphularia, tab. SATI, B.

pentaphylla, fig..

Sorovases, tal. II, B.

serratifolium.

STENOCHLANA, tab. V, A.

Stevoloma, tab. MIVII (bis), A.

scandens, J. Snı., fig. 2.

aculeatum, fig. 4 .

Blumeanum, fig. 2.

claratum, fig. 3.

dumosun, tab. IIVII, fig. 2.

fumarioides, fig. 6 .

? lindsay oides, fig. 5 .

Schlechtendalii, fig. 1.

Stexosexild, tal,. III, $\perp$.

aurita.

Srigranine, tals. IV, B.

vittæformis (redtuct.).

TARACHAt, vor. Asplenimu.

Trisueria, tab. XIV, I.

argentea, fig. I.

aurea, fig. 2.

Vagisularia, tal. IS, I3.

trichoidea.

Vitrakia, tab. VIII, B.

bisulcata, fig. 2.

WibeLiA, tab. XIVII (bis), B. pinnata.

WOOIи ARDIA, tab. XVII, A.

lunulata, fig. 2. (Doodya.)

radicans, fig. I. (Euwood" ardia.)

Xiphopteris, lab. $\mathrm{A}, \mathrm{I}$.

serrulata.

I. B. Nous notts proposons de publier successirement dans les llémoires de la societé d"histoire naturelle du inuséttm de Strashourg les espèces notrelles décriles dans le Genera. 


\section{TABLE GÉNÉRALE ILPILABETTOQUE.}

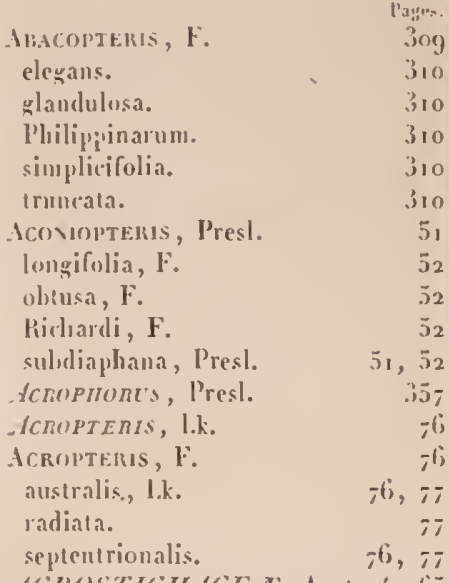

HCROSTICIICEA: Auct. 41,63

ICROSTICIIE.E.

Icrostichi:, Auct. 41, 44, 46, 48, $49,51-62,66,76,77,80,81,94$ $152,155,158,164,168,182-184$, $205,207,33-$

Acrosticilum, $\mathrm{F}$.

arrocapum, Mart.

aclinotrichum, Mart.

adenolepis, Kze.

æmulım, Klfss.

Elhiopicmm, Palis. B.

of $f$ ne, Galeott.?

alatum, $\mathrm{F}$.

albidulum, Su. (roy. Cincinalis

nivea).

"lbum, Irrab.

alcicorne, IVillem., Turp.

alismafolinm, $\mathrm{F}$.

andicola, $\mathrm{F}$.

angulatum, Blum.

anguslalum, Sihkh.

angustum, Kze.

aphlebium, Kze.

apodum, kifss.

aspleniffolium, Bory.

attemuatum, $\mathrm{F}$.

Auliertii, $\mathrm{F}$.

aureun, Arrab.

aureum, I.

auricommu, $\mathrm{F}$

Bauksianum, F.

bellermaıianum, KI.

bifurcalum, Sw.

lilepharodes, F.

Hlumeanum, If. Gen. ', spec. I0.
Borvalum, F.

? Ireutelianum, Kze.

lırevipes, Kze.

liraclinnevron, $\mathrm{k}$.

buxifolium, Kze.

iallaefolinm, Blum.

calophỵllum, Kze.

calomelanos, I., Schklr.* , 01

Ceropteris calomelona, I.k. $\quad 183$ (audatum, Ilook.

cochlearixfoliun, F. $\{2 ; 4$

cochleatum, F.

rouforme, Sw.

conforme, lil.

colsobrinum, Kze.

rrassinerve, hze.

(rispatulum, F.

curvaus, Kze.

ruspijlatum, Willd.

dansáfoliuns, Willd.

lecoratum, Kize.

decurrens, Blualt.

decurrens, Desi.

did!namum, $\mathrm{F}$.

dimorphum, II. et Gr..43, 46, 184

- var. bifurcalum, Schkh. 43

dissimile, Kze.

diversifolium, Blum.

Domlies anum, $\mathrm{F}$.

elliplicim, F.

elougatım, Kze.

erinaceum, $\mathrm{F}$.

ery lhrolepis, $\mathrm{F}$.

faltatum, $\mathrm{F}$.

Feci, Bory.

Aabellalum, llook. et B.

flaccidum, $\mathbf{F}$.

Aacens, Sw., Willd.

faniculareunt, IIook.

Funckii, F.

Gardnerianum, Kze.

Gayanuın, F.

glandulosum, Carm.

gorgoneum, Kilss.

IInmillonianum, Ilook.

Ilartuegii, $\mathbf{F}$.

hastalum, Thunb.

heleroclilum, Presl.

heterolepis, $\mathrm{F}$.

3 lietcromorphum, Kl.

4.3 lirtum, Sw.

43 horridulum, Klfss.

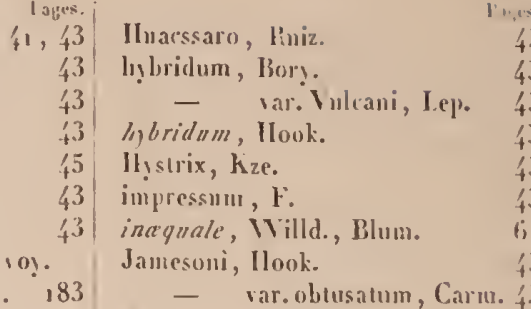

harsteniamum, Kze.

laminarioides, Bory.

Ianceolatum, b. 8 i

Langsdorfii, Presl.

Ianuginosum, I)esf. $\quad 150$

laurifolinm, Du Pelit-7h.

Lepersanchii, Bory.

lepidotum, Willıl.

leptophyllum, $\mathrm{F}$.

b'Ilerwinieri, Bors.

lindenii, lory.

lineare, $\mathrm{F}$.

lingun, Sw., Thunl. $\quad$ (i)

lingua, IRadd.

I.locuse, Ilook.

lomariviles, Bory.

lonchophorum, Kze. fo

lurilun, F.

macropolium, F.

marginafum, Silikh. fi

marginatum, Wallich.

Tartinicense, Desv.

llathensii, $\mathrm{F}$. $\{1,43$

melanolepis, $\mathrm{F}$.

Meridense, Klotz. $\{1,4.3$

micradenimu, $\mathbf{F}$.

minutum, Pslrl.

Morilziantum, Kl. •

muscosum, $\mathrm{S}_{w}$.

niveum, Sw. 160

notatum, F.

numm la riafolium, Sw., Blun. 2 in

obductum, klfss.

obliquum, Bl.

oboralum, Binn. $26 \%$

oblusifolium, lil.

8. ophioglossoides, Goldm. $\quad 41,4^{3}$

()rbign! anum, F.

oratum, Jalleson. 43

parhydernum, F. 43

pilikillm, Sw., Schkh. \$9

perelegans, $\mathrm{F}$.

Permionmm, Ruiz. I51

petiolosuns, Dess. 43 
piloselloides, Presl. pilosum, Ilook. et B.

platynesron, F. Plumieri, F.

plumosum, $\mathbf{F}$. Poepiggianun, $\mathrm{F}$.

Preslianum, F. quercifolium, Schkh. Quoyanum, Gaud. rndinlum, Kœnig. ramosissimum, $\mathrm{F}$. repandun, Blum. Requienimum, Gand. rhabdolepis, $\mathrm{F}$. rubiginosum, $\mathrm{F}$. rufum, I. (Nothuchlæena rufa, Link). scandens, Bors.

scandens, Itadd. (roy. IIeteroner. Raddianum).

Scapellum, Mart.

Scliomburghii, $\mathbf{F}$.

scolopendrifulium, $\mathbf{F}$

sessile, $\mathrm{F}$.

Sieberi, Hook.

simplex, $S_{w}$.

sinunlura, Sw.

spathulatum, Bory. speciosun, Willd., Blum. spheusphyllum, Kze.

splendens, Bory.

supuamatum, Cas au.

synamipgs, Hook.

squarrosum, KI.

stemmaria, Palis., Blum. (Ne-

vropl. NEthiopicus).

stenopteris, Kl.

stigmatolepis, $\mathrm{r}$.

stipitatnm, liors.

strictum, Radd.

subcreualum, Ilook.

subdiaphanum, llook.

succisæfolium, A. du Petit-Th.

Tamilillense, Kl.

Irifolialum, I.

trifolialum, Pohl.

trinerve, Ilassk., ing. Cheiropleu-

ria bicuspis, Presl.

triparlitum, IIook.

Iriste, Arrab. (roy. Ileteronerion

serratifolium, F.)

undulatum, Willd.

unitum, Bory.

relleum, dit.

restitum, Schlecht.

villosnm, Sw.

virens, Hook. et Grev.

iscosum, $\mathrm{S}_{w}$.

Weblii, liory.

Gen. 7, spec. 222

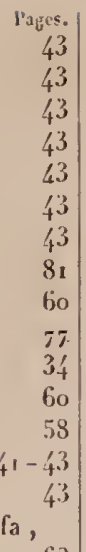

Zollingeri, Kze.
ACTINIOPTERIS, J.Sm. non I.k.

k. 357

ACTINIOPTERIS, Lk. $\quad 76$

australis, Lk:

radiala, I.k.

ACTINOPHLEDI.A, Presl. 35̄o, 35ı

horridn, Presl. 350, 351

ADECTL: , I.K.

Anexophorus, Gaud.

bipinnatus, Gaud.

hymenophylloides, Gaud.

rainulus, Gaud.

tamarisci, Hook. et Gr.

tripinnatifidus, $\mathrm{Gaud}$.

ADIANTACEA, Presl.

ADIANTARIXE, Presl.

88 ADIANTEAE.

43 Adiantopsis, F.

Capensis.

chlorophylla.

paupercula.

radiata.

spectabilis.

ADIANTYY, Anct. 119, 120, 122 ,

$145,146,183,329$.

41,43 Anastu $\mathbf{L}$.

159 NEthiopicum, I.

43 affine, Willil.

G1 amanum, Hook. et Gr.

49 asarifolium, Willd.

43 asperum, $\mathrm{F}$.

4.3. assimile, $\mathrm{Sw}$

4.3. Brasiliense, Madd.

3 calcareum, Gard.

Capillus-Veneris, L.

cardiochlæna, Kze.

raudatum, I..

- var. fissum, $\mathrm{f}$.

Cayenuense, IVilld.

Chilense, Klfss. - sar 3 hirsutum II, et $\mathrm{Gr}$. 1

Clausenii, $1: \quad 113,115$

concinum, llumb., B. et K.

crenatum, Willd.

iristatum, $\mathrm{L}$.

Cubense, Hook.

cuneatum, L. et Fisch.

56 Cunninghamii, llook.

49 curvatnm, Kilss.

delicatultum, Mart.

60 denticulatım, $\mathrm{S}_{w}$.

43 deltoiderun, Sw.

43 diaphanum, IIonk

${ }_{159}$ dicksoninides, Bory.

4.3 dolabriforme, Ifook.

43 dolosum, llook.

(bo Edgeworthii, Ilouk.

43 effusuar, Sloan.

4.3 emarginatunı, lior:

43 excisum, Kze. extensum, $\mathbf{F}$.

falcatum, Sw.

flagellum, $\mathrm{F}$. 114

filiforme, Gard. 114

formosum, R. Br. IIf

fovenrum, Radd. $\quad$ I 3

fragile, $\mathrm{S}_{\mathrm{W}}$. $\quad 114$

fructuosum, Spr. $\quad 113$

frulicosum, Arrab. $\quad 217$

fuliginosum, $\mathrm{F}$. $\quad 113,1 \mathrm{tl}$

fulvum, Raoul. 114

Galcoltianum, Hook. $\quad 114$

glaucescens, Kl.

glaucophyllum, Ilook. $\quad 114$

gracile, $\mathrm{F}$. 113,116

grande, F. $\quad 113,116$

gratum, F. $\quad 114,119$

Guyanense, Aubl. 105

Hewardia, Kze. , soy. Hewardia

adiantoides, J. Sm.

hirtum, Kl. 113

hispidulum, $\mathrm{Sw}$. $\quad 113$

incisum, Presl.

intermedium, $S_{w}$. 113

Jacobinx, F. $\quad 113,115$

11 Kaulfussii, Kze. 113

11.3 Klotzschianum, Hook. 113

I14 Kunzeanum, Kiltr. 113

I13 Lancea, I. 113

113, I15 lanceolatum, $\mathrm{F} . \quad 113,115$

I1 4 Leprieurei, Hook. 123

i13 lobatum, Presl. 114

114 Lobbianum, Hook. . 114

112,114 lucidum, $S_{w}$. 113

$112,111_{\text {f lunulatum, Burn. }}$

IIf lutescens, Houg. I14, 119

114 macrocladum, Kl. 113

II3 macrodon, Kliss. II3

14 macrophyllum, Sw. 112, 113

Hathewsiannm, Hook. 113

unirroph!̣llum, Klfss. · 113

Yoritzianum, Klot. 114

nigrescens, $\mathrm{F}$ 113, 117

obliquum, Willd. 113

obliqum, Ilook. et Gr. 113

obliquau, Schlecht. 12.3

obtusnim, Desr. It3

pachysorum, Reich. 113

patens, Willd.

pauperculun , Kze. $\quad 1 \frac{4}{4}$

pedatum, L. II3

pelluciduan, Mart. et G. 114

pealndnct,lon, Langsd., F. 114

pensile, Kze.

- rar. alchemillæfolium. ooo

Perusianum, Kl. 114

Philippense, I..

Phyllitidis, J. Sm. 113

pilosum, F. $\quad 114,118$ 


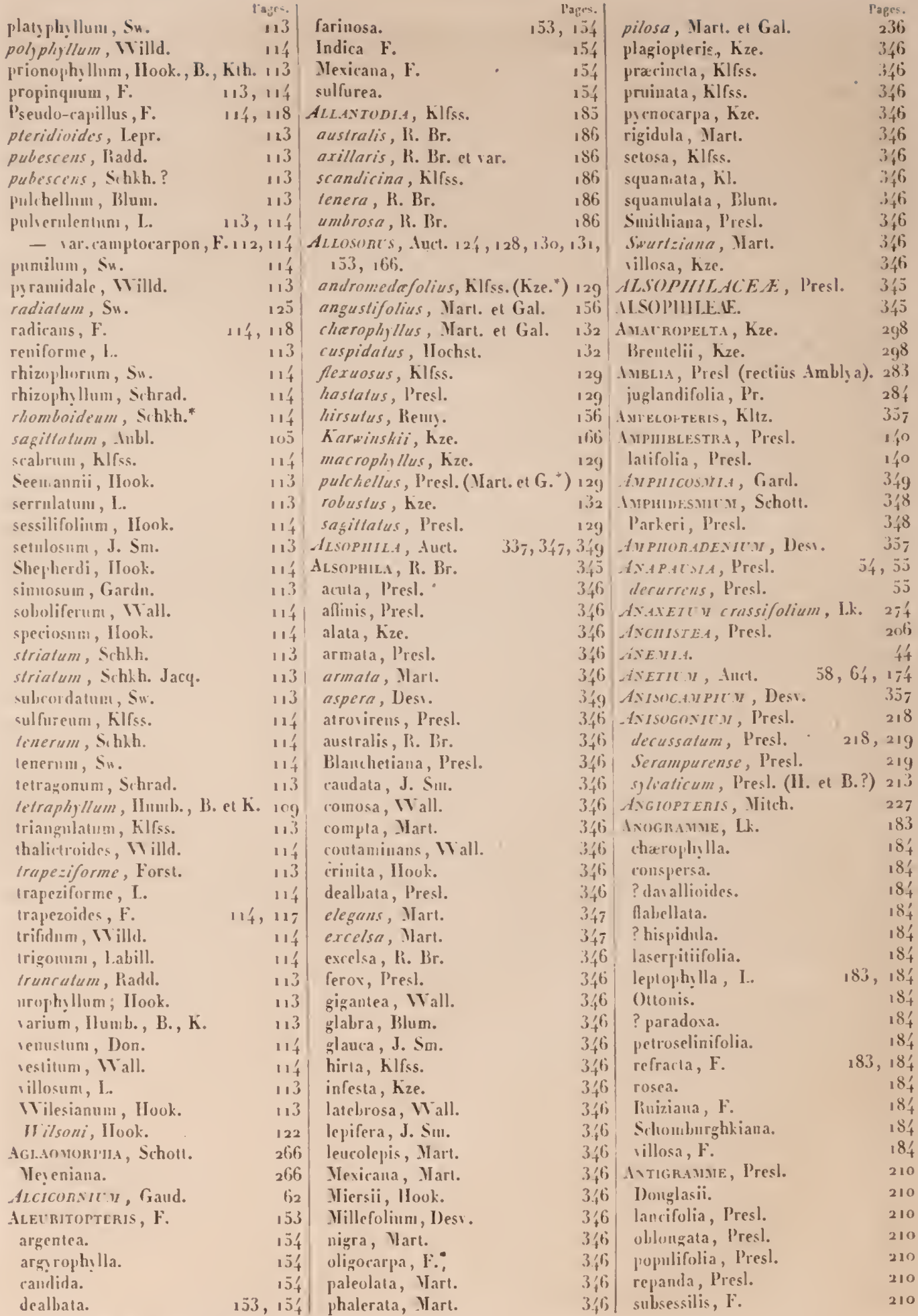


TABLE GÉNÉrALE ALPHABÉTIQLE.

Axtrophise.

AxtrophIU, Auct.

Axтrofhyci, Klfss.

aienium, Blum.

Borianum, Klfss.

callæfolium, Blum.

Cayennense, Desv.

itrifolium.

coriaceum, Blun.

Cuningii.

elongatum.

folcatuu, Mart. et Gal.

falcolum, Blum.

Galeottii.

giganteum, Borr.

Ilookerianum.

lanceolatum, KIfss.

lanceolalum, Blum.

latifolium, Blum.

latipes, Kze.

Eessuni, Bory.

lineatun , KIfss.

marginale, Blum.

nanum.

obtusum, Blum.

oltusum, KIfss.

pariuluru, Blium.

pendulum, Lepr.

plantagincun, KIfss.

plantagineum, Blum.

plicatum.

pumilum, Blum., var.

pumilum, II. et $\mathrm{Gr}$

punilum, Klfss.

reticulatum, KIfss.

semicostatum, Blum.

sessilifolimm, Spr.

spatluulatum, $\mathbf{F}$.

subsessile, Kze.

zosterxfolium.

APAIOPHLEBTA, Presl.

coslata, Presl.

ienosa, Presl.

Аротоми.

AOULUI:

AnfCuNTodes, Blum.

ARGYRIS.

Angr rochos.uA, J. Sm.

ASPIDI LCE $E$, Auct.

ASP]IDIARIEAE, Presl.

ASPIIUIE:AE.

Aspinuvi, Auct. 146, $185,200,216$

$277,281-286,297,299,301-304$,

$309,311,312,314,319,329,337$

$3.38,3 \frac{1}{4}, 3$ ' 9 .

ASPIDIT:I , Sw.

abbreviatum, Schrad.

acrostichoides, $\mathrm{S}_{w}$.

acuminatum, Willd.

afline, Fisch. et Mey.

Gen. 18, spec. 119

alatum, Hook. et Grev.
Ambojnense, Willd.
angustum, Presl.
apiifolium, Schkh.
asplenioides, Sw., Schhh.
athanianticum, Kze.
athyrioides, Mart. et Gal.
augescens, I.k.
auricuialum, Sw., Schkh., voy.

Polsstichum auriculatum, $\mathrm{Pr}, 2-8$

boryanum, Willd.

carvifolium, Kze.

carjolideum, Wall.

catopterum, Kze.

cicutariun, $\mathrm{S}_{w}$.

cocdunatum, IVall.

312,313

confertum, Ilook, et Gr. $\quad 285$

conlluens, F. 292, 29.3

conjugatum, Blum.

consolirinum, Bory.

conspersinm, Schrad.

crinitum, Mart. et Gal.

cristatun, $S_{w}$.

cyclochlams, F.

iecompositum, Kze.

delloideum, Sw.

denticnlalum, $\mathrm{S}_{w}$

dilatatum, Sw.

Donianum, $S_{p}$ r.

Dregei.

Eckloni, Kze.

elongatum, $\mathrm{S}_{\boldsymbol{w}}$.

cricarpon, IVall.

? exiguum, J. Snu.

expansum, Mart.

expansum, ror. extensum.

extensum, F.

falciculatum, Radd.

ferrugineum, $\mathrm{F}$.

lilix-famina, Sw., Schkh. ${ }^{292} 86$

Filix-mas, $\mathrm{S}_{w}$.

Fonisecii, I.оwe

fontonum, Sw., Schlh.

forlanum, Willd., 186.

formosum, $\mathbf{F}$.

ragile, Mart, et Gal.

fragrans, $\mathrm{Sw}_{\text {: }}$

? glandulosum, Ilook. et Grer.

Goldianum, Hook.

grande, $\mathbf{F}$.

herncleifolium, Willd.

lirsululum, Schkh.

hispidum, Sihkh.

inuressum, $\mathbf{F}$.

292 inxuluale, Schledit.

278 internedium, Villd.

invisum, $\mathrm{Sw}$

irriguus, J. Sm.
87. Kaulfussii, Lk.

Lancastriense, $\mathrm{Sw}$.

leucopis.

lomalopus, Kze.

Lonchitis, Sw., Schkh.

longifolium, Pohl.

macrothlamı, $\mathbf{F}$.

macrophyllum, $\mathrm{Sw}$.

Madagascariense, $\mathrm{F}$.

Malaccense.

marginale, $\mathrm{S}_{w}$.

marginatum, $S_{w}$.

Mascarenhense, $\mathrm{F}$.

melanochlam!s, $\mathrm{v}$.

melanostictum, Kze.

membranaceun.

meniunllidis, Presl.

microsorum, Presl.

mohrioilles, Borr.

Worilzii, Kze.

mucronalmm, Schkh.

mucronifolium, Blum.

muscefolium, Blum.

Capoleonis.

nenophỵllum, Kze.

nivale, Borr.

nobile, Sihlerht.

nodosim, Schkh.

Noreboracense, Sw.

oppositum, kifss.

ordinatum, Kze.

Oreopleris, Sw.

pallidum. parusificum, Sw., voy. Nephro-

dium parasiticun. 305 patens, Guenz. 253 patens, Milld. pedatum, Desw. $\quad 298$ pendulum, Radd. 319 pennigerum, Sw. $\quad 29^{2}$ Phillipinum. $2 \mathrm{~g}^{2}$ phyllarthron, Blum. 30 ' poljblepliarum, Riœm. $\quad 278$ proliferum, Hook. et Gr. 317 prolongum, $F$. 292 propinquum. $29^{2}$ pubescens, Sw. $\quad 29^{2}$ pumilum, Mart. et Gal. $\quad 282$ punctulatum, $\mathrm{Sw}$. $30 \mathrm{r}$ radicans, F. $\left.2 y^{2}, 29\right)^{\prime}$ remotum, A. Braun. 291 repandunt, J. Sm., roy. Cardioihlæna Menianthidis. 3,5 Rhaficum, $\mathrm{S}_{w}$. 299 rigidum, $\mathrm{S}_{w}$. 291 rufescens, Schrad. 301 sanctoides, F. $29^{2}, 293$ \begin{tabular}{l|ll}
292 & scandicinum, Willd. & 186 \\
269 & semi-cordatum, Sw. & 292
\end{tabular} 


selosum, langsd. el F.
Sheplerdi, Kze.
Singaporianum, Wall.
sinualum, labill.
Sloanei, hze.
spectabile.
spinulosum, SH.
Sprengelii, Klfss.
tenuiculum, F.

tenuiculum, $\mathrm{F}$.

terminans, Wall.

Thelipteris, Kze. non $S_{W}$

Thelipteris, Sw.

trichotomun, $\mathrm{F}$

trifolialum, Sw.

triste, Kze.

Tussaci, $\mathrm{F}$

varium, Sil

s errucosum.

reslitum, Sw.

reslilum, Sicl,

villosum, Sw.

Wallichii, Ilook.

Zeylanicum, $\mathrm{F}$.

ASPLEYIARIA, Presl.

ASPIENIEAF.

303

Pages.
278
305

305

286

$2 \mathrm{~S}$

$2+3$

292

291

$2 y^{2}$

$29^{2}$

291

$2 y^{2}, 29^{5}$

287

$29^{2}$

292,297

278

$2 g^{2}$

$2-8$

$2-8$

$29^{2}$

304

292,297

163
185

ASPLEYI: 17 , AuCl. $76,168,179,185$,

$200,202,203,211,212,217$, $221,31+, 3 j_{2}$.

Asplexitu, $\mathrm{I}$.

abrotanoides, Presl.

abscissum, Klotz. non Milld.

abscissun, IVilld.

Abyssinicum, $\mathbf{l}$.

ac'utum, Bory.

adiantoicles, liadd.

Adiantum-nigrum, $\mathbf{L}$.

alæopteron, Kize.

alatum, II. el lionpl.

nmliguum, Schkh., Su. 200, 21

amliliolon, $\mathrm{r}$.

ancepjs, Solander.

angustatum, Presl.

angustifolium, Mich.

anuustum, $S_{w}$.

anisodontiun, Presl.

anisophyllum, Kze.

argutans, $\mathbf{F}$.

argutum, lior!.

aspidiiforme, $\mathbf{F}$.

aspidiiforme, $\mathrm{F} . \quad 192,199$
Alh rium, Spreng. Schkh., 101.

Aihirium asplenioides.

altenuatum, Ilonk. et Gr.

anricularium, Dess.

auritunı, Sw.

"lustrnle, l.k.

lifissum, F.

Lipartitum, Bory.

Brasiliense, liadd.

Bresnii, liclz.

lulbiferunı, Foorst.

192,199

191

$19^{2}$

191

I 91

190,192

191

191

$191,19 !$

191

186

191

Iy1

$191,19^{2}$

77
139

$1.92,1.99$

191
191

191
190

190
191

Callipteris, F.
calophyllum, J. Sm.
Camariense, IVilld.
caudatum, Forst.
Celernch, Auct.
chlanopteron, F.
cicutarium, Sw.
cilialum, Presl.
cirrhatum, Rich.

concinnum, IVall.

consimile, Remy.

coriaceum, F.

crenatum, F.

crenatum; Fries.

crenulatum, Presl.

cuncnlum, IT. Schinu.

cuneatum, Lmrk.

dareifolium, Bory.

decurrens, Milld.

lecussatum, Kze.

delicatulum, Presl.

dentatum, $\mathrm{L}$.

dimidiatum, Sw.

dindon, F.

distans, $\mathbf{F}$.

divaricatum, Kze.

Dolabella, Kze

Dorei, Kze.

18) Douglnsii, Sw.

192 Dregeanum, Kze.

ebenum, Ait.

192 clasticum, F.

clongatum, Sw.

ensiforme, Wall.

erectum, Bors.

excisum, Presl.

alcatuın, Lmrk.

fnlcalum, Thunb., non Willd. Igi

falcalum, Mart. et Gal.? 192, 19;

191 Falx, Des:

I91 Feci, Kze.

191 Fernandezianum, Kze.

192 firmum, F.

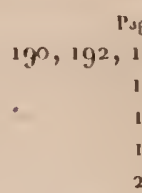

giblosum, F. Ig1, 192, igj gracile, $\mathbf{F}$. hastatum, Klot.?

lieterochroum, Kze.

Ilohenackerianum, Kze

19t, 19 incouilaterale, $1 g^{2}$

Gr. 192

integrifolium, voy. Integrum.

integrum, $\mathrm{F}$.

190,193

intermedium, Kilfss.

Karstenianum, Klot. $\quad 192$

191 laserpitiifolium, l.mrk. 191

$190,192,193$ Iamprocaulon, F. 19!1, 192, 197

lanceolatum, Iluds. $190^{\circ}$

lanciforne, $\mathrm{F}$. 192

lanciforme, lium, liors.

190,192 lacerum, Sihlecht.

191,192 laclum, Schkh.

ig) Inxum, Radd.

191 lineare, Jacr.

191 lineatum, Sw.

192 longipes, F. 191, igs

igi lucidum, Forst.

$191,19^{3}$ lunulatum, Sw. 191

I $)^{2}$, igs macilentum, Kze. 19$)^{2}$

eg2 Ylacrxi, Honk. et B.

19. macrophỵllum, Sw. 191

191 macrosorum, liert. 191

210 Magellanicum, Klfss. 191

191,192 marinum, l. 190

Marinum, l.. Vinicense, Villd. $19 \mathrm{r}$

191, 196 Masearenhense, F. 191, 194

Mevenianum, P'resl. 191

melanocaulon, Villd. $\quad 1()^{2}$

Menziezii, Ilook et Gr. 19I

IIexicanum, Mart. el Gr. Iyz

Michauxii, Spr. 136

Michauxii, Mart. el Gr. 192

minimum, Mart. et Gal. 192

monunthemum, Mart. et Gal. 197 monanthenum, Sil. 191, 192 moutanum, Will. 192 mucronatum, Presl. 191

mulilalum, Klfss. 191

myriophllum, Presl. 192

Neeanum, Kze. 191

Nidus, liadd. 190

Nidus, L. 202

nigricans, Kze. 19r, 192

nitens, Sw. 191

obliquunt, Forst. 191

obliquuns, Ialill. 191

oloonlum, Viv. $\quad 186$

oblusatum, 1.abill.

obtusatum, Forst. 191

obtusifolium, 1.. 191

obtusissimmm, $1 \% \quad 192,197$

olstusum, Kitail. 191

opacum, Kze. 
TABLE GÉNÉrale ALPHaBÉTIQUe.

oxı phyllum, J. Sm. paimatum, Lnırk. parrulum, Mart. et G. pendulum, $\mathbf{F}$. persicifolium, J. Sm. Yetersenii, Kze. Petrarclix, D. C. pinnatifidum, Nuttal. plunosum, Bory. polymorphum, ilart. et Gal. prionitis, Kze. procerum, Bernh. produclum, Pres!. præmorsum, Sw. protensum, Schkh. pseudonitidum, Radd. pulchellum, Radd. pumilum, Sw. rachirhizon, liadd. Raaddii, F.

radicans, Sw. recognitum, Kze. regulare, $\mathrm{Sw}$. repandulum, Kze. resectum, Sw. rhizophorum, Sw. Ruta-muraria, I. salicifolium, L. sarmentosum, Willd. scandens, J. Sm.

Schimperianum, Horhst. Schkuhrianum, Presl.

Schomburgkianum, Kil.

Schuttuorthianum, Kze. semi-cordatum, Radd. semi-cordalum, Mart. et Gal. septentrionale. Serra, Lang. et Fisch. serratum, $\mathbf{L}$. Serpentini, Tausch. Serricula, $\mathrm{F}$. setosum, Desr. Sibiricum, Kze. solidum, Kze. splendens, Kze. sloloniferum, Presl. subsinualum, Ilook. et Gr.

Surinamense, F. icnellum, F. tenerum, Forst. tenuifolium, Guss. tenue, Presl. llielipleroides, Mich. trapezoides, $\mathrm{Sw}$.

Trichomanes, I. truncatilobum, $\mathbf{F}$. varians, Wall., J. Sm. viride, Iluds. zaniæfolium, Willd. ITIXIOCARPE.E.
Athrriur, Auct. achilleifolium. angustum, Presl. asplenoides, Presl. australe, Presl. axillare, Presl.

Azoricum.

basilare.

cunchatum, F. Corsicum, F. crenatum, Rupreshe decurtatum, Presl. Filix-fœemina, Presl. fontanum, Presl. Galeottii, F.

Gaudichaudịi, F IIalleri, Rosh. incisum, $\mathbf{F}$. macrocarpon, $\mathbf{F}$. Michauxii.

oboratum. Yoirelianum, Gaud. Sandwichianum, Presl. scandicinum, Presl. Sihimperi, Moug. splixrocarpon, $\mathbf{F}$. tenerum, R. Br.

191 Thelipteroides.

191 unthrosum.

$33_{2}$ B.ALANTIEAE.

19i Balavtiun, Presl

191, 192 auricomum, Klfss.

Igo, I9I antarcticum, Presl.

192 Berteroanum, Kze.

191 Brownianum, Presl. fibrosum.

77 Karstenianum, Klotz. Igı lanatum.

19o, 192 squarrosum, Kze. 190 BALASTIEM, Klfss. 334, 340, 34

191, 196 B.tTIMIL, Presl.

19), 191 Bathmic

190 alatum, Fresl.

191 Billardieri.

191 ebeneum, $\mathrm{F}$.

191 heracleifolium.

213 inacrocarpon, $F$.

$19^{\circ}, 19^{2}$

191,198 repandum, Presl.

191 ? subfateatum.

igo trifoliatum.

192 ? undulatum.

186 ? villosum, $\mathrm{F}$.

191 BELTISIA, Mirb.

190 BLECINACEA, Presl.

191 BLECHYopsIs, Presl. 72,7 ' $, 78,8$

$19 \mathrm{M}$ Malaccensis, Presl.

igo slenophylla, Presl.

192 BLECIIVI , Auct $72,-8,79,101$

4 Beechuma, I..

Pages.
185, 299

186
186

186

186
186

186

186

186

186,188

186

186

186

186

186,187

186,188

$186^{\circ}$
187

נ 86,188

186

$186^{\circ}$

I 86

186

186

186,187

เ 86

186

186

เ86

33 , 3 ; 34
$3+1$

$3+1$
341

Gen. 2.5, spec. 685 . acuminatum, F. $\quad-3,75$

ambiguum, Klfss. $\quad 68$

arruatum, Rem.

asplenioides, Sw.

australe, $\mathrm{L}$.

Brasiliense, Desr.

calophyllum, Langsd. et F. 7 .

cartilagineun, $\mathrm{Sw}$.

carlilagineun, Sihkh.

caudatum, Car. 72,73

celeraccinum, Radd.

ciliatum, Galeott.

cognatum, Presl.

Corcoindense, Radd. If

distans, Presl.

extensum, F. $\quad 7_{2}, 75$

falciculatum, Presl.

Finlaysonianunt, Hook. et Gr.

Fluminense, Arrab. if

Fontunesianum, Gaud. 8

fraxincum, $\mathrm{F}$. 74

glandulosum, Kze.

glandulosum, Lk. $\quad 72,73$

gracile, Kllss.

hastatum, Klfss. $\quad 72,7$,

helveolum, F. 73,7

heterocarpum, F. $\quad 73,7$

heterophy/lum, Schlecht. 68

impressum, $\mathrm{F}$. $\quad 73,75$

intermedium, Lk.

Lanceola, $\mathrm{S}_{\mathrm{H}}$. $\quad 73$

lanceolatum, Radd. $\quad 73$

longifolium, Ilook. et P. $\quad 73$

Mlalaccense. $\quad 72,7$,

Meridense, Klotz.

meridionale, Presl.

occidentale, L. $\quad 72,73$

orientale, J. Sm.

pectinatum, llook.

Pollianum, Presl.

polypodioides, Radd.

procerum, Iabill. $\quad 68$

pubescens, llook. 74

pubesrens, Desr. $\quad 7^{3}$

pyrojhyllum, Blum. if

punctulalum, hze. $\quad 68$

punctulatum, $\mathrm{Sw}$. $\quad 7$ f́

remotum, Presl.

rigidum, $\mathrm{S}_{w}$. $\quad 7$ t

serrulatum, Rich. 74

Spicant., L. 698

squamulosum, Sieb. $\quad$ it

slagninum, Radd. 妊

stenophỵllum.

stramineum, Iabill. 係

striatum, R. Br. if

suburbicum, Arrab.

trilobum, Presl, Ilook. et Gr. 68, 7'

unilaterale, Willd. $\quad 73$

alidum, F. $\quad 73,7$ f 
volubile, Bory.

rolubile, Kze.

BLEPH.AROC ILE.Y, KzC.

Dus BITIS, Sidiotl.

serratifolia, Silioti., F.

HOTRJOGRAMME, F.

Karninskii.

JitnYoth.1LLes, Hortul.

Bn.tCIIsont's, P'resl. 185, 186, 208

Moodwardioides, Mrest., 109.

Alhirium basilare.

CAMPTERS, luct. $95,326,33$

ashillaifotia, Mart. et Gal. 186 appeadiculata, Labill. ricularia, Thunb.

fencride, Thumb.

furcola, Beroni.

inaqualis, Bory.

Japonica, IVilld.

iil) riopliflla, Sw.

odontites, Thunh.

rhisopliglta, Thunl.

rulafolio, Berym.

?halictroides, l.ond.

rivipara, liergur.

vivaru, Ilortul, non Bergnt "3.3

Carratiti, Presl.

Callipteridistria.

Calcuptents, Bory.

CiIIIPTERIS, Auci.

utisnafolin, J. Sm.

attenuata, Presl.

clegans, J. Snı.

unicrophilla.

orata, J. Sin.

pinuatifula.

prolifera, Bors.

Serampurense.

scerrilata.

s!luatica, Hory.

indulosa, Presl.

Zollingeri, Presl.

Calengliame, $\mathrm{F}$.

Carrilix.

CA1.o.y El.t.yos, Presl.

C.ALY PTEnIC:M, Bernh.

Canparar

C.1.PIL:y, Presl.

costalum, Presl.

sulicreantum, Piesl.

C.smptrisis, I'resl.

finllisiuad.

Iiottlerianta.

Walfichiana.

C.mptoniv, $\mathrm{F}$.

pedatum.

Caniptosurus, I.k.

rhizophyllıs, I.k.

C.mprovertor, Presl.

amphostenon, Kl.
Pogers.

8

218, 219 CANDOLLE.t, Y

220 Cardiochlexi, F.

219 alata.

219 anipla.

219 confluens.

219 lavis.

219 Inacrophylla el var.

218,219 Venianthidis.

219 simuosa.

219 subpinuatifida.

219 CASELEERIA, Au(1.

219 Caseliekria, Kilfs.

Ifig triph!lla, Klfss.

ibg pedaia, J. Sn.

357 CATHETOGTRATE

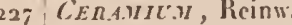

bo CEnATOD.ACTILIS, J. Sm.

59 osnundoides, J. Sm.

6o Cenoptenis, Ik.

fo ralomelana, Lk.

13' rhrysoplịlla, 1.k.

133 distans, I..

135 Lyrida, Mart.

13.3 I.'llerminicri, Borı, sub G!ın-

298 nogranme.

298 Vlartensii, Bory, sul, G!mno-

211 granume.

211 Massoni, Ik.

257 l'ermiana, I.k.

2.58 sulfurea, Desi.
219 trilobata.

\section{Pages.}

257 tartarea, I.k.

257 CETERACH, Anct.

258 Ceterach, Villd.

258 aspidioides, Klfss.

258 Capensis, Kze.

258

257,259

$257,25 y$

258

$25 \overline{7}, 259$

258

258

258

25

258

258

258

258

258

258

258

257,258

258

latifolium.

Maraala, Desv.

oflicinarum, IVilld.

peduacutala, llook. et Gr.

CHEILATTHEAE.

CHEIL SITIISTILUM.

CIIEILANTHES, AUCt $120,131,14$

Cheil.a.sties, $\mathrm{S}_{\mathrm{w}}$.

Mabamensis, Kze.

angustifolia.

anthrisrifolia, ITilld.

Arabica, hize.

arboresceas, $\mathrm{S}_{\mathrm{w}}$.

argenten, hize.

aspera, Kifss.

aspera, Kize.

aspidioides, $\mathrm{F}$.

auriculata, I.t.

Bergiana, Srhlecht.

brach pus, Kze.

$257,25 \%$ Brasiliensis, liadd.

candida, Varı. et Gal.

31 Cipeasis, Sw.

3 is chærophilla, Kze.

315 chlorophllla, liadd.

315,316 Chilensis, F.

315,316 commulata, Kze.

315 contracla, Kze.

3,5 cornuta, kze.

$315,3,6$ ? cumeata, kilss.

35 deltoiles, hzc.

315,3 I6 ? densa.

120 Dichsonioides, Endl.

119 ? elata, hze.

119, 120 ferruginen, Milld., voy. So-

130 lhochlana rufa, Presl.

41 fariaosa, klfss.

216 farinosa, llook, cl Gr.

228 glandulosa, F.

228

I 82

Griflithana, F.

hirla, $S_{w}$.

- var. contracta, Kze.

- lar. intermedia, Kze.

- var. parivitolin.

- iar. olivacea.

hostitis, kize.

induta, hic.

tentigera, Vart. et Gal.

teatigera, $\mathrm{S}_{w}$.

183 Malacicensis, F.

183 Mallewsii, Kzc.

183 micromera, l.k.

36,3

of, 363

of, 36.3

159

177
181

15

156

1 it;

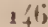

1 .io

14 (i)

14

$1+7$

$1 \div$

126

$1 \div 5$

154

145 polypodioides, Radd.

$1\{6,148,150,153$.

83

180

36.3

I 仿 
TABLE GÉNÉrALE ALPHabétique.

microphylla, $S_{w}$.

micropteris, $\mathrm{Sw}_{\mathrm{w}}$.

minor, Mart. et Gal.

multifida, Sw.

Mysorensis, Wall.

odora, Sw:

olivacca.

paleacea, Mart. et Gal.

parallelogramma, Kze.

parviloba.

profusa, Kze.

pulveracea, Presl.

rufescens, Lmrk.

scariosa, Klfss.

Schimperi, Kze.

semi-glabra.

Sieleri, Kze.

speciosissima, Al. Br.

squamosa, Hook. ct Gr.

suarcolens, $\mathrm{S}_{w}$.

tenuifolia, Sw.

lomenlosa, Lmrk.

triangula, Kze.

Assamicum, Hook.

Paypes.

antarcticum, Klrss.

Chamissoi, Klfss.

343 CTENOCHLANA, Kze.

Pages

156 glaucum, Ilook. et Arn.

341 Crevopteris, Blum. 35

Iว̈6 glaucescens, Kze.

343 Crjecita, Presl. 3 .

เ56 Menziezii, Hook.

3 Cuspidaria, F.

136 Schiedei, Schlecht. et Cham. $3 / 3$ subpinnatifida.

149 Cibotie:M, Auct.

147 CrNcinalis, Auct.

156 Cincisalis, Dest.

r56 dealbata.

15. Fendleri.

156 flavens.

149 nivea.

147 tenera.

156 CNEMIDARIA, Auct.

$₫ \breve{56}$ horrida, Presl.

151 Kohautiana, Presl.

I59 oblusa, Presl.

156 speciosa, Presl.

156 subincisa, Kze.

I 9 COCHLIDIEM, Klfss.

I

? restita, Sw.

iscosa, Lmrk.

Cheiloleptox, $\mathbf{F}$.

Blumeanum, $\mathbf{F}$.

Cheiropleviria, Presl.

bicuspis, Presl.

Vespertilio, ejust.

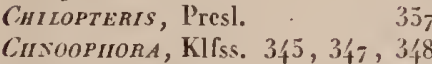

Colposoria, Presl.

Colysis, Presl.

136 hemionitidea, Presl.

macrophylla, Presl.

336,341

subpinnatifida. $\quad 88$

marginata, Presl.

57 pothifolia, Presl.

56 tridactılis, $\mathrm{F}$.

56 Wallichiana.

56 Coniogranue, $\mathbf{F}$.

rostrata, Hart.

Jaranica.

Serra, F. var. macrophỵlla.

158,182

tricuspis. 88

Cinovt.1, Molin.

Chnysodia.

Chrsodrus, F.

Caycnnense.

danææfolium.

fravinifoliun.

hirsutuin.

- var. ? marginatum.

inæriuale.

35 t serrulata.

183 - var. candata, F.

160,362 Cratres, SMr. 345,3

160 aculeata, Willd. 350

160 affinis, Schkh. 3 Jo

160 aspera, $\mathrm{Sw} . \quad 350$

I6o aurea, Kl. 35

160 Beyrichiana, Presl. 3 '?

3ł9, 3з̆ I Brunonis, Wall.

3 so Burkei, Hook. $3 \mathrm{~J}_{2}$

$33_{1}$ canaliculata, Willd. 352

$33 \mathrm{~s}$ Commersoniana, F. $3 \mathrm{jaz}_{2}$

$3 \overrightarrow{3} 1$ commulata, $\mathrm{Spr}$. $35 \mathrm{~s}$

351 cuspidata, Kze. 352

101 dealbata, Rich. 352

101 discolor, Bory. $3 \vec{j}_{2}$

$33_{7}$ divergens, Kze. $33_{2}$

175 Drcgei, Kze. 352

$I_{7} f_{6}$ excelsa, Sw. $35_{2}$

1;6 Gardneri, Hook. $3 \mathrm{Ju}_{2}$

1-6 glanca, Bory. 332

1,6 grandifolia, Willd. $35 \mathrm{~s}$

176 Greilleana, Mart. 352

$1 ; 6$ hirtula, Mart. 352

167 integra, J. Sm. 352

167 I.indeniana, Presl. 332

167 medullaris, Sw. 332

Ifj Mexicana, Schlecht. $33_{2}$

I67 Mexicana, Kl. 3 J $_{2}$

167 muricala, Willd. 3.30

CRASPEDARIA, Lk.

61 Craspedaria, Lk.

fi auriseta.

$f_{1}$ calva.

$f_{21}$ ciliata, L.k.

sralpturatum.

speciosum.

$61-$ iar. Hostmanni, F. cuspiditlora.

61 lagopodioides.

61 nummularia.

Urillei.

vulgare.

- minus.

- rigens.

Chrysopteris, Lk.

aurea, Lk.

decumana.

dictyocallis, F.

dulcis.

glauca.

sporadocarpa, L.k.

trilobata, F.

CHBOTIEAE.

is piloselloides, I.k.

bi serpens.

61 surinamensis, $\mathbf{F}$.

bi vaccinifolia, Lk.

26't veronicæfolia, $\mathbf{F}$.

265 Cripsines, Presl.

265 nummularius, $\mathrm{Pr}$

265 CIYPTOGnAYYA, R. Br.

265 acrostichoides, Ilook. et Gr.

260 Perrilliana, $\mathrm{F}$.

263 petiolata, J. Sm.

264 Schanschin, Mart.

$26 \%$ Serra, Willd.

Gr. $\quad 33$

264 speciosa, Humb., B. et Kth. 349

$266_{4}^{\prime}$ spinulosa, IVall. $3 \overline{3}_{2}$

264 iestita, Mart. 352

264 villosa, IIumb., B. et Kth. $\quad 3 \frac{4}{6}$

263, 26 Halkerice, llook. 3ł9

${ }_{26} 6$ CYATIIEACEA, Presl. , , 345

264 CiATHE.

264 CYCIODIEAE. 277

$26 \%$ Crcrodium, Presl. 284, 309

264 albbreviatum, Presl. 285

$26 \%$ confertum, Presl. 284, 285

130 glandulosum, Presl. $3{ }_{10}$

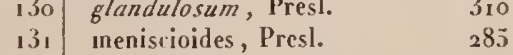

fij Brunoniana, IVall. 131 CYCLOPELTIS, J. Sm. 282

26,5 Crmptosorus, F. 231 CYclophones, Desץ., Presl. 260,262

${ }_{2} 6 \overrightarrow{3},{ }_{26} 66^{2}$ Blumei, voy. elasticus.

2.32 allicans, l'resl. 262

CIнотIUм, KIfss.

$3\{3$ Dionæa.

3,3 elasticus

\begin{tabular}{r|ll}
231,232 & flocciger, Presl. & $2 f_{2}$ \\
231 & glaber, Presl. & $2 \hat{f}_{2}$
\end{tabular}

Gen. 49 , spec. 866 . 
puberulus, Presl.

Crclosones, Lk.

Ciлtogosity, J. Sm.

Cintomun, Presl.

raryotideum, Presl.

falratum, P'resl.

C'YRTOPII.EBI'.Y, R. Br.

Cistonum, J. Sm.

sorbifoliun, J. Sm,

C.rste.t, Sm.

regia, Sm.

CYSTOPTERIS, Iuct.

Crstopteris, Bernh.

acuta, F.

affuis.

bulbifera, Beruh.

Caucasica, C. Hey.

brevinersis, $\mathrm{F}$.

dentala, J. Sm. var. Pontederæ.

Pages

bullata, 17 all.

285,28

85 Canariensis, $\mathrm{Sm}$.

35, 286 ciliata, Ilook.

286 ? concinna, Sihrad.

257 conligua, $\mathrm{Sw}_{w}$

342 Cumingii, Ilook.

$3 \frac{4}{4}, 34^{3}$

299, 300

fragilis, Bernh. et iar. plur.

fumarioides, Sihott.

ntontana, Lk.

regia.

Rhrlica.

rufescens, F'.

tenuis, Sihott.

illosa.

I)AREA, Juss.

appendiculata, IVilld.

bifida, Klfss.

cicutaria, IVilld.

forcunda.

Hacrida, viilld.

furcans, liory.

furcata, IVillil.

inæqualis, 17 illd.

intermedin, KIss.

? Millefolium, Cuming., Pl.chil. ก. ${ }^{0} 32$ \%.

myriophilla, 17illd.

odontites, 17 illd.

? palınata, Klıss.

rhizophỵlla, 17 illd.

rutæfolia, Willd.

scandens.

? thalictroiles.

visipara, 17 illd. - var. foeniculacea, Sieb. 332

Dareastrex. $190,192,199$

D. ArALLIA, InCt. $319-321,324$, $328-33 i, 3 f i$

I).tvalla, $\mathrm{Sm}$.

aculeala, Sni.

adianlifolia, llook.

Amboynensis, Ilook.

angustata, Viall.

lidentala, Schkh.

Blumeana, Ilook.

Boryana, Hook.
299

299

3.38

299

299

299

299

299,300

299

299

decurrens, Hook.

dumosa, Sw.

lata, Sw.

clegans, $\mathrm{S}_{w}$.

Emersoni, Ilook. et Gr.

falcinella, Presl.

Fejeensis, Ilook.

fagellifera, Hook. el Gr.

fumarioides, $\mathrm{S} w$.

giblerosa, $\mathbf{S}_{w}$.

299 incequalis, Kze.

299 heterophy/la, Sm.

299 hirta, Klfss.

299, 300 Hookeriana, IVall.

Khasjiana, Ilook.

299 Iindeni, Ilook.

33.2 Iindlevi, Hook.

332 lonclitiden, Ilook.

332 Luzonica, Hook.

333 Mauritiana, Hook.

333 membranulosa, IIook.

332 nitidula, Kze.

18' Nor $x$-Zelandix, Colens.

332 parallela, Wall., Hook.

332 Parkeri, Ilook.

332 parsula, $\mathbf{W a l l}$

pectinala, Sm.

pedala, Sw.

pentaphylla, Blum.

pinnala, Cavan.

pinnalifida, $\mathrm{Sw}$.

polyantha, Hook.

Preslii, Hook.

pyxidata, Cavan.

relusa, Cav.

Srhimperi, Ilook.

Schechendalii, Presl.

sessilifolia, Blum.

solida.

tenuifolia, $\mathrm{S}_{\mathrm{w}}$

326 trichosticha, llook.

330 Iripli)/la, Ilook.

329 uncinclla, Kze.

329 verusta, Silkh.

322 vestita, Blum.

329 villos, $1 \mathrm{Vall}$

330 Vogelii, Ilook.

329 DAVAILIEAF.
299 Imrayann, Ilook.

2.99 hemiplera, Bory.

Page

${ }_{29}$ Devinogi.ossa, Presl.

327 Dexnroglossa, $\mathbf{F}$.

329 lanceolata, Presl.

329 latifolia.

327 normalis, Presl.

329 quercifolia.

324 subquinquefila.

322 taccrifolia.

326 Devist.̈̈tI-1, Beruh.

325, 330 faccida, Bernh.

329 Depalis, IIook. et B.

329 Malhew'sii, Ilook.

$32 \div$ prolifera, Ilook. el B.

329 Diacaner, Blum.

329 aspidioides, Bhım.

331 Marlagascariensis, F.

330 ? Dineemia, J. Sin.

329 Samarensis, J. Sm.

330 Dicks.y. Blum.

329 Dichasium, Al. Br.

326 patentissimum, Al. Br. 302, 303

329 DichorexIA, Presl. 3ұ5, 3;6

322 Dicksovid, Auct. 146, 329, 336,

$327 \quad 340-3 \frac{1}{4}$

32 I Dicksonis, L'llérit. $33_{+}^{\prime}$

326 aliupla, Borr. 342

329 adiantoiles, Hook, , 13., K. 3:35

329 antarclica, Labill. 3f

327 anthriscifolia, Klfss. 335

331 a piifolia, $S_{w}$. 335

329 arborescens, L'Ilerit. 3́,

329 asperula. 335

329 Berteroana, Hook. 3'i

329 cicntaria, $\mathrm{S}_{\mathrm{w}}$. $33 \mathrm{~J}$

320 cuncata, Ilook. 335

329 delioidea, Ilook. 335

329 disserta, $\mathrm{S}_{W}$. 335

322 disienta, Kze. 335

322 dubia, Gand. 3.35

325 expansa, $\mathrm{K} l \mathrm{~s} s \mathrm{~s}$. $33 \mathrm{~J}$

33 I fibrosa, Colens. 341

322 faccida, $\mathrm{S}_{\mathrm{w}}$. 327

327 Kaulfussiana, Gaud. 327

32.4 Ianala, Colens. 341

328,329 Lindeni, llook. 327

330 Vathewsii. 335

329,332 Noluccana, Blum. 335

33o neglecta, F. 335

322 obfusa, Moritz. 335

329 I'aroni, Ilook. 335

33o Plumieri, Ilook. 327

326 puliescens, Sihkh. 335

325 punctiloba, Ilook. 335

325,326 ruljiginosa, Klfss. 33.3

330 scabra, $\mathbf{W a l l .} \quad 335$

329 scandens, Hortul. 335

327 Suthii, Ilook. 335

320 syuarrosa, $\mathrm{Sw}$. 34

323 stenochlana, F. 335,336

Gen. 60, spec, 9艹ı. 
TABLE GÉNÉRALE aLPHABÉTIQUE.


Gen. 72 , spec. 1075. 
ORYOPTERIS, linmph. campes/ris, Rumph.

DICTIMIA, J. Sin.

Egexol.FIA, Schott.

aspleniifolia, $\mathbf{F}$.

Gaudichandiana.

llamiloniana, $\mathbf{F}$

Ilamilloniaaa, Schott.

intermedia, $\mathrm{F}$.

montana.

? nalla, $F$.

neglecta, $\mathrm{l}$.

nodiflora, $\mathrm{l}$.

rhizophslla, F.

Sclottii, F.

serrulata, F.

ElaPllogiossex, Schott.

alalum, Gaud.

simplex, Sihott.

EPICHL NMYDE

ERtochosira, J. Sul.

Eriosorlis, F:

? liuizianus.

scanderus.

Eeaconioteris.

Eetsplexicu.

Elbeechisum.

Elciandochl.zisa.

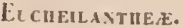

ElCRasifidaria.

ELCyatuet:。

Exdichsonia.

Eediplazicu.

Eid DORYOPTERIS, Kl.

Ex DR YAIOGLOSSI U.

ELDRYAARIA.

Ecegexolfia.

EcheNistegia.

Echenituela.

Eilitobrocita.

Erconaria.

Ecmyriopteris.

ECPULEGODIC:.

E. POLYBOtRy.

Expteris.

Erselliguea.

Er:WOODWARDL.

Fadesia, Hook. et Gr. prolifera, Hook. et Gr.

G.tlenglossi, Presl. aummulariafolia, Presl.

obovala, P'resl.

rolundifolia, Presl.

GLAPIITROPTERIS, Pres!.

rudis, Prest., voj. Poly podium rude, Kze.

Goviopilemun, Presl.

albo-punctatum.

arcuatum, F.

arcolatım, l'resl.

\section{TABLE GÉNÉRALE ALPHABÉTIQLE.}

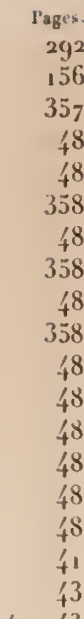

4,43

27

357

1.52

152

152

52

Igo, 194

73

315

148

${ }_{2} 6$ '

$35 \mathrm{I}$

3.35

213,215

133

9'

270

48

351

349

13.1

68

149

26,

46,47

125

176,177

207

317

3 I 7

$9^{\prime}, 26_{2}$

262

$2 b_{2}$

${ }_{2} 6_{2}$

357

236

25 4

255
255

argutum, J. Sm.
attenuatum, P'resl.
Californicum.
Cathariuz.

reptans, l'resl.

Rivoirei, I. submarginalis, Presl.

subtetragona, Prest. $\quad 2 / 9,250$

tetragona, Prest. 250

Granutis, Sw. 2.,2

ihnoodes. 255 Billardieri, Villd. 233

distans. $\quad 253$ caudala, Wall. $\quad 167$

clatum, F. 255, 256 Celerach, Scltkh., voy. Ceterach

elcutherophlebium, F. 255 offrinarum. 206

cnsiforme. $\quad 254,255,269$ congener, Blum. 233

falcarium. $\quad 255$ coriacea, kilss. 177

gladiatum, F. $\quad 255,256$ crassa, F. 233,234

glaucophyllum. $\quad 255$ cucullala, J. Sm. 230

grandidens. $\quad 255$ decurrens, llook. el Gr. $\quad 1 ; 6$

loricean. $\quad 25.5$ fasciculata, Blum.

menisciifolium. $\quad 255 \mid$ faresceas, Wall. 177

neriifolium. $\quad 254,255,315$ furcata, llook. et Gr. 232,233

ornatum. 255 ? graninoides, $S_{w .}$ IoI

pachynesron. 255 heleroply $l l a$, Labill. 2.36

pallens. 255 hirta, Blum. 233

Pleopeltis. $\quad 255,256$ involula, Don., llook. et Gr. 177

ramosuni. 255 lanccolula, Sw., 11. et Gr. 177

Heinwardtianum. $\quad 255$ leplophylla, Sw. 18 年

semi-pinnatifum, F. 255,256 limbata, F. 233

? serpens. $25 j$ linearis, $\mathrm{S}_{w}$. 233

$\begin{array}{llll}\text { solutum. } & 255 & \text { longa, F. } & 23.3 \\ & & \end{array}$

translucens. $\quad 253$ Magellanica, Dess. $\quad 232,233$

racillans. $\quad 255$ marginella, Sw.

verrucosun. 25.5 injosuroides, Schlh. 100

Goviopteris, Presl. $\quad 248$ parictina.

allinis, F. $\quad 249,250$ pilosiuscula, Blum. 233

aristata, F. $\quad 250,253$ pollifolia, llook. et Gr. $\quad 1,6$

aspera, J. Sm. 250 punctata, liadd. 233

aspera, l'resl. 250 pusilla, 131 m. 23.3

asplenioides, Prest. 250 rulafolin, R. Br. 180

asterothrix, F. $250,253 \quad$ scolopeadrina, Bory. $\quad 177$

asinetrica, F. 250,253 seminuda, TVilld. 101

$\begin{array}{llll}\text { barbata, } F . & 250,252 & \text { tenella, Kilfs. } & 233\end{array}$

Berleriana, Presl. $250 \quad I$ ulcanica, Blum. 177

cheilocarpa, F. $\quad 250,251 \quad$ Zẹlanic'a, F. 233,23 f

crenata, P'resl. $\quad 249,250$ GRAMuITS, Auct. $98,100,101,167$,

crenato-dentata, F. $\quad 250,252 \quad 175,183,184,230$.

ferax, F. $\quad 249,250$ GR.YYITIDEX, Auct. $g^{6},{ }_{163}$

fraxinifolia, Presl. 250 Gnascusa, Bory. 48

incisa, l'resl. $\quad 249,250$ Gr.MOGR.M.ME, Auct. 46, 48, 161 ,

Lobliana, F. $\quad 250,251 \quad 164,167,168,171,179,184$,

lucila, F. $\quad 250,2.53 \quad 178,204,205,248$.

Iadagascariensis, F. 250, 25I GmognAmuE, Desv. 180

megalodus, Presl. $\quad 250$ aspidioides, Blum. 204

meniscioides, $\mathbf{F}$. $\quad 2$ 5o, 253 aspidioides, Klfss. 181

mollis, $\mathbf{F}$. 250,252 cheilanthoides, Blum.

patens, F. 250,253 charophllla, Ilook. et Gr. 184

peunigera, Presl. 250 conspersa, Kze. 184

pilosa, Presl. 250 corilala, llook. el Gr. $206^{\circ}$

Portoricensis, Presl. 24:3 eloagala, llook. $\quad 161$ prolifera, Prest. 250 falicllala, Hook. 18 ; prolifera, J. Su. $\quad 250$ Aaicas, Klfss. 160

\begin{tabular}{lr|ll} 
prepanda, 1. & 250 & flaicas, Klss. & \\
incisa, Mart. et Gal. & 251 & 181
\end{tabular}

scolopendrioides, Presl. 249,250
Japonicu, Kze, vo1. Dictyo-

giamme Japonica, $\mathrm{F}$. 17

$\begin{array}{ll}\text { Jananica, Blum. } & 167\end{array}$

Gen. 79, spec. 1170. 
TABLE GÉNÉRALE ALPHABÉTIQUE.

laserpitiifolia, Kze. leptophylla, Hook. et Gr.

Linkiana, Kze.

Lowei, Hook. el Gr.

obtusata, Blum.

Ottonis, $\mathrm{Kl}$.

papaverifolia, Kze.

petroselinifolia, $\mathrm{Kl}$.

Philippinensis, $\mathbf{F}$.

pilosa, Mart. et Gal.

polypolioides.

prolifera, $\mathbf{F}$.

pteroides, $\mathbf{F}$

pubescens, F. (pour rufescens) 23

pumila, A. Spreng.

refractur, Kze.

reniformis, Mart.

rufescens, $\mathbf{F}$.

Ruiziana, Kl.

rutcefolia, Hook. et $\mathbf{G r}$.

Schomburghiana, Kze.

serrulate, Blum.

subglandulosa, Hook. et G

tartarea, Willd.

totta, Schlecht.

unita, Kze.

villosa, Lk.

GYMNOPTERIS, Juc. $46,54-56$,

$80,81,183,204,205$

Grivoptenis, Bernh.

acuminata, Pres.

aliena, Presl.

axillaris, Presl.

decurrens, vor. Leptochilus decurrens, Blum.

dentata, $F$.

Heudelotii, F., Bory.

latifolia, Presl.

nicotianæfolia, Presl.

Portoricensis, $\mathbf{F}$.

quercifolia, Bernh.

semi-pinnatifida, $\mathrm{F}$.

spicata, Presl.

subsimplex, F.

taccrefolia, J. Sm.

Vespertilio, Hook.

GYvNospHsina, Blum.

gigantea, J. Sm.

glabra, Blum.

squamulata, Bluni.

GYAATA: R. Br.

Grnosonivy, Presl.

Africanum, Presl.

fissum, Prest.

Samarense, I'resl.

Haplodiction, l'resl.

? exiquum, $\mathbf{F}$.

heterophyllum, Prest.

HAPLOPHLEBA, Mart.

H.aploptenis, Presl.

Gen. 9:, spec. 1265

\section{Papes.}

179 speciosa, Klfss.

179 speciosa, Hook.

$3 \Varangle 5$ subincisa, Kze.

282 Walkeræ, F.

282 HENITHELIEAF.

HELICOGYRAT

Hevicardion, $\mathbf{F}$.

Corhinchinæ, F.

crenatum.

Cumingianum, $\mathbf{F}$.

Nephrolepis.

subhastatum, $F$.

282,283

282, 283 HeTERonertoy, Pres!

282 Heteronetron, $F$.

282 diversifolium.

205 heteroclitum.

205 lobulosum, $\mathbf{F}$.

Hemidictron, Presl.

HEMHONITIDE E, Auct. 96, 163

178 .

lonchophorum.

meniscioides.

164

HEMIONITIS, Juct. 66, 168,171 $174,175,182-18 \frac{1}{4}, 221$.

HeMrosits, $\mathrm{L}$

80,181 cordata, Roxb.

184 discolor, Willd.

i8o falcata, Willd.

184 ? internedia.

palmata, Willd.

peduta, Sw.

peregrina, Tournef.

rosea, Bory.

rufa, Sw., Schkh.

tomentosa, Radd.

sagittata, $\mathbf{F}$.

IIemistegia; Presl.

55 grandifolia, Presl.

horrida.

55,56 Kohautiana, Presl.

lucida, $\mathrm{F}$.

marginalis.

obtusa, l'rest.

repanda, $\mathbf{F}$.

speriosa.

spectabilis.

Willdenowii.

Hemithelia, Presl.

aculeata, Willd.

?alternans, Hook.

arborea.

aspera.

Berrichiana, Presl.

Capensis, R. Br.

extensa, Presl.

grandifolia, Hook.

Guyanensis, Hook.

Hookeri.

horrida, Hook.

Hostmanni, Hook.

integrifolia, Klotz.

Imrayana, Hook.

macrocarpa, Presl.

muricala.

obtusa, KIfss.

oblusa, Hook.

? Parkeri, Ilook.

petiolata, Hook.
172

68

175

172

$I=2$

200 virens.

184 Heterophlebuvi, $F$.

I69 grandifolium.

169 HETEROPTERIS, F.

I 72 Hewardi, J. Sm.

3 jo adiantoides, J. Sm.

350,351 dolosa.

350,351 Ieprieurei.

$3{ }_{1}$ serrata, $F$.

3 I $_{1}$ Wilsoni.

351 HIPPODIL: , Gaud.

35 IISTIOPTERIS, Ag. 357

351 HL:MTA, Auct. 319, 320, 321

3.5 Humata, Caran. 322

351 ophioglossa, Cavan. 322

$33_{1}$ pinnatifida, Cavan. 322

349 HYALLEPIS, Kze. 357

350 HY H ENocystis, А. Мey. 299

349 Caucasica. 299

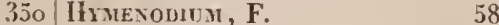

350 . crassifolium. 59

349 crinitum. $5 y$

349 Kunzeanum. 59

349 HY.MENODILY, Presl. 58, 174

35. HYMENOLANA, E. Mey. 358

349 Hriesolepis, Klfss. 81

349 nucronata, $\mathrm{F} . \quad 81,8_{2}$

349 oplicoglossoides, Blum. $8_{2}$

3 ophioglossoides, Klfss. $\quad 81,82$

349 platyrynchos, Kze. $\quad \delta_{2}$

349 revoluta, Blum. 82

349 validinervis, Kze. $\quad 82$

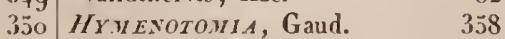

$33_{1}$ IIYPOCIIL. IIIYDEAE. 33 亿

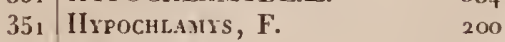

349 pectinata. 200

351 Sorgonensis. 200 
squanulosa.

Tussaci.

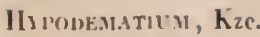

nivale, $F$.

onustum, hze.

liupuclianum, Kze.

UIPUUEIRIS, R. br.

Brow nii, J. Sm.

HYP()LEPIDEAF.

I/JPULEPIS, NuCt.

IIYOA.EPIS, Bernh

authriscifolia, Presl.

aspera, Presl.

Bergiana.

Borvana, Presl.

coniniutata, Hook.

Eckloniana, Presl.

Endlicheriana, Presl.

Ileleucusis, $\mathbf{F}$.

Instilis, Presl.

nigrescens, llook

pauperculu, llook.

parallelogramma, Presl.

repens, J. Sill.

repeus, Presl.

S.himperi.

Sellowiana, Kl.

Smithii, Mous.

speclabilis, Presl.

temuifolia, licrnlı.

trichodes.

IIYPOPELTIS, Bor!.

Vaurilinnn, Bory.?

squnrrosn, Bor!.

stramiuea, Bors.

HI:sT EROCARPL s, langsd.

Isi)Lo.IA, J. Suı.

divergens, J. Sn.

Guerinianum.

laumginosunı, J. Snı.

Willerex.

JaMesnyt.1, llook. et Gr.

?adnala, Kze.

lipinnata.

rancscens, Kze.

cinnanomea, Kze.

?hispidula, hic.

pulchira, Hook.

scalaris, hze.

verticalis, hize.

Je、k1NStA, llook. et B.

undulata, llook. et B.

L.C.AT'SS.ADE.4, Gaud.

"ppendirulnta, Gaud.

moulana, Gaud.

rhizophylla, Gaud.

J.Astre, I'resl et Auct. 201, 20 .ion, $30 \%, 304$. allenuala, J. Sn. cognala, Presl.

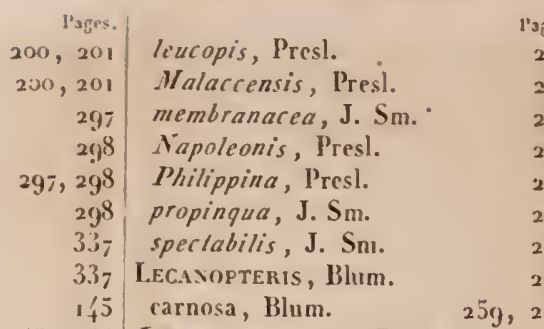

145,155 LEM.YAPIYLLEM, Presl.

146 cnrnosume, Presl.

16 LePICHos.rA, J. Sni.

Í LEPICrstIS, J. Sm.

147 LeFinosernos, F.

146 armminatum.

146 liauritum.

177 bicentatum.

I 7 hiserratum.

147 dislans.

I'7 hirsutulnu.

16 longifolium.

$1 \div 5$ obtusatum.

17 punctulatun.

146 rufescens.

146 trichonanoides.

I's volubile.

I 7 LEPTOC.IRPEAF.

$146,1_{4}^{\prime}$ LEPTOCHII.'S, Auct.

I j Leptochilus, Klfss.

$1 \frac{1}{6}, 1 \frac{4}{7}$ axillaris, Kifss.

iffi decurrens, Blum.

27 hilocarpus, $\mathrm{F}$.

2-8 lauccolatus, $\mathbf{F}$.

2-8 Linnaanus, $\mathrm{F}$.

2-8 lomnrioides, Blum.

2ifi mintor, $\mathrm{F}$

Inj quercifolius, F., vo!. Dendrogl.

108 quercifolia.

108 subquinquefidus, F.

10 - lacrafolius, J. Sin., F.

108 Zollingeri.

I6I LePTOGRAIIVE, J. SแI

16. I.EPTOGI IIIYEAF

ibi Leptopleuria, J'resl.

161 alorupta, Presl.

16 I Leptostegit, J. Sin.

184 LEICOSTEGIA, Iuct.

${ }_{161} 1$ affinis, J. Sm.

If) hirsula, J. Sm

ifi! ligulala, J. $\mathrm{Sm}$.

92 LINDSA.LCE, PresL

$9^{2}$ JIITSSELE, Hook

358 I.IXUS.IY AE.4F

338 Livis

$358 \quad 330,333$.

358 Livosayt, Dryand.

97, adiantoides, J. Sm.

apiculata, hze.

3os arcuata, Kze.

$2 y_{2}$ Catharinæ, Hook. caudata, Ilook.

caudifera, F.

Chilensis, Dess.

concinna, J. Sil

crcuulata, $F$.

cultrata, Sw.

runeifolia, Presl.

curvans, $\vec{F}$. $10 \overrightarrow{3}, 106$

dasallioisles, Blum. 105

divergens, Wall., Hook, et Gr. ins

dubia, hac. 3.37

elcgans, F. 105, inti

falcata, Driand.

falcifornis, Hook. 10.5

filiformis, llook, 105

Fraseri, llook. $\quad 108$

Galcottii, F. 105,107

Gardneri, Ilook. 105

Grifflhinna, llook.

Gurancusis, Driand.

heteroplỵlla, Dryand.

horizontalis, Ilook. I0,j

Javilensis, Humb., l., K. Im.

inlermedin, Hook. In

inlerrupla, d'Uru. non Wall. Ist

lanceolata, Labill. Iot

Lessonii, Bory.

I.epricurci, IÍook. 105

linearis, $S_{11}$.

Lobbiana, Iloot. 10.5

membranncea, Kze.

microph!lla, Presl.

microphylla, Sw., Hook. el Gr. 3.3o

multifroudulosa, F. 105

oblongifolia, Reinw: 10.7

oьala, J. Sur In

pallida, Kl. $\quad$ inj

pendula, Klotz.

pentaplijlla, Hook. 108

polymorplia, Ilook. el Gr. 10 '

propingua, Hook.

quadrangularis, Rarld.

reniformis, $S_{w}$.

rigida, J. Sur.

ruferrens, hize.

sagitlata, Dryand

scandens, Hook.

299,327 Schomburgkii, Klotz.

securifolia, Press

329 stricta, Dryaud.

$10 \%$ tenera, Driand.

10' trapeziformis, Drsand. $10_{4}^{\prime}, 105$

10 ' trichomanoides, Briand. 105

virescens, Mart. 103

Irallere, Hlool. 108

ó I.Musarxum, F. 333

Ioj rigidunt. 333

(oj LITOBnoCIII A, Presl. 1.33, 133

105' Jatromocilı, $\mathrm{F}$.

105 aculeats.

len. 107, spec. 1.)60. 
TABLE GÉNÉraLE ALPHABÉTIQUE.

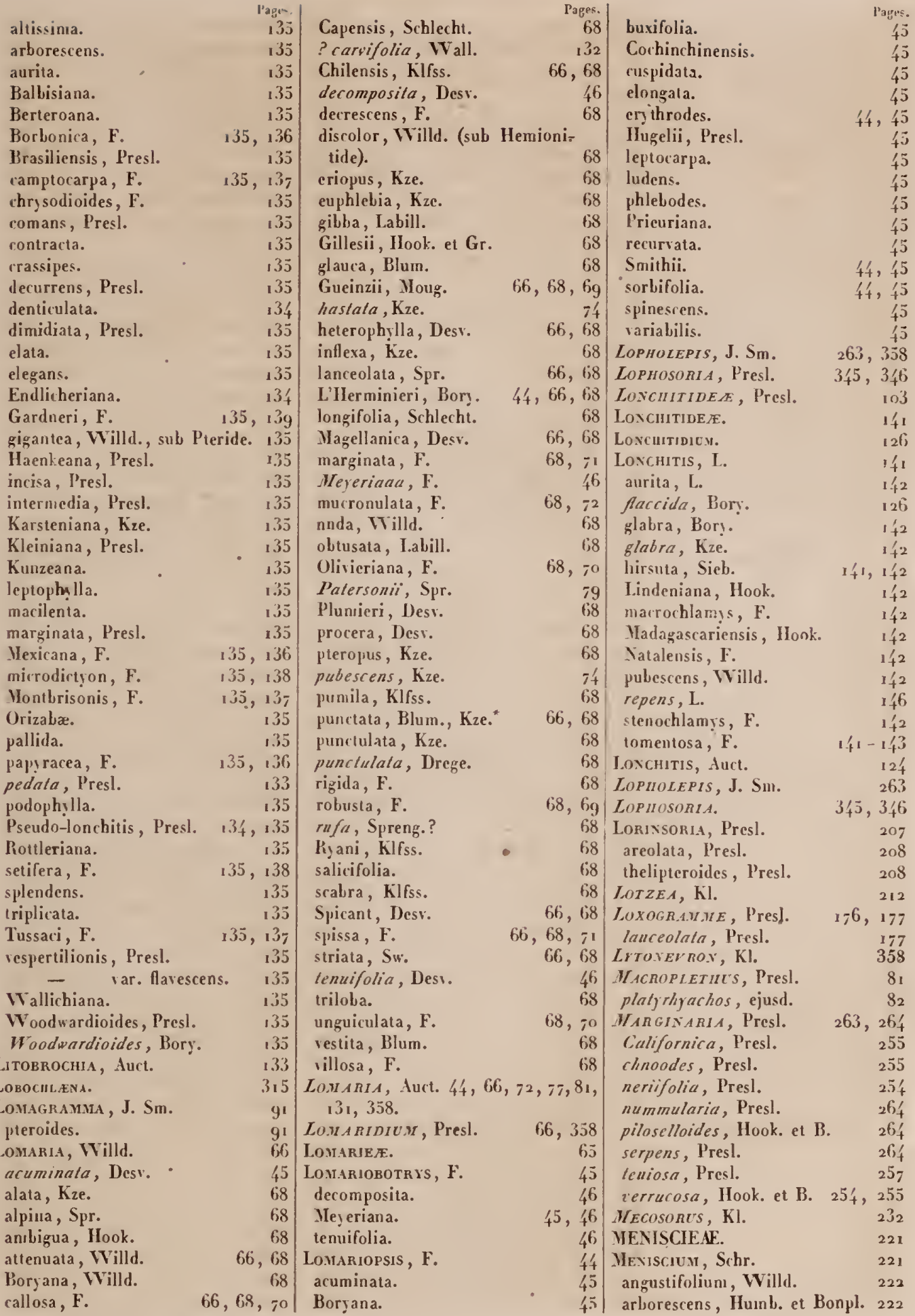
Gen. 114, spec. $1: 8 \%$. 
chr! sodioides, F.

Cumingii, $\mathbf{F}$.

cuspirlatum, Blum.

Guṛanense, $\mathrm{F}$.

Jungersenii, $\mathbf{F}$.

Kapplerianum, F.

inacrophilluin, Kze.

palustre, Radil.

proliferum, $\mathrm{S}_{w}$.

reticulatum, Sw.

reliculatum, Sihkh.

rostratum, $\mathrm{F}$.

Salzmanui, F.

sorbifoliım, Willı.

triphỵllum, Sw.

MESUCHLAYA, R. Br.

Jasaaica, R. Br.

Joluccaaa, R. Br.

MESITIEEYA, Presl.

liastoluan, Presl.

Nesothena.

MIETAXIA, Presl.

rosirala, Presl.

MIICROBnocills, resl.

apiifolia, Presl.

MICHOGRAYME persicarirefolia. 270

Microlepia, p'resl.

edematosa, l:

alata, J. Sm.

caudata, F.

ralrescens.

decurrens, llook.

flaccida.

Galeottii, F.

liirsuta, P'resl

hirta.

inaqualis, Presl.

incisa, $\mathbf{F}$.

ihasi ana.

lindenii.

? lonkhitidea.

mollis, $\mathrm{F}$.

multifida, Prest

nigricans, Presl.

l'umieri.

polyantha.

rhomboidea, Wall.

strigosa, l'resl.

tenuifolia.

trichosticha, J. Sill

villosa.

IICROLEPIA, Iuct. $326,328,331$

$$
\text { 3.3\%. }
$$

MICRUPTERIS, Dest.

VICROSORHY, LK.

irioides.

irregulare, l.k.

longissimum.

? palınatum.

sessile.

\begin{tabular}{|c|c|c|}
\hline & $\begin{array}{ll}0 \\
225\end{array}$ & ? trifidum. \\
\hline & 222 & MÍcRost_A PUYLA, Presl. \\
\hline & 222 & Mickostegla, Presl. • \\
\hline 222, & $22 !$ & esculenla, Presl. \\
\hline 222, & 223 & serrulata, Presl: \\
\hline
\end{tabular}

22 graadifolius, Presl.

ilictoterics, Presl.

aeglectus, Presl.

Mov.1CHosont':, Kze.

datallioides, Kze.

WONOCHLANA, Gaud.

222, 223 Moxognvi.t, Presl.

221, 222 palustris, Presl.

222 MOXOGR MYYE, Auct.

204 Ioxogramie, Comm.

204 ?extensa, $\mathrm{F}$.

204 furcala.

$66,72,83$ graminea, Schkh.

;2 liaearifolia, Dess.

ít linearis, Klfss.

3\%8 Irichoidea, J. Sm.

3\%8 IIrriopteris, F.

312 contracta.

313 gracilis, $\mathbf{F}$.

intermedia.

induta.

lentigera.

marsupianthes, $\mathrm{F}$.

minor, $\mathrm{F}$.

paleacea.

scariosa.

tomentosa.

villosa, $\mathrm{F}$.

$33_{2}, 328$ Nebroglossa, Presl.

327 NeOtTOPTERIDASTRLM.

32 f) Neottopteris, J. Sm.

327,328 elliptica, F.

326 Mauritiana,

327 Nidus, J. Sm.

327 orientalis.

327,328 orata, J. Sul.

327 pach! phylla.

326 phyllitidis, J. Sm.

327 rigida, $\mathrm{F}$.

327 simplex.

326 squamulata.

326 stenocarpa, $\mathrm{F}$.

327 stipitata.

326 tæniosa.

NEPIRODIARIE, Presl. 3. 3

331, NEPHNODIK, Auct. 277, 284, 2y1,

I0I $320,33 \%, 33 \%$.

26- Nerhroniun, Kich.

268 albreviatum, $\mathbf{F}$.

${ }_{2} 68$ Amboinense, Presl.

268 angustifolium, Presl.

269 asplcaioides, Wirh.

268 attenuanim.
2 figy

$97,9^{S}$

9 ,

augescens, Lk.

Benoitianum, Presl.

bidentalum, Presl.

Elunaci, J. Sill.

candirulatum, Presl.

chrı̣ sobolsum, L.k.

conionerron, $\mathrm{F}$.

decurtatum, Kze.

deltoideum, l'resl.

denticulatum.

dicarpum, F.

diversilobum, Presl.

Eekloni.

fragrans, Ilook. et Gr.

Cajmardicunum, Gaud.

glandulosum, Presl., vor. Aba-

copteris glandulosa, F.

gongyloides, Srhkh.

IIilsenbergii, P'resl.

hirsutum, J. Sm.

impressuru, Blun.

latifolinu, Presl.

latifolium, J. Sm.

leuconerron, $\mathrm{F}$.

lucens, Bojer.

Mauritianum, F.

microcarpon, $\mathrm{F}$.

molle, Sthott.

mucronatum, J. S.I.

multilineatum, Presl.

obliteratum, K. Br.

obtusatuin.

Oreopteris, F.

pullidum, Bory.

parasiticum.

plectochlæna, $\mathrm{k}$.

Pohlianuu, l'resl.

propinquum, R. Br.

yuadrangulare, $\mathrm{F}$.

simplicifolium, J. Snı.

Shepherdi, Kze.

Smithianum, l'resl.

terninans, Wall.

unitum, Schott.

violasrens, Lk.

NEPHIROLEPIDEAE.

NEPIIROLEPIS, Auct.

Nephrolepis, Schott.

biaurila, P'resl.

biserrala, Schott.

exaltata, Presl.

imbricata, Presl.

obliterata.

pendula.

Stlkuhrii, ld.

- var. minor

Irichomanoides, Presl.

tuberosa, Presl.

undulata, J. Sim.

rolutile, J. Sm.
Papes.

303

उot

309

305

305

305, 308

303

305

305

303

ไกว

305

291

320

310

305

305

305

305

305

3 ro

$304-306$

303

30.5, 3ื०8

305,307

304,305

305

305

319

305

305, 306

291

$30 \overrightarrow{3}$

305,$30 ;$

305

303

$30.5,308$

310

305

305

303

305

305

318

301,319

319

301

301

319

"iो

314

319

319

319

301

319

ing

301

ren. 121, spec 1599. 
TABLE GÉNÉRALE ALPHABÉTIQUE.

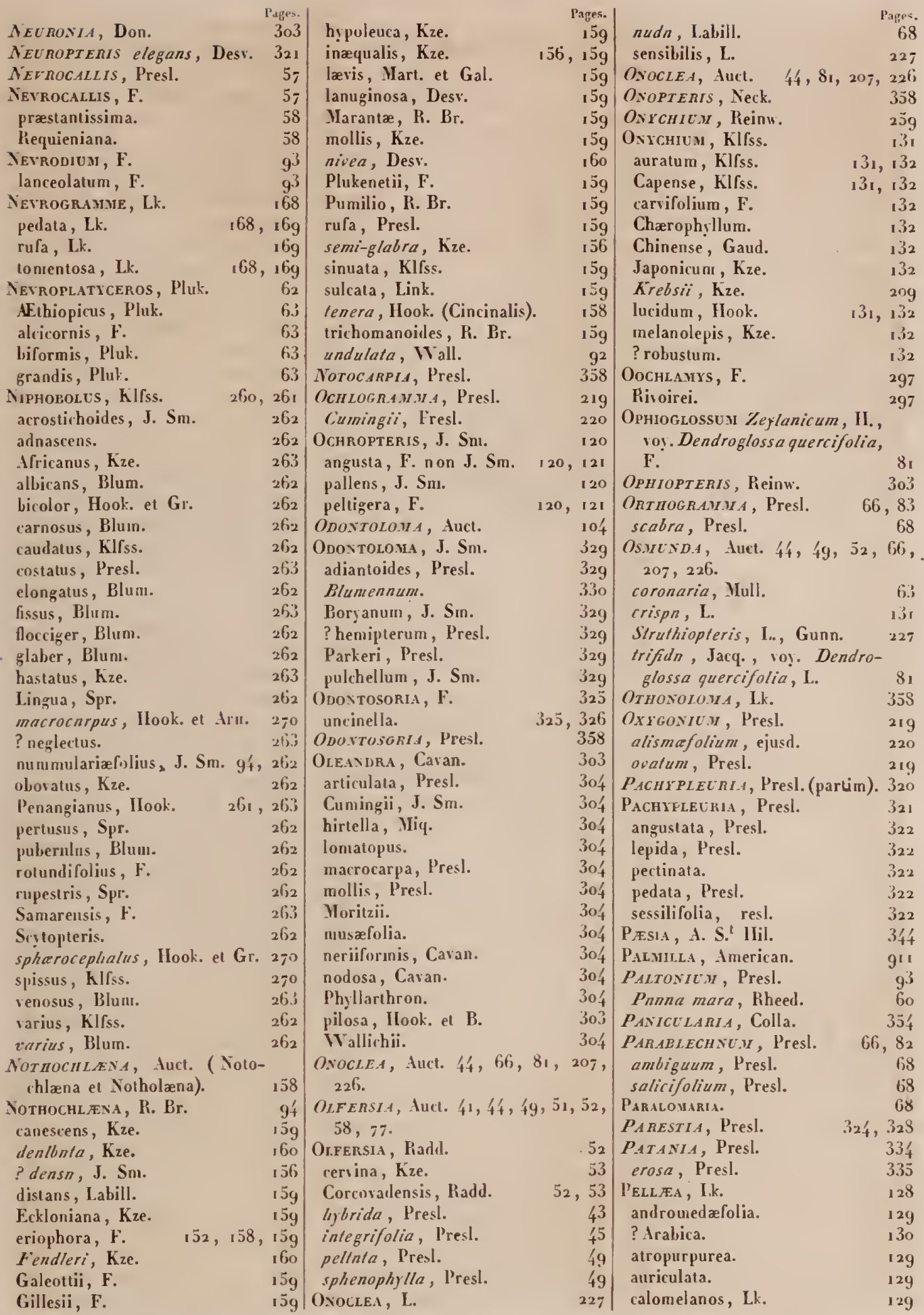
Gen. 155, sper. 1698. 


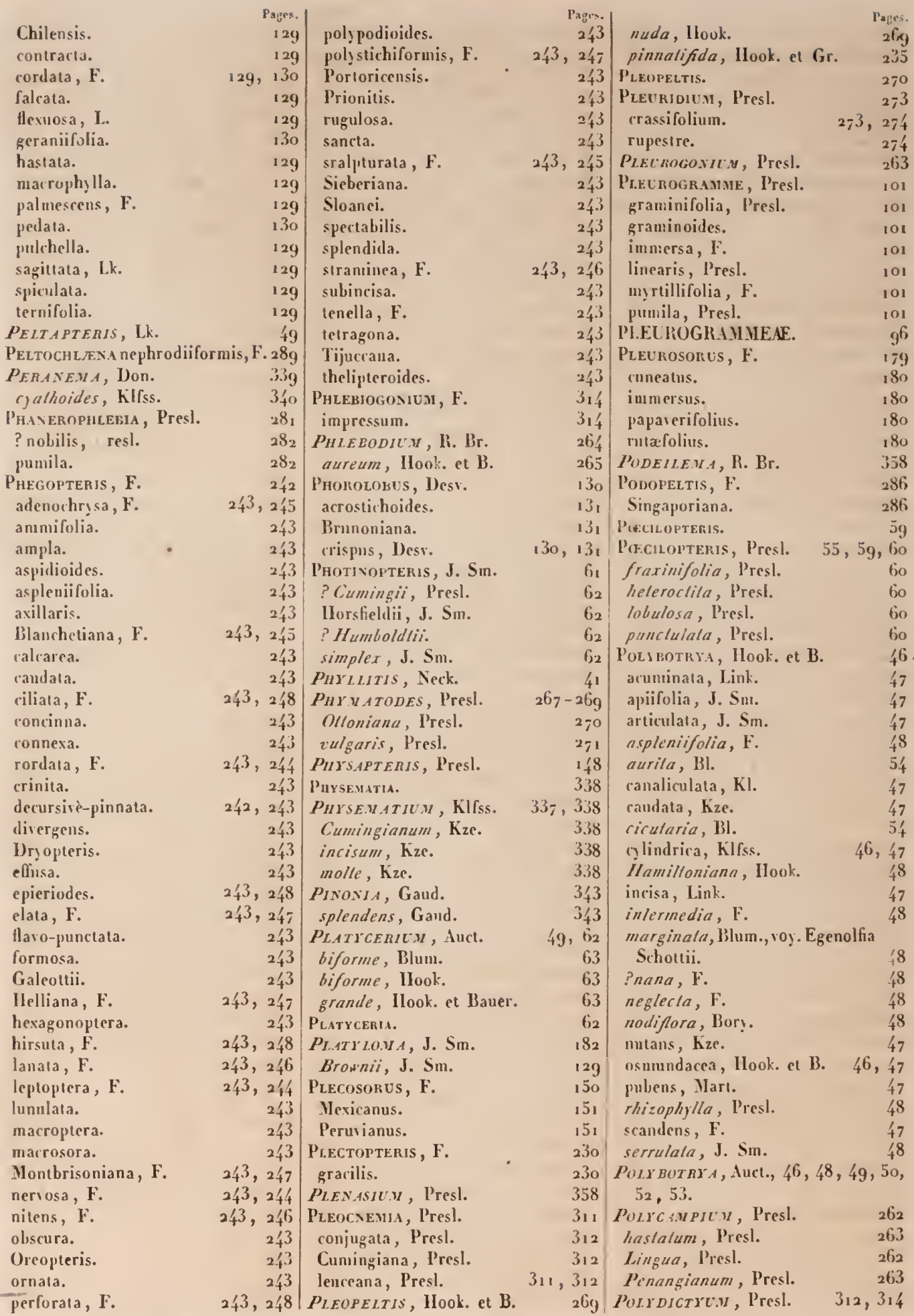
Gen. 1301 , spec. IS0 
TABLE GÉNÉRALE ALPHABÉTIQLE.

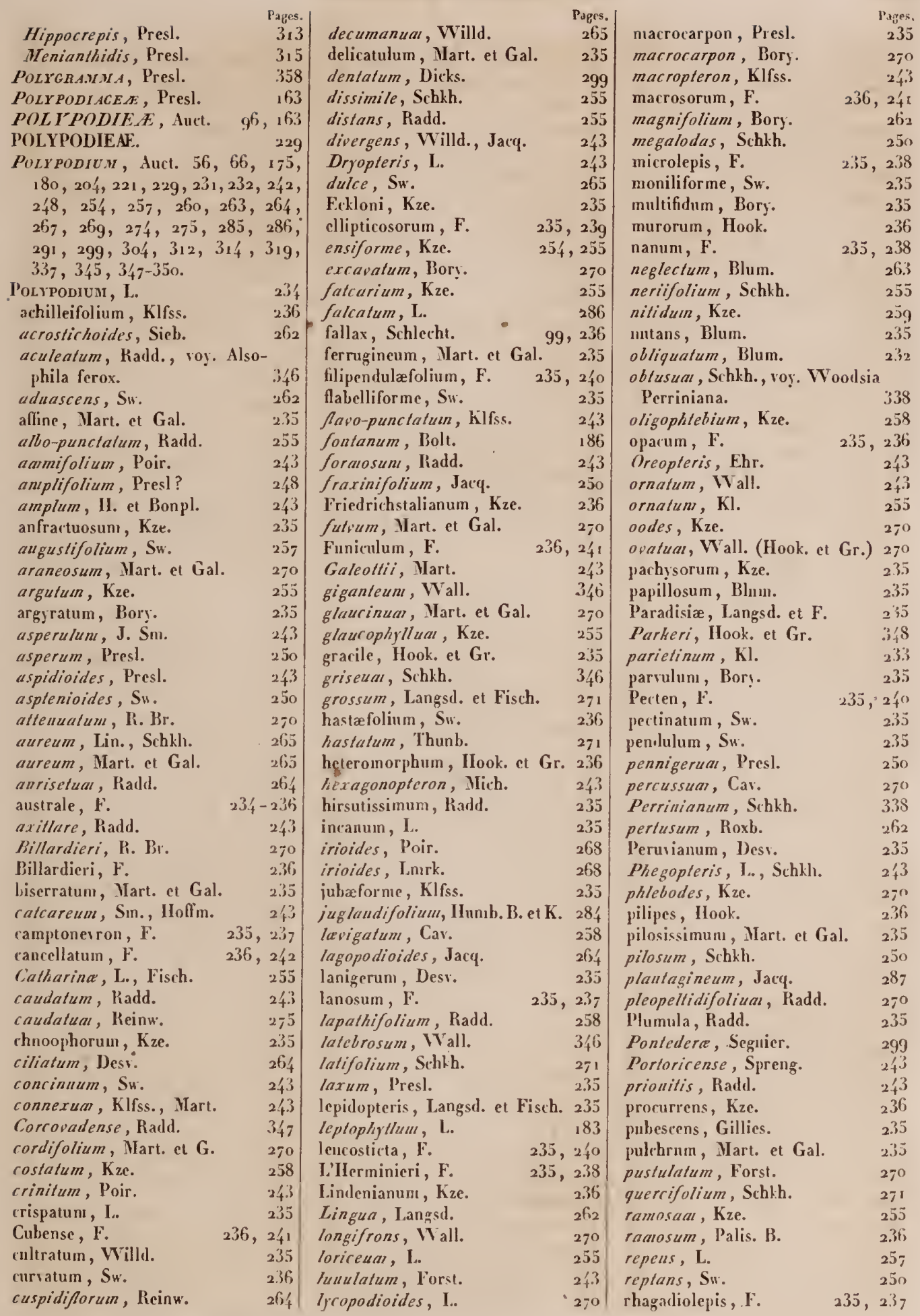
Gen. 132, spee. 186\%. 
rigescens, Bor

rude, Kze.

rugulosum, Labill.

saccatum, F.

scaadens, Forst.

Schkuhrii, Radd.

schomburghianum, Kze.

scolopend rioides, Ilool. et Gr. 335 - var. trifurcatum. 235 scolopendrioides, Sw. non Hook.,

vo!. Goniopteris scolopendrioides., Presl.

Scouleri, Hool. et Gr. serpeas, $\mathbf{L}$.

Serricula, F.

sessile, Klfss.

Sieberiaaum, hlfss.

solutum, Kze.

spectabile, Kilss.

splendidum, hilss.

sporodocarpon, Willd.

squanıatum, L.

stellatum, Schkh.

subcrenatum, llook.

subfalcatum, Blum.

subincisum, Willd., Mart.

submarginate, Langsd. et

subletragonum, I.k. $\quad 249,250$

Surinamease, Leprieur.

suspensun, I.

stellaluza, Schkh.

taxifoliun, $\mathrm{L}$.

tenuiculun, $\mathrm{F}$.

tenellum, Forst.

thelipteroides, Desv., Sieb.

Thouinioaual, fraud.

Tijuccaaum, Radd.

traasluceas, Kze.

trapezoides, $\mathrm{Sw}$.

trichodes, Reinw.

trichomanoides, Sw.

tridartyon, Wall.

tridens, Kize.

235

zacillaas, Kze.

variolatum, Willd., vor. Car-

diochlæna macrophylla.

zarium, Blum.

Virginianum, L.

sulgare, L.

$$
\text { - var. Canıbricum. }
$$

Mullichii, Hook. et Gr.

Pusrsticuley Auct $180,291,304$

Polrstichum, Roth.

acrostichoides, Schott.

aculeatum, Koth.

$$
\text { - var. hastul atum. }
$$

anılissimunu, Prest iar. Tayget.

278

278 angulare, Presl.

a ristatum, $\mathrm{Su}$.

auriculatum, Schoth

Braunii, Spenn.

caudatum, $S_{\text {r. }}$.

chlænostitta, F.

coniifulium, Presl.

coriaceum, Roth.

cyphochlamys, F.

discretun, $\mathrm{Sm}$.

elegans, Rem.

falcatun, $\mathbf{F}$.

gelidum, Kze.

? glandulosum, Presl.

heterolepis, $F$.

ilicifolium, F.

incisum, $F$.

? inerme.

Iobatum, Presl.

Lonchitis, Roth.

marginatum, Schkh.

Mauritianun.

mohrioides.

murronatum.

mucronifolium, Kze.

muricatum.

obtusum, J. Sm.

ordinatum, Sieb.

polyblepharum, liœm.

pungens, Kliss.

radicans, Sieb.

rhizophyllum, Presl.

rhomboideum, Schott.

setosum.

Sieljerianum, Presl.

sijuarrosum.

stramineum.

tenerum, $\mathrm{F}$.

trapezoides, Presl.

triangulnm.

varium.

iestitum.

iiviparun, F. 278, 28

5 Prionopteris, Wall.

Profere.t, Presl.

3,5 Prose pirnicu, Presl.

262 Pros.aptia, Presl.

2.35 contigua, Presl.

$23 \%, 2.35$ Emersoni, Presl.

235 Preslii.

274 Psomocarpia, Presl.

PIIG.YIV:Y, Presl.

277 PTERIDE 2 .

278 P'TERIDINEAE.

278 Pterigliphis, $\mathbf{F}$.

278 elegans, $F$.

Pter1S, Auct. 52, 66, 85, 87, 88,

$9^{\circ}, 9^{3}, 9^{\prime}, 9^{8}, 108,128,130,131$ $133,134,139,140,153,161$.

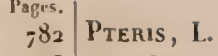

${ }_{27}-8$ aculeata, $\mathrm{Su}$.

278 Adscensionis, Forst.

278 xqualis, Presl.

2-8 alata, Luurk

278,280 alata, Gaud.

chia altissima. 1.35

aupla, Kze. $\quad 135$

aquilina, I. $\quad 12$, 126

$\begin{array}{rll}278,279 & \text { arachnoidea, Klfss. } & 126 \\ 278 & \text { arboresceas, Mart. et Gal. } & 135\end{array}$

2,8 b argentea, $\mathbf{G m}$. 15 t

278, 279 arguta, Wahl. 126

278,279 argyroplylla, $S_{w}$. et Willd. 154

$2-8$ । ? articulata, Klfss. 133, 13 f

278,281 aspera, F. 125,126

278 asperula, J. Sm.

278 atropurpurea, L. (Schkh.*) 129

${ }_{278}$ auriculata, Thunb. (Ilook. et

278 Gr.") 1.29

278 aurita, Blum. 135

2-8 Bahamensis, F. 125

278 Berieroaaa, Ag. 135

2-8 biaurita, L. 26 i

278 lirasilieusis, Radd. 135

278 calouelanos, Sw. (Schlecht.") 129

278 candata, L. 126

278 chnsocarpa, Ilook. et Gr. 12 '

278 clirjsosperma, llook. 132

278 comaas, Forst. 135

2-8 coutracta, Lmrk.

278 cordata, Sieb. 129

278 costata, Bory. 125

278 crassipes, Ag. 135

278 crenata, $\mathrm{Su}_{\mathrm{w}} \quad 125$

278, 280 creuala, J. Sm. 127

278 Cretica, L. 12, 125

278 Ciretica, L., zar. Ciapensis. 125

278 crusus, Bory. 126

278 decurrens, Arrab. 135

decurrens, Radd. 153

deflexa, Lmrk. 126

denliculata, Su. $\quad 135$

358 denliculata, Su.
358 distans, J. Sn.

358 diversifolia, Agardh. var. $\beta . \quad 125$

32 ' elata, Ag. 135

32 elegans, $\mathrm{S}_{\mathrm{w}}$. 135

32 í esculenta, Forst. 126

32 Salcata, R. Br. 129

$46,47,6:$ felosma, J. Sm. $126^{\circ}$

103,124 fubellata, Schkh.

124 fabellata, Schkh.
103 flaccida, $\mathrm{F}$.

219 geninata, Wall. 135

2 geraniifolia, Radd. 130

gigantea, Sieb. $\quad 135$

giguntea, Hort. 1.35

gracilis, $\mathbf{F}$ 126, 128

Gen. 136, spec. 1931. 
TABLE GÉ.IÉr.LE ALPIIABÉTIQLE.

\begin{tabular}{|c|c|c|c|c|c|}
\hline & Paficio & stenophilla, IIook. et Gr. & $\begin{array}{r}\text { Pages: } \\
125\end{array}$ & sorbifolia, Presl. & $\begin{array}{l}\text { Pages. } \\
313\end{array}$ \\
\hline hastalu, Radd. & $\begin{array}{l}1+40 \\
133\end{array}$ & $\begin{array}{l}\text { stipularis, I.. } \\
\text { stionot. el Gr. }\end{array}$ & $\begin{array}{l}123 \\
125\end{array}$ & $\begin{array}{l}\text { varia, Presl. } \\
\text { valosion }\end{array}$ & \\
\hline heleroclita, Bory. & 127 & sulfurea, Caran. & $1 \ddot{3}_{t}^{\prime}$ & SALPICHL Fxa, J. Sm. & \\
\hline eteromorpha, $\dot{\mathrm{F}} . \quad 125$ & 127 & Swartziana, tgh. & 126 & Cumingiana, $\mathrm{F}$. & \\
\hline heterophỵlla , I. (basi bipin- & & tæniosa, J. Snı. & 123 & Finlaysoniana, $\mathrm{F}$. & \\
\hline natà). & 125 & lia, Cavan. & 129 & orie & \\
\hline heterophylla, I. (fronde tripin- & & tremula, R. Br. & 126 & I'atersonii, $\mathrm{F}$. & \\
\hline & 126 & trichomanoides, Schlh. & 159 & scandens, Presl. & \\
\hline neisa, Thunb. & 135 & tricuspidala, I. & 88 & rolubilis, Presl. & 78, \\
\hline intermedia, Blum. & 135 & Irifoliala, Pory., Herb. & 133 & rolulitis, J. Sm. & \\
\hline inlerrupia, Willd., vọ. Ne- & & Iriplicala, Agh. & 135 & SCHELLOLEPIS, J. Sm. & \\
\hline phroolium obtusatum. & 305 & Irili & 135 & SCIII & \\
\hline $\begin{array}{l}\text { nalis, KIfss. } \\
\text {, Kifss. }\end{array}$ & 126 & $u m$ & 135 & SCHIZOCAXA, J & 353,354 \\
\hline Fudl. & 126 & $\begin{array}{l}\text { unbrosa, K. Br. } \\
\text { vespertilionis, Lal,ill. }\end{array}$ & $\begin{array}{l}123 \\
135\end{array}$ & Gaudichaudii, F. & , \\
\hline Igh. & 135 & villosa, $\mathrm{F}$. & 126,128 & sinuata. & \\
\hline Trilld. & 126 & villarioides, A. Pet. Th. & & Schizoleptos, $\mathrm{F}$. & \\
\hline nginosa, Bory. & 126 & rillata, Sihlh. & $125^{\prime}$ & & \\
\hline - ₹ Capensis. & 126 & Hoodwardioides, Bory. & 135 & ons, Gaud. & 89,108 \\
\hline tifolia, Hook., B. et Kith. & 140 & $o s, F$ & 320 & icri, Gaud. & \\
\hline I. $\quad 12 \%$, & 125 & parall & 320 & im, Gau & \\
\hline Less. et Rich. & 135 & , Presl. & 87 & , J. Sin. & \\
\hline Bory. & 135 & a, Desı. & 87 & & \\
\hline ulon, $\mathrm{F}$. & 127 & Blu & 87 & ianum. & \\
\hline & 126 & lan & $9 ?$ & Guerinianum, Gaud. & \\
\hline Villd. & 126 & ala, Presl. & 88 & & 108,109 \\
\hline J. Sni. & 125 & PTEROPSIS, Auct. 87 , & $, 9^{3}, 9^{\prime}$ & macrophỵllum, Presl. & \\
\hline Inssoides, Arrab. (roy. & & Pterozo & 178 & & \\
\hline radensis). & 53 & & $1 ; 8$ & , Gaud. & 84,10 \\
\hline rt. et Gal. & 1.35 & A, Presl. & 338 & $\sec$ & \\
\hline mundoides, Bor!. & 68 & , Virb. & 358 & SCOLOPENDRIE $Y$, Anct. & 41,210 \\
\hline & 126 & $R_{1 G}$ & 358 & , J. Sm. & \\
\hline 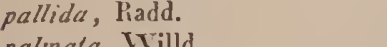 & 135 & iris, Schott. & 49 & $a m b$ & \\
\hline $\begin{array}{l}\text { Willd. } \\
\text { Poir. }\end{array}$ & 1.33 & oldliana, Schott. & 49 & f. & \\
\hline $\begin{array}{l}\text { s, Poir. } \\
\text { Kze. }\end{array}$ & $\begin{array}{l}1,4 \\
1.30\end{array}$ & $\begin{array}{l}\text { IIumboldtiana, Schott. } \\
\text { peltata. }\end{array}$ & $\begin{array}{l}49 \\
49\end{array}$ & $\begin{array}{l}\text { Durvallet. } \\
\text { IIenionitis, Sw. }\end{array}$ & \\
\hline tala, I & 133 & - var. Coniculacea. & 49 & & 209,211 \\
\hline$-\quad$ & ז33 & sphenoplịlla. & 49 & inm, Presl. & \\
\hline data, I & 1.30 & & 49 & & \\
\hline & 126 & Rc:yornts, Radd. & 277 & officinarum, Sin. et rar. pl & plur. 209 \\
\hline & 125 & $S_{A C C}$ & 329,331 & & 209 \\
\hline s. & 135 & SACC $_{\text {S }}$ & 320 & repan & 210 \\
\hline & 126 & adia & .329 & sagill & 209 \\
\hline & 94 & Bor & & Sctit & \\
\hline & 1.35 & cleg & 321 & , A. Pet. Th. & \\
\hline & 1.35 & Hoo & 321 & & 324 \\
\hline 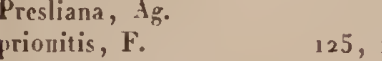 & 126 & & 321 & & \\
\hline m. & 126 & , Klfss. & 79 & & \\
\hline $\begin{array}{l}\text { Sm. } \\
\text { d. }\end{array}$ & 125 & teoides, Klfss. & So & $\begin{array}{r}\text { SCYTL } \\
\text { aCro }\end{array}$ & \\
\hline d. & $\begin{array}{l}126 \\
133\end{array}$ & $\begin{array}{l}\text { Kaulfussiana, Gaud. } \\
\text { Souleytiana, Gaud. }\end{array}$ & $\begin{array}{l}\text { So } \\
\text { 8o }\end{array}$ & $\begin{array}{l}\text { choides, Presl. } \\
\text { gr:Y, Kze. }\end{array}$ & 358 \\
\hline$T_{-1}$ & 126 & sa, Gaud. & 80 & $S_{E}$ & 175 \\
\hline L. & 125 & SAGENA, Presl. & 312 & UEA, Bory. & 176 \\
\hline & 125 & & 313 & & 177 \\
\hline 124, & 125 & coadunata, J. Sm. & 3,3 & eana. & 177 \\
\hline & & & & & 177 \\
\hline & 129 & s, l'resl. & 313 & ens, Presl. & 176 \\
\hline escer & 126 & a, F. & 312,313 & , Bory. & 177 \\
\hline nulos & 153 & Mexican & 31.3 & $A a$ & 177 \\
\hline$n d c$ & 135 & plalyphilla, J. Sm. & 287 & Mamilloni, Presl. & 177 \\
\hline
\end{tabular}
Gen. 170. spec. $205 \mathrm{~s}$. 
liemionitidea, Presl. heteroearpa, Blun.

insoluta.

lanceolata.

macropliylla, Blım. marginata, Iley.

Iexicana, F. minor, $\mathbf{F}$.

pedunculata, l'resl. polhifolia, J. Sm. scolopendrina.

Iralficliana, Ilook.

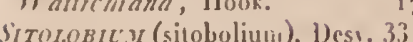
3.35.

runeatum, J. Sut.

Sitoboticil.

SiLEXOPTER, WS, Wall.

S) Mom.1Nes, l'.

inlegrifolium, $\mathbf{F}$. serratifolium.

SPHJ:LOPTERYS medullaris, Iieruh.

Sumziopteris, R. Br.

barluata, IVall.

SPIISHOSTEPIIINOS, Kze. asplenioides, J. Sul. (aspidioiiles).

SPIIATROSTICIIV.M, Presl. acrostichoides, Presl.

SPIC.ANT.t, l'resl.

STEG,Avi, Aluet.

I'atersonii, 1k. Br.

procera, Rirh.

Steguogramime, Bluin.

aspidioides, Blum.

Jaranica.

Yesochlona.

Voluciana.

StEMCHTIs:A, Aurt.

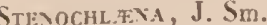

fraxinifolia, I'resl.

gracilis, Kze.

II ugetii, $\mathrm{F}$. juglandifolia, Presl.

laurifolia, Presl.

ecandens, J. Sm.

- var. З, J. Sin.

$$
\text { - var. \%, J. Su. }
$$

JTENOLOBLS, l'res!

solidus, Presl.

Stexol.oma, F.

aculeatum.

Bhıucanun.

das atum.

dumosum.

funsarioides.

? Goudeotianum.

lindsajoides.

retusum.

S.hlechtendalii.

\begin{tabular}{|c|c|}
\hline 175 & tcmuifolium. \\
\hline 177 & Stemosevia, I'resl. \\
\hline 177 & aurita, Presl. \\
\hline 177 & ? eirutaria, Presl. \\
\hline $1 ; 6$ & obscura, J. Snl.? \\
\hline $1 ; f_{3}$ & STIUUTHLOPTERIJ)EAF. \\
\hline 177 & Strutuolteris, Willd. \\
\hline 177 & Gernanira, Willd. \\
\hline 1,7 & Pensılvaniea, Willd. \\
\hline $1 ; 6$ & STAAYMAA, Presl. \\
\hline $17 \%$ & efongata, Presl. \\
\hline $1 ; 6$ & triloba, Presl. \\
\hline
\end{tabular}

lin.

i is aurea.

5.3 nierrophylla, $\mathbf{F}$.

$5.3,5$ Vagivelaria, $f$.

5 trichoidea, $\mathrm{F}$.

2,3 VITTAлIA, Auct.

226 Vitтakia, J. Sm.

et Gr. 86

226, 22; Amboinensis, F.

227 angustifolia, Blum. $86^{\circ}$

254,$2 ; 0$ anguslifolia, J. Sm. $\quad 86$

270 anodontolenis, $\mathrm{F}$. 86

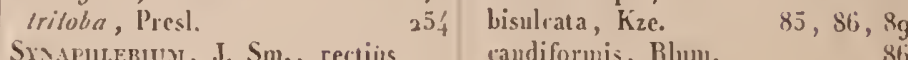

109,4 í

333 obtusum, J. Sm.

33. propinquum.

358 recursatum, J. Sin.

50 tetraphyllunt.

$5 n, 285$ Irnillei, F.

50 SYNECIIS

Sisgramine, J. Sn.

352 vittæformis.

339 Trstupsts, J. Sin.

339,3 io gruminifolia, J. Sm.

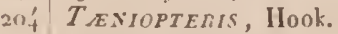
Forbesii, Hook.

20 ' TAENITIDEAE, Auct.

263 T क्जitis, Sw.

262 blechnoides, Willd.

66,83 furcala, Willd.

$77,-8 \mid$ graminifolia, llook.

79 linearis, Mart. et Gal.

68 linearis, Kllss.

20.' sagillifera, Bory.

(llook. et Gr. 88

its , duet. 87, 88, 90, 93, 101

20: TAR.ACH H. 189,208

20: TAXIOCARPEE.

44,45 Tectarita, Cavan.

i7 TEGLLARLA, licinw.

;8 TII.ANopteTs, Presl.

-8 Nauriliunu, Presl.

¡3. Orientatis, l'resl.

78 pachipliyila, Presl.

-8 simplex, Presl.

i7, 78 squamulata, Presl.

-8 slipilata, Yresl.

78 laniosit, Presl.

328 TIIELIPTERIS, AUC1.

329 TIIYLISOI'TERIDENE.

3io Turrsoptens, Kze.

33o elegans, Kze.

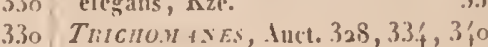

330 34.

63

109 ensiformis, Willd.

109 falcata, hze.

109 filifolia, F.

109 ?filiformis, Caran

109,110 flexuosa, F.

112 Forbesii, 5 . 55,86

170 Gardueriana, IV. 86

170 eracilis, Kze.

55, 86 graminifolia, Klfss.

86 Gninensis, Desv.

85 isoelifolia, Borı.

$85,8 b^{\circ}$ lineata, Siw.

$9^{\circ}$

90

88

101

86

tis

pusilla, Blum.

resoluta, Willı.

rizida, Klfss.

- var. elongata, sw.

liuiziana, $\mathrm{F}$.

277 sarincutosa.

216 scabridla, Kifss.

202 stipitata, Kze.

20.3 tenera, $f$

20.3 Iruncala, Gaud.

203 Zeylanira, F.

3o.3 zosteræfolia, Bor!.

20.3 VITTARIF LE.

203 IITT IRI ACEA, Presl.

203 MIEELII, Intrt.

дgy Wibrals.

$35 \%$ lipinnata.

35 Jav

3.5 pertinalis.

25, 33o Thonontenus, P'resl.

33o dentirnlata, presl.

330 elegans, Presl.

330 excelsa, Presl.

330 Tusmerse, I:

33o argentea, F.

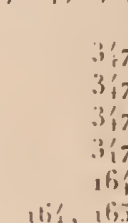

$3: 7$
317
$3: 7$
317
36
16
167
Wouosu, furt.

; Wonnsia, R. Br.

7 Cunningiana, llook.

elongata, Jlook.

Gnatemalensis, Hook.

glabella, R. Br.

hiperborea, li. Ijr.
$6 ;, 165$

165
.97

97 4

(2)

(2)

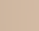

;

\footnotetext{
lien. 186, spec. 212i.
} 
TABLE GÉxÉRALE ALPHABÉTIQLE.

Ilvensis, R. Br.

incisa, Gill.

mollis, J. Sm.

Peruviana, Hook

Perriniana, Kze.

Woodwardia, F.

aspera.

blechnoides.
207 onocleoidt

connex

dives.
Pages. Br., sub Doodyà. 207 radicans, $S_{w}$

Japonica, Sw.

Kunthiana.

lunulata, R. Br., sub Doodỵâ. 207 Xiphopterus, Klfss.

\begin{tabular}{ll|l} 
& 207 & serrulata, Klfss.
\end{tabular}
Pages.

207

207

207

208

206

100

100

Gen. 188 (inter que $\mathbf{T}$, incerla aut minus cognitre), spec. 21:1. 


\section{TABLE DES MATIËRES.}

Prolègomenes

Pages.

2. 1. Fougérus à sporanges, portant un anneau vertical : Catıétogratités

2. 2. Fougères a sporanges, portant un anneau oblique : HÉlicogrratées . . . . . . . 29 GENERA.

Conspectus ordinum.

Introduction

Ordo generun.

Explicatio signorum et verborum abureviatorum in genere filicum usitatorum. . . . . . . . . 39

l. Cathetogirate.e.

Icrostichea . . . . . . . . . . . . . . . . . . . . . . il

lomariere. . . . . . . . . . . . . . . lij

Vittariece . . . . . . . . . . . . . . . . . . . . . . 84

Pleurogrammece. . . . . . . . . . . . . . . . . . . . . . . . 96

Limelsayere . . . . . . . . . . . . . . . . . . . . . . . . . . . . 10 1

Adiantere . . . . . . . . . . . . . . 112

Pteridece. . . . . . . . . . . . . . . . . . . . . . . . 124

Cheilanthece . . . . . . . . . . . . . 115

Hemionitidere. . . . . . . . . . . . . . . . . . . . . . . . . . 16 !

Antrophyece . . . . . . . . . . . . . . . . . . 17t

Leptogrammece. . . . . . . . . . . . . . . . . . . . . . . . . . 178

Asplenier . . . . . . . . . . . . . . . . 185

Scolopendrice . . . . . . . . . . . . . . . . . . . . . . . . . . 209

Diptaziç . . . . . . . . . . . . . . . . . . . . . 212

Mlenisciea. . . . . . . . . . . . . . . . . 221

Struthiopteridece . . . . . . . . . . . . . . . 220

Polypodiece. . . . . . . . . . . . . . . . . . . . . . . . . . 229

Cyclotiere . . . . . . . . . . . . . . . 2 . . .

Aspidiea . . . . . . . . . . . . . . . . . . . . . . . 290

Nephlokpidea . . . . . . . . . . . . . . . . . . . . . 318

Dacatlica . . . . . . . . . . . . . . . . . . . 323

Dicksonice. . . . . . . . . . . . . . . . . 33

Balantiece. . . . 340

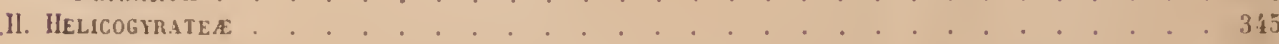

Cyathea. . . . . . . . . . . . . . . . . . . 34

Alsophilex. . . . . . . . . . . . . . . . . . . . . . . . . . . . .

Hemithelicæ . . . . . . . . . . . . . . . . . . . . . . . 349

Eucrathere . . . . . . . . . . . . 351

Thyrsopteridece . . . . . . . . . . . . . . . 35

Genres et sous-genres non adoptés oụ omis dans les synonymies . . . . . . . . . . . . . . . 357

Liste alphabétique des ourrages iconocraphiques cités. . . . . . . . . . . . . . . . . 359

Liste indiquant comme complément la date de la creation de divers genres . . . . . . . . . . . 361

Etymologic des noms de genres créés dans les mèmoires sur la famille des fougères . . . . . 361

Additions et corrections . . . . . . . . . . . . . . . . . . . 36?

Listc des espèces figurées en tout ou en partie. . . . . . . . . . . . . . . . . . . 36 f $^{2}$

Table génèrale alphabétique. 


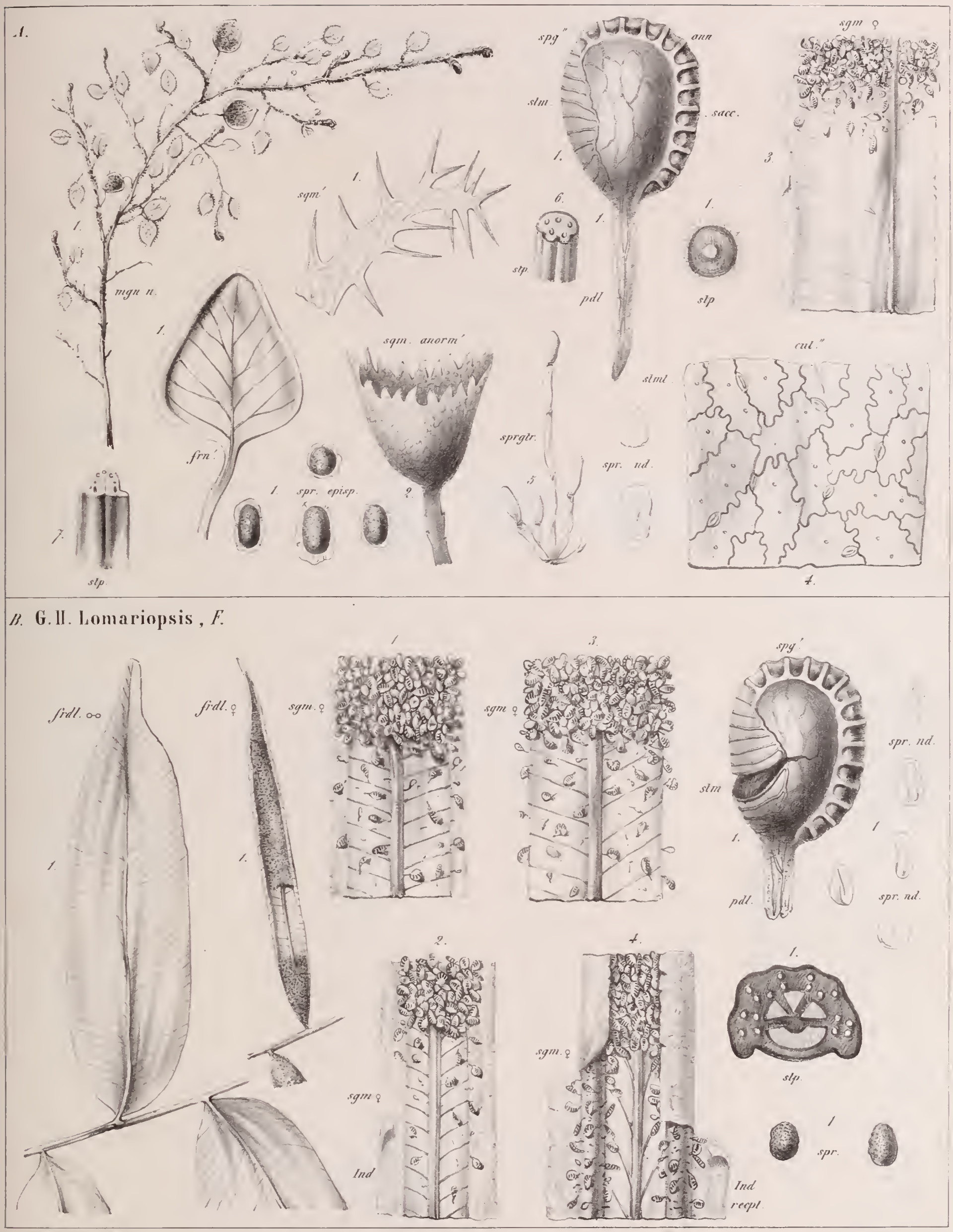

A.6.I. Fig. Acrostichum rabdulepis, $F$.

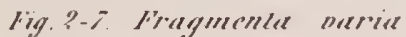

B. (G. II . Fig 1. Lomariopsis erylhrodes, $F$

Fig.? se 3. Fragmenta maria, Figy f. Lomaria

I'llerminieri, (fragmenlum) Bory. 



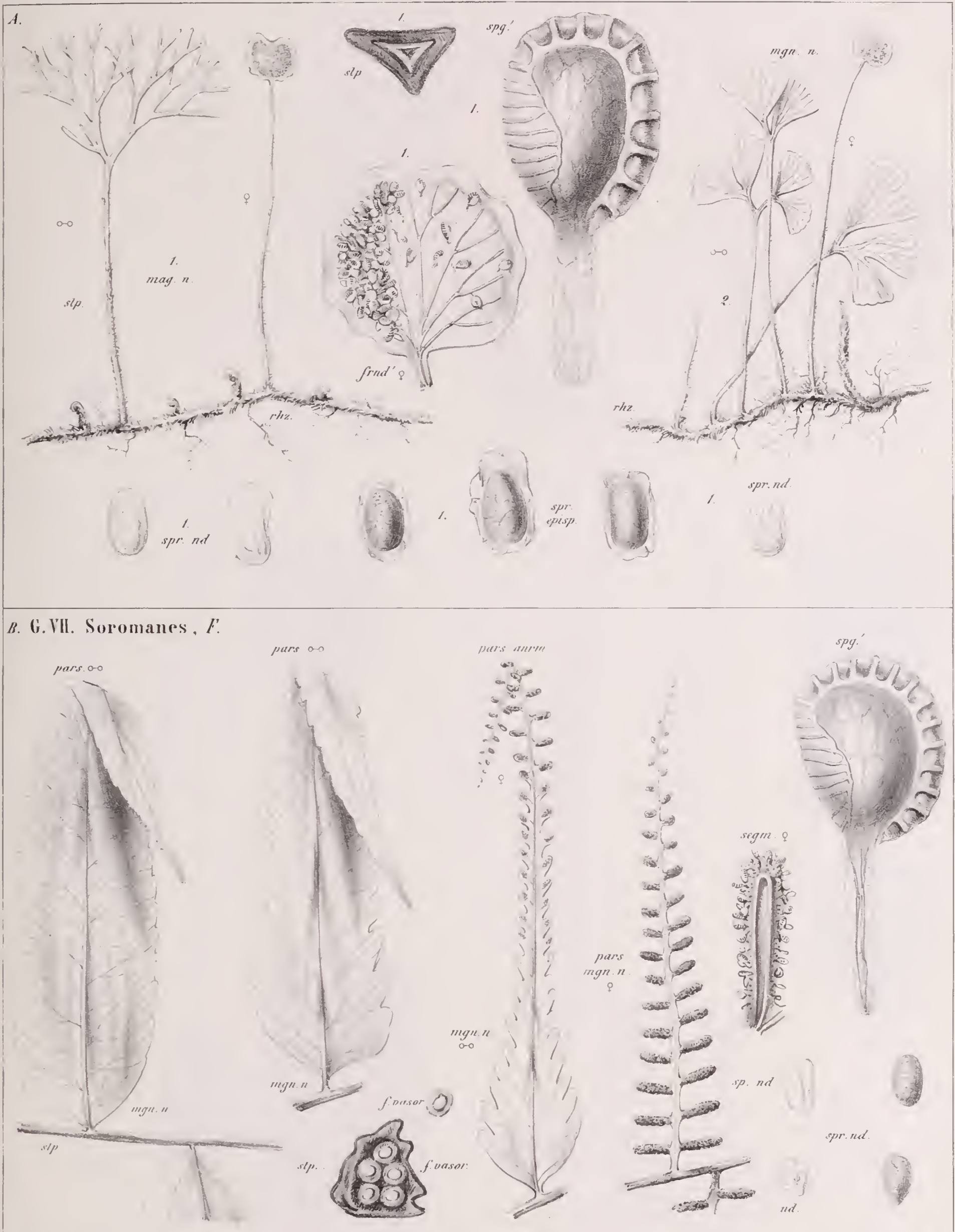

1. G. IT. Fig. Rhipidopteris peltuta uar: rig.? R 



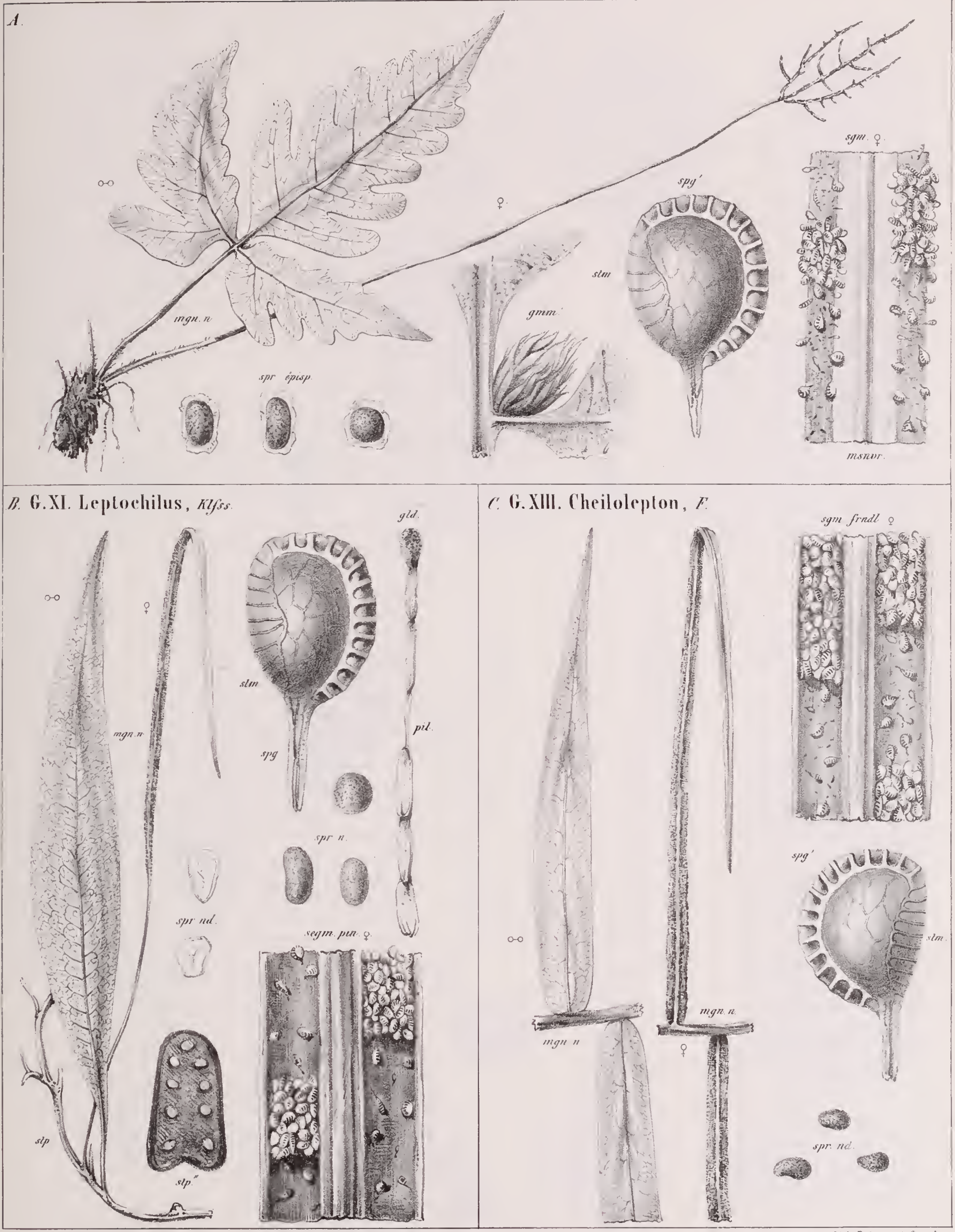

A.G. X. Stenosemia aurita, Prest

B. G. XI. Leptochilus axillaris, kifss. 

G.XII. Nevrocallis, I?

1. ICROSTICHEA.
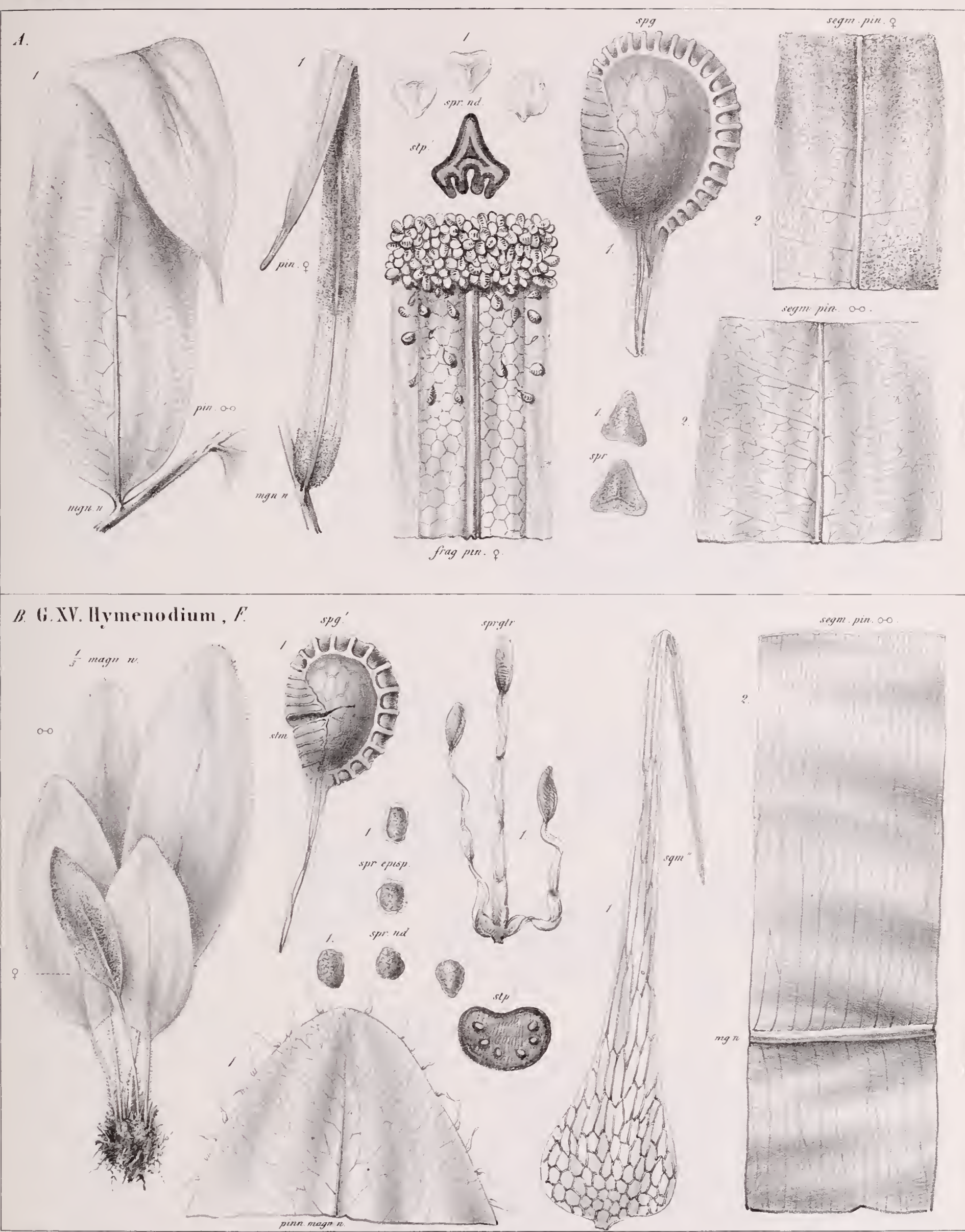

A. G. XII. Fig t. Nerrocallis prastuntissimar, $F$.

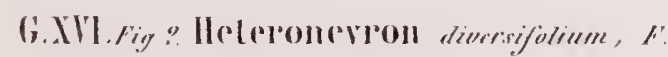
(fragmetulum)
B. G.XY. Fig.t. Hymenodimm creneuse, $\quad F$

rig? H

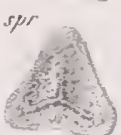

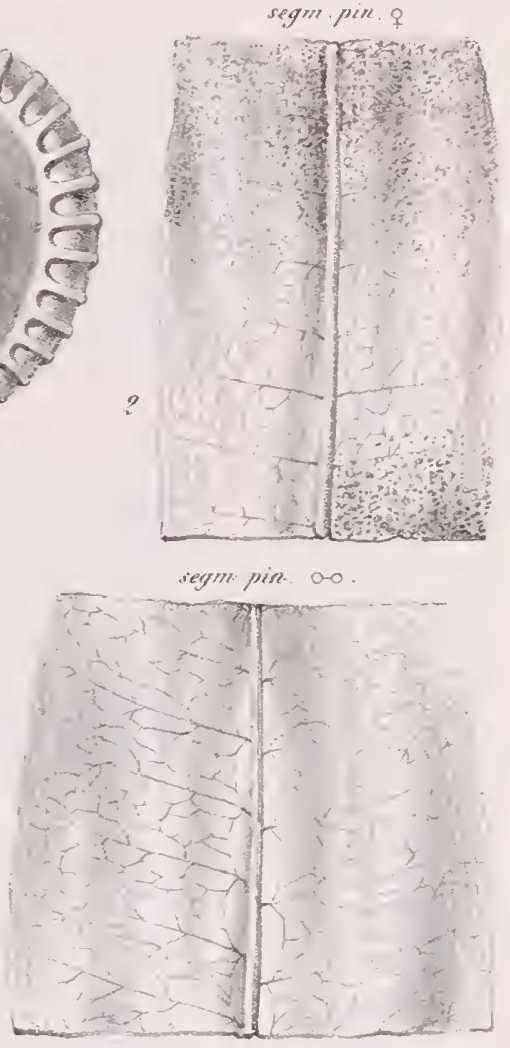





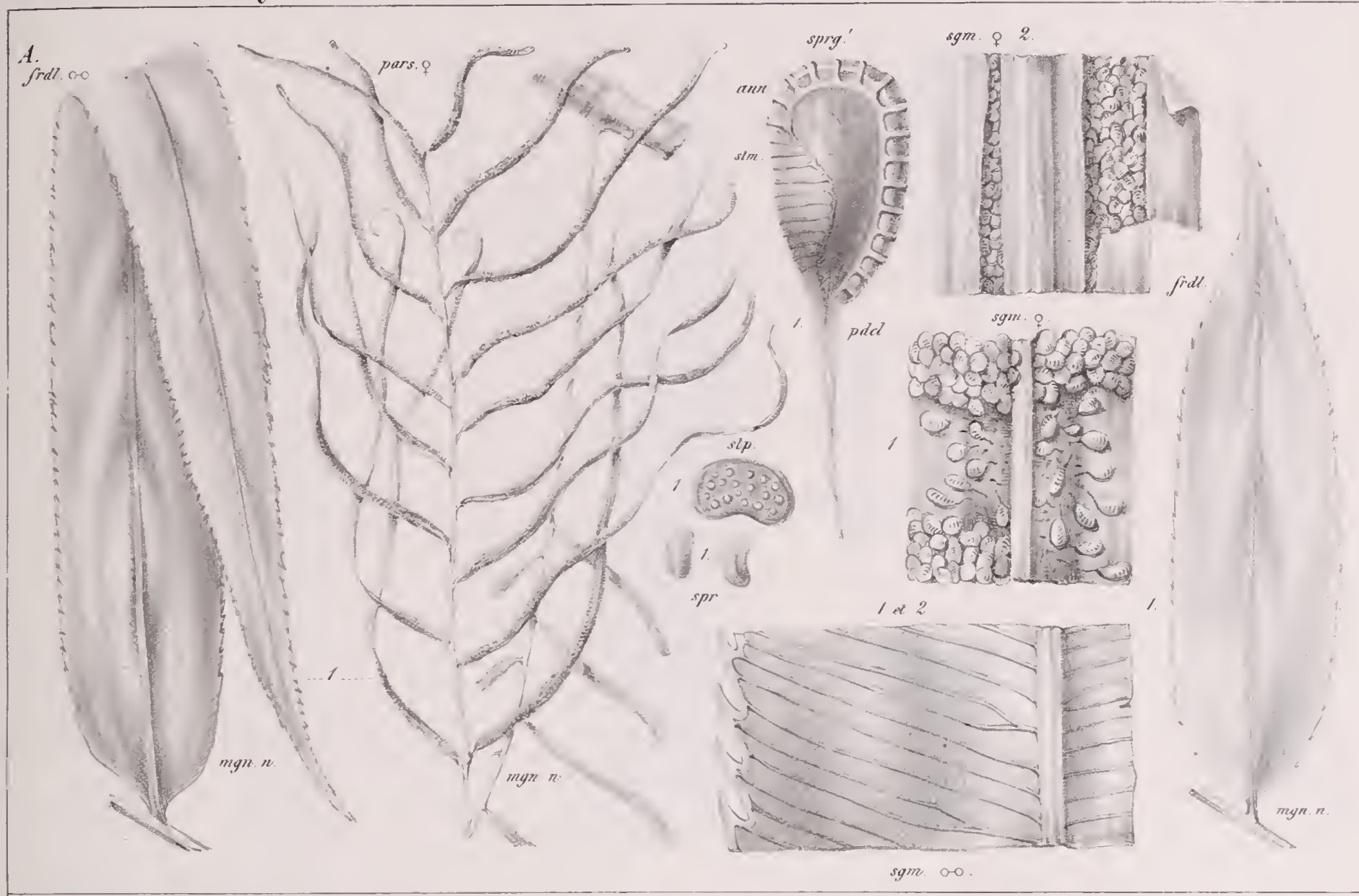

B. T, onturiea (fragmerna).

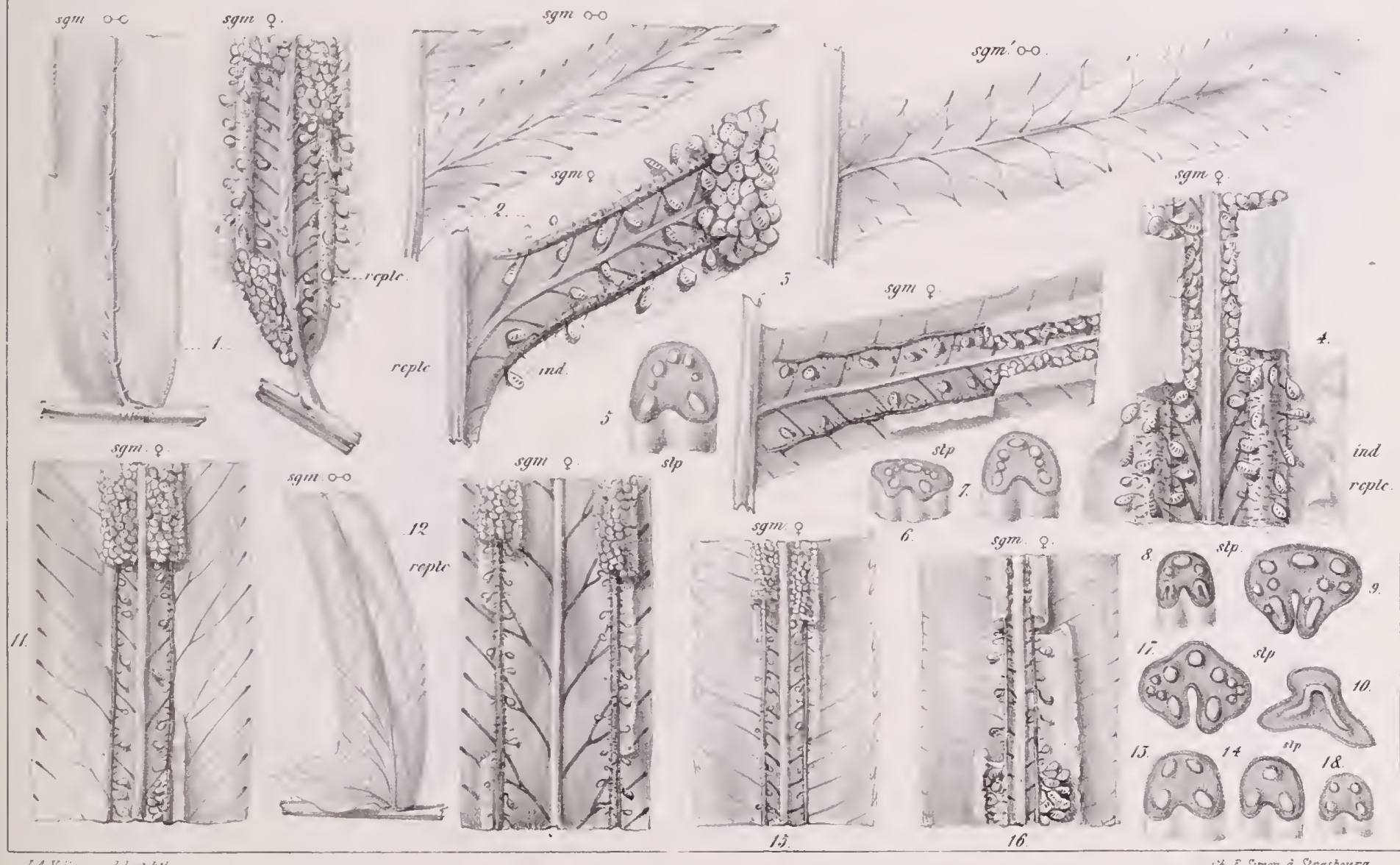

A. G. Ill. Fing Lomatriobotrys Meyeriana, $F$ :

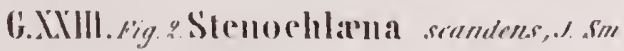

B. G.XX. Fig.ten. Lomaria (Fragm, meria)

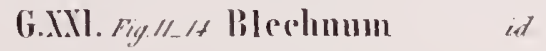

G.XIIT.ryg so Salpiehlarna 

II. L.OMARIE.X.

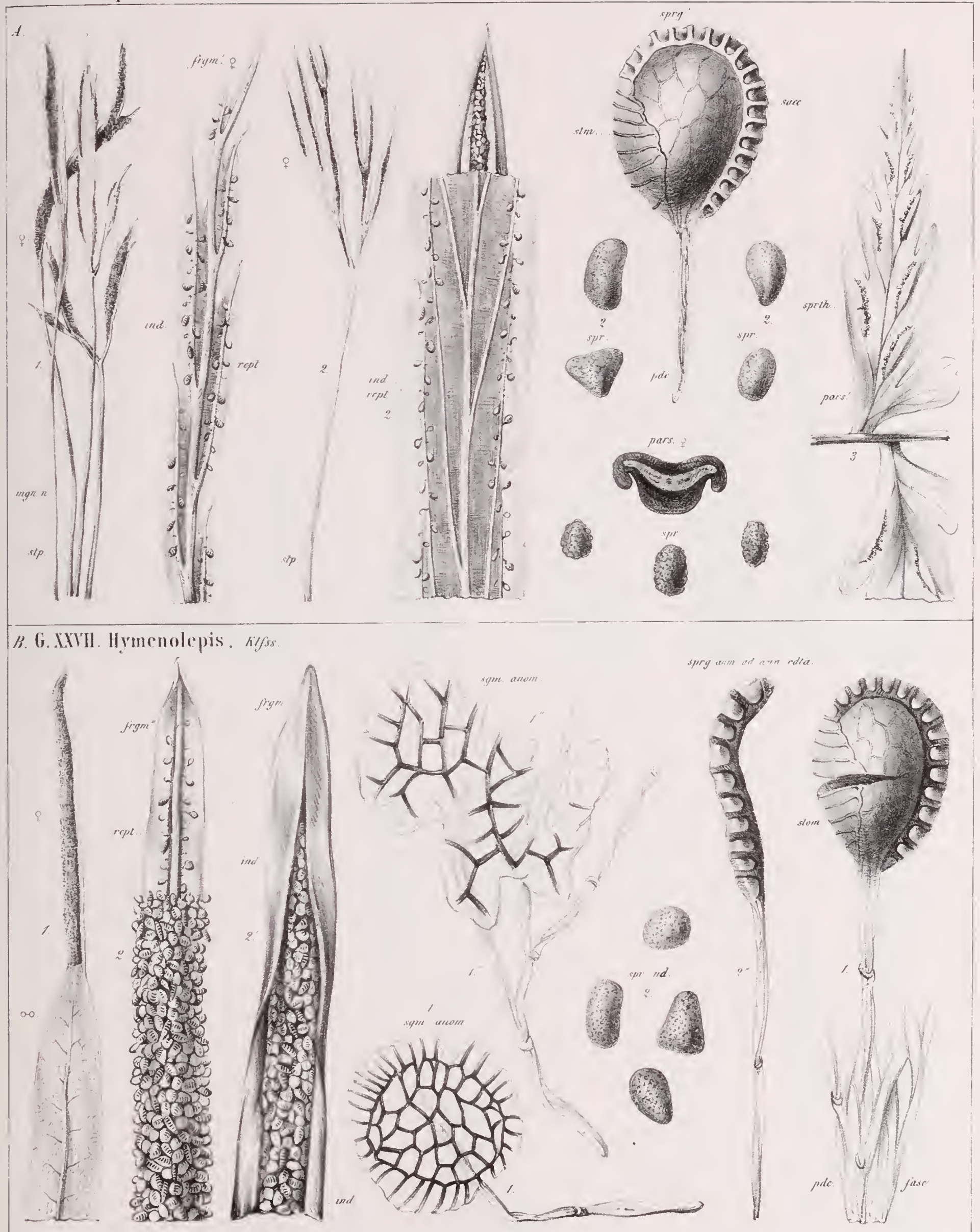

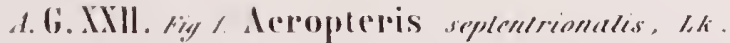

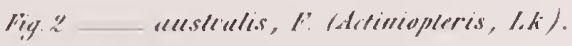

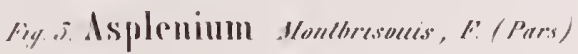

B. G. XIVII. Fig, Mrmenolepis mucronata, $F$

fig.? _ oplioglensoudes, rifss

fy. $2^{\prime}$ 



\section{IOMLRIEE. (A. H.) VII, P'TERIBFA, (C/I)}

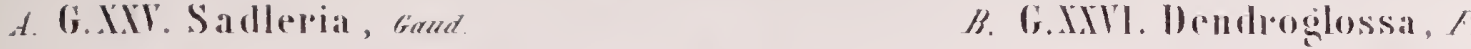

Tab. III

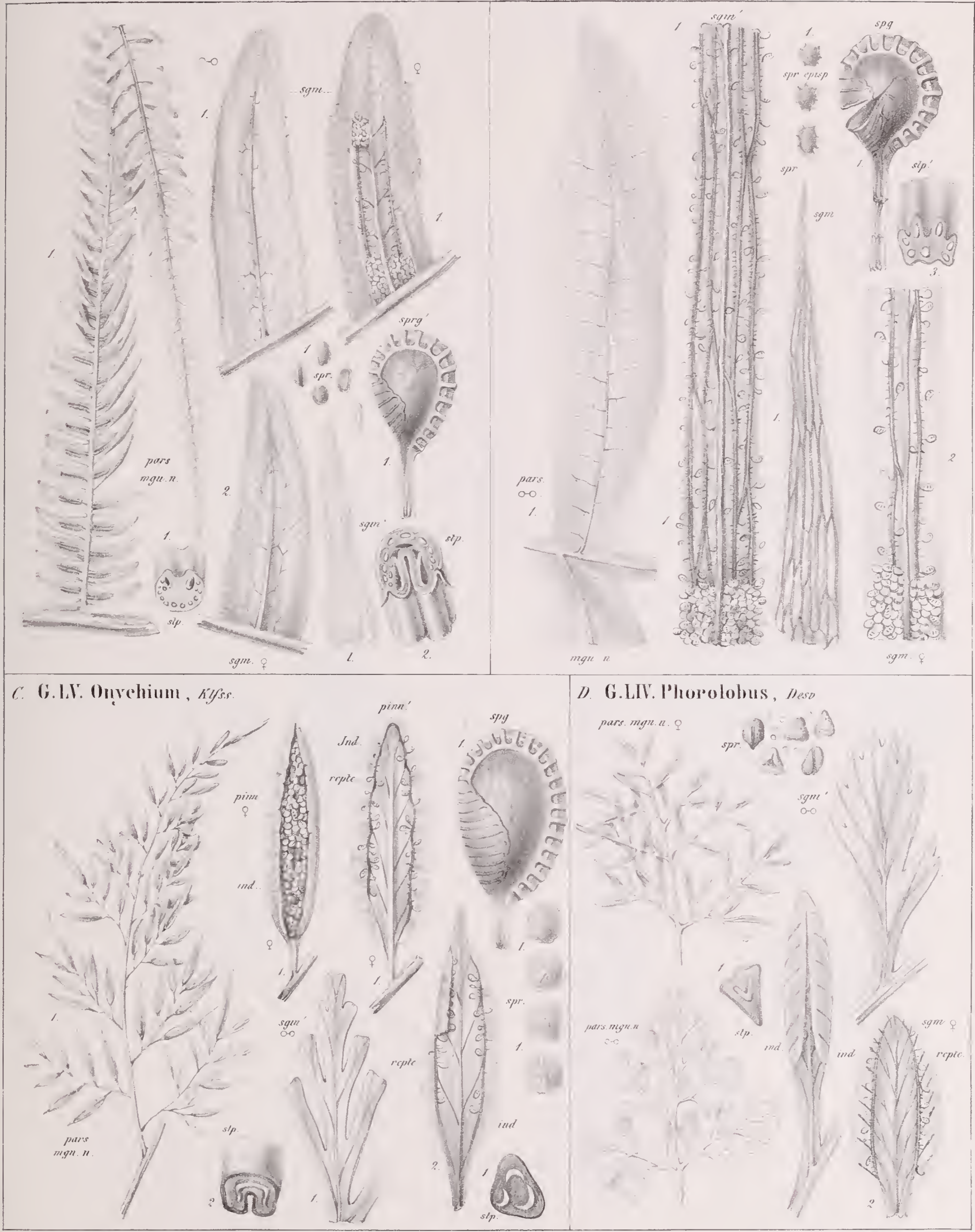

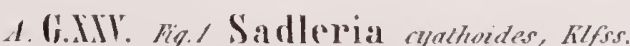

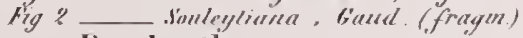

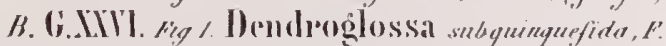
Fig ? - yuercijolitio,

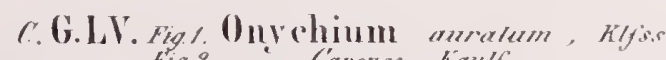

D. G.LIV. Figi, Phopolobus crispmes, Devo 



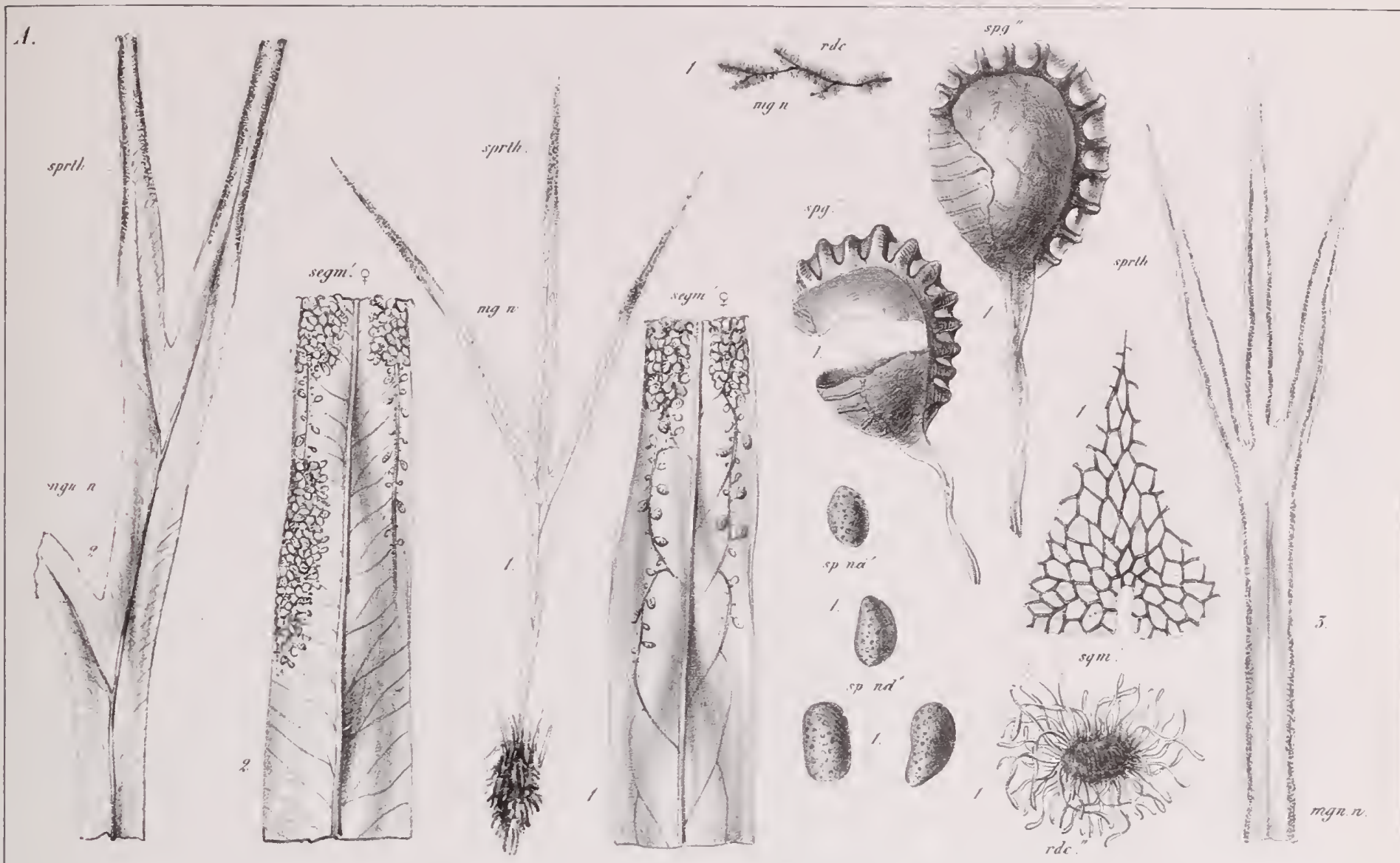

B. G. XXXIl. Silhizolepton, $f$ '.

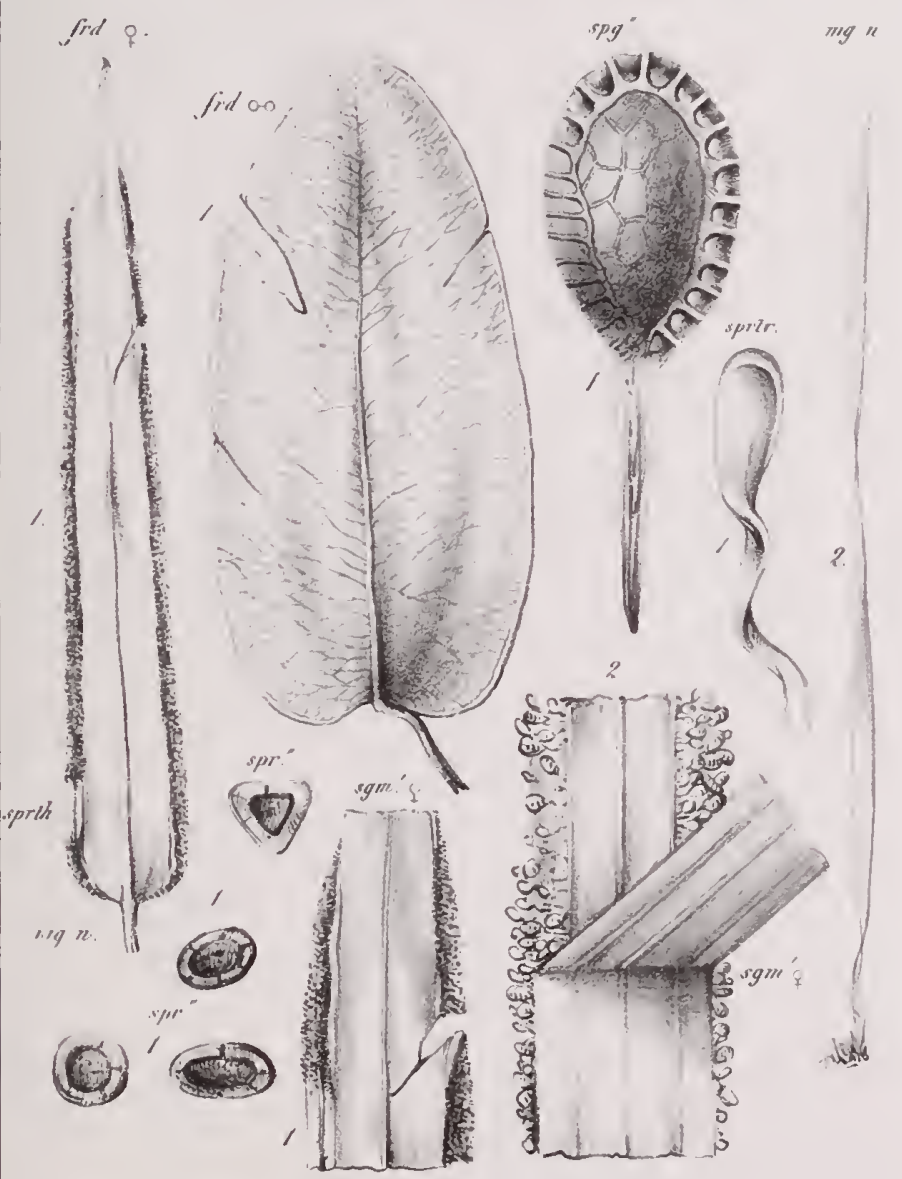

c. G. XXXYYT. Nevrodium, F

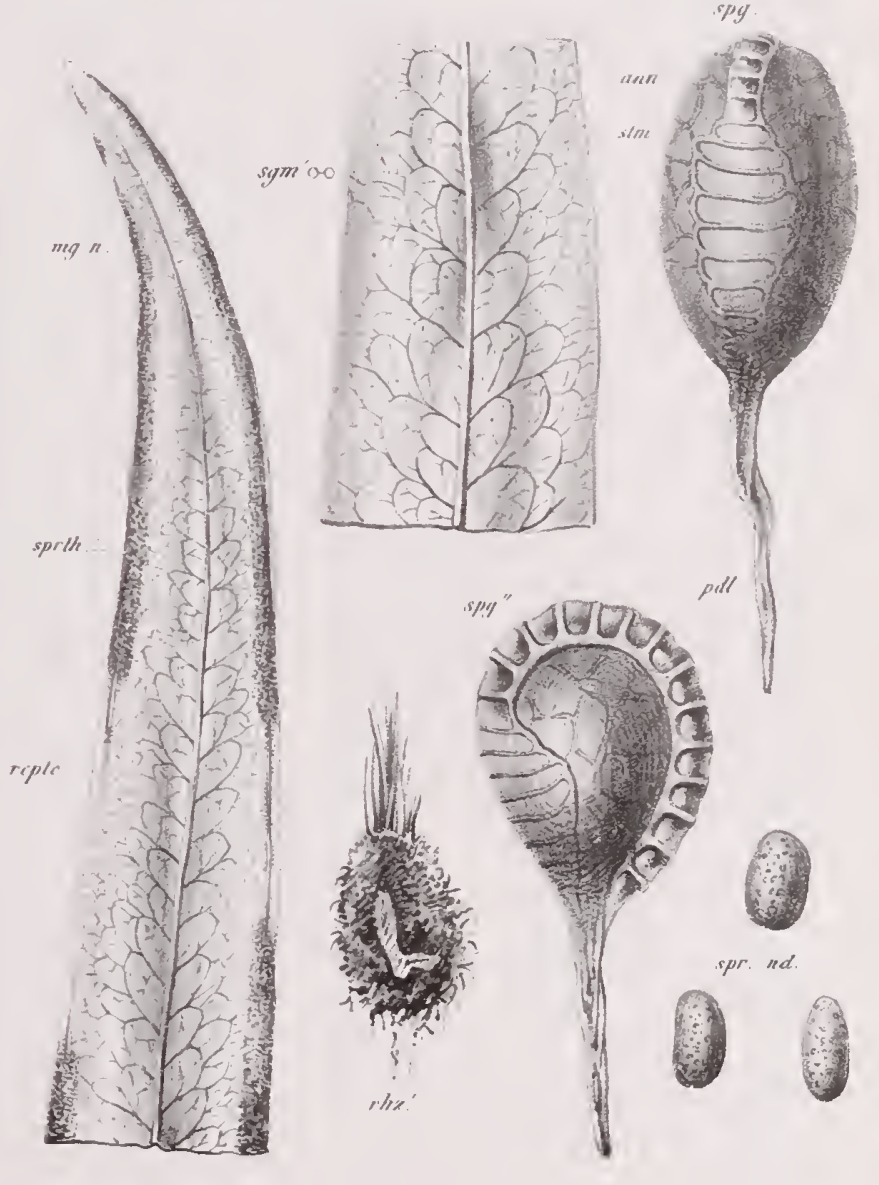

A. G. XXXI. Fug 1. C'uspidaria sutpinnutifida, $F$

Fig 21 . - furcalu, $F$ - Fig 31 . - Iricusprio, $F$

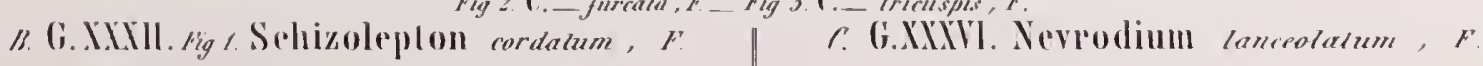

(i. VW'lll. frig 2. Villaria bisulcula, haze (fray) 

III. VITTARIEE. (A). IV. PIEUROGRAMMEL. ( B. el (l.)

6. XXXVII. Mrymoglossum, Presl.

Tab $/ X$

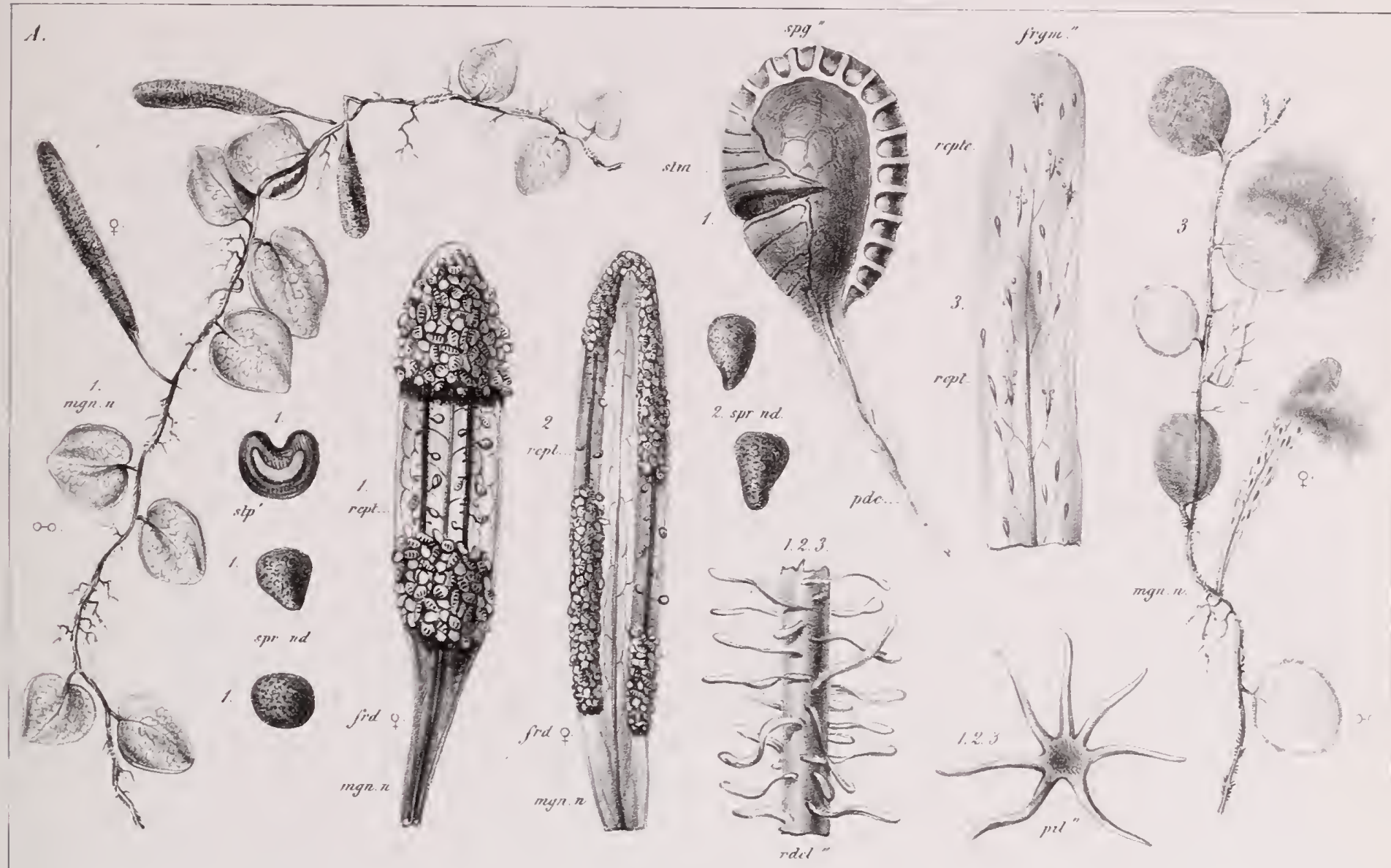

B. G. XXYYIII. Yagimularia, $F$.

1. G. MAXTK. Monogiramme,

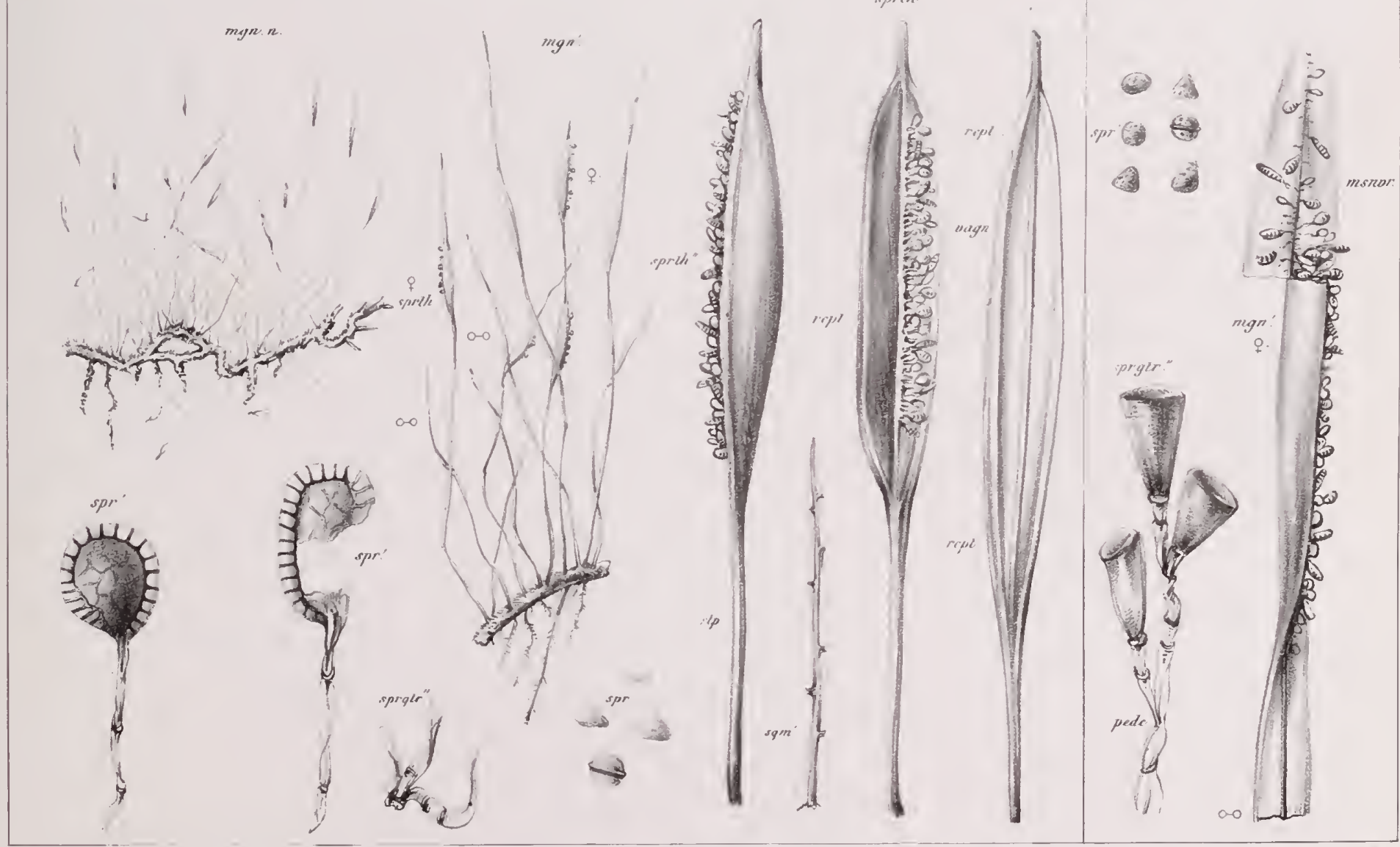

1. C. CXXYll. Fiy a Drymoglossum subcordatum, F.

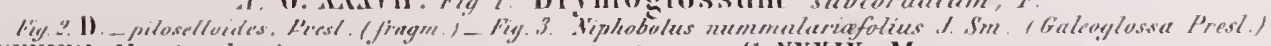

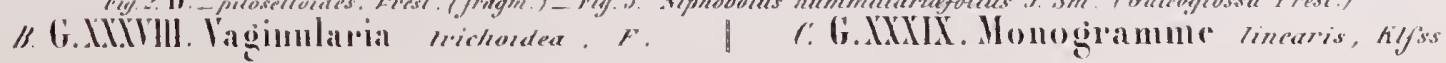





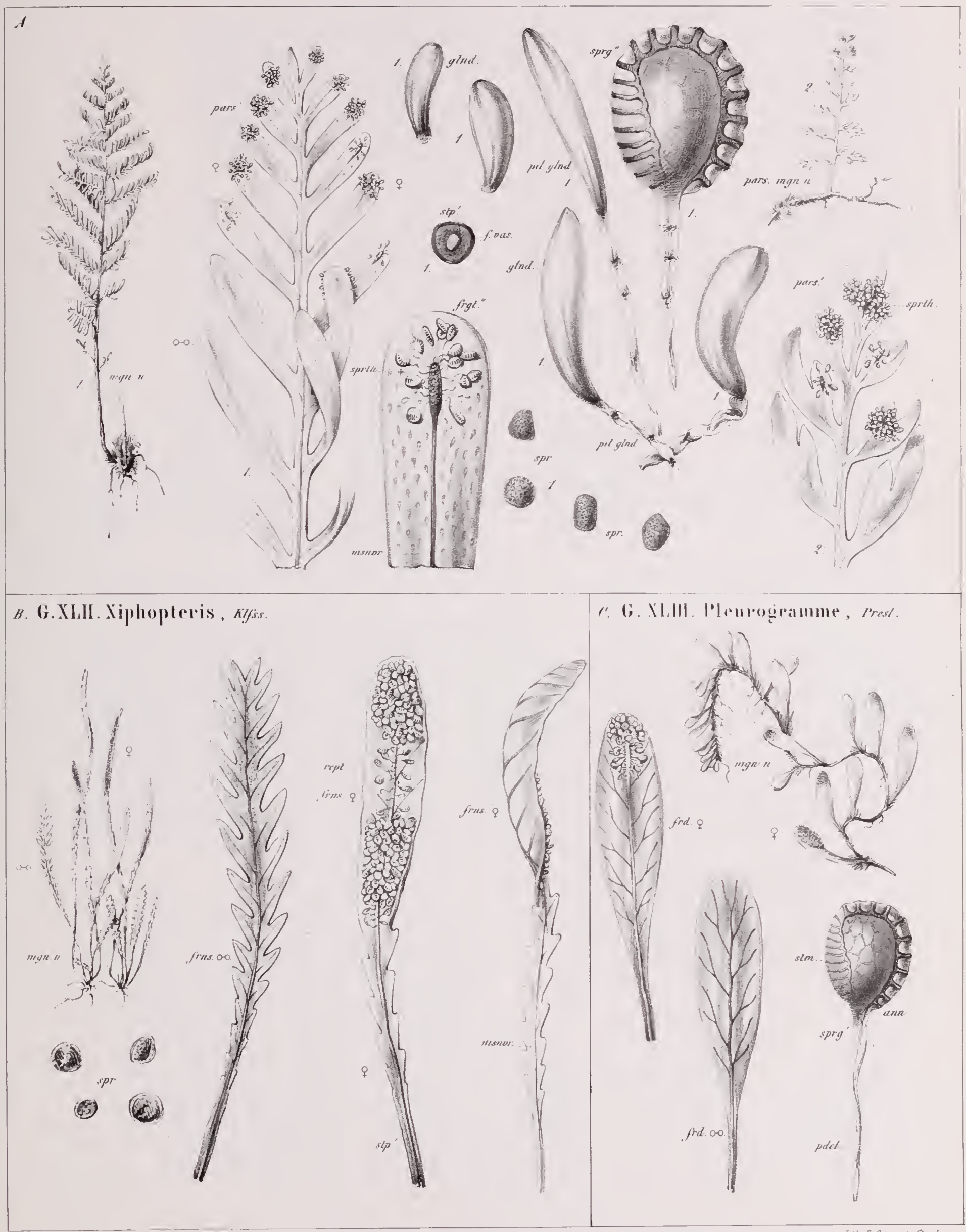

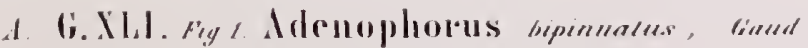
- ryg. Z loblypodium, firrlem.

b. G. Xlall. Xiphopteris 

V. IINDSAYEA, VI.ADIANTEA, VII. P'TERIDEA.

G.LII. Pterideat, (fragmenta).

(fragmenla)

Tab $\mathrm{XI}$

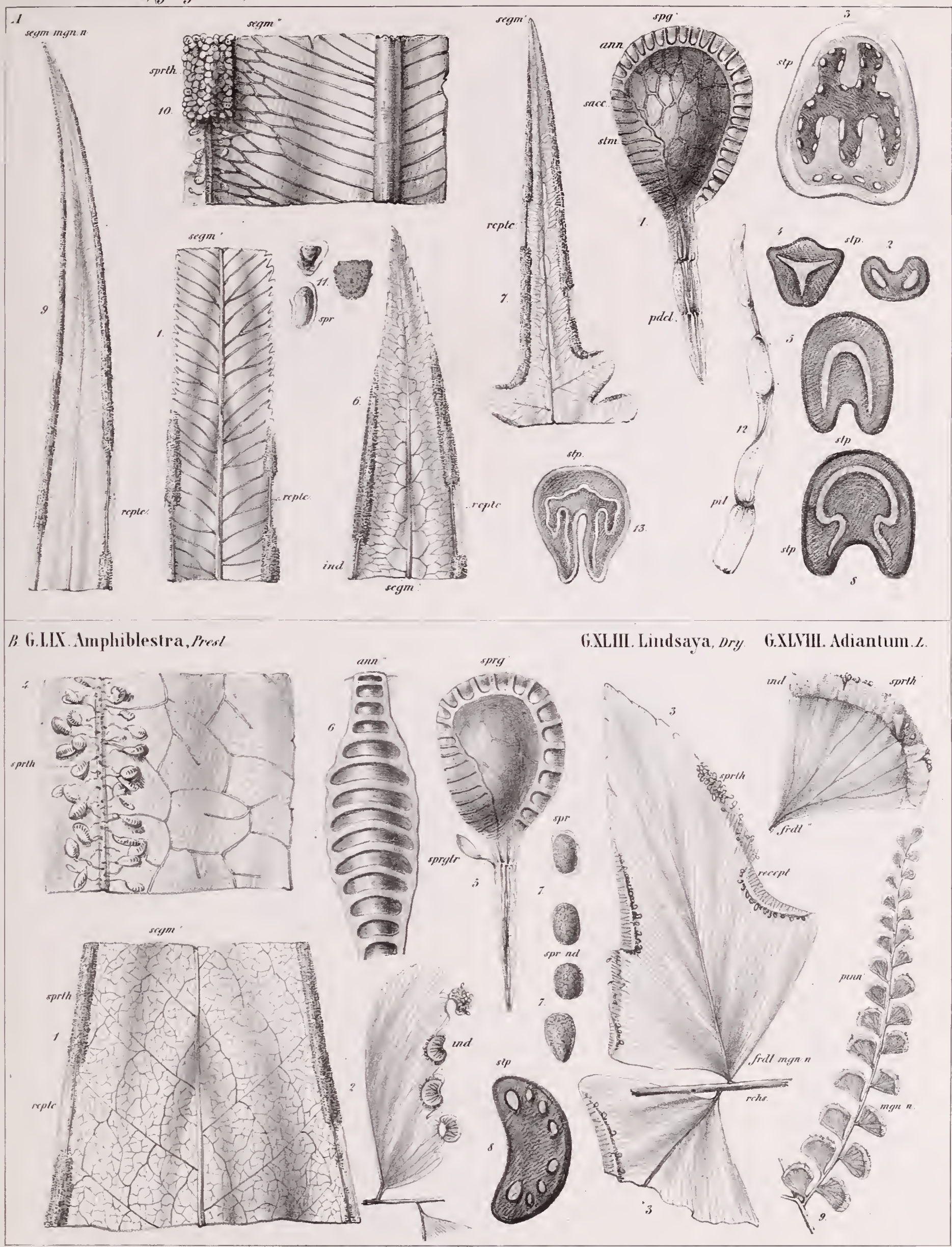

A. G.LII. Fig, 1.5. Pleris, $L$

G. LVII. Fig. 6-8. Lit obrochia , Prest.

G.LVIII. Figg r. Heterophlebium, $F$

G.LX. Fig. 13. Lonchitis, I.
B. G.LIX. Figr. \& Amphiblestra latufolia, Prest.

(j. XLIII. Fig.'senel lindsaya polymorphan. Hook

G. XLIII. Fiy ? Adiantum cardeschlenna, Kze

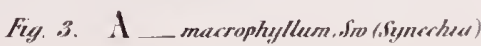



VIII. CHEILANTHEA.

G.LXIII. Mỵriopteris, $f$ :
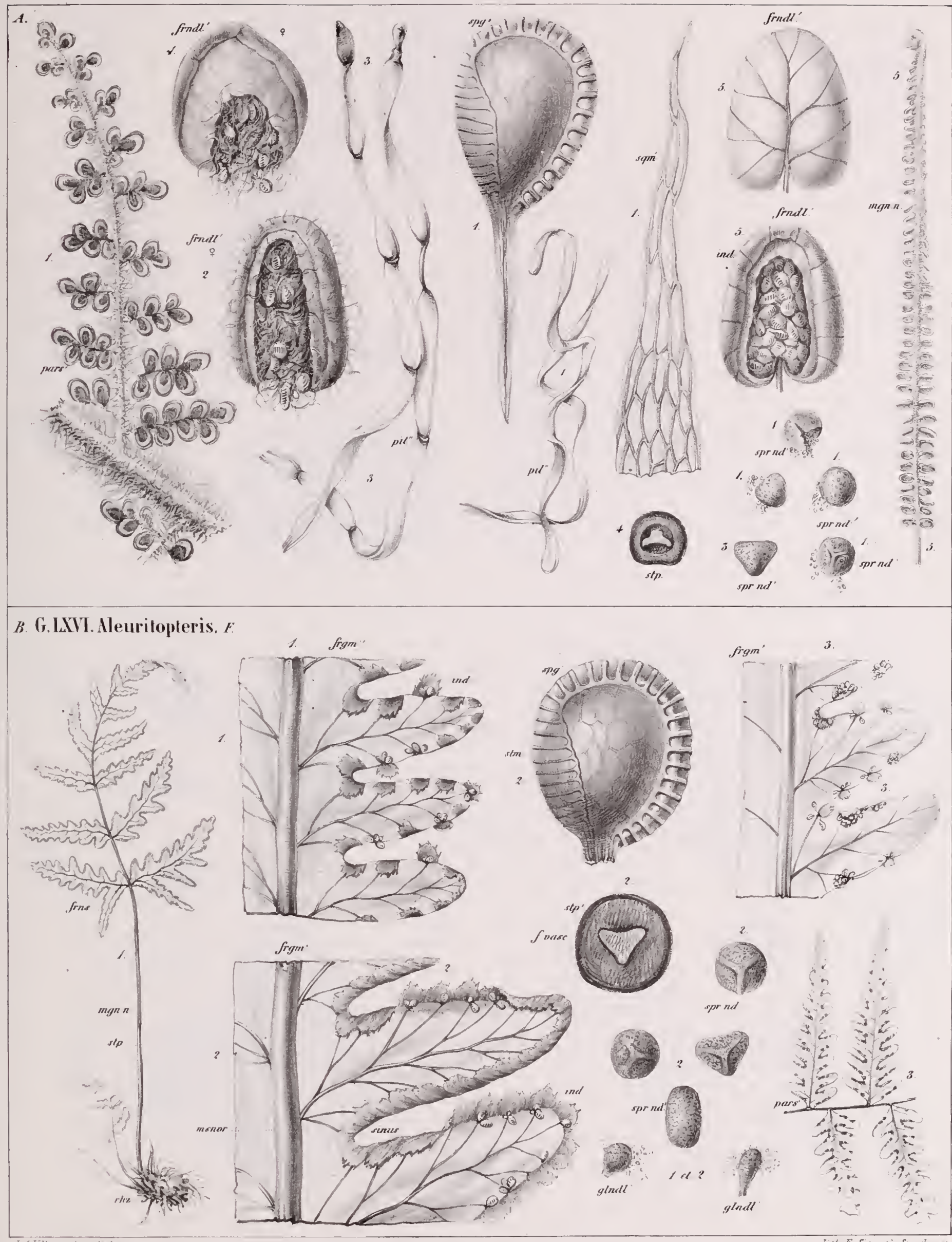

1. G. LXIII. Fig. I Myriopteris massuppanehos, $F$

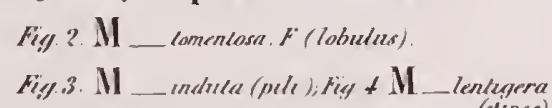

G. LXIX. Fig, j. Jamesonia scelares, hże

\section{(sipes).}

B (G.LXVL.Fig , Aleuritopleris furinasa, $F$. rig? 1 _ Acalbala $F$

G.LXII. Figz Ilypolepis repens, Presl. 

G. I.XIV. Hecosorus, $F$

VIII. CHEJLANTHEA.

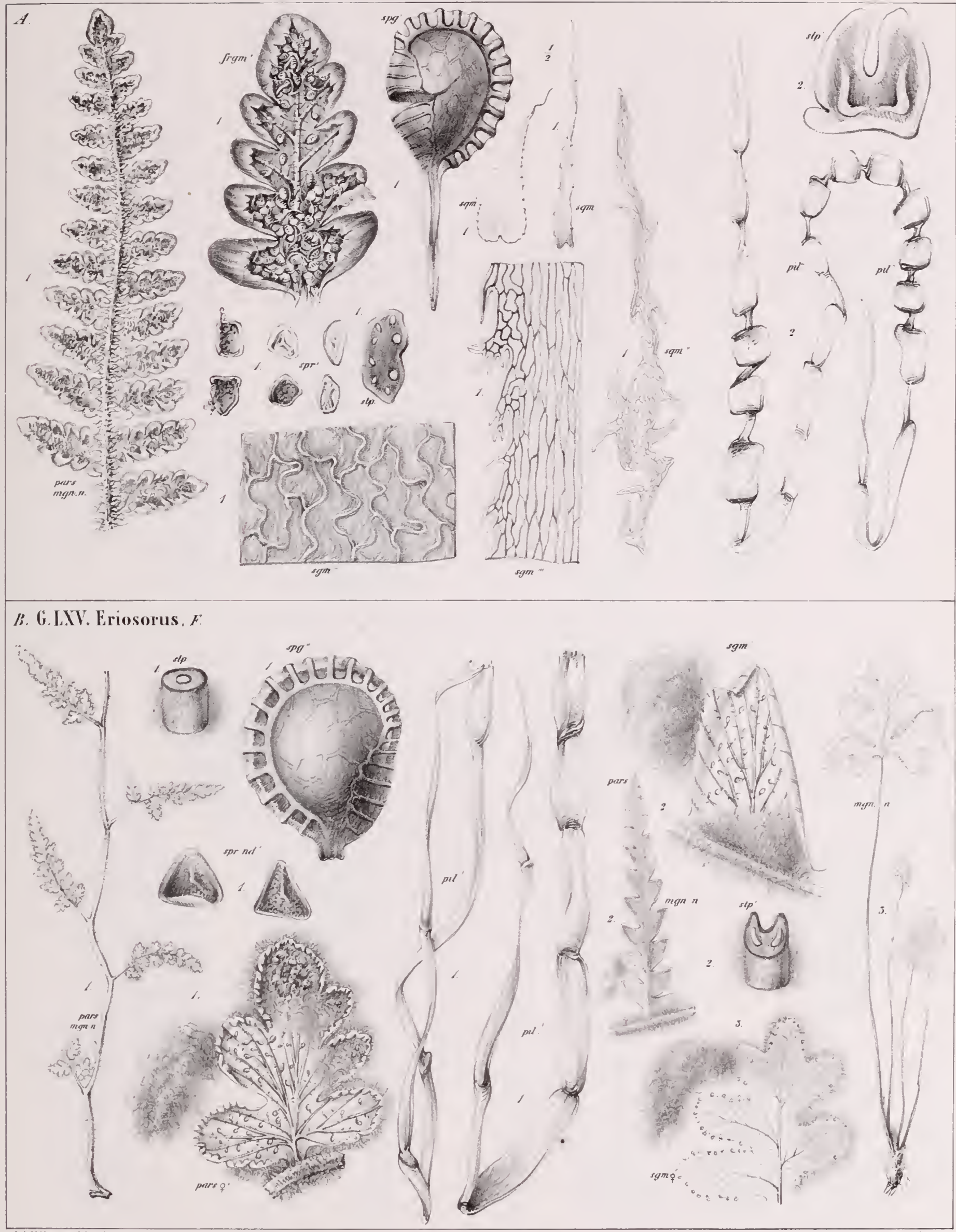

A. G.LXIV. Fig., Plecosorus Mexicanus, F. Fig. 2 P.
B. G.LXV. Fig, Finosorus scandens, $F$.

Fig? $\mathrm{E}$ Ruizianus, $F$

G.LVVIIL fig 3 Nothochlien a errophoru, $f$ 

IX. HEMIONITIILE.

G. LXX. Trismeria, $F$

G. IXXII. Coniogramme, $F$ :

Tab. $\mathrm{W} / \mathrm{l}$.

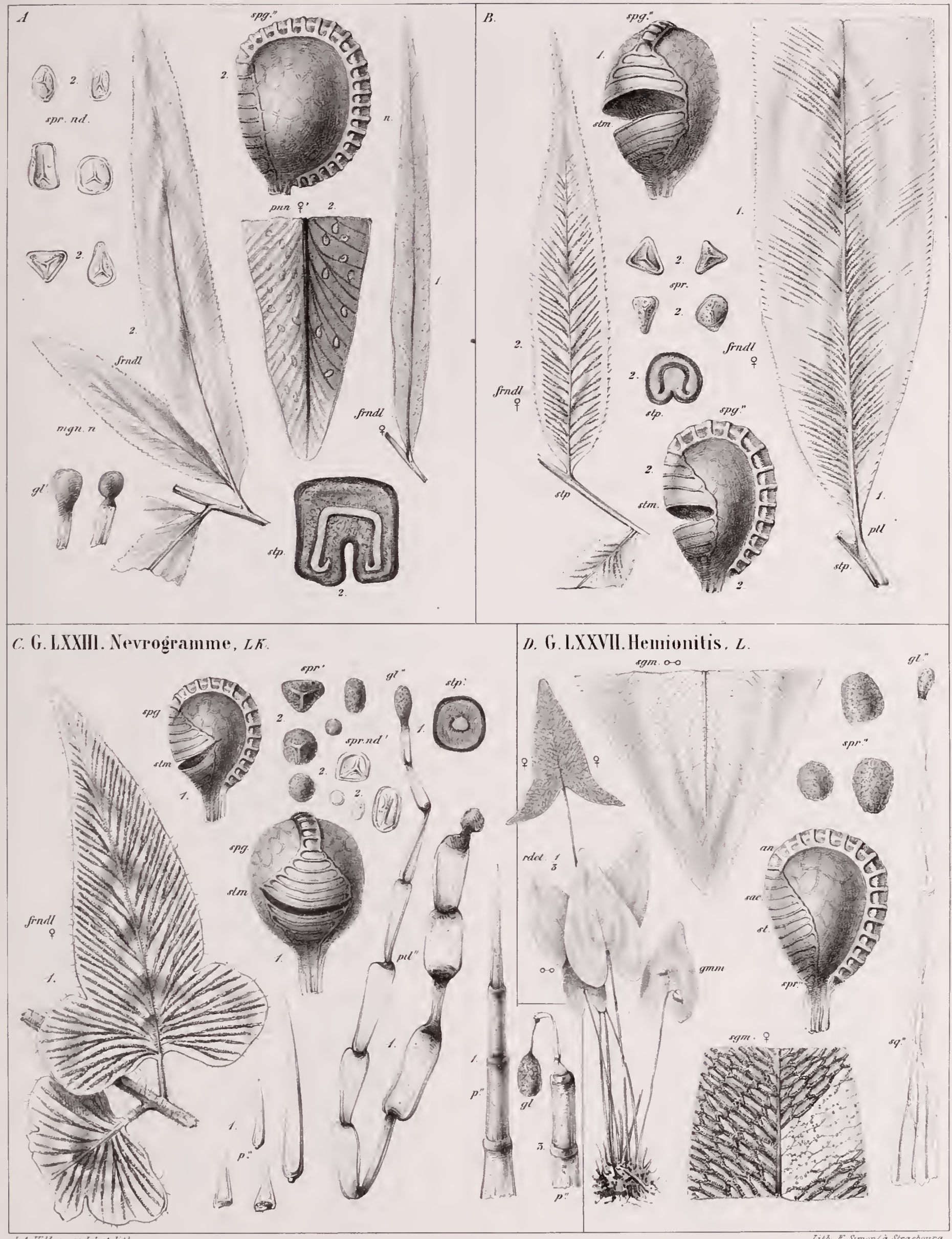

A. G.LXX. Fig. Trismeria aryentox, $\not$ T

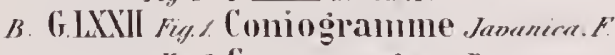
Fig. 2 C

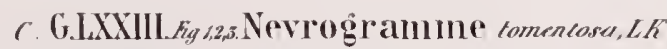

1) G.LXXTII. Hemionitis sergitenta, F. 


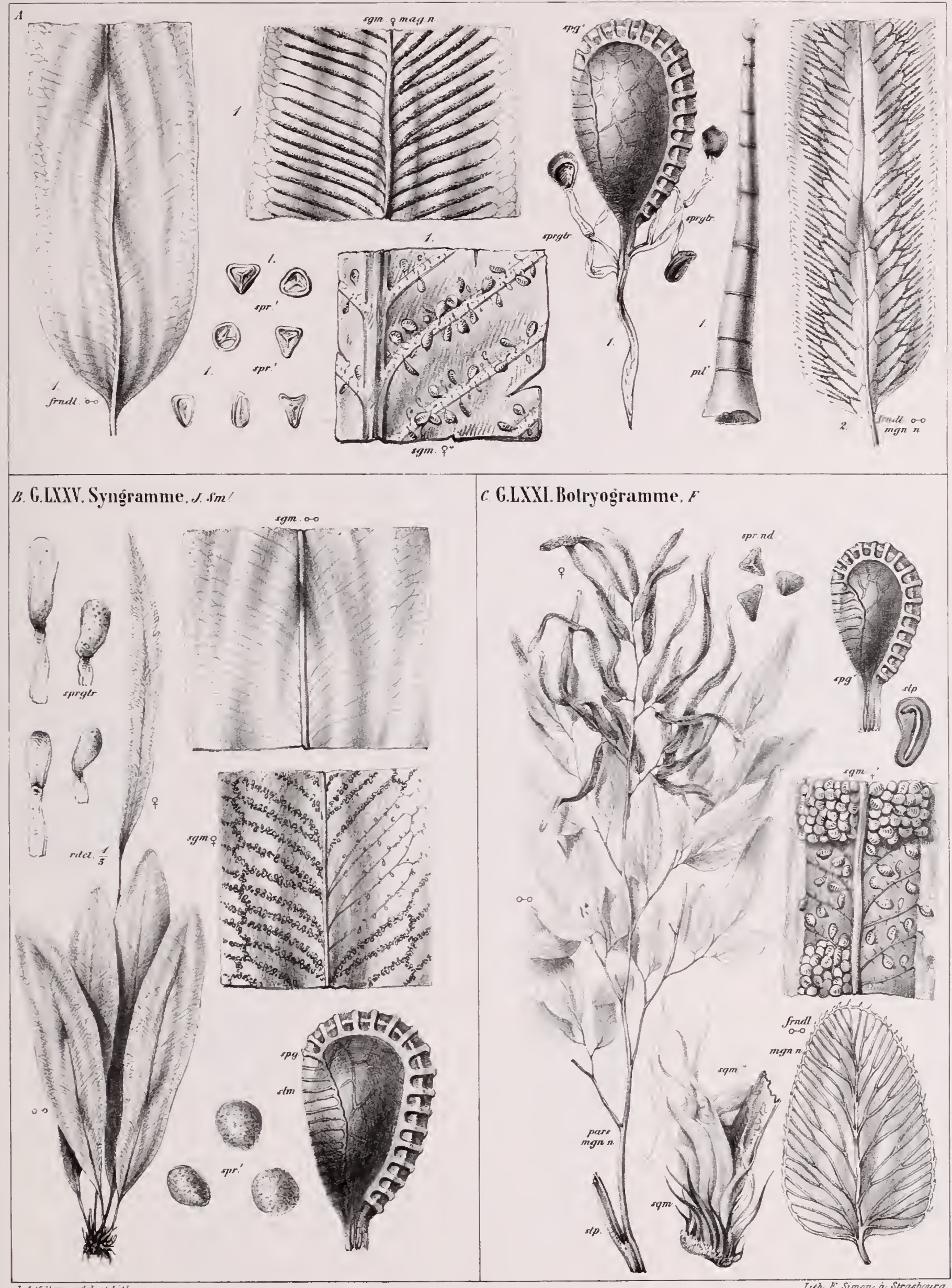

A. G. IXXIV.Fig.1. Callogramme Ceciliee, $r$.

GLLXVV.rig. 2. Diclyogramme saponisn. $F$

b. G.LXXY.Syngramme oillreformis, d. Sm

c. G. LXXI. Botryoggramme Farminsku , f 


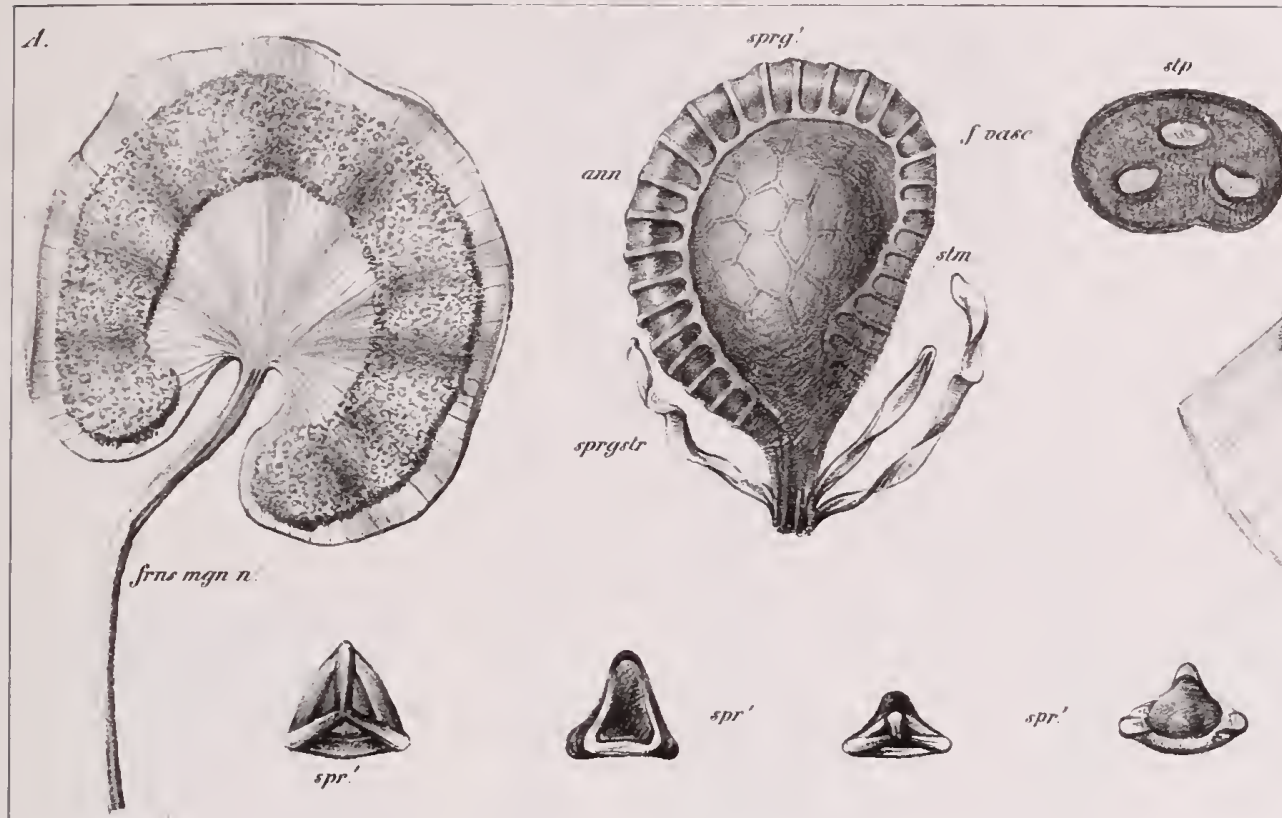

B. G. LXXXII. Hecistopteris, $J \mathrm{sm}$
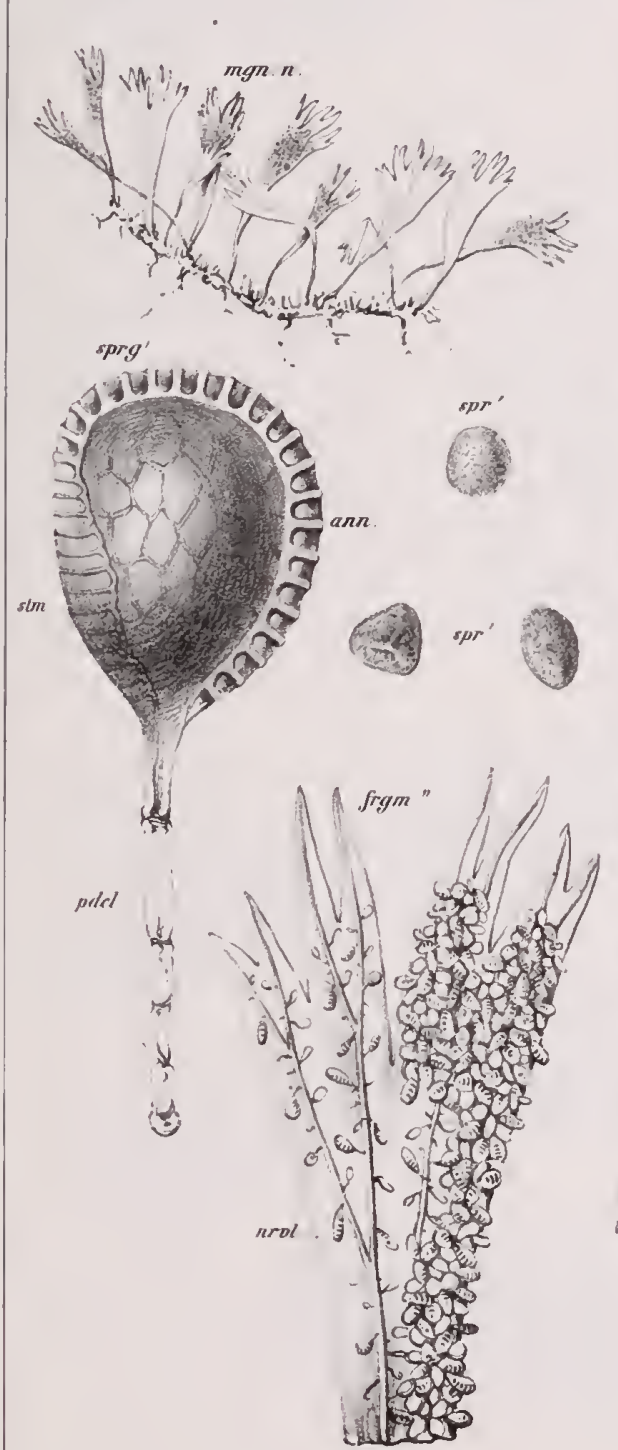

c. G.LACXIII. Plemposorus, $F$.
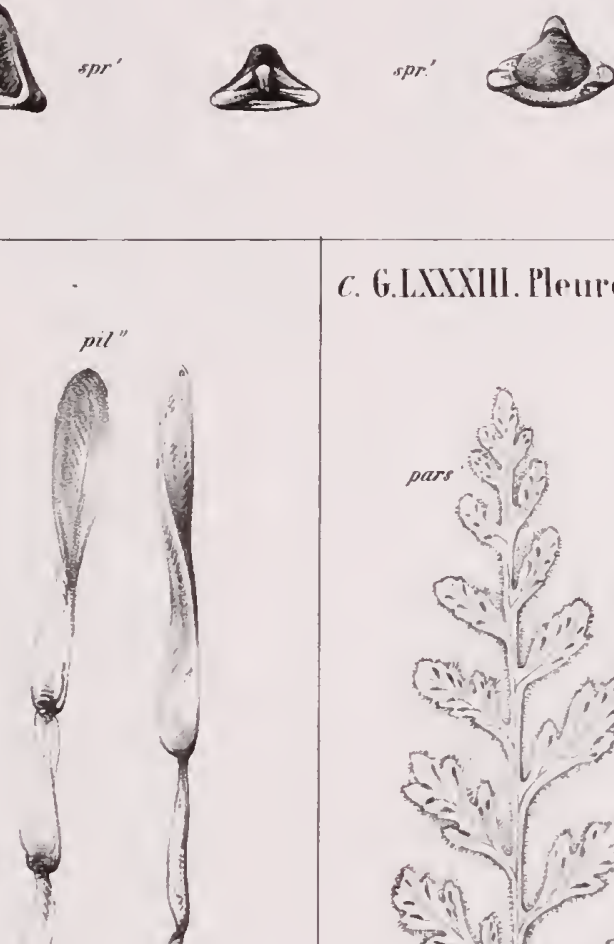
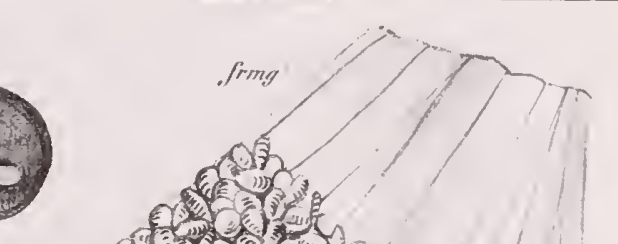

at 5 है।
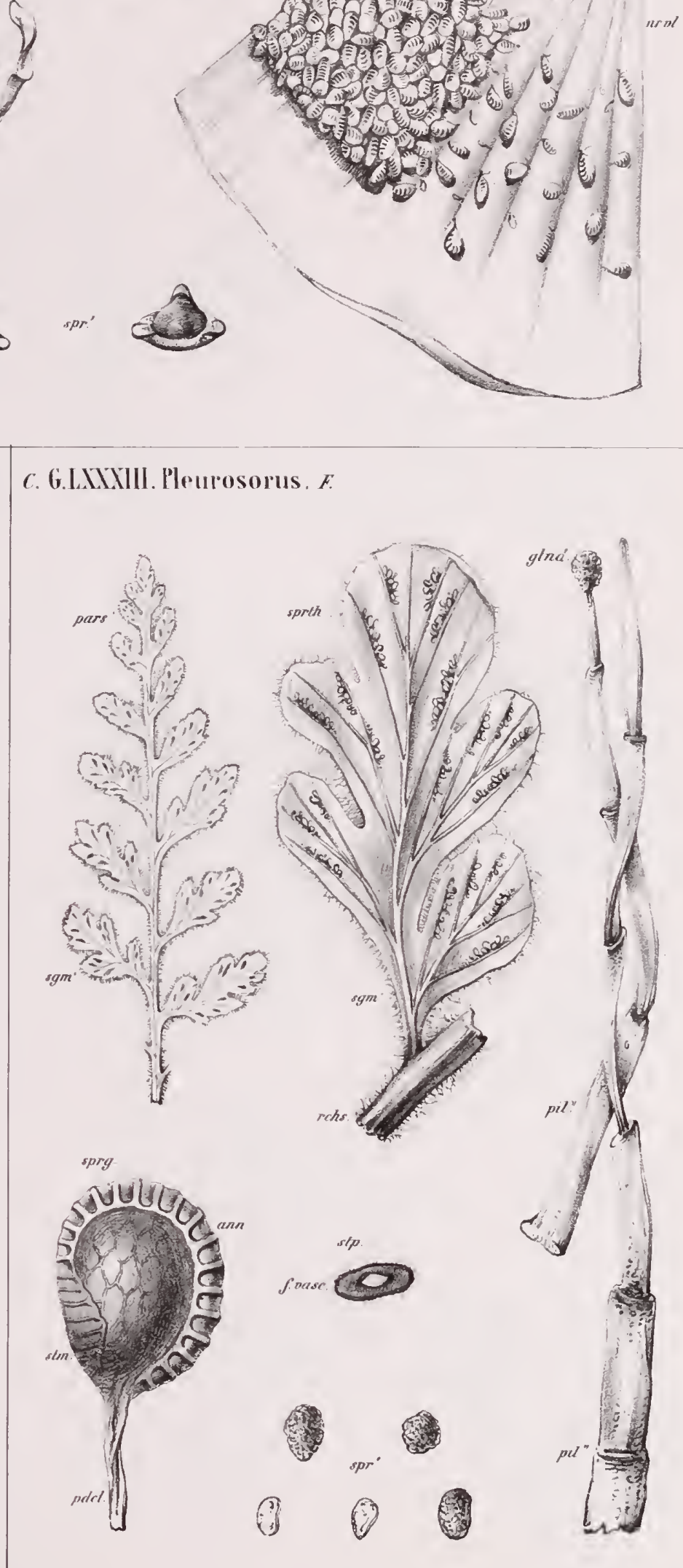

A. G. LXXXI. Pterozonium reniforme, $F$

?. G. LXXXII. Hecistopleris pumiln, e. efm

r. G. LXXXIll.Pleurosorus immersus, $F$. 


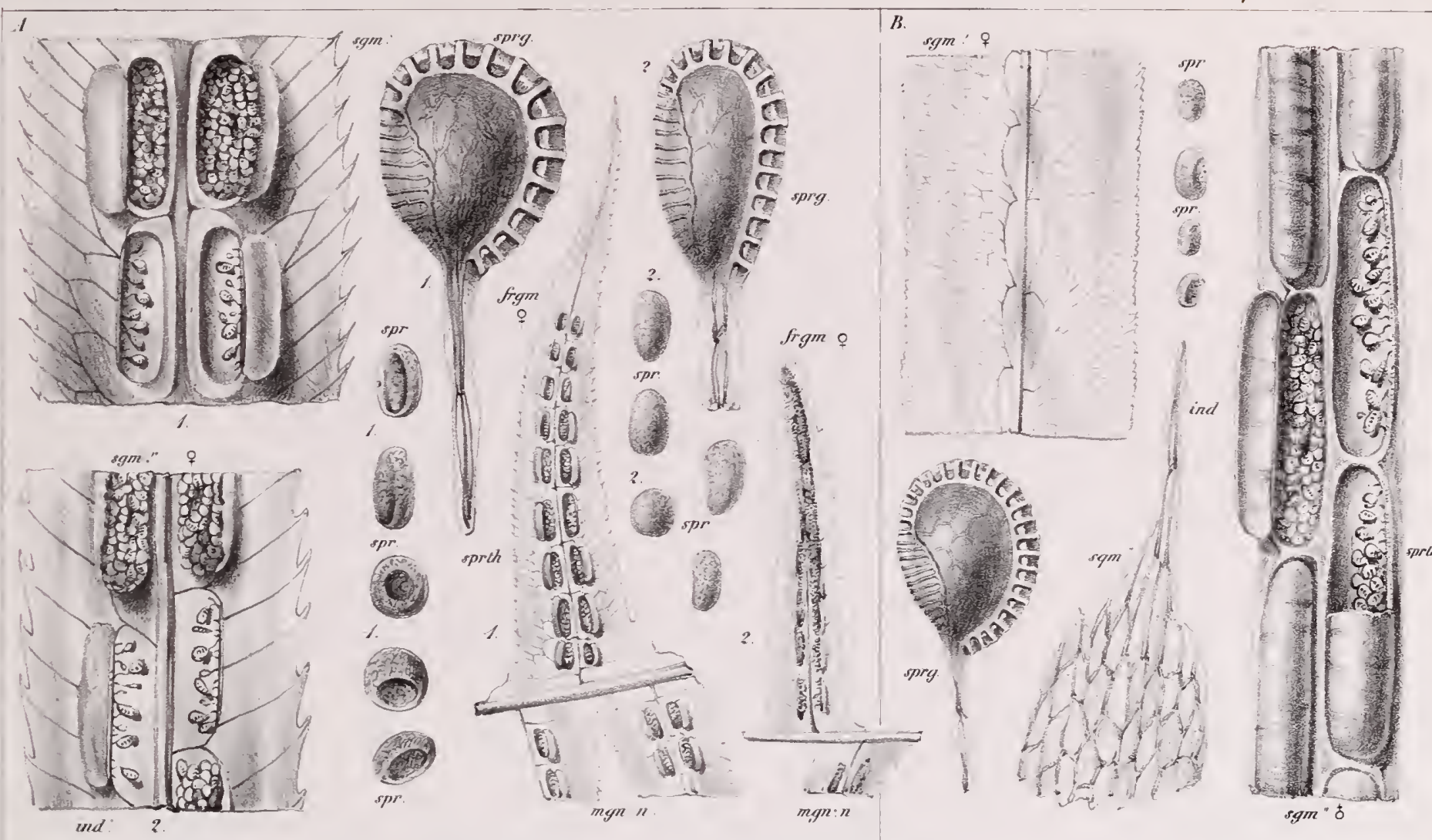

r. G. LXXXVIII. Asplenieat (ouria.
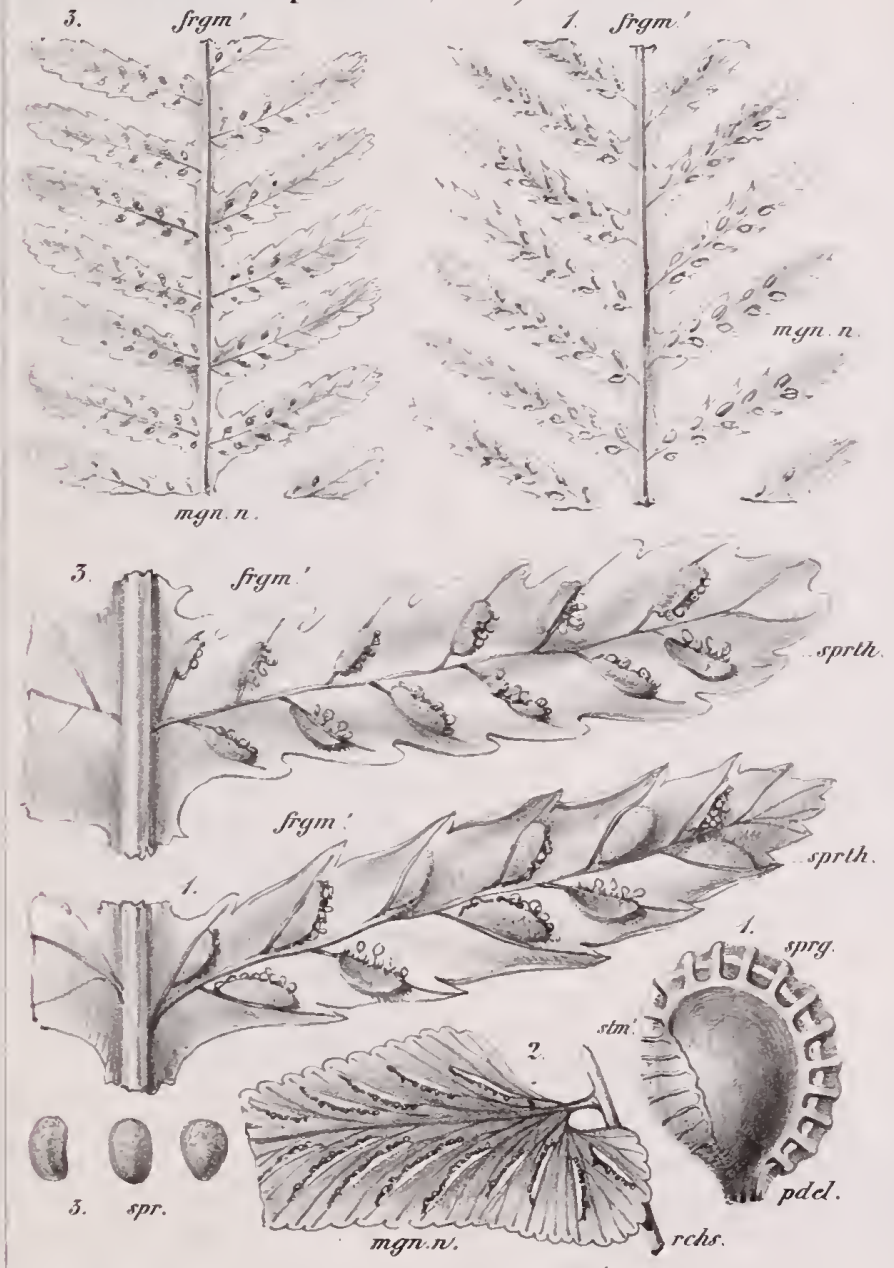

A. G.XCIV. Fig. L. Woodwardia radicans, sn Pig. 2. Innnlata, F. (Doodya).

B. G. XCl. Lorinsopia areotala, Presl.

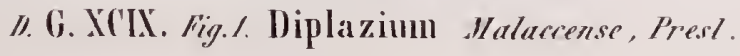

1) G.XVTT. Scolopendriea \& Diplaziea (variu) sqm
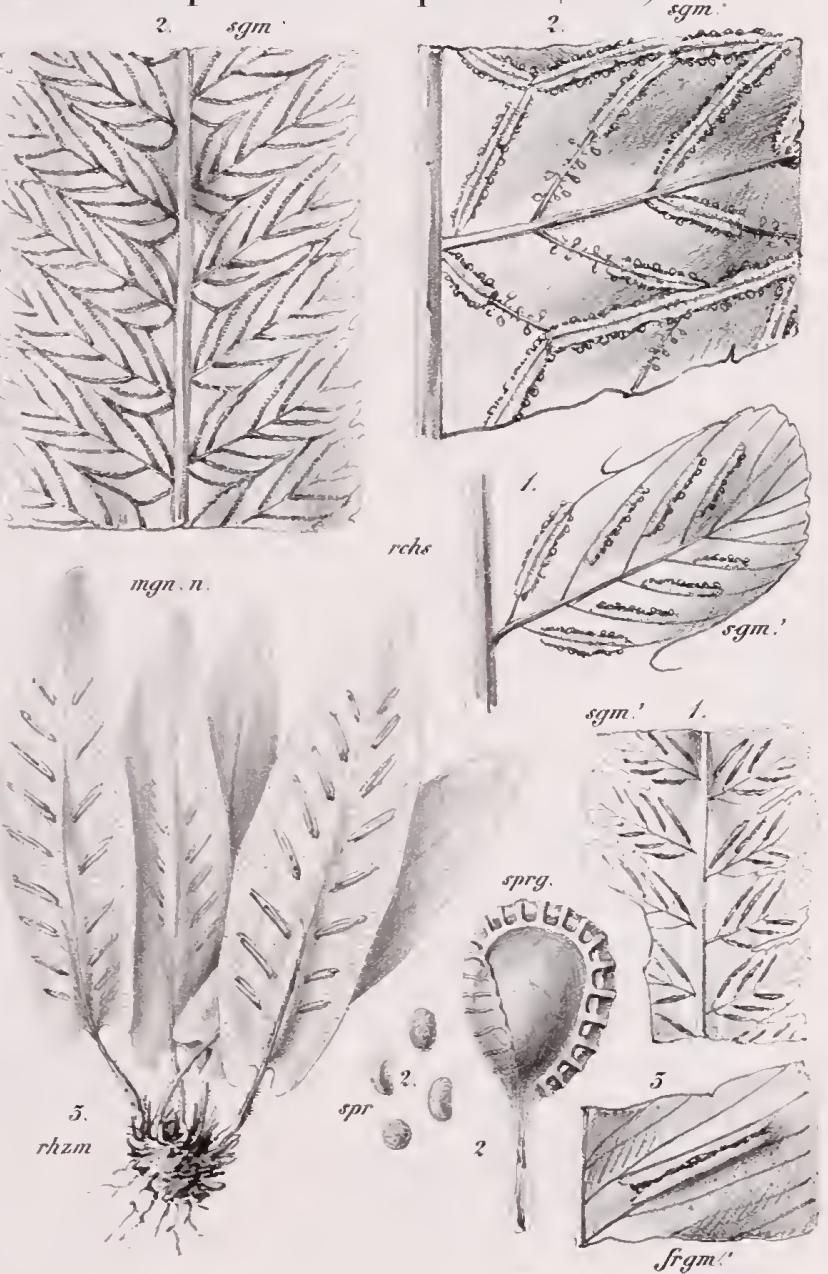

G. LXXXYII. Fig. I. Mhyrium conchalmm, $P$

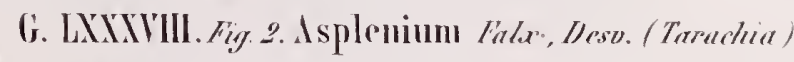

G. LXXXIX. Fig.j. Ilypochlamys pectimete, fro 



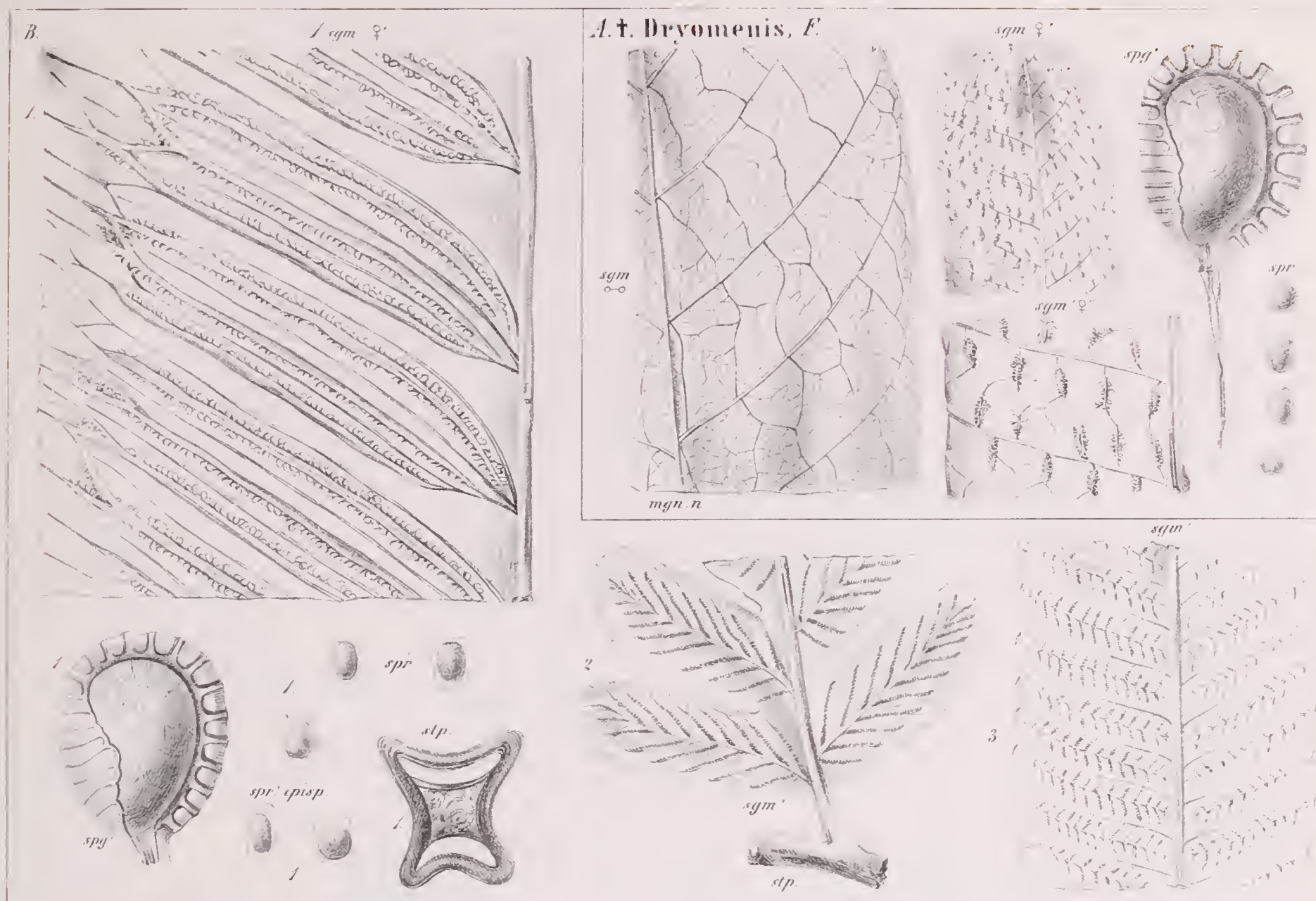

c. f. CXLI . Abacopteris, $F$.
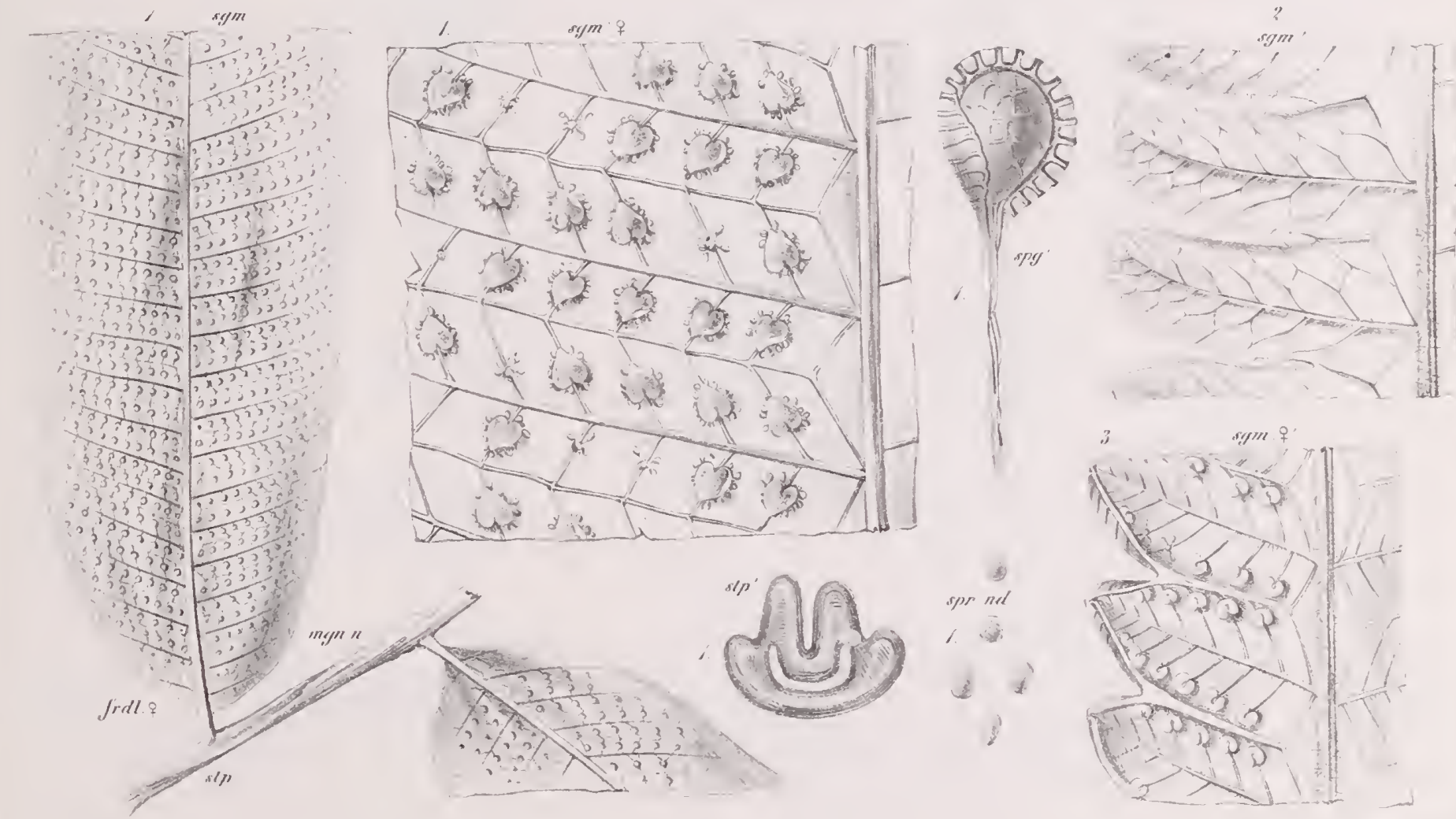

1 t Iryomenis mymatoder,

B. G. CIII. Fiy, Pteriglyphis seynns. Friy? Digrremmariet robustel Fe figy 3 menescresn rostsulum, F ad comparasudurn)
C. G. CXIII Fig Abacopteris Phetrppenurume

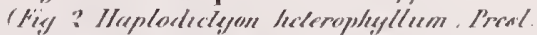
ef Fig. 3 . Itphereluem Iruconceron, $F$ ad comparenelum ) 

XI.LEPTOGRAMME丸. XVII. POLYPOIEIE.

f. LXXXVI. Anoggramme, $L K$ :

Fab. $1 / X$

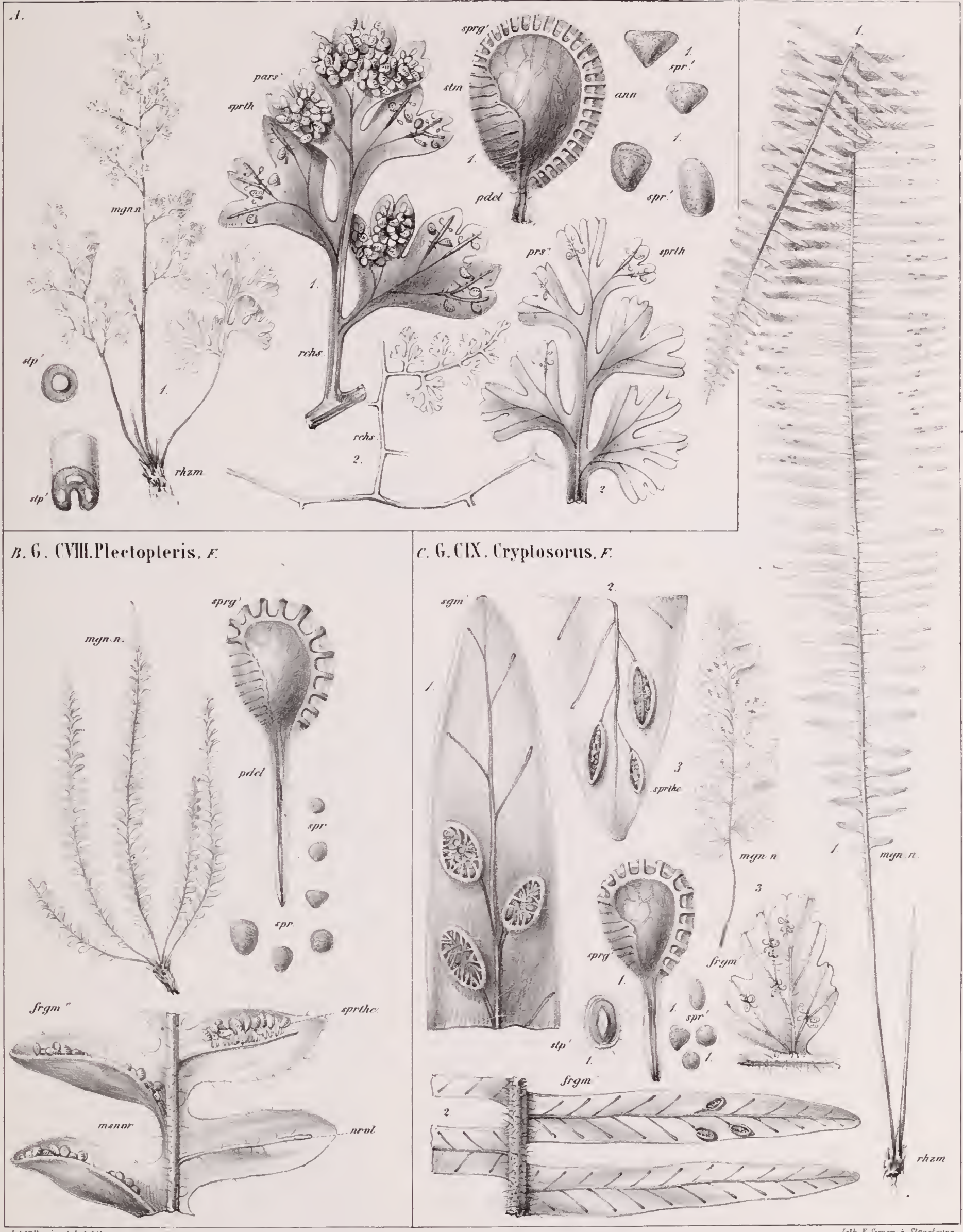

1. G. LXXXVI. Fig., Anogiramme leptophylla, I, Ir. Fig. 2. A refracke, $F$ B. G. CVIII. Plectopteris gracilis, $F$. a. G. CIX. Fig /. ('ryplosorus Dionar, F' Fig? C C elasticus, $P$.

C. G. LXXXIV. Fig. 3. Gymmogiranime rufescens, $F^{\prime}$ 

XVII. POLYPODIEA.

G. CXII. Phegopteris, $F$

Tib.TY.

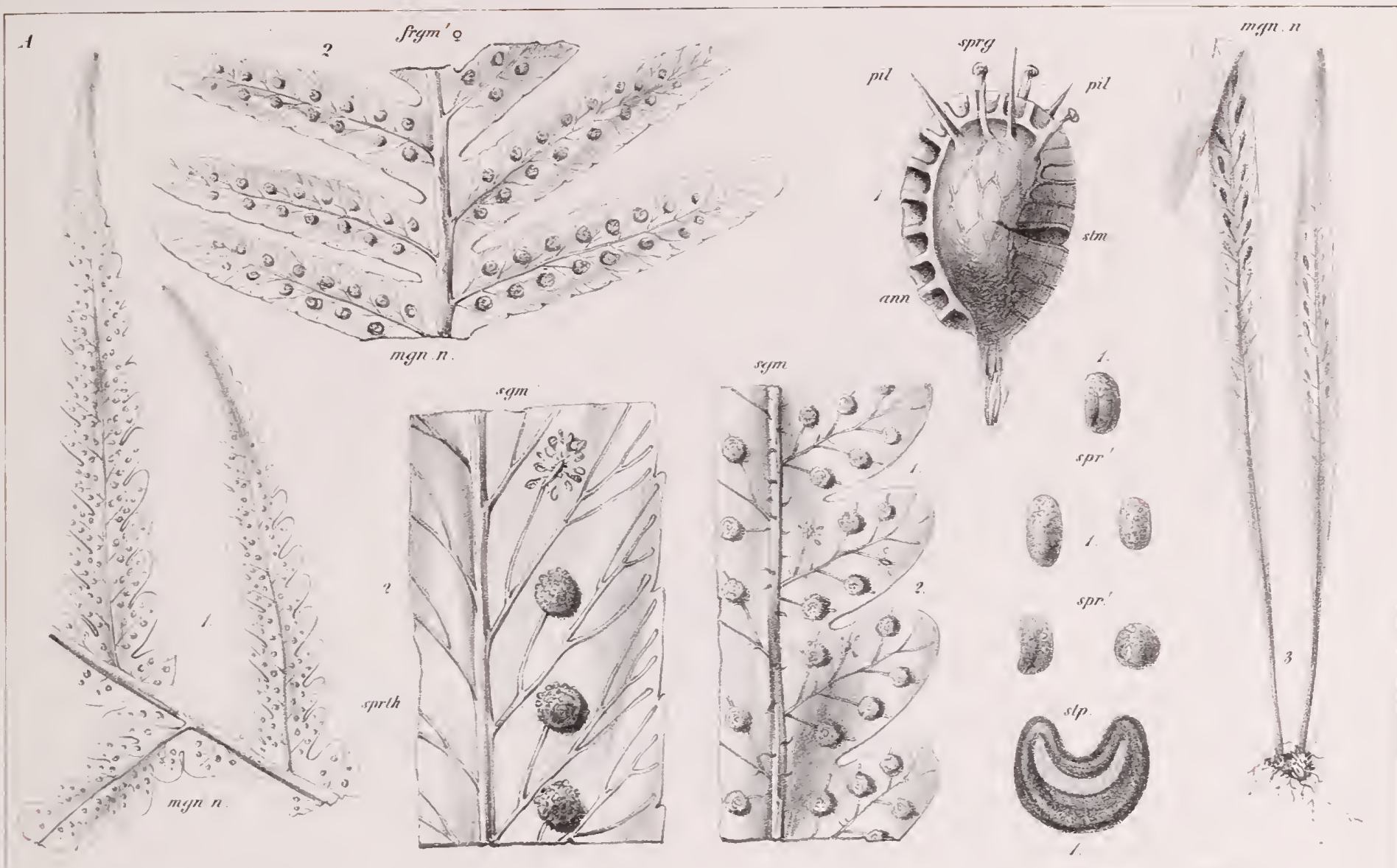

G.CXYIL.Microsorium, $L K$
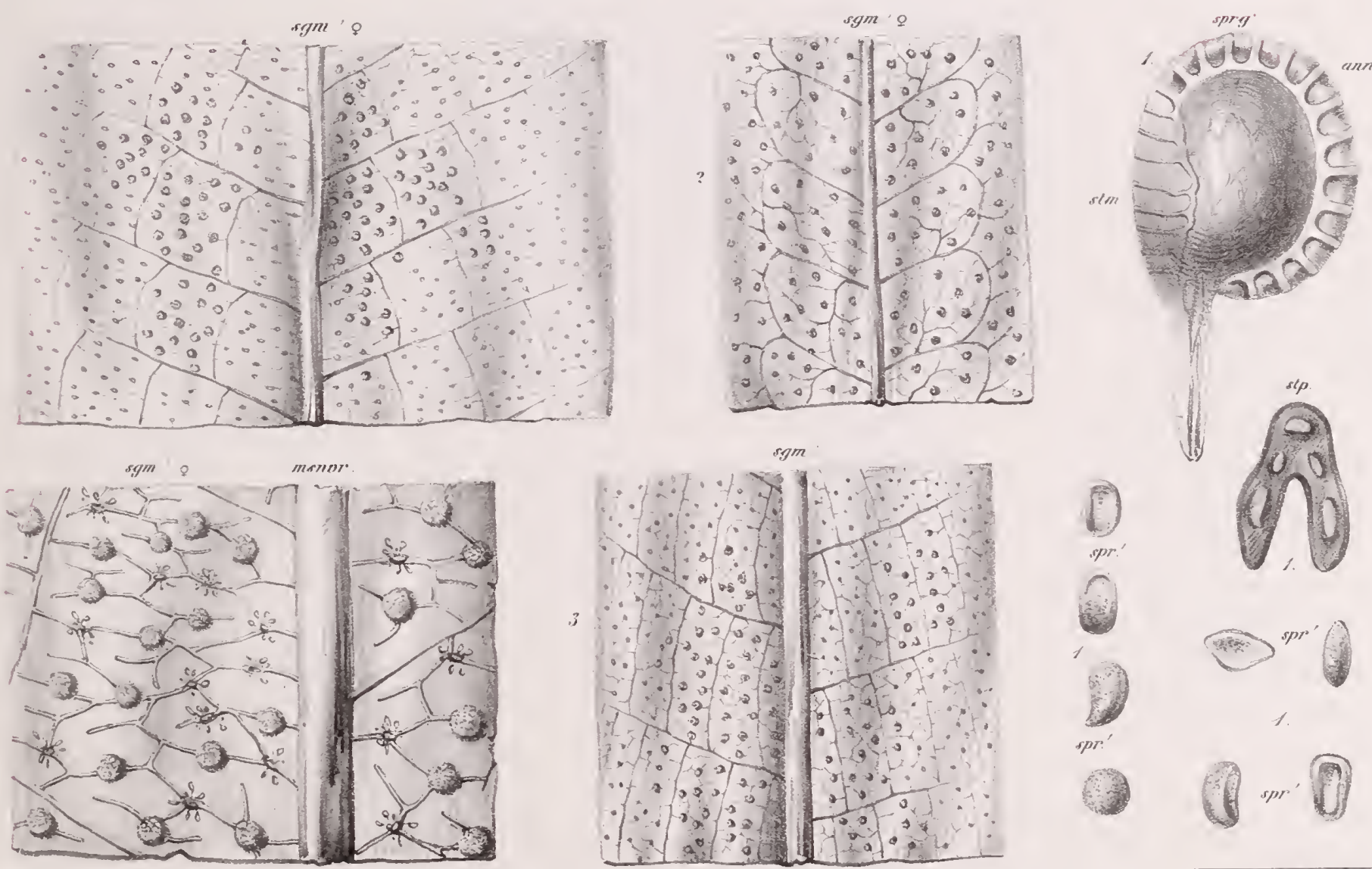

i)

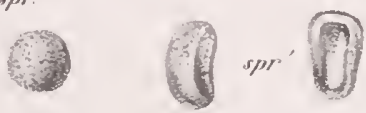

A. G.CXII.Fig. Phe gopteris decursine pinnara, G.CXI.fig.? Polypodium stustrale:

G.CX. Fig.s. Grammitis Magellanica. JesD
B. G.CXXIL. rig. 1. Mirposorium arudendes. $f$

Hig.?. M

Fig. 3. II
Longisirimum . F

irreguluer $L h$ 

XVII. POLYPODIEA.

G. CXXI. I)ictyopteris, Presl

Tab XIT

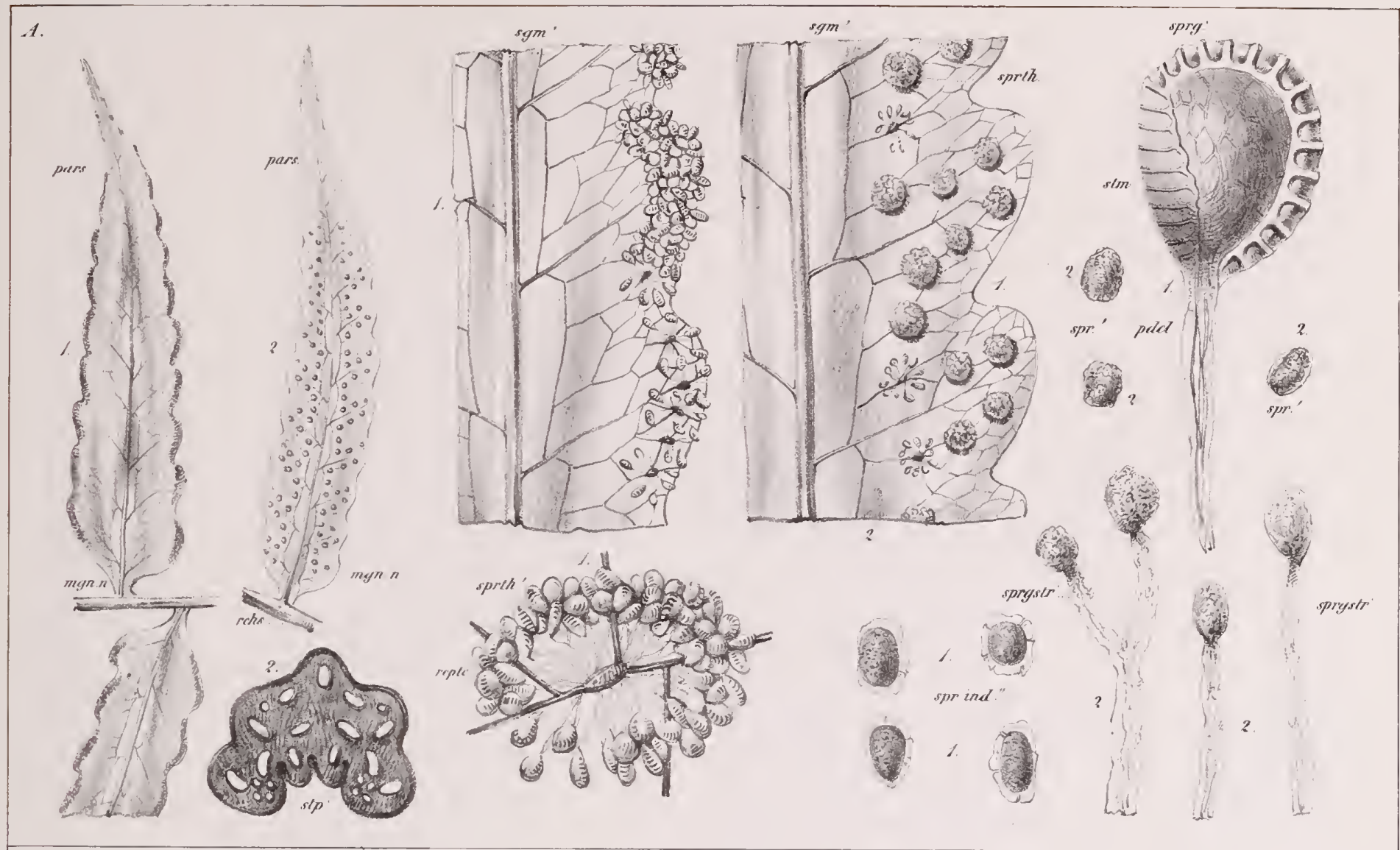

B. G. CXXIII. Irynaria, Bory

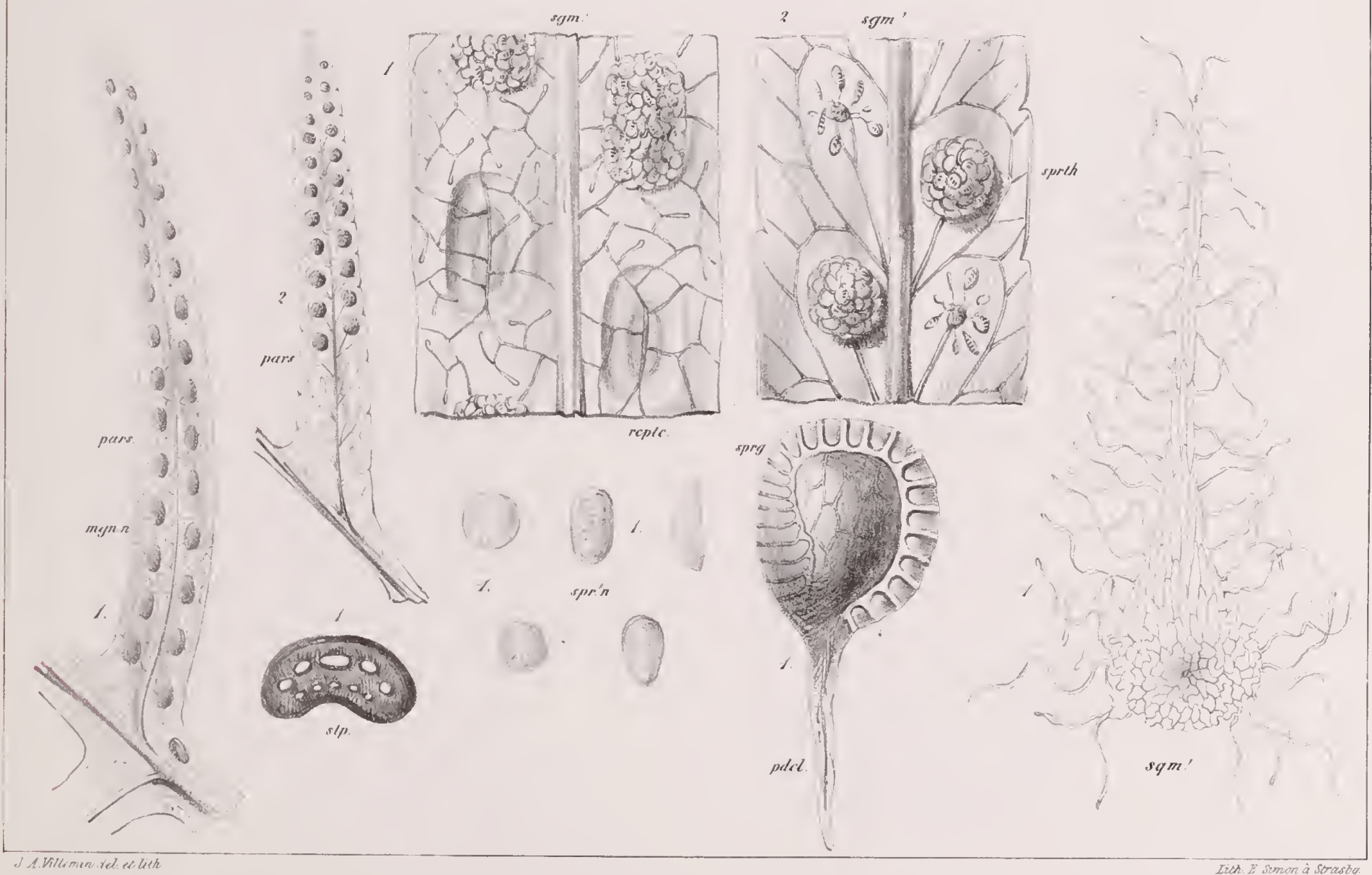

1. G. CXXI fig / Dictyopteris perroidar, Irest. Fig ?. I)
B. G. CXXIII.rig. / Drynaria Phymalorkes, f.

G. CXIV. Fig ? Goniophlebium ensiforme, Prese 



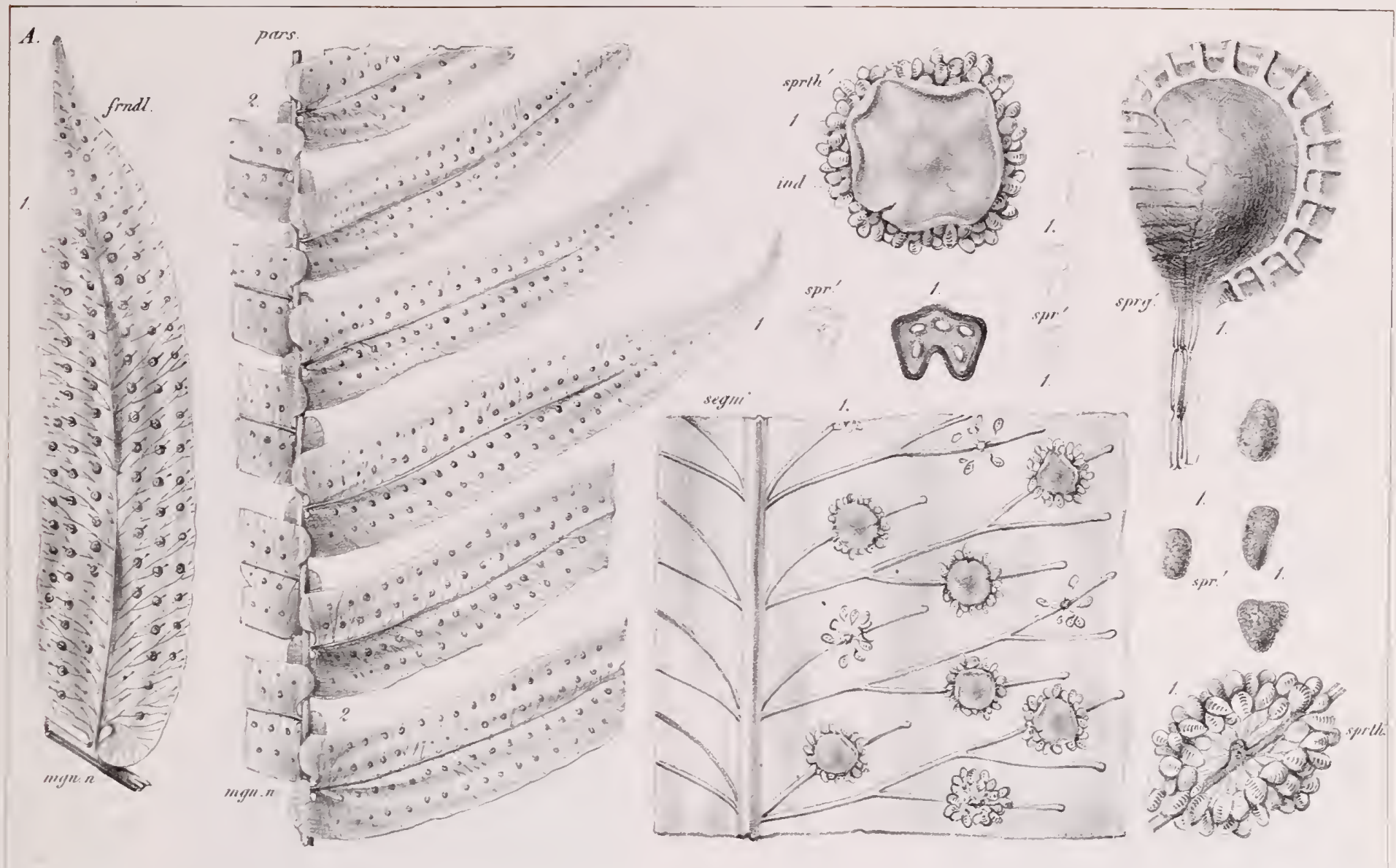

B. G. CXXX. Amblia, Presl.
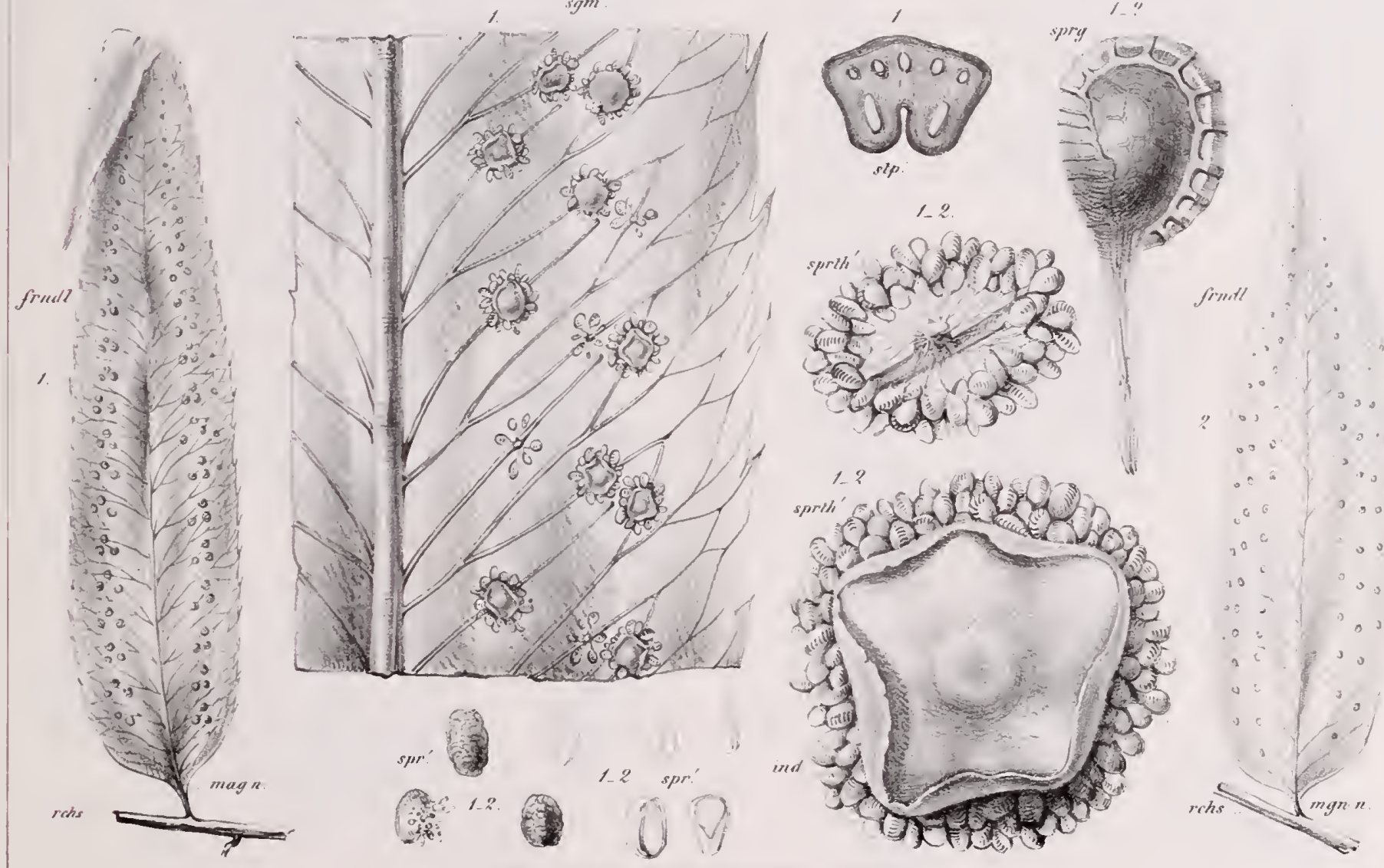

A. G. CXXIX. Fig, Hemicardion cronutum, ${ }^{\prime}$.

P. (j. CXXX. Mig. / Amblia juglandifoliu, Prest 

XVHI. CYCLODIES (A.). XIX. ASPUDIES (R.r.).

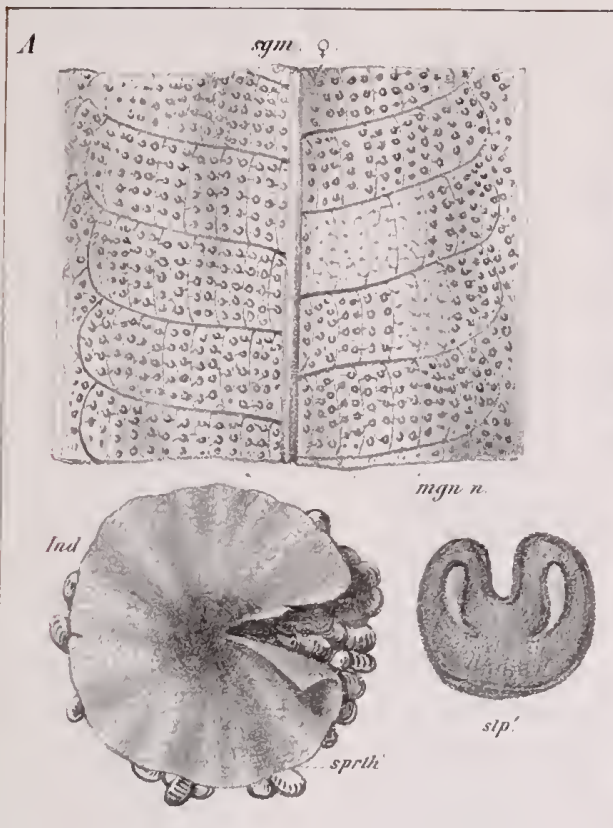

B. (i. ('XXXY'III. I)ichasimu, A. Br.

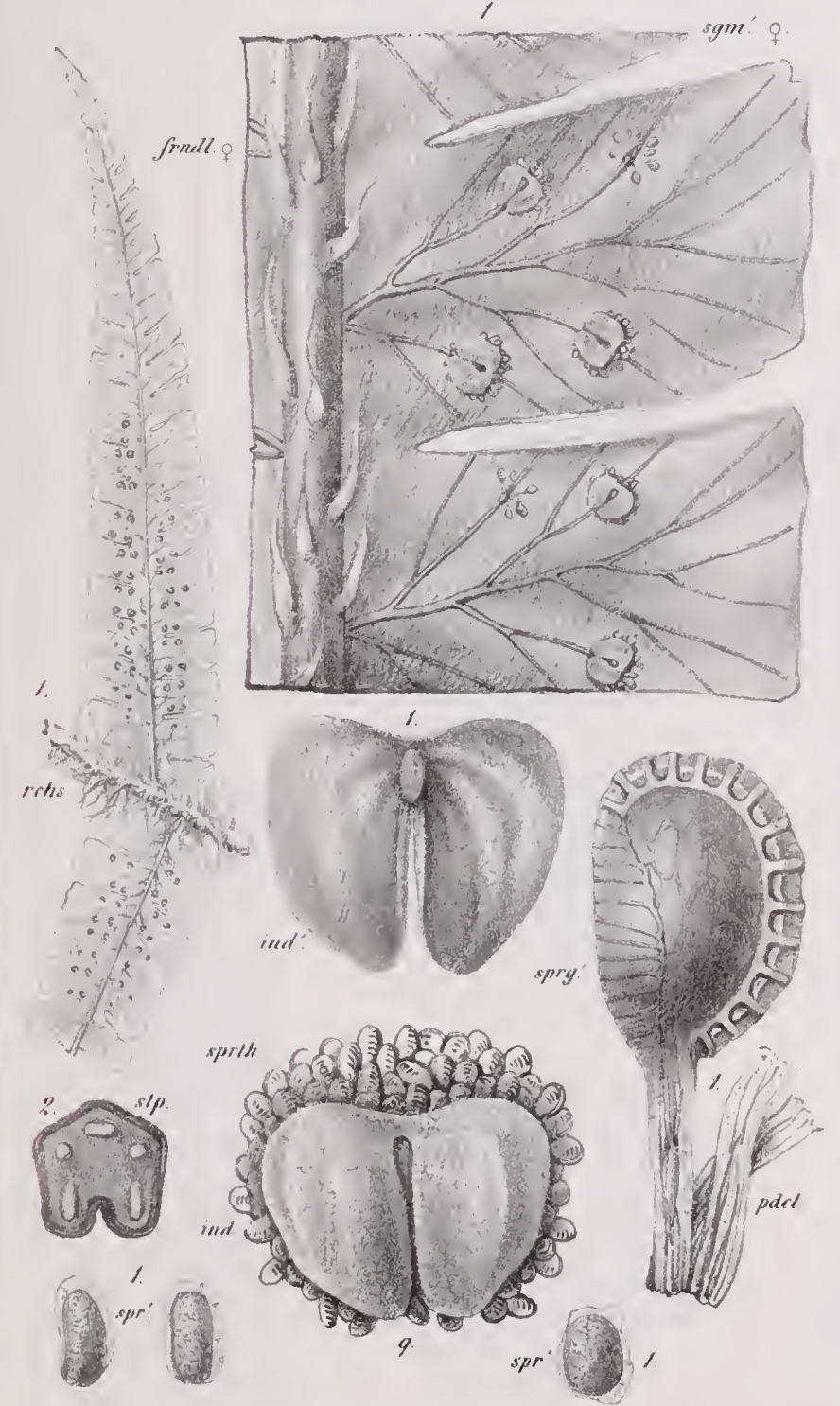

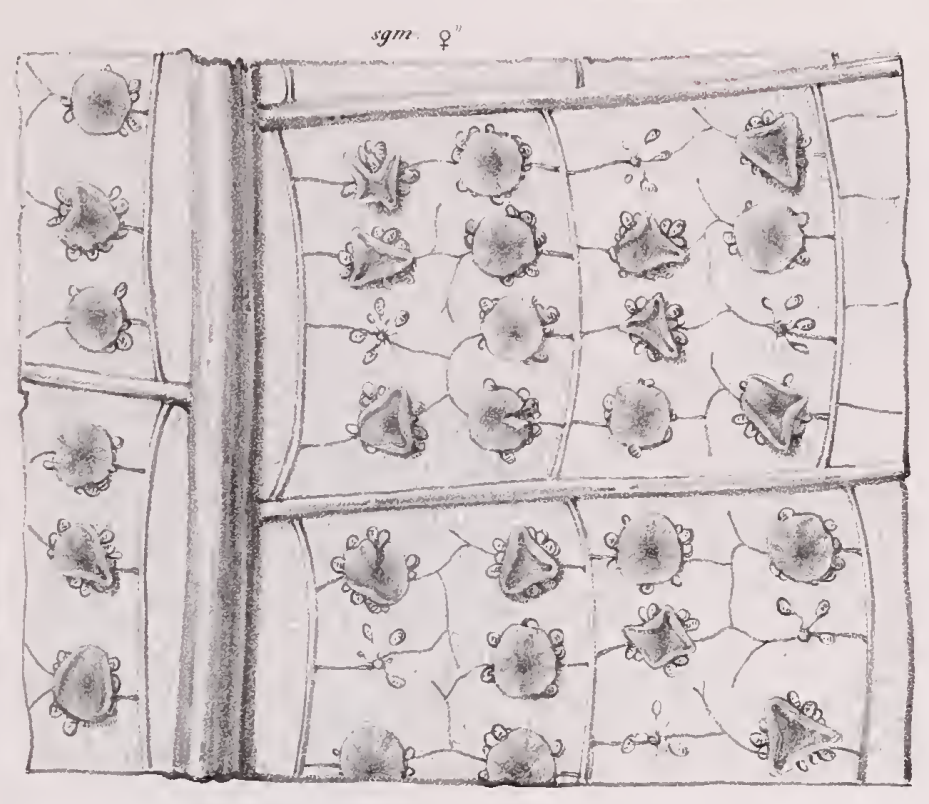

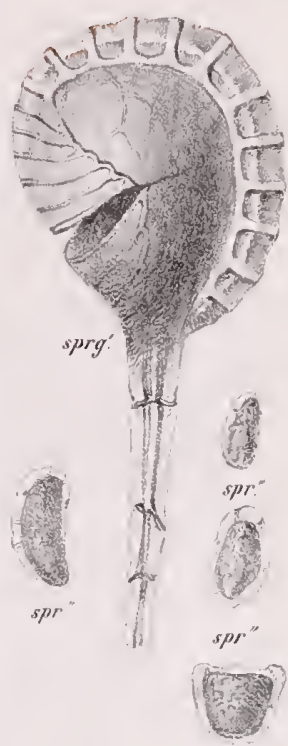

r. G. CXXXYII. Lepidoner'on, f?
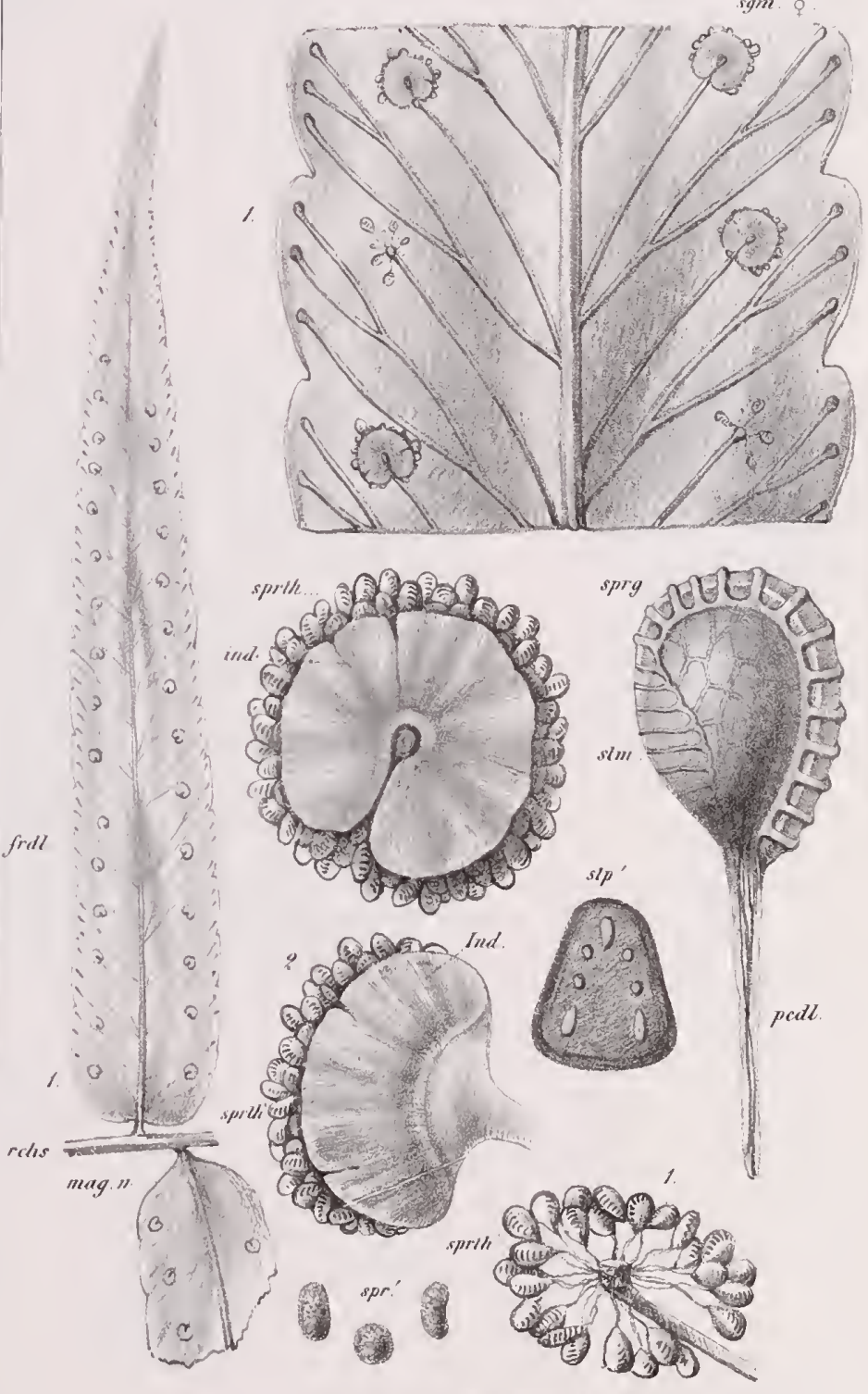

A. C.CXXYIII. I'odopeltis simgaporianar, ,

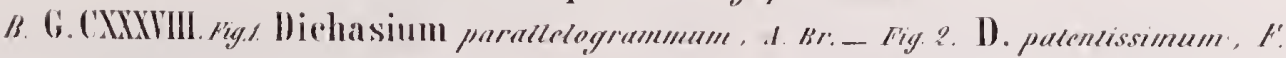

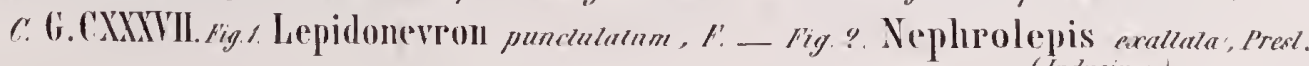



XIX ASPIIIEA.

G. CXIIN. Sagenia, Prest.

Tab $\mathrm{XY}$ "I

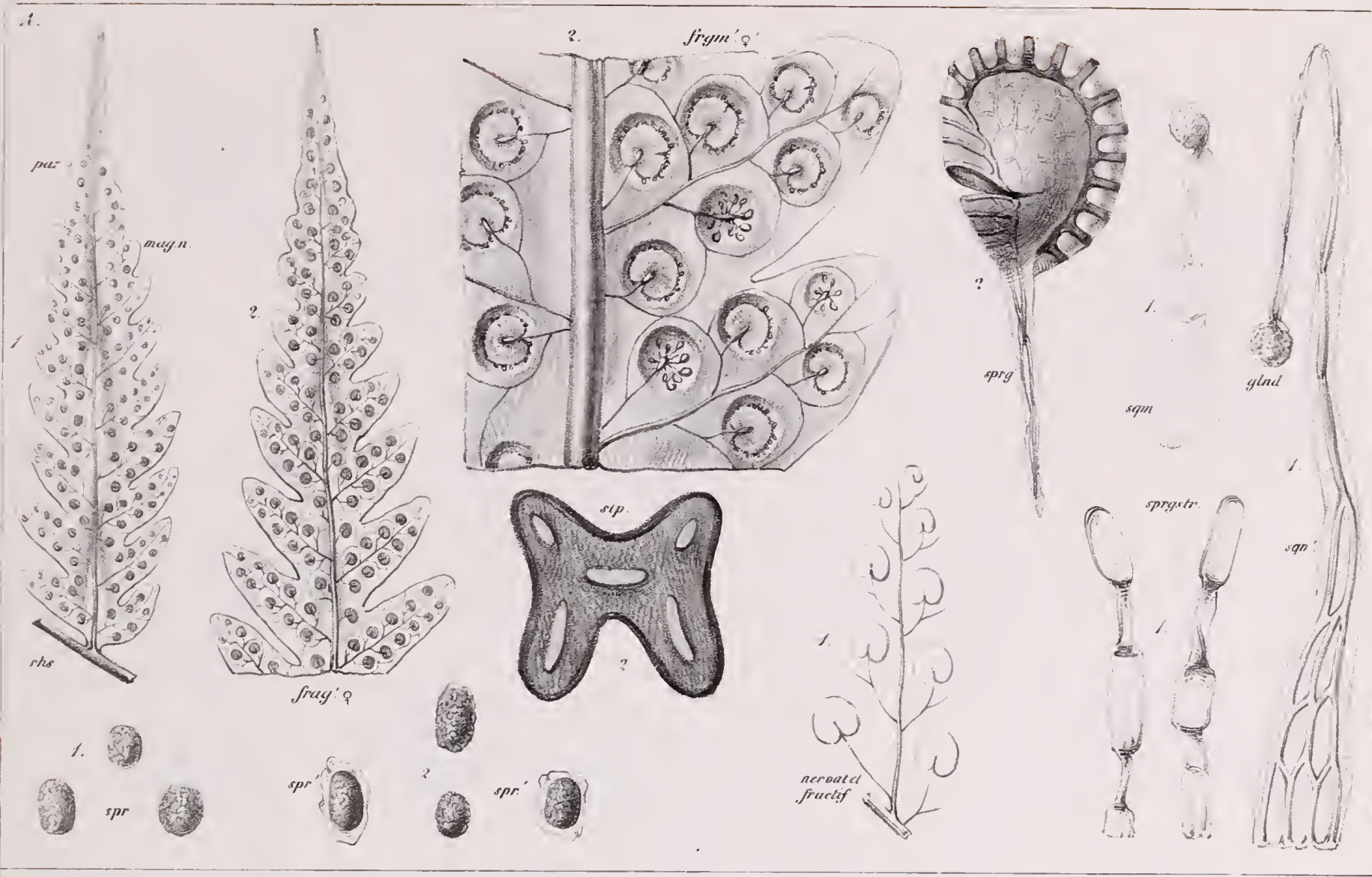

R. C. CXIVI. Cardiochlana, F
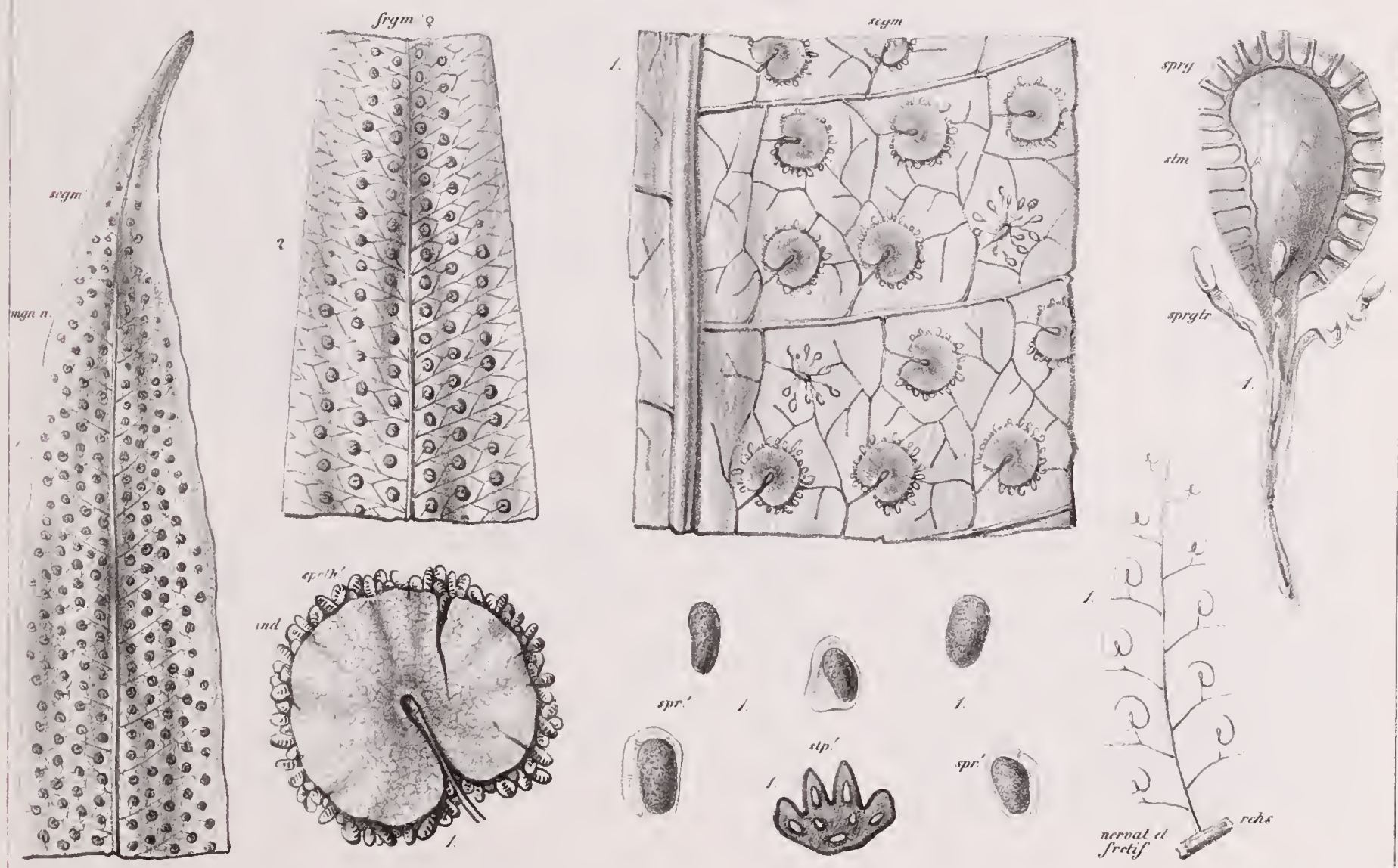

f. G.CXLIV. kig. Sagenia marrodonea,

G.CXLV. Fig? Phlebiogonium immersum, f

B. G. CXIVI. Fig., l'ardiochlarna macrophyller. $f:$

G. CXIV. Fig. ?. Goniophlebium nerufolium, $F$. 



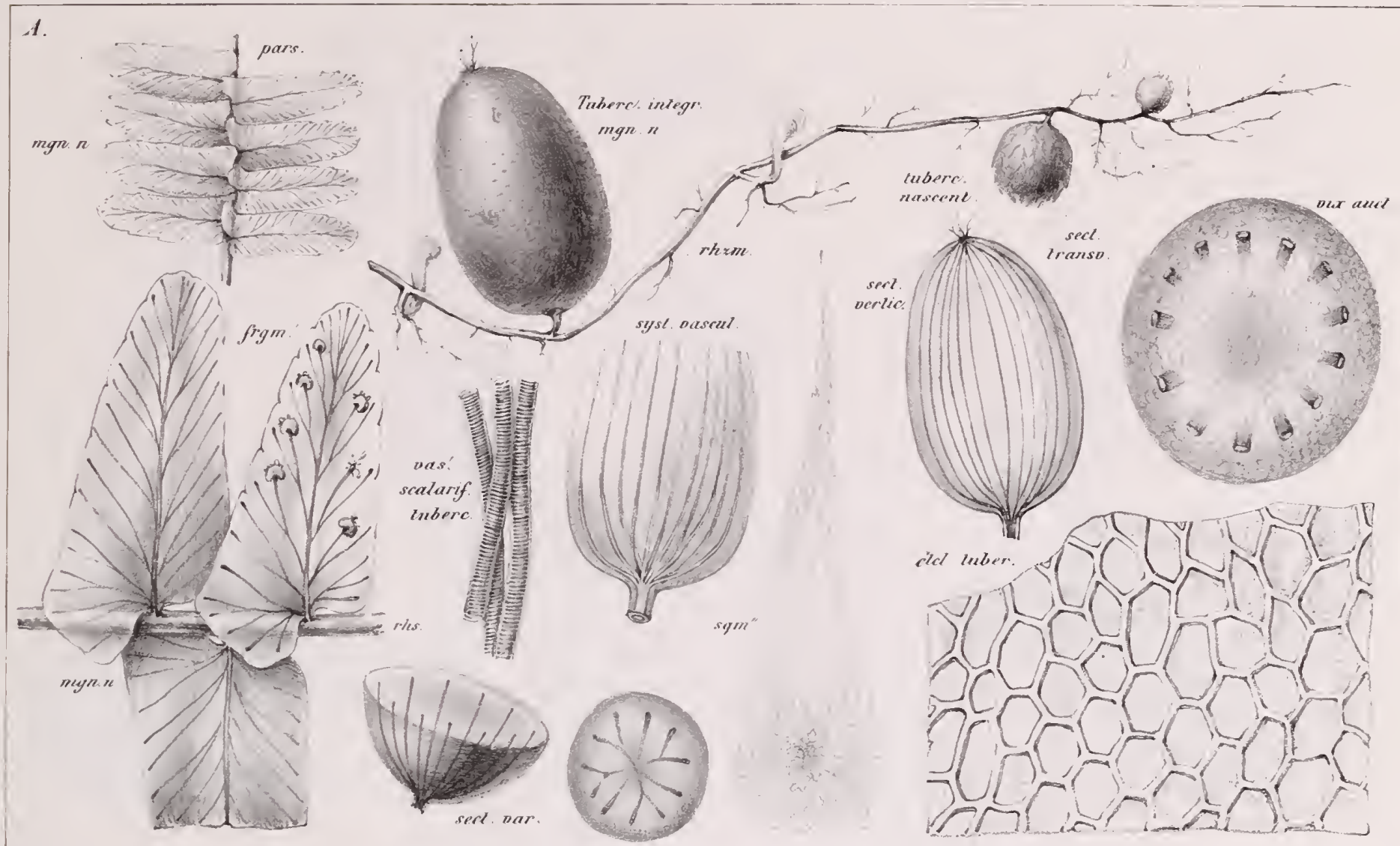

B. G. CXLIX. Pleponevion, Fe et C'L. Saccoloma, Kyf.s.
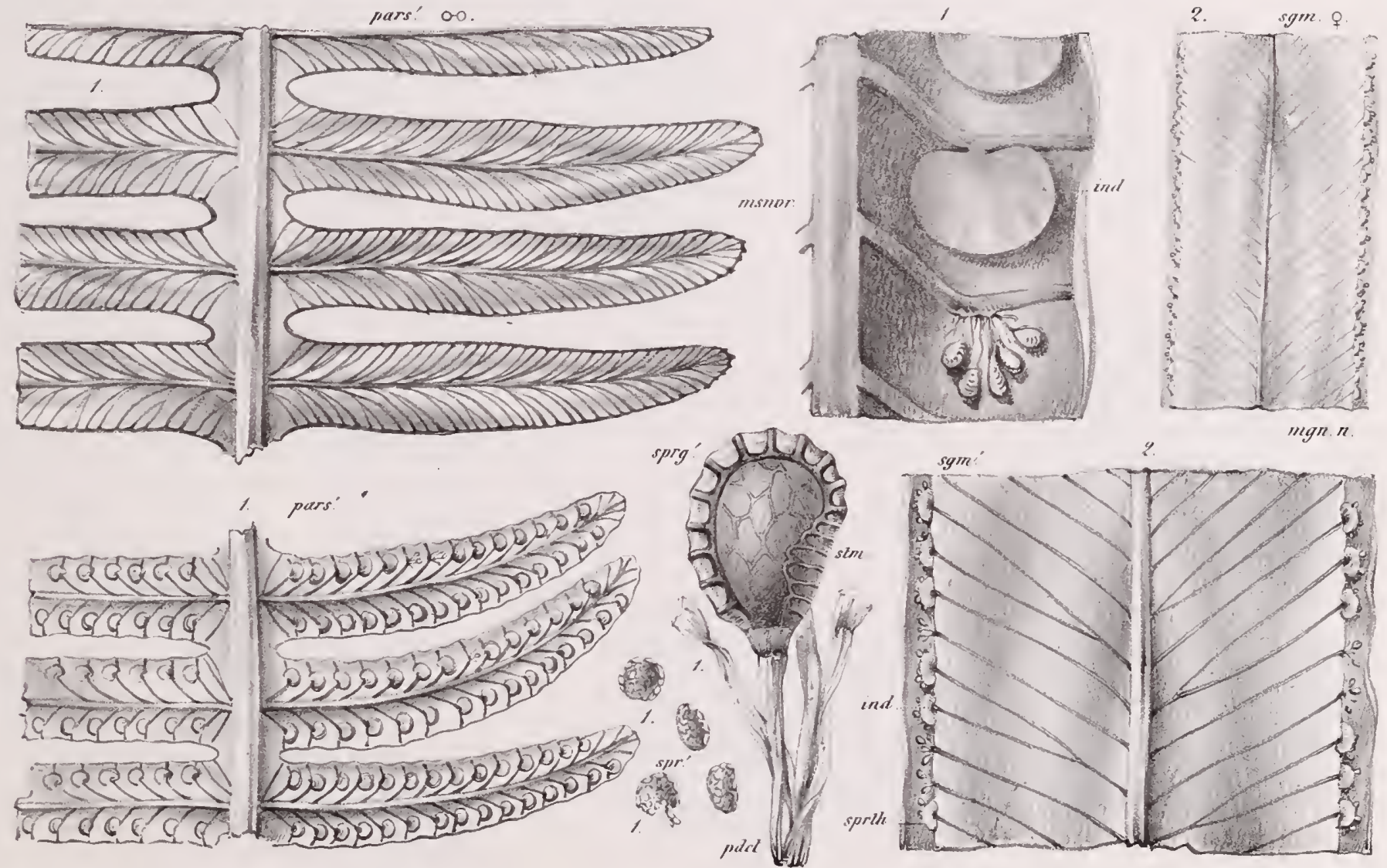

mgn. $n$

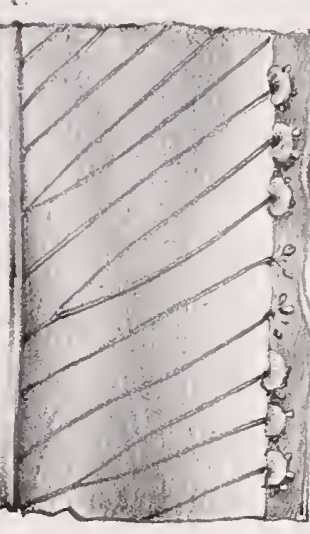

A. G. CXLVIII. Nephrolepis nberosa, Prest.

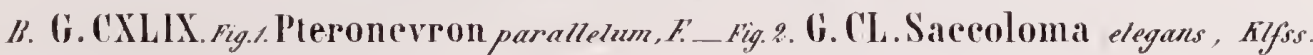



G. CLII. Ilumata, Cao.

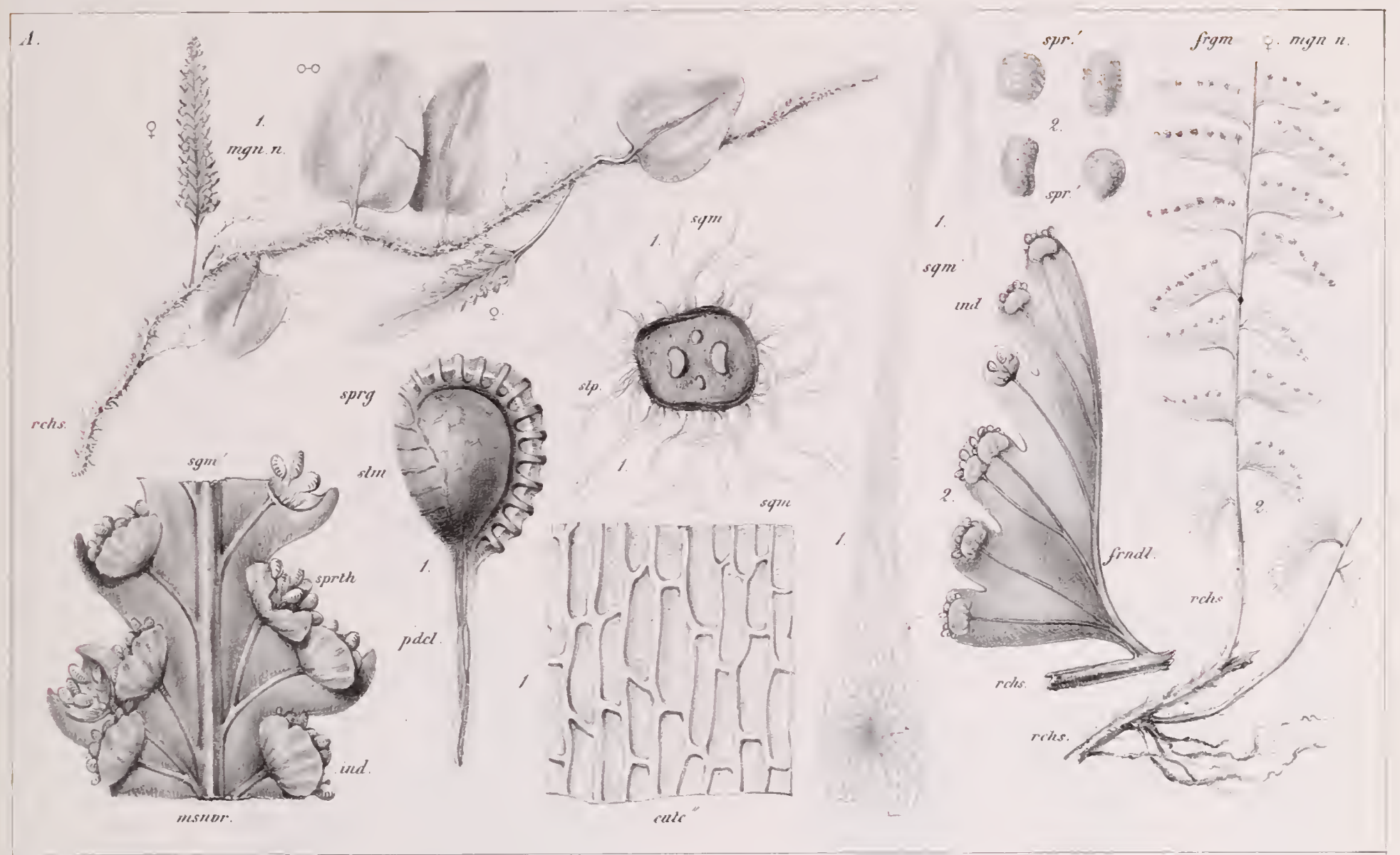

b. G. I'THIII. Odontoloma, J.Sm.

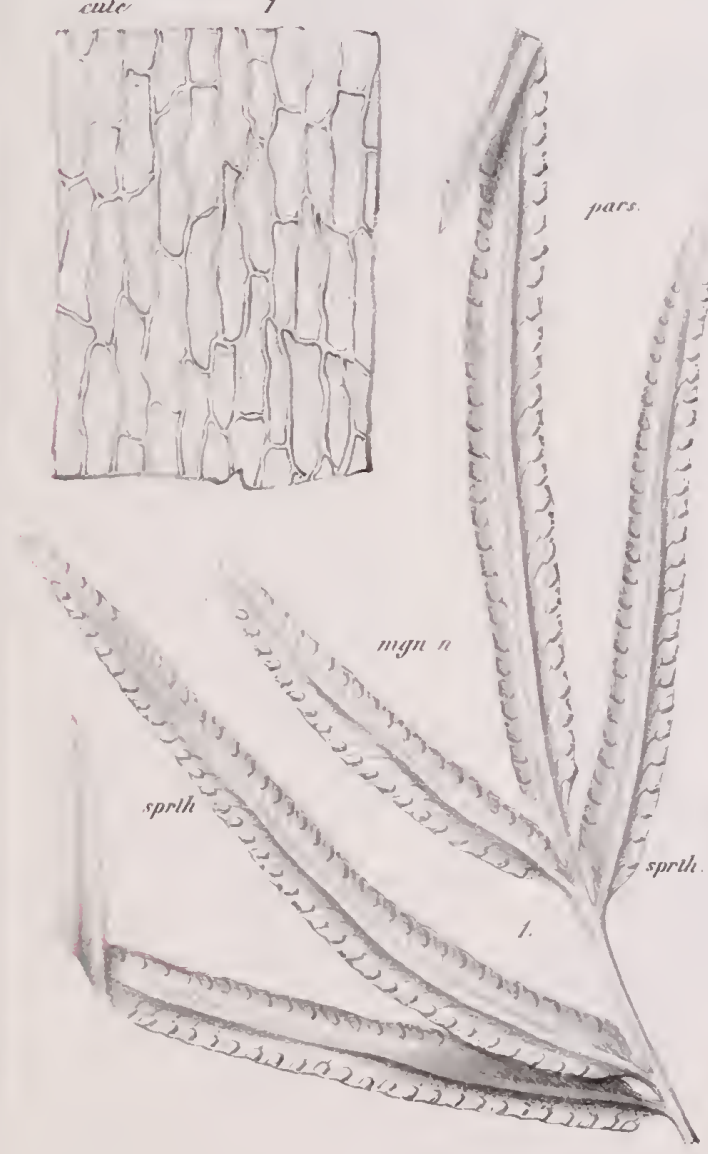

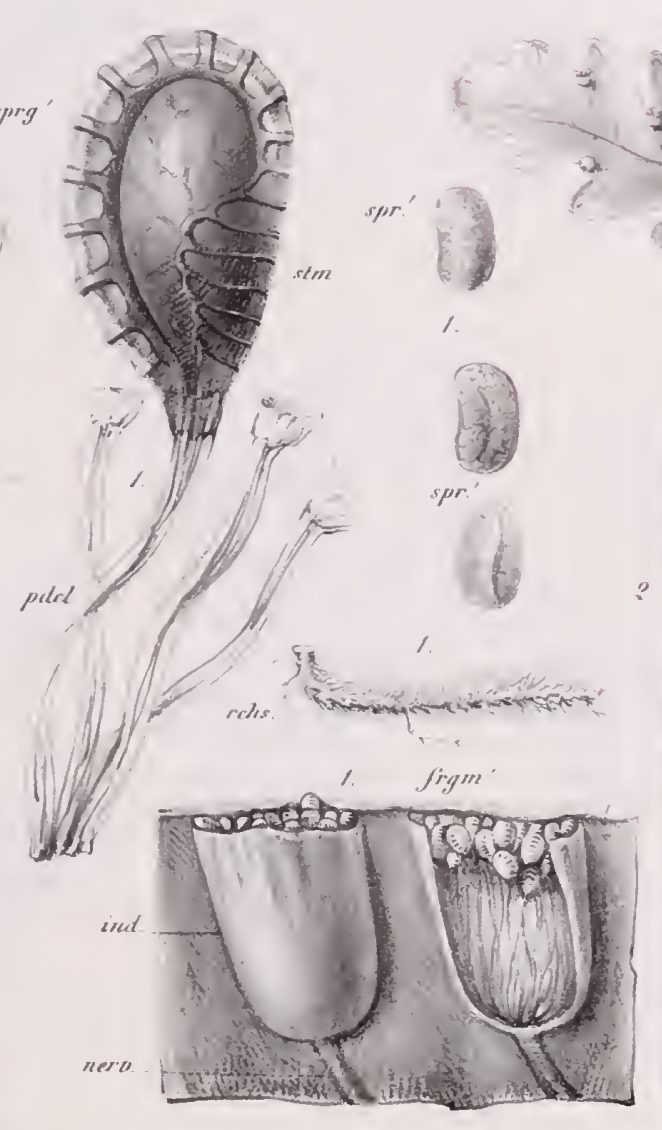

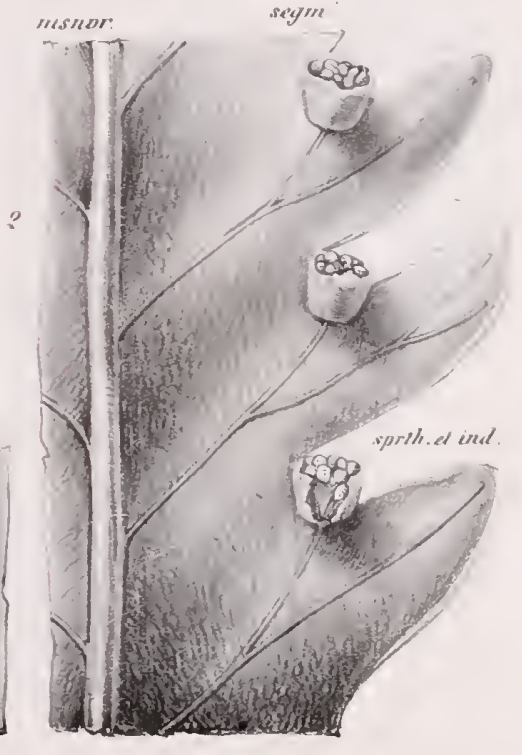

A. G. CLII. Fig. Ilumala ophioglossa, Cao. (i.CLIIIL. Fig.?. Odontolom a Baryanum, J.Sm
B. G. ('III'Fig Seyphularia pentaphylea, $F$.

G.('LXIII.Fig.? Dicksonia lenera, Mart. 

XXI. IDAVALLIEA.

f. l'bIll. Prosaptia, Prest

G. CLV. Odontosoria , $F$.

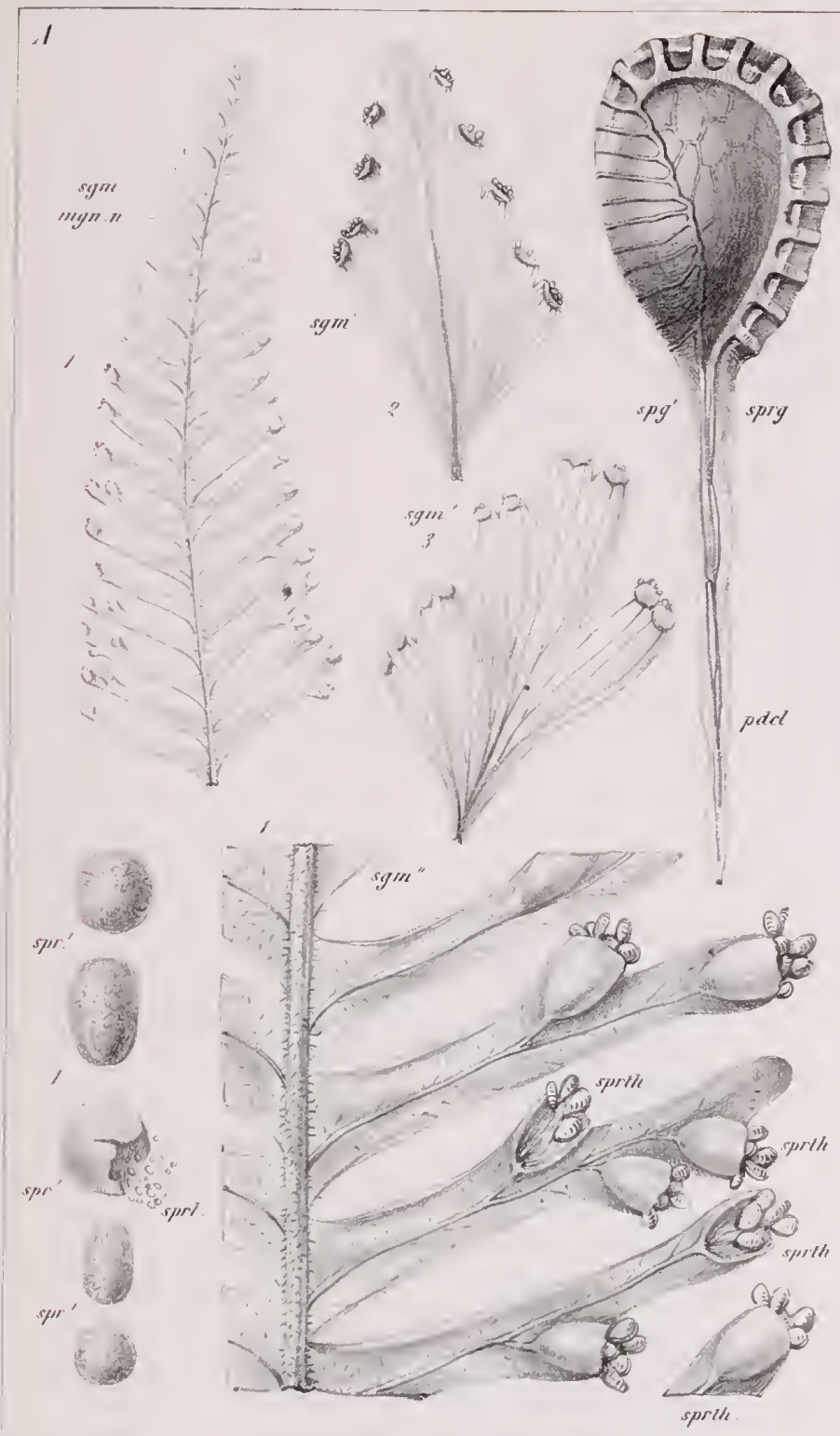

$B$.
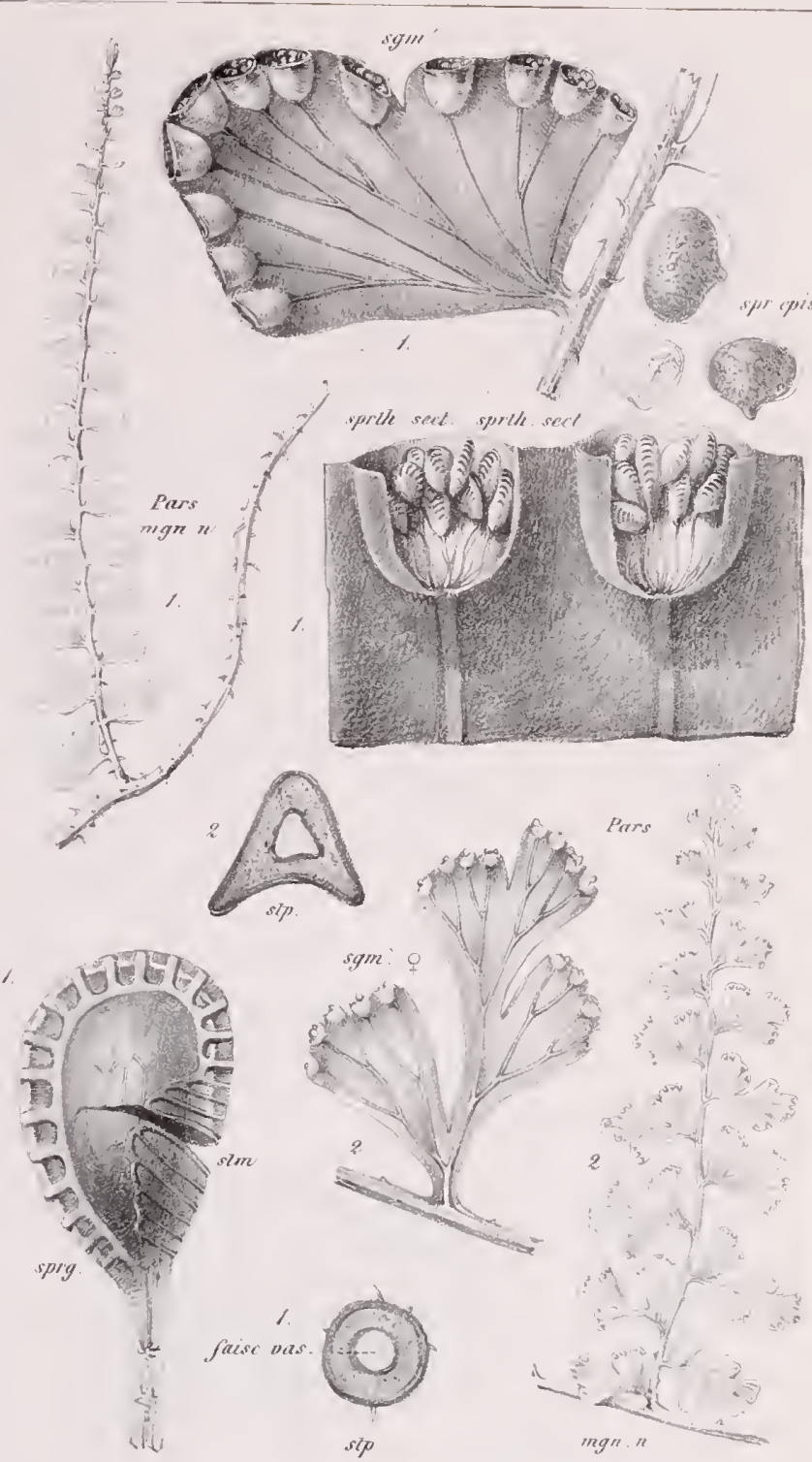

(r. G. ('ILIT. I) apea, Jus.s.

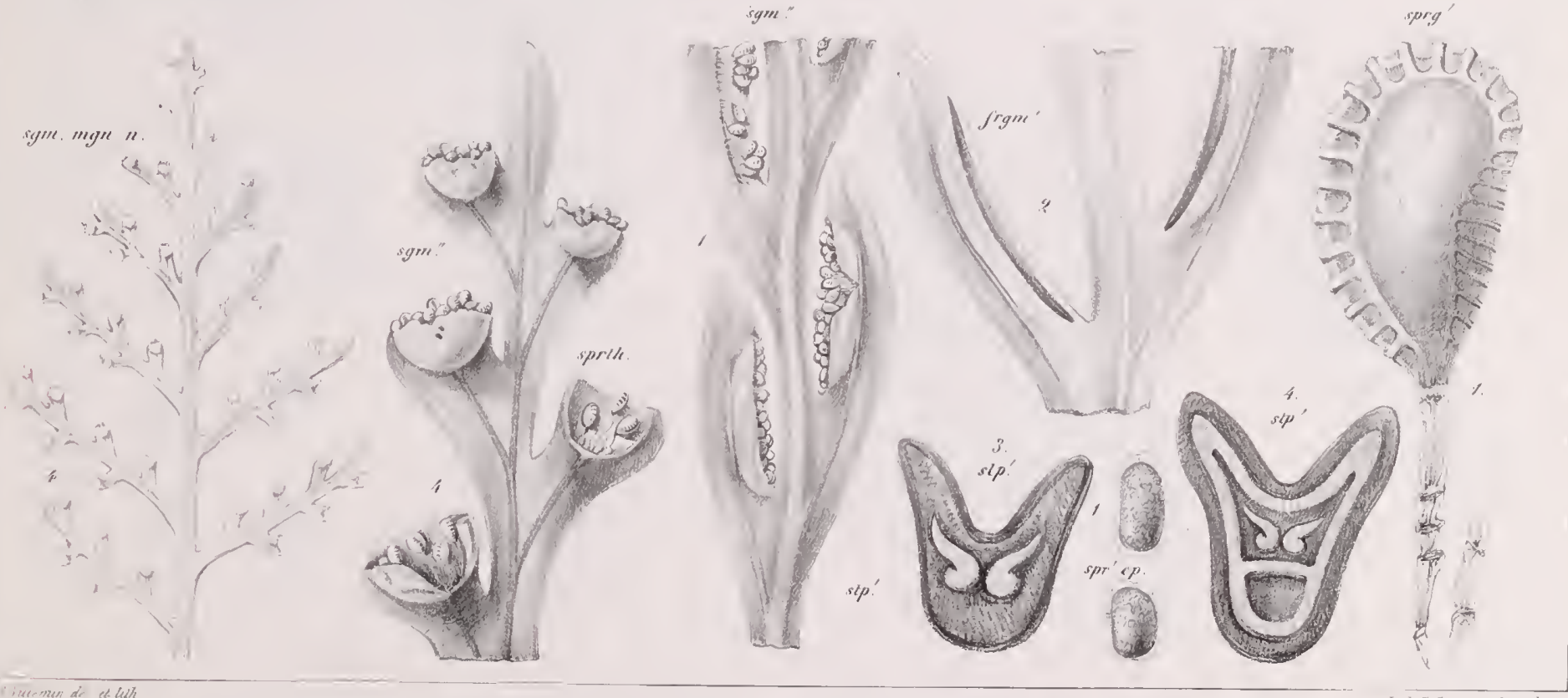

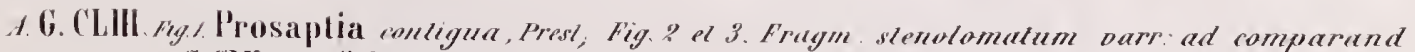

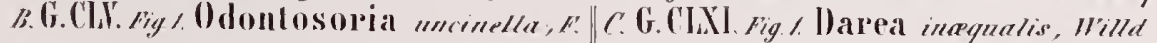

$$
\begin{aligned}
& \text { Fig?.Stenoloma dumosum, F! "2.__ flacerda, Willd } \\
& \text { - } 3 \text { - minipara, llilld } \\
& \text { "4. Davallia Schimperi, Hook }
\end{aligned}
$$



XXI. DAVALLIE. .

G. CIIX. Stenoloma, $r$ :

Tab $X A T I^{\text {bis }}$
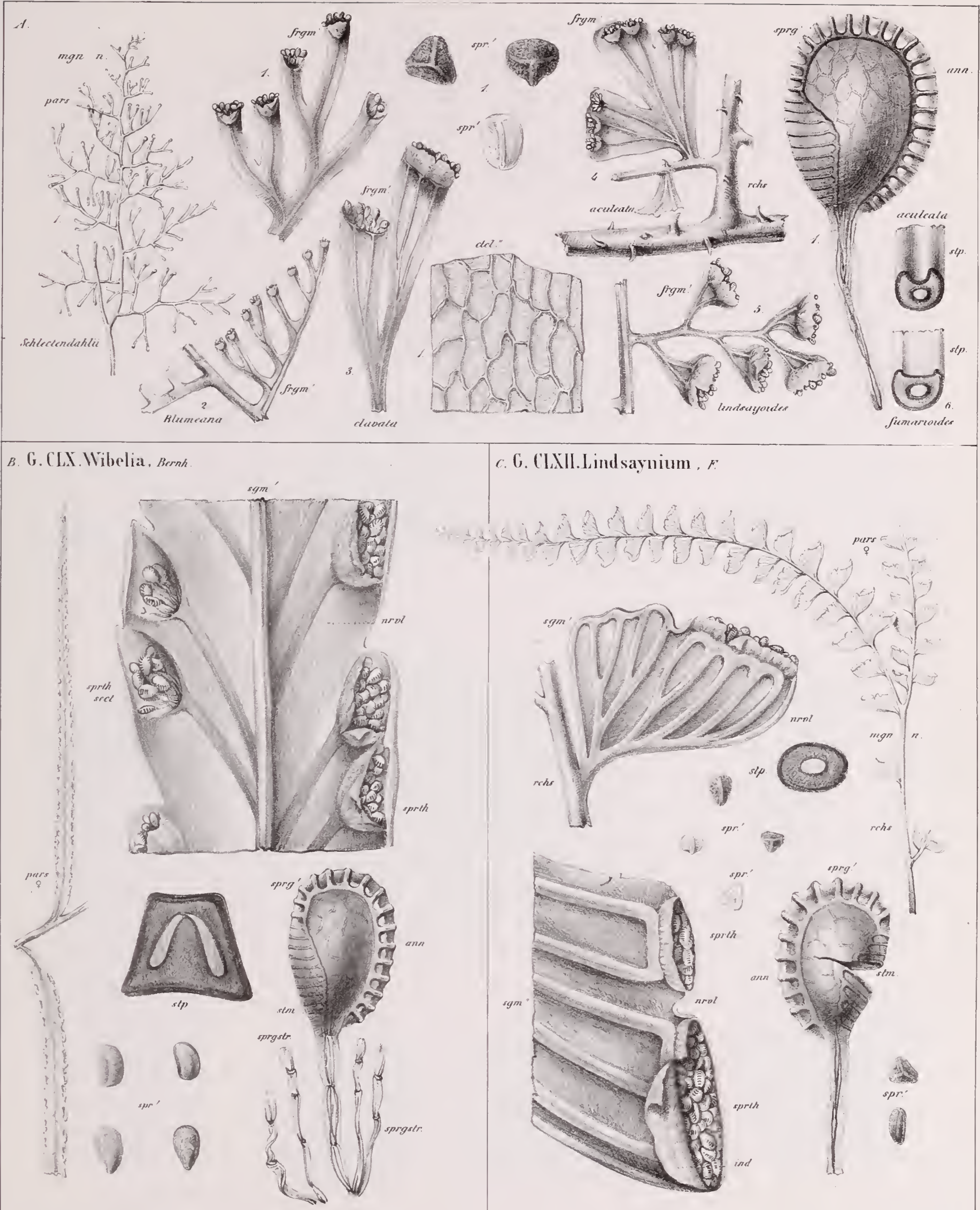

c. G. ClXIL.Lind saynium , $F$ 

XXV. CYATHEA.

G. CLXXVIII. Hemistegia, Prest.

Tab XTVII

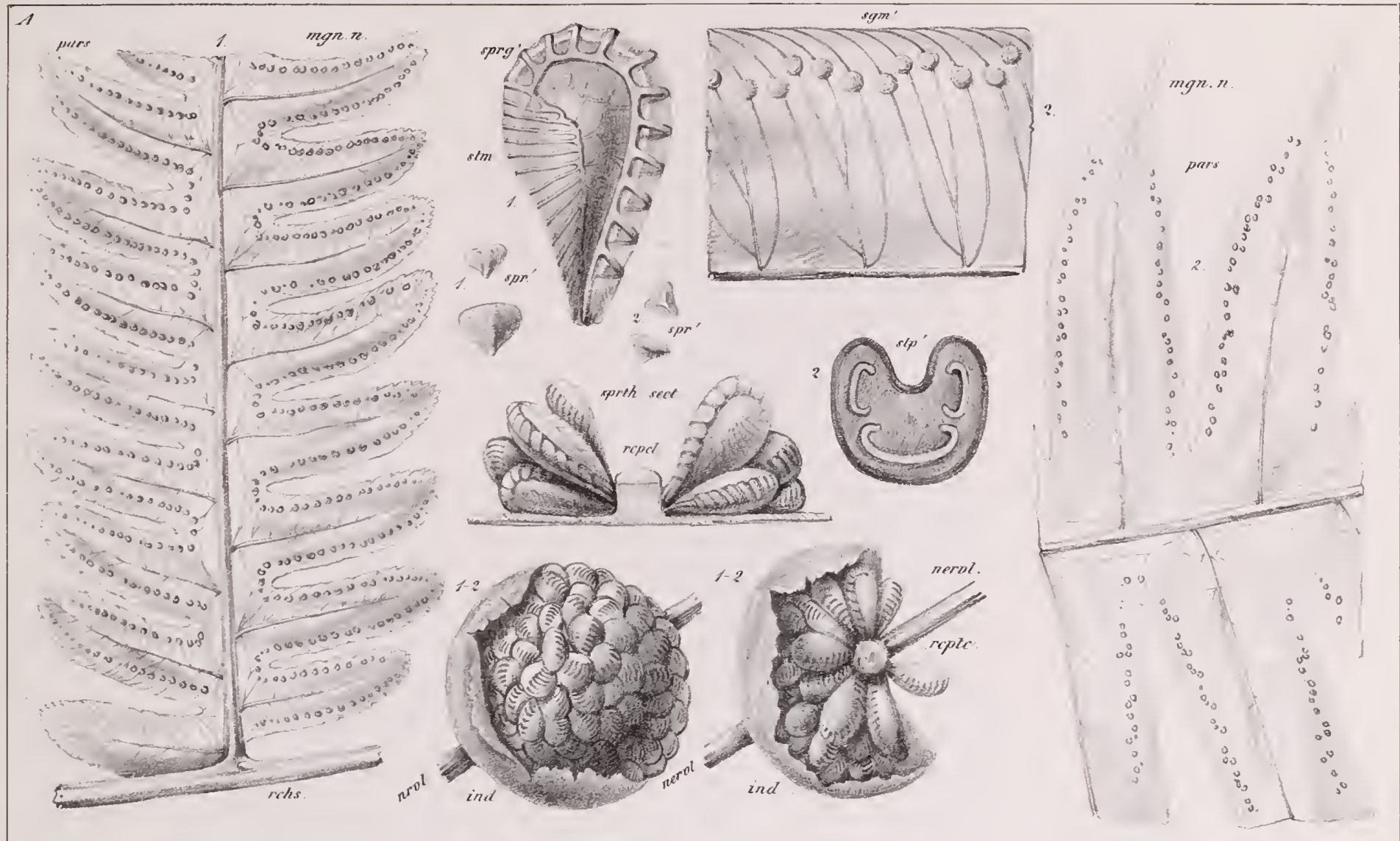

B. li. CldXX.Schizocana, $J s_{m}$.
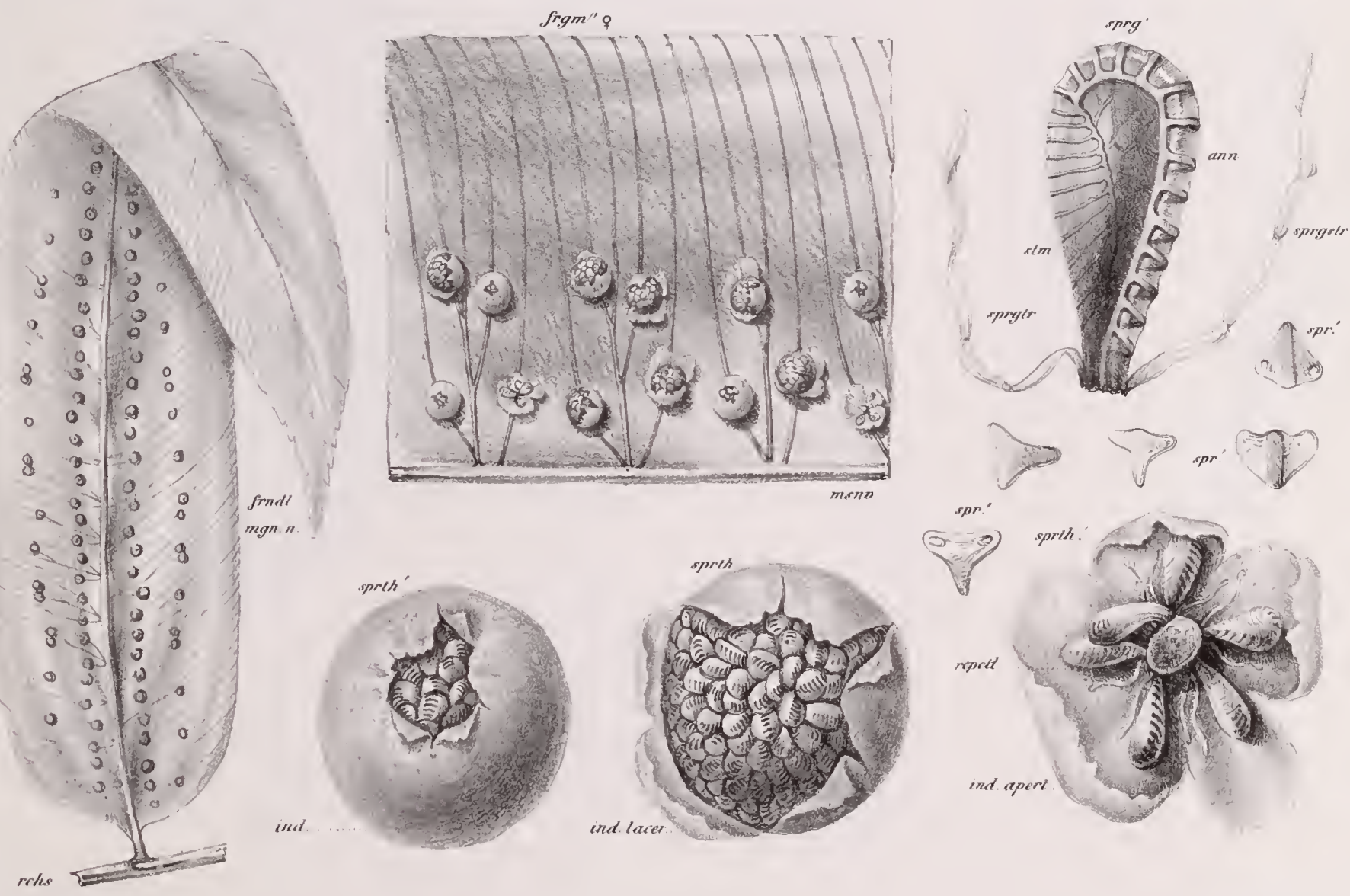

1. (G. CLXXVIII. Kig. Hemistegia grandifolia

B. G. CLXXX. Schizocsena Brnoonis.J. Sm 



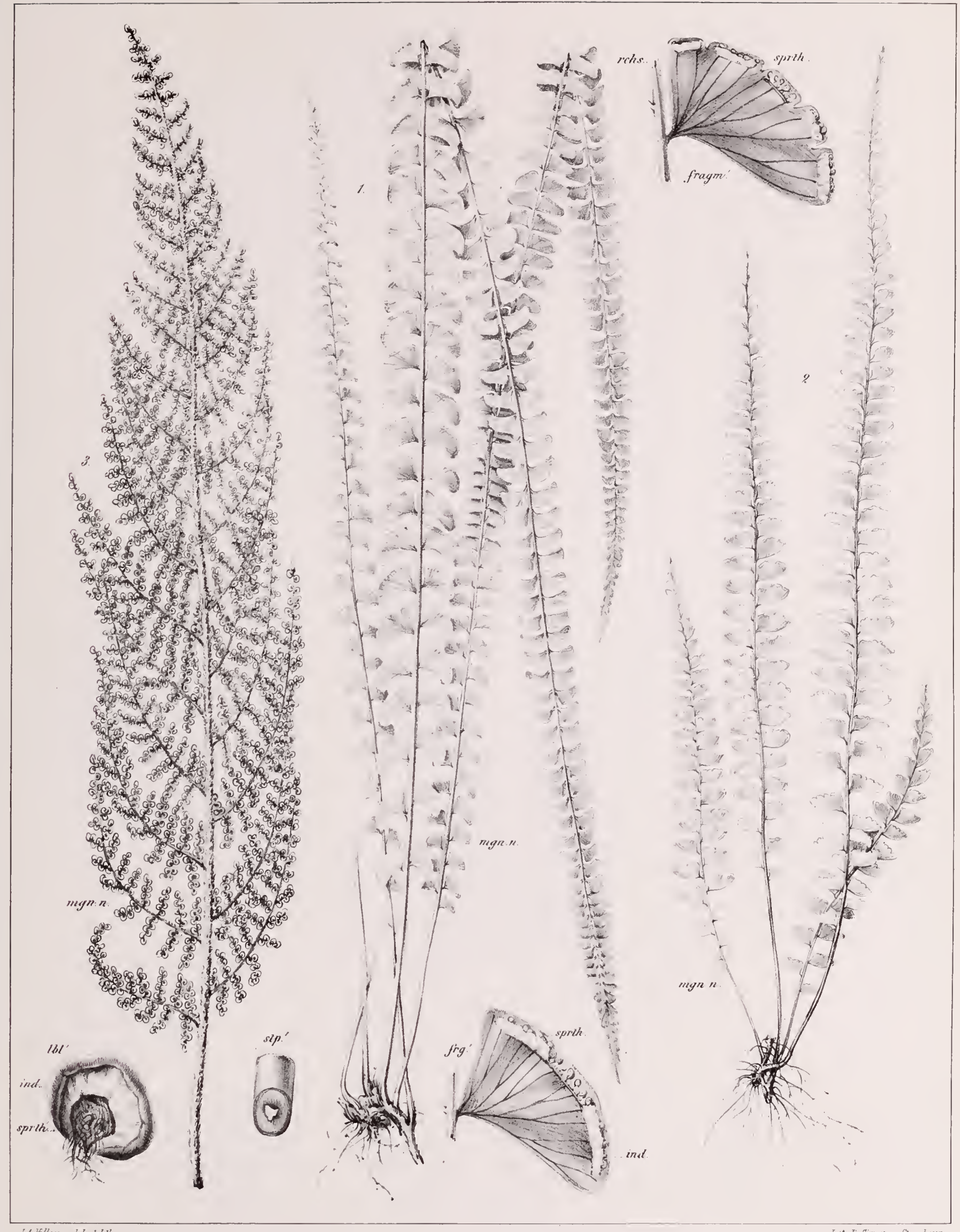

Fig 1. Lindsạa mulufromdulosa, $F$.|| Fig. 2. Lindsạva crenalaln, ${ }^{\prime}$. 

VARIA.

Tab. IXIX

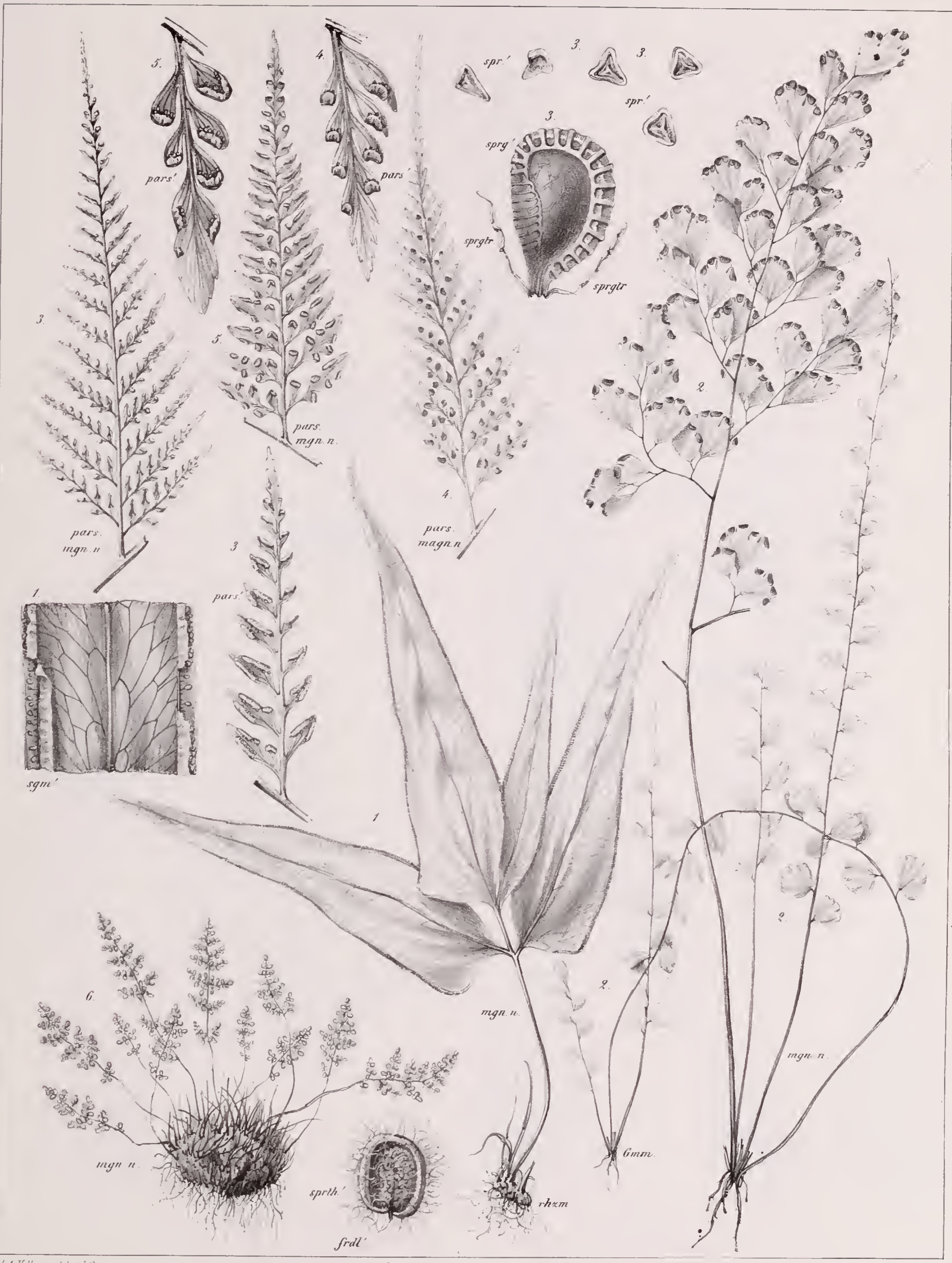

rig. I. Srhizoloma Java, $P$.

- 2 Adiantum radicans, $F$.

- 3. Ochropleris angusla, $f$
Fig 4. Ochropteris peltigera, $F$

"5.— pallens, J. Sm

- 6. Uvriopteris graciles, $F$. 



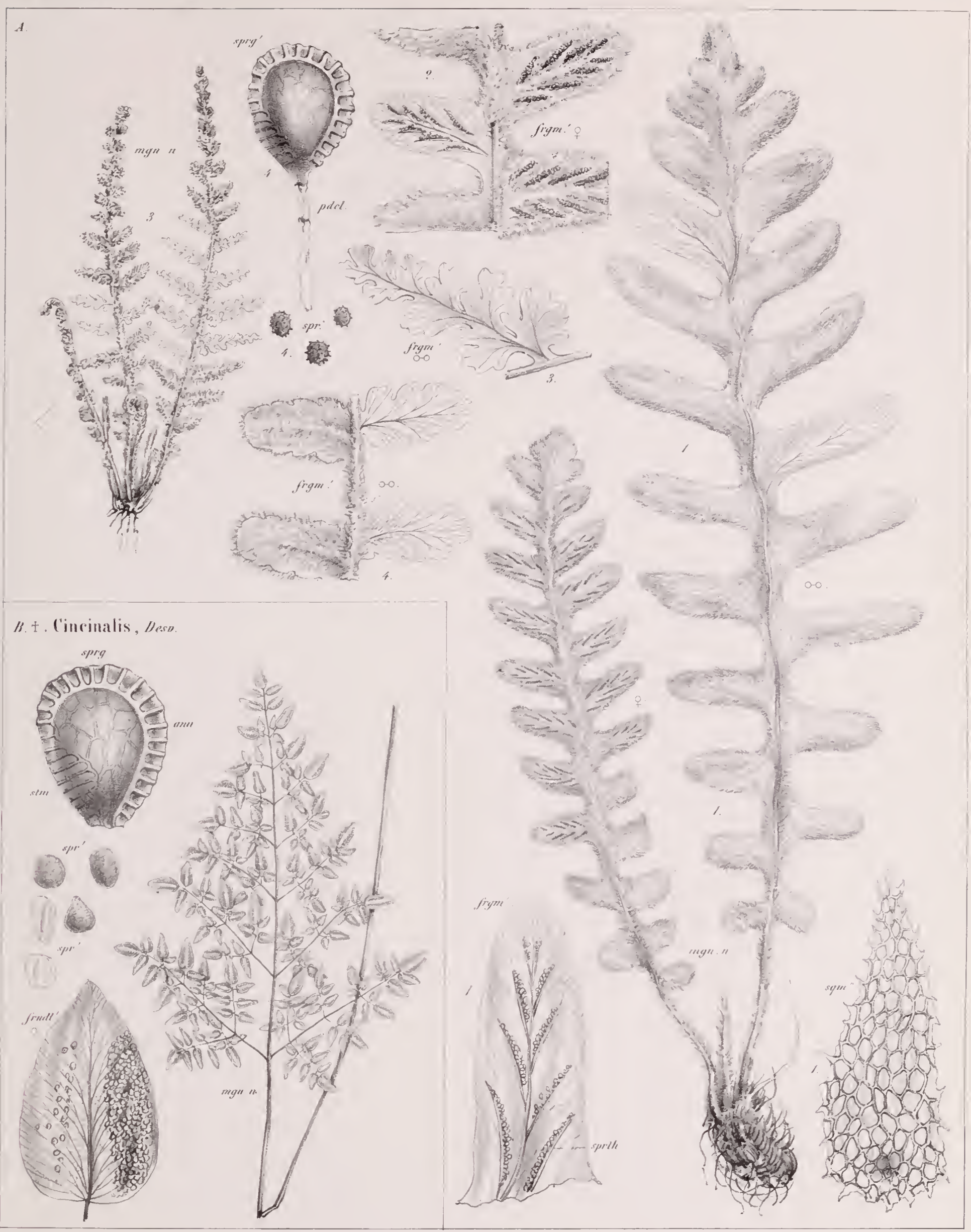

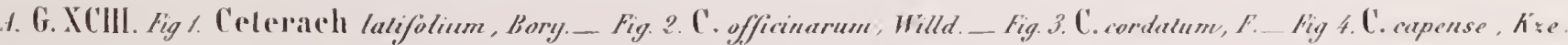

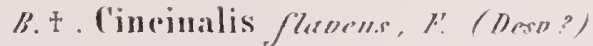





